MÉLODIE KERN SARUBO DORTH

PROPOSTA DE CLASSIFICAÇÃO DE LINHAS DE BASE OBTIDAS COM DADOS GPS, A LUZ DE ÁRVORE DE DECISÃO.

SÃO CARLOS

2010 



\title{
PROPOSTA DE CLASSIFICAÇÃO DE LINHAS DE BASE OBTIDAS COM DADOS GPS, A LUZ DE ÁRVORE DE DECISÃO.
}

\begin{abstract}
Dissertação apresentada ao Departamento de Transportes da Escola de Engenharia de São Carlos/ Universidade de São Paulo para obtenção do título de Mestre em Ciências, Programa de Pós-Graduação em Engenharia de Transportes.

Área de Concentração: Infraestrutura de Transportes

Orientador: Prof. Associado Paulo César Lima Segantine.
\end{abstract}

São Carlos 
AUTORIZO A REPRODUÇÃO E DIVULGAÇÄO TOTAL OU PARCIAL DESTE TRABALHO, POR QUALQUER MEIO CONVENCIONAL OU ELETRÓNICO, PARA FINS DE ESTUDO E PESQUISA, DESDE QUE CITADA A FONTE.

Ficha catalográfica preparada pela Seção de Tratamento

da Informação do Serviço de Biblioteca - EESC/USP

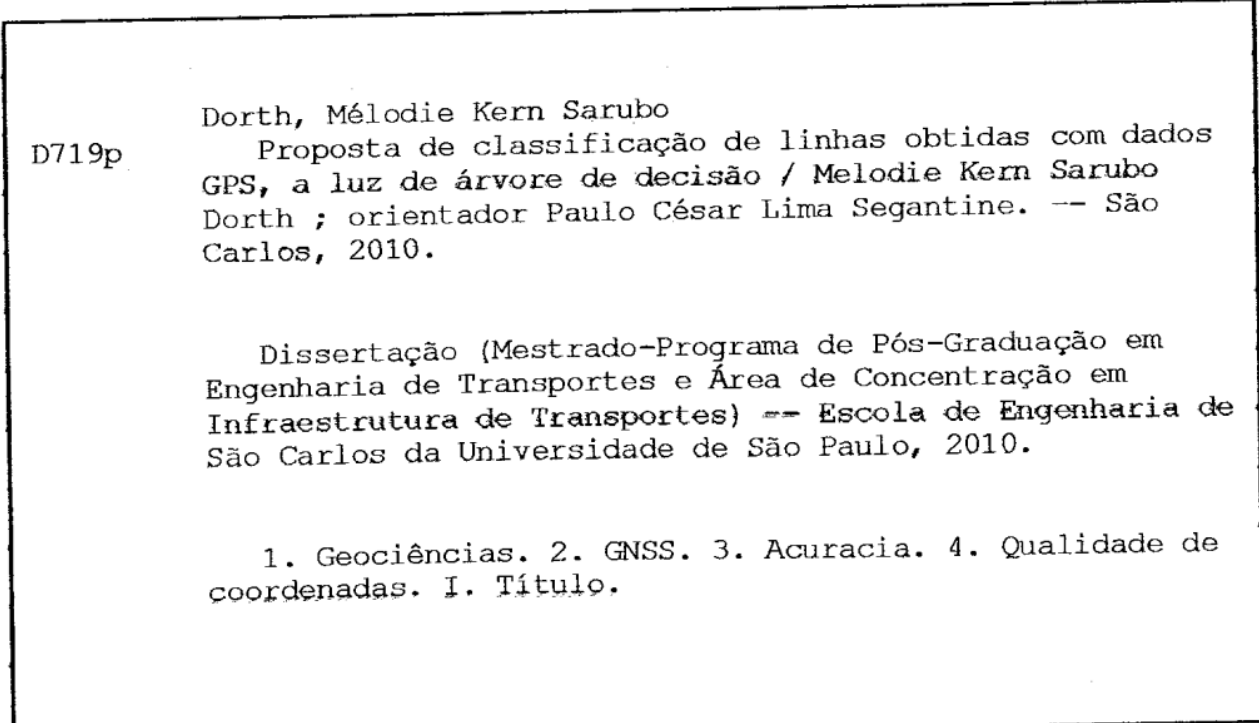




\section{FOLHA DE JULGAMENTO}

\section{Candidato(a): Engenheiro MÉLODIE KERN SARUBO DORTH.}

Dissertação defendida e julgada em 17/05/2010 perante a Comissão Julgadora:

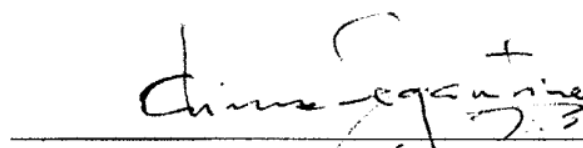

Prof. Associado PAULo CÉSAR LIMA SEGANTINE - (Orientador)

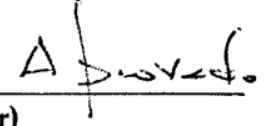

(Escola de Engenharia de São Carlos/USP)

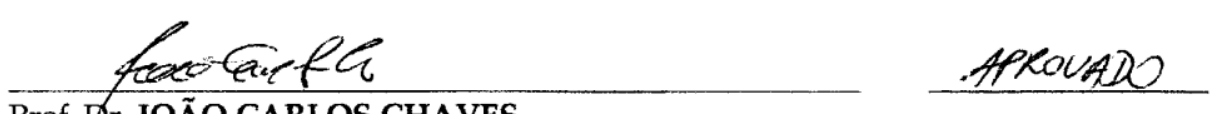

Prof. Dr. JOÃO CARLOS CHAVES

(Wnifersidade Estadual Paulista "Julio de Mesquita Filho"/UNESP/Campus de Presidente Prudente)
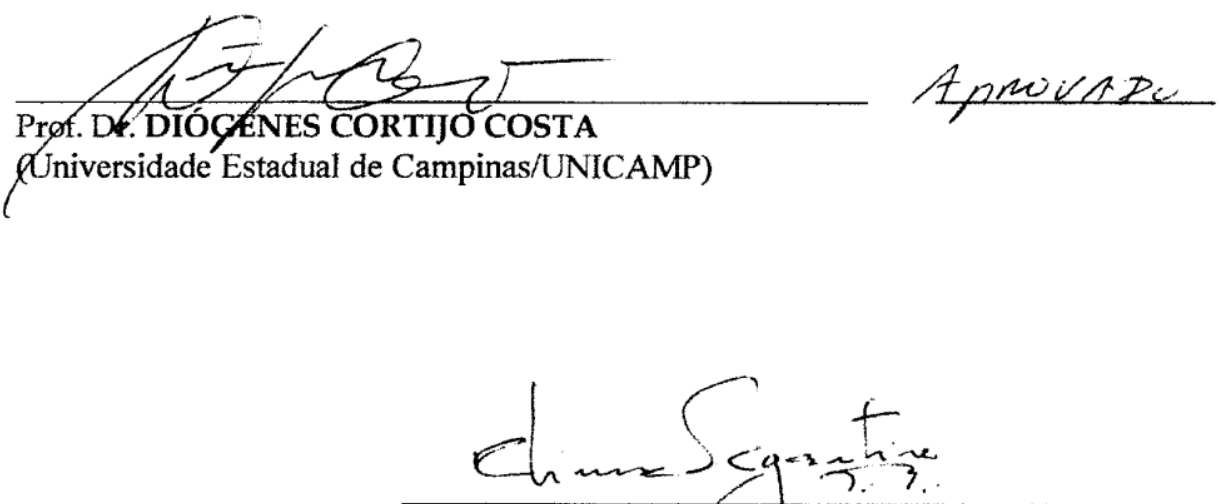

Prof. Associado PAUL L CESAR LIMA SEGANTINE

Coordenador do Programa de Pós-Graduação em Engenharia de Transportes

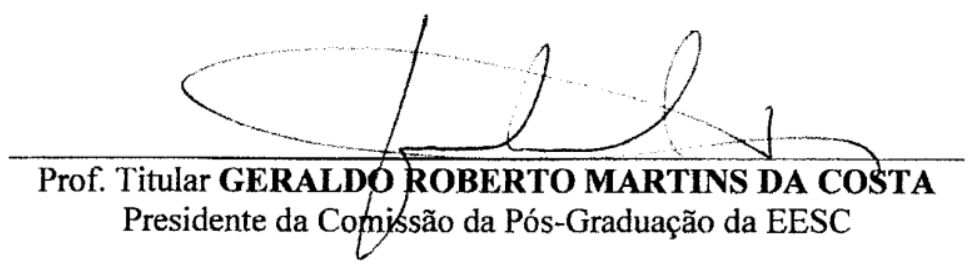



À Deus, à minha família e ao meu marido, pelo amor e dedicação. 



\section{AGRADECIMENTOS}

À Deus, pela força nos momentos difíceis.

À minha família e ao meu marido, pelo simples fato de sempre estarem ao meu lado.

Ao Professor Associado Paulo César Lima Segantine, pela orientação deste trabalho, bem como por todo o apoio prestado.

Aos professores do Departamento de Transportes da EESC/USP, por todo incentivo.

Ao IBGE, pela disponibilização dos dados utilizados neste trabalho.

À empresa EMBRATOP, pelo suporte técnico do software Topcon Tools, versão 7.1.

Aos amigos, por todo o apoio indispensável.

À todos que contribuíram, mesmo que indiretamente, para a conclusão deste trabalho. 



\section{SUMÁRIO}

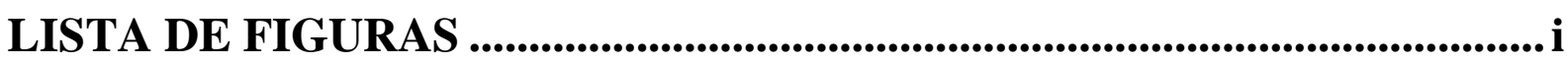

LISTA DE TABELAS.....................................................................................................iii

LISTA DE ABREVIATURAS E SIGLAS....................................................... v

RESUMO ................................................................................................................... vii

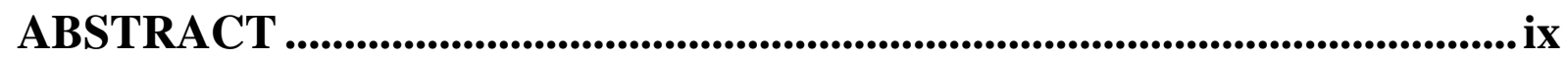

CAPÍTULO 1 - INTRODUÇÃO .................................................................... 1

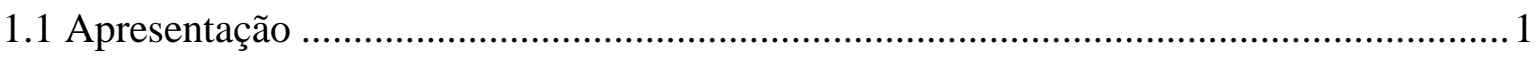

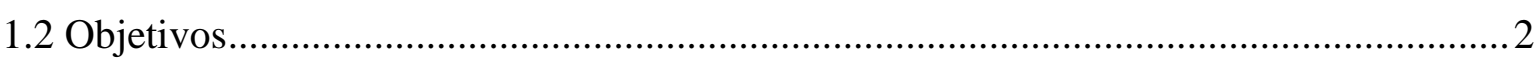

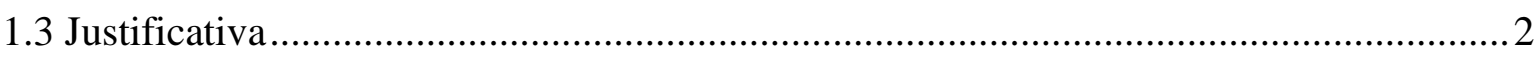

CAPÍTULO 2 - REVISÃo BIBLIOGRÁFICA ...................................................... 5

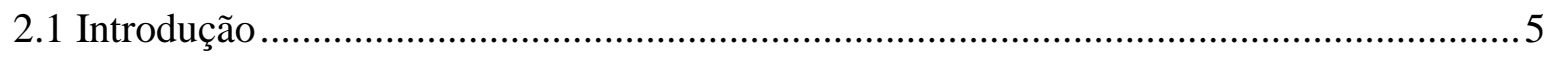

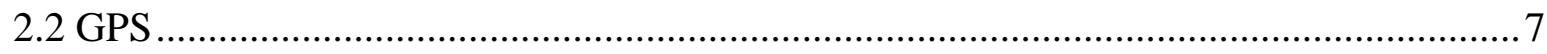

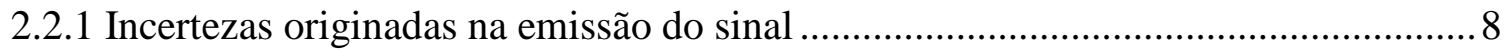

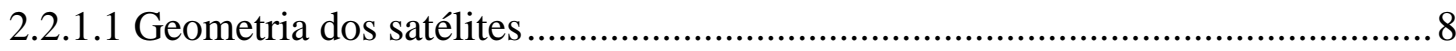

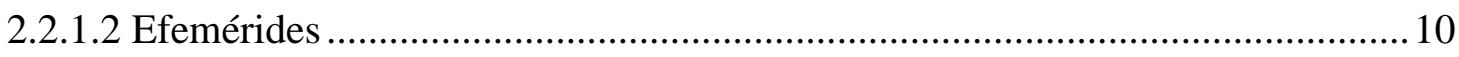

2.2.2 Incertezas originadas na propagação e recepção do sinal....................................... 11

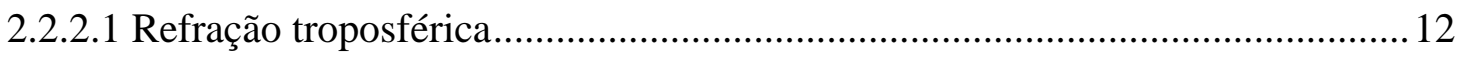

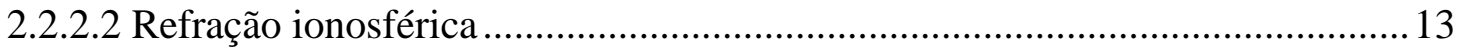

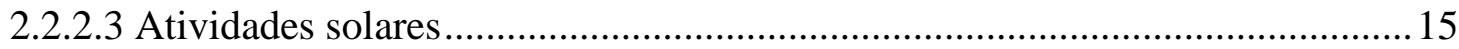

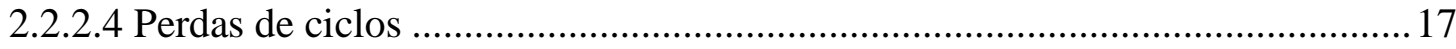

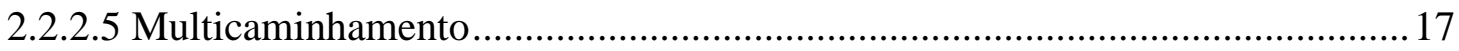

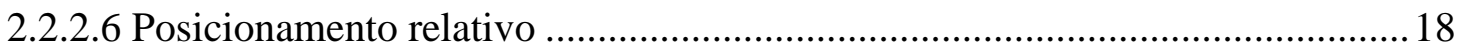

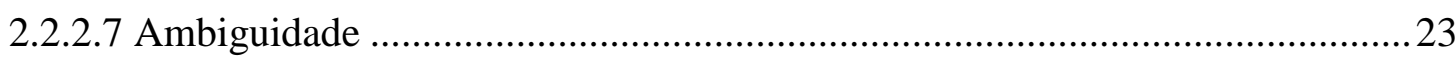

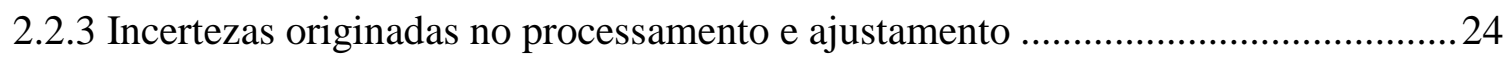


2.2.3.1 Distância e geometria entre as estações RBMC

2.2.3.2 Precisão, acurácia e exatidão

2.2.3.3 Ajustamento pelo método dos mínimos quadrados e análise da qualidade do

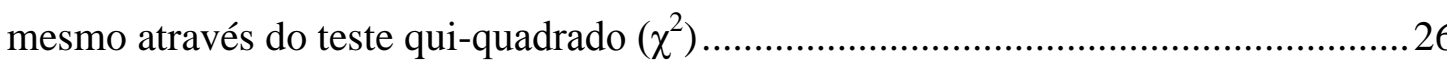

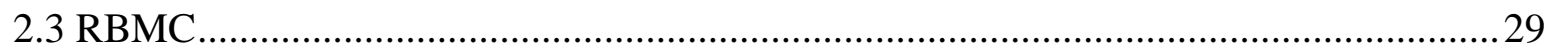

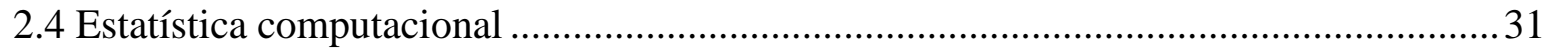

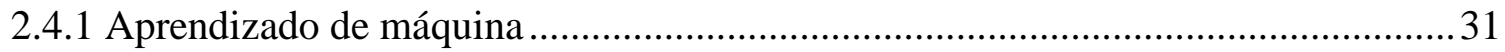

2.4.2 Hierarquia e paradigmas do aprendizado de máquina...........................................32

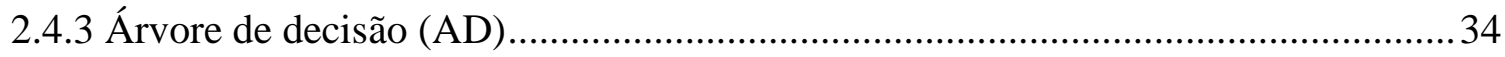

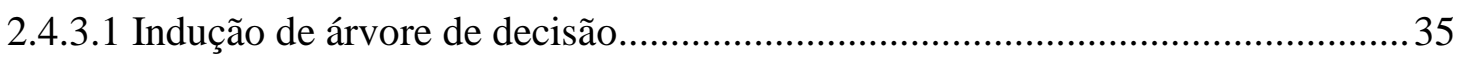

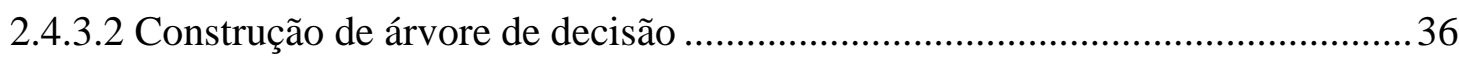

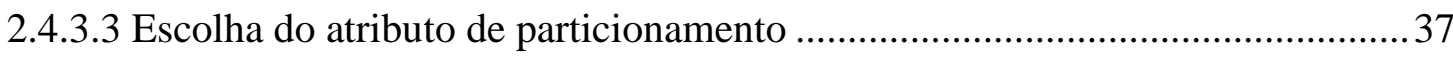

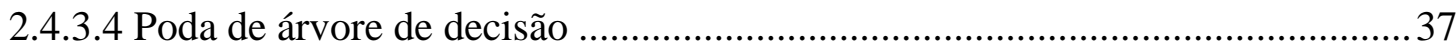

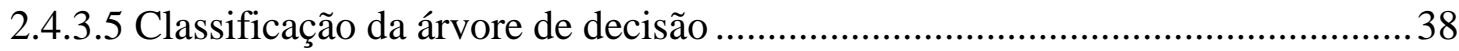

\section{CAPÍTULO 3 - MATERIAIS, MÉTODOS E RESULTADOS DOS}

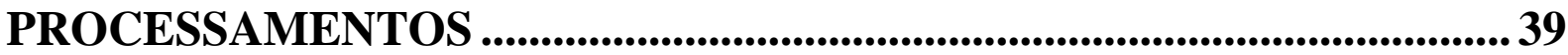

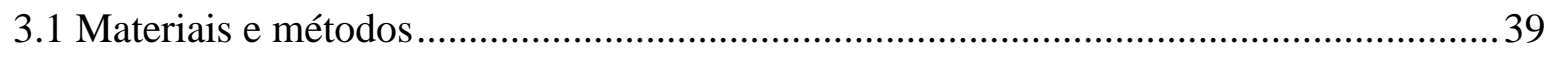

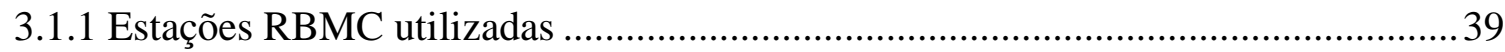

3.1.2 Precisão dos equipamentos utilizados pelas estações RBMC ................................ 41

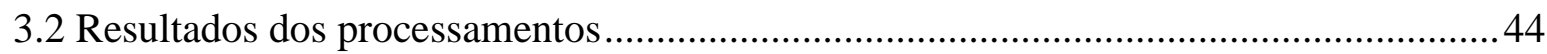

3.2.1 Distâncias menores que $300 \mathrm{~km}$ e geometria ideal entre as estações da RBMC..... 44

3.2.2 Distâncias diferentes (com pelo menos uma menor que $300 \mathrm{~km}$ ) e geometria ruim

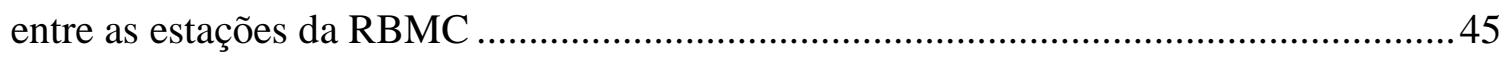

3.2.3 Distâncias maiores que $700 \mathrm{~km}$ e geometria ideal entre as estações da RBMC .....46

3.2.4 Distâncias diferentes (com pelo menos uma maior que $700 \mathrm{~km}$ ) e geometria ruim

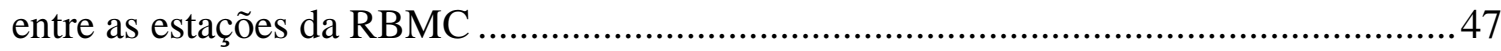

\section{CAPÍTULO 4 - CLASSIFICAÇÃO E ANÁLISE DOS RESULTADOS ... 49}

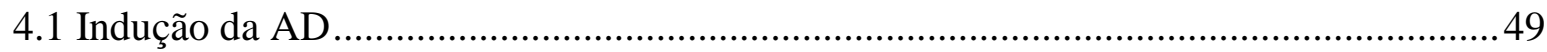

4.2 Parâmetros para a classificação da $\mathrm{AD}$....................................................................51

4.2 Estrutura do banco de dados e legenda da classificação da AD ....................................52 
4.3.1 Distâncias menores que 300 km e geometria ideal (VARG-VICO-RIOD) ............54

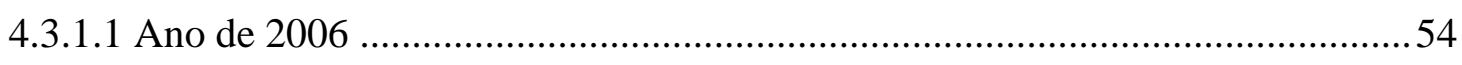

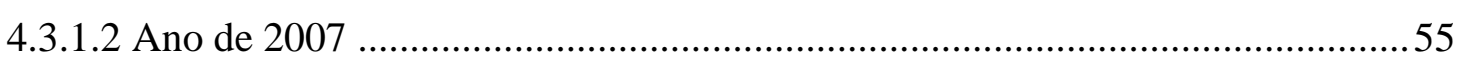

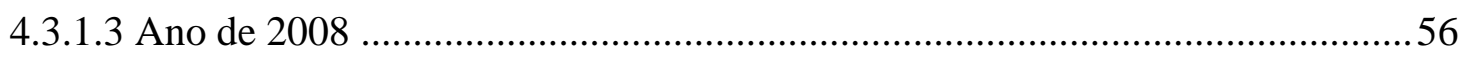

4.3.2 Distâncias diferentes (com pelo menos uma menor que $300 \mathrm{~km}$ ) e geometria ruim entre as estações da RBMC (VARG-RIOD-UBER) .......................................................57

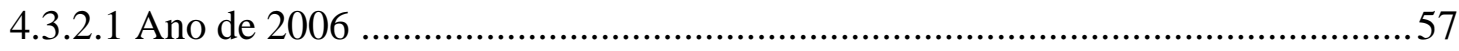

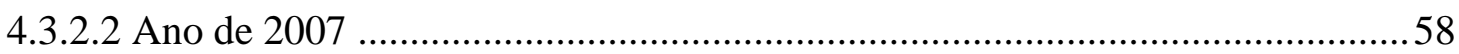

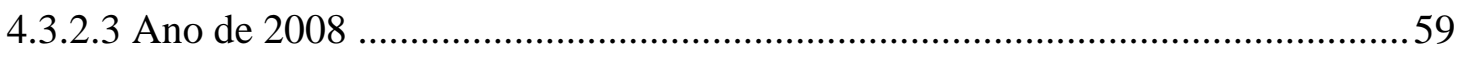

4.3.3 Distâncias maiores que 700 km e geometria ideal entre as estações da RBMC

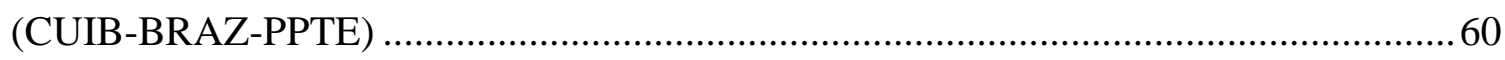

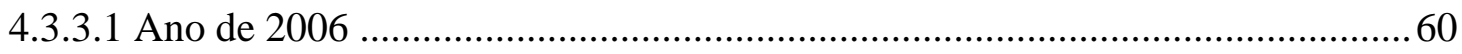

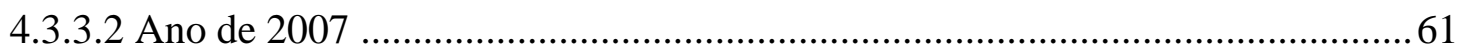

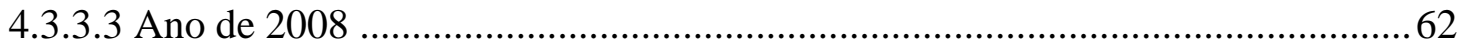

4.3.4 Distâncias maiores que 700 km e geometria ruim entre as estações da RBMC

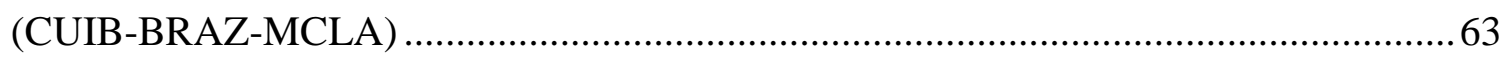

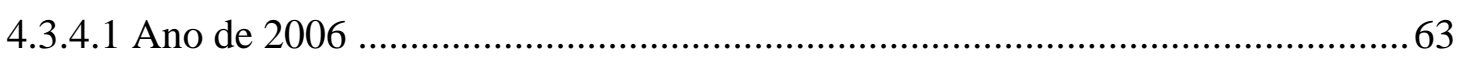

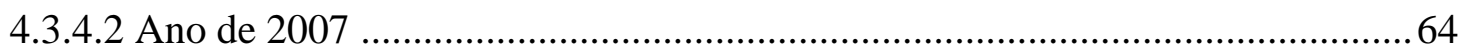

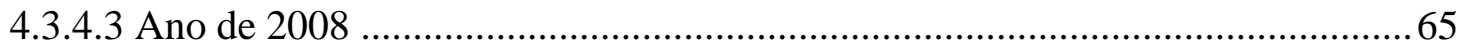

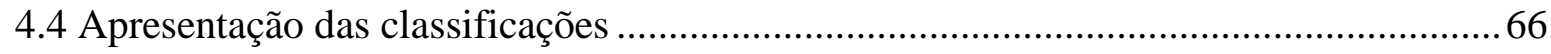

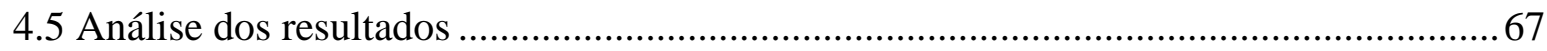

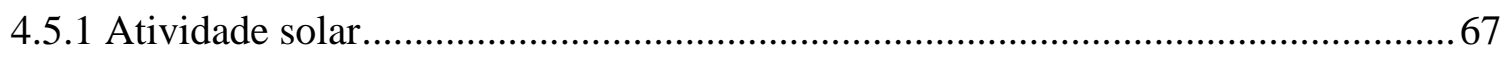

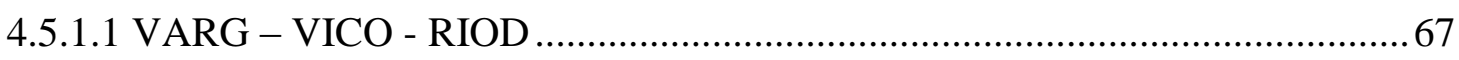

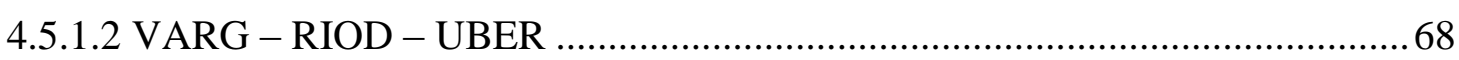

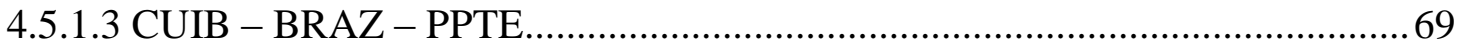

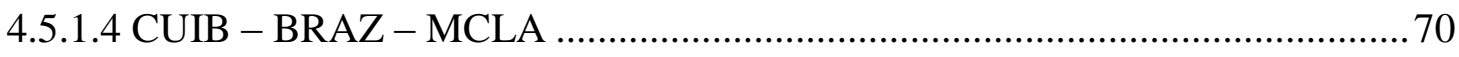

4.5.2 Distância entre as linhas de base e configuração entre as estações da RBMC........71

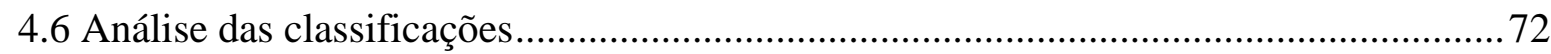

4.7 Tabela de classificação de acurácia recomendada..................................................... 74

4.8 Validação da tabela de classificação de acurácia ...................................................... 75

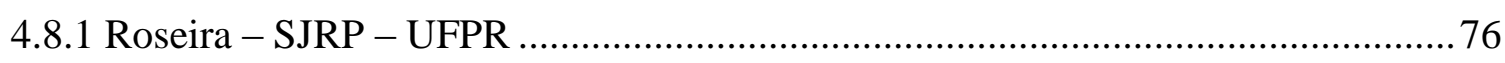

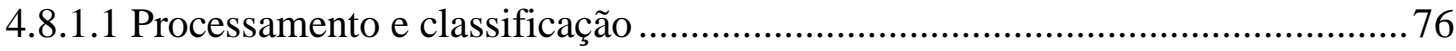

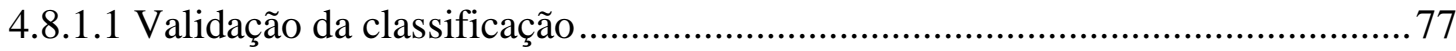




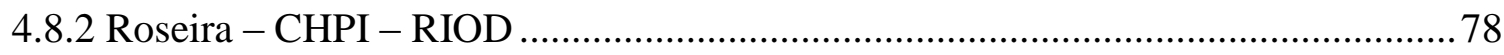

4.8.2.1 Processamento e classificação ....................................................................... 78

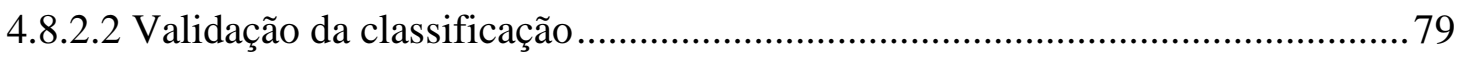

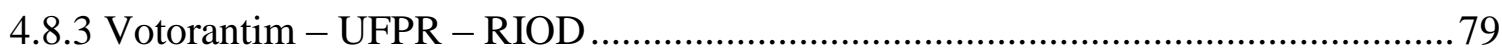

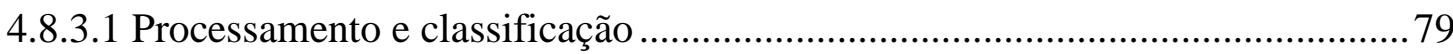

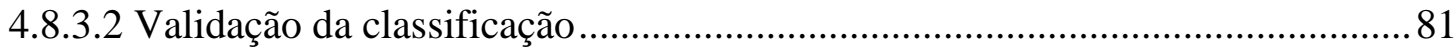

CAPÍTULO 5 - CONCLUSÕES ..........................................................................8 83

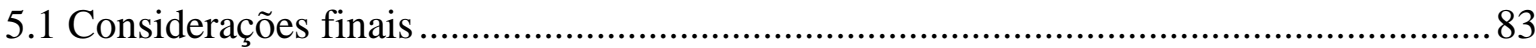

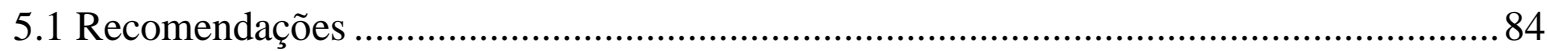

CAPÍTULO 6 - REFERÊNCIAS BIBLIOGRÁFICAS....................................87

ANEXO A - Manual de processamento no Topcon Tools..................................91

ANEXO B - Relatórios de processamento e ajustamento..................................97

ANEXO C - Monografias das estações RBMC ..........................................281 


\section{LISTA DE FIGURAS}

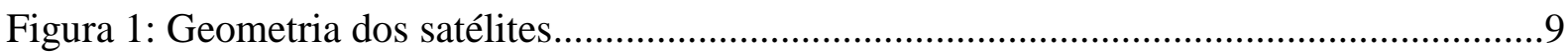

Figura 2: Movimento oscilatório de um elétron gerando uma onda eletromagnética..............12

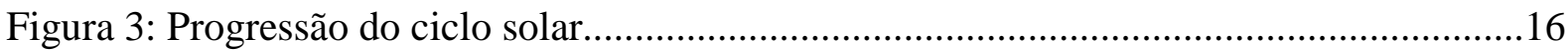

Figura 4: Demonstração do efeito de multicaminhamento......................................................18

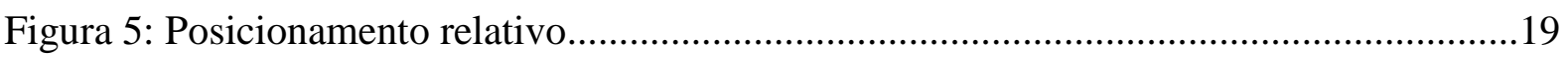

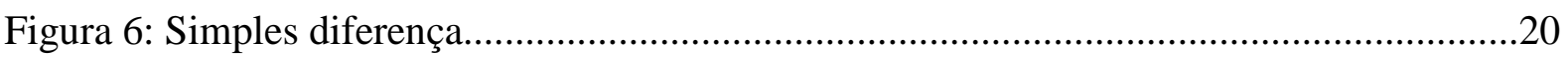

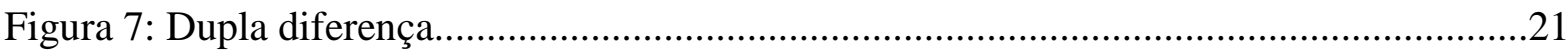

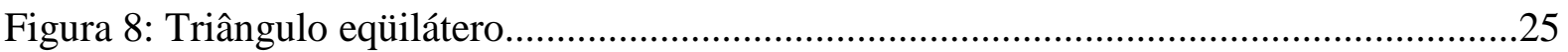

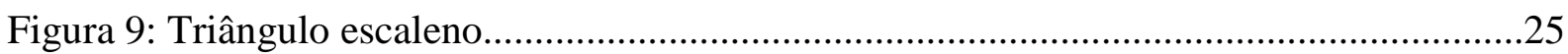

Figura 10: Ajustamento pelo método dos mínimos quadrados...........................................27

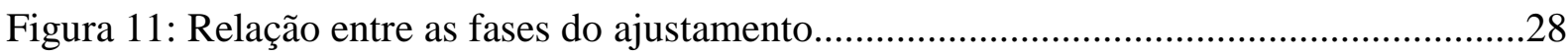

Figura 12: Disposição das estações da RBMC existentes em 2010.........................................30

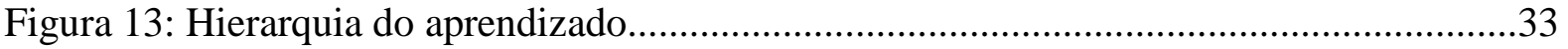

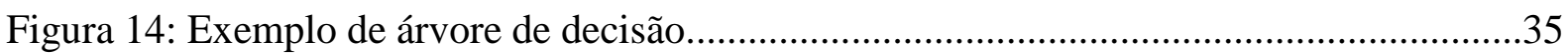

Figura 15: Geometria entre as estações CUIB - BRAZ - PPTE...........................................39

Figura 16: Geometria entre as estações CUIB - BRAZ - MCLA.........................................40

Figura 17: Geometria entre as estações VARG - VICO - RIOD ...........................................40

Figura 18: Geometria entre as estações VARG - RIOD - UBER ........................................40

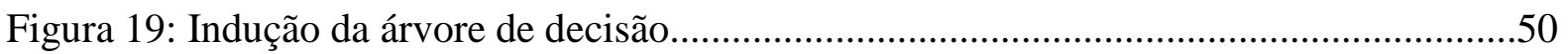

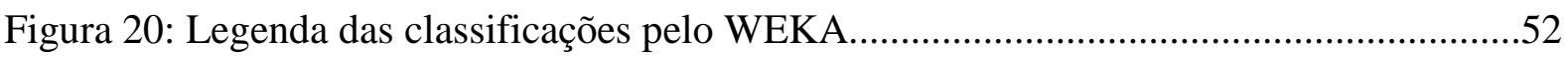

Figura 21: Exemplo de estrutura do banco de dados utilizado pela AD.................................53

Figura 22: Gráfico da classificação pelo WEKA.....................................................................54

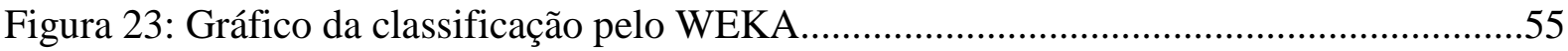

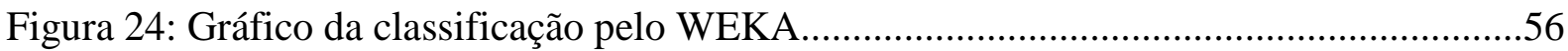


Figura 25: Gráfico da classificação pelo WEKA...................................................................57

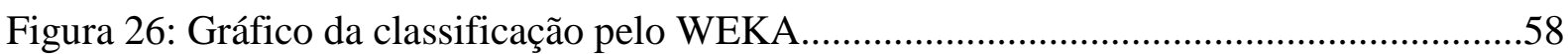

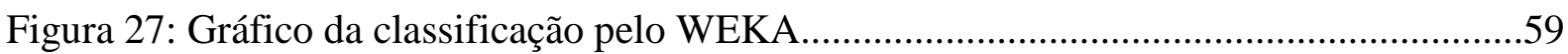

Figura 28: Gráfico da classificação pelo WEKA..................................................................60

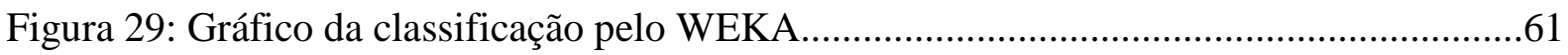

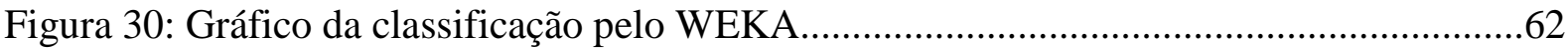

Figura 31: Gráfico da classificação pelo WEKA.....................................................................63

Figura 32: Gráfico da classificação pelo WEKA..................................................................64

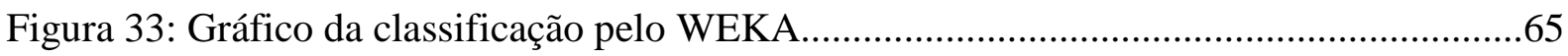

Figura 34: Configuração geométrica entre o ponto de interesse e as estações SJRP e UFPR

Figura 35: Gráfico da classificação pelo WEKA do ponto Roseira.........................................77

Figura 36: Configuração geométrica entre o ponto de interesse e as estações CHPI e RIOD

Figura 37: Gráfico da classificação pelo WEKA do ponto Roseira........................................79

Figura 38: Configuração geométrica entre o ponto de interesse e as estações RIOD e UFPR. .80

Figura 39: Gráfico da classificação pelo WEKA do ponto Votorantim .81 


\section{LISTA DE TABELAS}

Tabela 1: Coordenadas das estações VICO e RIOD, Sistema de Referência SIRGAS2000

Tabela 2: Coordenadas da estação VARG (Sistema de Referência SIRGAS2000)..... .45

Tabela 3: Resultados da configuração VARG-VICO-RIOD

Tabela 4: Coordenadas das estações RIOD e UBER (Sistema de Referência SIRGAS2000) .46

Tabela 5: Resultados da configuração VARG-RIOD-UBER.

Tabela 6: Coordenadas das estações BRAZ e PPTE (Sistema de Referência SIRGAS2000)

Tabela 7: Coordenadas da estação CUIB (Sistema de Referência SIRGAS2000) 47

Tabela 8: Resultados da configuração CUIB-BRAZ-PPTE.

Tabela 9: Coordenadas das estações BRAZ e MCLA (Sistema de Referência SIRGAS2000). .48

Tabela 10: Resultados da configuração CUIB-BRAZ-MCLA. 48

Tabela 11: Tabela de classes das linhas base .52

Tabela 12: Classificação da configuração VARG-VICO-RIOD .66

Tabela 13: Classificação da configuração VARG-RIOD-UBER .66

Tabela 14: Classificação da configuração CUIB-BRAZ-PPTE .66

Tabela 15: Classificação da configuração CUIB-BRAZ-MCLA .66

Tabela 16: Variação da discrepância para as diferentes configurações. .72

Tabela 17: Variação do PDOP para as diferentes configurações. .73

Tabela 18: Variação das precisões horizontais e verticais para as diferentes configurações .73

Tabela 19: Classificação da Acurácia. .75 
Tabela 20: Relatório de Processamento do ponto Roseira....................................................76

Tabela 21: Relatório de Processamento do ponto Roseira.......................................................78

Tabela 22: Relatório de Processamento do ponto Votorantim.................................................80 


\section{LISTA DE ABREVIATURAS E SIGLAS}

\begin{tabular}{|c|c|}
\hline $\mathrm{AD}$ & - Árvore de Decisão \\
\hline BRAZ & - Estação da RBMC de Brasília \\
\hline CC-RBMC & - Centro de Controle da RBMC \\
\hline CHPI & - Estação da RBMC de Cachoeira Paulista \\
\hline CUIB & - Estação da RBMC de Cuiabá \\
\hline DD & - Dupla Diferença \\
\hline DEGED & - Departamento de Geodésia \\
\hline DJ & - Dia Juliano \\
\hline DoD & - Departament of Defense \\
\hline DOP & - Dilution of Precision \\
\hline EPUSP & - Escola Politécnica da Universidade de São Paulo \\
\hline EUA & - Estados Unidos da América \\
\hline FNMA & - Fundo Nacional de Meio Ambiente \\
\hline GDOP & - Geometric Dilution of Precision \\
\hline GNSS & - Global Navigation Satellite System \\
\hline GPS & - Global Positioning System \\
\hline HDOP & - Horizontal Dilution of Precision \\
\hline IBGE & - Instituto Brasileiro de Geografia e Estatística \\
\hline IGS & - International GNSS Service \\
\hline INCRA & - Instituto Nacional de Colonização e Reforma Agrária \\
\hline MCLA & - Estação da RBMC de Montes Claros \\
\hline MMQ & - Método dos Mínimos Quadrados \\
\hline MVC & - Matriz Variância-Covariância \\
\hline
\end{tabular}




\begin{tabular}{|c|c|}
\hline NEIA & - Estação da RBMC de Cananéia \\
\hline NNSS & - Navy Navigation Satellite System \\
\hline NOAA & - National Oceanic and Atmospheric Administration \\
\hline PDOP & - Positional Dilution of Precision \\
\hline PLL & - Phase Locked Loop \\
\hline PPTE & - Estação da RBMC de Presidente Prudente \\
\hline RBMC & - Rede Brasileira de Monitoramento Contínuo \\
\hline RIOD & - Estação da RBMC do Rio de Janeiro \\
\hline $\mathrm{SD}$ & - Simples Diferença \\
\hline SGB & - Sistema Geodésico Brasileiro \\
\hline SIRGAS & - Sistema de Referência para as Américas \\
\hline SJRP & - Estação da RBMC de São José do Rio Preto \\
\hline TD & - Tripla Diferença \\
\hline TDIDT & - Top Down Induction of Decision Trees \\
\hline TDOP & - Time Dilution of Precision \\
\hline TEC & - Total Electron Content \\
\hline UBAT & - Estação da RBMC de Ubatuba \\
\hline UBER & - Estação da RBMC de Uberlândia \\
\hline UFPR & - Estação da RBMC da Universidade Federal do Paraná \\
\hline VARG & - Estação da RBMC de Varginha \\
\hline VDOP & - Vertical Dilution of Precision \\
\hline VICO & - Estação da RBMC de Viçosa \\
\hline WEKA & - Waikato Enviroment Knowledge Analysis \\
\hline
\end{tabular}




\section{RESUMO}

DORTH, M. K. S. Proposta de Classificação de linhas de base obtidas com dados GPS, a luz de Árvore de Decisão.

Ao se efetuar levantamentos utilizando a tecnologia GNSS, o processamento desses dados, bem como uma análise dos fatores oriundos dos processamentos e a correta interpretação dos resultados obtidos, consiste em fator primordial para se definir a qualidade de um levantamento. Contudo, os resultados estatísticos fornecidos pelos softwares comerciais após o processamento e ajustamento dos dados, apesar de garantir maior confiabilidade aos levantamentos, não fornecem a acurácia das coordenadas encontradas, apresentando apenas a sua precisão. Assim, este trabalho tem por objetivo final, fornecer uma tabela onde seja possível, através de uma comparação dos resultados oriundos dos processamentos, classificar a acurácia dos mesmos. Para tanto, foram efetuados os processamentos e ajustamentos de dados inerentes as quatro estações do ano, durante os anos de 2006, 2007 e 2008, e após adequada análise dos mesmos, foi implementada uma Tabela de Acurácia Recomendada, onde os profissionais da área de mensuração poderão, através de uma comparação entre os relatórios de processamento fornecidos e os itens da referida tabela, efetuar a classificação da acurácia dos trabalhos de interesse.

Palavras-Chave: GNSS, Acurácia, Qualidade de Coordenadas. 


\section{ABSTRACT}

DORTH, M. K. S. Proposal for Classification of baselines obtained with GPS data, in light of Decision Tree

When making surveys using GNSS technology, the processing of these data, as well as an analysis of the factors resulting from the processing and the correct interpretation of results, is to prime factor for defining the quality of a survey. However, the statistics provided by commercial software after processing and adjustment of the data, while ensuring high reliability of surveys, do not provide the accuracy of the coordinates found, showing only its precision. This paper aims to provide a table where possible, by comparing the results from the processing, The classification accuracy of them. To do so, we made adjustments and the processing of data relating the four seasons, during the years 2006, 2007 and 2008, and after proper analysis of the same purpose, a Table of Accuracy Recommended where professionals in the area of measurement may, through a comparison between the reports provided and processing the items of the tariff, to perform the classification accuracy of the work of interest.

Palavras-Chave: GNSS, Accuracy, Coordinate Quality. 


\section{CAPÍTULO 1 - INTRODUČ̃̃O}

\subsection{Apresentação}

Esta pesquisa tem por objetivo a criação de uma tabela que possibilite efetuar uma estimativa da acuracia dos resultados de processamentos de observações obtidas quando se faz uso de dados GNSS (Global Navigation Satellite System), através da correlação de informações provenientes do processamento de observações, com a acurácia e precisão dos mesmos, utilizando, para isso, os dados coletados de estações da Rede Brasileira de Monitoramento Contínuo (RBMC), disponibilizados pelo Instituto Brasileiro de Geografia e Estatística (IBGE).

Inicialmente será realizado o processamento de observações referentes as linhas de base de estações previamente escolhidas e, após, será feita uma análise das discrepâncias entre as coordenadas obtidas com os processamentos de observações das estações adotadas como desconhecidas, e as coordenadas conhecidas (homologadas pelo IBGE). Após, serão considerados fatores, tais como a distância e geometria entre as estações da RBMC, estações do ano, PDOP, atividade solar, precisão horizontal e vertical e a solução da ambigüidade. A partir desta análise, e com critérios estabelecidos, fazendo-se uso da técnica das Árvores de Decisão (AD), será feita uma classificação da acurácia das coordenadas, segundo os fatores especificados anteriormente, e após, a partir dos dados obtidos, será implementada uma tabela de classificação de acurácia, onde a mesma será dividida em 4 classes: A, B, C e R, onde:

- Processamentos em que todas as condições definidas forem atendidas, serão enquadrados numa classe A;

- Processamentos em que um item não atender as condições definidas, serão enquadrados numa classe B;

- Processamentos em que dois itens não atenderem as condições definidas, serão enquadrados numa classe $\mathrm{C}$;

- Processamentos em que três ou mais itens não atenderem as condições definidas, serão enquadrados numa classe $\mathrm{R}$;

A idéia de se analisar a acurácia das coordenadas provenientes de dados oriundos de levantamentos geodésicos partiu do fato de que as coordenadas obtidas com processamentos diferem das coordenadas homologadas das mesmas, com essa discrepância podendo chegar a 
1 metro, e, este fato não é levado em consideração com a devida importância pelos profissionais envolvidos na área de Mensuração.

\subsection{Objetivos}

Esse trabalho visa analisar as coordenadas obtidas com o processamento de dados inerentes somente ao sistema GPS (Global Positioning System), alertando para o problema das soluções da ambigüidade em linhas de base com diferentes comprimentos, e para o problema da diferença encontrada entre a coordenada obtida através de processamentos, com as coordenadas homologadas pelo IBGE. Assim um banco de dados será implementado, e uma tabela de classificação de acurácia será criada, para que posteriormente essas informações possam ser utilizadas em trabalhos cotidianos da área de Mensuração.

Assim, este projeto de pesquisa tem por objetivos principais:

- Analisar dados provenientes de processamentos de dados GPS e os fatores que degradam a qualidade das informações obtidas, por exemplo, erros introduzidos nas coordenadas devido a interferência das camadas atmosféricas em diferentes estações do ano, atividade solar, distância e geometria entre as estações da RBMC, PDOP, precisão horizontal e vertical;

$>$ Verificar em quais magnitudes de linhas de base a acurácia dos resultados dos processamentos realizados com dados GPS sofrem maior degradação;

> Implementar um banco de dados correlacionando os dados citados anteriormente com a acurácia de coordenadas oriundas de levantamentos GPS, e após implementar uma tabela que possa ser utilizada como parâmetro de qualidade para os profissionais da área de Mensuração.

\subsection{Justificativa}

O advento de técnicas que utilizam satélites artificiais para gerar posicionamento, otimizou o campo da Geomática, visto que com esta tecnologia os métodos para obtenção de coordenadas de pontos sobre a superfície da Terra se tornaram mais rápidos. Contudo, esta tecnologia só pode ser considerada benéfica, quando se é capaz de conhecer os dados obtidos e os efeitos que exercem influência sobre eles para que além de resultados precisos, tenham-se resultados acurados. 
Logo, surge no cenário atual a necessidade de se conhecer a acurácia de trabalhos cotidianos, através de critérios pré-estabelecidos, utilizando para isso uma validação dos dados obtidos através dos processamentos de linhas-base fazendo uso de softwares comerciais. 


\section{CAPÍTULO 2 - REVISÃO BIBLIOGRÁFICA}

\subsection{Introdução}

Geodésia é a ciência que se ocupa da determinação dos parâmetros definidores das formas, das dimensões e do campo de gravidade da Terra, (IBGE, 2010). Pode ser dividida em Geodésia Global, Levantamentos Geodésicos (nacional e supranacional) e Topografia. A Geodésia Global é responsável pela determinação da figura da Terra e pelos parâmetros definidores do campo de gravidade. Os Levantamentos Geodésicos estabelecem os fundamentos para a determinação da superfície e gravidade referente a uma região de interesse (normalmente um país ou grupo de países), obtidos através de pontos de controle de redes geodésicas e gravimétricas, levando em conta a curvatura da Terra, e na Topografia (levantamentos topográficos, cadastrais ou de engenharia), busca-se um detalhamento da superfície em um nível local, sendo a curvatura e a gravidade geralmente ignoradas (SEEBER, 2003).

Posicionar-se sempre foi uma preocupação experimentada pelos homens. Inicialmente, a Lua, algumas constelações e o Sol eram utilizados para esse fim. Na década de 20, foi introduzido pela companhia de Germann-Lorenz, um sistema de rádio-navegação, permanecendo em operação por várias décadas. Este sistema era baseado na transmissão do código Morse por duas estações distintas. O piloto, ao manter a aeronave no alinhamento da bissetriz do ângulo formado com as duas estações, recebia um tom continuo (SCHAAL, 2006).

Em meados da década de 40, com intuito militar, foram criados sistemas de navegação baseados na emissão de sinais codificados de rádio a partir de estações localizadas em pontos estratégicos para dar cobertura nas áreas de interesse. Usando um conjunto mínimo de três estações e com um apropriado espaçamento geográfico entre elas, sendo uma usada como padrão de referência de tempo, já era possível determinar as coordenadas de pontos de interesse por meio da diferença do tempo de recepção dos sinais provenientes das estações. Esta técnica passou a ser amplamente explorada com os sistemas LORAN e ÔMEGA (FRANK $^{1}, 1983$ e Swanson ${ }^{2}, 1983$, apud SCHALL, 2006).

Com o advento da Era Espacial, satélites artificiais começaram a ser largamente utilizados na determinação das coordenadas de pontos localizados na superfície terrestre. $\mathrm{O}$

\footnotetext{
${ }^{1}$ FRANK, R. L. Current Development in Loran C. Proceedings of IEEE, New York, v. 71, n. 10, Oct. 1983.

${ }^{2}$ SWANSON, E. R. Omega. Procedings of IEEE, v. 71, n. 10, Oct, 1983.
} 
sistema TRANSIT, também conhecido como NNSS (do inglês, Navy Navigation Satellite System), foi o primeiro sistema de navegação por satélite a ser usado operacionalmente e fornecia informação de posição horizontal a partir do desvio Doppler do sinal transmitido pelos satélites. O TRANSIT foi desenvolvido pelo Laboratório de Física Aplicada da Johns Hopkins University (JHUAPL) para a marinha dos Estados Unidos. O primeiro teste bem sucedido do sistema foi realizado em 1960. Os satélites conhecidos como OSCAR ou NOVA foram colocados em órbitas polares de baixa altitude, a $1100 \mathrm{~km}$ acima da superfície terrestre, com um período orbital aproximado de 106 minutos. A "constelação" de cinco satélites foi necessária para permitir uma cobertura global. Foi um dos predecessores do GPS, tendo permanecido operacional ao longo de um período ininterrupto de 33 anos, até 1996, durante os quais foi extensivamente utilizado pela navegação marítima.

Na década de 1970 foi proposto um novo sistema de navegação, o NAVSTAR-GPS, ou simplesmente GPS, desenvolvido pelo Departamento de Defesa (DoD) dos Estados Unidos da América (EUA), com o intuito de ser o principal sistema de navegação das forças armadas americanas. Ele resultou da fusão de dois programas financiados pelo governo norteamericano, o Timation e o System 621B, sob responsabilidade da marinha e da força aérea dos EUA.

As atividades geodésicas têm experimentado uma verdadeira revolução com o advento dos sistemas de posicionamento globais via satélites artificiais. A capacidade que estes sistemas possuem de permitir a determinação de posições, estáticas ou cinemáticas, aliando rapidez e precisão muito superiores aos métodos clássicos de levantamento, provocou a necessidade de revisão das características do SGB (Sistema Geodésico Brasileiro). A implantação da RBMC (Rede Brasileira de Monitoramento Contínuo) representa a conseqüência desta rediscussão. Com o seu funcionamento, os usuários de informações do IBGE passaram a contar com uma infraestrutura ativa e compatível com os métodos atuais de posicionamento baseados no GNSS, (IBGE, 2010).

Contudo, as coordenadas obtidas com o GNSS sofrem uma série de influências, desde o momento da emissão das ondas eletromagnéticas pela antena do satélite, até o momento de recebimento das informações pela antena do receptor terrestre, o que causa certa degradação na precisão e na exatidão das coordenadas obtidas.

Neste trabalho, serão analisados exclusivamente dados provenientes do sistema GPS e mais a frente serão feitas algumas explanações sobre o mesmo e os erros que degradam a qualidade das informações com ele obtidas. 


\subsection{GPS}

Como o próprio nome sugere, o GPS é um sistema de abrangência global que tem facilitado atividades inerentes a posicionamento, e a sua concepção permite que um usuário, em qualquer local da superfície terrestre, ou próximo a ela, tenha à sua disposição no mínimo 4 satélites para serem rastreados, número este suficiente para que se tenha um posicionamento em tempo real. O princípio básico de navegação pelo GPS consiste na medição de distâncias entre a antena do receptor e os satélites rastreados pelo mesmo, onde conhecendo-se as coordenadas dos satélites num determinado sistema de referência apropriado, pode-se calcular as coordenadas da antena do receptor nesse mesmo sistema de referência. Geometricamente, três distâncias seriam o suficiente para o cálculo das coordenadas, onde o problema se reduziria a um sistema com três equações a três incógnitas, porém uma quarta distância é requerida devido ao erro de não-sincronismo entre os relógios dos satélites e o do receptor, (MONICO, 2008).

Há, basicamente, três tipos de observáveis GPS: o efeito Doppler, a pseudodistância e a fase portadora, e segundo BAIO et al. (1998), as principais fontes de erros para o posicionamento, ao se utilizar este sistema, são: a disposição geométrica dos satélites, o efeito do multicaminhamento, o erro do relógio do receptor, a interferência da ionosfera e troposfera e o erro orbital do satélite. Afirmam, ainda, que a acurácia do sistema depende de vários fatores, dentre eles: configuração da geometria dos satélites no momento do posicionamento; frequência do sinal utilizado para o posicionamento (L1, L2, L2c); configuração do receptor, como taxa de aquisição, ângulo de elevação, influência do multicaminhamento, resolução da ambiguidade e o método utilizado para a correção diferencial (satélite, rádio, pós-processado).

Investigar como as incertezas se propagam no resultado das medições com o GPS, implica em controlar todo componente que possa vir a causar algum tipo de erro nesta medida, comprometendo assim a exatidão do posicionamento (Menzori, 2005). Assim, os erros relevantes neste trabalho serão classificados em 3 grupos maiores, sendo eles:

(1) Incertezas originadas na emissão do sinal;

(2) Incertezas originadas na propagação e recepção do sinal; e

(3) Incertezas originadas no processamento e ajustamento dos dados. 


\subsubsection{Incertezas originadas na emissão do sinal}

Neste trabalho, as incertezas relacionadas com a emissão do sinal, ao se utilizar o posicionamento de pontos pelo GPS, dizem respeito a geometria resultante da distribuição dos satélites e das qualidades das efemérides.

\subsubsection{Geometria dos satélites}

A geometria formada pela distribuição dos satélites em relação à antena receptora também influencia na precisão do posicionamento, e pode ser avaliada através dos fatores DOP ("Dilution of Precision"). Os indicadores DOPs são funções dos elementos diagonais da matriz das covariâncias, e resultam dos ajustamento pelo Método Paramétrico para quatro satélites, expressa no sistema geocêntrico cartesiano por (LEICK, 2004):

$$
Q_{X}=\left[\begin{array}{llll}
q_{X X} & q_{X Y} & q_{X Z} & q_{X t} \\
q_{Y X} & q_{Y Y} & q_{Y Z} & q_{Y t} \\
q_{Z X} & q_{Z Y} & q_{Z Z} & q_{Z t} \\
q_{t X} & q_{t Y} & q_{t Z} & q_{t t}
\end{array}\right]
$$

Logo, os indicadores de qualidade podem ser individualizados de maneira correlacionada com os elementos desta matriz, cada um em função do elemento variável de interesse, onde (MENZORI, 2005):

$>$ HDOP - indicador de diluição da precisão usado para avaliar o posicionamento horizontal;

$>$ VDOP - indicador de diluição da precisão usado para avaliar o posicionamento vertical

$>$ PDOP - indicador de diluição da precisão usado para avaliar o posicionamento tridimensional

TDOP - indicador de diluição da precisão usado para avaliar o efeito da disposição espacial dos satélites no tempo

$>$ GDOP- indicador de diluição da precisão usado para avaliar o posicionamento tridimensional considerando a determinação do tempo.

Neste trabalho, o fator DOP de interesse é o PDOP, e o mesmo pode ser interpretado geometricamente como sendo o inverso do volume de um tetraedro (formado entre a antena receptora e quatro satélites), onde a melhor geometria ocorre quando o volume é máximo 
(valor DOP mínimo (LANGLEY, 1999). Assim, quanto maior o volume do tetraedro formado entre a antena receptora e os satélites (Figura 1b), o PDOP encontrado será melhor. Da mesma forma, quanto menor o volume do tetraedro formado, pior será o valor do PDOP (Figura 1a).

Figura 1: Geometria dos satélites

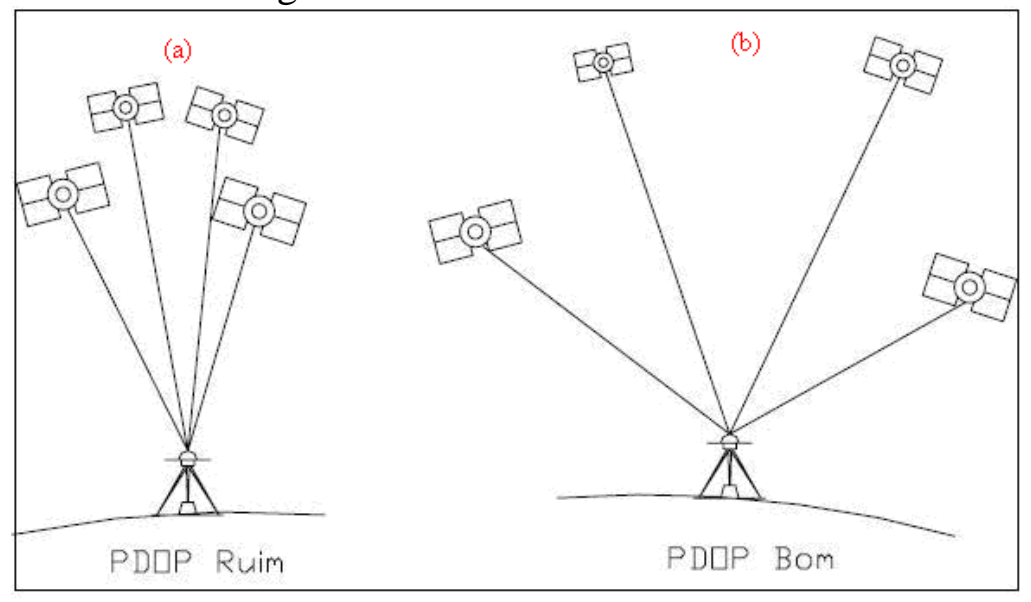

Fonte: Adaptado de ABREU (2007).

A definição dos diversos DOPs, a partir do conceito de ajustamento de observações, deixa claro que, quanto maior o número de satélites sendo rastreados, é de se esperar que melhores serão os diversos DOPs (MONICO, 2008).

O PDOP de uma determinada estação pode ser encontrado através da seguinte fórmula (LEICK, 2004):

$$
P D O P=\sqrt{q_{X X}+q_{Y Y}+q_{Z Z}}
$$

onde, $q_{X X}, q_{Y Y}$ e $q_{Z Z}$, diz respeito a qualidade da latitude, da longitude e da altura geométrica h do ponto;

Neste trabalho, o PDOP a ser considerado na proposta de classificação para uma classe A, será o que tiver valor menor ou igual a 3, devido a usualidade deste valor segundo as literaturas clássicas da área.

\section{A NORMA TÉCNICA PARA GEORREFERENCIAMENTO DE IMÓVEIS RURAIS} (INCRA, 2003) adota como valor de referência para o PDOP como sendo igual ou inferior a 6 para aceitar os trabalhos de georreferenciamento, porém este valor só pode ser considerado bom para condições locais de bloqueio. 
Em décadas anteriores, devido a constelação GPS contar com uma menor quantidade de satélites, este valor de referência podia ser considerado aceitável, pois a dificuldade de se obter uma boa configuração entre a pequena quantidade de satélites GPS era maior. Porém, atualmente, este problema foi solucionado, pois, em qualquer ponto da superfície terrestre há pelo menos 7 satélites a disposição do usuário, o que permite que em trabalhos onde os pontos de interesse estejam em um horizonte mais aberto (caso do Transporte de Coordenadas) este valor de referência possa ser alterado para 3.

\subsubsection{Efemérides}

A determinação das coordenadas de pontos utilizando o GPS, implica no conhecimento da posição do satélite, no instante da emissão do sinal. Essa posição, obtida através dos parâmetros transmitidos pelos próprios satélites, se constitui na efeméride transmitida (broadcast ephemeris) (MENZORI, 2005).

Em geral, o método para produção das efemérides transmitidas consiste em duas etapas: inicialmente, efetua-se um processamento onde produz-se as efemérides de referência para um determinado período, baseando-se em um modelo que considera as forças que atuam nos satélites, sendo elas, basicamente, a força de atração gravitacional da Terra, forças de atração do Sol e da Lua bem como a pressão da radiação solar incidida sobre os satélites, e após, as discrepâncias entre as observações coletadas nas estações monitoras, e as calculadas com base nas efemérides de referência são processadas, usando-se o algoritmo de filtragem Kalman, com a inclusão de quatro semanas de dados para a predição das correções das efemérides de referência e do comportamento dos relógios dos satélites (procedimento este que envolve as observações de pseudodistância de todos os satélites visíveis nas estações monitoras, as quais são corrigidas das refrações troposféricas e ionosféricas, bem como dos efeitos relativistas), (MONICO, 2008).

Assim, a partir da predição da órbita de um satélite, com um arco de 28 horas dividido em intervalos de 4 horas, com sobreposição de 1 hora, geram-se nove efemérides diferentes, que uma vez por dia, ou mais (quando necessário), são transmitidas aos satélites (MONICO, 2008).

Entretanto, quando o grau de acurácia requerido para o trabalho for maior, deve-se fazer uso das efemérides precisas ou pós-processadas (precise ephemeris). Elas resultam do registro ponderado das posições percorridas pelos satélites em suas órbitas em dias consecutivos. Instituições oficiais como o IGS (International GNSS Service) monitoram 
continuamente a órbita dos satélites e disponibilizam estas informações através de suas páginas na Internet (MENZORI, 2005). Assim, a partir das órbitas produzidas nas instituições oficiais, realizam-se combinações que resultam em efemérides identificadas pelas siglas IGS, IGR e IGU, conforme pode ser visto a seguir (MONICO, 2008):

- IGS - resulta da combinação das órbitas dos vários centros de análise, e são disponibilizadas treze dias após a coleta dos dados;

- IGR - órbitas IGS rápidas, disponíveis após dezessete horas após a coleta dos dados; e

- IGU - órbitas IGS ultra-rápidas, compostas de duas partes: uma predita, disponível em tempo real, e outra com inclusão de observáveis, disponível após três horas da coleta dos dados e são disponibilizadas quatro vezes por dia.

Segundo (MONICO, 2008), a acurácia das posições dos satélites das efemérides IGS, IGR e IGU observada, são de $5 \mathrm{~cm}$, enquanto a da IGU predita é da ordem de $10 \mathrm{~cm}$, e no que concerne ao erro dos relógios dos satélites, tem-se acurácia de 0,1 ns para as efemérides IGS e IGR, e 0,2 e 5 ns para as efemérides IGU observadas e preditas.

Neste trabalho, devido ao grau de acurácia exigido, serão utilizadas efemérides precisas IGS, obtidas através do site http://igscb.jpl.nasa.gov/components/prods.html (último acesso em 29/01/2010).

\subsubsection{Incertezas originadas na propagação e recepção do sinal}

As incertezas originadas na propagação do sinal são as perturbações que atuam sobre a frente de onda, em sua propagação desde o ponto de transmissão do sinal localizado na antena do satélite, até a antena do receptor (Menzori, 2005).

A onda eletromagnética, por si só, é um fenômeno fundamental do universo, constituído pela composição de dois campos de força: o campo elétrico $\vec{E}$ e o campo magnético $\vec{H}$. Trata-se de um fenômeno e, em sua maioria, é decorrente do movimento dos elétrons. Quando o elétron é forçado a se movimentar, ele gera uma onda de acordo com o seu movimento. A Figura 2 apresenta pictoricamente a geração de uma onda, composta pelos dois campos, se propagando na direção Z, devido ao movimento forçado do elétron entre os semicírculos (SCHAAL, 2006). 
Figura 2: Movimento oscilatório de um elétron gerando uma onda eletromagnética

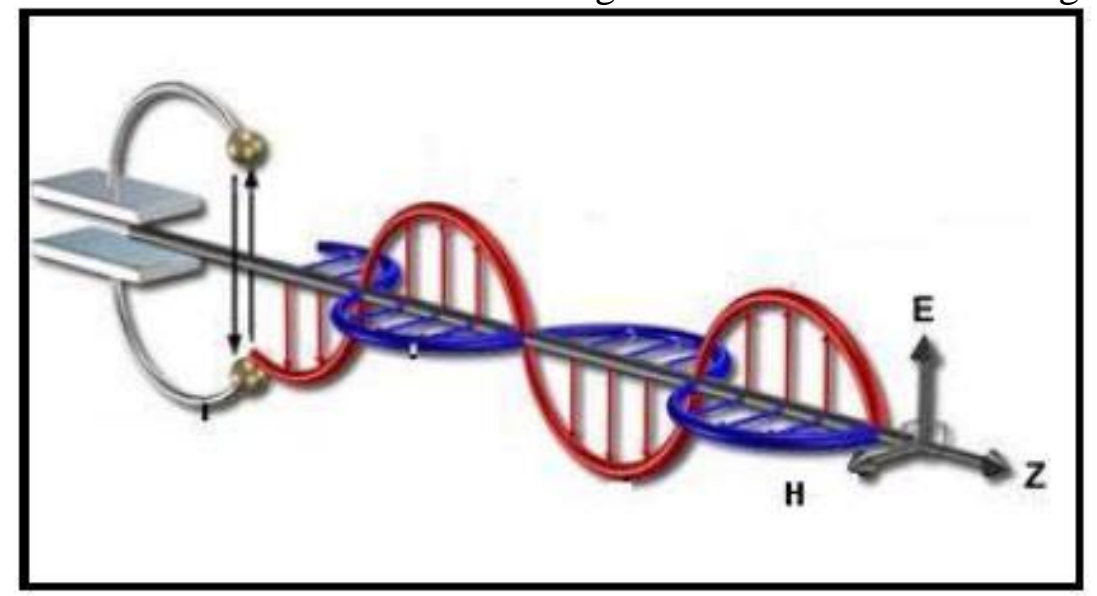

Fonte: Adaptado de Movimento de Elétron apud SCHAAL (2006).

Depois que a onda eletromagnética é gerada, ela está sujeita as influências do meio em que está se propagando e de objetos próximos a ela. O primeiro efeito sofrido pela onda é a diminuição de sua potência, à medida em que vai se afastando da antena.

O meio em que o sinal GPS se propaga consiste basicamente das camadas atmosféricas que vão da superfície terrestre até $50 \mathrm{~km}$ acima dela e de 50 a $390 \mathrm{~km}$, denominadas troposfera e ionosfera, respectivamente. O restante da distância entre o satélite e a antena receptora é basicamente vácuo.

\subsubsection{Refração troposférica}

A atmosfera é definida como um conjunto de camadas de gases, concêntricas à Terra. A sua estrutura está relacionada com elementos térmicos, químicos e eletromagnéticos. Existem duas camadas atmosféricas diretamente relacionadas à propagação de sinais GPS, sendo elas: troposfera e ionosfera.

A troposfera é compreendida entre a superfície terrestre até aproximadamente $50 \mathrm{~km}$ de altitude, formada em sua maioria por concentração de gases, contendo basicamente: Nitrogênio $\left(\mathrm{N}_{2}\right)$, Oxigênio $\left(\mathrm{O}_{2}\right)$, Dióxido de Carbono $\left(\mathrm{CO}_{2}\right)$, Argônio (Ar), vapor d'água e partículas neutras. O sinal propagado é influenciado diretamente pelo vapor d'água, pressão atmosférica e temperatura (Matsuoka et al, 2003).

O efeito da troposfera pode causar nas coordenadas variações na ordem de metros, em virtude do ângulo de elevação do satélite e da densidade da atmosfera. Daí a necessidade de conhecer as condições atmosféricas locais, em especial o monitoramento da troposfera para 
encontrar uma possível correlação entre um efeito atmosférico induzido e a variação de coordenadas.

Vários trabalhos procuram modelar a refratividade do ar a partir das variáveis atmosféricas, sendo divididos no estudo da influência do vapor d'água de equilíbrio, conhecido como componente não-hidrostática, e a influência do vapor d'água e demais gases em equilíbrio hidrostático, denominada componente hidrostática. A componente hidrostática varia com a temperatura e a pressão atmosférica local e é predita com razoável precisão, pois depende basicamente da pressão local, cuja variação é pequena, da ordem de $1 \%$ durante várias horas (Matsuoka et al, 2003).

Alguns modelos têm capacidade de modelar com boa acurácia a componente hidrostática responsável pela maior parte da refração troposférica, cerca de 90\%. A componente não-hidrostática é mais difícil de modelar, devido ao fato da alta variabilidade dos valores de temperatura e pressão do vapor d'água ao longo da coluna atmosférica.

Os efeitos da troposfera são evidenciados no posicionamento por GPS, principalmente na determinação da altura. Alguns programas computacionais de processamento de dados GPS apresentam modelos de correções para tais efeitos, onde é estimado o atraso zenital troposférico, através de técnicas de estimação estocástica variando o filtro de Kalman, que filtra as aproximações para estimar o atraso. Um problema na estimativa do atraso dos efeitos da troposfera é a correlação elevada entre a altura e os parâmetros da mesma (Matsuoka et al, 2003).

\subsubsection{Refração ionosférica}

A ionosfera é um gás ionizado pela energia de radiações eletromagnéticas que interagem com os seus constituintes, passando para o quarto estado da matéria, denominado plasma $\left(\mathrm{CHEN}^{3}\right.$ (1984) apud SCHAAL (2006)). A ionização depende das moléculas constituintes do gás, das suas condições físicas e da intensidade das radiações. À medida em que estas radiações se aproximam da superfície, encontram camadas mais densas aumentando a densidade de elétrons livres por meio de um processo fotoquímico. Simultaneamente, ocorre um processo de transporte das partículas formando uma distribuição em camadas com densidades distintas. Assim, a ionosfera causa um atraso das medidas da pseudodistância e o avanço equivalente da medida da fase da portadora, devido aos elétrons livres da ionosfera.

\footnotetext{
${ }^{3}$ CHEN, F. F. Introduction to plasma physics and controlled fusion. Nova York: Plenum, 1984.
} 
A ionosfera vem sendo estudada desde os primórdios das comunicações com as ondas de rádio devido à sua importância vital nos enlaces entre pontos distantes. Antes da Era Espacial, por volta da década de 60, as comunicações entre os continentes eram efetuadas por meio das ondas de rádio ou por cabos submarinos. No caso das ondas de rádio foi necessária uma ampla pesquisa das frequiências dos transmissores para gerar ondas que ficassem confinadas entre a ionosfera e a superfície da Terra (SCHAAL, 2006).

Os sinais de rádio que são transmitidos de um ponto na superfície terrestre, refletem na ionosfera e retornam para a superfície terrestre, e devido a curvatura da Terra, o sinal pode alcançar locais afastados em centenas de quilômetros do ponto em que foi transmitido inicialmente, e esse processo de reflexão é amplamente positivo devido ao fato de que grande parcela do sinal propagado permanece entre a ionosfera e a superfície física da Terra (Leick, 2004).

O comportamento da ionosfera é função da hora do dia, da época do ano, da latitude e da longitude dos pontos de transmissão e recepção e da atividade solar (Leick, 2004).

Como a ionosfera apresenta um comportamento diuturno e é muito sensível às radiações solares e cósmicas, este método de comunicação requer um amplo leque de conhecimentos de seu comportamento e de técnicas de transmissão.

Pode ser dividida em 3 camadas (Menzori, 2005):

$>$ A camada ionosférica F, a mais elevada (entre 140 e $390 \mathrm{~km}$ de altitude), e interfere de forma moderada no sinal. Durante o dia, dependendo da incidência solar, pode ser subdividida nas camadas F1 e F2, com espessuras variáveis entre 60 e $80 \mathrm{~km}$, respectivamente;

$>$ A camada ionosférica E, localizada entre 90 e $140 \mathrm{~km}$ de altitude, e que tem grande influência sobre o sinal. É nela que se confina grande parte do sinal propagado, e o aspecto negativo é que age como um obstáculo para os sinais GPS;

A camada ionosférica D, situada entre 50 e $90 \mathrm{~km}$ de altitude. Tem grande capacidade de absorção das ondas de rádio e não interfere significativamente no sinal GPS, principalmente a noite, quando é quase nula.

As diferentes estações do ano influenciam diretamente no grau de ionização a que a Terra é submetida, assim, para o Hemisfério Sul, no verão há maior ionização e no inverno, menor. 


\subsubsection{Atividades solares}

O erro devido à ionosfera em distâncias medidas com GPS é diretamente proporcional ao conteúdo total de elétrons (TEC - Total Electron Content) presente na ionosfera, e este varia regularmente no tempo e no espaço com relação ao ciclo de manchas solares (em longos períodos), época do ano, hora do dia, localização geográfica, entre outros. Contudo, o TEC pode sofrer abruptas modificações em seu comportamento, devido, por exemplo, à ocorrência de intensas explosões solares (solar flares) (Matsuoka et al, 2006).

Explosões solares são atividades de grande magnitude, que acontecem na superfície e no interior do Sol (Menzori, 2005). Assim, na ocorrência deste evento solar, acontece um rápido aumento do fluxo solar de radiação eletromagnética, especialmente na faixa dos raios $\mathrm{X}$ e extremo ultravioleta, que, se direcionado para a Terra, pode provocar uma série de fenômenos na ionosfera, genericamente chamados de Distúrbios Ionosféricos Súbitos (Matsuoka et al, 2006).

As explosões solares são facilmente identificadas e classificadas por sua intensidade, pelo volume do fluxo de raios $\mathrm{X}$ ou pela luz visível que emanam, e podem ser divididas em 3 classes (Menzori, 2005):

- A classe X, que contém as maiores explosões solares;

- A classe M, que caracteriza as explosões intermediárias, por possuírem $10 \%$ da intensidade da classe anterior; e

- A classe $\mathrm{C}$, que caracteriza as explosões solares que possuem $1 \%$ de intensidade da primeira classe.

Basicamente as explosões solares acontecem de duas formas: de maneira inesperada, onde são registradas devido ao mapeamento sistemático da superfície solar feita pelos observatórios terrestres, e a maneira prevista, que segue um ciclo de atividades percebidas desde 500 A.C. e monitoradas por entidades oficiais na Europa e nos Estados Unidos, há mais de um século. $\mathrm{O}$ monitoramento constatou que elas apresentam um ciclo regular e repetitivo, com a duração de aproximadamente 11 anos (Menzori, 2005).

Esses ciclos regulares são associados a ocorrências de manchas solares e ao aumento de ionização, e o último período de máxima de manchas solares ocorreu em 2000-2001 (Matsuoka et al, 2006). Os comportamentos das explosões solares podem ser acessados através de páginas na internet do NOAA (National Oceanic and Atmospheric Administration) (www.sec.noaa.gov) e de outros órgãos como hfradio (www.hfradio.org). 
Neste trabalho, foi avaliada a propagação da incerteza originada pelas atividades solares, e o comportamento previsto e o ocorrido da atividade solar de janeiro de 2000 até janeiro de 2010 pode ser visualizado na figura abaixo:

Figura 3: Progressão do Ciclo Solar

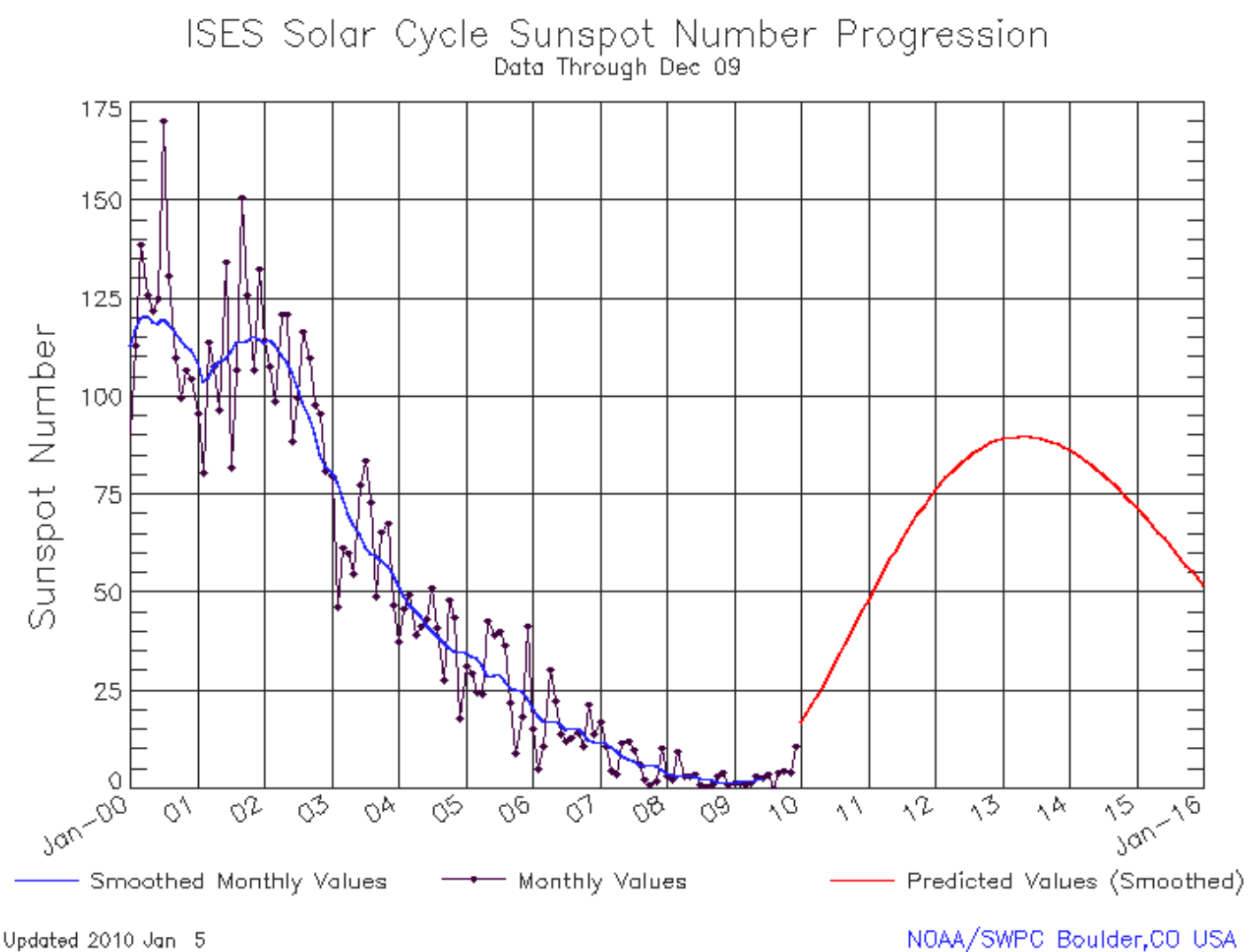

Fonte: www.swpc.noaa.gov/SolarCycle (acesso em 29/01/2010).

Assim, de acordo com a figura acima pode-se visualizar que os meses que tiveram atividade solar nos anos de 2006, 2007 e 2008 foram:

- 2006: maio, junho, julho, agosto e dezembro;

- 2007: abril, maio, novembro e dezembro;

- 2008: janeiro, maio, junho, julho e dezembro.

Os meses em negrito são os que tiveram dados utilizados neste trabalho, e o fato de ter ocorrido ou não degradação da qualidade dos dados será discutido mais adiante. 


\subsubsection{Perdas de ciclos}

A ambigüidade é um número inteiro para compatibilizar a medida da fase com o seu modelo. Este número depende do contador de ciclos do PLL (Phase Locked Loop). Caso ocorra uma perda de sincronismo durante um pequeno período de tempo, pode acontecer que na retomada de sincronismo o contador de ciclos comece a recontagem com um valor muito diferente do valor anterior, apresentando um salto significativo nas medições. Este salto é denominado na literatura por "cycle slip", considerado como uma descontinuidade nas medidas da fase e não o erro esporádico (SCHALL, 2006).

As perdas de ciclo ocorrem devido à existência de obstruções nas estações de rastreio, como: construções, árvores, pontes, montanhas, aceleração da antena; variações abruptas na atmosfera; interferências de outras fontes de rádio e problemas no programa e hardware. No caso da detecção de perdas de ciclos, as observações podem ser corrigidas somando-se o número de ciclos que provocou o salto nas observações afetadas, ou ainda desconsiderando os dados ou adicionando novas incógnitas ao modelo.

\subsubsection{Multicaminhamento}

O multicaminhamento pode ser denominado "reflexão" e é o processo que ocorre quando a frente de onda encontra uma descontinuidade do índice de refração (SCHAAL, 2006).

Assim, o receptor pode, em algumas circunstâncias, receber, além do sinal que chega diretamente à antena, sinais refletidos em superfícies vizinhas a ela, como construções, carros, árvores, massas d'água, cercas, etc.

Do ponto de vista de eletromagnetismo, a reflexão de uma onda ocorre quando há uma mudança brusca da impedância intrínseca ao longo de sua propagação, e assim como a velocidade de fase, a impedância intrínseca depende das constantes eletromagnéticas do meio. Esta impedância nada tem a ver com uma resistência elétrica que é associada à dissipação de energia. Todo meio que permite a propagação de uma onda apresenta uma impedância intrínseca. A intensidade da onda refletida depende da relação da impedância intrínseca do meio que se encontra com a impedância sobre o qual está incidindo. De modo geral, uma fração da energia da onda incidente é refletida e o restante se propaga no novo meio (ORSINI $^{4}(1963)$ apud SCHAAL (2006)).

\footnotetext{
${ }^{4}$ ORSINI, L. Q. Eletromagnetismo. Anotações de aula EPUSP, 1963.
} 
O efeito do multicaminhamento nas observações do código é praticamente o dobro que os susceptíveis na fase da portadora, e para se reduzir os efeitos do multicaminhamento, os cuidados a serem tomados dizem respeito ao local onde as antenas receptoras devem ser instaladas, ou seja, a escolha dos locais deve ser em função da não existência, ou, quando esta não for possível, da existência mínima de prédios ou quaisquer outros meios que possam colaborar para a reflexão do sinal GPS, tais quais outdoors, árvores, rios, carros, etc. muito próximos aos mesmos (SEGANTINE, 2005), conforme pode ser visto na Figura 4.

Figura 4: Demonstração do efeito de multicaminhamento.

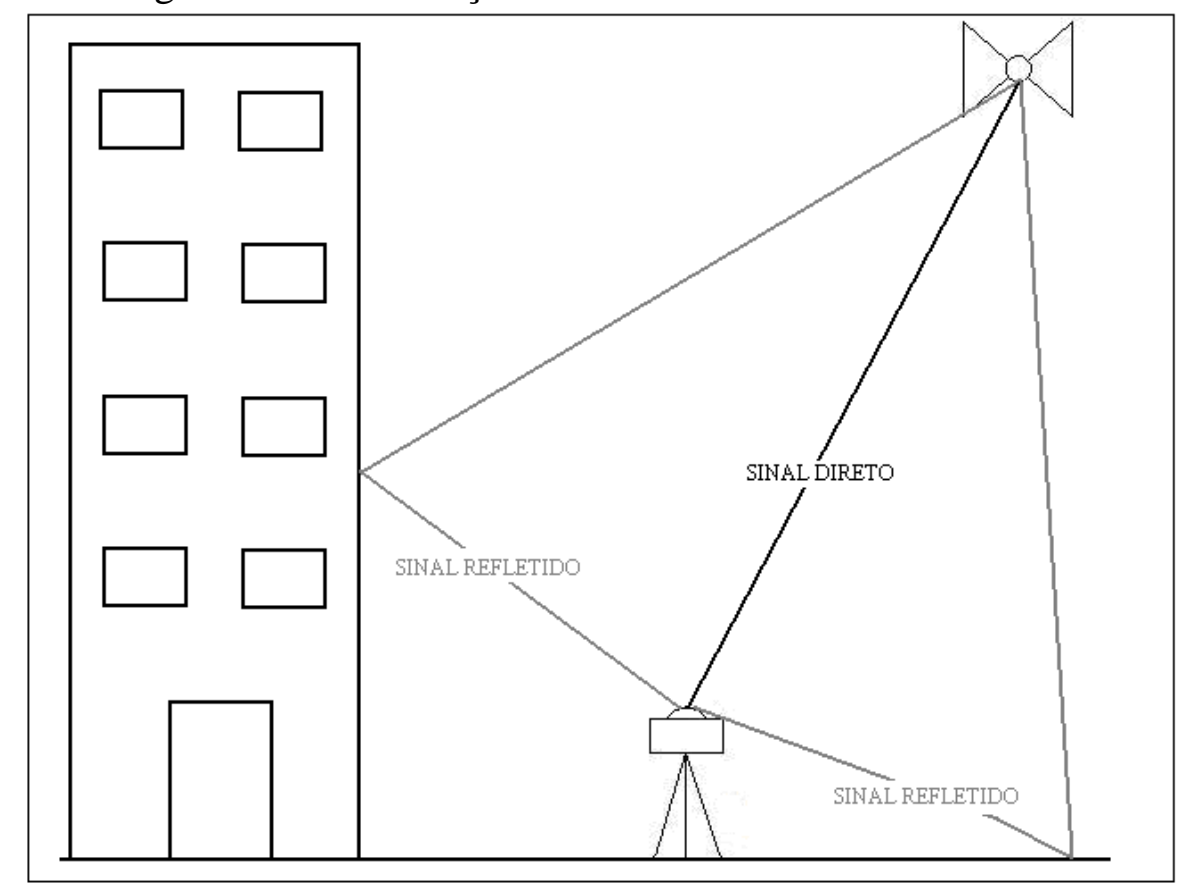

\subsubsection{Posicionamento relativo}

O posicionamento relativo é uma técnica usada particularmente quando há duas estações coletando simultaneamente observações do código ou da fase ou de ambos. Existe uma grande variedades de técnicas para a execução deste tipo de levantamento, e este é o método mais utilizado para levantamentos terrestres (WELLS, 1999).

Neste método se determina um vetor espacial $\overrightarrow{L B}$, conhecido como linha-base, que liga o ponto de coordenadas conhecidas $R 1$ (estação de referência) ao ponto $R 2$ (a ser determinado). As componentes vetoriais $d x, d y$ e $d z$, são as projeções desta linha-base nos eixos $\mathrm{X}, \mathrm{Y}$ e $\mathrm{Z}$ do sistema geocêntrico cartesiano e se constituem nas incógnitas do 
processamento (Menzori, 2005). Um exemplo de Posicionamento Relativo pode ser visto na Figura 5.

Figura 5: Posicionamento relativo.

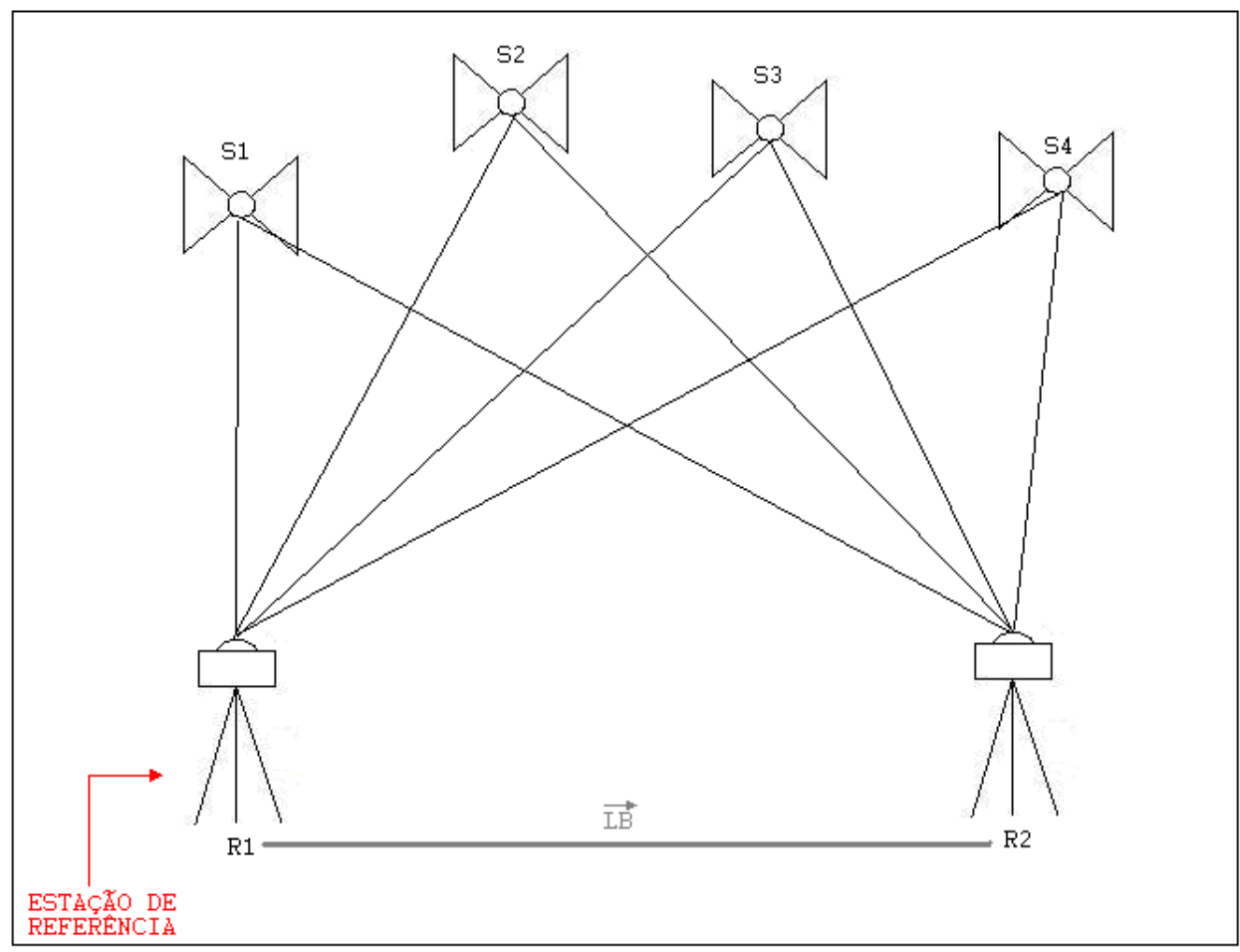

Fonte: Adaptado de MENZORI (2005).

Quando se faz uso do posicionamento relativo, pode-se reduzir os erros presentes nas observações ao se formar as diferenças entre as observáveis, como por exemplo, as correções para a influência da troposfera e da ionosfera podem ser calculadas com acurácia, além do que, devido ao tempo de coleta ser sempre superior a 20 minutos, a ambiguidade, geralmente, é solucionada (LEICK, 2004)

Essas observavações são, em geral, denominadas Simples, Dupla e Tripla Diferença. A observável normalmente adotada no posicionamento relativo estático é a Dupla Diferença (DD) da fase da onda portadora, muito embora também se possa fazer uso da DD da pseudodistância, ou de ambas, sendo o último o que proporciona melhores resultados em termos de acurácia (Monico, 2008).

Hofmann-Wellenhof et al. (2001) relatam que ao se empregar as combinações lineares de simples, dupla e tripla diferença no processamento, pode-se:

determinar os valores ajustados das posições $R 1$ e $R 2$, usando as pseudodistâncias do código; 
> estimar as componentes $d x, d y$ e $d z$ do vetor $\overrightarrow{L B}$, através da tripla diferença de fase;

> calcular a solução através das duplas diferenças de fase e obter o valor real das duplas diferenças de ambiguidades;

- Fixar o valor inteiro para os diferentes conjuntos de duplas diferenças de ambiguidade possíveis para se solucionar o posicionamento;

Demonstrar estatisticamente, que o conjunto de valores inteiros adotados para as duplas diferenças de ambiguidades é o melhor entre as alternativas possíveis.

\subsection{Simples diferença (SD)}

Simples diferenças podem ser formadas entre dois satélites, dois receptores ou duas épocas, sendo a mais usual a que dois receptores $\left(r_{1}\right.$ e $\left.r_{2}\right)$ rastream simultaneamente o mesmo satélite $\left(s^{1}\right)$, conforme pode ser visto na Figura 6.

Figura 6: Simples Diferença

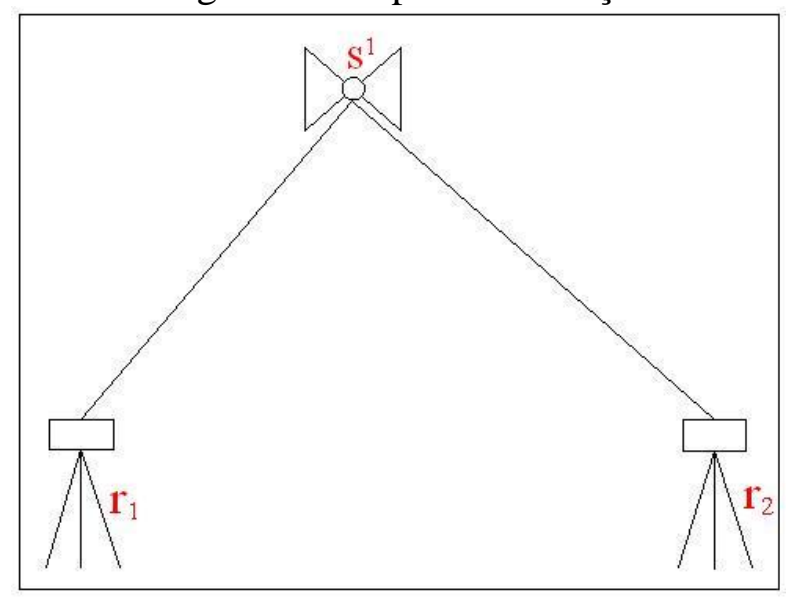

A diferença entre as pseudodistâncias observadas simultaneamente em duas estações é a Simples Diferença da pseudodistância, e a equação de observação pode ser dada por (MONICO, 2008):

$$
\Delta P D_{r 1, r 2}^{s 1}+v_{S D_{P D}}=\Delta \rho_{r 1, r 2}^{s 1}+c\left(d t_{r 1}-d t_{r 2}\right)
$$

$\operatorname{com} \Delta \rho_{r 1, r 2}^{s 1}=\rho_{r 1}^{s 1}-\rho_{r 2}^{s 1}$

onde, $v_{S D_{P D}}-$ diz respeito ao vetor dos resíduos; 
$\rho_{r i}^{s i}$ - distância geométrica entre a antena do satélite e a antena do receptor;

$c$ - velocidade da luz no vácuo; e

$d t_{r i}$ - erro do relógio do receptor.

O cálculo da SD permite eliminar o erro do relógio do satélite, bem como erros inerentes as posicões do satélite e as refrações atmosféricas são minimizadas para bases curtas (menores que $100 \mathrm{~km}$ ). Para bases longas, ambas as refrações podem ser modeladas, processo realizado pela maioria dos softwares comerciais. Considerando os fatores mencionados, a SD da fase da onda portadora pode ser dada por (MONICO, 2008):

$$
\Delta \phi_{r 1, r 2}^{s 1}+v_{S D_{\phi}}=\frac{f^{s 1}}{c} \Delta \rho_{r 1, r 2}^{s 1}+f^{s 1}\left(d t_{r 1}-d t_{r 2}\right)+\phi_{r 1, r 2}\left(t_{0}\right)+N_{r 1, r 2}^{s 1}
$$

onde, $v_{S D_{\phi}}$ - diz respeito ao vetor dos resíduos;

$f^{s 1}$ - frequência da observável em consideração;

$\phi_{r 1, r 2}\left(t_{0}\right)$ - fase inicial no receptor correspondente à época de referência $t_{0} ; \mathrm{e}$

$N_{r 1, r 2}^{s 1}$ - ambiguidade da fase.

\subsection{Dupla diferença (DD)}

A DD considera que dois receptores e dois satélites estão envolvidos (Figura 7). É a subtração das SD dos satélites observados num determinado instante, adotando-se um deles como referência (MENZORI, 2005).

Figura 7: Dupla Diferença

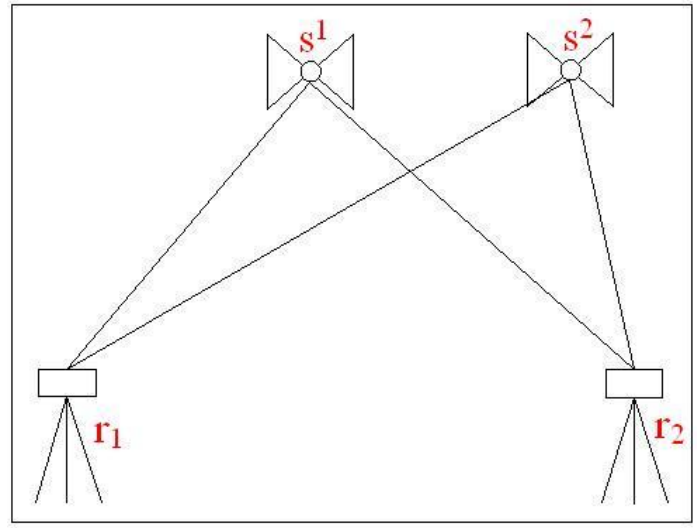


A equação da DD para a pseudodistância e para a fase da onda portadora podem ser dadas por (MONICO 2008):

$$
\begin{aligned}
& \Delta P D_{r 1, r 2}^{s 1, s 2}+v_{P D_{D D}}=\Delta \rho_{r 1, r 2}^{s 1, s 2} \\
& \Delta \phi_{r 1, r 2}^{s 1, s 2}=\frac{f}{c} \Delta \rho_{r 1, r 2}^{s 1, s 2}+N_{r 1, r 2}^{s 1}+v_{\phi_{D D}}
\end{aligned}
$$

O cálculo da DD permite eliminar os erros dos relógios dos receptores, e no que diz respeito a fase da onda portadora, permite eliminar as combinações da fase inicial dos receptores. Esta é a equação geralmente utilizada nos processamentos de dados GNSS que envolvem a fase da onda portadora, pois a mesma proporciona a melhor relação entre o ruído resultante da combinação e a eliminação de erros sistemáticos envolvidos nas observáveis GPS.

\subsection{Tripla diferença (TD)}

A TD, assim como a DD considera que dois receptores e dois satélites estão envolvidos, sendo a diferença entre elas que a TD combina os dados recebidos em instantes diferentes.

No que concerne a pseudodistância, a TD não apresenta nenhuma vantagem com relação à $\mathrm{DD}$, porém na $\mathrm{TD}$ para a fase da onda portadora, a ambiguidade é eliminada. $\mathrm{A}$ fórmula da TD para a fase da onda portadora é dada por (MONICO, 2008):

$$
\Delta \phi_{r 1, r 2}^{s 1, s 2}\left(t_{1}\right)-\Delta \phi_{r 1, r 2}^{s 1, s 2}\left(t_{2}\right)+v_{\phi_{1 D}}=\frac{f}{c}\left[\Delta \rho_{r 1, r 2}^{s 1, s 2}\left(t_{1}\right)-\Delta \rho_{r 1, r 2}^{s 1, s 2}\left(t_{2}\right)\right]
$$

A TD, além de eliminar a ambiguidade também identifica de forma individual as perdas de ciclos ocorridas e localiza e remove valores muito discrepantes, e nos métodos baseados na geometria satélite receptor, ela auxilia na determnação da posição aproximada do ponto desconhecido (MENZORI, 2005). 


\subsubsection{Ambiguidade}

Os receptores GNSS medem a parte fracionária da fase da onda portadora, iniciando a contagem dos ciclos no receptor a partir disto. A ambigüidade é o número de ciclos inteiros da primeira época de observação, e é um parâmetro determinado no ajustamento, juntamente com os demais parâmetros (como por exemplo os erros dos relógios), Mônico, 2008. É inerente a medição de fases, e depende tanto do receptor quanto do satélite. Não há um longo tempo de rastreio em que não ocorra interrupção (Hofmann-Wellenhof et al., 2001).

Os valores de ambiguidade estimados podem ser números reais (ambiguity float ou free solution) ou podem ser fixados em números inteiros (ambiguity fixed solution) (LEICK, 2004).

Contudo, fixar as ambiguidades inteiras não é uma tarefa simples, e a solução das mesmas são afetadas pelos efeitos ionosféricos, refração troposférica, multicaminho, geometria e número de satélites disponíveis, bem como do tempo de coleta das observações (MONICO, 2008).

Os métodos de solução da ambiguidade podem ser classificados em Método de solução no domínio das observações, Método de procura no domínio das coordenadas e Método de Procura no domínio das ambiguidades (KIM e LANGLEY, 2000).

\subsection{Método de solução no domínio das observações}

Diz respeito às técnicas que utilizam combinações entre as medidas de pseudodistâncias e da fase da onda portadora, pois, como a precisão das pseudodistâncias não é suficiente para a solução das ambiguidades, é necessário realizar uma suavização pela fase da onda portadora, onde, dependendo da qualidade do receptor, podem ser necessárias várias épocas (MONICO, 2008).

Devido ao fato das medidas das pseudodistâncias serem ruins para se obter uma solução confiável, têm-se empregado a observável wide-lane, cuja ambiguidade pode ser solucionada com maior confiabilidade, mesmo com pseudodistâncias de qualidade reduzidas. Outra vantagem desta observável é que independe do comprimento da linha de base (MONICO, 2008).

As técnicas que utilizam este método para a solução da ambiguidade são independentes de geometria, podendo ser identificadas em algumas literaturas como "geometric free" (livre de geometria) (MONICO, 2008). 


\subsection{Método de procura no domínio das coordenadas}

Utiliza apenas o valor fracionário medido da fase da onda portadora, não sendo afetado nem pelas mudanças de ciclos inteiros, nem pelas perdas de ciclos (ABREU, 2007), e a observável básica é SD entre duas estações, das quais uma dispõem de coordenadas conhecidas, e na outra será construído um espaço de procura. Assim, as incógnitas consistem nas coordenadas da estação e as diferenças dos erros dos relógios dos receptores, onde um algoritmo de procura é definido de forma que as incógnitas vão sendo alteradas até produzir um vetor de SD compatível com o observado (MONICO, 2008).

\subsection{Método de procura no domínio das ambiguidades}

Compreende os modelos baseados no Método dos Mínimos Quadrados (MMQ), onde inicialmente é determinada a solução flutuante e após, utilizando a sua Matriz de VariânciaCovariância (MVC) são estimadas as ambiguidades inteiras, e após as mesmas são ajustadas até se obter uma solução fixa (ABREU, 2007).

Algumas técnicas que fazem uso desse método são: Método Sequencial, Fara (Fast Ambiguity Resolution Approach) e Método de Euler/Landau (MONICO, 2008).

\subsection{Validação do vetor das ambiguidades}

Outro fator a ser considerado diz respeito a validação da solução encontrada, pois é preferível a solução das ambiguidades como real (solução flutuante) a uma solução fixa obtida de forma incorreta, que tem sua qualidade degradada devido a introdução de erros sistemáticos nas coordenadas da estação. Assim, pode-se lançar mão de testes que validem esses resultados (MONICO, 2008).

Esses testes são conhecidos como testes de discriminação, e visam comparar a probabilidade da solução fixa considerada correta com outros conjuntos de solução de vetores de ambiguidades inteiras, onde, se a probabilidade de uma, não for suficientemente maior que a da outra, nenhuma das duas soluções pode ser discriminada com confiança suficiente (MONICO, 2008).

\subsubsection{Incertezas originadas no processamento e ajustamento}

Os fatores influentes na acurácia de uma coordenada, oriundos do processamento e ajustamento, para este trabalho, podem ser definidos como a distância e geometria entre as 
estações da RBMC, a qualidade dos dados das mesmas, o erro médio quadrático, as precisões horizontais e verticais, obtidas do ajustamento de observações, bem como as combinações lineares das observáveis GPS entre diferentes estações (simples, duplas e triplas diferenças).

\subsubsection{Distância e geometria entre as estações RBMC}

Para se analisar a influência da distância entre as estações e a geometria entre elas, no processamento serão utilizados casos de geometria ideal (neste trabalho, se adotará que uma situação ideal para a geometria das estações equivale aproximadamente a de um triângulo eqüilátero - Figura 8) e casos onde a geometria obtida entre as estações não tem boa configuração (neste trabalho, esta geometria equivale aproximadamente a de um triângulo escaleno - Figura 9).

Com relação às distâncias entre as estações devido a alta qualidade dos dados oriundos da RBMC, distâncias até $300 \mathrm{~km}$ serão consideradas pequenas e com a solução da ambiguidade requerida sendo fixa, e acima de $300 \mathrm{~km}$ serão consideradas grandes e aceita-se solução flutuante para a ambiguidade.

Figura 8: Triângulo Equilatero

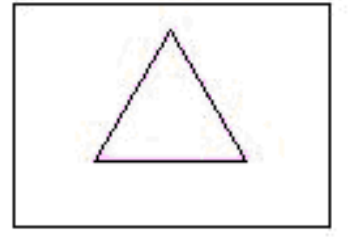

Figura 9: Triângulo Escaleno

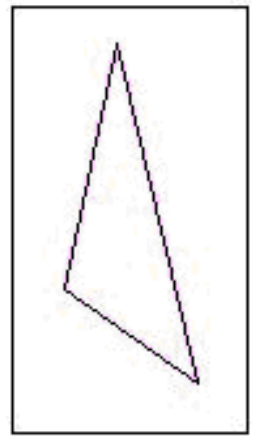

\subsubsection{Precisão, acurácia e exatidão}

A precisão pode ser definida como sendo o grau de concordância de uma série de observações ou medições, enquanto a acurácia está relacionada a proximidade de uma 
observação ou medida do seu valor real, $\left(\mathrm{HUSCH}^{5}\right.$ et al, 1982 apud ANTUNES e LINGNAU, 1997).

Assim, a precisão está associada aos erros aleatórios e a acurácia está associada aos efeitos dos erros aleatórios e sistemáticos.

No que concerne a exatidão, uma observação pode ser considerada exata se não houver ocorrência de erro sistemático ou bias. A falta de exatidão de observações são geralmente oriundas dos erros sistemáticos, e tendem a se acumular num mesmo sentido, (ANTUNES e LINGNAU, 1997).

Como o próprio nome sugere, erros aleatórios são erros cuja causa tem um caráter randômico, ou seja, não podem ser associados a uma causa específica, ao passo que erros sistemáticos ocorrem devido às condições do meio e imperfeições nos equipamentos. Na estatística o erro sistemático introduz bias, que pode ser definida como a diferença entre o valor esperado do estimador e o verdadeiro valor do parâmetro a estimar, assim, é observada uma tendência nos valores medidos (GEMAEL, 1994).

Assim, ao se considera uma amostragem, a acurácia é relacionada com o desvio padrão da amostra do valor real da população, enquanto a precisão pode ser relacionada ao desvio padrão da média da amostra, sendo possível que uma amostra possua uma alta precisão, ou seja, um pequeno desvio em relação à média, porém, devido à falta de exatidão, um grau de acurácia inferior (ANTUNES e LINGNAU, 1997).

\subsubsection{Ajustamento pelo método dos mínimos quadrados e análise da} qualidade do mesmo através do teste qui-quadrado $\left(\chi^{2}\right)$

O ajustamento de observações é um ramo da Matemática Aplicada, e objetiva a solução única para problemas onde o número de observações é redundante e o sistema de equações inconsistente, bem como uma estimativa da precisão da solução adotada. A solução única pode ser encontrada através do MMQ, desenvolvido por Gauss (1777 - 1855) e Legendre (1752 - 1833) (CAMARGO, 2004).

O MMQ é uma ferramenta estatística usual em Geomática, e consiste numa técnica de otimização matemática que procura o melhor ajustamento para um conjunto de dados

\footnotetext{
${ }^{5}$ HUSCH, B., MILLER, C.I., BEERS,T.W. Forest mensuration. New York: John Wiley \& Sons, 1982. 402p.
} 
minimizando a soma das diferenças quadráticas entre a reta e os pontos, divididas pelas respectivas variâncias (desvio-padrão ao quadrado) (Figura 10).

Figura 10: Ajustamento pelo Método dos Mínimos Quadrados

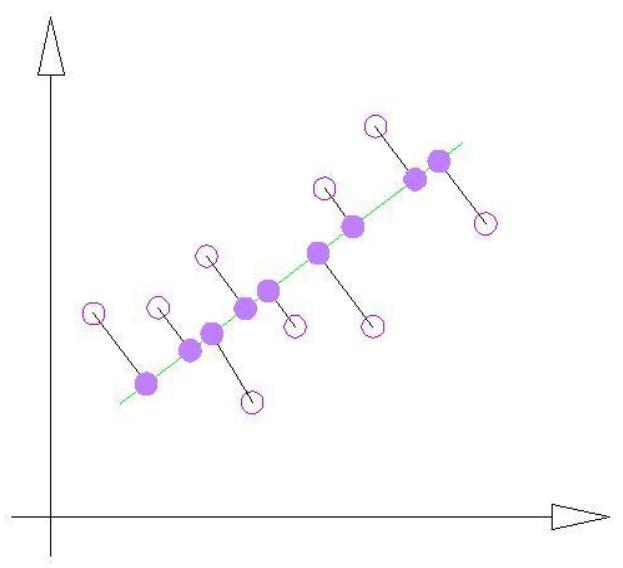

Um requisito implícito para o método dos mínimos quadrados trabalhar é que os erros em cada medida sejam distribuídos aleatoriamente, e que os resíduos sejam independentes.

Assim, seja $f(x)=y$ uma função onde $x$ seja obtido experimentalmente, o ajustamento pelo MMQ consiste em obter uma função $f^{\prime}(x)$ de modo que a soma dos quadrados das diferenças $y_{i}-f^{\prime}(x)$ seja mínima.

O ajustamento de observações pelo MMQ pode ser efetuado utilizando-se o método das equações de observação (Método Paramétrico), das equações de condição (Método Condicionado) ou um método que combine os dois anteriores (Método Combinado). Em geral, no processamento de dados GNSS, o método mais utilizado é o Paramétrico (MONICO, 2008). No ajustamento pelo Método Paramétrico cada observação proporciona uma equação. O modelo matemático do método paramétrico pode ser dado por (CAMARGO, 2004):

$$
L_{a}=F\left(X_{a}\right)
$$

onde, $L_{a}$ - vetor das observações ajustadas;

$X_{a}$ - vetor dos parâmetros ajustados; e

$F$ - função que relaciona $L_{a}$ e $X_{a}$, podendo ser linear ou não.

Uma maneira de se aumentar a qualidade de um ajustamento é mediante a inserção de injunções. Injunções são informações extras, inerentes aos parâmetros, como funções ou 
condições que relacionam os mesmos (MONICO, 2008). As injunções podem ser obtidas através de ajustamentos anteriores, trabalhos anteriores ou órgãos qualificados. Neste trabalho, as injunções a serem consideradas, dizem respeito a informações obtidas do IBGE.

O cálculo pelo MMQ produz observações ajustadas, bem como as suas precisões. Depois do algoritmo computacional, é necessário a avaliação estatística dos resultados (CAMARGO, 2004). A relação entre as fases do ajustamento pode ser vista na Figura 11, a seguir.

Figura 11: Relação entre as fases do ajustamento

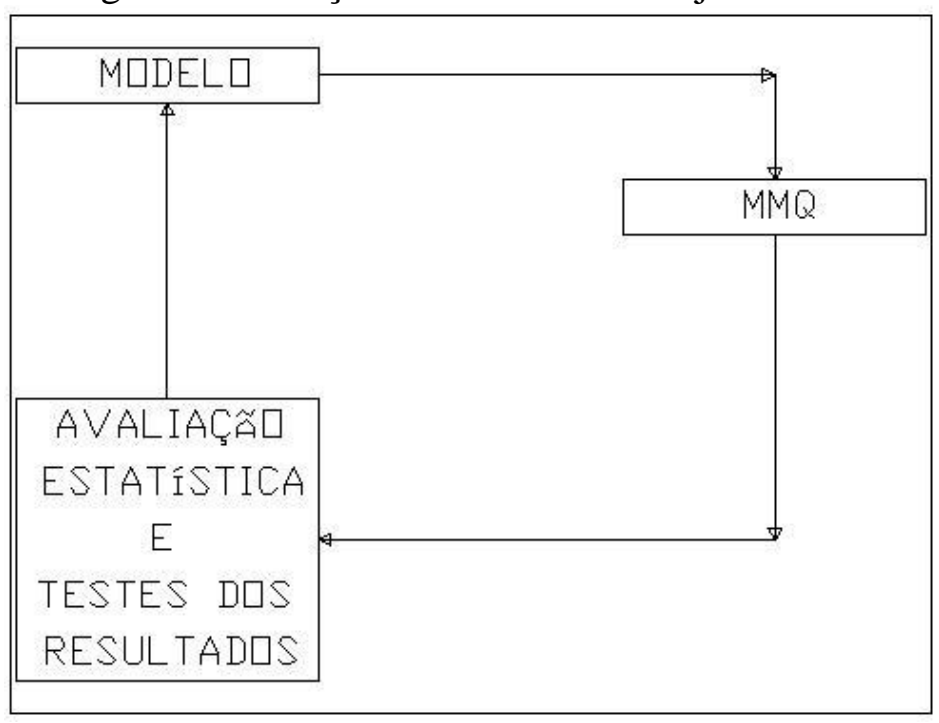

Fonte: CAMARGO (2004).

Com relação a qualidade de um ajustamento, um critério de avaliação é essencialmente um método para se determinar se a curva ajustada foi boa em relação aos pontos experimentais (Turco et al, 2008).

Neste trabalho, o controle de qualidade do ajustamento será feito utilizando o Teste do Qui-Quadrado $\left(\chi^{2}\right)$. Em um âmbito geral, este teste consiste em comparar frequências obtidas $\left(F_{o}\right)$ com frequências esperadas $\left(F_{e}\right)$, através de duas hipóteses:

○ Hipótese Nula: dada por $H_{0}: F_{0}=F_{e}$, onde as frequiências observadas não são diferentes das obtidas, e;

○ Hipótese Alternativa: dada por $H_{1}: F_{0} \neq F_{e}$, onde as freqüências observadas são diferentes das obtidas.

Após, é estabelecido o nível de significância, e determinado o valor do $\chi^{2}$ calculado: 


$$
\chi^{2} \text { calculado }=\sum \frac{\left(F_{o}-F_{e}\right)^{2}}{F_{e}}
$$

Para que o ajustamento seja aceito, é necessário que o $\chi^{2}$ calculado seja menor que o $\chi^{2}$ tabelado, para o nível de significância adotado.

Neste trabalho, o nível de significância adotado será de 68\%, devido a usualidade deste valor (INCRA, 2003).

\subsection{RBMC}

O advento da tecnologia GPS provocou uma verdadeira revolução, nas atividades de navegação e posicionamento. Os trabalhos geodésicos e topográficos passaram a ser realizados de forma mais rápida, precisa e econômica. Tais vantagens vêm melhorando cada vez mais os métodos de observação e as técnicas de processamento estão e constante evolução. É nesse contexto que se insere a RBMC (IBGE, 2010).

A RBMC começou a ser implantada no final de 1996, quando, seguindo a tendência mundial do estabelecimento de redes GPS permanentes, o IBGE, por intermédio de seu Departamento de Geodésia (DEGED), e em colaboração com o Fundo Nacional de Meio Ambiente (FNMA) e com a Escola Politécnica da Universidade de São Paulo (EPUSP), efetuou a instalação das estações de Curitiba /PR e de Presidente Prudente /SP. (FORTES, 1997).

A RBMC tem por objetivo constituir uma infraestrutura geodésica de referência para posicionamentos utilizando-se as modernas técnicas apoiadas nos GNSS, facilitando assim o emprego do sistema pelo usuário e, ao mesmo tempo, garantindo a qualidade dos resultados obtidos. Cabe destacar que a RBMC é também a principal ligação com os sistemas de referência globais. Devido ao crescente avanço e popularização do GPS, cada vez mais usuários utilizam esta tecnologia, e as redes ativas desempenham importante papel nas diferentes aplicações (McArthur and Steeves ${ }^{6}, 1988$ apud PEREIRA et al, 2003).

Desde sua concepção, a RBMC encontra-se baseada no funcionamento automático das estações e na transferência diária dos arquivos de observação para o Centro de Controle da

\footnotetext{
${ }^{6}$ McArthur, D.J. ; Steeves, R.R.. ON THE IMPACT OF THE ACTIVE CONTROL SYSTEM ON SURVEY CONTROL NETWORKS. Geodetic Survey Division, Canada Center for Surveying, Otawa, 1988.
} 
RBMC (CC-RBMC), no Rio de Janeiro (FORTES, 1997). Assim, arquivos de dados das estações constituintes da mesma são colocados à disposição no dia seguinte ao observado.

Antes da disponibilização das observações para os usuários, é realizado o controle de qualidade dos dados. Comprovando-se esta qualidade, os arquivos de observação são liberados pela internet (PEREIRA et al, 2003).

A RBMC pode ser utilizada tanto para trabalhos práticos quanto para pesquisas científicas. Nas aplicações geodésicas com uso do GPS onde se faz a utilização do método relativo, antes da RBMC, o usuário interessado em obter, com GPS, as coordenadas geodésicas de um ponto qualquer em território nacional era obrigado a trabalhar com dois receptores, ocupando o ponto de seu interesse e um marco do Sistema Geodésico Brasileiro (SGB) próximo. As estações da RBMC desempenham justamente o papel do ponto de coordenadas conhecidas, eliminando a necessidade de que o usuário imobilize um receptor em um ponto que, muitas vezes, oferece grandes dificuldades de acesso. Além disso, os receptores que equipam as estações da RBMC são de alto desempenho, proporcionando observações de grande qualidade e confiabilidade (IBGE, 2010).

A Figura 12 mostra a disposição das estações da RBMC existentes em 2010.

Figura 12: Disposição das estações da RBMC existentes em 2010

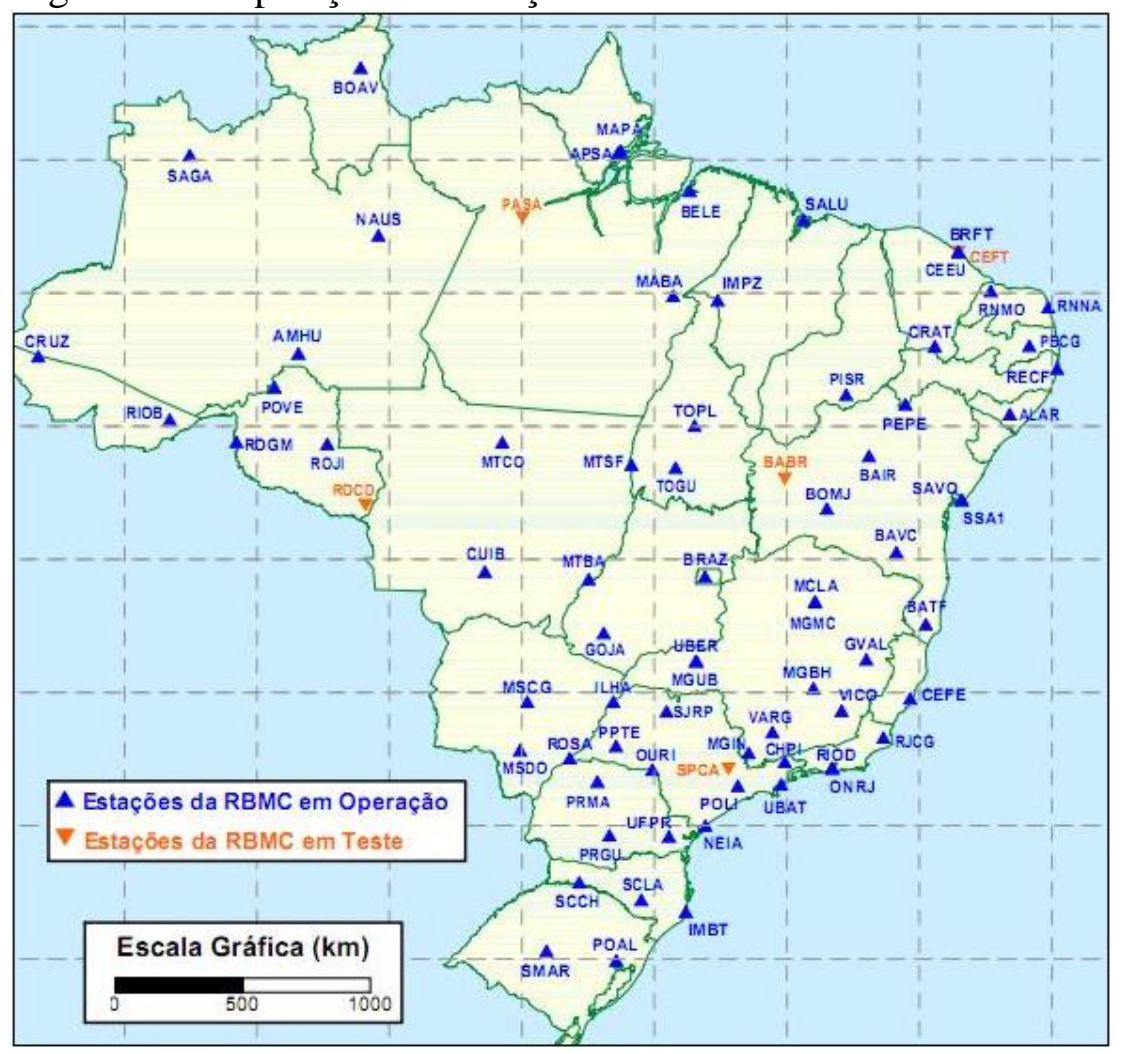

Fonte: IBGE (acesso em 04/03/2010). 
Neste trabalho, as oito estações utilizadas foram: VARG, VICO, RIOD, UBER, CUIB, BRAZ, PPTE e MCLA.

Devido ao alto nível de precisão nas suas coordenadas, estas serão adotadas nesse trabalho como "verdadeiras".

\subsection{Estatística computacional}

A informática vem sendo inserida em áreas de engenharia e correlatas desde meados de 1960, quando calculadoras com capacidade de programação começaram a ser introduzidas no mercado (LEVINE et al, 1988).

Em especial, a área relacionada a levantamentos geodésicos e topográficos vem sendo beneficiada de tal maneira que atualmente todas as etapas de um processamento de dados faz uso de dispositivos computacionais. Contudo, áreas correlatas a Geomática ainda fazem uso limitado da Estatística e das ferramentas de análise que ela possa vir a oferecer, limitando-se o uso aos indicadores de precisão, como o erro médio quadrático, por exemplo.

No entanto, ao se fazer uso dessas ferramentas, somente se está analisando a precisão de uma medida, desconsiderando sua acurácia. Assim, nesta dissertação, será feito o uso da técnica da Árvore de Decisão (AD), para a classificação dos dados, de forma a permitir a elaboração de uma tabela em que seja possível classificar a acurácia de processamentos, levando em conta as influências mencionadas anteriormente.

Os métodos inferenciais que demonstram maior aptidão para esse fim são os que têm por características básicas o aprendizado através de exemplos, capacidade de generalização e tolerância a falhas (MENZORI, 2005). Um sistema computacional seleciona com base no conhecimento adquirido anteriormente, e a cada nova experiência analisa os fatores que agora serão considerados como errados (LEVINE et al.1988).

\subsubsection{Aprendizado de máquina}

O aprendizado de máquina está relacionado com a área de Inteligência Artificial cujo objetivo é o desenvolvimento de técnicas computacionais sobre o aprendizado e sistemas capazes de adquirir conhecimento de forma automática, ou seja, sistemas que sejam capazes de tomar decisões baseadas em experiências anteriores que foram bem-sucedidas (MONARD e BARANAUSKAS, 2003). Em outras palavras, um sistema de aprendizado de máquina é um 
programa computacional que toma decisões para um determinado problema baseado em soluções bem sucedidas de problemas anteriores, usando, para isso, características comuns entre os problemas.

Segundo (RICH e KNIGHT, 1991) as técnicas de Aprendizado de Máquina são ferramentas cada vez mais utilizadas nas mais diferentes áreas, tais quais, Matemática, Medicina e Biologia, visto a sua capacidade de aprender automaticamente a partir de grandes quantidades de dados, e produzir hipóteses aplicáveis. A aprendizagem é característica do sistema mutável, permitindo assim que numa próxima vez, a tarefa realizada por um grupo possa ser feita com mais eficácia.

O Aprendizado de Máquina é uma ferramenta poderosa, mas não existe um algoritmo único que apresente o melhor desempenho para todos os problemas. Dessa forma, é importante compreender a capacidade e a limitação dos diferentes algoritmos utilizando alguma metodologia de avaliação que permita comparar algoritmos.

Neste trabalho, o método de avaliação das medidas GPS a ser empregado será a técnica da Árvore de Decisão, e esta escolha tem por base quatro motivos principais:

$>$ São fáceis de trabalhar;

> Permitem a classificação simultânea de dados tanto alfa quanto numéricos com a condição de que o atributo de saída seja sempre uma classe alfa;

> Não exige que seja definido parâmetro "a priori" sobre a natureza dos dados;

$>$ Tratam com um número ilimitado de exemplos de teste, com infinitas classes e revelando as regras utilizadas no processo de classificação, de acordo com o modelo associado.

\subsubsection{Hierarquia e paradigmas do aprendizado de máquina}

A Indução pode ser definida como o raciocínio originado num determinado conceito e que o generaliza, ou seja, um conceito é aprendido com base nos exemplos anteriores, fazendo-se uso de inferência indutiva.

A inferência indutiva é um dos métodos mais utilizados para a predição de eventos futuros, e apesar de ser um método bastante utilizado, o seu uso requer algumas ressalvas, visto que caso os exemplos sejam insuficientes, ou não forem escolhidos de forma adequada, a hipótese encontrada pode não ser a mais adequada. 
O aprendizado indutivo pode ser dividido em supervisionado e não-supervisionado, onde no primeiro caso é fornecido ao algoritmo um conjunto de exemplos de treinamento para os quais o rótulo da classe associada é conhecido.

Em geral, cada exemplo é descrito por um vetor de valores de características (conhecidos também como atributos) e pelo rótulo da classe associada. O objetivo do algoritmo de indução é construir um classificador que possa determinar corretamente a classe de novos exemplos ainda não rotulados.

Para rótulos de classe discretos, esse problema é conhecido como classificação e para valores contínuos como regressão.

No aprendizado não-supervisionado, o indutor analisa os exemplos fornecidos e tenta determinar se alguns deles podem ser agrupados de alguma maneira, formando agrupamentos ou clusters (MONARD e BARANAUSKAS, 2003). Após a determinação dos agrupamentos, normalmente, é necessária uma análise para determinar o que cada agrupamento significa no contexto do problema que está sendo analisado.

A Figura 13, a seguir, demonstra a hierarquia do aprendizado.

Figura 13: Hierarquia do aprendizado

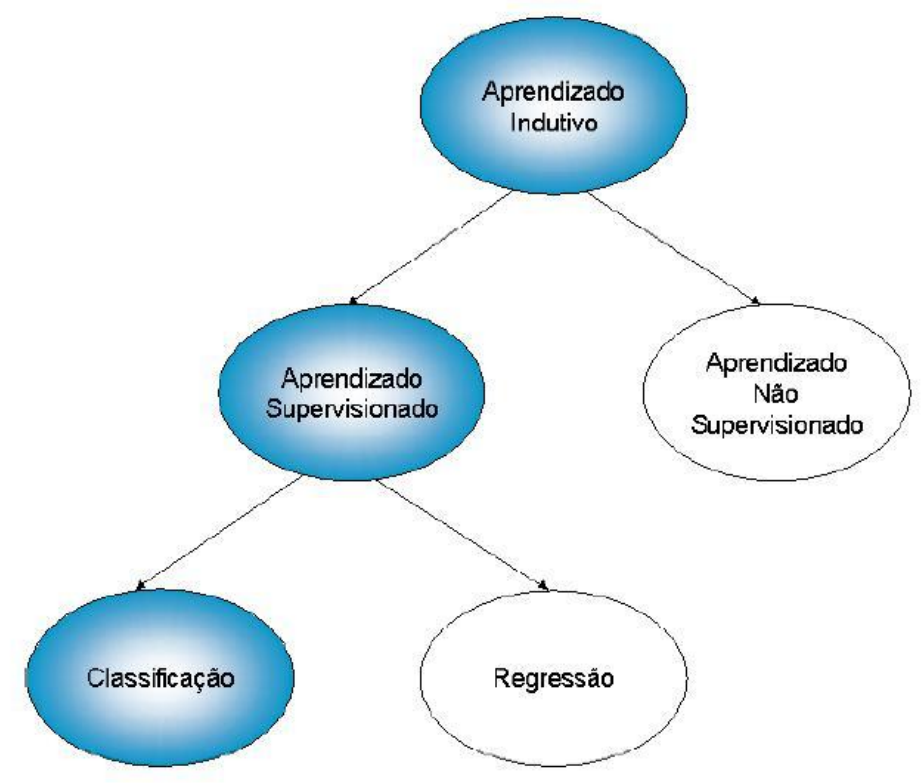

Fonte: Adaptado de MONARD e BARANAUSKAS, (2003).

Os paradigmas de Aprendizado de Máquina são (MONARD e BARANAUSKAS, 2003): 
Simbólico: aprendem através de representações simbólicas de um conceito, a partir de análises de exemplos sobre o mesmo, e dentre os métodos simbólicos pode-se citar os representados por árvores de decisão, regras ou semântica;

> Estatístico: aprendem através de modelos estatísticos utilizados para encontrar uma boa aproximação do conceito induzido, e dentre os métodos estatísticos pode-se citar os de aprendizado bayesiano;

Baseado em exemplos: classificam um problema através do exemplo de um problema similar cuja classe é conhecida e assumindo-se que o novo exemplo terá a mesma classe. Esse tipo de sistema de aprendizado é denominado lazy (do inglês: preguiçoso), e os algoritmos mais conhecidos utilizados para esse paradigma são o Nearest Neighbours e o Raciocínio Baseado em Casos (RBC); Conexionista: conhecidos também pela denominação Redes Neurais, são construções matemáticas simplificadas inspiradas no modelo do sistema nervoso, onde as unidades são altamente interconectadas, e possuem um grande potencial quando o problema requer intenso processamento sensorial humano, como visão e reconhecimento de voz;

Genético: um classificador genético consiste de uma população de elementos de classificação que competem para fazer a predição, ou seja, elementos que possuem argumentos fracos são descartados, ao passo que os elementos mais fortes proliferam, produzindo variações de si mesmo.

Conforme já mencionado, neste trabalho o método de Aprendizado de Máquina a ser utilizado é o da Árvore de Decisão, cujo paradigma é o Simbólico.

\subsection{3 Árvore de decisão (AD)}

Uma AD pode ser construída a partir de um conjunto de dados amostrais, selecionando os atributos de entrada, subdividindo o processo de treinamento em instâncias de treinamento que correspondem a cada atributo selecionado, interpretando a relação de ganho de cada um, destacando aquele que apresente a melhor relação para ser adotado como raiz da AD.

O processo acima é aplicado recursivamente para formar as sub-árvores do modelo, terminando quando um dado contém somente o atributo da classe.

A $\mathrm{AD}$ deve consistir de decisões mais precisas e menos específicas, ampliando-se assim o banco de treinamento e desenvolvendo um processo conhecido como "Poda da 
Árvore", que consiste na retirada dos nós que não contribuem para a predição de novos valores, gerando desta forma, uma árvore menos complexa e mais geral, o que é preferível, visto que as mais simples classificam com maior rigor.

\subsubsection{Indução de árvore de decisão}

Algoritmos que induzem ADs pertencem à família de algoritmos Top Down Induction of Decision Trees — TDIDT.

Uma $\mathrm{AD}$ é uma estrutura de dados definida recursivamente como um nó folha que corresponde a uma classe ou um nó de decisão que contém um teste sobre algum atributo. Para cada resultado do teste existe uma aresta para uma sub-árvore. Cada sub-árvore tem a mesma estrutura que a árvore (MONARD e BARANAUSKAS, 2003), conforme pode ser visualizado na Figura 14.

Figura 14: Exemplo de Árvore de Decisão

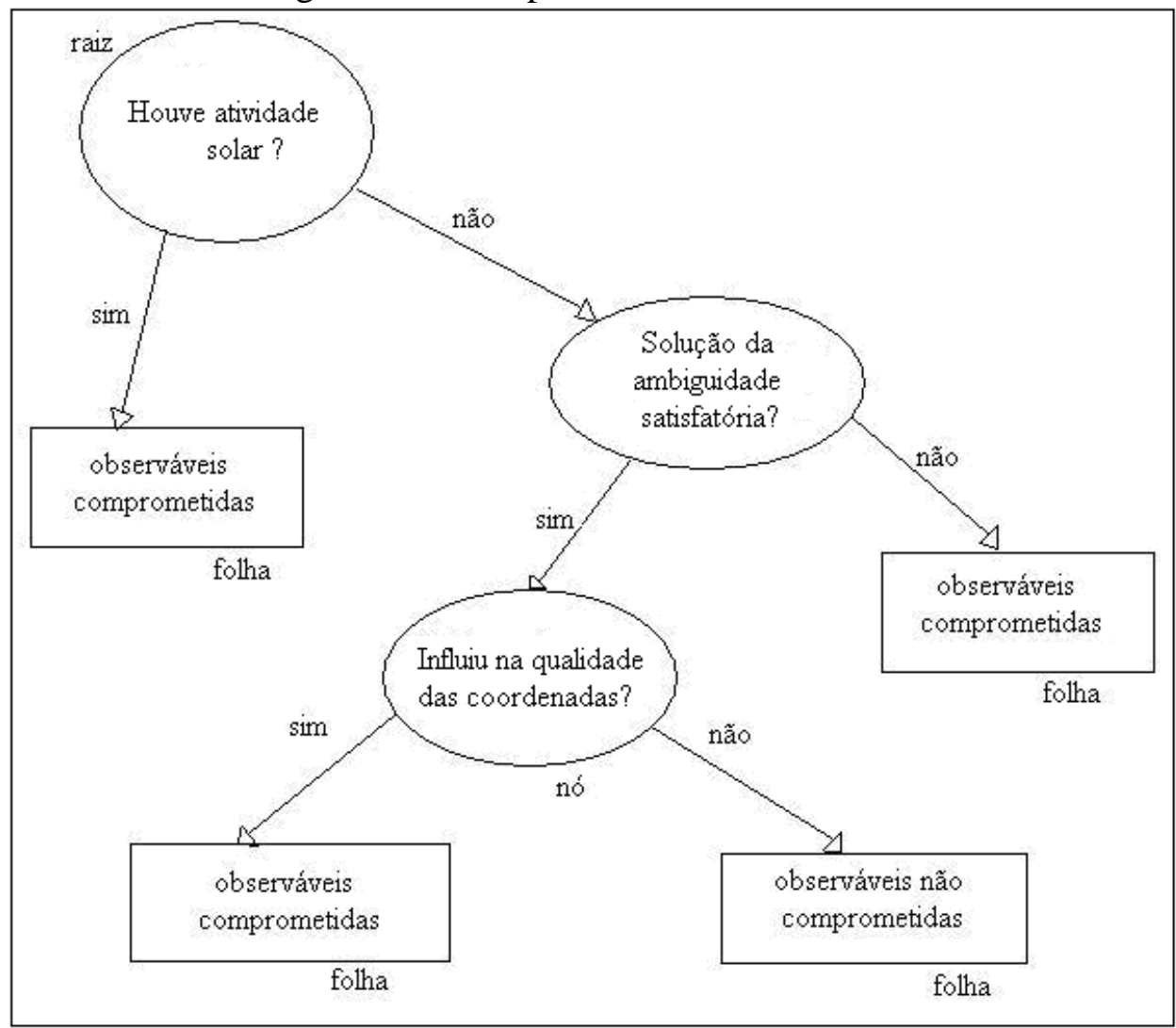

Para classificar a observação, inicia-se na raiz e segue cada teste até alcançar a folha que melhor sintetize a resposta. Computacionalmente, a $\mathrm{AD}$ pode ser sintetizada como a seguir: 
if não houve atividade solar then

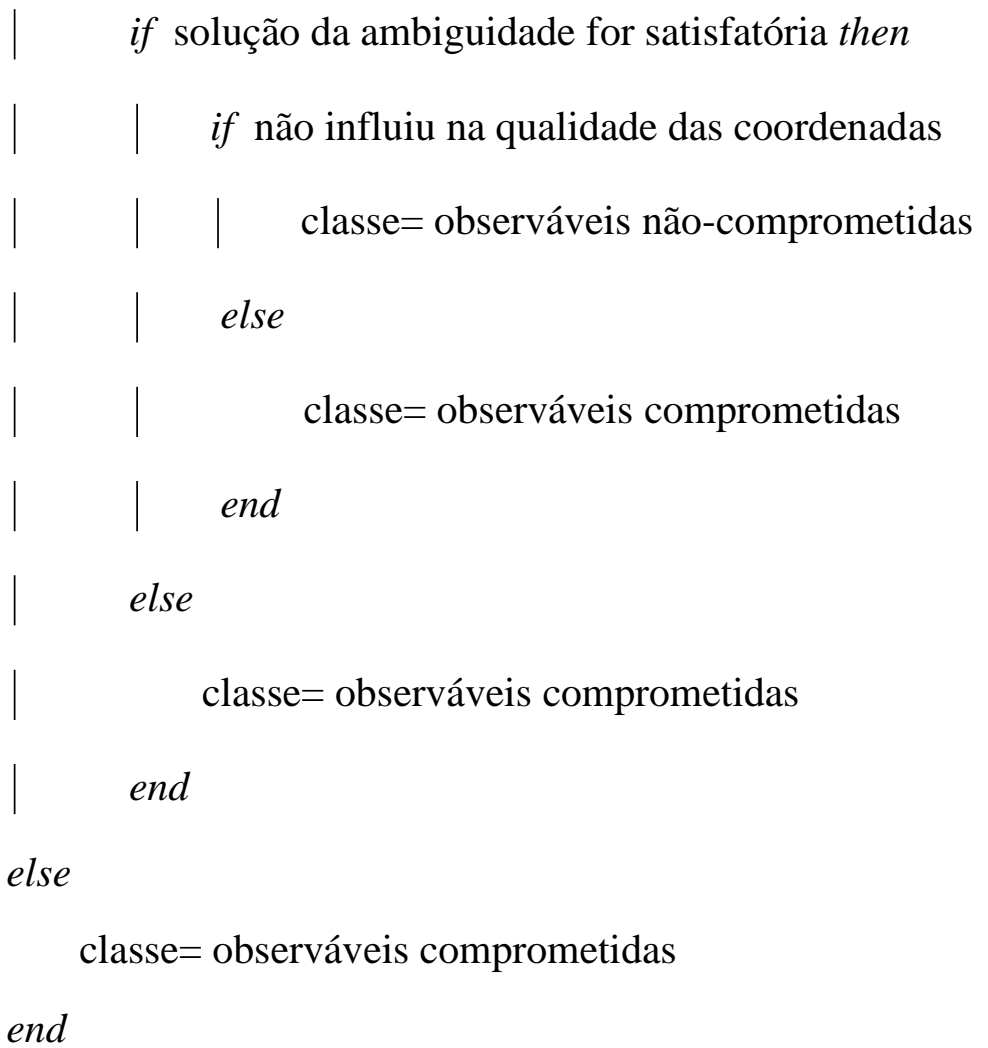

\subsubsection{Construção de árvore de decisão}

$\mathrm{O}$ método para a construção de uma $\mathrm{AD}$ a partir de um conjunto $\mathrm{T}$ é simples. Assumindo que as classes sejam denotadas por $G_{1}, C_{2}, \ldots, C_{k}$, os seguintes passos devem ser seguidos:

1) T contém um ou mais exemplos, todos pertencentes à mesma classe $C_{j}$. Nesse caso, a AD para T é um nó folha identificando a classe $C_{j}$;

2) T não contém exemplos, então a $\mathrm{AD}$ é uma folha, mas a classe associada à folha deve ser determinada a partir de informação além de $\mathrm{T}$ (por exemplo, a classe mais frequente para o "nó pai" desse nó, pode ser utilizada);

3) T contém exemplos que pertencem a várias classes. Nesse caso, a idéia é refinar $T$ em subconjuntos de exemplos pertencentes a uma única classe. Geralmente é escolhido um teste baseando-se em um único atributo que possua resultados mutuamente exclusivos. Sejam os possíveis resultados do teste denotados por $\bigotimes_{1}, O_{2}, \ldots, O_{r}$. T é então dividido em subconjuntos $T_{1}, T_{2}, \ldots, T_{r}$, nos quais cada $T_{i}$ contém todos os exemplos em $\mathrm{T}$ que possuem como resultado daquele teste o valor $O_{i}$. A AD para $\mathrm{T}$ 
consiste em um nó interno identificado pelo teste escolhido e uma aresta para cada um dos resultados possíveis;

4) Os passos 1, 2 e 3 são aplicados recursivamente para cada subconjunto de exemplos de forma que, em cada nó, as arestas levam para as sub-árvores construídas a partir do subconjunto de exemplos $T_{i}$;

5) Após a construção da $\mathrm{AD}$, a poda pode ser realizada para melhorar a capacidade de generalização da mesma.

\subsubsection{Escolha do atributo de particionamento}

Todo algoritmo deve estabelecer um critério para escolher o atributo que particiona o conjunto de exemplos em cada iteração, e algumas possibilidades para a escolha desse atributo seguem abaixo (MONARD e BARANAUSKAS, 2003):

Aleatória: seleciona qualquer atributo aleatoriamente;

> Menos Valores: seleciona o atributo com a menor quantidade de valores possíveis;

$>$ Mais Valores: seleciona o atributo com a maior quantidade de valores possíveis;

Ganho Máximo: seleciona o atributo que possui o maior ganho de informação esperado.

\subsubsection{Poda de árvore de decisão}

Após a construção da $\mathrm{AD}$, é possível que o classificador induzido seja muito específico para o conjunto, e nesse caso, diz-se que o classificador "super-ajustou" os dados (MONARD e BARANAUSKAS, 2003). Como os exemplos iniciais são apenas uma amostra de todos os exemplos possíveis, pode-se adicionar arestas na $\mathrm{AD}$ que melhoram seu desempenho nos dados de iniciais, mas que pioram seu desempenho em um conjunto de teste.

Para tentar solucionar o problema de super-ajuste dos dados, alguns indutores podam a $\mathrm{AD}$ depois de induzi-la. Esse processo, reduz o número de nós internos, reduzindo a complexidade da árvore enquanto produz um desempenho melhor que a árvore original. Em geral, os indutores de AD separam por si próprios o conjunto de exemplos em um conjunto de exemplos de treinamento (que é utilizado para construir a $\mathrm{AD}$ ) e um conjunto de exemplos de poda, o qual é efetivamente utilizado para realizar o processo de poda. Esse tipo de poda é 
conhecido como pós-poda, visto que ele ocorre após a indução da $\mathrm{AD}$. Existem vários métodos de pós-poda, incluindo Complexidade do Erro e Erro Pessimista.

Também é possível realizar a pré-poda na $\mathrm{AD}$, e esse processo é efetuado quando da indução da AD. Contudo, a pré-poda pode ter a desvantagem de numa conjunção de teste a partição dos exemplos ser a melhor, mas os atributos individuais podem não distinguir muito bem cada exemplo. Assim, a pré-poda deve evitar que determinados tipos de conjunções apareçam na AD (MONARD e BARANAUSKAS, 2003).

\subsubsection{Classificação da árvore de decisão}

A AD, após construída, pode ser utilizada para classificar novos exemplos, iniciandose pela raíz da árvore e caminhando através de cada nó de decisão até que uma folha seja encontrada, e então a classe do novo exemplo pode ser definida pela classe dessa folha, conforme já descrito anteriormente. 


\section{CAPÍTULO 3 - MATERIAIS, MÉTODOS E RESULTADOS DOS PROCESSAMENTOS}

\subsection{Materiais e métodos}

\subsubsection{Estações RBMC utilizadas}

Inicialmente efetuou-se o processamento de observações de linhas de base de estações previamente escolhidas do Sistema Geodésico Brasileiro, e para o mesmo, foram utilizados dados disponibilizados pelo IBGE referentes às estações da RBMC, coletados nos anos de 2006, 2007 e 2008.

Os processamentos foram realizados levando em conta fatores considerados de maior relevância para este trabalho, sendo eles a geometria das linhas de base, distância entre as estações RBMC utilizadas, a estação do ano, a ocorrência de atividade solar expressiva e a utilização de pontos de controle horizontal e vertical.

Para a análise da influência da geometria das estações, no processamento foram utilizados casos de geometria ideal e casos onde a geometria obtida entre as estações não apresentaram boa configuração, conforme definido no item 2.2.3.1.

Com relação a distância, as estações utilizadas para grandes distâncias foram: CUIB, BRAZ e PPTE para uma geometria ideal, e CUIB, BRAZ e MCLA para uma geometria de pior qualidade. A estação considerada como "desconhecida" nesses processamentos foi CUIB, e essa escolha foi feita de modo a se ter a geometria requerida e maior quantidade e qualidade dos dados para essas estações. As Figuras 15 e 16 a seguir, demonstram essas duas situações:

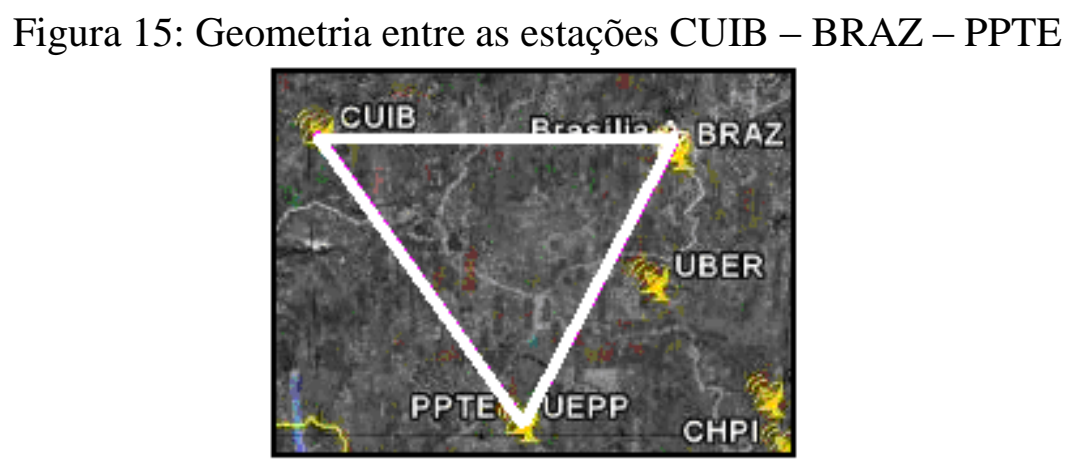

Fonte: IBGE, 2010. 
Figura 16: Geometria entre as estações CUIB - BRAZ - MCLA

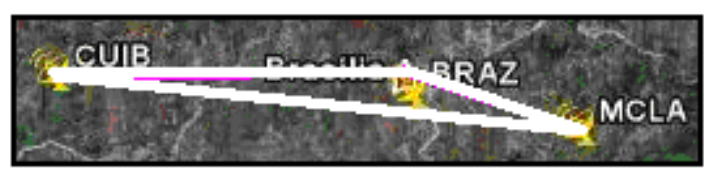

Fonte: IBGE, 2010.

As estações utilizadas para distâncias menores foram: VARG, VICO e RIOD para uma geometria ideal, e VARG, RIOD e UBER para uma geometria de pior qualidade. A estação considerada como "desconhecida" nesses processamentos foi VARG, e essa escolha foi feita de modo a se ter a geometria requerida e maior quantidade e qualidade dos dados para essas estações. As Figuras 17 e 18 abaixo demonstram essas duas situações:

Figura 17: Geometria entre as estações VARG - VICO - RIOD

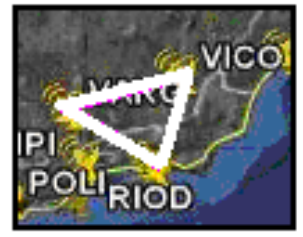

Fonte: IBGE, 2009.

Figura 18: Geometria entre as estações VARG - RIOD - UBER

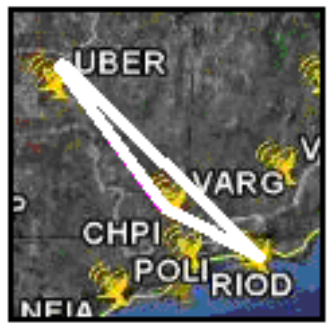

Fonte: IBGE, 2009.

Foram utilizados quatro dias de dados, referentes as quatro estações do ano, aproximadamente 20 dias após o início da mesma (os dias foram escolhidos de acordo com a disponibilidade de dados pela RBMC). Os processamentos foram efetuados utilizando-se do período de dados disponibilizado pelo IBGE para cada dia (na maioria dos casos, estes períodos foram de 24 horas). Os dias escolhidos foram:

- OUTONO (21/03 A 21/06)

11 a 14 de abril (dias julianos 101 a 104 nos anos de 2006 e 2007 e 102 a 105 no ano de 2008 (ano bissexto)); 
- $\operatorname{INVERNO~(21/06~A~23/09)~}$

12 a 15 de julho (dias julianos 193 a 196 nos anos de 2006 e 2007 e 194 a 197 no ano de 2008 (ano bissexto));

- PRIMAVERA (23/09 A 21/12)

13 a 16 de outubro (dias julianos 286 a 289 nos anos de 2006 e 2007 e 287 a 290 no ano de 2008 (ano bissexto);

- $\quad$ VERÃO (21/12 A 21/03)

11 a 14 de janeiro (dias julianos 11 a 14).

No ajustamento de observações foram utilizadas duas estações conhecidas, ou seja, foram utilizadas duas injunções, sendo elas VICO e RIOD para o primeiro caso, UBER e RIOD para o segundo caso, BRAZ e PPTE para o terceiro caso e BRAZ e MCLA para o quarto caso.

O intuito dos processamentos e ajustamento é verificar a ocorrência da solução da ambigüidade, verificar a discrepância das coordenadas obtidas no processamento com as coordenadas tidas como verdadeiras pelo IBGE (segundo as monografias das estações), e, além disso, será observada a confiabilidade das coordenadas calculadas segundo o padrão de qualidade inserido nas configurações do software.

O software para o processamento dos dados foi o Topcon Tools, versão 7.1, e os processamentos dos dados será feito utilizando-se dos parâmetros do Sistema de Referência SIRGAS2000. Nos processamentos foram utilizadas efemérides precisas adquiridas no site http://igscb.jpl.nasa.gov/components/prods.html, data do último acesso em 29/01/2010.

O manual de uso do Topcon Tools, versão 7.1 pode ser encontrado no ANEXO A deste trabalho.

O software utilizado para a Árvore de Decisão foi o WEKA (Waikato Enviroment Knowledge Analysis), versão 3.5, disponibilizado gratuitamente no site www.cs.waikato.ac.nz (último acesso em 06/10/2009).

O site utilizado para obtenção de informações referentes a atividade solar foi o www.sec.noaa.gov (último acesso em 29/01/2010).

\subsubsection{Precisão dos equipamentos utilizados pelas estações RBMC}

A fim de avaliar a correlação entre a precisão e acurácia das coordenadas obtidas no processamento com um maior grau de confiança, um dado relevante diz respeito a precisão dos equipamentos utilizados nas estações RBMC de interesse neste trabalho. 
Os equipamentos uilizados pelas estações da RBMC, apresentam precisões distintas entre si, assim, cada classificação levará em conta este fator, sendo os equipamentos por estação e por mês/ano de interesse listados a seguir:

- VARG

1) Receptor: Astech Z-FX;

Precisão horizontal para o método estático: $5 \mathrm{~mm}+1 \mathrm{ppm}$;

Precisão vertical para o método estático: $5 \mathrm{~mm}+1 \mathrm{ppm}$;

Período: desde 18/04/2001.

\section{- VICO}

1) Receptor: Trimble 4000 SSI

Precisão horizontal para o método estático: $5 \mathrm{~mm}+1 \mathrm{ppm}$

Precisão vertical para o método estático: $10 \mathrm{~mm}+1 \mathrm{ppm}$

Período: 20/08/1999 até 03/04/2007.

1) Receptor: Trimble NetR5

Precisão horizontal para o método estático: $3 \mathrm{~mm}+0.1 \mathrm{ppm}$

Precisão vertical para o método estático: $3.5 \mathrm{~mm}+0.4 \mathrm{ppm}$

Período: desde 04/04/2007.

\section{- RIOD}

1) Receptor: Trimble 4000 SSI

Precisão horizontal para o método estático: $5 \mathrm{~mm}+1 \mathrm{ppm}$

Precisão vertical para o método estático: $10 \mathrm{~mm}+1 \mathrm{ppm}$

Período: 21/07/2001 até 19/03/2007.

2) Receptor: Trimble NetRS

Precisão horizontal para o método estático: $5 \mathrm{~mm}+1 \mathrm{ppm}$

Precisão vertical para o método estático: $10 \mathrm{~mm}+1 \mathrm{ppm}$

Período: desde 19/03/2007.

\section{- UBER}

1) Receptor: Astech Z-FX; 
Precisão horizontal para o método estático: $5 \mathrm{~mm}+1 \mathrm{ppm}$;

Precisão vertical para o método estático: $5 \mathrm{~mm}+1 \mathrm{ppm}$;

Período: desde 18/04/2001.

\section{- CUIB}

1) Receptor: Trimble 4000 SSI

Precisão horizontal para o método estático: $5 \mathrm{~mm}+1 \mathrm{ppm}$

Precisão vertical para o método estático: $10 \mathrm{~mm}+1 \mathrm{ppm}$

Período: 18/06/1997 até 30/03/2007.

2) Receptor: Trimble NetRS

Precisão horizontal para o método estático: $5 \mathrm{~mm}+1 \mathrm{ppm}$

Precisão vertical para o método estático: $10 \mathrm{~mm}+1 \mathrm{ppm}$

Período: desde 31/03/2007.

\section{- PPTE}

2) Receptor: Trimble NetRS

Precisão horizontal para o método estático: $5 \mathrm{~mm}+1 \mathrm{ppm}$

Precisão vertical para o método estático: $10 \mathrm{~mm}+1 \mathrm{ppm}$

Período: desde 11/12/2005.

\section{- BRAZ}

1) Receptor: Trimble 4000 SSI

Precisão horizontal para o método estático: $5 \mathrm{~mm}+1 \mathrm{ppm}$

Precisão vertical para o método estático: $10 \mathrm{~mm}+1 \mathrm{ppm}$

Período: 21/08/1998 até 12/03/2007.

2) Receptor: Trimble NetRS

Precisão horizontal para o método estático: $5 \mathrm{~mm}+1 \mathrm{ppm}$

Precisão vertical para o método estático: $10 \mathrm{~mm}+1 \mathrm{ppm}$

Período: desde 13/03/2007.

- MCLA

1) Receptor: Astech Z-FX;

Precisão horizontal para o método estático: $5 \mathrm{~mm}+1 \mathrm{ppm}$;

Precisão vertical para o método estático: $5 \mathrm{~mm}+1 \mathrm{ppm}$; 
Período: desde 18/04/2001.

\subsection{Resultados dos processamentos}

Os processamentos foram efetuados no software Topcon Tools, versão 7.1, utilizando os seguintes parâmetros:

- Sistema de referência: SIRGAS2000;

- Tipo das coordenadas: latitude, longitude e altura elipsoidal, com base no datum escolhido;

- Coeficiente de Refração: 0.14;

- Máscara de Elevação: 15º

- Ajustamento pelo Método dos Mínimos Quadrados;

- Nível de Confiança do Ajustamento: 68\%;

- Número de pontos ajustados: 3

- Número de pontos de controle: 2;

- Número de vetores: 2 (quando, devido a interrupções na coleta pela própria estação, forem processados um número maior de vetores, o fato será mencionado no tópico do próprio dia de processamento);

- Critério de Rejeição do Ajustamento: Teste do Qui-quadrado (UWE).

Para cada dia escolhido do ano foram efetuados 4 processamentos distintos, levandose em conta: a distância entre as estações (maior ou menor que $300 \mathrm{~km}$ ) e a geometria formada entre elas (geometria boa ou ruim).

Os relatórios de processamento e ajustamento, discriminados por estações RBMC, estação do ano e dia e ano, podem ser encontrados no Anexo B deste trabalho.

\subsubsection{Distâncias menores que 300 km e geometria ideal entre as estações da RBMC}

Para este caso foram utilizadas as estações da RBMC VARG, VICO e RIOD (as monografias podem ser encontradas no Anexo C) deste trabalho.

Foram utilizadas como pontos de controle (base) as estações VICO e RIOD, sendo as coordenadas das mesmas fixadas para os processamentos (vide Tabela 1), e como ponto desconhecido a estação VARG (vide coordenadas UTM homologadas pelo IBGE na Tabela 2). 
TABELA 1: Coordenadas UTM das estações VICO e RIOD, Sistema de Referência SIRGAS2000.

\begin{tabular}{|c|c|c|}
\hline Estação & $\mathbf{E}$ & $\mathbf{N}$ \\
\hline RIOD & $673.825,217 \mathrm{~m}$ & $7.475 .648,024 \mathrm{~m}$ \\
\hline VICO & $721.757,711 \mathrm{~m}$ & $7.702 .785,751 \mathrm{~m}$ \\
\hline
\end{tabular}

Fonte: www.ibge.gov.br (último acesso em 23/02/2010).

TABELA 2: Coordenadas UTM da estação VARG (Sistema de Referência SIRGAS2000).

\begin{tabular}{|c|c|}
\hline \multicolumn{2}{|c|}{ COORDENADAS DE VARG (MONOGRAFIA) } \\
\hline E & N \\
\hline $454.968,971 \mathrm{~m}$ & $7.617 .727,294 \mathrm{~m}$ \\
\hline
\end{tabular}

Fonte: www.ibge.gov.br (último acesso em 23/02/2010).

Os resultados dos processamentos de observações, a luz dos critérios relevantes, divididos por ano, podem ser visualizados na Tabela 3, abaixo.

TABELA 3: Resultados da configuração VARG-VICO-RIOD.

\begin{tabular}{|c|c|c|c|}
\hline PARÂMETROS & $\mathbf{2 0 0 6}$ & $\mathbf{2 0 0 7}$ & $\mathbf{2 0 0 8}$ \\
\hline Processamento e Ajustamento & - & - & - \\
\hline Discrepância & - & - & - \\
\hline Ambigüidade & 4 & - & - \\
\hline PDOP & 2 & - & - \\
\hline Precisão Horizontal & - & - & - \\
\hline Precisão Vertical & - & - & - \\
\hline
\end{tabular}

3.2.2 Distâncias diferentes (com pelo menos uma menor que $300 \mathrm{~km}$ ) e geometria ruim entre as estações da RBMC

Por se tratar de casos de geometria ruim, as distâncias sofreram grandes variações (aproximadamente 300, 400 e $700 \mathrm{~km}$ ).

Para este caso foram utilizadas as estações da RBMC VARG, RIOD e UBER (as monografias podem ser encontradas no Anexo C) deste trabalho. 
Foram utilizadas como pontos de controle (base) as estações RIOD e UBER, sendo as coordenadas das mesmas fixadas para os processamentos (vide Tabela 4).

TABELA 4: Coordenadas UTM das estações RIOD e UBER (Sistema de Referência SIRGAS2000).

\begin{tabular}{|c|c|c|}
\hline Estação & $\mathbf{E}$ & $\mathbf{N}$ \\
\hline RIOD & $673.825,217 \mathrm{~m}$ & $7.475 .648,024 \mathrm{~m}$ \\
\hline UBER & $782.656,488 \mathrm{~m}$ & $7.909 .251,415 \mathrm{~m}$ \\
\hline
\end{tabular}

Fonte: www.ibge.gov.br (último acesso em 23/02/2010).

Os resultados dos processamentos de observações, a luz dos critérios relevantes, divididos por ano, podem ser visualizados na Tabela 5, abaixo.

TABELA 5: Resultados da configuração VARG-RIOD-UBER.

\begin{tabular}{|c|c|c|c|}
\hline PARÂMETROS & $\mathbf{2 0 0 6}$ & $\mathbf{2 0 0 7}$ & $\mathbf{2 0 0 8}$ \\
\hline Processamento e Ajustamento & 2 & 1 & - \\
\hline Discrepância & - & - & - \\
\hline Ambigüidade & - & - & - \\
\hline PDOP & 2 & - & - \\
\hline Precisão Horizontal & - & - & - \\
\hline Precisão Vertical & - & - & - \\
\hline
\end{tabular}

\subsubsection{Distâncias maiores que $700 \mathrm{~km}$ e geometria ideal entre as estações da} RBMC

Para este caso foram utilizadas as estações da RBMC BRAZ, CUIB e PPTE (as monografias podem ser encontradas no Anexo C) deste trabalho.

Foram utilizadas como pontos de controle (base) as estações BRAZ e PPTE, sendo as coordenadas das mesmas fixadas para os processamentos (vide Tabela 6), e como ponto desconhecido a estação CUIB (vide coordenadas UTM na Tabela 7). 
TABELA 6: Coordenadas UTM das estações BRAZ e PPTE (Sistema de Referência SIRGAS2000).

\begin{tabular}{|c|c|c|}
\hline Estação & $\mathbf{E}$ & $\mathbf{N}$ \\
\hline BRAZ & $191.901,220 \mathrm{~m}$ & $8.234 .747,341 \mathrm{~m}$ \\
\hline PPTE & $457.866,057 \mathrm{~m}$ & $7.553 .844,608 \mathrm{~m}$ \\
\hline
\end{tabular}

Fonte: www.ibge.gov.br (último acesso em 23/02/2010).

TABELA 7: Coordenadas UTM da estação CUIB (Sistema de Referência SIRGAS2000).

\begin{tabular}{|c|c|}
\hline \multicolumn{2}{|c|}{ COORDENADAS DE CUIB(MONOGRAFIA) } \\
\hline E & $\mathbf{N}$ \\
\hline $599.737,357 \mathrm{~m}$ & $8.280 .040,831 \mathrm{~m}$ \\
\hline
\end{tabular}

Fonte: www.ibge.gov.br (último acesso em 23/02/2010).

Os resultados dos processamentos de observações, a luz dos critérios relevantes, divididos por ano, podem ser visualizados na Tabela 8, abaixo.

TABELA 8: Resultados da configuração CUIB-BRAZ-PPTE.

\begin{tabular}{|c|c|c|c|}
\hline PARÂMETROS & $\mathbf{2 0 0 6}$ & $\mathbf{2 0 0 7}$ & $\mathbf{2 0 0 8}$ \\
\hline Processamento e Ajustamento & 5 & 1 & - \\
\hline Discrepância & - & - & - \\
\hline Ambigüidade & - & - & - \\
\hline PDOP & 2 & - & - \\
\hline Precisão Horizontal & - & - & - \\
\hline Precisão Vertical & - & - & - \\
\hline
\end{tabular}

3.2.4 Distâncias diferentes (com pelo menos uma maior que $700 \mathrm{~km}$ ) e geometria ruim entre as estações da RBMC

Para este caso foram utilizadas as estações da RBMC BRAZ, CUIB e MCLA (as monografias podem ser encontradas no Anexo C) deste trabalho.

Foram utilizadas como pontos de controle (base) as estações BRAZ e MCLA, sendo as coordenadas das mesmas fixadas para os processamentos (vide Tabela 9), e como ponto desconhecido a estação CUIB. 
TABELA 9: Coordenadas UTM das estações BRAZ e MCLA (sistema de referência SIRGAS2000).

\begin{tabular}{|c|c|c|}
\hline Estação & $\mathbf{E}$ & $\mathbf{N}$ \\
\hline BRAZ & $191.901,220 \mathrm{~m}$ & $8.234 .747,341 \mathrm{~m}$ \\
\hline MCLA & $619.257,849 \mathrm{~m}$ & $8.151 .040,841 \mathrm{~m}$ \\
\hline
\end{tabular}

Fonte: www.ibge.gov.br (último acesso em 23/02/2010).

Os resultados dos processamentos de observações, a luz dos critérios relevantes, divididos por ano, podem ser visualizados na Tabela 10, abaixo.

TABELA 10: Resultados da configuração CUIB-BRAZ-MCLA.

\begin{tabular}{|c|c|c|c|}
\hline PARÂMETROS & $\mathbf{2 0 0 6}$ & $\mathbf{2 0 0 7}$ & $\mathbf{2 0 0 8}$ \\
\hline Processamento e Ajustamento & 4 & 1 & 1 \\
\hline Discrepância & - & 1 & 2 \\
\hline Ambigüidade & - & - & - \\
\hline PDOP & 12 & 12 & 14 \\
\hline Precisão Horizontal & - & - & - \\
\hline Precisão Vertical & - & - & - \\
\hline
\end{tabular}

A seguir, ilustraremos o algoritmo utilizado para a classificação dos resultados dos processamentos, bem como será feita uma análise dos mesmos. 


\section{CAPÍTULO 4-CLASSIFICACÃ̃o E ANÁLISE DOS RESULTADOS}

\subsection{Indução da AD}

O algoritmo utilizado para a Classificação por AD deste trabalho pode ser visualizado na Figura 19. 
Figura 19: Indução da Árvore de Decisão

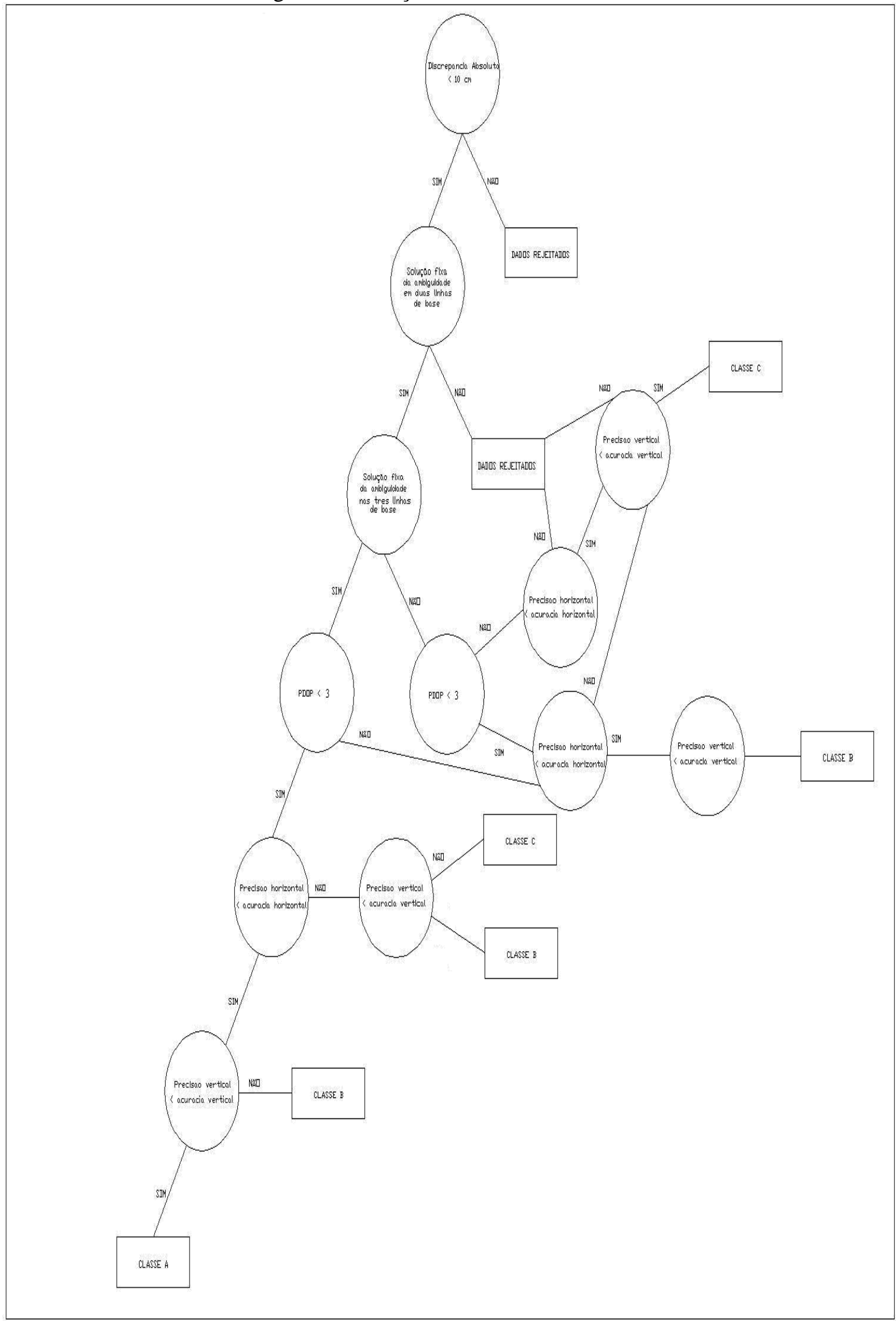


Onde os parâmetros utilizados para a classificação foram:

- Quando a discrepância entre as coordenadas homologadas pelo IBGE e a encontrada no processamento ultrapassou $10 \mathrm{~cm}$, os dados foram imediatamente rejeitados. Este valor foi adotado baseando-se na Norma Técnica para Georreferenciamentode Imóveis Rurais - 1 edição (INCRA, 2003), assim, após uma análise criteriosa de todos os processamentos e da bibliografia inerente ao assunto, chegou-se a este valor como sendo o máximo de discrepância aceita;

- A solução da ambiguidade, onde a solução "float" foi aceita para linhas de base maiores que $300 \mathrm{~km}$. A classificação foi feita da seguinte forma: se apenas uma linha de base não obteve a solução da ambiguidade esperada, este processamento passa a ser de uma classe inferior, porém, caso duas ou as três linhas de base não obtiveram a solução esperada, este processamento foi rejeitado. Esta decisão foi baseada em trabalhos anteriores (ver MENZORI, 2005) e observando-se o padrão dos processamentos deste trabalho;

- O PDOP, onde o valor máximo aceito para uma a classificação A foi 3. Para valores de PDOP em uma linha de base entre 3 e 6, este processamento passou a ser de uma classe inferior. Com dois ou três processamentos entre 3 e 6 , ou apenas um com valor acima de 6, este processamento foi rejeitado;

- As precisões horizontais e verticais, onde para se estimar o valor limite para este parâmetro, levou-se em conta a acurácia estimada de cada equipamento em cada linha de base e o seu período de funcionamento na referida estação.

\subsection{Parâmetros para a classificação da AD}

Os resultados foram separados por ano, e pela geometria entre as estações da RBMC. A Tabela 11 apresenta a classificação proposta com as condições a serem atendidas.sendo classificados em: 
Tabela 11: Tabela de classes das linhas base.

\begin{tabular}{|c|c|}
\hline $\mathbf{A}$ & $\begin{array}{c}\text { Todas as condições foram atendidas } \\
\text { satisfatoriamente conforme os critérios } \\
\text { estabelecidos no item anterior }\end{array}$ \\
\hline B & $\begin{array}{c}\text { Uma das condições não foi atendida } \\
\text { satisfatoriamente. } \\
\text { Por exemplo: o PDOP de uma determinada } \\
\text { estação foi maior que } 3 \text {, ou uma das linhas de } \\
\text { base não teve a ambiguidade solucionada } \\
\text { conforme o esperado, etc }\end{array}$ \\
\hline C & $\begin{array}{l}\text { Duas ou mais condições não foram atendidas } \\
\text { satisfatoriamente. }\end{array}$ \\
\hline $\mathbf{R}$ & $\begin{array}{l}\text { Três ou mais condições não foram atendidas } \\
\text { satisfatoriamente. }\end{array}$ \\
\hline
\end{tabular}

A Legenda das classificações pelo WEKA podem ser visualizadas na Figura 20 a seguir:

Figura 20: Legenda das Classificações pelo WEKA.

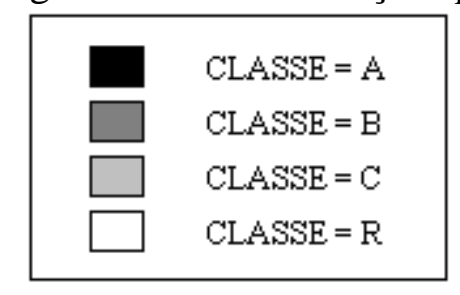

\subsection{Estrutura do banco de dados e legenda da classificação da AD}

Os bancos de dados gerados para a classificação utilizando o WEKA, versão 3.5 têm a estrutura conforme pode ser visualizado na Figura 21: 
Figura 21: Exemplo de Estrutura do Banco de Dados utilizado pela AD

\begin{tabular}{|c|c|c|}
\hline $\begin{array}{l}\text { Dia Juliano } 011 \\
\text { Dia Juliano } 012 \\
\text { Dia Juliano } 013 \\
\text { Dia Juliano } 014 \\
\text { Dia Juliano } 101 \\
\text { Dia Juliano } 102 \\
\text { Dia Juliano } 103 \\
\text { Dia Juliano } 104 \\
\text { Dia Juliano } 193 \\
\text { Dia Juliano } 194 \\
\text { Dia Juliano } 195 \\
\text { Dia Juliano } 196 \\
\text { Dia Juliano } 286 \\
\text { Dia Juliano } 287 \\
\text { Dia Juliano } 288 \\
\text { Dia Juliano } 289\end{array}$ & 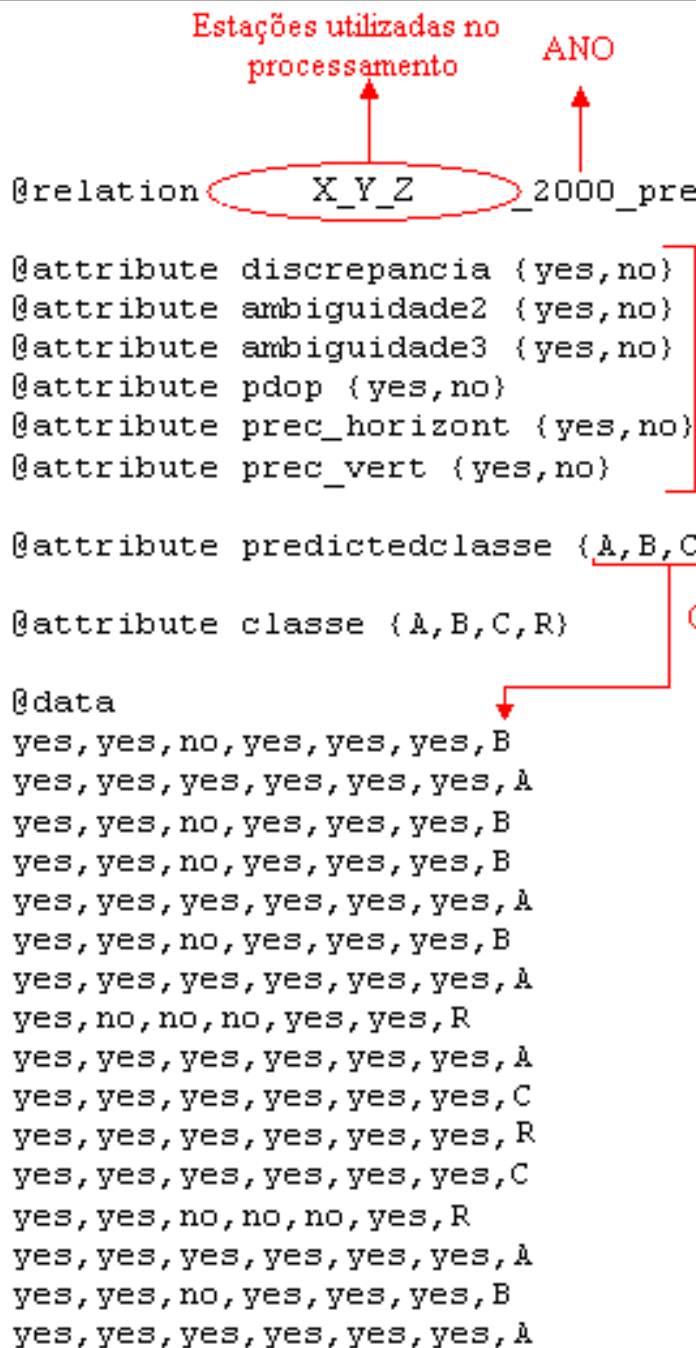 & $\begin{array}{l}\text { Atributos } \\
\text { classificatórios } \\
C, \mathrm{R} \text { : } \\
\text { Classes previstas pela } A D\end{array}$ \\
\hline
\end{tabular}

Conforme pode ser visto na Figura 21, no cabeçalho constam as estações utilizadas (X, Y e Z) e o ano do processamento (que no caso é 2000), nos parágrafos seguintes constam os atributos classificatórios (discrepância entre coordenada homologada e coordenada obtida do processamento, solução da ambiguidade em duas e três linhas de base, PDOP com valor igual ou inferior a 3 e precisão horizonal e vertical abaixo do permitido pelo manual do fabricante para cada linha de base), após a classificação feita pela AD e então, os resultados obtidos para cada Dia Juliano daquele ano e configuração entre estações (Dia Juliano 011 em 2000, configuração: X_Y_Z). 


\subsection{Classificação dos processamentos}

\subsubsection{Distâncias menores que 300 km e geometria ideal (VARG-VICO-RIOD)}

\subsubsection{Ano de 2006}

A Figura 22 a seguir mostra os gráficos com a classificação dada pelo Weka:

Figura 22: Gráfico da classificação pelo WEKA

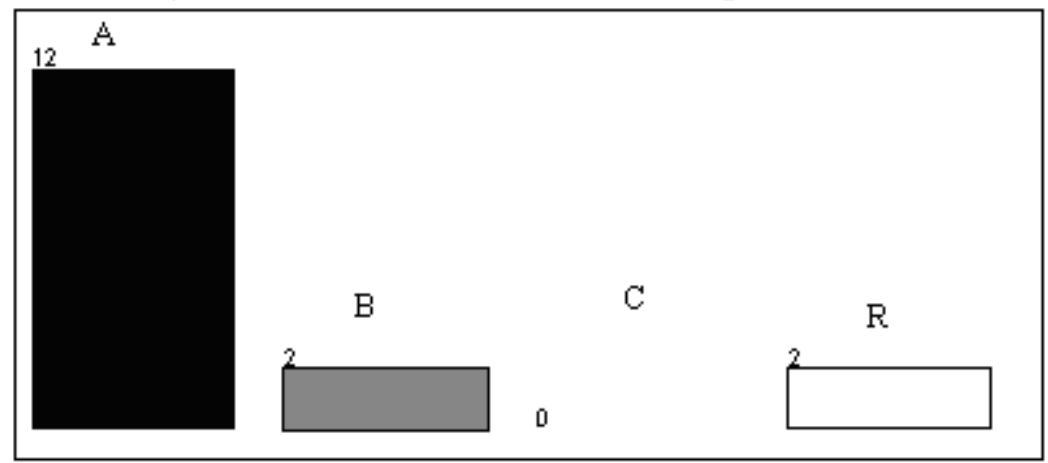

\section{BANCO DE DADOS}

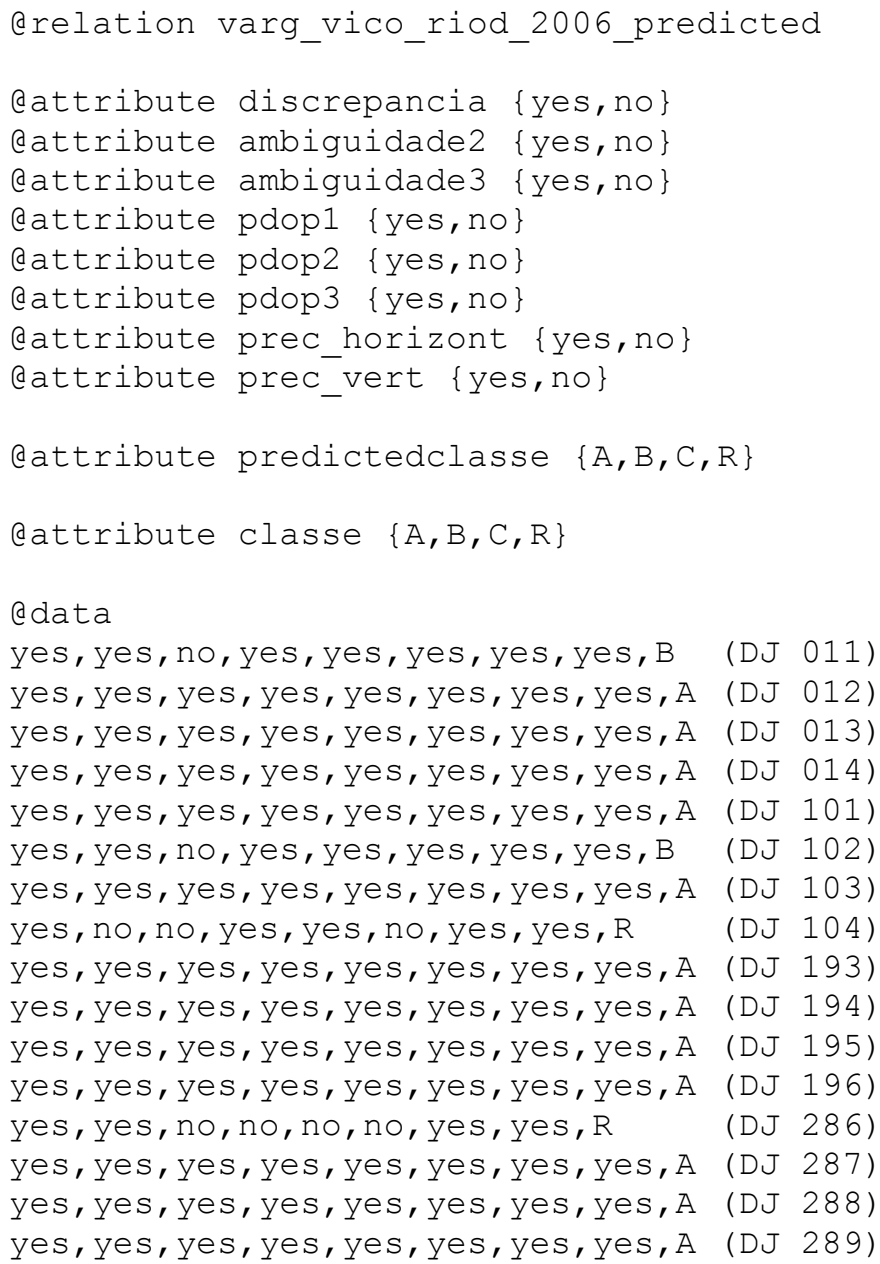




\subsubsection{Ano de 2007}

A Figura 23 a seguir mostra os gráficos com a classificação dada pelo Weka:

Figura 23: Gráfico da classificação pelo WEKA

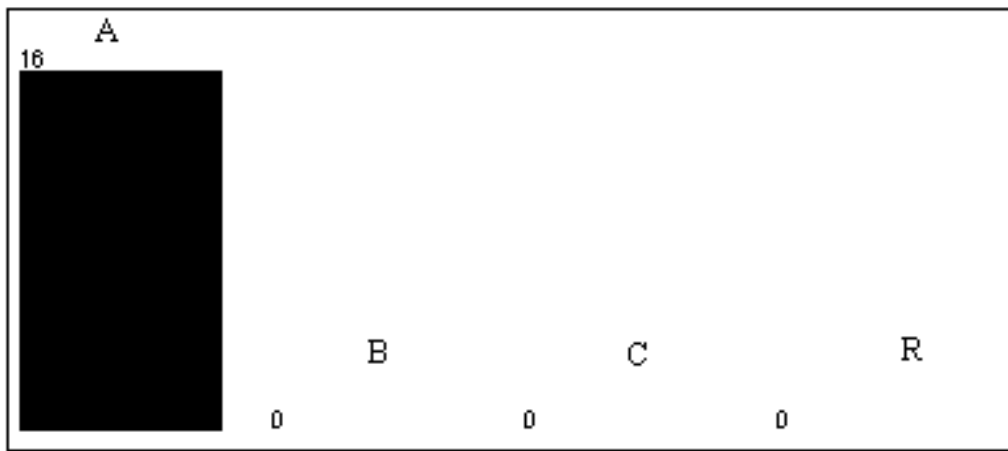

\section{BANCO DE DADOS}

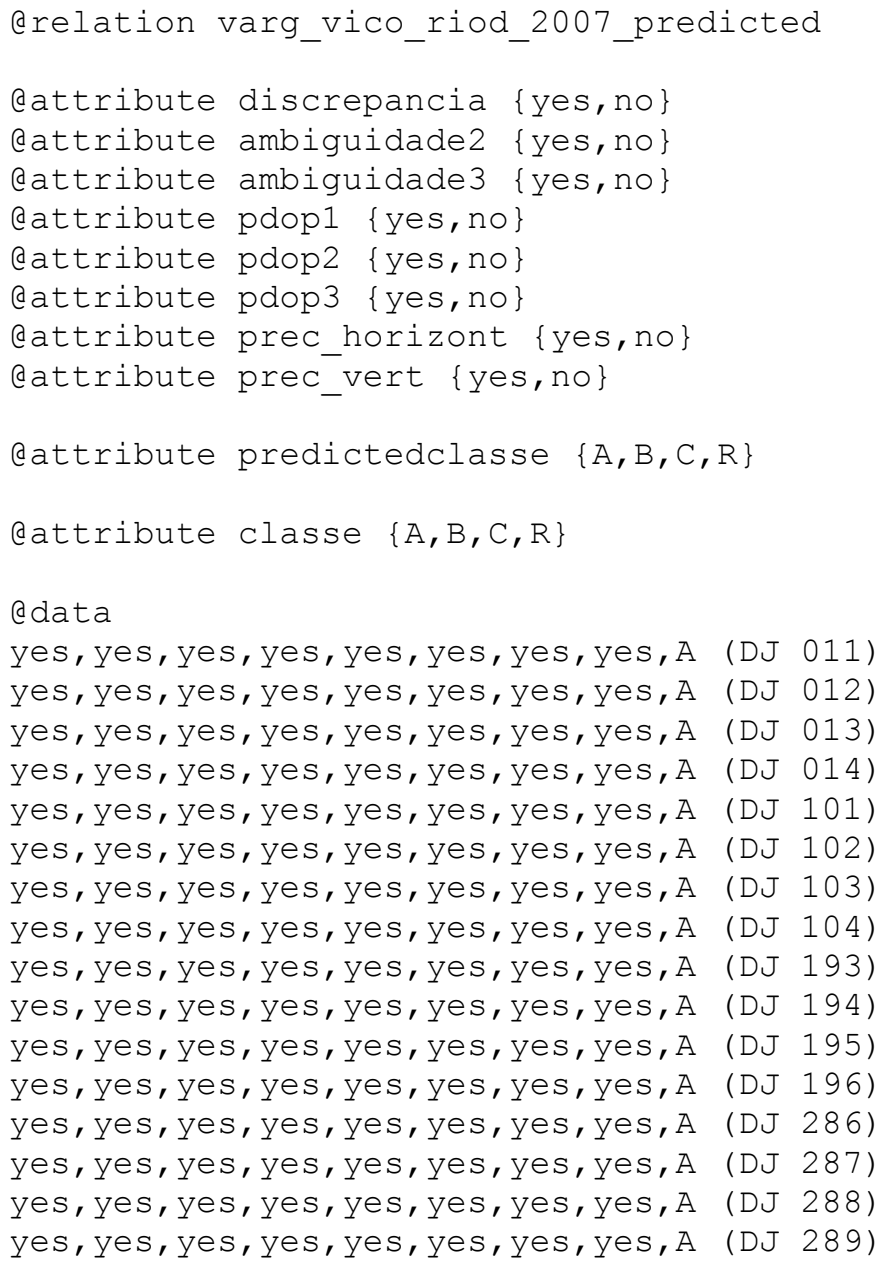




\subsubsection{Ano de 2008}

A Figura 24 a seguir mostra os gráficos com a classificação dada pelo Weka:

Figura 24: Gráfico da classificação pelo WEKA

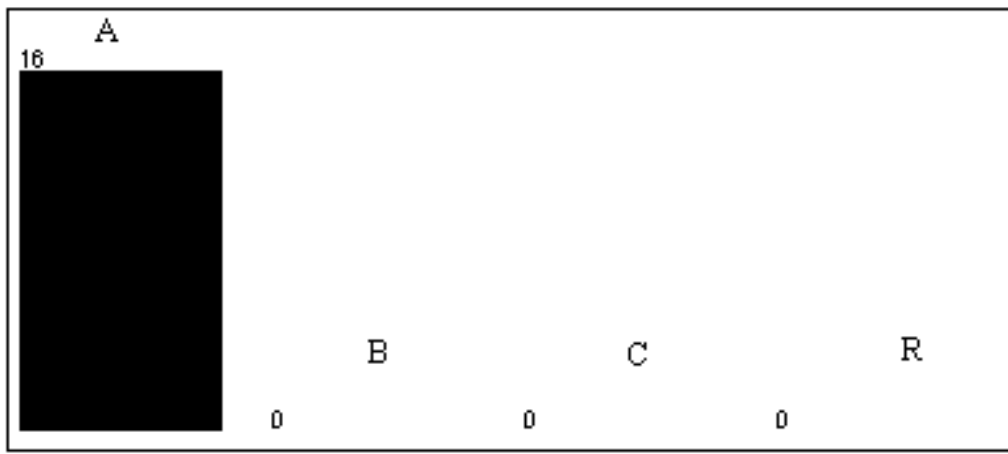

\section{BANCO DE DADOS}

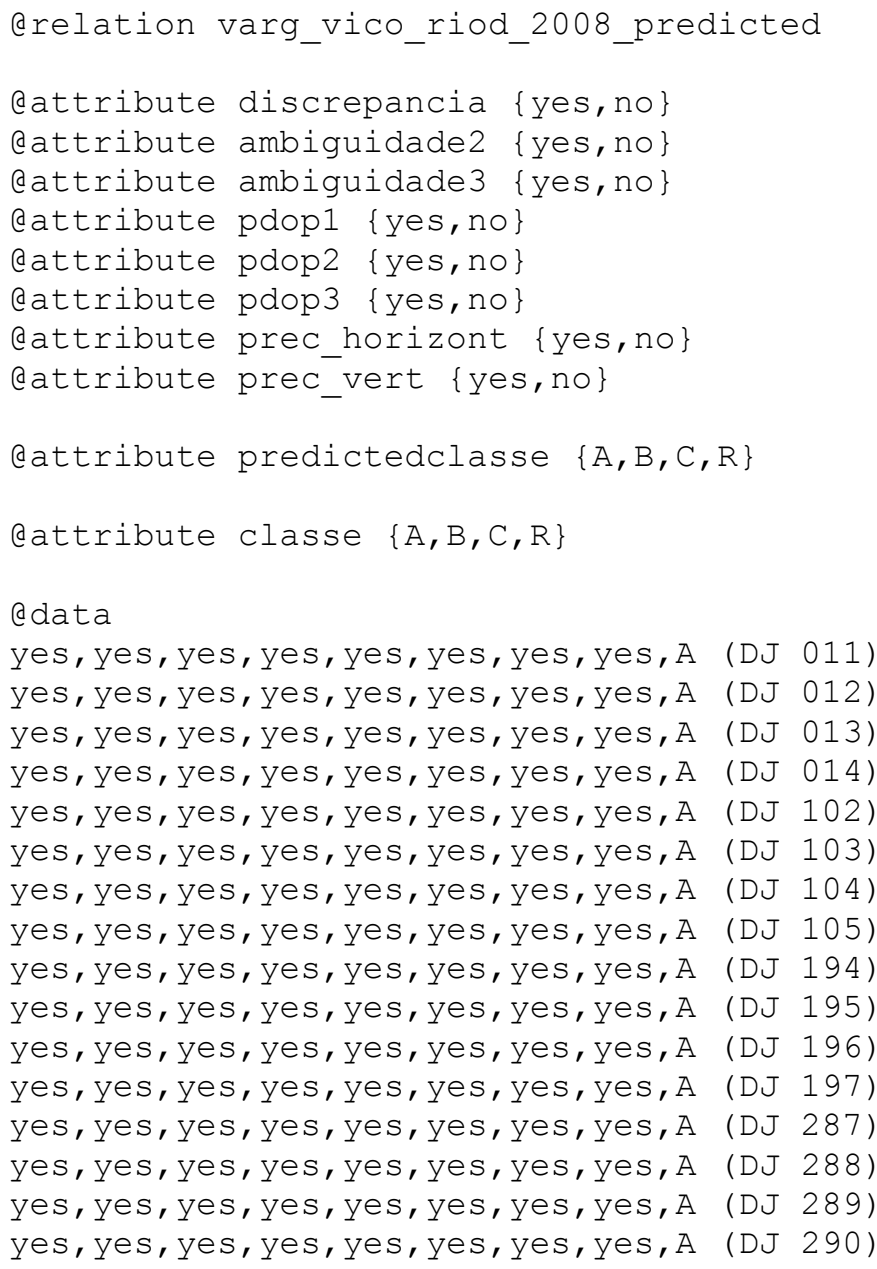




\subsubsection{Distâncias diferentes (com pelo menos uma menor que $300 \mathrm{~km}$ ) e geometria} ruim entre as estações da RBMC (VARG-RIOD-UBER)

\subsubsection{Ano de 2006}

A Figura 25 a seguir mostra os gráficos com a classificação dada pelo Weka:

Figura 25: Gráfico da classificação pelo WEKA

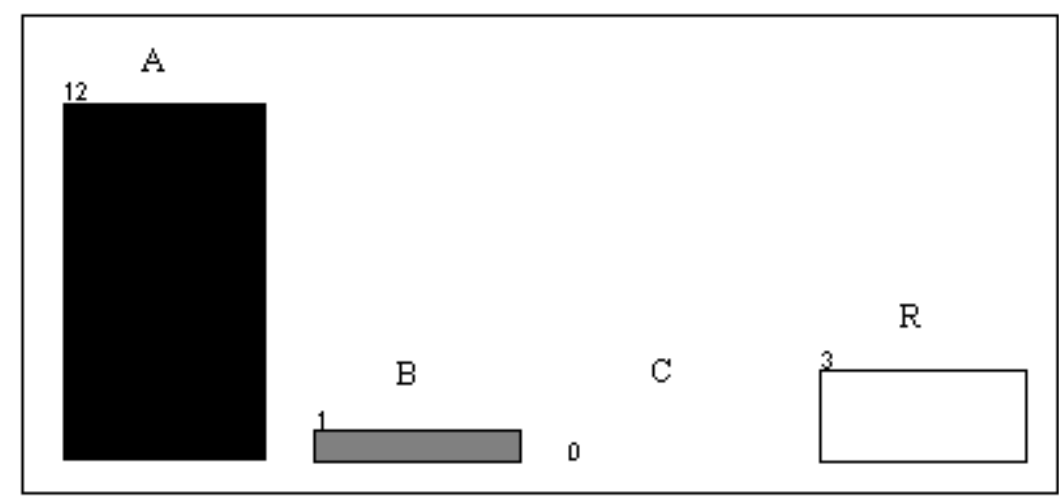

\section{BANCO DE DADOS}

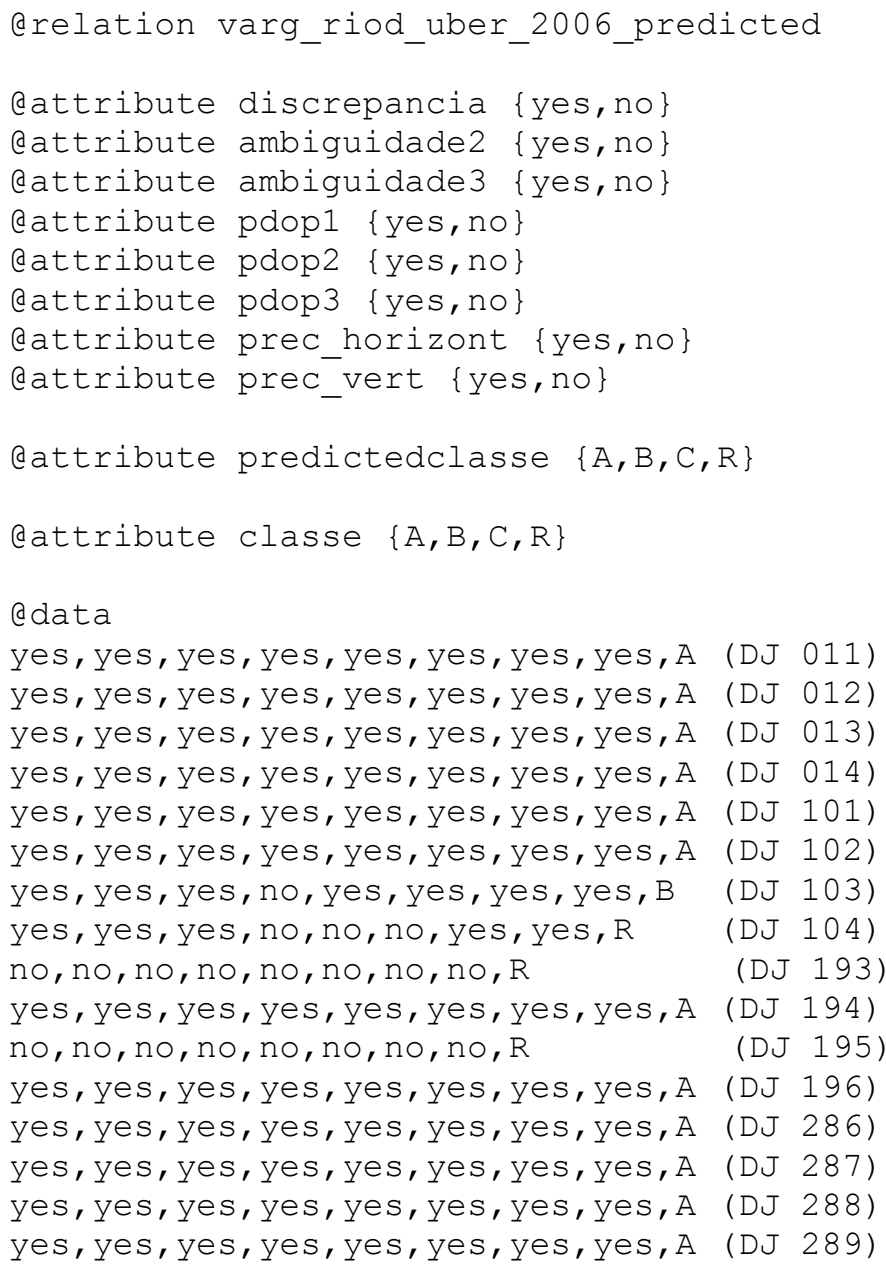




\subsubsection{Ano de 2007}

A Figura 26 a seguir mostra os gráficos com a classificação dada pelo Weka:

Figura 26: Gráfico da classificação pelo WEKA

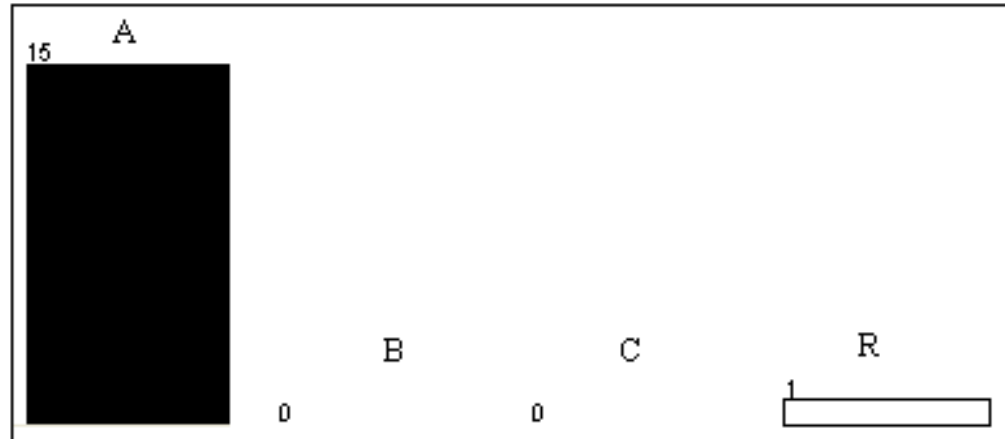

\section{BANCO DE DADOS}

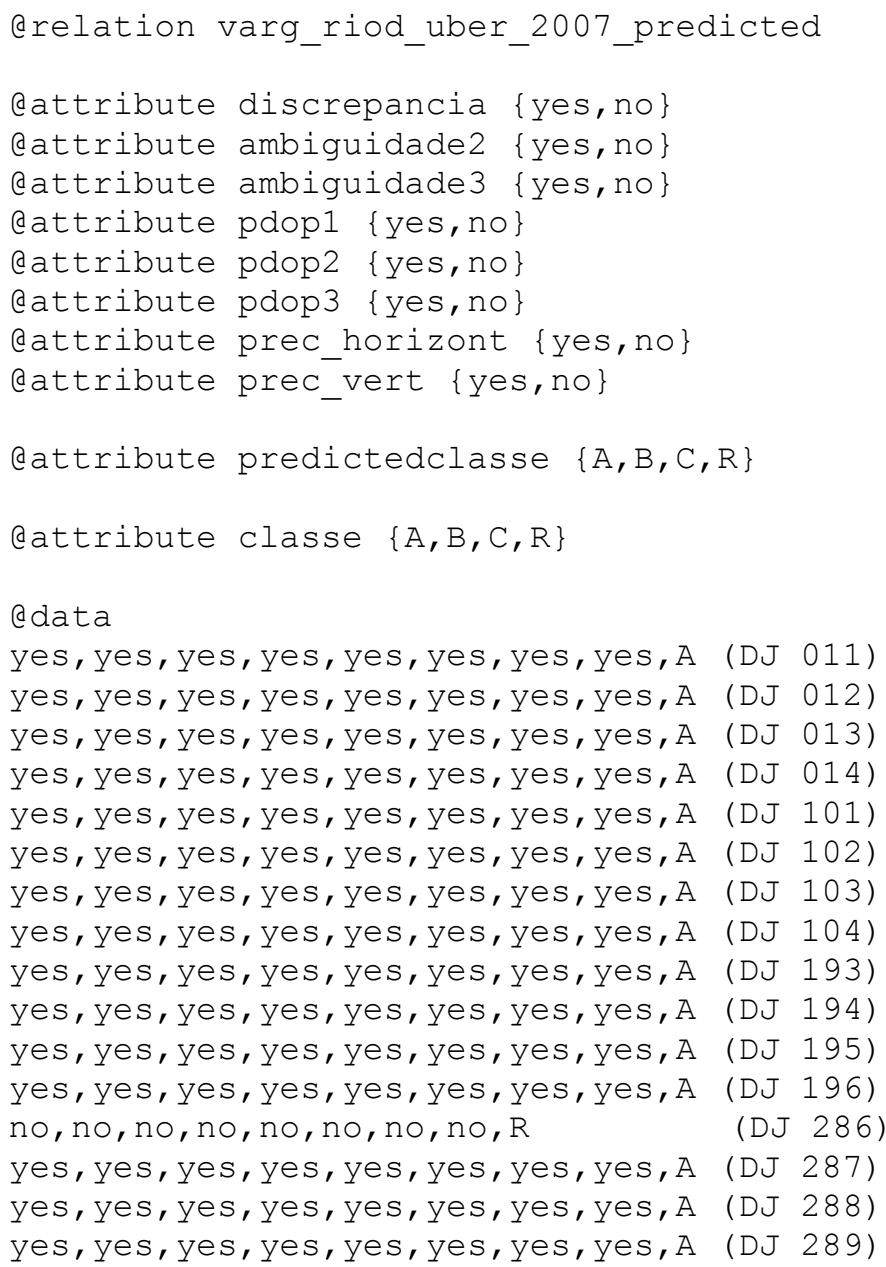




\subsubsection{Ano de 2008}

A Figura 27 a seguir mostra os gráficos com a classificação dada pelo Weka:

Figura 27: Gráfico da classificação pelo WEKA

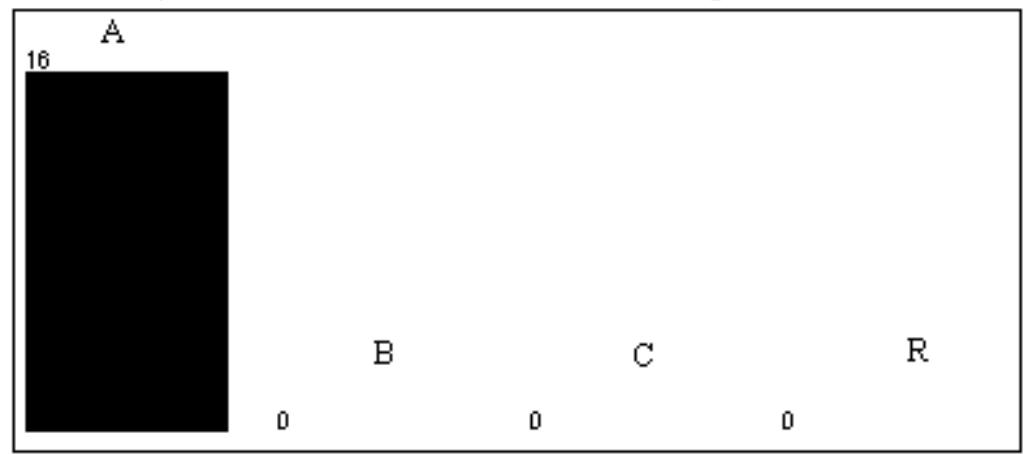

\section{BANCO DE DADOS}

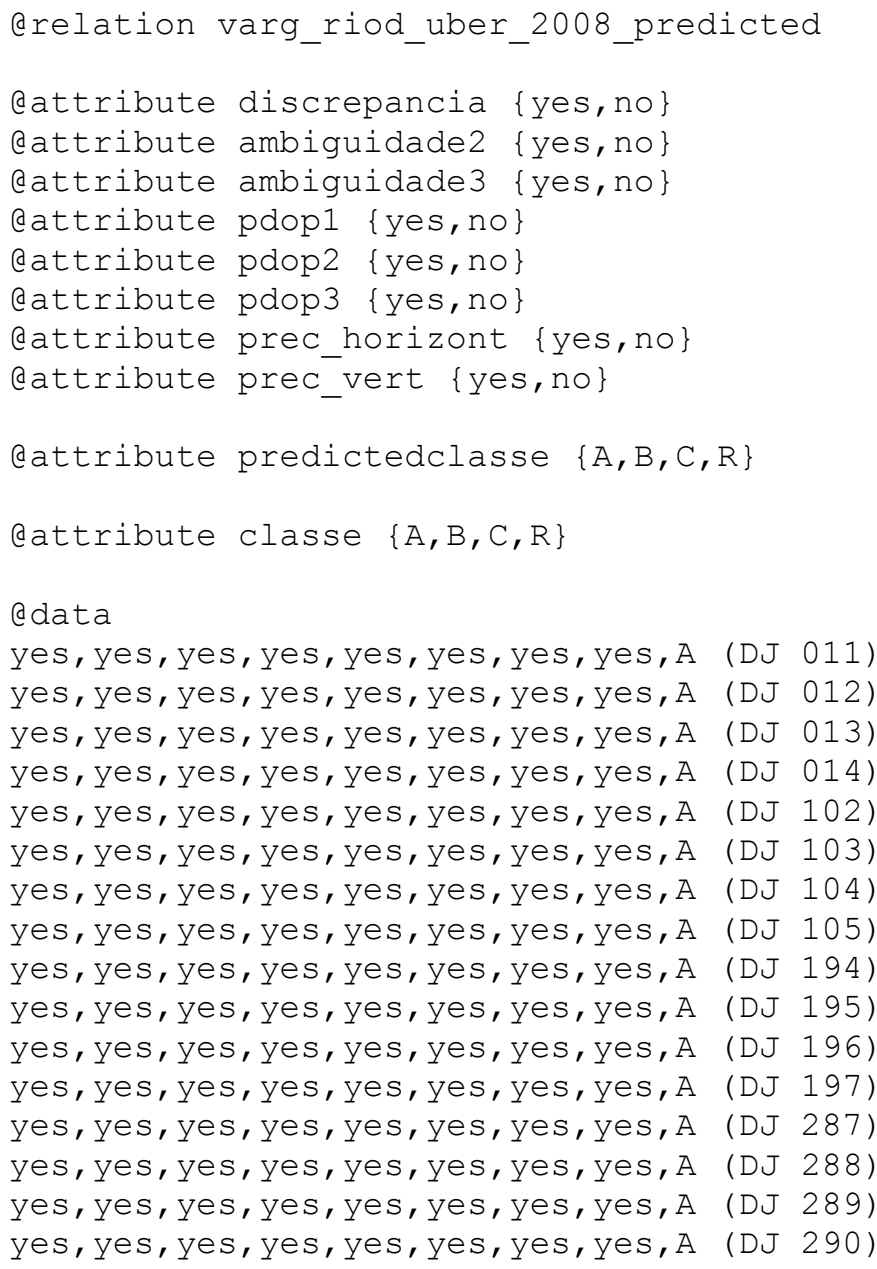


4.3.3 Distâncias maiores que $700 \mathrm{~km}$ e geometria ideal entre as estações da RBMC (CUIB-BRAZ-PPTE)

\subsubsection{Ano de 2006}

A Figura 28 a seguir mostra os gráficos com a classificação dada pelo Weka:

Figura 28: Gráfico da classificação pelo WEKA

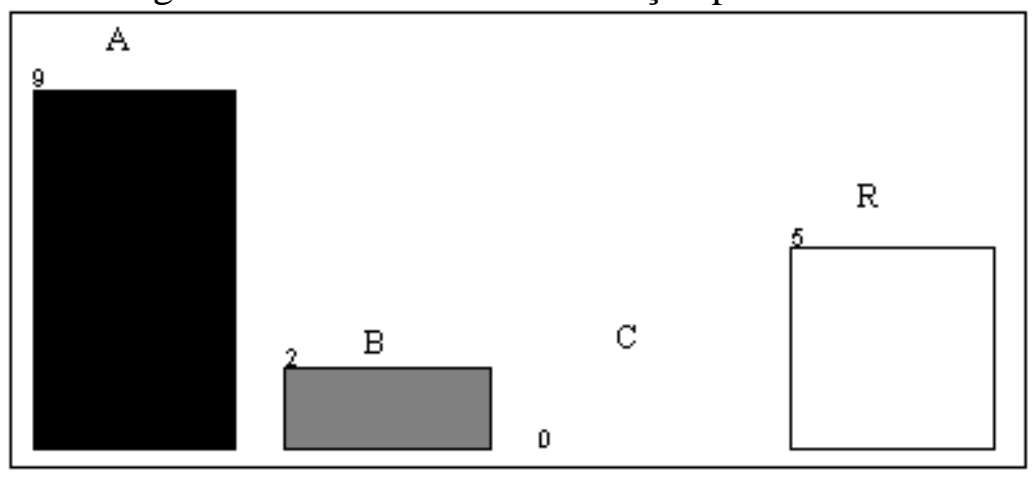

\section{BANCO DE DADOS}

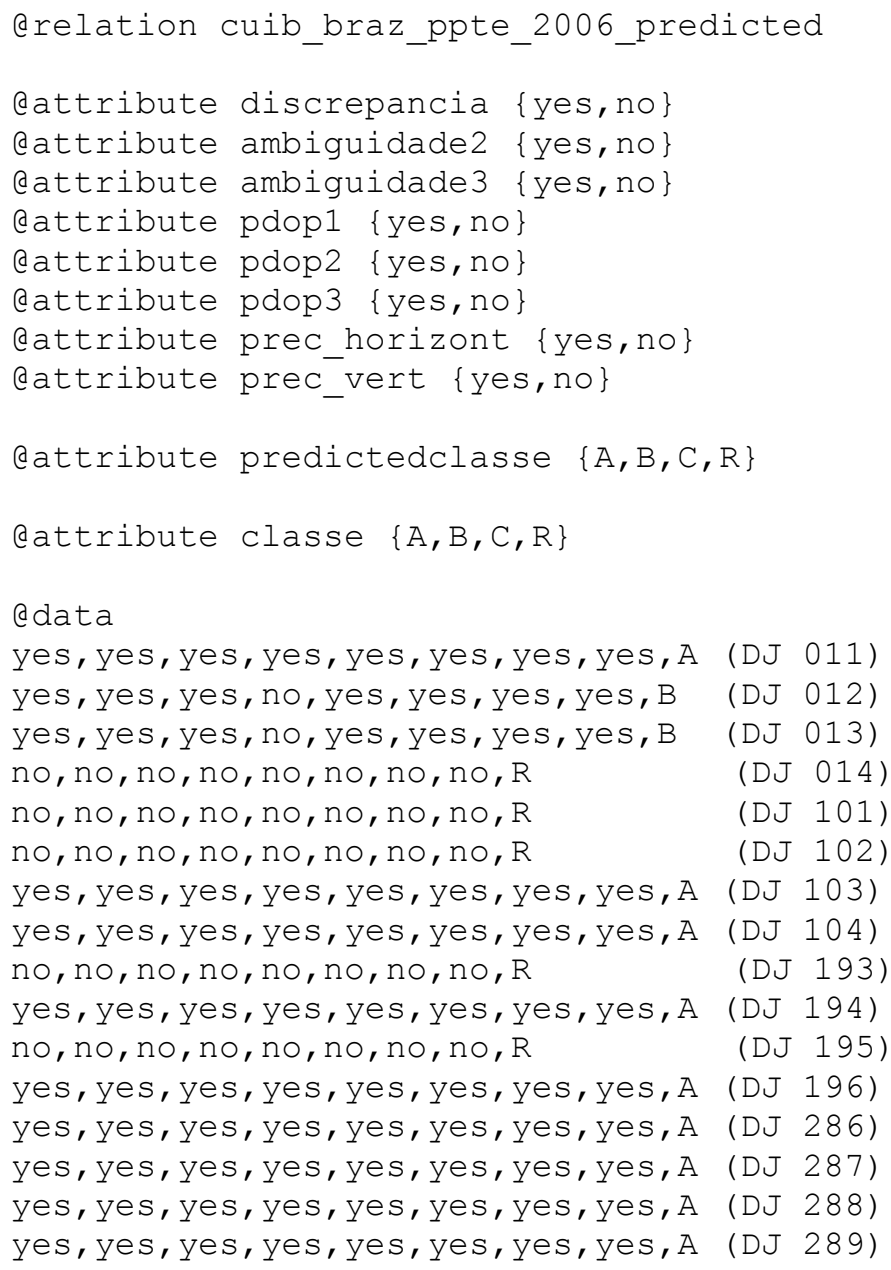




\subsubsection{Ano de 2007}

A Figura 29 a seguir mostra os gráficos com a classificação dada pelo Weka:

Figura 29: Gráfico da classificação pelo WEKA

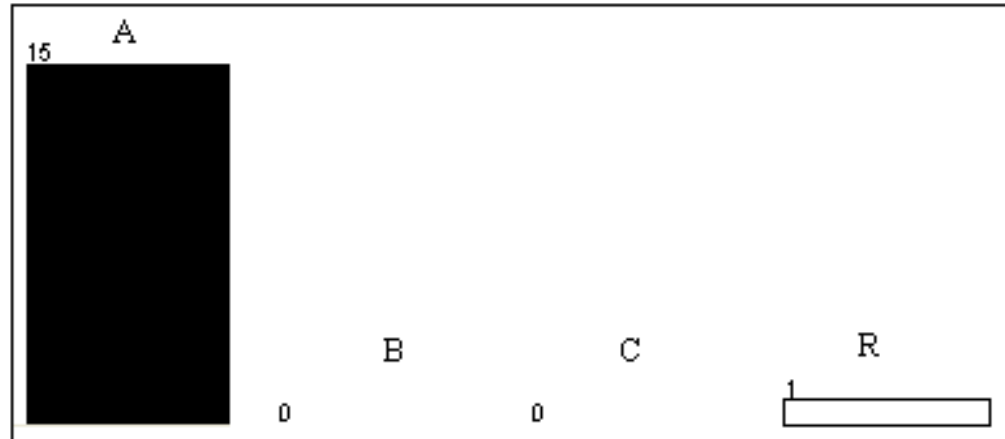

\section{BANCO DE DADOS}

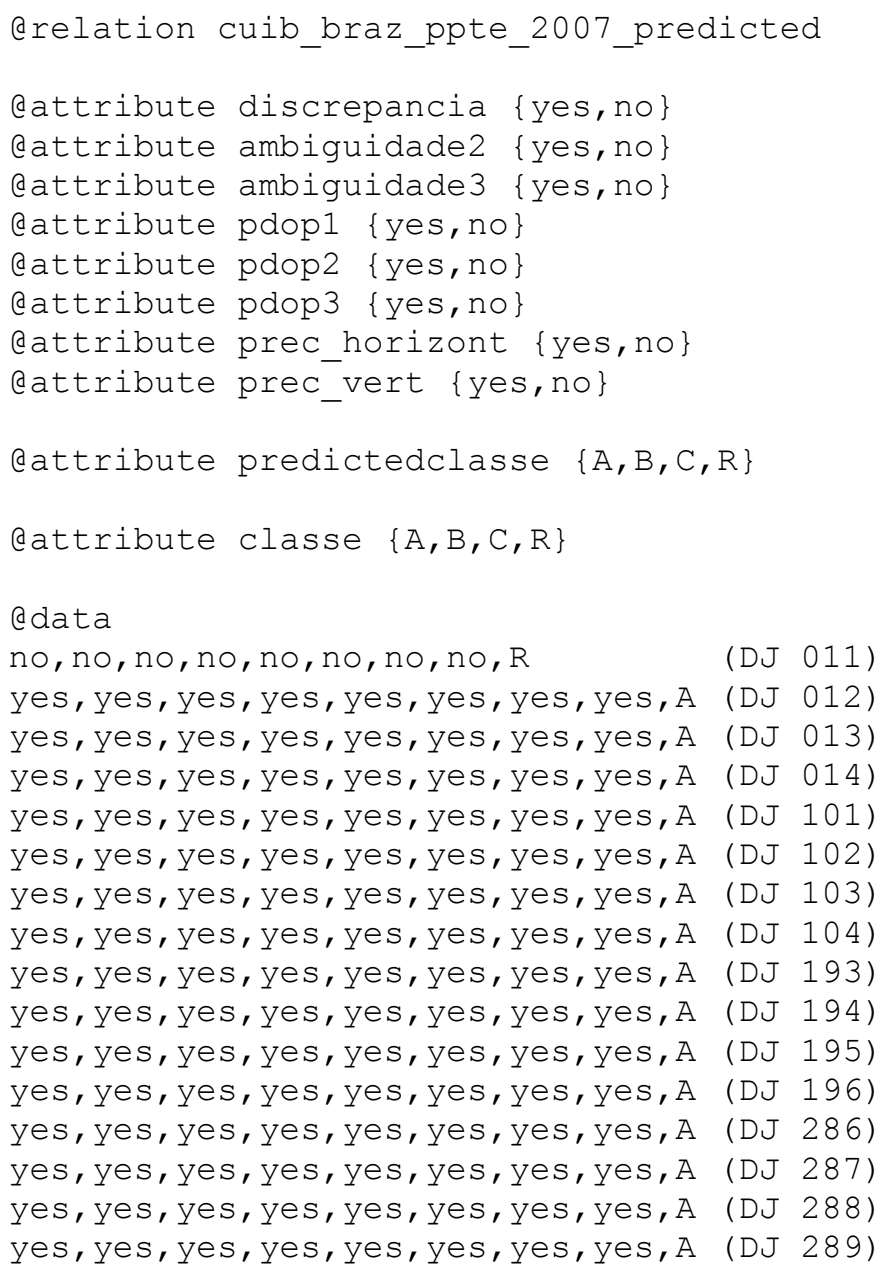




\subsubsection{Ano de 2008}

A Figura 30 a seguir mostra os gráficos com a classificação dada pelo Weka:

Figura 30: Gráfico da classificação pelo WEKA

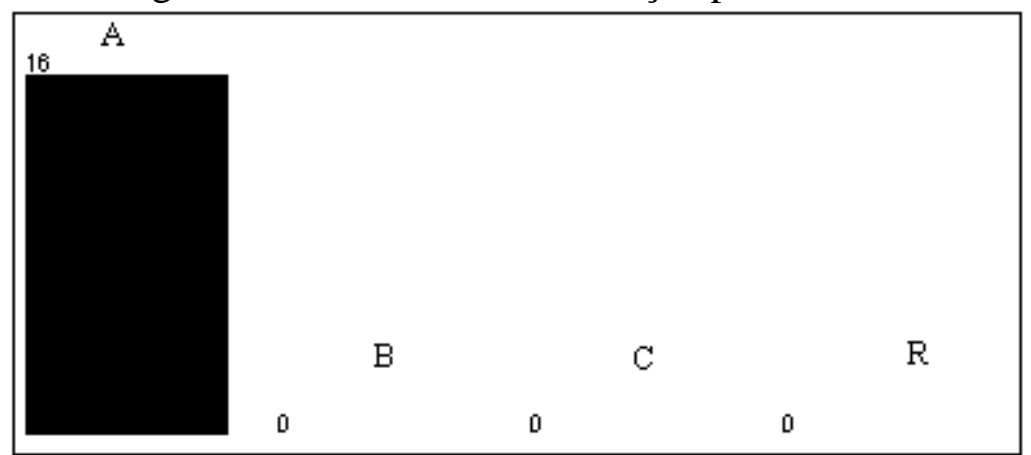

\section{BANCO DE DADOS}

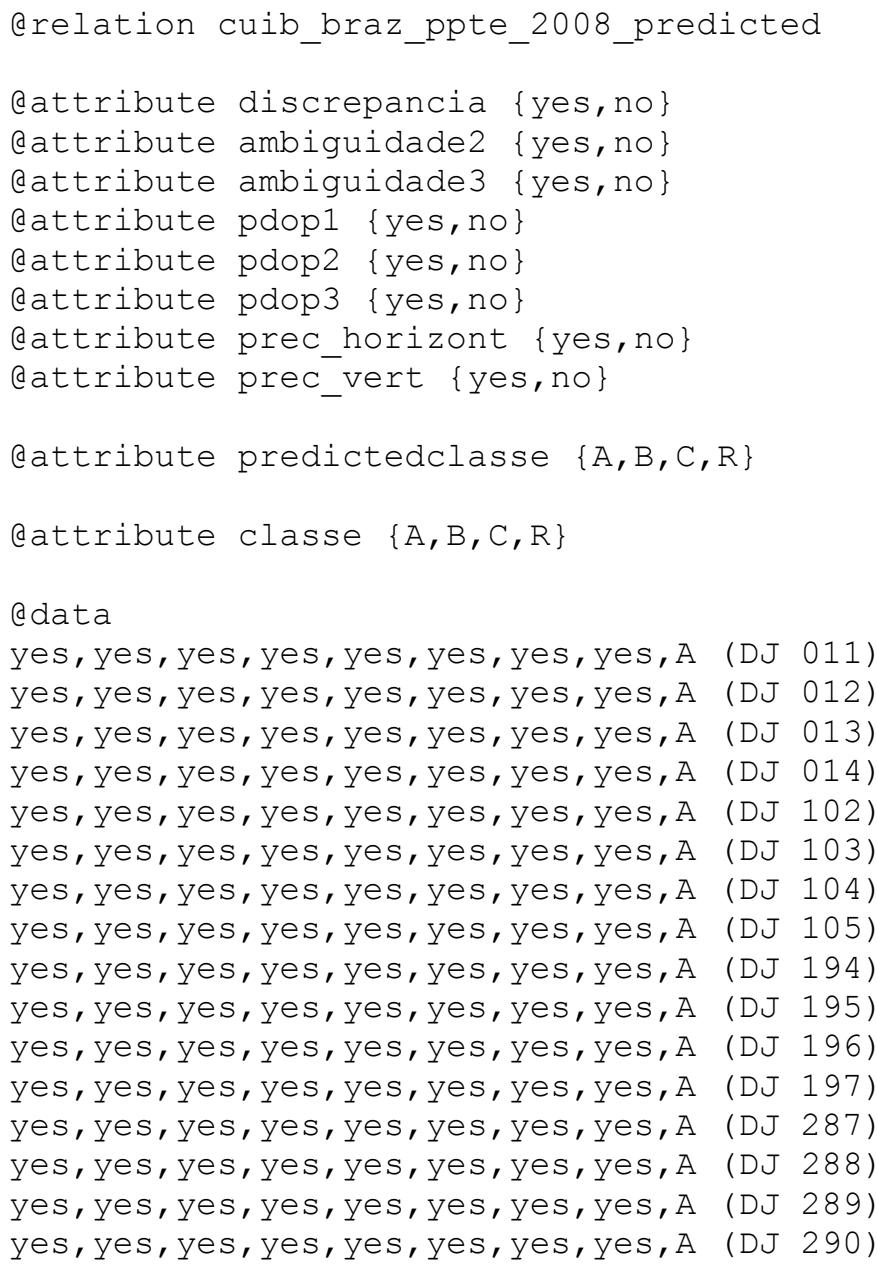




\subsubsection{Distâncias maiores que $700 \mathrm{~km}$ e geometria ruim entre as estações da RBMC (CUIB-BRAZ-MCLA)}

\subsubsection{Ano de 2006}

A Figura 31 a seguir mostra os gráficos com a classificação dada pelo Weka:

Figura 31: Gráfico da classificação pelo WEKA

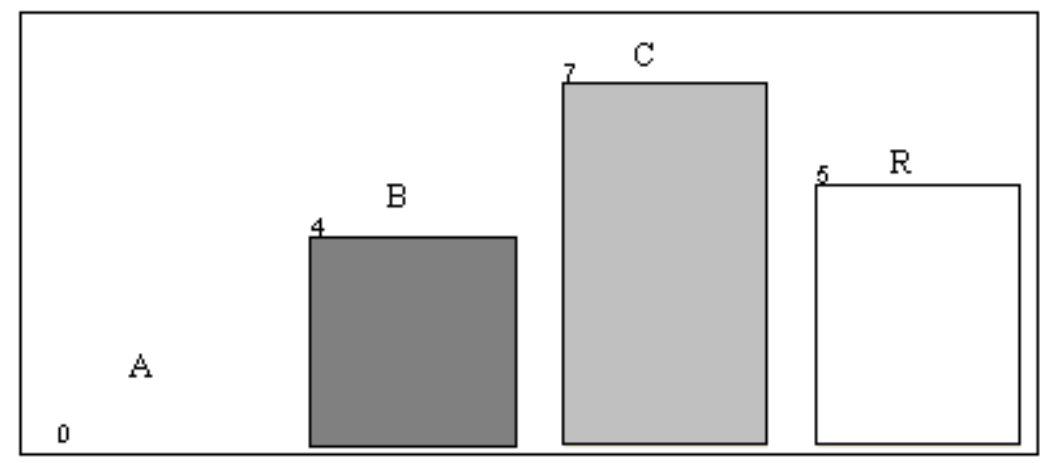

\section{BANCO DE DADOS}

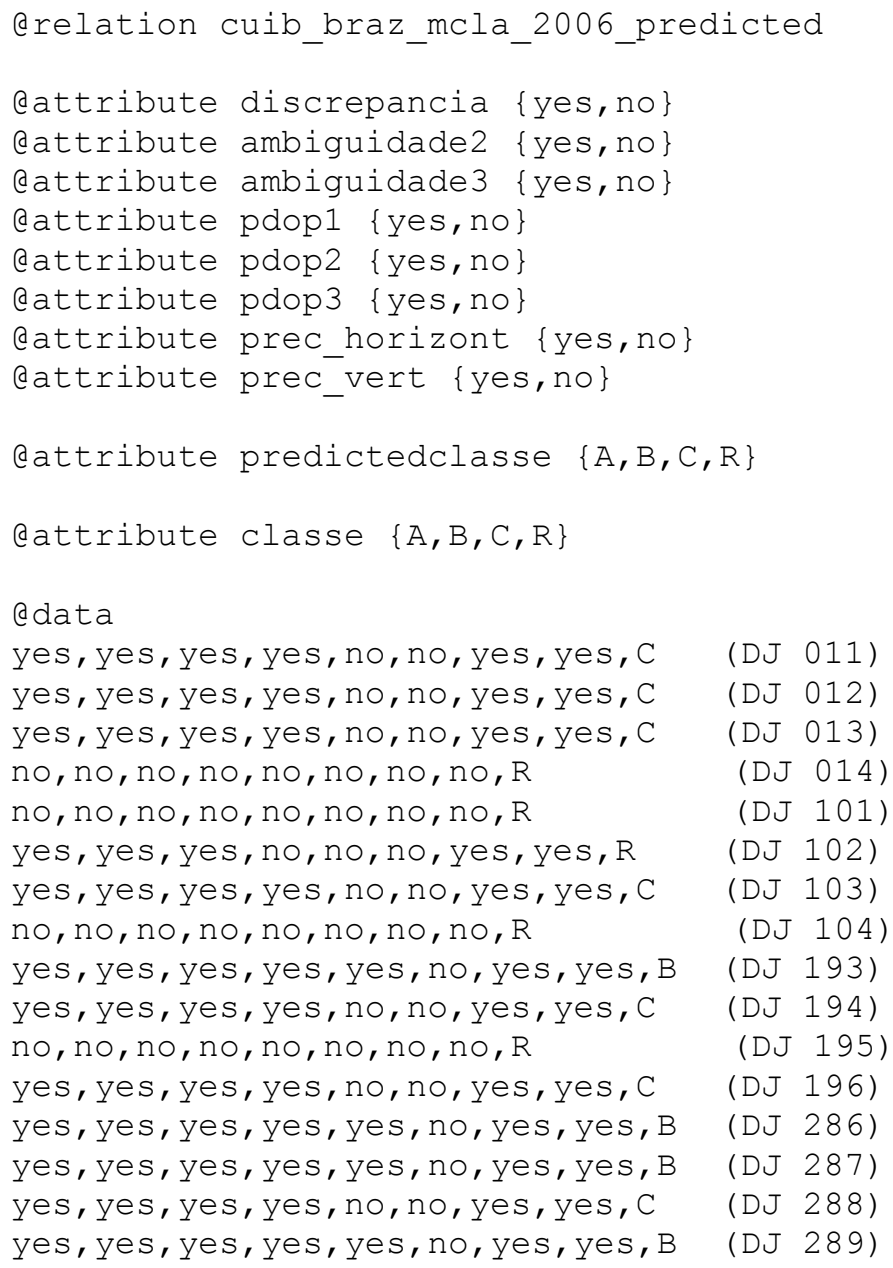




\subsubsection{Ano de 2007}

A Figura 32 a seguir mostra os gráficos com a classificação dada pelo Weka:

Figura 32: Gráfico da classificação pelo WEKA

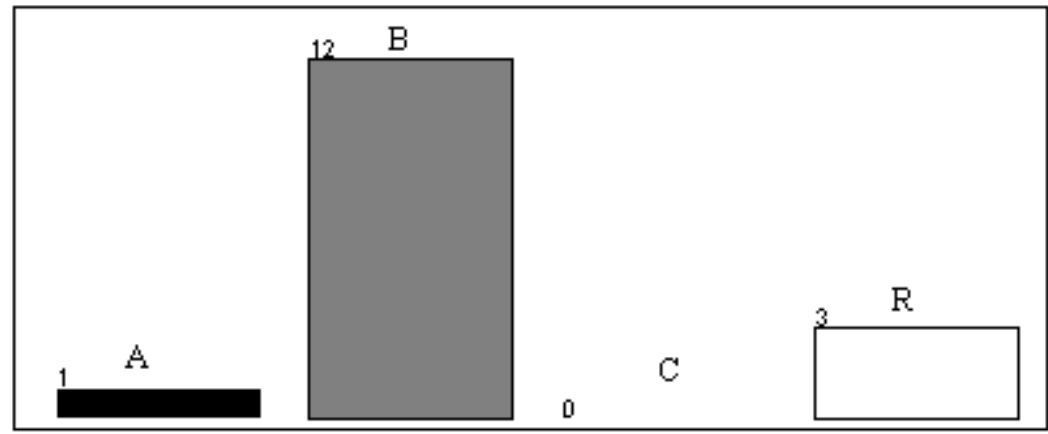

\section{BANCO DE DADOS}

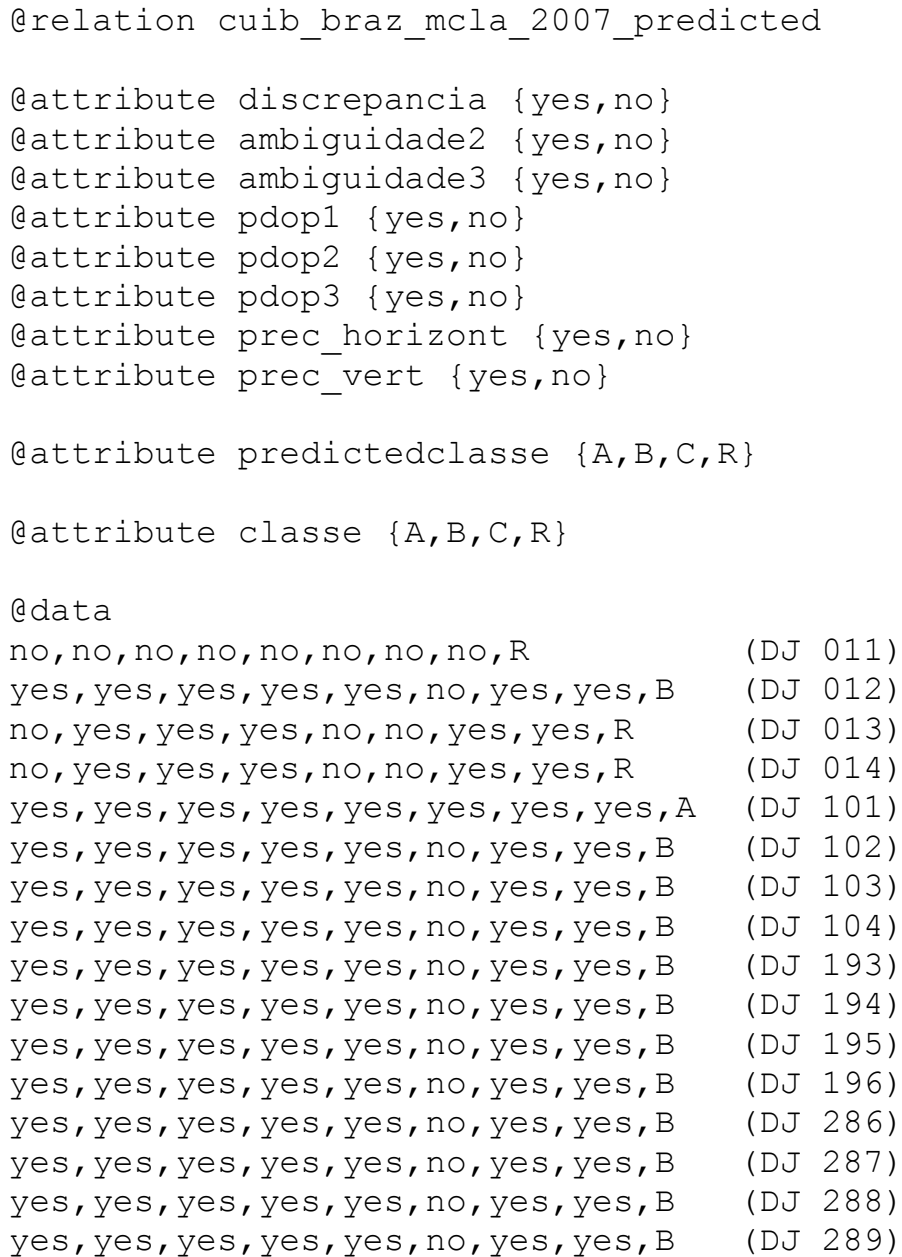




\subsubsection{Ano de 2008}

A Figura 33 a seguir mostra os gráficos com a classificação dada pelo Weka:

Figura 33: Gráfico da classificação pelo WEKA

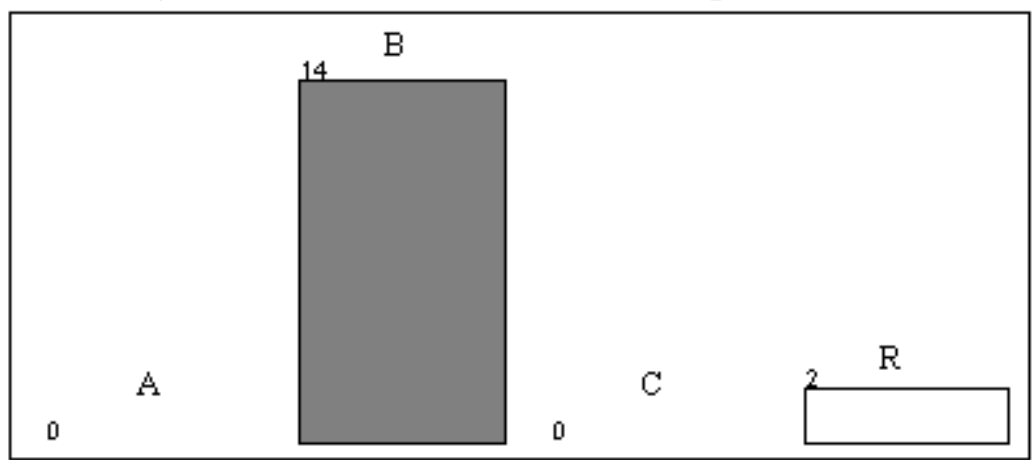

\section{BANCO DE DADOS}

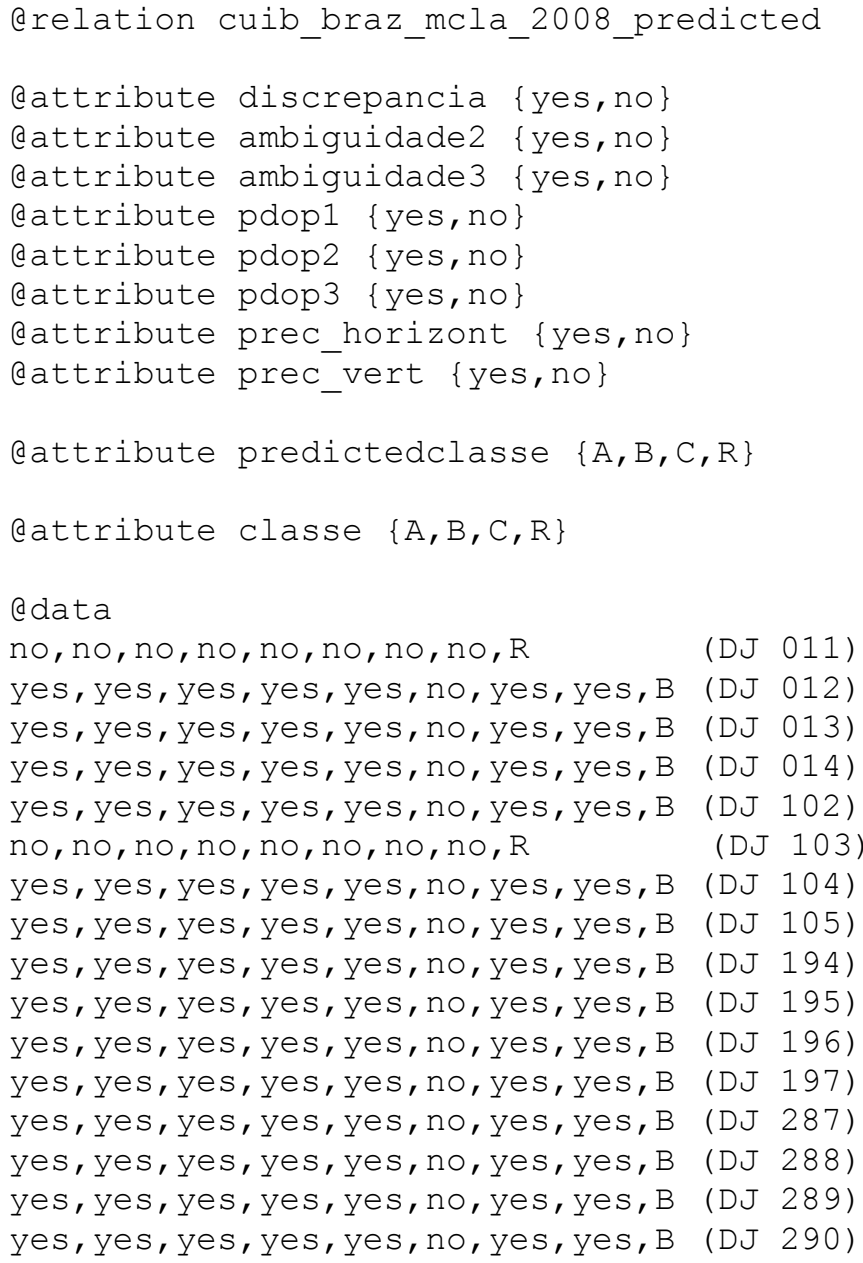


A seguir, as classificações acima serão sintetizadas em quatro tabelas, separadas por configuração, onde será possível visualizar a quantidade de processamentos que obtiveram classe A, B, C ou R em cada ano estudado.

\subsection{Apresentação das classificações}

TABELA 12: Classificação da configuração VARG-VICO-RIOD

\begin{tabular}{|c|c|c|c|}
\hline CLASSE & $\mathbf{2 0 0 6}$ & $\mathbf{2 0 0 7}$ & $\mathbf{2 0 0 8}$ \\
\hline A & 12 & 16 & 16 \\
\hline B & 2 & - & - \\
\hline C & - & - & - \\
\hline R & 2 & - & \\
\hline
\end{tabular}

TABELA 13: Classificação da configuração VARG-RIOD-UBER

\begin{tabular}{|c|c|c|c|}
\hline CLASSE & $\mathbf{2 0 0 6}$ & $\mathbf{2 0 0 7}$ & $\mathbf{2 0 0 8}$ \\
\hline $\mathrm{A}$ & 12 & 15 & 16 \\
\hline $\mathrm{B}$ & 1 & - & - \\
\hline $\mathrm{C}$ & - & - & - \\
\hline $\mathrm{R}$ & 3 & 1 & \\
\hline
\end{tabular}

TABELA 14: Classificação da configuração CUIB-BRAZ-PPTE

\begin{tabular}{|c|c|c|c|}
\hline CLASSE & $\mathbf{2 0 0 6}$ & $\mathbf{2 0 0 7}$ & $\mathbf{2 0 0 8}$ \\
\hline A & 9 & 15 & 16 \\
\hline B & 2 & - & - \\
\hline C & - & - & - \\
\hline R & 5 & 1 & \\
\hline
\end{tabular}

TABELA 15: Classificação da configuração CUIB-BRAZ-MCLA

\begin{tabular}{|c|c|c|c|}
\hline CLASSE & $\mathbf{2 0 0 6}$ & $\mathbf{2 0 0 7}$ & $\mathbf{2 0 0 8}$ \\
\hline $\mathrm{A}$ & - & 1 & - \\
\hline $\mathrm{B}$ & 4 & 12 & - \\
\hline $\mathrm{C}$ & 7 & - & 2 \\
\hline $\mathrm{R}$ & 5 & 3 & 14 \\
\hline
\end{tabular}




\subsection{Análise dos resultados}

A classificação dos resultados foi efetuada de modo a analisar o comportamento dos fatores oriundos do processamento e ajustamento (discrepância entre as coordenadas homologadas e as calculadas, solução da ambiguidade, PDOP e precisões horizontais e verticais), considerando a influência direta da atividade solar, da distância entre as linhas de base e da configuração entre as estações da RBMC.

Assim, uma análise detalhada destes 3 fatores será feita a seguir.

\subsubsection{Atividade solar}

A investigação do comportamento dos resultados para dias que tiveram atividade solar expressiva, utilizou os parâmetros fornecidos na Figura 3, do item 2.2.2.3, onde pôde-se perceber que houve atividade solar expressiva em julho de 2006, abril de 2007 e janeiro e julho de 2008.

\subsubsection{VARG - VICO - RIOD}

\subsection{Ano de 2006}

No ano de 2006, houve atividade solar expressiva no mês de julho, e ao se analisar os dados provenientes do referido mês/ano constatou-se que, em geral os processamentos obtiveram classificação A, obtendo-se apenas 4 processamentos com valor inferior a este, sendo eles:

- Os dias julianos 11 e 102 do ano de 2006, que obtiveram classe B, devido ao fato de não se obter solução fixa da ambiguidade em uma das três linhas de base;

- Os dias julianos 104 e 286 do ano de 2006 com classe R, devido ao fato de não solucionar a ambiguidade em pelo menos duas linhas de base e de não se ter obtido PDOP abaixo de 3 em pelo menos uma das linhas de base.

Um fato peculiar, é que dos quatro meses analisados, para esta configuração, o único com atividade solar expressiva foi julho, e este também foi o único mês onde todos os processamentos obtiveram classificação A. 


\subsection{Ano de 2007}

No ano de 2007, houve atividade solar expressiva no mês de abril, e ao se analisar os dados provenientes do referido mês/ano constatou-se que a atividade solar não influiu na qualidade dos resultados para esta configuração, visto que todos os processamentos efetuados obtiveram classe A.

\subsection{Ano de 2008}

No ano de 2008, houve atividade solar expressiva nos meses de janeiro e julho, e ao se analisar os dados provenientes dos referidos meses/ano constatou-se que a atividade solar não influiu na qualidade dos resultados para esta configuração, visto que todos os processamentos efetuados obtiveram classe A.

\subsubsection{VARG - RIOD - UBER}

\subsection{Ano de 2006}

No ano de 2006, houve atividade solar expressiva no mês de julho, e ao se analisar os dados provenientes do referido mês/ano constatou-se que apenas cinco processamentos não obtiveram classificação A, sendo eles:

- O dia juliano 103, que obteve classe B devido ao fato de o valor de PDOP ser superior a 3 em uma das linhas de base;

- Os dias julianos 104, 193 e 195, que obtiveram classe R, rejeições estas que ocorreram por dois diferentes motivos: (1) o dia juliano 104 não obteve valores de PDOP inferiores a 3 em nenhuma das linhas de base; e (2) os dias julianos 193 e 195 foram descartados imediatamente por não terem o ajustamento aceito.

Pode-se observar que em 2 dos quatro dias analisados no mês de julho, ocorreu degradação na qualidade dos resultados, porém, nos outros dois dias, os processamentos obtiveram classe $\mathrm{A}$, assim, aparentemente não houve influência considerável da atividade solar para esta configuração

Um fator singular inerente a este mês foi que mesmo em linhas de base onde a solução da ambiguidade esperada era float, em alguns casos, as soluções foram fixas nas três linhas de base. 


\subsection{Ano de 2007}

No ano de 2007, houve atividade solar expressiva no mês de abril, e ao se analisar os dados provenientes do referido mês/ano constatou-se que a atividade solar não influiu na qualidade dos resultados para esta configuração, visto que todos os processamentos efetuados para o mês de abril obtiveram classe A.

\subsection{Ano de 2008}

No ano de 2008, houve atividade solar expressiva nos meses de janeiro e julho, e ao se analisar os dados provenientes dos referidos meses/ano constatou-se que a atividade solar não influiu na qualidade dos resultados para esta configuração, visto que todos os processamentos efetuados obtiveram classe A.

\subsubsection{CUIB - BRAZ - PPTE}

\subsection{Ano de 2006}

No ano de 2006, houve atividade solar expressiva no mês de julho, e ao se analisar os dados provenientes do referido mês/ano constatou-se que:

○ Os dias julianos 12 e 13 obtiveram classe B e em ambos os casos, o fator degradante foi o valor de PDOP ser, em uma das linhas de base, superior a 3;

○ Os dias julianos 14, 101, 102, 193 e 195 obtiveram classe R, e o fator determinante para estas rejeições, em quatro, dos cinco casos foi a qualidade dos arquivos RINEX disponibilizados pelo IBGE para estes dias, que por estarem parcialmente corrompidos, não puderam ser processados e ajustados corretamente. No que concerne ao dia juliano 193, o processamento foi imediatamente rejeitado por não ter sido aceito no ajustamento de observações.

Assim, em dois dos quatro dias processados do mês de julho, a atividade solar não provocou degradação nos resultados, e, no dia juliano 195, o arquivo RINEX estava corrompido. Assim, como apenas um dos dias do referido mês, apresentou degradação nos valores de referência deste trabalho, não é possível afirmar que houve influência da atividade solar no mesmo. 


\subsection{Ano de 2007}

No ano de 2007, houve atividade solar expressiva no mês de abril, e ao se analisar os dados provenientes do referido mês/ano constatou-se que a atividade solar não influiu na qualidade dos resultados para esta configuração, visto que todos os processamentos efetuados, referentes ao mês de abril, obtiveram classe A.

\subsection{Ano de 2008}

No ano de 2008, houve atividade solar expressiva nos meses de janeiro e julho, e ao se analisar os dados provenientes dos referidos meses/ano constatou-se que a atividade solar não influiu na qualidade dos resultados para esta configuração, visto que todos os processamentos efetuados obtiveram classe A.

\subsubsection{CUIB - BRAZ - MCLA}

\subsection{Ano de 2006}

No ano de 2006, houve atividade solar expressiva no mês de julho, e ao se analisar os dados provenientes do referido mês/ano constatou-se que o mesmo não apresentou influência nos resultados, visto que o comportamento da classificação foi igualmente variado independente da estação do ano.

\subsection{Ano de 2007}

No ano de 2007, houve atividade solar expressiva no mês de abril, e ao se analisar os dados provenientes do referido mês/ano constatou-se que não houve influência da atividade solar nos resultados, visto que um dos dias obteve classe A, e os outros três obtiveram classe $\mathrm{B}$, comportamento muito parecido com as demais estações do ano para esta configuração.

\subsection{Ano de 2008}

No ano de 2008, houve atividade solar expressiva nos meses de janeiro e julho, e ao se analisar os dados provenientes dos referidos meses/ano constatou-se que a atividade solar não influiu na qualidade dos resultados para esta configuração, visto que todos os processamentos efetuados obtiveram comportamento parecido com os demais para esta configuração. 
Assim, de acordo com os dados apresentados acima, pode-se afirmar que o comportamento dos resultados para meses onde a atividade solar foi expressiva, foi muito parecido com o comportamento dos resultados para meses sem atividade solar atípica em todos os comprimentos de linhas de base e configuração das estações utilizadas neste trabalho. Para linhas de base menores que $100 \mathrm{~km}$, o comportamento de ambos os casos também é muito parecido, conforme pode ser visto em Menzori, 2005.

\subsubsection{Distância entre as linhas de base e configuração entre as estações da RBMC}

Com relação às magnitudes das linhas de base, conforme pode ser visto no Anexo B, os grandes índices de rejeição dos processamentos, bem como de classes B e C aconteceram para as linhas de base superiores a $700 \mathrm{~km}$, enquanto que em linhas de base menores que 300 $\mathrm{km}$ a grande maioria dos processamentos obteve classe A.

No que concerne a solução da ambiguidade, a mesma se comportou de maneira esperada, com poucas exceções, onde, para linhas de base com comprimentos menores que $300 \mathrm{~km}$, nem todas as soluções da ambiguidade foram fixas, e em processamentos com linhas de base de até $800 \mathrm{~km}$, onde esperava-se que as soluções fossem do tipo flutuante, em diversos casos, a solução foi fixada.

Se por um lado, a magnitude da linha de base não influenciou diretamente os resultados no que concerne a solução da ambiguidade, por outro lado, as magnitudes das linhas de base, em conjunto com a configuração das estações da RBMC, influenciou nos valores de precisão horizontal e vertical, onde, apesar dos valores encontrados estarem no limiar para serem aceitos pelos fabricantes, em linhas de base com grandes magnitudes e com a configuração ruim, estas precisões praticamente dobraram quando comparadas a situações onde as linhas de base obtiveram comprimentos máximos de $300 \mathrm{~km}$, e uma configuração ideal entre as estações, ficando claro que este último permite uma melhor qualidade do processamento.

Outro fator relevante diz respeito aos valores de PDOP encontrados, onde para linhas de base inferiores a $300 \mathrm{~km}$, quase todos os valores foram inferiores a 3, e em linhas de base com magnitude superior a $1.000 \mathrm{~km}$, e uma configuração geométrica ruim entre as estações, (conforme pode ser visto no Anexo B deste trabalho, para a configuração CUIB-BRAZMCLA, para a linha de base CUIB-MCLA de magnitude aproximada de $1300 \mathrm{~km}$ ), a grande maioria dos processamentos obteve valor de PDOP superior a 3, degradando a qualidade dos processamentos. 
Outro fator interessante é que poucos processamentos foram rejeitados devido a discrepância entre as coordenadas processadas e as homologadas pelo IBGE, e que todos os casos ocorreram em configurações ruins entre as estações da RBMC, sendo que em situações onde houve boa configuração entre as linhas de base, mesmo com grandes distâncias, não se teve problema com relação a este fator, logo, novamente se evidencia a necessidade de se escolher uma boa configuração entre as estações utilizadas para o processamento.

\subsection{Análise das classificações}

Conforme explícito no iem 4.2, a classificação dos processamentos foi feita segundo 5 fatores, sendo eles, a discrepância entre as coordenadas encontradas e as homologadas pelo IBGE, a solução da ambiguidade, o valor calculado de PDOP e as precisões horizontais e verticais. Assim, pode-se afirmar que:

No que concerne à discrepância das coordenadas obtidas do processamento com as verdadeiras, os únicos processamentos que foram rejeitados devido a este critério, tinham uma configuração ruim entre as estações da RBMC, e geralmente esta discrepância se evidenciou na coordenada E. Com relação ao restante dos processamentos, as discrepâncias tiveram pouca variação, conforme pode ser visto na Tabela 8 a seguir:

TABELA 15: Variação da discrepância para as diferentes configurações

\begin{tabular}{|c|c|}
\hline CONFIGURAÇÃO & $\begin{array}{c}\text { DISCREPÂNCIA ENTRE AS } \\
\text { COORDENADAS OBTIDAS } \\
\text { E AS HOMOLOGADAS }\end{array}$ \\
\hline VARG-VICO-RIOD & entre 2 e $5 \mathrm{~cm}$ em E \\
entre 1 e $2 \mathrm{~cm} \mathrm{em} \mathrm{N}$
\end{tabular}


Com relação ao PDOP, observou-se uma tendência de que a maioria dos resultados ruins de PDOP foram situações de magnitudes de linhas de base superiores a 1300 km e com configuração geométrica ruim entre as estações da RBMC, em anos distintos. A variação do PDOP para o restante dos processamentos também foi pequena, conforme pode ser visto na Tabela 9 a seguir.

TABELA 16: Variação do PDOP para as diferentes configurações

\begin{tabular}{|c|c|}
\hline CONFIGURAÇÃO & $\begin{array}{c}\text { DISCREPÂNCIA ENTRE OS } \\
\text { VALORES DE PDOP }\end{array}$ \\
\hline VARG-VICO-RIOD & entre 2 e 3 \\
\hline VARG-RIOD-UBER & entre 2 e 3 \\
\hline CUIB-BRAZ-PPTE & entre 2 e 3 \\
\hline CUIB-BRAZ-MCLA & entre 2 e 5 \\
\hline
\end{tabular}

A ambigüidade teve a solução esperada em quase todos os processamentos, porém, alguns resultados surpreendentes quanto a solução da ambiguidade, dizem respeito a solução fixa em linhas de base maiores que $700 \mathrm{~km}$.

$>$ No que concerne as precisões horizontais e verticais, a tabela 10 mostra a variação dos resultados.

TABELA 17: Variação das precisões horizontais e verticais para as diferentes configurações

\begin{tabular}{|c|c|}
\hline CONFIGURAÇÃO & $\begin{array}{c}\text { DISCREPÂNCIA ENTRE AS } \\
\text { PRECISOES HORIZONTAIS E } \\
\text { VERTICAIS }\end{array}$ \\
\hline VARG-VICO-RIOD & entre 3 e $5 \mathrm{~cm}$ horizontal \\
entre 4 e $7 \mathrm{~cm}$ vertical
\end{tabular}


Os valores de precisão horizontal e vertical encontrados podem ser aceitos de acordo com a especificação do fabricante para as referidas distâncias, porém, pode-se constatar, que para linhas de base de grandes magnitudes, e para configurações ruins entre as estações RBMC, esses valores foram piores. Porém, mesmo com linhas de base maiores que $1000 \mathrm{~km}$, as precisões encontradas não ultrapassaram $20 \mathrm{~cm}$, assim, este valor pode ser adotado como confiável para trabalhos futuros no que concerne a precisão.

\subsection{Tabela de classificação de acurácia recomendada}

Os fatores utilizados nesta dissertação para a classificação dos resultados mostraramse confiáveis, assim, após análise dos resultados obtidos, foi criada a Tabela 18 para que os trabalhos futuros de profissionais da área de mensuração possam ter a sua acurácia estimada sem ter que repetir toda a metodologia deste trabalho. 
TABELA 18: Tabela de classificação de Acurácia

\begin{tabular}{|l|l|}
\hline \multicolumn{1}{|c|}{ Parâmetros analisados } & CLASSE \\
\hline $\begin{array}{l}\text { i. Boa configuração geométrica entre as } \\
\text { estações de controle e o ponto desconhecido, } \\
\text { e linhas de base inferiores a } 700 \mathrm{~km} \text {; } \\
\text { ii. Solução da ambiguidade satisfatória em } \\
\text { todas as linhas de base (com solução fixa } \\
\text { para linhas de base de até 300 km); } \\
\text { iii. PDOP menor que } 3 \text { para todas as linhas } \\
\text { de base; } \\
\text { iv. Precisão horizontal e vertical menor que } \\
\text { 20 cm em todas as linhas de base. }\end{array}$ & A \\
\hline $\begin{array}{l}\text { Quando um dos itens mencionados acima } \\
\text { não for satisfeito }\end{array}$ & B \\
\hline $\begin{array}{l}\text { Quando três o mais dos itens mencionados } \\
\text { não forem satisfeitos }\end{array}$ & \\
\hline
\end{tabular}

\subsection{Validação da tabela de classificação de acurácia}

Para a validação da Tabela de Classificação de Acurácia recomendada foram efetuados processamentos de dois pontos desconhecidos, denominados Roseira e Votorantim, onde os resultados encontrados foram analisados e classificados de acordo com a mesma. 


\subsubsection{Roseira - SJRP - UFPR}

\subsubsection{Processamento e classificação}

Para este caso, será efetuado o transporte de coordenadas de um ponto situado dentro de um imóvel rural denominado Chácara Santa Maria, no município de Roseira - SP, utilizando para isso as estações da RBMC SJRP e UFPR. A configuração geométrica entre o ponto a ser transportado e os pontos de controle podem ser visualizados na Figura 34.

Figura 34: Configuração geométrica entre o ponto de interesse e as estações SJRP e UFPR.

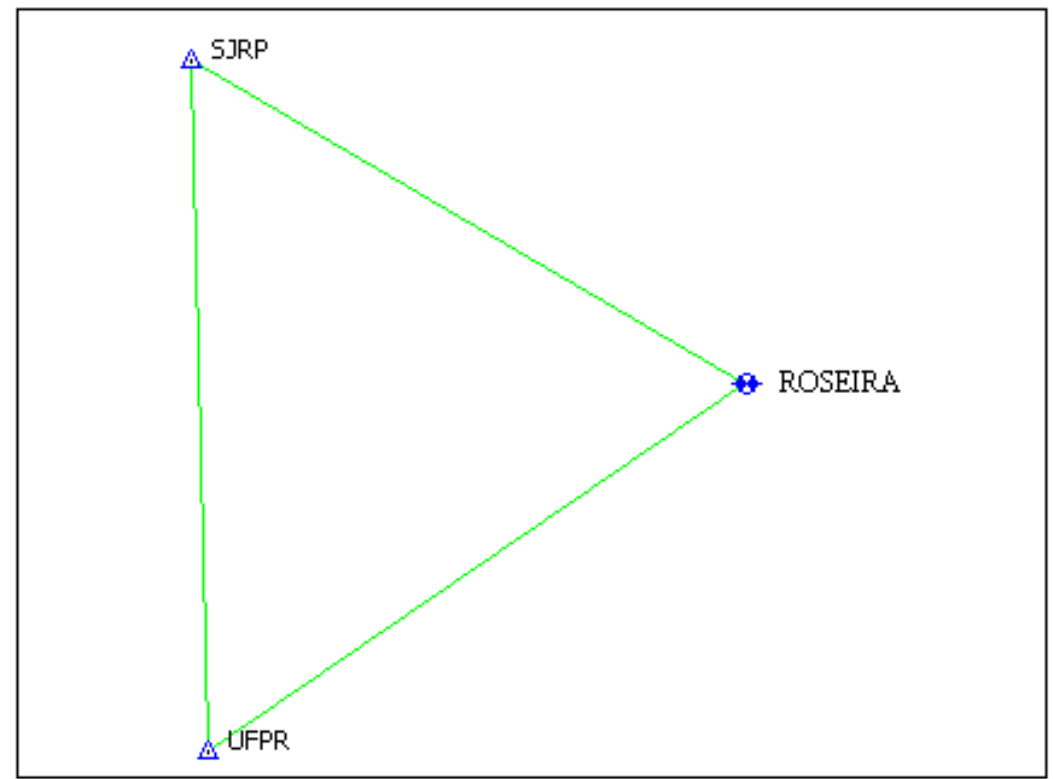

O ponto foi rastreado por um período de sete horas, e as informações de interesse referentes a este processamento podem ser visualizados na Tabela 19 a seguir:

TABELA 19: Relatório de Processamento do ponto Roseira

\begin{tabular}{|c|c|c|c|c|c|c|c|c|}
\hline \multicolumn{9}{|c|}{ GPS Obs Report } \\
\hline \multicolumn{9}{|c|}{ A posteriori UWE: 1.2183491, Bounds: $(0.6770032,1.241639)$} \\
\hline Name & $\begin{array}{c}\text { Horizontal } \\
\text { Precision (m) }\end{array}$ & \begin{tabular}{|c|} 
Vertical \\
Precision $(\mathrm{m})$
\end{tabular} & $\begin{array}{l}\text { Distance } \\
\text { (m) }\end{array}$ & $\begin{array}{c}\text { Solution } \\
\text { Type }\end{array}$ & $\begin{array}{c}\text { GPS } \\
\text { Satellites }\end{array}$ & PDOP & Status & RMS \\
\hline Roseira-SJRP & 0.091 & 0.080 & 483823.509 & $\begin{array}{l}\text { Float,Wide } \\
\text { Lane }\end{array}$ & 16 & 2.866 & Adjusted & 0.121 \\
\hline Roseira-UFPR & 0.075 & 0.081 & 483603.570 & $\begin{array}{l}\text { Float,Wide } \\
\text { Lane }\end{array}$ & 16 & 2.046 & Adjusted & 0.110 \\
\hline SJRP-UFPR & 0.072 & 0.091 & 516478.223 & \begin{tabular}{|l} 
Float,Wide \\
Lane
\end{tabular} & 29 & 2.815 & Adjusted & 0.116 \\
\hline
\end{tabular}


A configuração acima, foi a melhor obtida dentro das possibilidades, e, comparando-se os resultados obtidos com os parâmetros da Tabela de Acurácia Recomendada, pode-se verificar que a classificação deste processamento foi $\mathrm{A}$, pois em todos os itens, os resultados foram satisfatórios.

Para este processamento, um grande problema encontrado, foi que as duas estações que dariam a melhor configuração geométrica e com menores distâncias entre os pontos eram as estações da RBMC UBAT e NEIA, porém, ambas as estações não tiveram seus dados disponibilizados pelo IBGE para esse dia.

\subsubsection{Validação da classificação}

Para validar a classificação obtida através da Tabela de Acurácia, também foi verificada a classificação pelo WEKA para este exemplo, chegando-se a seguinte classificação:

Figura 35: Gráfico da classificação pelo WEKA do ponto Roseira

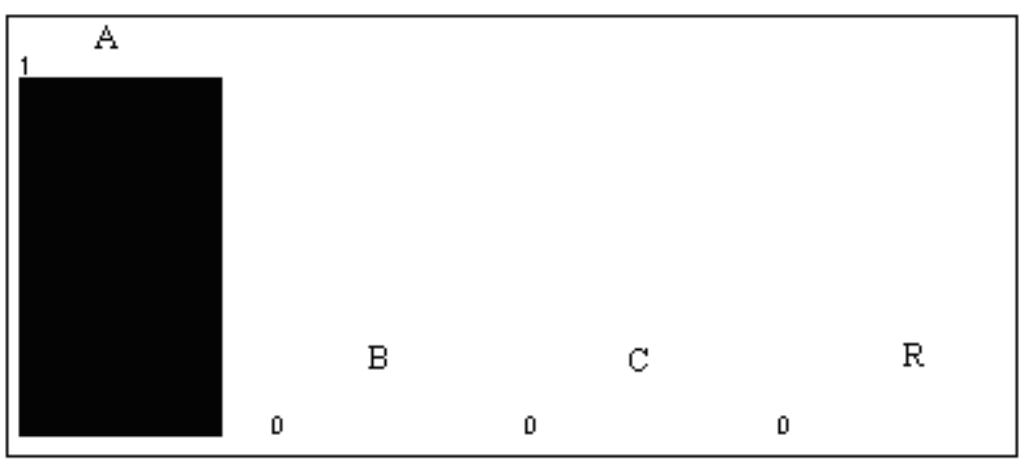

\section{BANCO DE DADOS}

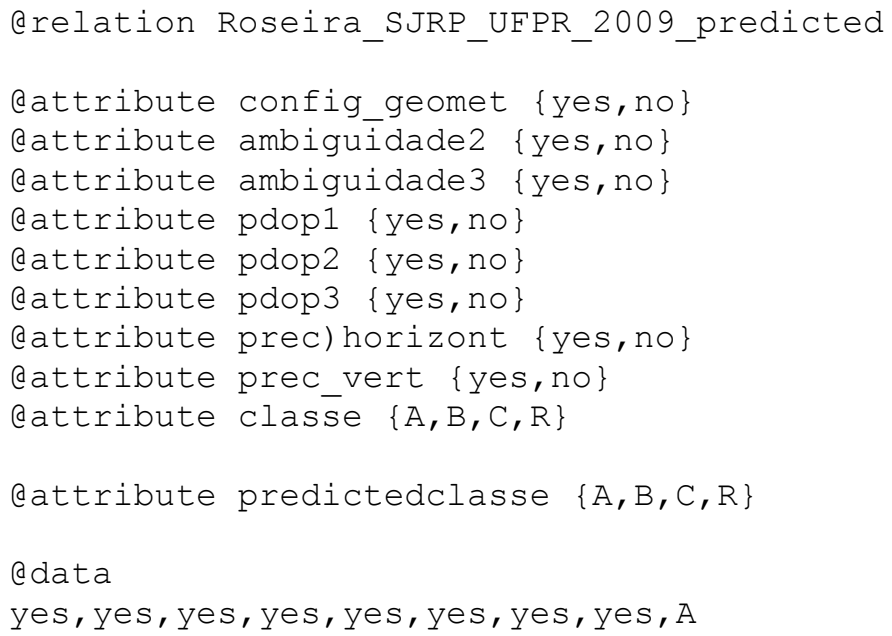


Logo, conforme pode ser visualizado acima, a Tabela de Acurácia mostrou-se totalmente compatível com o software de classificação WEKA, para este caso.

\subsubsection{Roseira - CHPI - RIOD}

\subsubsection{Processamento e classificação}

Para este caso, será efetuado o transporte de coordenadas de um ponto situado dentro de um imóvel rural denominado Chácara Santa Maria, no município de Roseira - SP, utilizando para isso as estações da RBMC CHPI e RIOD. A configuração geométrica entre o ponto a ser transportado e os pontos de controle podem ser visualizados na Figura 36.

Figura 36: Configuração geométrica entre o ponto de interesse e as estações CHPI e RIOD.

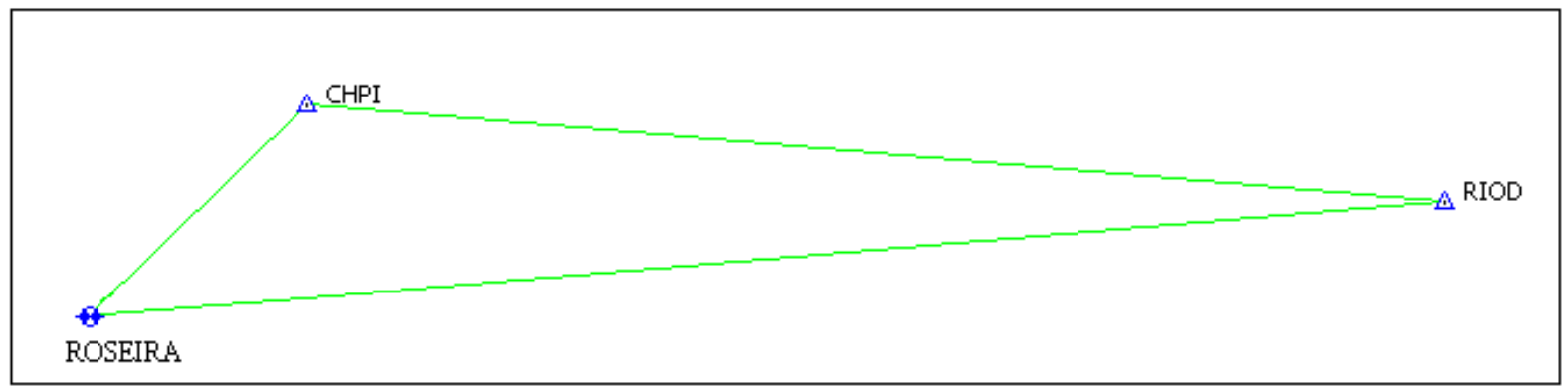

O ponto foi rastreado por um período de sete horas, e as informações de interesse referentes a este processamento podem ser visualizados na Tabela 20 a seguir:

TABELA 20: Relatório de Processamento do ponto Roseira

\begin{tabular}{|c|c|c|c|c|c|c|c|c|}
\hline \multicolumn{9}{|c|}{ GPS Obs Report } \\
\hline \multicolumn{9}{|c|}{ A posteriori UWE: 0.8991649 , Bounds: ( $0.6770032,1.241639)$} \\
\hline Name & $\begin{array}{c}\text { Horizontal } \\
\text { Precision (m) }\end{array}$ & \begin{tabular}{|c|} 
Vertical \\
Precision (m)
\end{tabular} & $\begin{array}{l}\text { Distance } \\
\text { (m) }\end{array}$ & $\begin{array}{c}\text { Solution } \\
\text { Type }\end{array}$ & $\begin{array}{c}\text { GPS } \\
\text { Satellites }\end{array}$ & PDOP & Status & RMS \\
\hline Roseira-CHPI & 0.014 & 0.029 & 45870.387 & $\begin{array}{l}\text { Fixed,Wide } \\
\text { Lane }\end{array}$ & 16 & 2.739 & Adjusted & 0.032 \\
\hline Roseira-RIOD & 0.030 & 0.062 & 206007.498 & $\begin{array}{l}\text { Fixed,Wide } \\
\text { Lane }\end{array}$ & 16 & 3.638 & Adjusted & 0.068 \\
\hline CHPI-RIOD & 0.024 & 0.058 & 173045.058 & $\begin{array}{l}\text { Fixed,Wide } \\
\text { Lane }\end{array}$ & 29 & 3.005 & Adjusted & 0.063 \\
\hline
\end{tabular}

Comparando-se os resultados obtidos na Tabela 20 com os parâmetros da Tabela de Acurácia Recomendada, pode-se verificar que a classificação deste processamento foi C, resultado este devido a configuração geométrica escolhida não ser a ideal (forma geométrica 
de um triângulo equilátero) e do PDOP da linha de base "Roseira-RIOD" ter sido superior ao valor exigido. Todas as outras exigências foram atendidas.

\subsubsection{Validação da classificação}

Para validar a classificação obtida através da Tabela de Acurácia, também foi verificada a classificação pelo WEKA para este exemplo, chegando-se a seguinte classificação:

Figura 37: Gráfico da classificação pelo WEKA do ponto Roseira

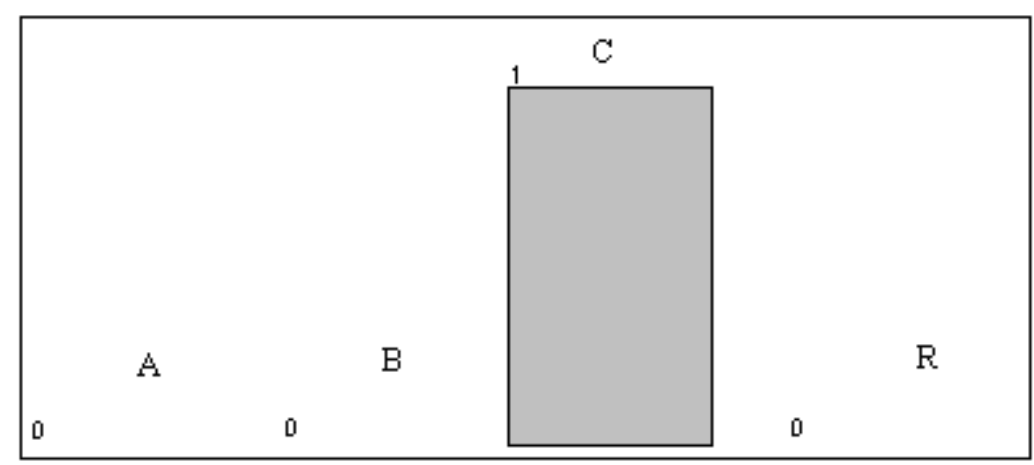

\section{BANCO DE DADOS}

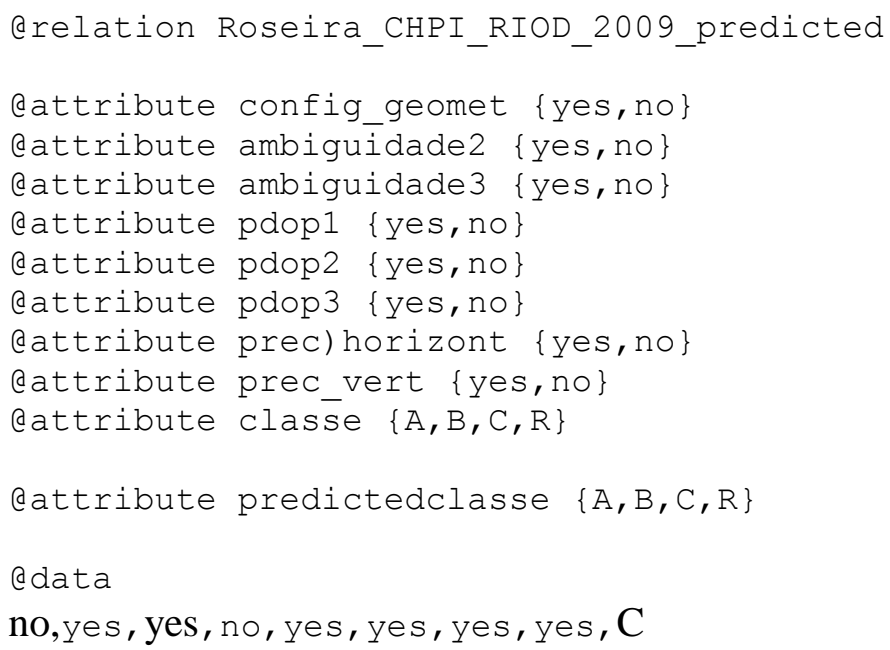

\subsubsection{Votorantim - UFPR - RIOD}

\subsubsection{Processamento e classificação}

Para este caso, será efetuado o transporte de coordenadas de um ponto situado dentro de um imóvel rural denominado Chácara Santo Amaro, no município de Votorantim - SP, 
utilizando para isso as estações da RBMC RIOD e UFPR. A configuração geométrica entre o ponto a ser transportado e os pontos de controle podem ser visualizados na figura 38 .

Figura 38: Configuração geométrica entre o ponto de interesse e as estações RIOD e UFPR.

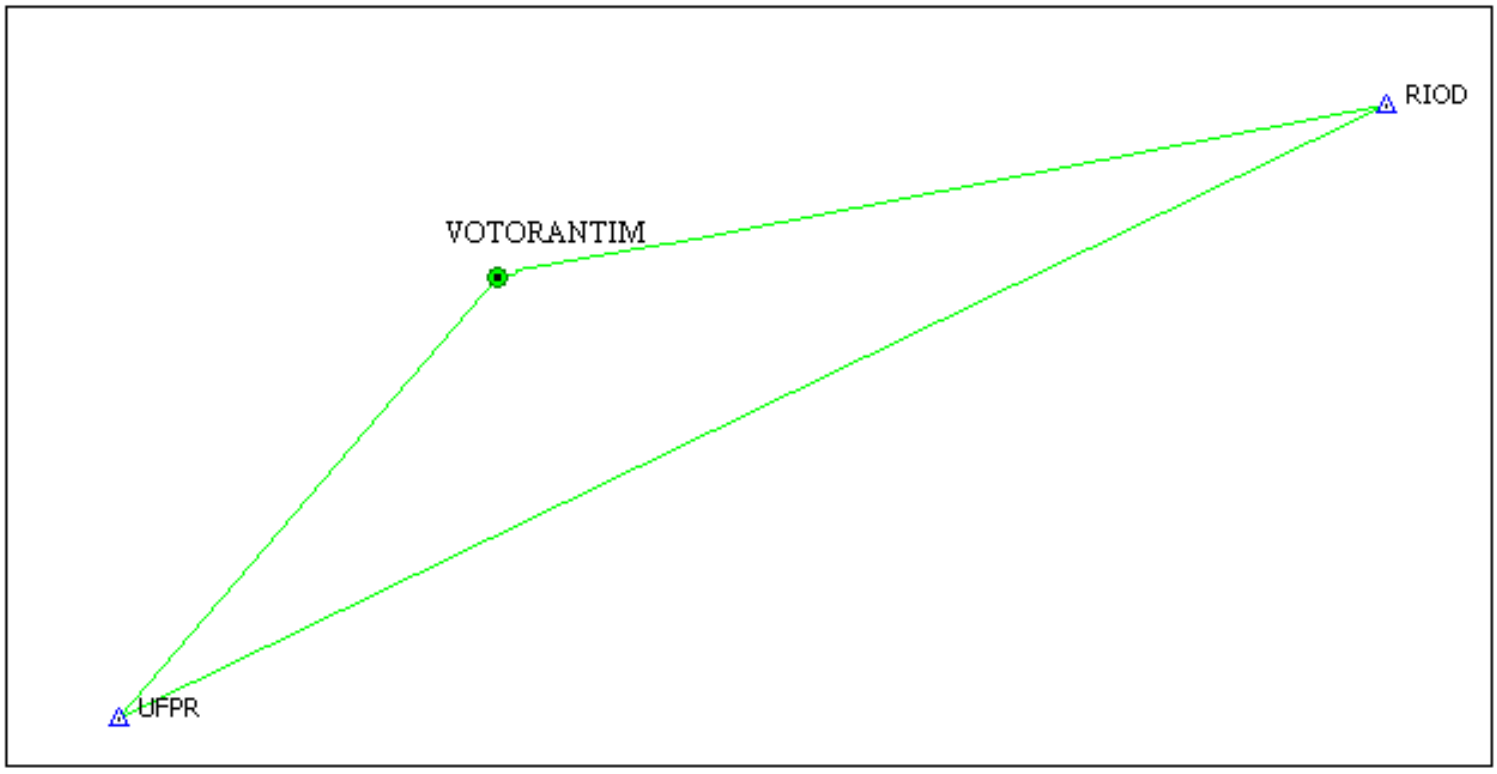

O ponto foi rastreado por um período de cinco horas, e as informações de interesse referentes a este processamento podem ser visualizados na Tabela 21 a seguir:

TABELA 21: Relatório de Processamento do ponto Votorantim

\begin{tabular}{|c|c|c|c|c|c|c|c|c|}
\hline \multicolumn{9}{|c|}{ GPS Obs Report } \\
\hline \multicolumn{9}{|c|}{ A posteriori UWE: 0.9823763, Bounds: $(0.6770032,1.241639)$} \\
\hline Name & $\begin{array}{c}\text { Horizontal } \\
\text { Precision (m) }\end{array}$ & $\begin{array}{c}\text { Vertical } \\
\text { Precision } \\
\text { (m) }\end{array}$ & $\begin{array}{l}\text { Distance } \\
\text { (m) }\end{array}$ & $\begin{array}{c}\text { Solution } \\
\text { Type }\end{array}$ & $\begin{array}{c}\text { GPS } \\
\text { Satellites }\end{array}$ & PDOP & Status & RMS \\
\hline Votorantim-RIOD & 0.047 & 0.089 & 433490.310 & $\begin{array}{l}\text { Fixed, Wide } \\
\text { Lane }\end{array}$ & 15 & 2.284 & Adjusted & $\mid 0.100$ \\
\hline Votorantim-UFPR & 0.037 & 0.070 & 275578.208 & $\begin{array}{l}\text { Fixed,Wide } \\
\text { Lane }\end{array}$ & 15 & 2.258 & Adjusted & 0.079 \\
\hline RIOD-UFPR & 0.087 & 0.089 & 668628.469 & $\begin{array}{l}\text { Float, Wide } \\
\text { Lane }\end{array}$ & 30 & 2.639 & Adjusted & 0.124 \\
\hline
\end{tabular}

Comparando-se os resultados obtidos na Tabela 14 com os parâmetros da Tabela de Acurácia Recomendada, pode-se verificar que a classificação deste processamento foi B, resultado este devido a configuração geométrica escolhida ser a melhor dentro das possibilidades, mas não a ideal (forma geométrica de um triângulo equilátero). Todas as outras exigências foram atendidas. 


\subsubsection{Validação da classificação}

Para validar a classificação obtida através da Tabela de Acurácia, também foi verificada a classificação pelo WEKA para este exemplo, chegando-se a seguinte classificação:

Figura 39: Gráfico da classificação pelo WEKA do ponto Votorantim

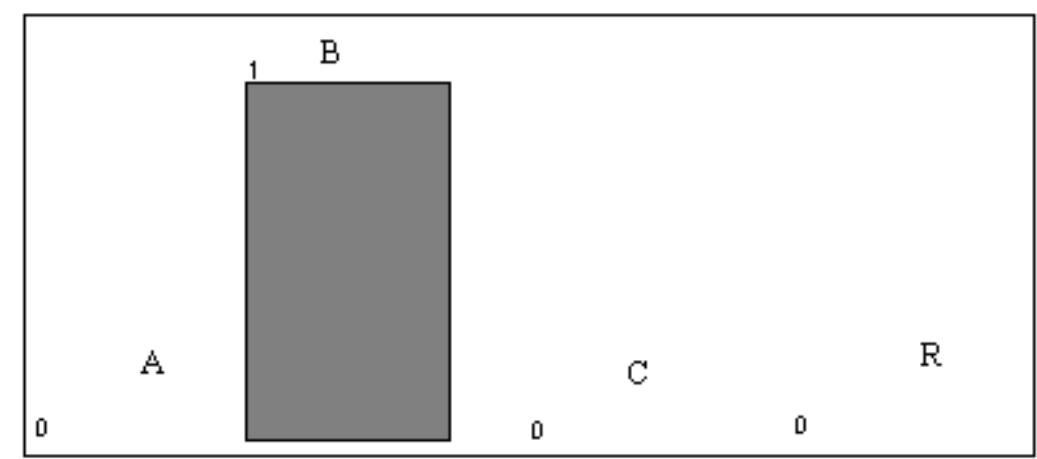

\section{BANCO DE DADOS}

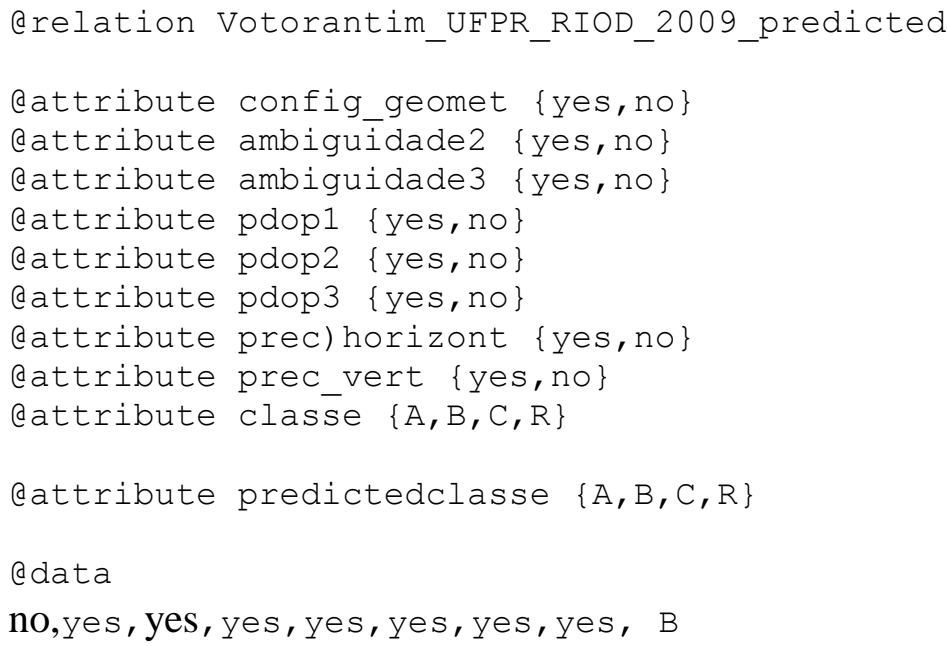




\section{CAPÍTULO 5 - CONCLUSÕES}

\subsection{Considerações finais}

A determinação de pontos de controle para levantamentos planialtimétricos é uma prática comum entre os profissionais da área, principalmente no que concerne a trabalhos de georreferenciamento de imóveis rurais. Contudo, apesar dos diversos softwares existentes no mercado fornecerem a precisão dos processamentos dos dados, e de a NORMA TÉCNICA PARA GEORREFERENCIAMENTO DE IMÓVEIS RURAIS (INCRA, 2003), fixar parâmetros de qualidade para estes, a acurácia dos pontos levantados não é fornecida pelos softwares, bem como não existe um parâmetro classificatório para a mesma, visto a ausência de estudos na área inerentes a fatores que influenciam na acurácia de pontos levantados com o GNSS.

Esta acurácia das coordenadas oriundas de processamentos de dados obtidos através do sistema GPS é um fator dificilmente determinado no dia-a-dia, e nesta dissertação, somente foi possível fazer uma estimativa da mesma e elaborar uma tabela classificatória, através de estudos sobre os diferentes fatores envolvidos na sua qualidade, bem como de processamentos efetuados em diversas situações encontradas no cotidiano de profissionais da área.

Assim, pôde-se verificar que a magnitude das linhas de base, bem como a configuração das estações utilizadas para o processamento dos pontos de interesse, afetam diretamente a qualidade deste dado, tornando decisiva a escolha de pontos de controle com magnitudes inferiores a $300 \mathrm{~km}$, e a boas configurações geométricas entre os mesmos e o ponto de interesse (geometricamente similar a um triângulo equilátero) para se obter um processamento com classificação A.

No que concerne aos fatores estatísticos fornecidos no processamento, individualmente não podem ser considerados como indicadores de acurácia confiáveis, pois conforme demonstrado em capítulos anteriores, em processamentos onde a discrepância calculada foi superior a $10 \mathrm{~cm}$, as precisões horizontais e verticais foram aceitas, bem como os valores de PDOP e a solução da ambiguidade, onde o único diferencial nesses casos, foi que todos os que tiveram acurácia acima do permitido consistiam, justamente, em configurações ruins e linhas de base de grande magnitude. 
Por outro lado, em processamentos onde a solução da ambiguidade, os valores de PDOP e as precisões foram altos ou acima do permitido, e ainda assim, a acurácia foi menor do que $10 \mathrm{~cm}$, a qualidade desses dados é de caráter duvidosa, e por isso, esses resultados obtiveram classe R.

Para a solução da ambiguidade, conforme foi demonstrado, é possível que a solução da mesma seja fixa em linhas de base de comprimento superiores a $300 \mathrm{~km}$, porém, a confiabilidade deste dado é de caráter duvidosa, evidenciando, novamente uma escolha adequada dos pontos de controle que irão compor o transporte de coordenadas.

A diluição da precisão dos levantamentos, evidenciada no fator PDOP, apresentou-se como fator decisivo na classificação dos processamentos. Um fator singular referente a este parâmetro, é a comprovação de que quanto maior a quantidade de satélites disponíveis no momento da observação, maior a probabilidade do mesmo obter valor satisfatório. Evidente também, a degradação das classes de processamentos com linhas de base superiores a 1300 $\mathrm{km}$ onde este fator obteve, em grande maioria, valores de PDOP acima do permitido (superior a 3).

A modelagem dos resultados obtidos dos processamentos efetuados, bem como a análise dos mesmos, possibilitou a classificação desses resultados em forma de uma tabela de acurácia, onde a mesma teve sua eficiência testada através do estudo de três diferentes casos, com a validação dos resultados obtidos efetuada através do software WEKA, onde todas as classificações obtidas através da mesma foram compatíveis com as classes obtidas pelo software, fornecendo resultados satisfatórios para todos os casos analisados.

Recomenda-se o uso da Tabela de Acurácia para análise da qualidade de trabalhos futuros, principalmente em levantamentos de imóveis rurais que visam atender a Lei 10267, onde o transporte de coordenadas consiste em etapa fundamental e determinante da qualidade do trabalho como um todo, sendo indicada a exigência das classes A e B para levantamentos com vistas a certificação pelo INCRA.

\subsection{Recomendações}

Baseando-se nos resultados apresentados e nas análises efetuadas, as sugestões para trabalhos futuros, consistem, basicamente em:

- Realizar uma maior quantidade de processamentos de dados em meses com atividade solar expressiva e em diferentes magnitudes de linhas de base; 
○ Estudos mais aprofundados sobre a interferência dos fatores DOP na qualidade dos processamentos;

- Análise e classificação de levantamentos efetuados com equipamentos GNSS mais novos, tendo em vista que os equipamentos constituintes da RBMC são antigos;

- Aplicação da Tabela de Acurácia recomendada neste trabalho em uma maior quantidade de levantamentos cotidianos da área para uma análise comprobatória da eficiência da mesma. 


\section{CAPÍTULO 6 - REFERÊNCIAS BIBLIOGRÁFICAS}

- ABREU, M. A. Análise da qualidade dos dados GPS: Estudo de caso da estação de Cananéia. São Paulo: Poli/USP, 2007. Dissertação de Mestrado;

- ANTUNES, A. F. B., LINGNAU, C. Uso de índices de acurácia para avaliação de mapas temáticos obtidos por meio de classificação digital. In: III Congresso e Feira para Usuários de Geoprocessamento da América Latina. 1997. Curitiba. www.geomatica.ufpr.br;

- BAIO, F.H.R.; ÂNGULO FILHO, R.; VETTORAZZI, C.A.; RAFFO, J.G.G.; ELIAS, A.I. Estudo da exatidão de um GPS operando em duas taxas de aquisição de dados. In: CONGRESSO BRASILEIRO DE ENGENHARIA AGRÍCOLA, 27., Poços de Caldas, 1998. Anais... Lavras: Sociedade Brasileira de Engenharia Agrícola, 1998. p.347 - 9;

- BERnARDi, J.V.E. \& LANDIM, P.M.B. Aplicação do Sistema de Posicionamento Global (GPS) na coleta de dados. DGA,IGCE,UNESP/Rio Claro, Lab. Geomatemática,Texto Didático 10, 31 pp. 2002. Disponível em <http://www.rc.unesp.br/igce/aplicada/textodi.html>. Acesso em: 14/09/2007;

- FORTES, L. P. S. Operacionalização Da Rede Brasileira De Monitoramento Contínuo Do Sistema Gps (RBMC). Tese de Mestrado, Instituto Militar de Engenharia (IME). 1997.

- CAMARGO, P. Ajustamento de Observações. Notas de Aula. UNESP. 2004.

- GEMAEL, C. Introdução ao Ajustamento de Observações - Aplicações Geodésicas. Curitiba: Editora da UFPR. 1994;

- HOFMANN-WELLENHOF, J., LICHTENEGGER, B. e COLLINS, H. 2001. GPS: Theory and Practice. Fifth Revised Edition. Springer Wien New YorK. p.382;

- IBGE. www.ibge.gov.br. Último acesso em 22/02/2010;

- IGS. http: igscb.jpl.nasa.gov.br/components/prods.html. Último acesso em 29/01/2010; 
- INCRA (Instituto Nacional de Colonização e Reforma Agrária). NORMA TÉCNICA PARA GEORREFERENCIAMENTO DE IMÓVEIS RURAIS - 1ª Edição; 2003.

- KIM, D.; LANGLEY, R. B. GPS Ambiguity Resolution and Validation: Methodologies, Trends and Issues. 7 GNSS Workshop - International Symposium on GPS/GNSS, Seul, Coréia, 2000.

- LANGLEY, R. B. Dilution of Precision, GPS world, Vol.10, No.5, pp. 52-59, 1999

- LAROCCA, A. P. C. Análise de Estratégias Para Processamento de Redes Geodésicas Com o Sistema De Posicionamento Global - GPS, São Carlos: EESC/USP, 2000. Dissertação;

- LEICK, A. GPS Satellite Surveying. 3 ed. - John Wiley\&Sons, New York, 2004.

- LEVINE, R. I., DRANG, D. E.; EDELSON, B. Inteligência Artificial e Sistemas Especialistas. Editora MacGraw Hill. São Paulo. 1988;

- Matsuoka, C. T., Redivo, I. A. C., FAustino, R. C., Controle de Deslocamento Horizontal Utilizando a Técnica GPS na Barragem UHE Três Irmãos. Trabalho de Graduação, Unesp: Universidade Estadual Paulista - Departamento de Cartografia: Presidente Prudente - SP, 2003.

- MATSuOKA, M. T., CAMARGO, P. O., BATISTA, I. S. Impacto de Explosões Solares no Comportamento da Ionosfera e no Posicionamento com GPS na Região Brasileira: Estudo de caso para o dia 28 de outunro de 2003. Boletim Ciências Geodésicas, v. 12, nº 2, p. 315-334, julhodezembro, 2006.

- MENZORI, M. Classificação da exatidão de coordenadas obtidas com a fase da portadora L1 do GPS. São Carlos: EESC/USP, 2005. Tese de doutorado;

- MONARD, M. C., BARANAUSKAS, J. A. . Conceitos sobre Aprendizado de Máquina. In: Solange Oliveira Rezende. (Org.). Sistemas Inteligentes - Fundamentos e Aplicações. 1 ed. Barueri - SP: Editora Manole Ltda, 2003, v. , p. 89-114. 
- MÔNICO, J. F. G. Posicionamento pelo GNSS - Descrição, Fundamentos e Aplicações. $2^{\mathrm{a}}$ Edição. Presidente Prudente: Unesp, 2008;

- PEREIRA, K. D., FAZAN, J.A., FORTES, L.P.S. Sete Anos Fornecendo Referência A Posicionamentos Gps No Brasil E Exterior. IBGE, 2003, p. 9.

- RICH, E. e KNIGHT, K. Artificial Intelligence. Second Edition. Editora MacGraw Hill. USA. 1991.

- SCHAAL, R. E. Influência Da Propagação Da Onda E Do Equipamento Nas Medidas Do Código E Da Fase Com O Sistema De Posicionamento Global - GPS. São Carlos: EESC/USP, 2006. Tese de livre-docência;

- SEEBER, G. Satellite Geodesy. Berlin: Walter de Gruyter, 2ª edição, 2003.

- SEGANTINE, P.C.L. GPS - Sistema de Posicionamento Global. São Carlos: EESC/USP, 2005;

- TIMBÓ, M.A. Levantamentos Através do Sistema GPS. Dep. de Cartografia UFMG,. Belo Horizonte: 2000. 35p

- TORGE W. 2001. Geodesy. 3rd completely rev. and extended ed. - Walter de Gruyter, New York, 389 p;

- TURCO, J. E. P., PERECIN, D., PINTO Jr., D.L. Influência da Acurácia de Instrumentos de Medidas na Comparação de Métodos de Estimativa da Evapotranspiração de Referência. Irriga, Botucatu, v. 13, n. 1, p. 63-80, janeiro-março, 2008.

- WELLS, D. et al. Guide to GPS Positioning. New Brunswick: Department of Geodesy and Geomatics Engineering/ University of New Brunswick, 1999. 


\section{$\underline{\text { ANEXO A - Manual de processamento no Topcon Tools }}$}

\section{A.1 Inicialização do software}

Ao inicializar o sofware o mesmo pedirá a chave de acesso, ou a seleção do modelo "demo" autorizada para processamento de no máximo 4 pontos:

Figura A1: Inicialização do Software.

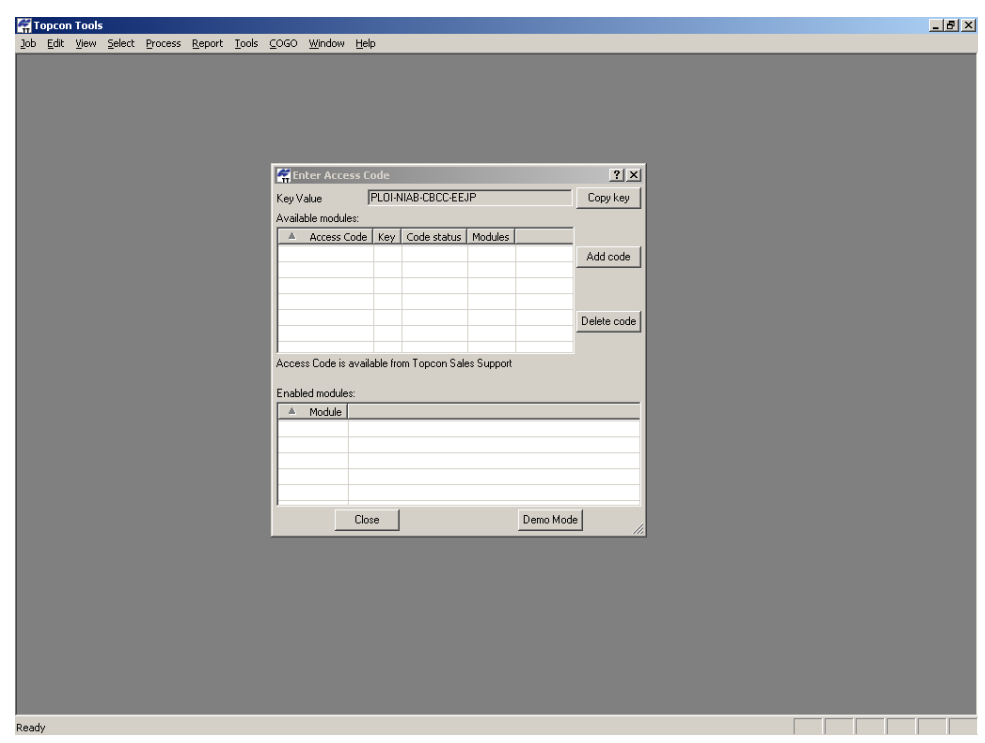

\section{A.2 Criar um projeto novo}

Após, abrirá uma caixa de diálogo, onde deve ser selecionado o item "New Job":

Figura A2: Criar um novo projeto.

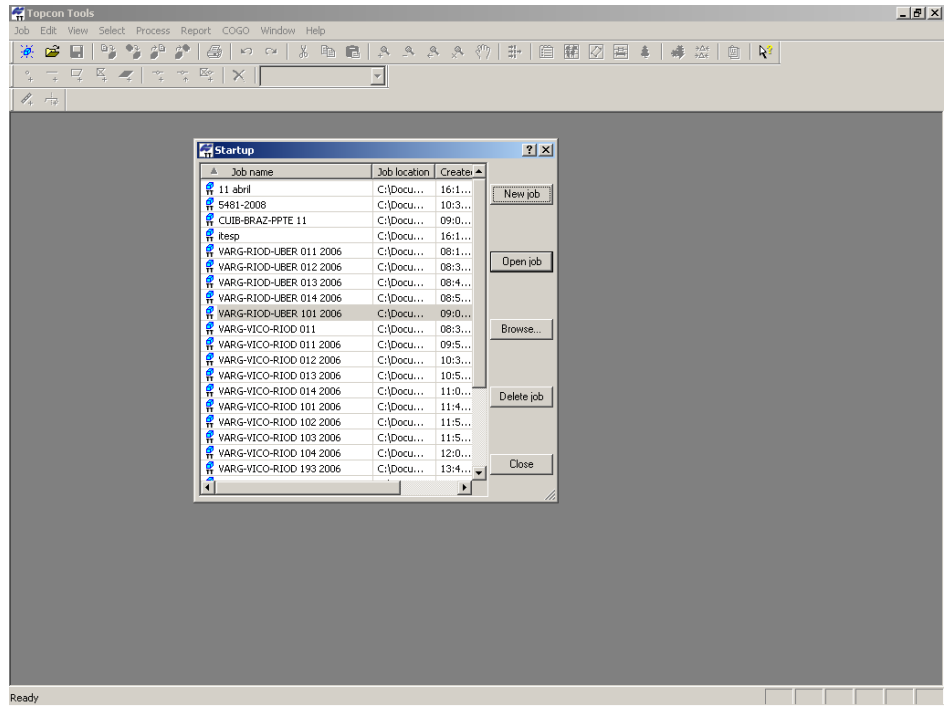


Após, abrirá uma caixa de diálogo, onde devem ser fornecidas as informações referentes ao novo trabalho:

Figura A3: Configuração do novo projeto.

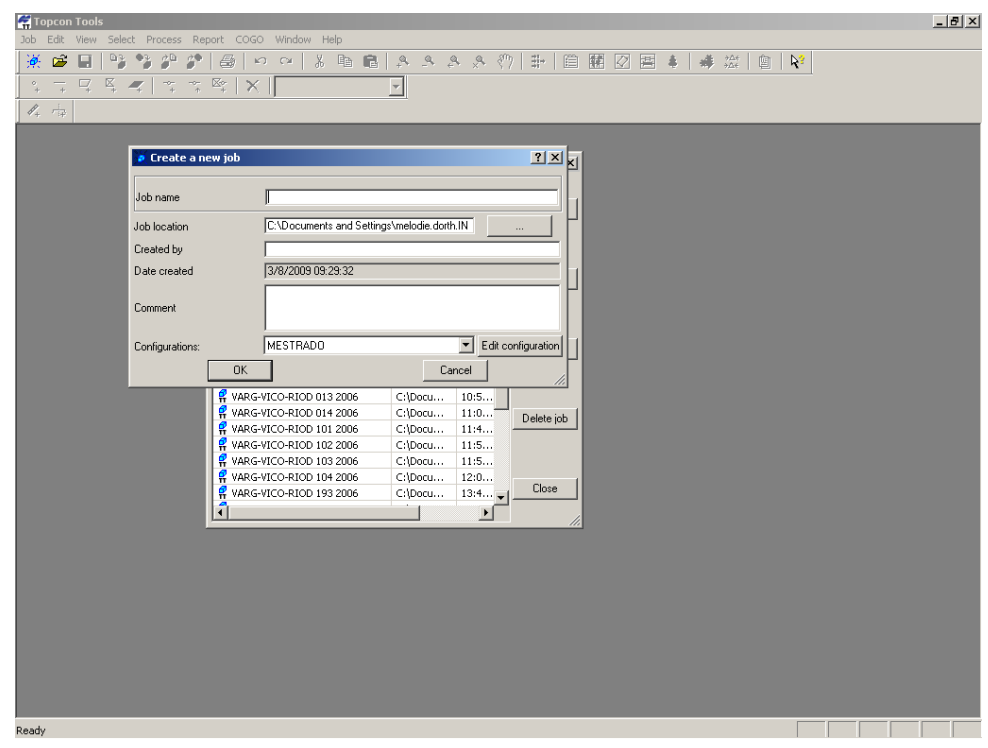

A configuração do software deve ser feia selecionando o item "Edit Configuration". Após, clicar em ok.

\section{A.3 Importar dados}

Job $\rightarrow$ Import

Figura A4: Importar dados.

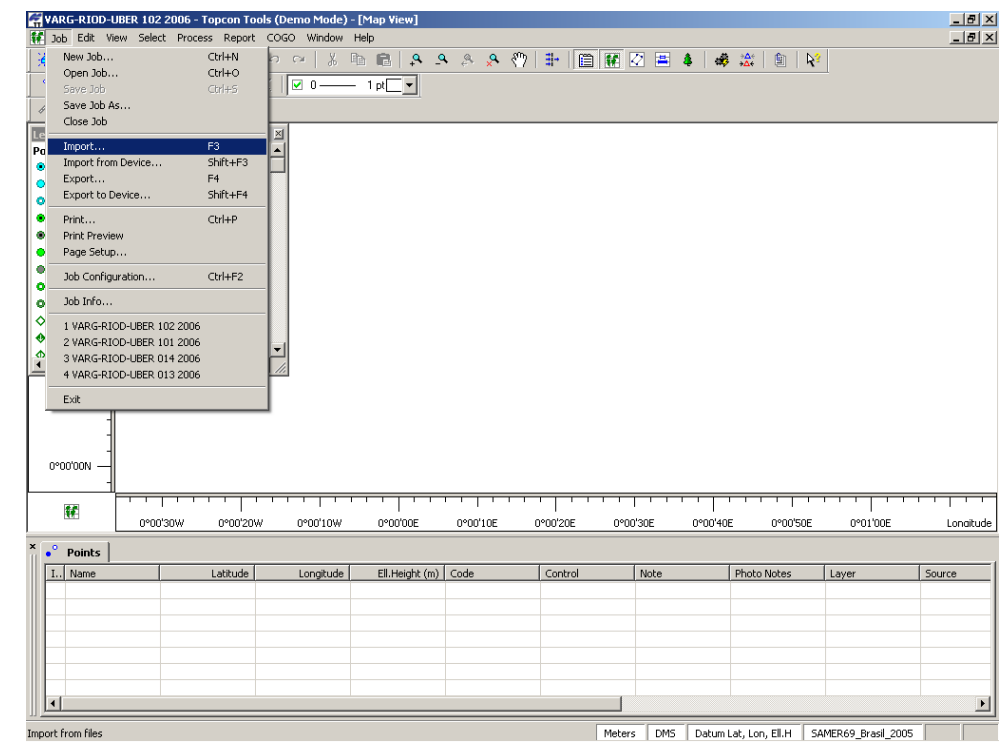


Clicar nos arquivos rinex a serem importados, e após em "Open":

Figura A5: Importar dados.

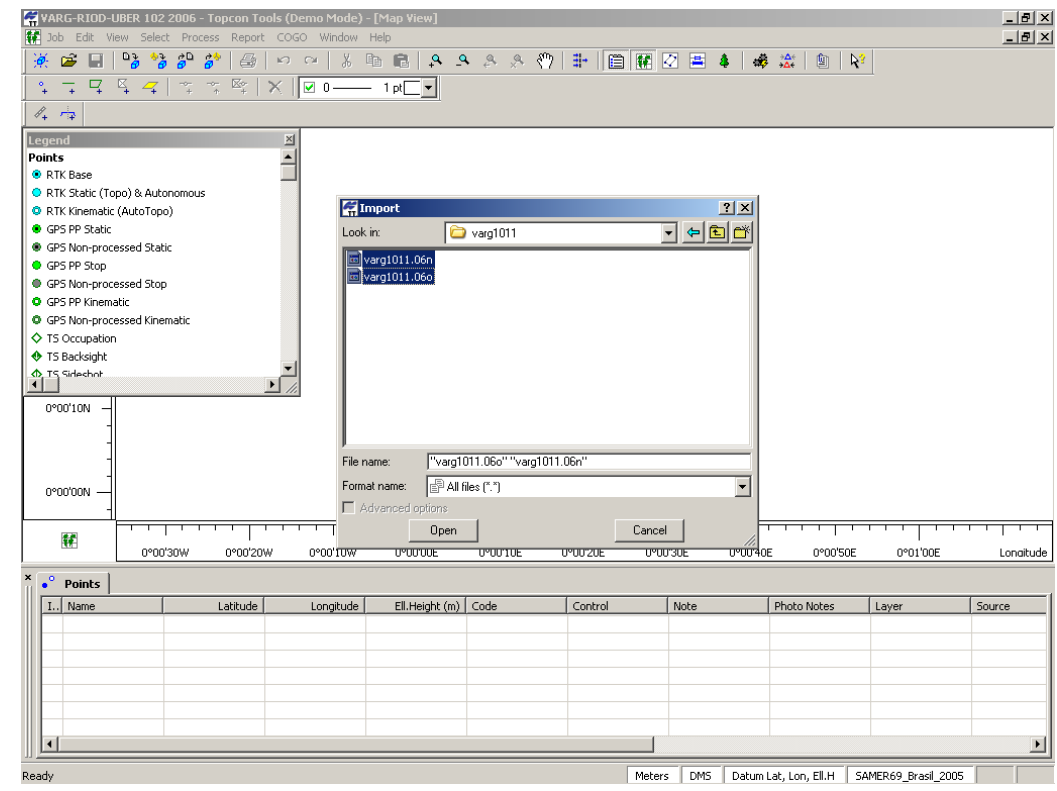

Após a importação de todas as estações, devem ser corrigidos os fatores inerentes aos pontos de controle. Para isso, deve-se clicar duas vezes sobre o item a corrigir:

Figura A6: Fixação das informações inerentes às estações (segundo a monografia das mesmas).

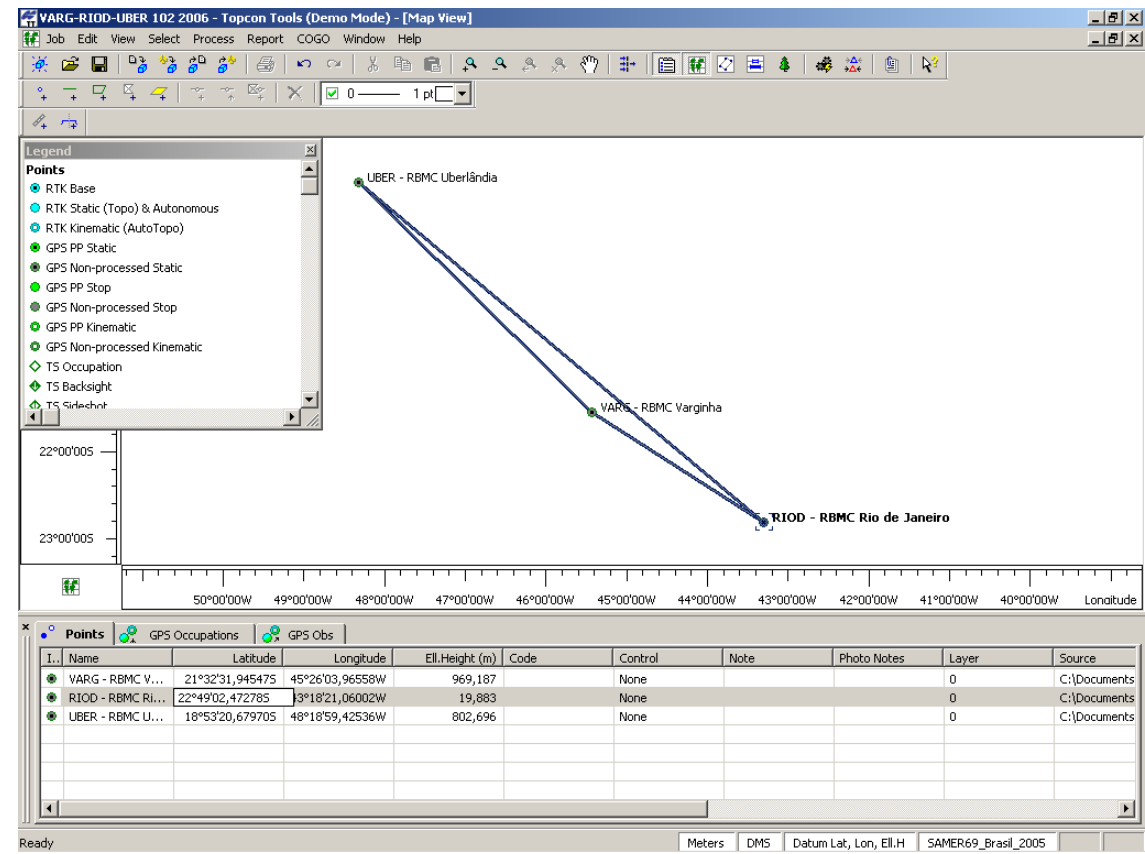


Após as devidas correções, para se fixar os pontos de controle deve-se clicar duas vezes na linha da estação de interesse na coluna "Control", e ser selecionado o item "Both" (quando o ponto será de controle horizontal e vertical):

Figura A7: Definição do ponto de controle.

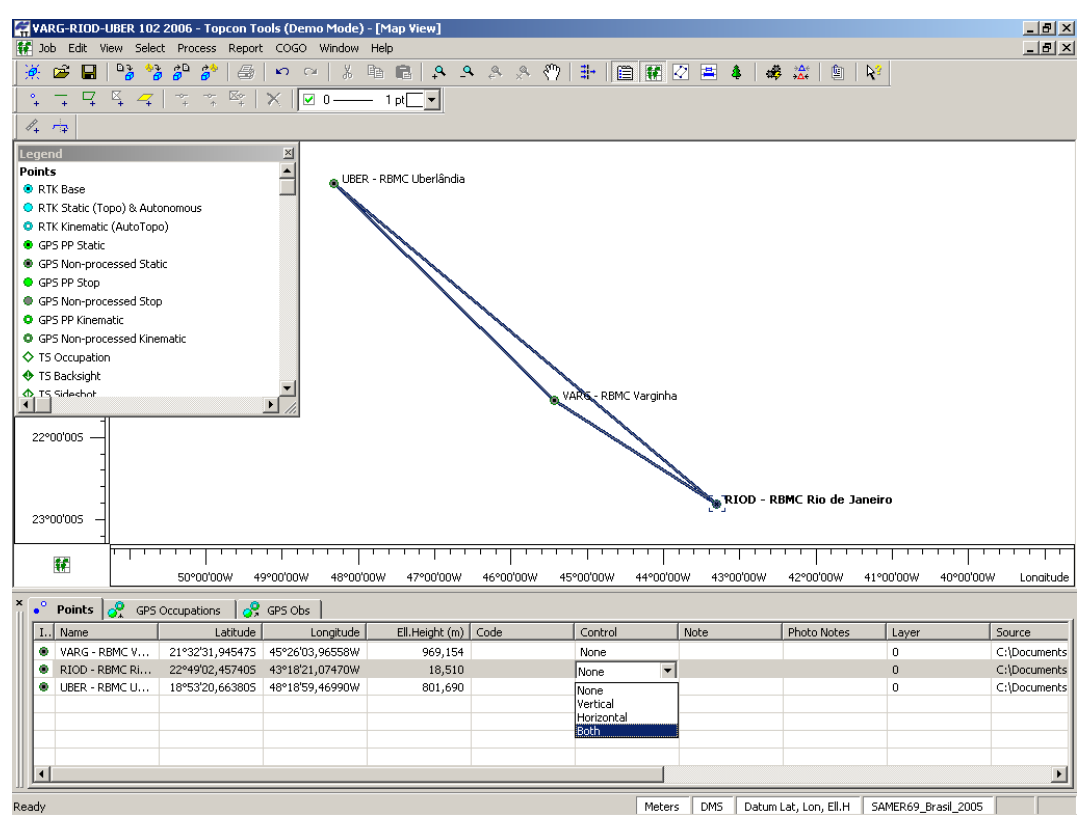

\section{A.4 Processamento e ajustamento}

Após, para processar os dados, no menu "Process" selecionar o item "GPS+PostProcessing":

Figura A8: Processamento.

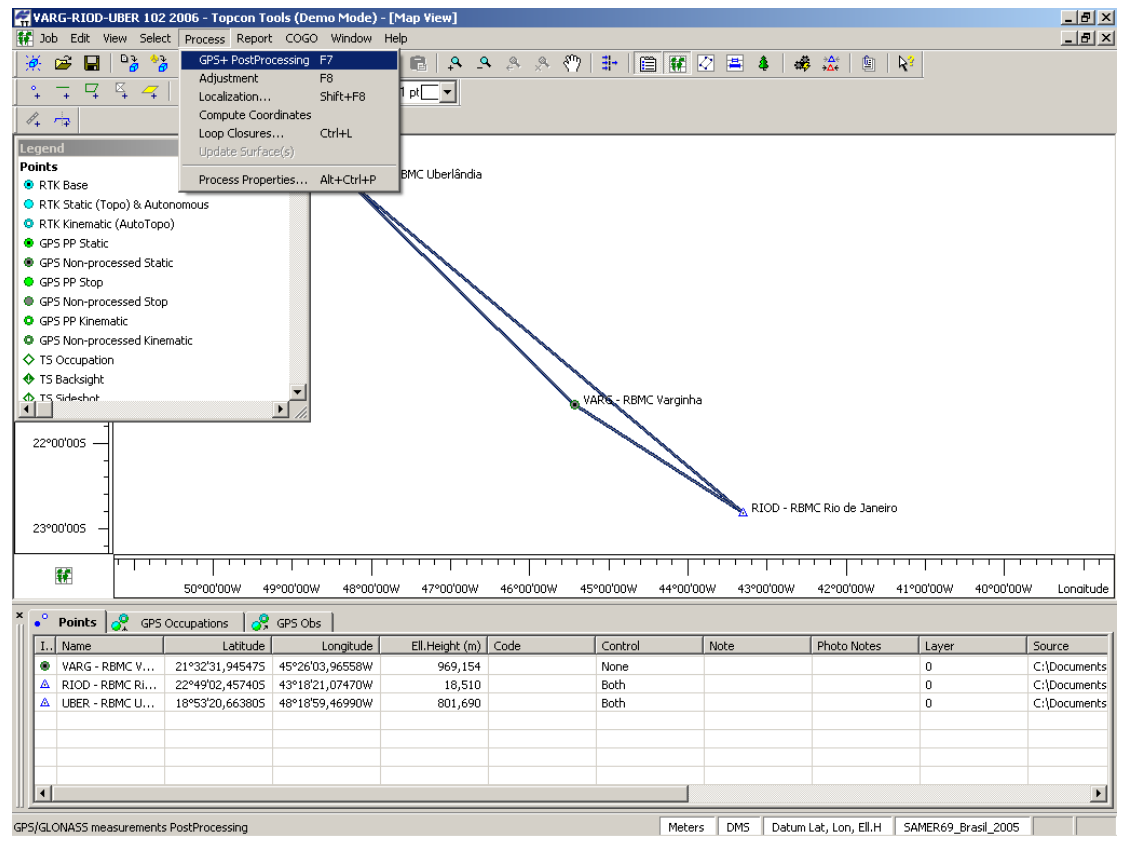


Após, para o ajustamento, no menu "Process" selecionar o item "Adjustment":

Figura A9: Ajustamento.

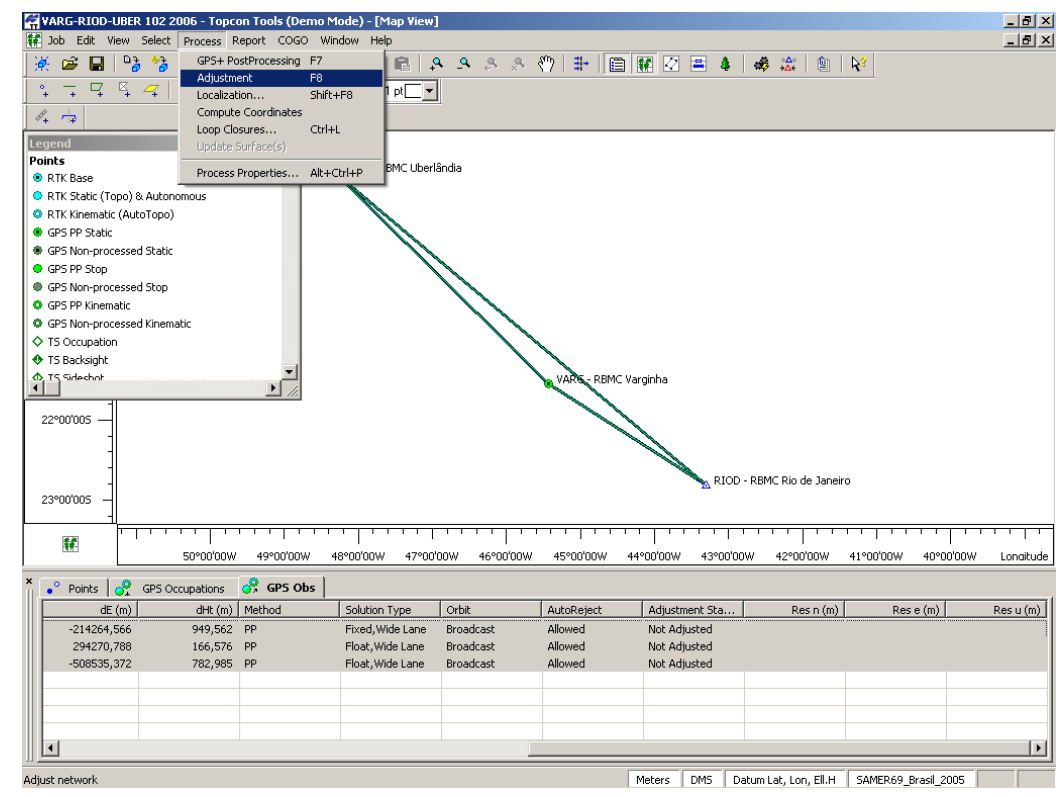

Após, aparecerá uma tela com os resultados do ajustamento. Clicar em "ok" e analisar os resultados:

Figura A10: Resultados do Ajustamento.

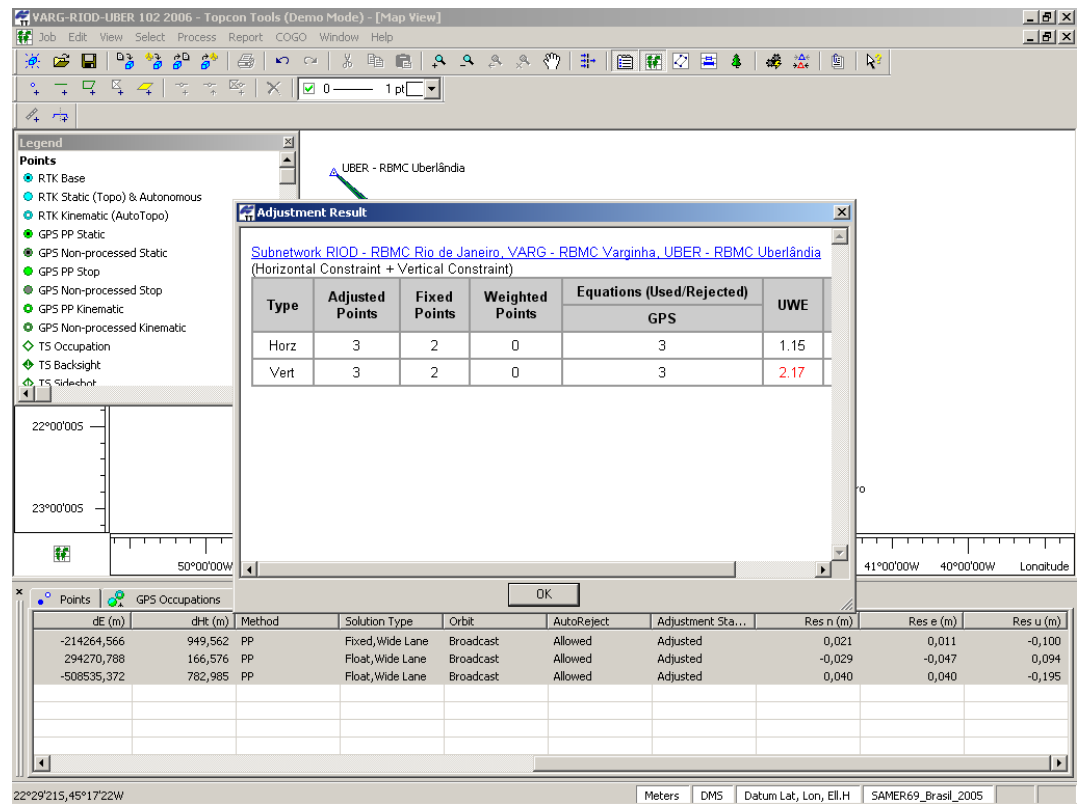




\title{
$\underline{\text { ANEXO B - Relatórios de processamento e ajustamento }}$
}

\section{B.1 Distâncias menores que $300 \mathrm{~km}$ e Geometria Ideal entre as estações da RBMC (VARG-VICO-RIOD)}

\author{
B.1.1 Ano de 2006
}

\section{B.1.1.1 Verão (Dias Julianos 011 a 014)}

- $\underline{011 / 2006}$

A posteriori UWE: 0.8242385 , Bounds: ( $0.6770032,1.241639)$

TABELA B1: Resultado do Processamento

\begin{tabular}{|c|c|c|c|c|c|c|c|c|}
\hline \multicolumn{9}{|c|}{ GPS Obs Report } \\
\hline Name & $\begin{array}{c}\text { Horizontal } \\
\text { Precision } \\
\text { (m) }\end{array}$ & $\begin{array}{l}\text { Vertical } \\
\text { Precision } \\
\text { (m) }\end{array}$ & $\begin{array}{c}\text { Distance } \\
\text { (m) }\end{array}$ & $\begin{array}{c}\text { Solution } \\
\text { Type }\end{array}$ & $\begin{array}{c}\text { GPS } \\
\text { Satellites }\end{array}$ & PDOP & Status & RMS \\
\hline $\begin{array}{l}\text { RIOD - RBMC Rio de } \\
\text { Janeiro-VARG - } \\
\text { RBMC Varginha }\end{array}$ & 0.043 & 0.064 & 261011.675 & $\begin{array}{l}\text { Fixed,Wide } \\
\text { Lane }\end{array}$ & 28 & 2.780 & Adjusted & 0.077 \\
\hline $\begin{array}{l}\text { RIOD - RBMC Rio de } \\
\text { Janeiro-VICO - } \\
\text { RBMC Vicosa }\end{array}$ & 0.051 & 0.051 & 232120.627 & $\begin{array}{l}\text { Float,Wide } \\
\text { Lane }\end{array}$ & 28 & 3.054 & Adjusted & $\mid 0.072$ \\
\hline $\begin{array}{l}\text { VARG - RBMC } \\
\text { Varginha-VICO - } \\
\text { RBMC Vicosa }\end{array}$ & 0.035 & 0.072 & 280097.780 & $\begin{array}{l}\text { Fixed,Wide } \\
\text { Lane }\end{array}$ & 28 & $\mid 3.026$ & Adjusted & 0.080 \\
\hline
\end{tabular}


Figura B1: Elipses de Erro

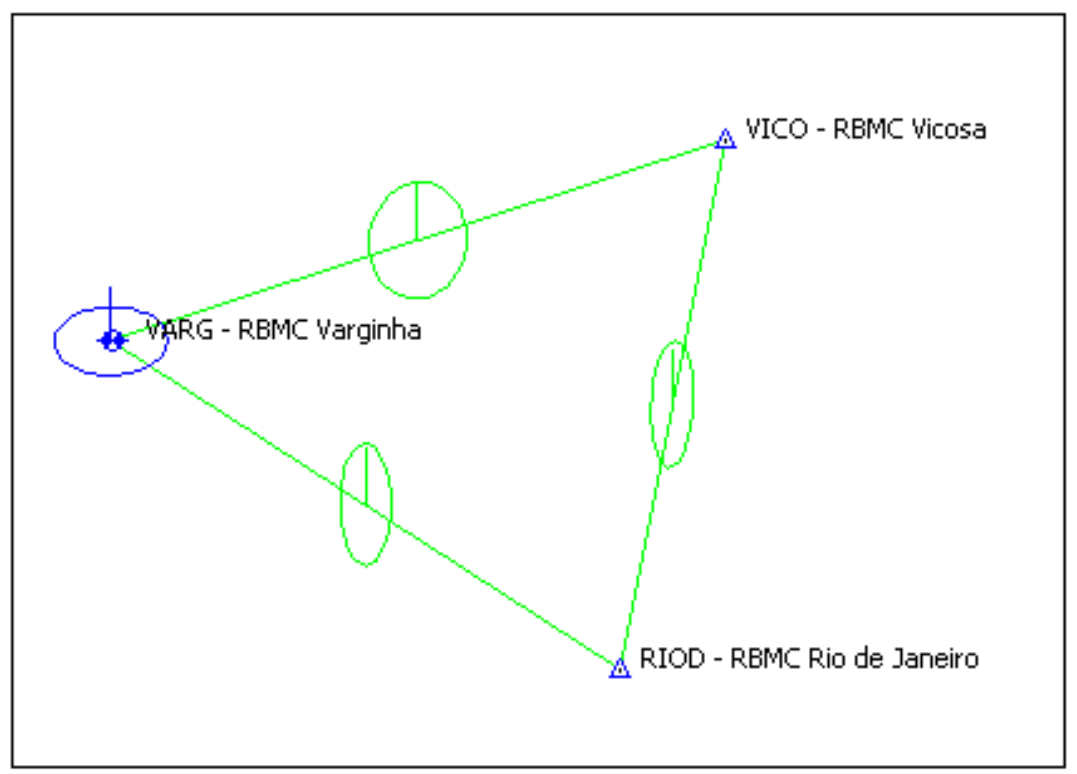

Coordenadas Ajustadas de VARG:

E (UTM): $454968.9504 \mathrm{~m}$

N (UTM): $7617727.2944 \mathrm{~m}$

- $012 / 2006$

A posteriori UWE: 0.8213519 , Bounds: $(0.6770032,1.241639)$

TABELA B2: Resultado do Processamento

\begin{tabular}{|c|c|c|c|c|c|c|c|c|}
\hline \multicolumn{9}{|c|}{ GPS Obs Report } \\
\hline Name & $\begin{array}{l}\text { Horizontal } \\
\text { Precision } \\
\text { (m) }\end{array}$ & $\begin{array}{l}\text { Vertical } \\
\text { Precision } \\
\text { (m) }\end{array}$ & $\begin{array}{l}\text { Distance } \\
\text { (m) }\end{array}$ & $\begin{array}{l}\text { Solution } \\
\text { Type }\end{array}$ & $\begin{array}{c}\text { GPS } \\
\text { Satellites }\end{array}$ & PDOP & Status & RMS \\
\hline $\begin{array}{l}\text { RIOD - RBMC Rio de } \\
\text { Janeiro-VARG - } \\
\text { RBMC Varginha }\end{array}$ & 0.041 & 0.068 & 261011.715 & $\begin{array}{l}\text { Fixed,Wide } \\
\text { Lane }\end{array}$ & 26 & $\mid 3.018$ & Adjusted & 0.079 \\
\hline $\begin{array}{l}\text { RIOD - RBMC Rio de } \\
\text { Janeiro-VICO - } \\
\text { RBMC Vicosa } \\
\end{array}$ & 0.034 & 0.066 & 232120.637 & $\begin{array}{l}\text { Fixed,Wide } \\
\text { Lane }\end{array}$ & 26 & $\mid 3.045$ & Adjusted & 0.074 \\
\hline $\begin{array}{l}\text { VARG - RBMC } \\
\text { Varginha-VICO - } \\
\text { RBMC Vicosa }\end{array}$ & 0.038 & 0.071 & 280097.792 & $\begin{array}{l}\text { Fixed,Wide } \\
\text { Lane }\end{array}$ & 27 & $\mid 3.021$ & Adjusted & 0.081 \\
\hline
\end{tabular}


Figura B2: Elipses de Erro

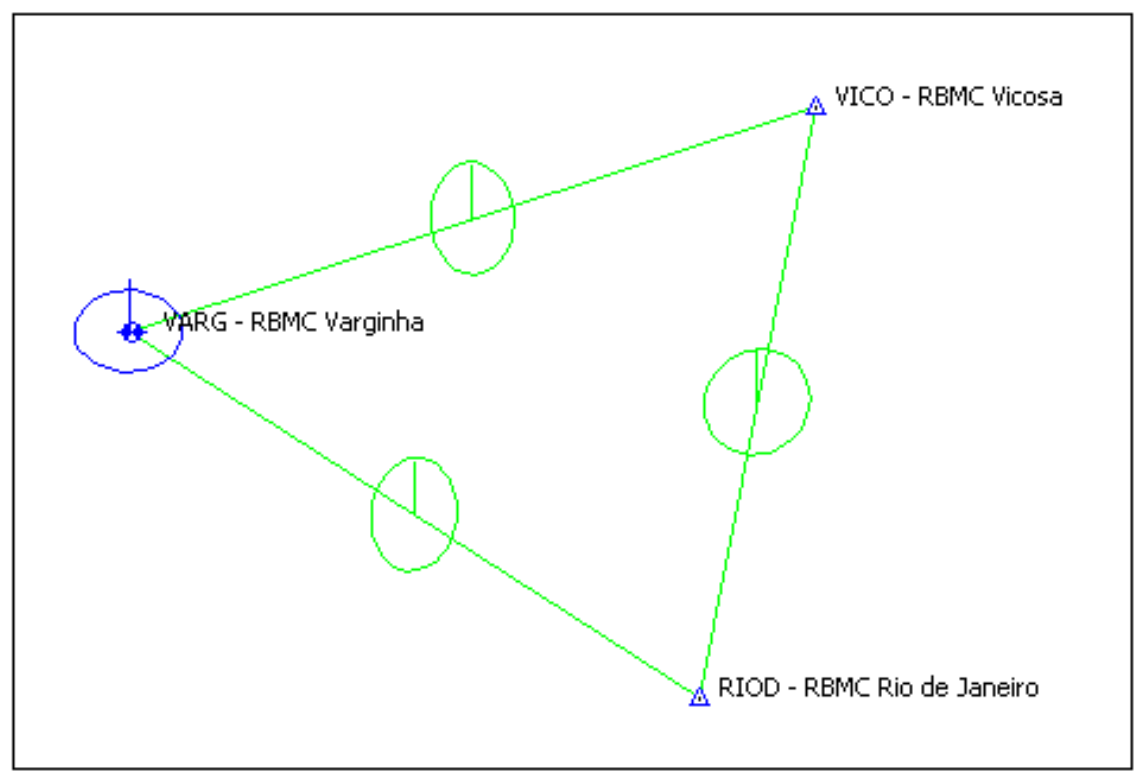

Coordenadas Ajustadas de VARG:

E (UTM): $454968.9210 \mathrm{~m}$

N (UTM): $7617727.2937 \mathrm{~m}$

- $\quad \underline{013 / 2006}$

A posteriori UWE: 0.7294839 , Bounds: ( $0.6770032,1.241639)$

TABELA B3: Resultado do Processamento

\begin{tabular}{|c|c|c|c|c|c|c|c|c|}
\hline \multicolumn{9}{|c|}{ GPS Obs Report } \\
\hline Name & $\begin{array}{l}\text { Horizontal } \\
\text { Precision } \\
\text { (m) }\end{array}$ & $\begin{array}{l}\text { Vertical } \\
\text { Precision } \\
\text { (m) }\end{array}$ & $\begin{array}{c}\text { Distance } \\
\text { (m) }\end{array}$ & $\begin{array}{c}\text { Solution } \\
\text { Type }\end{array}$ & $\begin{array}{c}\text { GPS } \\
\text { Satellites }\end{array}$ & PDOP & Status & RMS \\
\hline $\begin{array}{l}\text { RIOD - RBMC Rio de } \\
\text { Janeiro-VARG - } \\
\text { RBMC Varginha }\end{array}$ & 0.042 & $\mid 0.063$ & 261011.682 & $\begin{array}{l}\text { Fixed, Wide } \\
\text { Lane }\end{array}$ & 27 & $\mid 2.984$ & Adjusted & 0.077 \\
\hline $\begin{array}{l}\text { RIOD - RBMC Rio de } \\
\text { Janeiro-VICO - } \\
\text { RBMC Vicosa }\end{array}$ & 0.034 & $\| 0.060$ & 232120.620 & $\begin{array}{l}\text { Fixed,Wide } \\
\text { Lane }\end{array}$ & 26 & 2.073 & Adjusted & 0.072 \\
\hline $\begin{array}{l}\text { VARG - RBMC } \\
\text { Varginha-VICO - } \\
\text { RBMC Vicosa }\end{array}$ & 0.039 & $\mid 0.073$ & 280097.779 & $\begin{array}{l}\text { Fixed,Wide } \\
\text { Lane }\end{array}$ & 26 & 2.094 & Adjusted & 0.080 \\
\hline
\end{tabular}


Figura B3: Elipses de Erro

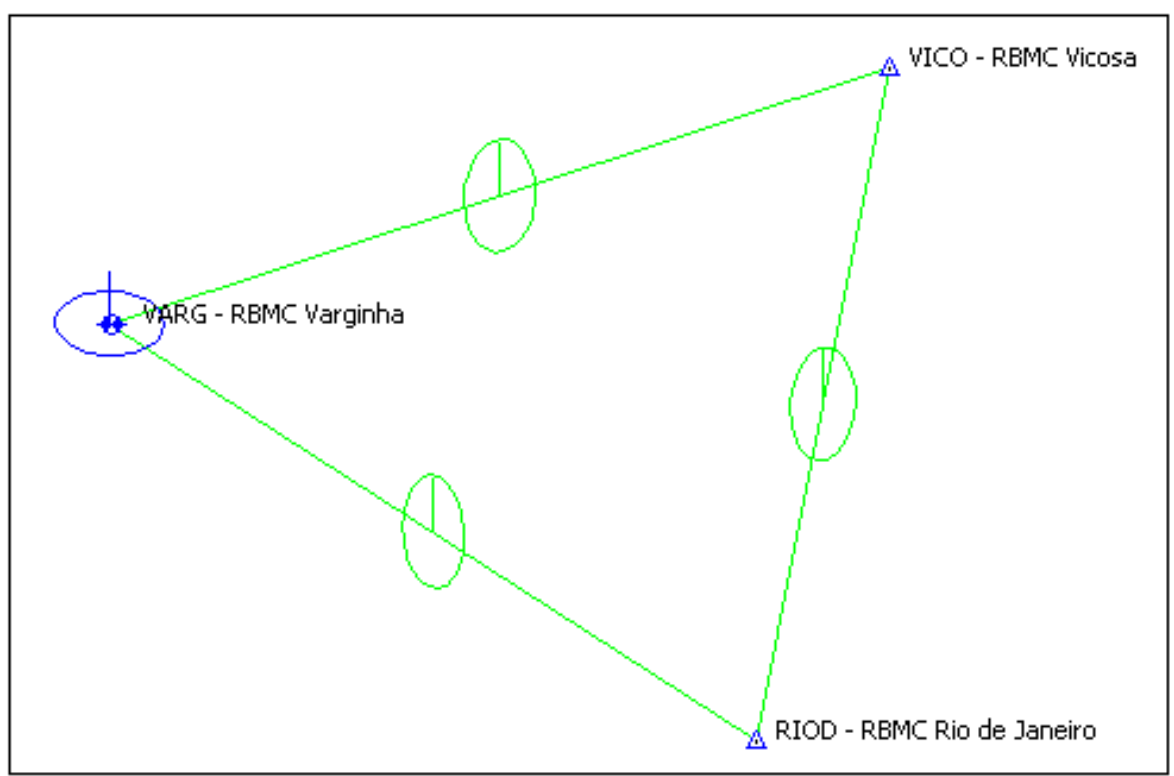

Coordenadas Ajustadas de VARG:

E (UTM): $454968.9419 \mathrm{~m}$

N (UTM): $7617727.2847 \mathrm{~m}$

- $014 / 2006$

A posteriori UWE: 0.834348 , Bounds: ( $0.6770032,1.241639$ )

TABELA B4: Resultado do Processamento

\begin{tabular}{|c|c|c|c|c|c|c|c|c|}
\hline \multicolumn{9}{|c|}{ GPS Obs Report } \\
\hline Name & $\begin{array}{l}\text { Horizontal } \\
\text { Precision } \\
\text { (m) }\end{array}$ & $\begin{array}{l}\text { Vertical } \\
\text { Precision } \\
(\mathbf{m})\end{array}$ & $\begin{array}{l}\text { Distance } \\
\text { (m) }\end{array}$ & $\begin{array}{c}\text { Solution } \\
\text { Type }\end{array}$ & $\begin{array}{c}\text { GPS } \\
\text { Satellites }\end{array}$ & PDOP & Status & RMS \\
\hline $\begin{array}{l}\text { RIOD - RBMC Rio de } \\
\text { Janeiro-VARG - } \\
\text { RBMC Varginha } \\
\end{array}$ & 0.052 & 0.066 & 261011.719 & $\begin{array}{l}\text { Fixed,Wide } \\
\text { Lane }\end{array}$ & 25 & 4.906 & Adjusted & 0.077 \\
\hline $\begin{array}{l}\text { RIOD - RBMC Rio de } \\
\text { Janeiro-VICO - } \\
\text { RBMC Vicosa }\end{array}$ & 0.037 & 0.063 & 232120.630 & $\begin{array}{l}\text { Fixed,Wide } \\
\text { Lane }\end{array}$ & 26 & 2.767 & Adjusted & 0.072 \\
\hline $\begin{array}{l}\text { VARG - RBMC } \\
\text { Varginha-VICO - } \\
\text { RBMC Vicosa }\end{array}$ & 0.036 & 0.068 & 280097.757 & $\begin{array}{l}\text { Fixed,Wide } \\
\text { Lane }\end{array}$ & 26 & 2.371 & Adjusted & 0.079 \\
\hline
\end{tabular}


Figura B4: Elipses de Erro

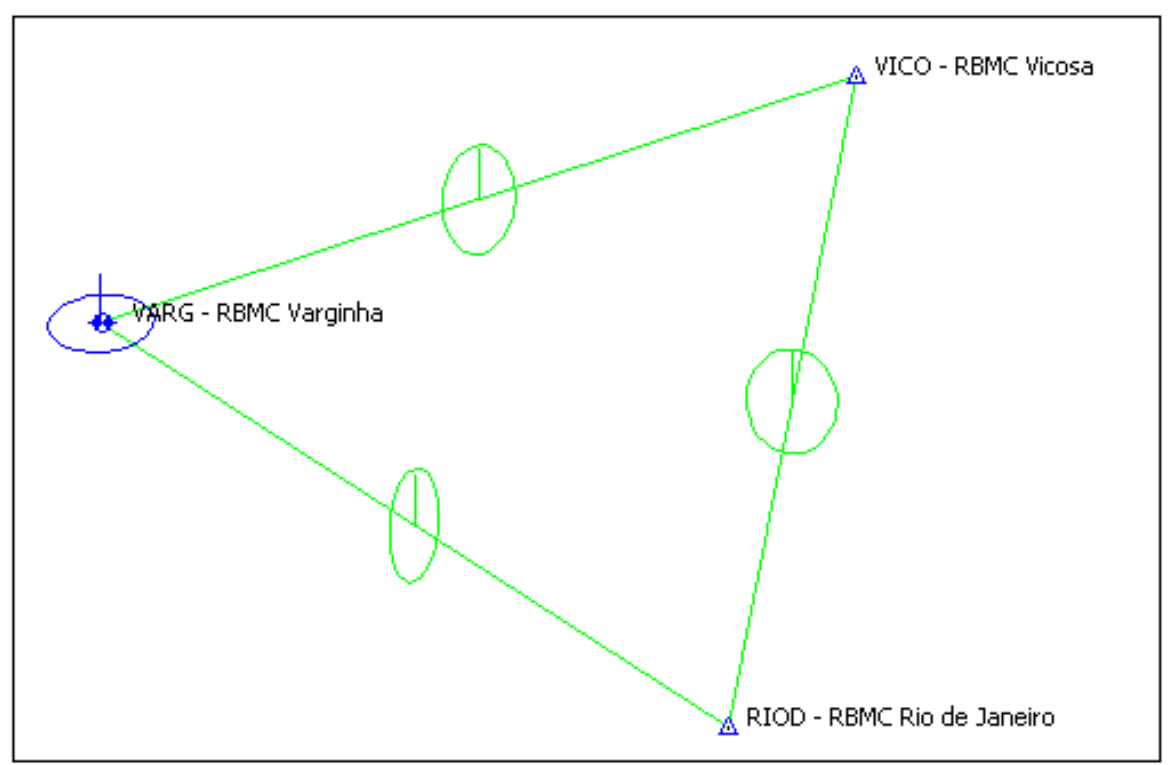

Coordenadas Ajustadas de VARG:

E (UTM): $454968.9452 \mathrm{~m}$

N (UTM): $7617727.3047 \mathrm{~m}$

\section{B.1.1.2 Outono (Dias Julianos 101 a 104)}

- $101 / 2006$

A posteriori UWE: 1.114961 , Bounds: ( $0.6770032,1.241639$ )

TABELA B5: Resultado do Processamento

\begin{tabular}{|c|c|c|c|c|c|c|c|c|}
\hline \multicolumn{9}{|c|}{ GPS Obs Report } \\
\hline Name & $\begin{array}{l}\text { Horizontal } \\
\text { Precision } \\
(\mathbf{m})\end{array}$ & $\begin{array}{l}\text { Vertical } \\
\text { Precision } \\
\quad(\mathbf{m}) \\
\end{array}$ & $\begin{array}{c}\text { Distance } \\
\text { (m) }\end{array}$ & $\begin{array}{c}\text { Solution } \\
\text { Type }\end{array}$ & $\begin{array}{c}\text { GPS } \\
\text { Satellites }\end{array}$ & PDOP & Status & RMS \\
\hline $\begin{array}{l}\text { RIOD - RBMC Rio de } \\
\text { Janeiro-VARG - } \\
\text { RBMC Varginha }\end{array}$ & 0.034 & 0.065 & 261011.688 & $\begin{array}{l}\text { Fixed,Wide } \\
\text { Lane }\end{array}$ & 28 & 2.659 & Adjusted & 0.077 \\
\hline $\begin{array}{l}\text { RIOD - RBMC Rio de } \\
\text { Janeiro-VICO - } \\
\text { RBMC Vicosa }\end{array}$ & 0.033 & 0.067 & 232120.623 & $\begin{array}{l}\text { Fixed,Wide } \\
\text { Lane }\end{array}$ & 28 & 2.887 & Adjusted & 0.072 \\
\hline $\begin{array}{l}\text { VARG - RBMC } \\
\text { Varginha-VICO - } \\
\text { RBMC Vicosa }\end{array}$ & 0.057 & 0.069 & 280097.762 & $\begin{array}{l}\text { Fixed,Wide } \\
\text { Lane }\end{array}$ & 27 & 3.004 & Adjusted & 0.080 \\
\hline
\end{tabular}


Figura B5: Elipses de Erro

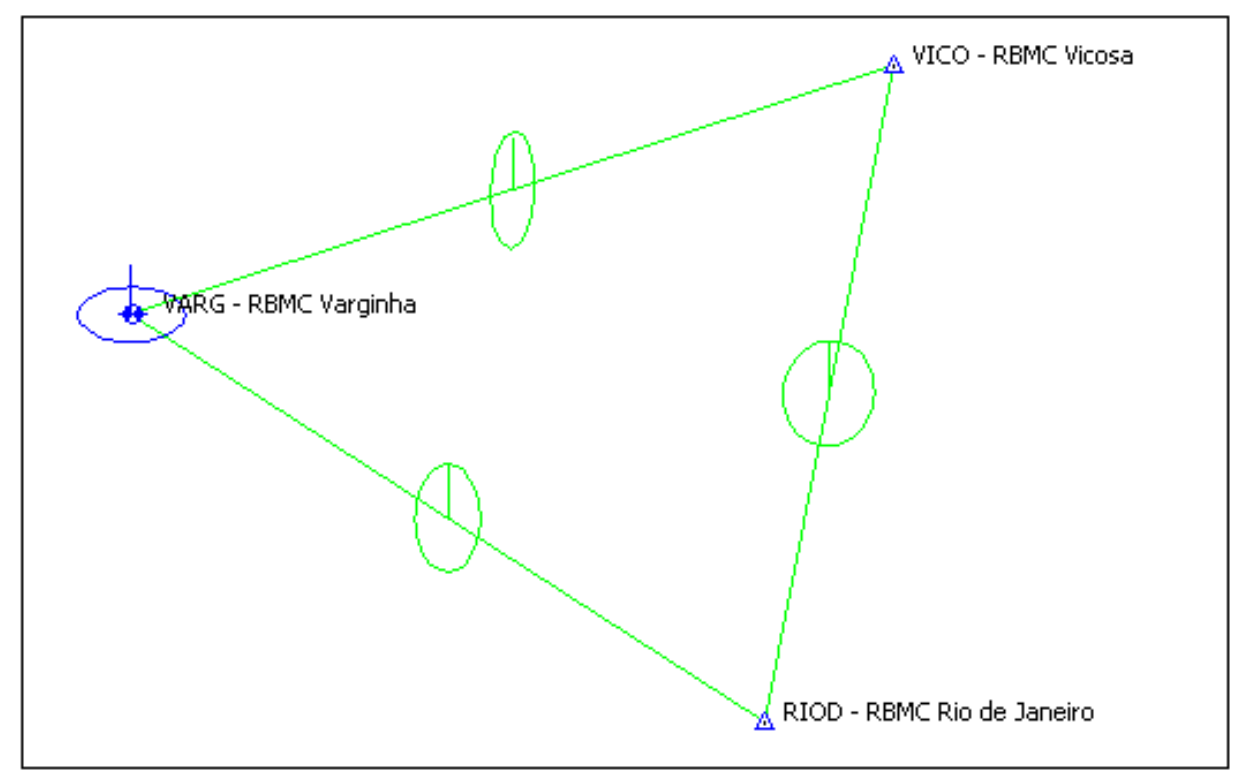

Coordenadas Ajustadas de VARG:

E (UTM): $454968.9541 \mathrm{~m}$

N (UTM): $7617727.3122 \mathrm{~m}$

- $102 / 2006$

A posteriori UWE: 0.70285039 , Bounds: ( $0.6770032,1.241639)$

TABELA B6: Resultado do Processamento

\begin{tabular}{|c|c|c|c|c|c|c|c|c|}
\hline \multicolumn{9}{|c|}{ GPS Obs Report } \\
\hline Name & $\begin{array}{l}\text { Horizontal } \\
\text { Precision } \\
(\mathrm{m})\end{array}$ & $\begin{array}{l}\text { Vertical } \\
\text { Precision } \\
\text { (m) }\end{array}$ & $\begin{array}{c}\text { Distance } \\
\text { (m) }\end{array}$ & $\begin{array}{c}\text { Solution } \\
\text { Type }\end{array}$ & $\begin{array}{c}\text { GPS } \\
\text { Satellites }\end{array}$ & PDOP & Status & RMS \\
\hline $\begin{array}{l}\text { RIOD - RBMC Rio de } \\
\text { Janeiro-VARG - } \\
\text { RBMC Varginha }\end{array}$ & 0.053 & 0.057 & 261011.682 & $\begin{array}{l}\text { Float,Wide } \\
\text { Lane }\end{array}$ & 27 & $\mid 3.987$ & Adjusted & 0.077 \\
\hline $\begin{array}{l}\text { RIOD - RBMC Rio de } \\
\text { Janeiro-VICO - } \\
\text { RBMC Vicosa }\end{array}$ & 0.029 & 0.059 & 232120.619 & $\begin{array}{l}\text { Fixed, Wide } \\
\text { Lane }\end{array}$ & 28 & 3.046 & Adjusted & 0.072 \\
\hline $\begin{array}{l}\text { VARG - RBMC } \\
\text { Varginha-VICO - } \\
\text { RBMC Vicosa }\end{array}$ & 0.035 & $\mid 0.070$ & 280097.763 & $\begin{array}{l}\text { Fixed,Wide } \\
\text { Lane }\end{array}$ & 28 & 2.985 & Adjusted & 0.080 \\
\hline
\end{tabular}


Figura B6: Elipses de Erro

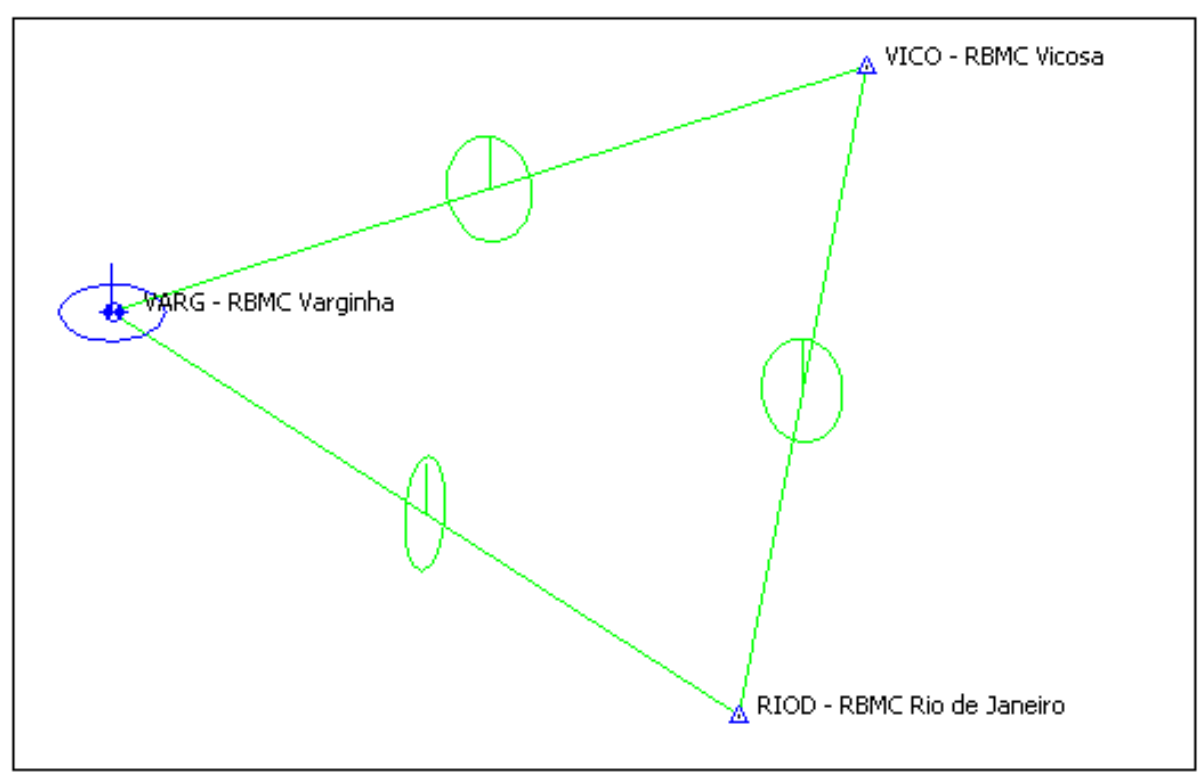

Coordenadas Ajustadas de VARG:

E (UTM): $454968.9432 \mathrm{~m}$

N (UTM): $7617727.3143 \mathrm{~m}$

- $\underline{103 / 2006}$

A posteriori UWE: 0.8072394 , Bounds: ( $0.6770032,1.241639)$

TABELA B7: Resultado do Processamento

\begin{tabular}{|c|c|c|c|c|c|c|c|c|}
\hline \multicolumn{9}{|c|}{ GPS Obs Report } \\
\hline Name & $\begin{array}{l}\text { Horizontal } \\
\text { Precision } \\
\text { (m) }\end{array}$ & $\begin{array}{l}\text { Vertical } \\
\text { Precision } \\
\text { (m) }\end{array}$ & $\begin{array}{c}\text { Distance } \\
\text { (m) }\end{array}$ & $\begin{array}{l}\text { Solution } \\
\text { Type }\end{array}$ & $\begin{array}{c}\text { GPS } \\
\text { Satellites }\end{array}$ & PDOP & Status & RMS \\
\hline $\begin{array}{l}\text { RIOD - RBMC Rio de } \\
\text { Janeiro-VARG - } \\
\text { RBMC Varginha }\end{array}$ & 0.035 & 0.068 & 261011.685 & $\begin{array}{l}\text { Fixed,Wide } \\
\text { Lane }\end{array}$ & 28 & 2.763 & Adjusted & 0.077 \\
\hline $\begin{array}{l}\text { RIOD - RBMC Rio de } \\
\text { Janeiro-VICO - } \\
\text { RBMC Vicosa } \\
\end{array}$ & 0.037 & 0.066 & 232120.626 & $\begin{array}{l}\text { Fixed,Wide } \\
\text { Lane }\end{array}$ & 27 & 2.294 & Adjusted & 0.072 \\
\hline $\begin{array}{l}\text { VARG - RBMC } \\
\text { Varginha-VICO - } \\
\text { RBMC Vicosa }\end{array}$ & 0.031 & 0.063 & 280097.765 & $\begin{array}{l}\text { Fixed,Wide } \\
\text { Lane }\end{array}$ & 28 & 3.023 & Adjusted & 0.080 \\
\hline
\end{tabular}


Figura B7: Elipses de Erro

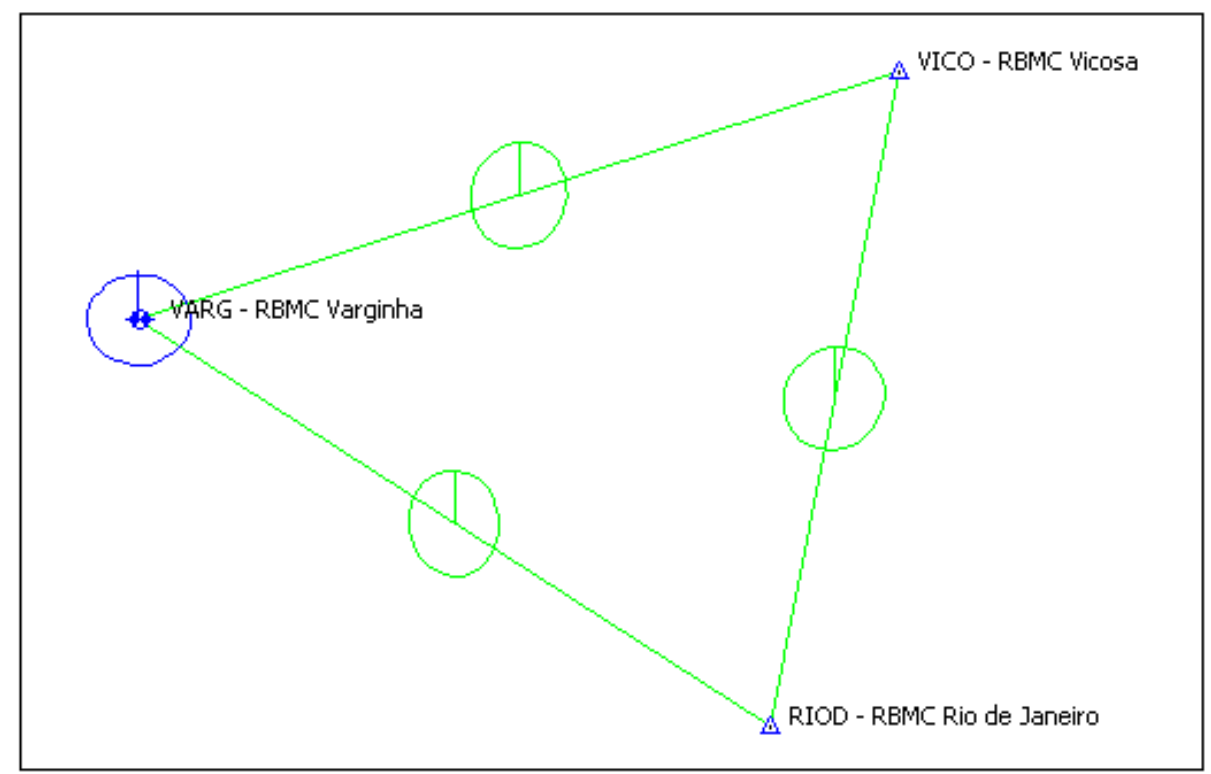

Coordenadas Ajustadas de VARG:

E (UTM): $454968.9415 \mathrm{~m}$

N (UTM): $7617727.3093 \mathrm{~m}$

- $\underline{104 / 2006}$

A posteriori UWE: 0.9532723 , Bounds: $(0.6770032,1.241639)$

TABELA B8: Resultado do Processamento

\begin{tabular}{|c|c|c|c|c|c|c|c|c|}
\hline \multicolumn{9}{|c|}{ GPS Obs Report } \\
\hline Name & $\begin{array}{l}\text { Horizontal } \\
\text { Precision } \\
\text { (m) }\end{array}$ & $\begin{array}{l}\text { Vertical } \\
\text { Precision } \\
\text { (m) }\end{array}$ & $\begin{array}{c}\text { Distance } \\
\text { (m) }\end{array}$ & $\begin{array}{l}\text { Solution } \\
\text { Type }\end{array}$ & $\begin{array}{c}\text { GPS } \\
\text { Satellites }\end{array}$ & PDOP & Status & RMS \\
\hline $\begin{array}{l}\text { RIOD - RBMC Rio de } \\
\text { Janeiro-VARG - } \\
\text { RBMC Varginha }\end{array}$ & 0.049 & $\mid 0.071$ & 261011.687 & $\begin{array}{l}\text { Fixed,Wide } \\
\text { Lane }\end{array}$ & 28 & 4.051 & Adjusted & 0.077 \\
\hline $\begin{array}{l}\text { RIOD - RBMC Rio de } \\
\text { Janeiro-VICO - } \\
\text { RBMC Vicosa } \\
\end{array}$ & 0.051 & 0.051 & 232120.618 & $\begin{array}{l}\text { Float,Wide } \\
\text { Lane }\end{array}$ & 29 & 4.348 & Adjusted & 0.073 \\
\hline $\begin{array}{l}\text { VARG - RBMC } \\
\text { Varginha-VICO - } \\
\text { RBMC Vicosa }\end{array}$ & 0.054 & 0.058 & 280097.770 & $\begin{array}{l}\text { Float,Wide } \\
\text { Lane }\end{array}$ & 29 & 6.289 & Adjusted & 0.079 \\
\hline
\end{tabular}


Figura B8: Elipses de Erro

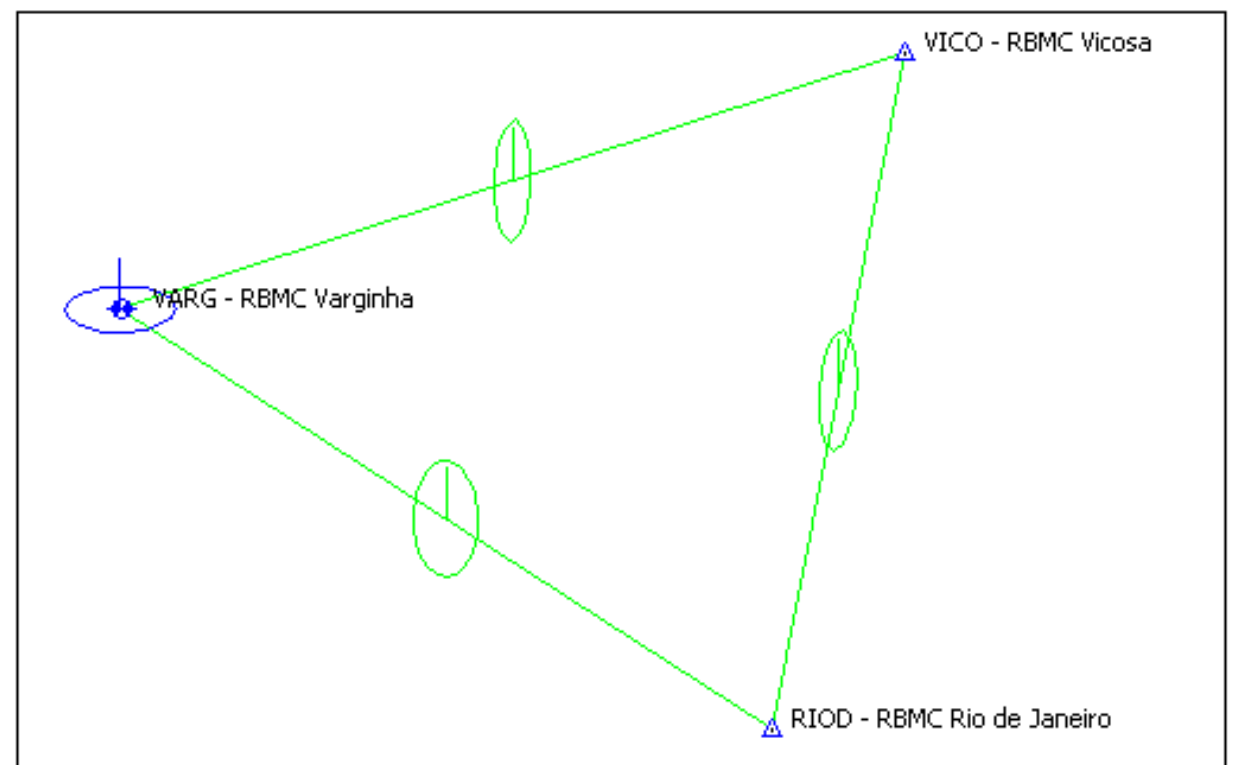

Coordenadas Ajustadas de VARG:

E (UTM): $454968.9432 \mathrm{~m}$

N (UTM): $7617727.3015 \mathrm{~m}$

\section{B.1.1.3 Inverno (Dias Julianos 193 a 196)}

- $193 / 2006$

A posteriori UWE: 0.7798707 , Bounds: ( $0.6770032,1.241639)$

TABELA B9: Resultado do Processamento

\begin{tabular}{|c|c|c|c|c|c|c|c|c|}
\hline \multicolumn{9}{|c|}{ GPS Obs Report } \\
\hline Name & $\begin{array}{c}\text { Horizontal } \\
\text { Precision } \\
(\mathbf{m})\end{array}$ & $\begin{array}{c}\text { Vertical } \\
\text { Precision } \\
\text { (m) }\end{array}$ & $\begin{array}{l}\text { Distance } \\
\text { (m) }\end{array}$ & $\begin{array}{c}\text { Solution } \\
\text { Type }\end{array}$ & \begin{tabular}{|c} 
GPS \\
Satellites
\end{tabular} & PDOP & Status & RMS \\
\hline $\begin{array}{l}\text { RIOD - RBMC Rio de } \\
\text { Janeiro-VARG - } \\
\text { RBMC Varginha }\end{array}$ & 0.033 & 0.070 & 261011.683 & $\begin{array}{l}\text { Fixed,Wide } \\
\text { Lane }\end{array}$ & 27 & 3.029 & Adjusted & 0.077 \\
\hline $\begin{array}{l}\text { RIOD - RBMC Rio de } \\
\text { Janeiro-VICO - } \\
\text { RBMC Vicosa } \\
\end{array}$ & 0.035 & 0.067 & 232120.636 & $\begin{array}{l}\text { Fixed,Wide } \\
\text { Lane }\end{array}$ & 25 & 3.003 & Adjusted & 0.078 \\
\hline $\begin{array}{l}\text { VARG - RBMC } \\
\text { Varginha-VICO - } \\
\text { RBMC Vicosa } \\
\end{array}$ & 0.034 & 0.072 & 280097.767 & $\begin{array}{l}\text { Fixed,Wide } \\
\text { Lane }\end{array}$ & 26 & 2.996 & Adjusted & 0.079 \\
\hline
\end{tabular}


Figura B9: Elipses de Erro

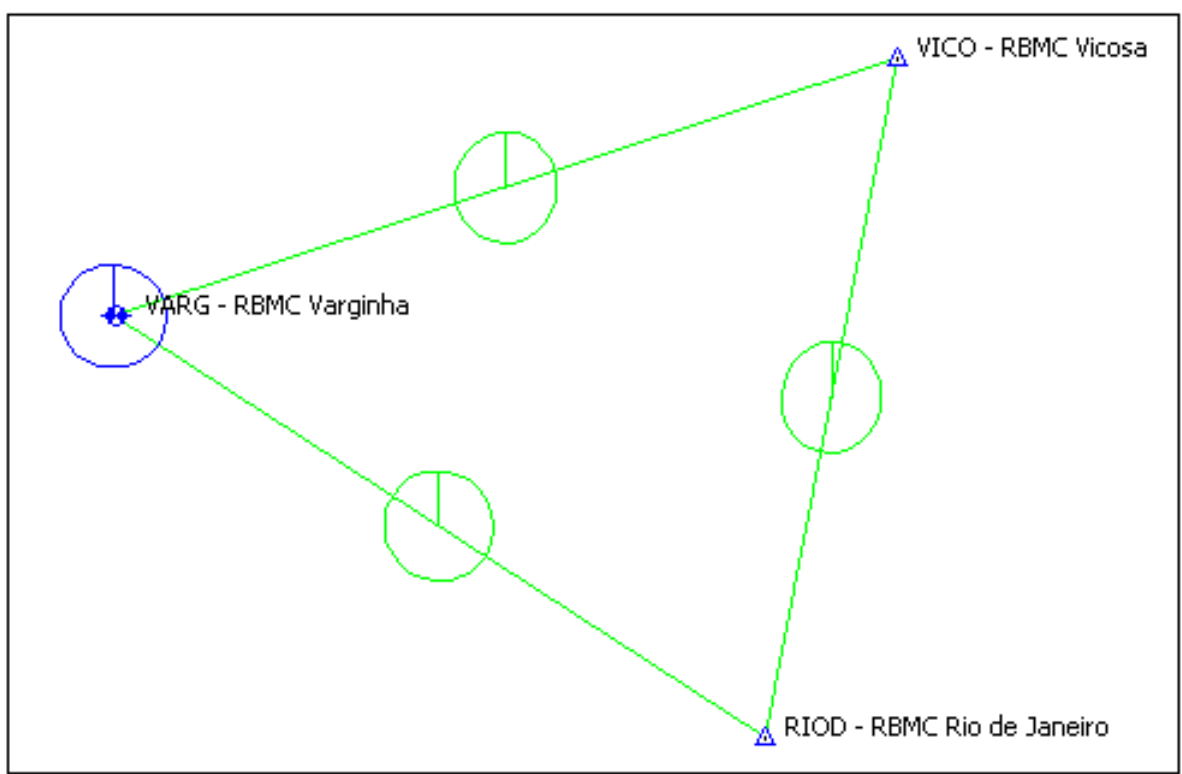

Coordenadas Ajustadas de VARG:

E (UTM): $454968.9541 \mathrm{~m}$

N (UTM): $7617727.3058 \mathrm{~m}$

- $194 / 2006$

A posteriori UWE: 1.028123 , Bounds: ( $0.6770032,1.241639$ )

TABELA B10: Resultado do Processamento

\begin{tabular}{|c|c|c|c|c|c|c|c|c|}
\hline \multicolumn{9}{|c|}{ GPS Obs Report } \\
\hline Name & $\begin{array}{l}\text { Horizontal } \\
\text { Precision } \\
\text { (m) }\end{array}$ & $\begin{array}{l}\text { Vertical } \\
\text { Precision } \\
\text { (m) }\end{array}$ & $\begin{array}{l}\text { Distance } \\
\text { (m) }\end{array}$ & $\begin{array}{c}\text { Solution } \\
\text { Type }\end{array}$ & $\begin{array}{c}\text { GPS } \\
\text { Satellites }\end{array}$ & PDOP & Status & RMS \\
\hline $\begin{array}{l}\text { RIOD - RBMC Rio de } \\
\text { Janeiro-VARG - } \\
\text { RBMC Varginha }\end{array}$ & 0.037 & 0.074 & 261011.676 & $\begin{array}{l}\text { Fixed,Wide } \\
\text { Lane }\end{array}$ & 27 & 3.026 & Adjusted & 0.077 \\
\hline $\begin{array}{l}\text { RIOD - RBMC Rio de } \\
\text { Janeiro-VICO - } \\
\text { RBMC Vicosa }\end{array}$ & 0.035 & 0.062 & 232120.603 & $\begin{array}{l}\text { Fixed,Wide } \\
\text { Lane }\end{array}$ & 28 & $\mid 3.001$ & Adjusted & 0.074 \\
\hline $\begin{array}{l}\text { VARG - RBMC } \\
\text { Varginha-VICO - } \\
\text { RBMC Vicosa }\end{array}$ & 0.038 & 0.080 & 280097.761 & $\begin{array}{l}\text { Fixed,Wide } \\
\text { Lane }\end{array}$ & 28 & 3.035 & Adjusted & 0.079 \\
\hline
\end{tabular}


Figura B10: Elipses de Erro

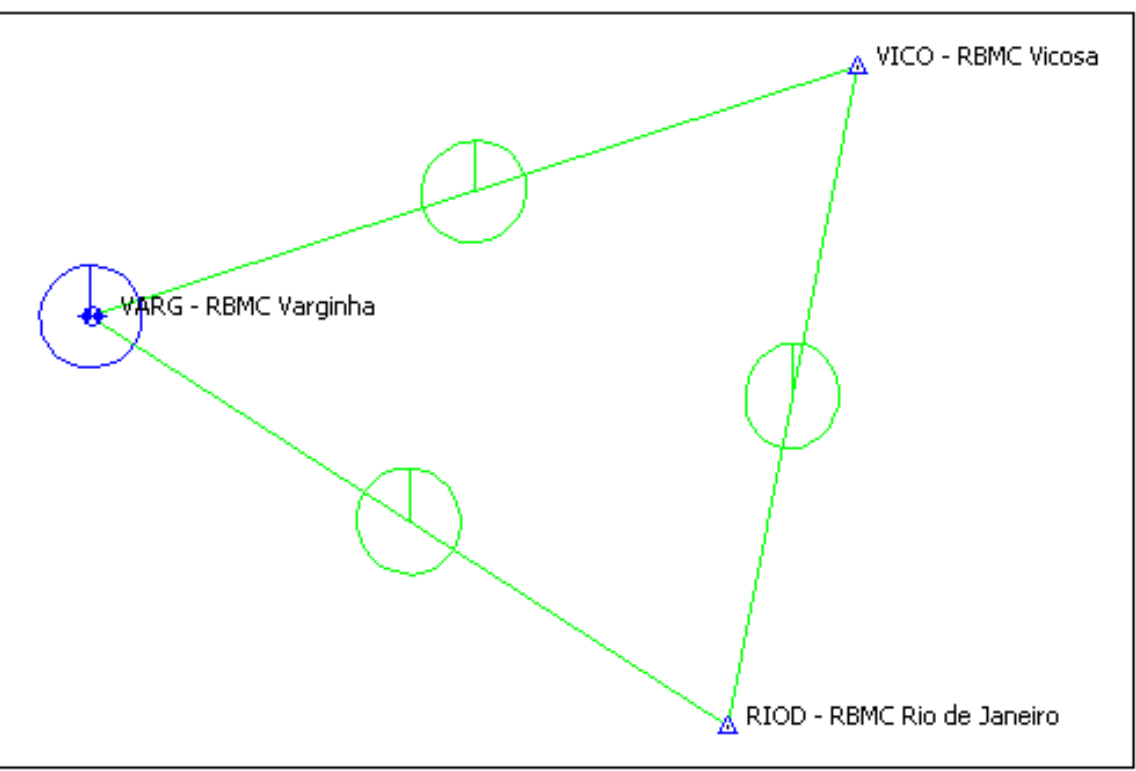

Coordenadas Ajustadas de VARG:

E (UTM): $454968.9492 \mathrm{~m}$

N (UTM): $7617727.2983 \mathrm{~m}$

- $195 / 2006$

A posteriori UWE: 0.6845620 , Bounds: $(0.6770032,1.241639)$

TABELA B11: Resultado do Processamento

\begin{tabular}{|c|c|c|c|c|c|c|c|c|}
\hline \multicolumn{9}{|c|}{ GPS Obs Report } \\
\hline Name & $\begin{array}{c}\text { Horizontal } \\
\text { Precision } \\
\text { (m) }\end{array}$ & $\begin{array}{l}\text { Vertical } \\
\text { Precision } \\
\text { (m) }\end{array}$ & $\begin{array}{c}\text { Distance } \\
\text { (m) }\end{array}$ & $\begin{array}{c}\text { Solution } \\
\text { Type }\end{array}$ & $\begin{array}{c}\text { GPS } \\
\text { Satellites }\end{array}$ & PDOP & Status & RMS \\
\hline $\begin{array}{l}\text { RIOD - RBMC Rio de } \\
\text { Janeiro-VARG - } \\
\text { RBMC Varginha }\end{array}$ & 0.032 & $\| 0.074$ & 261011.673 & $\begin{array}{l}\text { Fixed, Wide } \\
\text { Lane }\end{array}$ & 26 & $\mid 2.979$ & Adjusted & 0.077 \\
\hline $\begin{array}{l}\text { RIOD - RBMC Rio de } \\
\text { Janeiro-VICO - } \\
\text { RBMC Vicosa }\end{array}$ & 0.033 & 0.067 & 232120.615 & $\begin{array}{l}\text { Fixed,Wide } \\
\text { Lane }\end{array}$ & 24 & 2.437 & Adjusted & 0.073 \\
\hline $\begin{array}{l}\text { VARG - RBMC } \\
\text { Varginha-VICO - } \\
\text { RBMC Vicosa }\end{array}$ & 0.031 & 0.070 & 280097.766 & $\begin{array}{l}\text { Fixed,Wide } \\
\text { Lane }\end{array}$ & 24 & 3.009 & Adjusted & 0.079 \\
\hline
\end{tabular}


Figura B11: Elipses de Erro

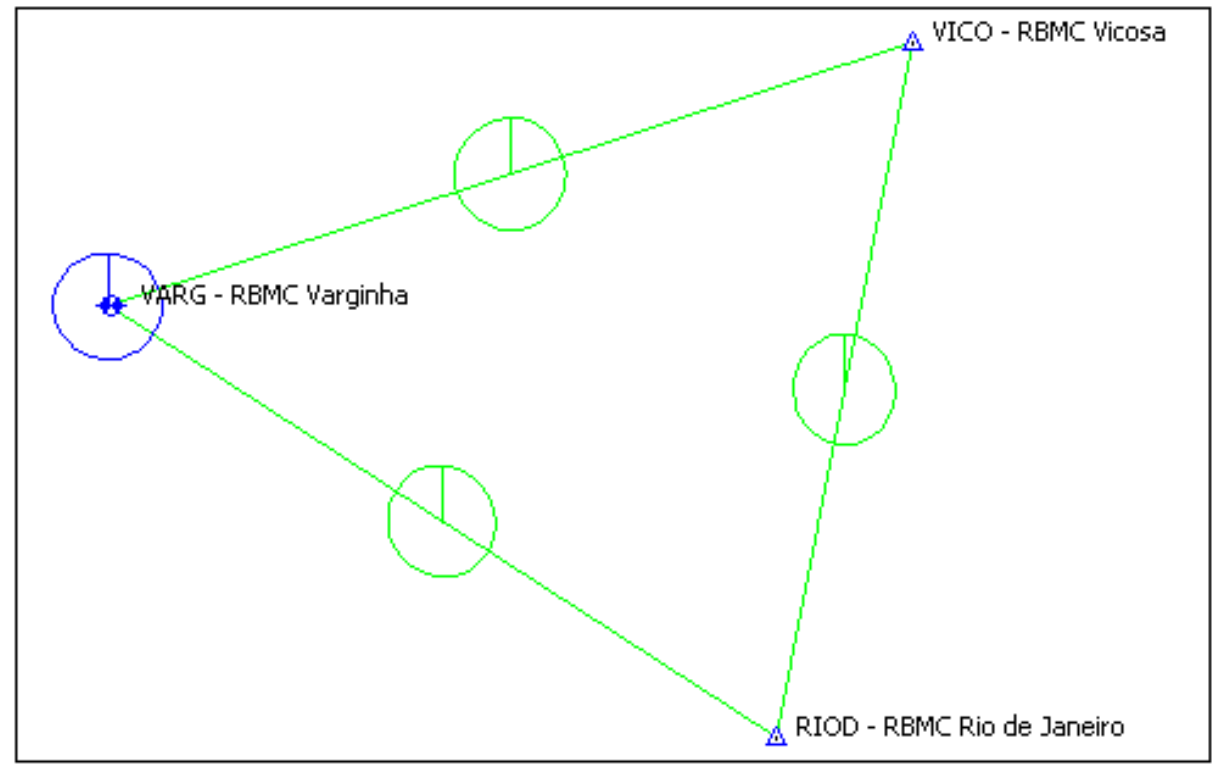

Coordenadas Ajustadas de VARG:

E (UTM): $454968.9543 \mathrm{~m}$

N (UTM): $7617727.3060 \mathrm{~m}$

- $196 / 2006$

A posteriori UWE: 0.7201946 , Bounds: ( $0.6770032,1.241639)$

TABELA B12: Resultado do Processamento

\begin{tabular}{|c|c|c|c|c|c|c|c|c|}
\hline \multicolumn{9}{|c|}{ GPS Obs Report } \\
\hline Name & $\begin{array}{l}\text { Horizontal } \\
\text { Precision } \\
\text { (m) }\end{array}$ & $\begin{array}{l}\text { Vertical } \\
\text { Precision } \\
\text { (m) }\end{array}$ & $\begin{array}{l}\text { Distance } \\
\text { (m) }\end{array}$ & $\begin{array}{c}\text { Solution } \\
\text { Type }\end{array}$ & $\begin{array}{c}\text { GPS } \\
\text { Satellites }\end{array}$ & PDOP & Status & RMS \\
\hline $\begin{array}{l}\text { RIOD - RBMC Rio de } \\
\text { Janeiro-VARG - } \\
\text { RBMC Varginha }\end{array}$ & 0.033 & 0.072 & 261011.681 & $\begin{array}{l}\text { Fixed,Wide } \\
\text { Lane }\end{array}$ & 25 & 3.025 & Adjusted & 0.077 \\
\hline $\begin{array}{l}\text { RIOD - RBMC Rio de } \\
\text { Janeiro-VICO - } \\
\text { RBMC Vicosa }\end{array}$ & 0.027 & 0.069 & 232120.604 & $\begin{array}{l}\text { Fixed,Wide } \\
\text { Lane }\end{array}$ & 20 & 2.791 & Adjusted & 0.072 \\
\hline $\begin{array}{l}\text { VARG - RBMC } \\
\text { Varginha-VICO - } \\
\text { RBMC Vicosa }\end{array}$ & 0.037 & 0.078 & 280097.770 & $\begin{array}{l}\text { Fixed,Wide } \\
\text { Lane }\end{array}$ & 20 & 2.996 & Adjusted & 0.079 \\
\hline
\end{tabular}


Figura B12: Elipses de Erro

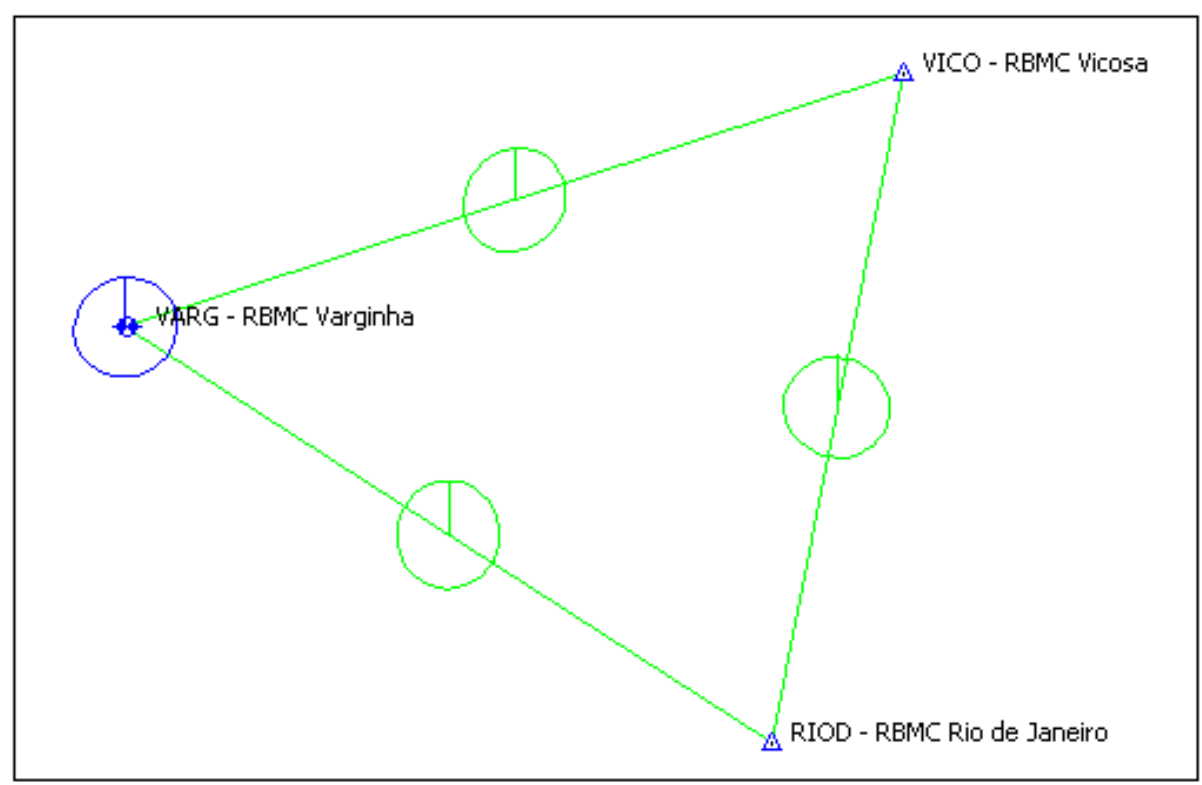

Coordenadas Ajustadas de VARG:

E (UTM): $454968.9497 \mathrm{~m}$

N (UTM): $7617727.3104 \mathrm{~m}$

B.1.1.4 Primavera (Dias Julianos 286 a 289)

- $286 / 2006$

A posteriori UWE: 1.1567296 , Bounds: ( $0.6770032,1.241639)$

TABELA B13: Resultado do Processamento

\begin{tabular}{|c|c|c|c|c|c|c|c|c|}
\hline \multicolumn{9}{|c|}{ GPS Obs Report } \\
\hline Name & $\begin{array}{l}\text { Horizontal } \\
\text { Precision } \\
\text { (m) }\end{array}$ & $\begin{array}{l}\text { Vertical } \\
\text { Precision } \\
\text { (m) }\end{array}$ & $\begin{array}{c}\text { Distance } \\
\text { (m) }\end{array}$ & $\begin{array}{c}\text { Solution } \\
\text { Type }\end{array}$ & \begin{tabular}{c|} 
GPS \\
Satellites
\end{tabular} & PDOP & Status & RMS \\
\hline $\begin{array}{l}\text { RIOD - RBMC Rio de } \\
\text { Janeiro-VARG - } \\
\text { RBMC Varginha }\end{array}$ & 0.049 & $\mid 0.062$ & 261011.731 & $\begin{array}{l}\text { Float, Wide } \\
\text { Lane }\end{array}$ & 24 & 3.198 & Adjusted & 0.079 \\
\hline $\begin{array}{l}\text { RIOD - RBMC Rio de } \\
\text { Janeiro-VICO - } \\
\text { RBMC Vicosa } \\
\end{array}$ & 0.057 & 0.036 & 232120.626 & $\begin{array}{l}\text { Float, Wide } \\
\text { Lane }\end{array}$ & 24 & 3.082 & Adjusted & 0.077 \\
\hline $\begin{array}{l}\text { VARG - RBMC } \\
\text { Varginha-VICO - } \\
\text { RBMC Vicosa }\end{array}$ & 0.036 & 0.082 & 280097.789 & $\begin{array}{l}\text { Fixed,Wide } \\
\text { Lane }\end{array}$ & 26 & 3.005 & Adjusted & 0.080 \\
\hline
\end{tabular}


Figura B13: Elipses de Erro

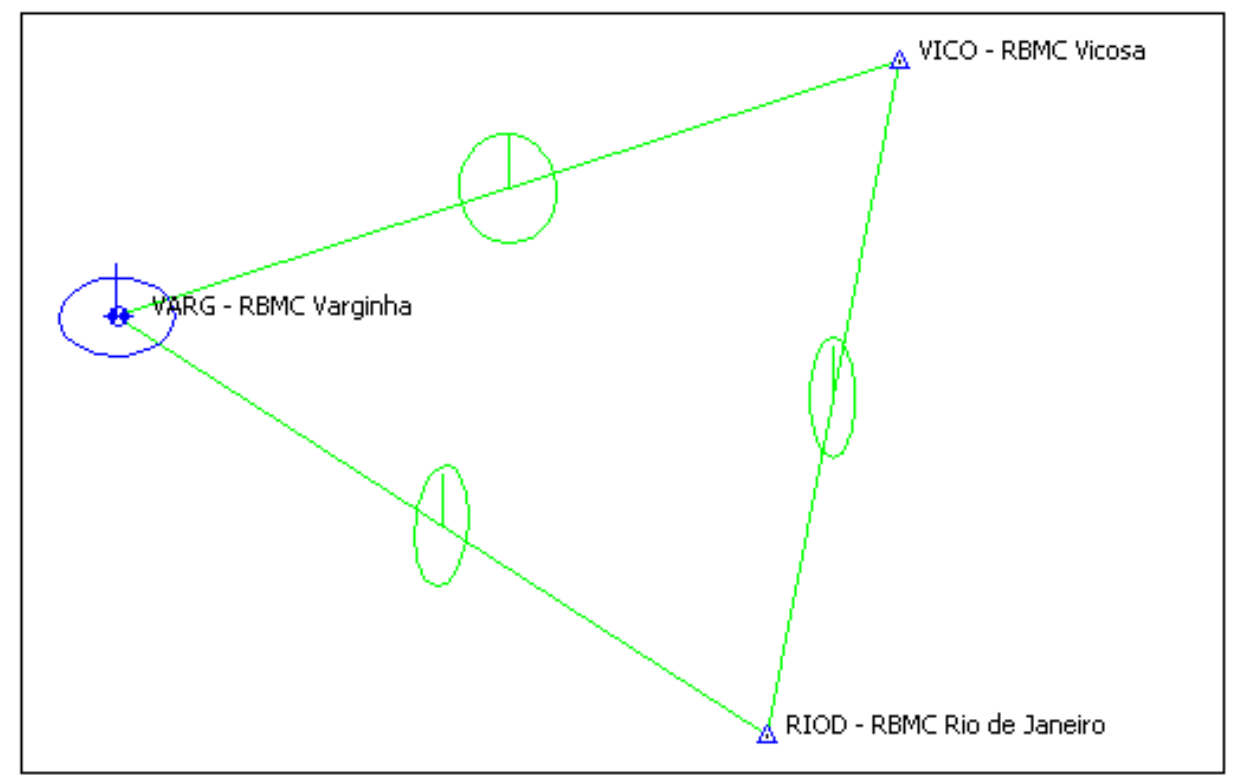

Coordenadas Ajustadas de VARG:

E (UTM): $454968.9197 \mathrm{~m}$

N (UTM): $7617727.3043 \mathrm{~m}$

- $\underline{287 / 2006}$

A posteriori UWE: 0.7461933 , Bounds: ( $0.6770032,1.241639$ )

TABELA B14: Resultado do Processamento

\begin{tabular}{|c|c|c|c|c|c|c|c|c|}
\hline \multicolumn{9}{|c|}{ GPS Obs Report } \\
\hline Name & $\begin{array}{c}\text { Horizontal } \\
\text { Precision } \\
\text { (m) }\end{array}$ & $\begin{array}{c}\text { Vertical } \\
\text { Precision } \\
(\mathbf{m})\end{array}$ & $\begin{array}{l}\text { Distance } \\
\text { (m) }\end{array}$ & $\begin{array}{c}\text { Solution } \\
\text { Type }\end{array}$ & $\begin{array}{c}\text { GPS } \\
\text { Satellites }\end{array}$ & PDOP & Status & RMS \\
\hline \begin{tabular}{|l} 
RIOD - RBMC Rio de \\
Janeiro-VARG - \\
RBMC Varginha \\
\end{tabular} & 0.036 & 0.059 & 261011.688 & $\begin{array}{l}\text { Fixed,Wide } \\
\text { Lane }\end{array}$ & 27 & 2.078 & Adjusted & 0.076 \\
\hline $\begin{array}{l}\text { RIOD - RBMC Rio de } \\
\text { Janeiro-VICO - } \\
\text { RBMC Vicosa }\end{array}$ & 0.035 & 0.056 & 232120.640 & $\begin{array}{l}\text { Fixed,Wide } \\
\text { Lane }\end{array}$ & 27 & 2.452 & Adjusted & 0.074 \\
\hline $\begin{array}{l}\text { VARG - RBMC } \\
\text { Varginha-VICO - } \\
\text { RBMC Vicosa }\end{array}$ & 0.033 & 0.068 & 280097.782 & $\begin{array}{l}\text { Fixed,Wide } \\
\text { Lane }\end{array}$ & 27 & 2.793 & Adjusted & 0.080 \\
\hline
\end{tabular}


Figura B14: Elipses de Erro

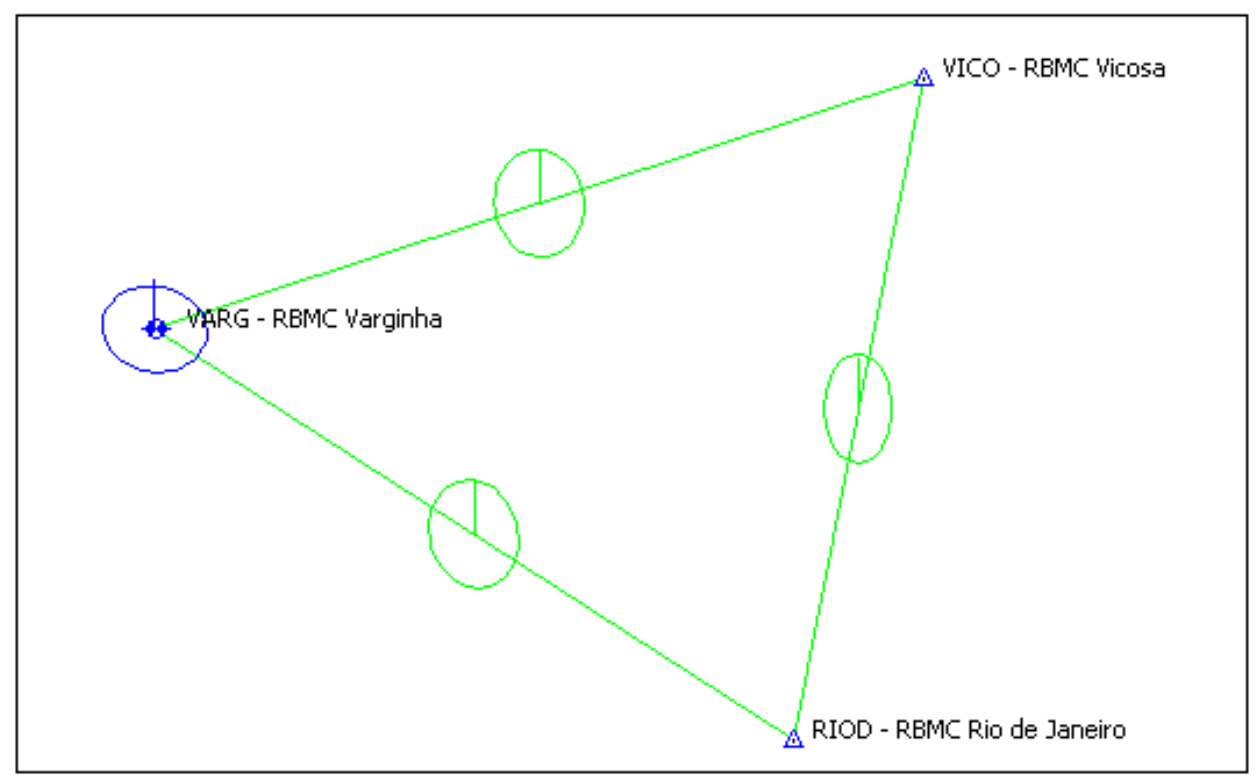

Coordenadas Ajustadas de VARG:

E (UTM): $454968.9341 \mathrm{~m}$

N (UTM): $7617727.2867 \mathrm{~m}$

- $288 / 2006$

A posteriori UWE: 0.6781938 , Bounds: ( $0.6770032,1.241639)$

TABELA B15: Resultado do Processamento

\begin{tabular}{|c|c|c|c|c|c|c|c|c|}
\hline \multicolumn{9}{|c|}{ GPS Obs Report } \\
\hline Name & $\begin{array}{c}\text { Horizontal } \\
\text { Precision } \\
(\mathbf{m}) \\
\end{array}$ & $\begin{array}{l}\text { Vertical } \\
\text { Precision } \\
(\mathbf{m}) \\
\end{array}$ & $\begin{array}{l}\text { Distance } \\
\text { (m) }\end{array}$ & $\begin{array}{c}\text { Solution } \\
\text { Type }\end{array}$ & $\begin{array}{c}\text { GPS } \\
\text { Satellites }\end{array}$ & PDOP & Status & RMS \\
\hline $\begin{array}{l}\text { RIOD - RBMC Rio de } \\
\text { Janeiro-VARG - } \\
\text { RBMC Varginha }\end{array}$ & 0.051 & 0.049 & 261011.693 & $\begin{array}{l}\text { Fixed,Wide } \\
\text { Lane }\end{array}$ & 24 & 2.976 & Adjusted & 0.078 \\
\hline $\begin{array}{l}\text { RIOD - RBMC Rio de } \\
\text { Janeiro-VICO - } \\
\text { RBMC Vicosa }\end{array}$ & 0.046 & 0.063 & 232120.626 & $\begin{array}{l}\text { Fixed,Wide } \\
\text { Lane }\end{array}$ & 25 & 2.836 & Adjusted & 0.074 \\
\hline $\begin{array}{l}\text { VARG - RBMC } \\
\text { Varginha-VICO - } \\
\text { RBMC Vicosa }\end{array}$ & 0.034 & 0.068 & 280097.782 & $\begin{array}{l}\text { Fixed,Wide } \\
\text { Lane }\end{array}$ & 27 & $\mid 3.020$ & Adjusted & 0.078 \\
\hline
\end{tabular}


Figura B15: Elipses de Erro

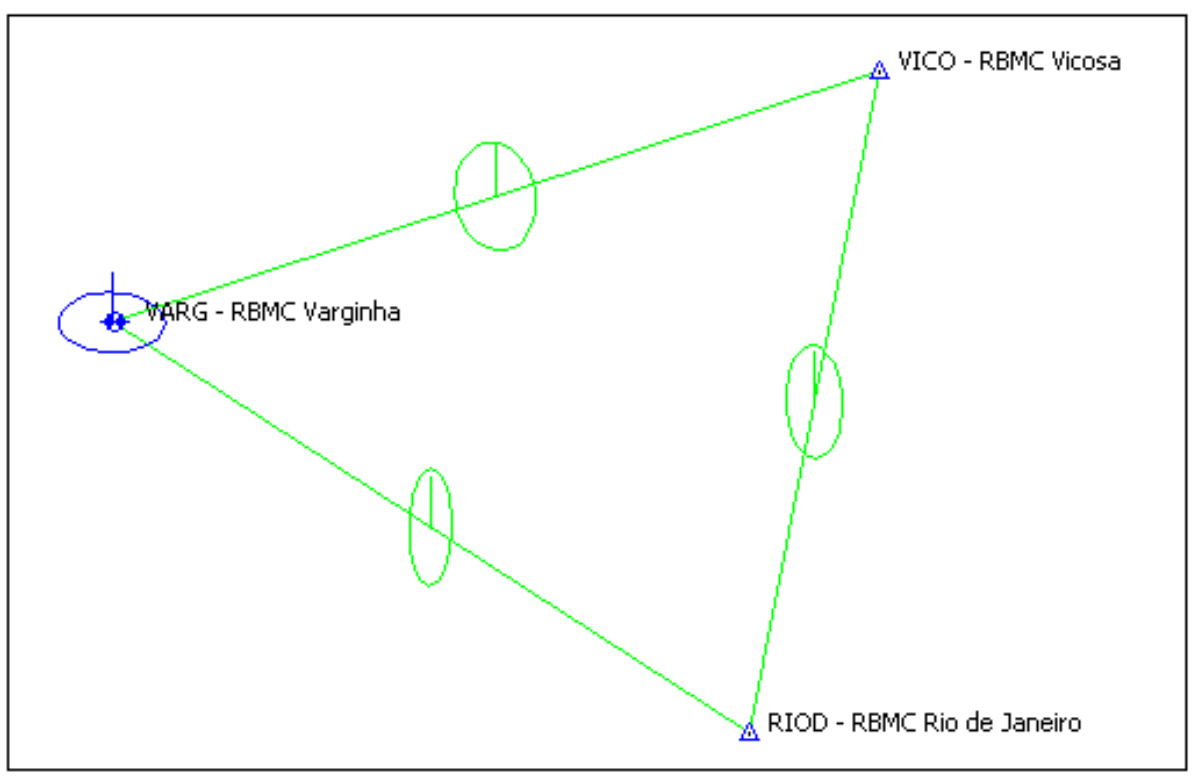

Coordenadas Ajustadas de VARG:

E (UTM): $454968.9521 \mathrm{~m}$

N (UTM): $7617727.3197 \mathrm{~m}$

- $\underline{289 / 2006}$

A posteriori UWE: 0.9482362 , Bounds: ( $0.6770032,1.241639)$

TABELA B16: Resultado do Processamento

\begin{tabular}{|c|c|c|c|c|c|c|c|c|}
\hline \multicolumn{9}{|c|}{ GPS Obs Report } \\
\hline Name & $\begin{array}{l}\text { Horizontal } \\
\text { Precision } \\
(\mathbf{m})\end{array}$ & $\begin{array}{l}\text { Vertical } \\
\text { Precision } \\
(\mathbf{m})\end{array}$ & $\begin{array}{l}\text { Distance } \\
\text { (m) }\end{array}$ & $\begin{array}{c}\text { Solution } \\
\text { Type }\end{array}$ & $\begin{array}{c}\text { GPS } \\
\text { Satellites }\end{array}$ & PDOP & Status & RMS \\
\hline $\begin{array}{l}\text { RIOD - RBMC Rio de } \\
\text { Janeiro-VARG - } \\
\text { RBMC Varginha }\end{array}$ & 0.036 & $\mid 0.071$ & 261011.677 & $\begin{array}{l}\text { Fixed,Wide } \\
\text { Lane }\end{array}$ & 27 & 2.465 & Adjusted & 0.073 \\
\hline $\begin{array}{l}\text { RIOD - RBMC Rio de } \\
\text { Janeiro-VICO - } \\
\text { RBMC Vicosa }\end{array}$ & 0.031 & 0.069 & 232120.616 & $\begin{array}{l}\text { Fixed,Wide } \\
\text { Lane }\end{array}$ & 27 & 2.971 & Adjusted & 0.074 \\
\hline $\begin{array}{l}\text { VARG - RBMC } \\
\text { Varginha-VICO - } \\
\text { RBMC Vicosa }\end{array}$ & 0.035 & 0.077 & 280097.768 & $\begin{array}{l}\text { Fixed,Wide } \\
\text { Lane }\end{array}$ & 27 & 2.867 & Adjusted & 0.081 \\
\hline
\end{tabular}


Figura B16: Elipses de Erro

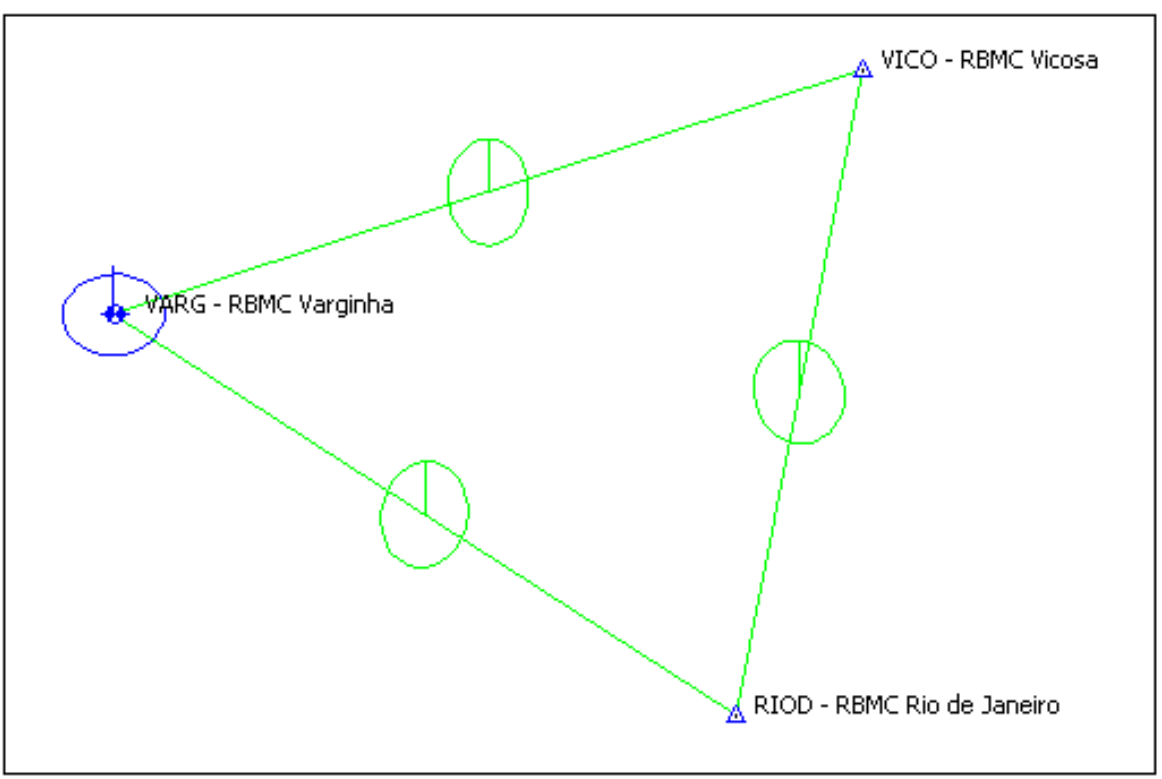

Coordenadas Ajustadas de VARG:

E (UTM): $454968.9456 \mathrm{~m}$

N (UTM): $7617727.2987 \mathrm{~m}$

\section{B.1.2 Ano de 2007}

\section{B.1.2.1 Verão (Dias Julianos 011 a 014)}

- $\underline{011 / 2007}$

A posteriori UWE: 0.7882987 , Bounds: ( $0.6770032,1.241639)$

TABELA B17: Resultado do Processamento

\begin{tabular}{|c|c|c|c|c|c|c|c|c|}
\hline \multicolumn{9}{|c|}{ GPS Obs Report } \\
\hline Name & $\mid \begin{array}{c}\text { Horizontal } \\
\text { Precision (m) }\end{array}$ & $\begin{array}{c}\text { Vertical } \\
\text { Precision } \\
(\mathbf{m}) \\
\end{array}$ & $\begin{array}{l}\text { Distance } \\
\text { (m) }\end{array}$ & $\begin{array}{c}\text { Solution } \\
\text { Type }\end{array}$ & $\begin{array}{c}\text { GPS } \\
\text { Satellites }\end{array}$ & PDOP & Status & RMS \\
\hline $\begin{array}{l}\text { RIOD - RBMC Rio de } \\
\text { Janeiro-VARG - } \\
\text { RBMC Varginha } \\
\end{array}$ & 0.042 & 0.065 & 261011.671 & $\begin{array}{l}\text { Fixed,Wide } \\
\text { Lane }\end{array}$ & 28 & 2.739 & Adjusted & 0.078 \\
\hline $\begin{array}{l}\text { RIOD - RBMC Rio de } \\
\text { Janeiro-VICO - RBMC } \\
\text { Vicosa }\end{array}$ & 0.031 & 0.062 & 232120.629 & $\begin{array}{l}\text { Fixed,Wide } \\
\text { Lane }\end{array}$ & 28 & 3.016 & Adjusted & 0.072 \\
\hline $\begin{array}{l}\text { VARG - RBMC } \\
\text { Varginha-VICO - } \\
\text { RBMC Vicosa } \\
\end{array}$ & 0.035 & 0.067 & 280097.768 & $\begin{array}{l}\text { Fixed,Wide } \\
\text { Lane }\end{array}$ & 27 & 2.461 & Adjusted & 0.081 \\
\hline
\end{tabular}


Figura B17: Elipses de Erro

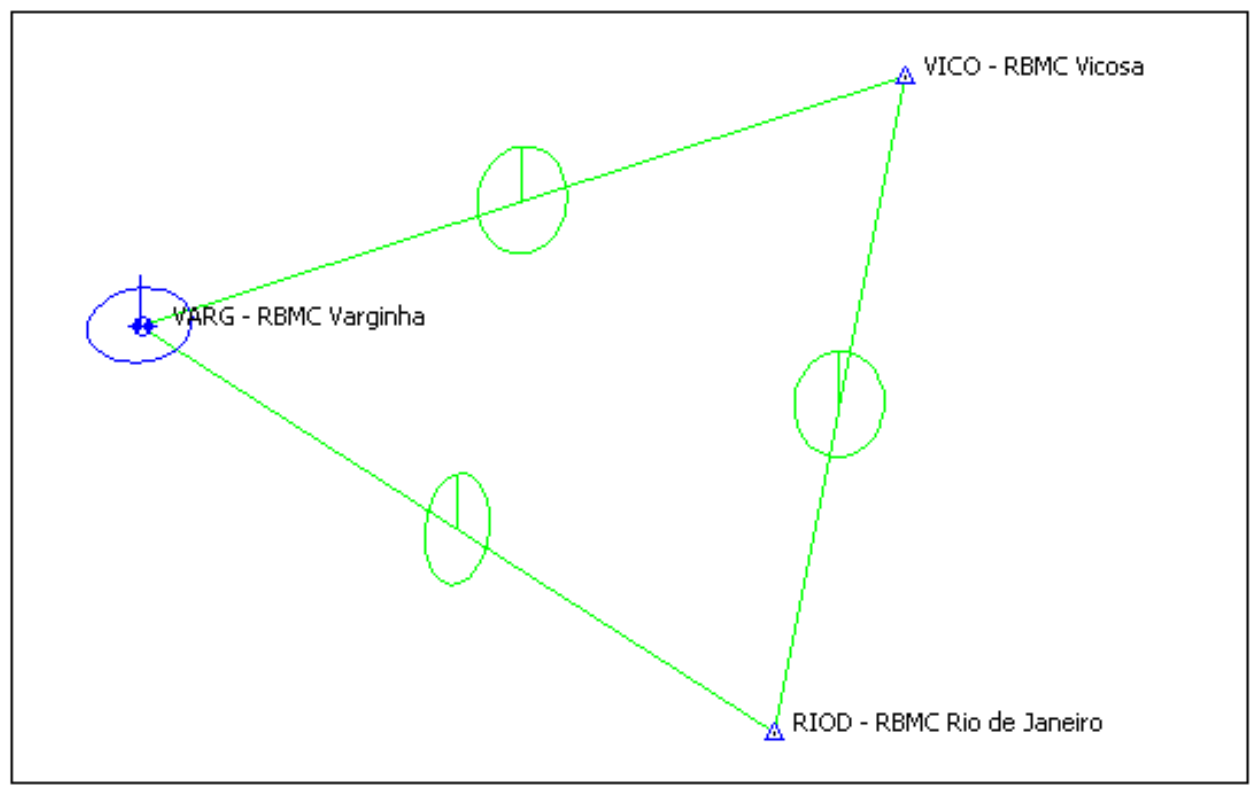

Coordenadas Ajustadas de VARG:

E (UTM): $454968.9534 \mathrm{~m}$

N (UTM): $7617727.3112 \mathrm{~m}$

- $\underline{012 / 2007}$

A posteriori UWE: 1.106714 , Bounds: ( $0.6770032,1.241639$ )

TABELA B18: Resultado do Processamento

\begin{tabular}{|c|c|c|c|c|c|c|c|c|}
\hline \multicolumn{9}{|c|}{ GPS Obs Report } \\
\hline Name & $\begin{array}{c}\text { Horizontal } \\
\text { Precision (m) }\end{array}$ & $\begin{array}{l}\text { Vertical } \\
\text { Precision } \\
(\mathbf{m}) \\
\end{array}$ & $\begin{array}{l}\text { Distance } \\
\text { (m) }\end{array}$ & $\begin{array}{c}\text { Solution } \\
\text { Type }\end{array}$ & $\begin{array}{c}\text { GPS } \\
\text { Satellites }\end{array}$ & PDOP & Status & RMS \\
\hline $\begin{array}{l}\text { RIOD - RBMC Rio de } \\
\text { Janeiro-VARG - } \\
\text { RBMC Varginha }\end{array}$ & 0.042 & 0.065 & 261011.693 & $\begin{array}{l}\text { Fixed,Wide } \\
\text { Lane }\end{array}$ & 29 & 3.004 & Adjusted & 0.075 \\
\hline $\begin{array}{l}\text { RIOD - RBMC Rio de } \\
\text { Janeiro-VICO - RBMC } \\
\text { Vicosa }\end{array}$ & 0.036 & 0.064 & 232120.634 & $\begin{array}{l}\text { Fixed,Wide } \\
\text { Lane }\end{array}$ & 29 & 3.032 & Adjusted & 0.072 \\
\hline $\begin{array}{l}\text { VARG - RBMC } \\
\text { Varginha-VICO - } \\
\text { RBMC Vicosa }\end{array}$ & 0.043 & 0.070 & 280097.772 & $\begin{array}{l}\text { Fixed,Wide } \\
\text { Lane }\end{array}$ & 29 & 2.952 & Adjusted & 0.078 \\
\hline
\end{tabular}


Figura B18: Elipses de Erro

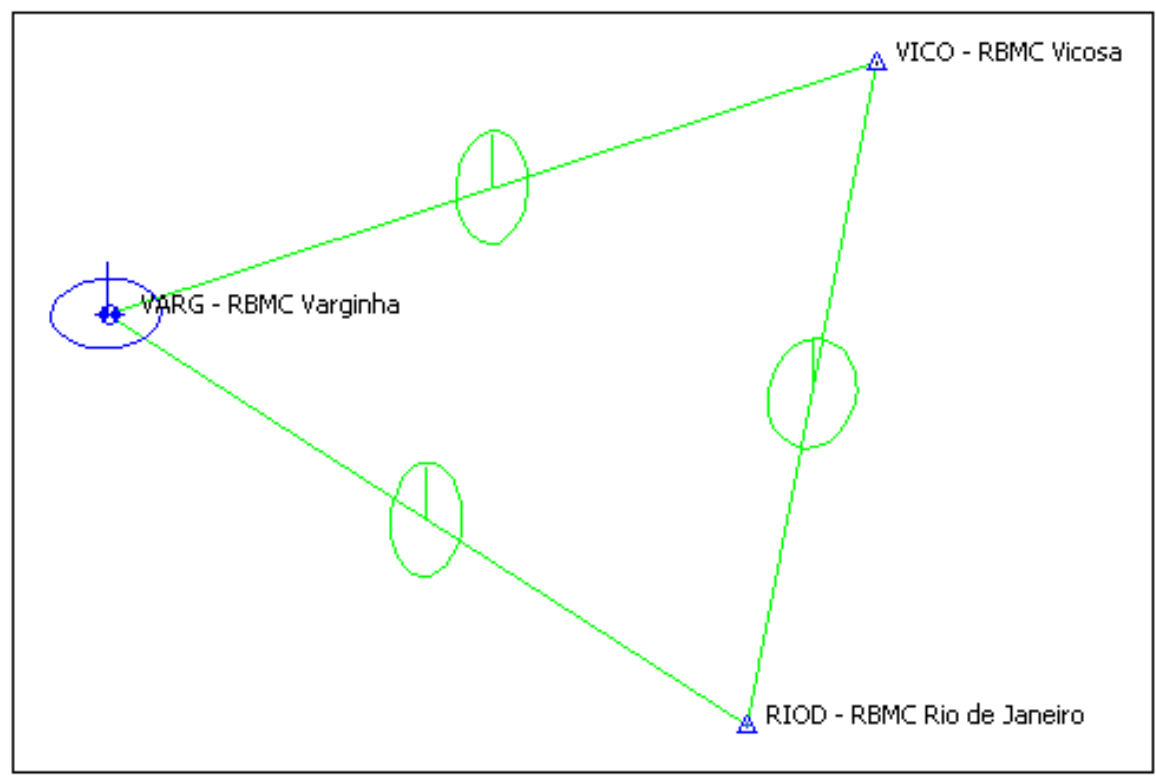

Coordenadas Ajustadas de VARG:

E (UTM): $454968.9321 \mathrm{~m}$

N (UTM): $7617727.2983 \mathrm{~m}$

- $\underline{013 / 2007}$

A posteriori UWE: 0.8459114 , Bounds: ( $0.6770032,1.241639)$

TABELA B19: Resultado do Processamento

\begin{tabular}{|c|c|c|c|c|c|c|c|c|}
\hline \multicolumn{9}{|c|}{ GPS Obs Report } \\
\hline Name & $\begin{array}{c}\text { Horizontal } \\
\text { Precision (m) }\end{array}$ & $\begin{array}{c}\text { Vertical } \\
\text { Precision } \\
\text { (m) }\end{array}$ & $\begin{array}{l}\text { Distance } \\
\text { (m) }\end{array}$ & $\begin{array}{c}\text { Solution } \\
\text { Type }\end{array}$ & $\begin{array}{c}\text { GPS } \\
\text { Satellites }\end{array}$ & PDOP & Status & RMS \\
\hline $\begin{array}{l}\text { RIOD - RBMC Rio de } \\
\text { Janeiro-VARG - } \\
\text { RBMC Varginha } \\
\end{array}$ & 0.050 & 0.056 & 261011.720 & $\begin{array}{l}\text { Fixed,Wide } \\
\text { Lane }\end{array}$ & 29 & 2.391 & Adjusted & 0.077 \\
\hline $\begin{array}{l}\text { RIOD - RBMC Rio de } \\
\text { Janeiro-VICO - RBMC } \\
\text { Vicosa }\end{array}$ & 0.042 & 0.060 & 232120.656 & $\begin{array}{l}\text { Fixed,Wide } \\
\text { Lane }\end{array}$ & 29 & 2.971 & Adjusted & 0.073 \\
\hline $\begin{array}{l}\text { VARG - RBMC } \\
\text { Varginha-VICO - } \\
\text { RBMC Vicosa }\end{array}$ & 0.040 & 0.068 & 280097.779 & $\begin{array}{l}\text { Fixed,Wide } \\
\text { Lane }\end{array}$ & 29 & 2.415 & Adjusted & 0.080 \\
\hline
\end{tabular}

Figura B19: Elipses de Erro 


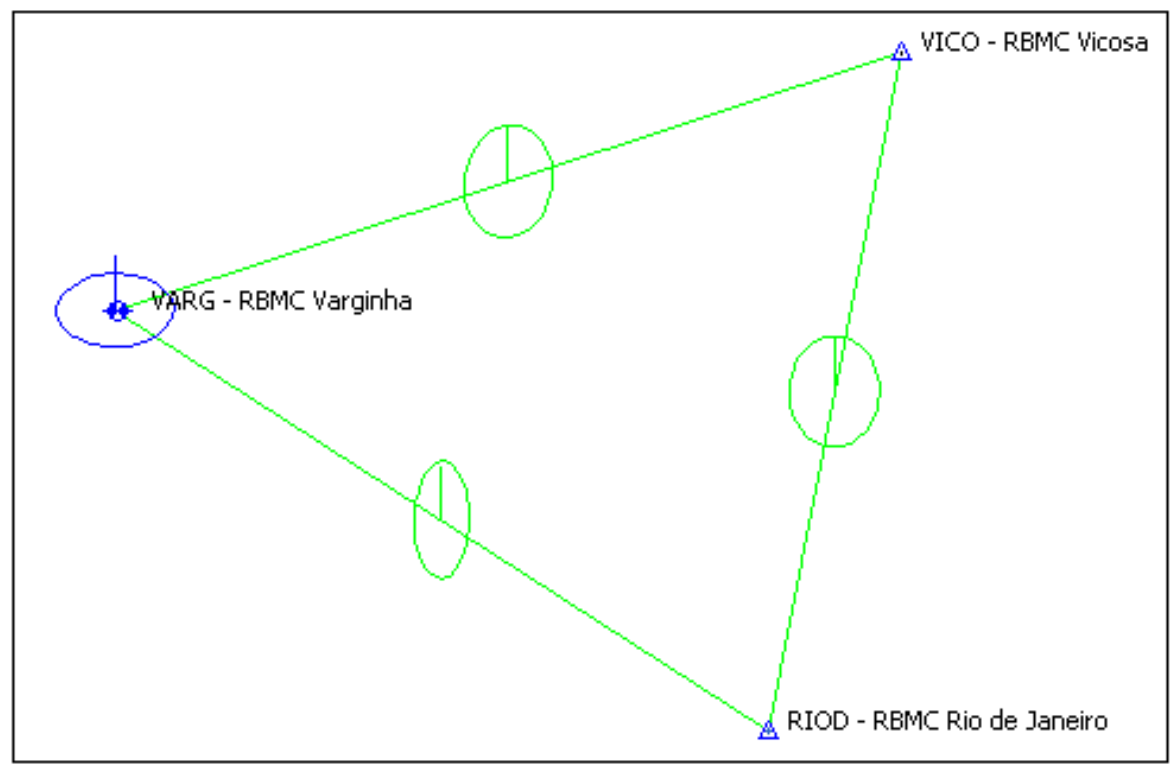

Coordenadas Ajustadas de VARG:

E (UTM): $454968.9345 \mathrm{~m}$

N (UTM): $7617727.3004 \mathrm{~m}$

- $\underline{014 / 2007}$

A posteriori UWE: 1.146192 , Bounds: ( $0.6770032,1.241639$ )

TABELA B20: Resultado do Processamento

\begin{tabular}{|c|c|c|c|c|c|c|c|c|}
\hline \multicolumn{9}{|c|}{ GPS Obs Report } \\
\hline Name & $\begin{array}{c}\text { Horizontal } \\
\text { Precision } \\
(\mathbf{m}) \\
\end{array}$ & $\begin{array}{l}\text { Vertical } \\
\text { Precision } \\
(\mathbf{m}) \\
\end{array}$ & $\begin{array}{l}\text { Distance } \\
\text { (m) }\end{array}$ & $\begin{array}{l}\text { Solution } \\
\text { Type }\end{array}$ & $\begin{array}{c}\text { GPS } \\
\text { Satellites }\end{array}$ & PDOP & Status & RMS \\
\hline $\begin{array}{l}\text { RIOD - RBMC Rio } \\
\text { de Janeiro-VARG - } \\
\text { RBMC Varginha }\end{array}$ & 0.046 & 0.067 & 261011.711 & $\begin{array}{l}\text { Fixed, Wide } \\
\text { Lane }\end{array}$ & 29 & 3.002 & Adjusted & 0.076 \\
\hline $\begin{array}{l}\text { RIOD - RBMC Rio } \\
\text { de Janeiro-VICO - } \\
\text { RBMC Vicosa }\end{array}$ & 0.036 & 0.061 & 232120.652 & $\begin{array}{l}\text { Fixed, Wide } \\
\text { Lane }\end{array}$ & 30 & 3.019 & Adjusted & 0.072 \\
\hline $\begin{array}{l}\text { VARG - RBMC } \\
\text { Varginha-VICO - } \\
\text { RBMC Vicosa }\end{array}$ & 0.045 & 0.065 & 280097.772 & $\begin{array}{l}\text { Fixed,Wide } \\
\text { Lane }\end{array}$ & 28 & 2.710 & Adjusted & 0.080 \\
\hline
\end{tabular}

Figura B20: Elipses de Erro 


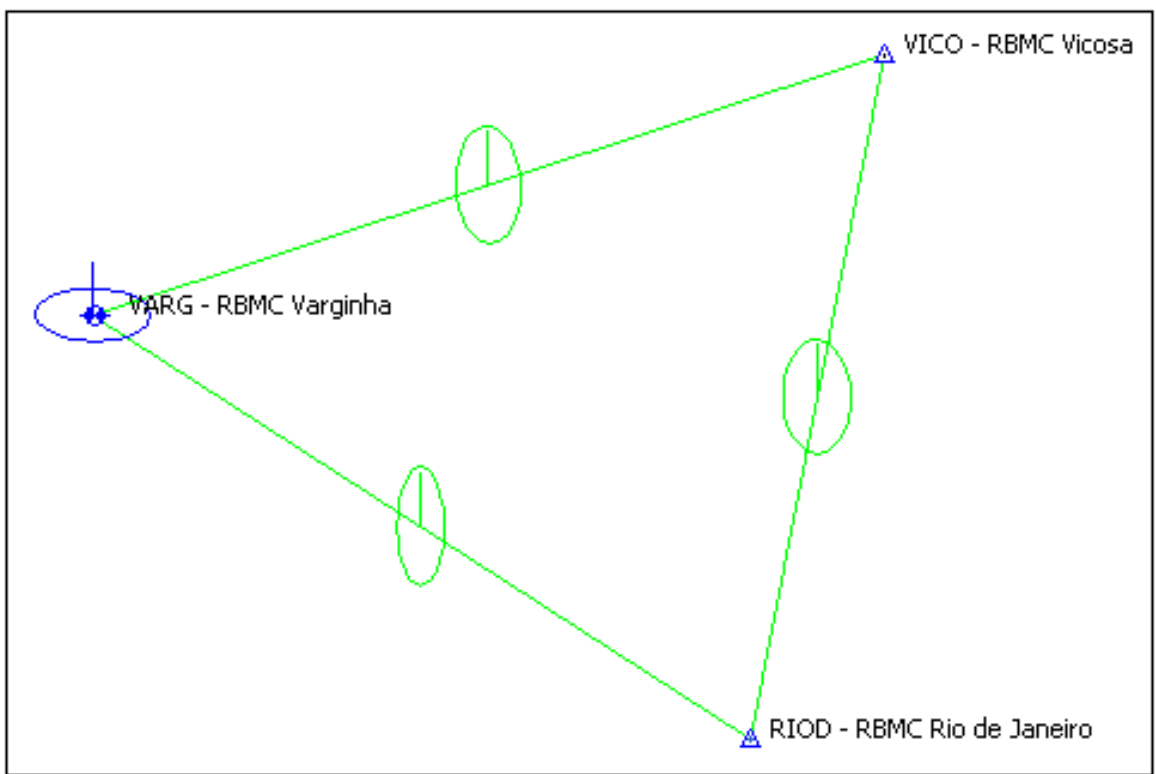

Coordenadas Ajustadas de VARG:

E (UTM): $454968.9329 \mathrm{~m}$

N (UTM): $7617727.3115 \mathrm{~m}$

\section{B.1.2.2 Outono (Dias Julianos 101 a 104)}

- $101 / 2007$

A posteriori UWE: 0.9266238 , Bounds: $(0.6770032,1.241639)$

TABELA B21: Resultado do Processamento

\begin{tabular}{|c|c|c|c|c|c|c|c|c|}
\hline \multicolumn{9}{|c|}{ GPS Obs Report } \\
\hline Name & $\begin{array}{c}\text { Horizontal } \\
\text { Precision }(\mathbf{m})\end{array}$ & $\begin{array}{l}\text { Vertical } \\
\text { Precision } \\
(\mathbf{m}) \\
\end{array}$ & $\begin{array}{l}\text { Distance } \\
\quad(\mathbf{m})\end{array}$ & $\begin{array}{l}\text { Solution } \\
\text { Type }\end{array}$ & $\begin{array}{c}\text { GPS } \\
\text { Satellites }\end{array}$ & PDOP & Status & RMS \\
\hline $\begin{array}{l}\text { RIOD - RBMC Rio de } \\
\text { Janeiro-VARG - } \\
\text { RBMC Varginha }\end{array}$ & 0.034 & 0.069 & 261011.686 & $\begin{array}{l}\text { Fixed,Wide } \\
\text { Lane }\end{array}$ & 30 & 2.764 & Adjusted & 0.077 \\
\hline $\begin{array}{l}\text { RIOD - RBMC Rio de } \\
\text { Janeiro-VICO - Vicosa }\end{array}$ & 0.029 & 0.067 & 232120.627 & $\begin{array}{l}\text { Fixed,Wide } \\
\text { Lane }\end{array}$ & 30 & 2.722 & Adjusted & 0.073 \\
\hline $\begin{array}{l}\text { VARG - RBMC } \\
\text { Varginha-VICO - } \\
\text { Vicosa }\end{array}$ & 0.034 & 0.072 & 280097.773 & $\begin{array}{l}\text { Fixed,Wide } \\
\text { Lane }\end{array}$ & 30 & 2.805 & Adjusted & 0.080 \\
\hline
\end{tabular}

Figura B21: Elipses de Erro 


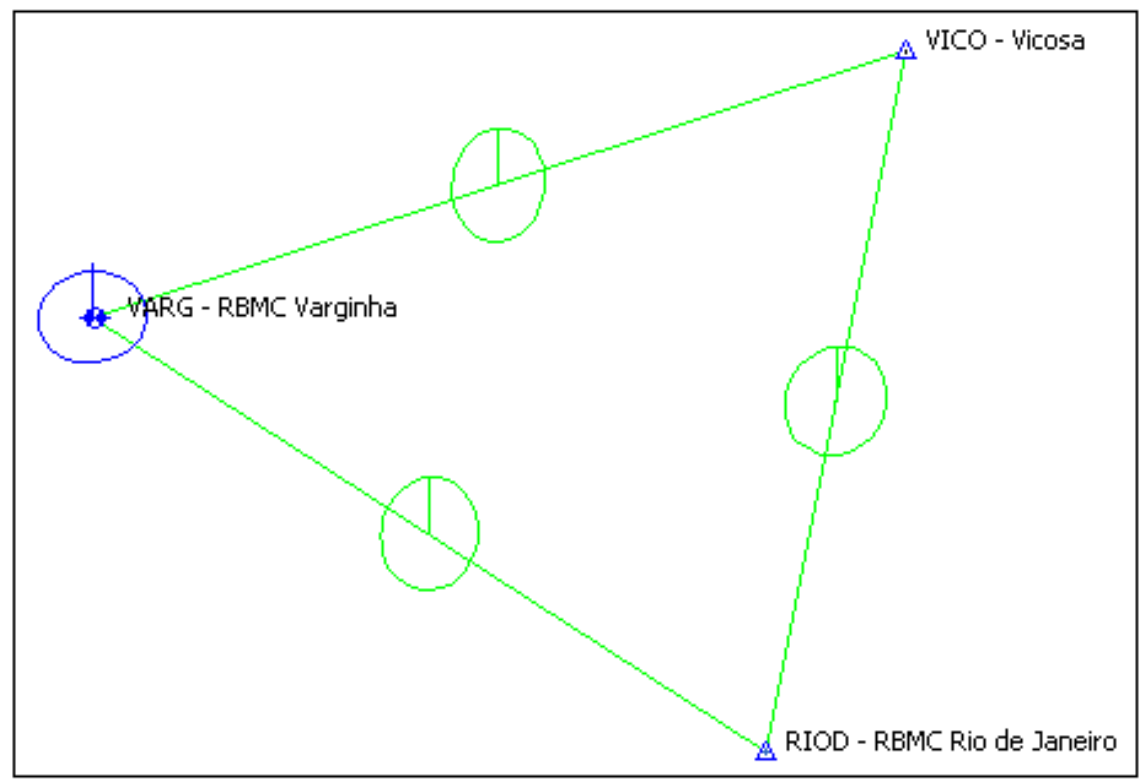

Coordenadas Ajustadas de VARG:

E (UTM): $454968.9495 \mathrm{~m}$

N (UTM): $7617727.3012 \mathrm{~m}$

- $102 / 2007$

A posteriori UWE: 0.7124591 , Bounds: ( $0.6770032,1.241639)$

TABELA B22: Resultado do Processamento

\begin{tabular}{|c|c|c|c|c|c|c|c|c|}
\hline \multicolumn{9}{|c|}{ GPS Obs Report } \\
\hline Name & $\begin{array}{c}\text { Horizontal } \\
\text { Precision (m) }\end{array}$ & $\begin{array}{l}\text { Vertical } \\
\text { Precision } \\
\quad(\mathbf{m})\end{array}$ & $\begin{array}{l}\text { Distance } \\
\text { (m) }\end{array}$ & $\begin{array}{l}\text { Solution } \\
\text { Type }\end{array}$ & $\begin{array}{c}\text { GPS } \\
\text { Satellites }\end{array}$ & PDOP & Status & RMS \\
\hline $\begin{array}{l}\text { RIOD - RBMC Rio de } \\
\text { Janeiro-VARG - } \\
\text { RBMC Varginha }\end{array}$ & 0.036 & 0.064 & 261011.672 & $\begin{array}{l}\text { Fixed,Wide } \\
\text { Lane }\end{array}$ & 30 & 2.752 & Adjusted & 0.077 \\
\hline $\begin{array}{l}\text { RIOD - RBMC Rio de } \\
\text { Janeiro-VICO - Vicosa }\end{array}$ & 0.030 & 0.062 & 232120.614 & $\begin{array}{l}\text { Fixed,Wide } \\
\text { Lane }\end{array}$ & 30 & 2.890 & Adjusted & 0.073 \\
\hline $\begin{array}{l}\text { VARG - RBMC } \\
\text { Varginha-VICO - } \\
\text { Vicosa }\end{array}$ & 0.031 & 0.075 & 280097.778 & $\begin{array}{l}\text { Fixed,Wide } \\
\text { Lane }\end{array}$ & 29 & 2.417 & Adjusted & 0.080 \\
\hline
\end{tabular}


Figura B22: Elipses de Erro

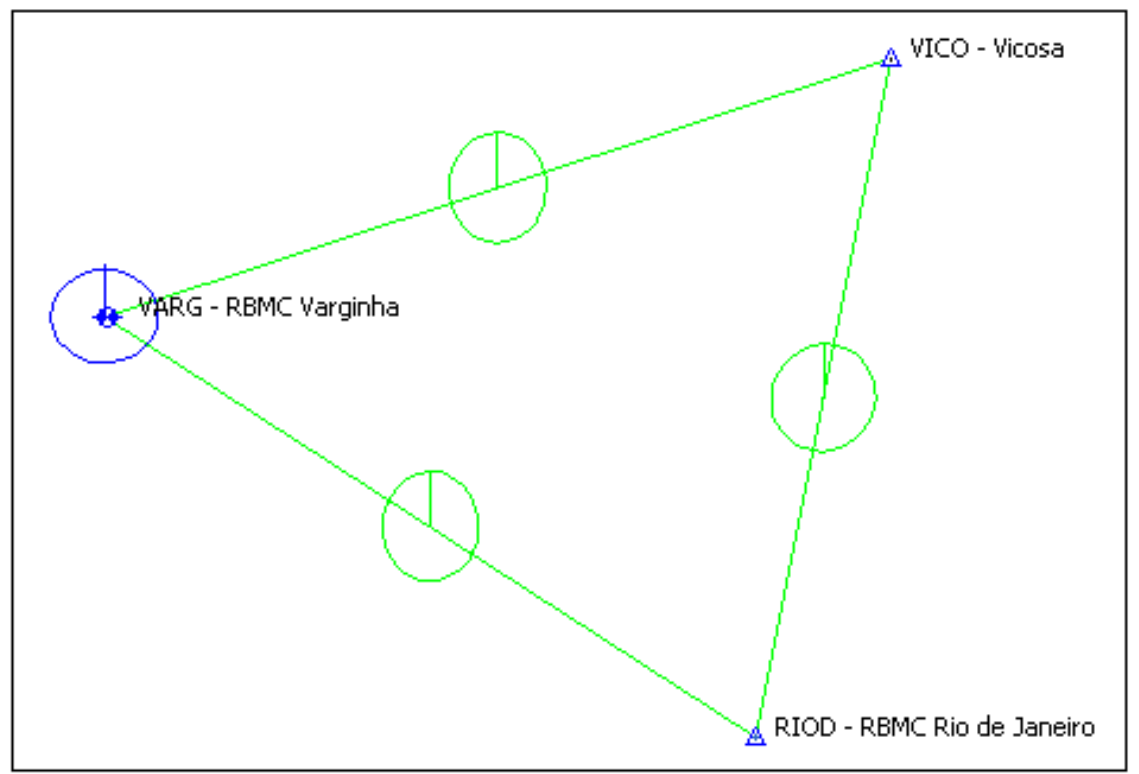

Coordenadas Ajustadas de VARG:

E (UTM): $454968.9447 \mathrm{~m}$

N (UTM): $7617727.2937 \mathrm{~m}$

- $103 / 2007$

A posteriori UWE: 0.8925105 , Bounds: $(0.6770032,1.241639)$

TABELA B23: Resultado do Processamento

\begin{tabular}{|c|c|c|c|c|c|c|c|c|}
\hline \multicolumn{9}{|c|}{ GPS Obs Report } \\
\hline Name & $\mid \begin{array}{c}\text { Horizontal } \\
\text { Precision }(\mathrm{m})\end{array}$ & $\begin{array}{l}\text { Vertical } \\
\text { Precision } \\
(\mathbf{m}) \\
\end{array}$ & $\begin{array}{l}\text { Distance } \\
\quad(\mathbf{m})\end{array}$ & $\begin{array}{l}\text { Solution } \\
\text { Type }\end{array}$ & $\begin{array}{c}\text { GPS } \\
\text { Satellites }\end{array}$ & PDOP & Status & RMS \\
\hline $\begin{array}{l}\text { RIOD - RBMC Rio de } \\
\text { Janeiro-VARG - } \\
\text { RBMC Varginha }\end{array}$ & 0.031 & 0.067 & 261011.682 & $\begin{array}{l}\text { Fixed,Wide } \\
\text { Lane }\end{array}$ & 29 & 2.891 & Adjusted & 0.077 \\
\hline $\begin{array}{l}\text { RIOD - RBMC Rio de } \\
\text { Janeiro-VICO - Vicosa }\end{array}$ & 0.031 & 0.063 & 232120.613 & $\begin{array}{l}\text { Fixed,Wide } \\
\text { Lane }\end{array}$ & 30 & 2.720 & Adjusted & 0.073 \\
\hline $\begin{array}{l}\text { VARG - RBMC } \\
\text { Varginha-VICO - } \\
\text { Vicosa }\end{array}$ & 0.036 & 0.070 & 280097.772 & $\begin{array}{l}\text { Fixed,Wide } \\
\text { Lane }\end{array}$ & 29 & 2.702 & Adjusted & 0.080 \\
\hline
\end{tabular}


Figura B23: Elipses de Erro

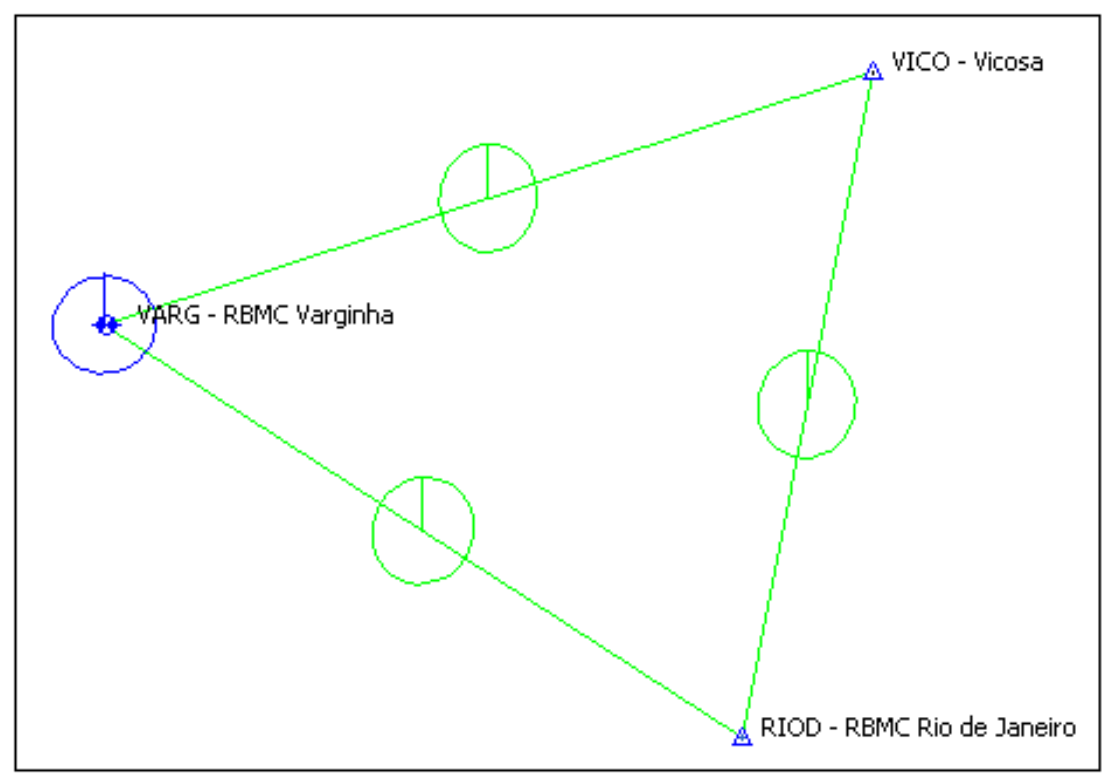

Coordenadas Ajustadas de VARG:

E (UTM): $454968.9349 \mathrm{~m}$

N (UTM): $7617727.2629 \mathrm{~m}$

- $\underline{104 / 2007}$

A posteriori UWE: 0.7258934 , Bounds: ( $0.6770032,1.241639$ )

TABELA B24: Resultado do Processamento

\begin{tabular}{|c|c|c|c|c|c|c|c|c|}
\hline \multicolumn{9}{|c|}{ GPS Obs Report } \\
\hline Name & $\begin{array}{l}\text { Horizontal } \\
\text { Precision (m) }\end{array}$ & $\begin{array}{c}\text { Vertical } \\
\text { Precision } \\
(\mathbf{m})\end{array}$ & $\begin{array}{l}\text { Distance } \\
\quad(\mathbf{m})\end{array}$ & $\begin{array}{l}\text { Solution } \\
\text { Type }\end{array}$ & \begin{tabular}{|c} 
GPS \\
Satellites
\end{tabular} & PDOP & Status & RMS \\
\hline $\begin{array}{l}\text { RIOD - RBMC Rio de } \\
\text { Janeiro-VARG - } \\
\text { RBMC Varginha } \\
\end{array}$ & 0.037 & 0.067 & 261011.690 & \begin{tabular}{|l} 
Fixed,Wide \\
Lane
\end{tabular} & 30 & 2.721 & Adjusted & 0.077 \\
\hline $\begin{array}{l}\text { RIOD - RBMC Rio de } \\
\text { Janeiro-VICO - Vicosa }\end{array}$ & 0.033 & 0.065 & 232120.627 & \begin{tabular}{|l} 
Fixed,Wide \\
Lane
\end{tabular} & 30 & 2.727 & Adjusted & 0.073 \\
\hline $\begin{array}{l}\text { VARG - RBMC } \\
\text { Varginha-VICO - } \\
\text { Vicosa }\end{array}$ & 0.036 & 0.071 & 280097.777 & $\begin{array}{l}\text { Fixed,Wide } \\
\text { Lane }\end{array}$ & $\mid 30$ & 2.768 & Adjusted & 0.080 \\
\hline
\end{tabular}


Figura B24: Elipses de Erro

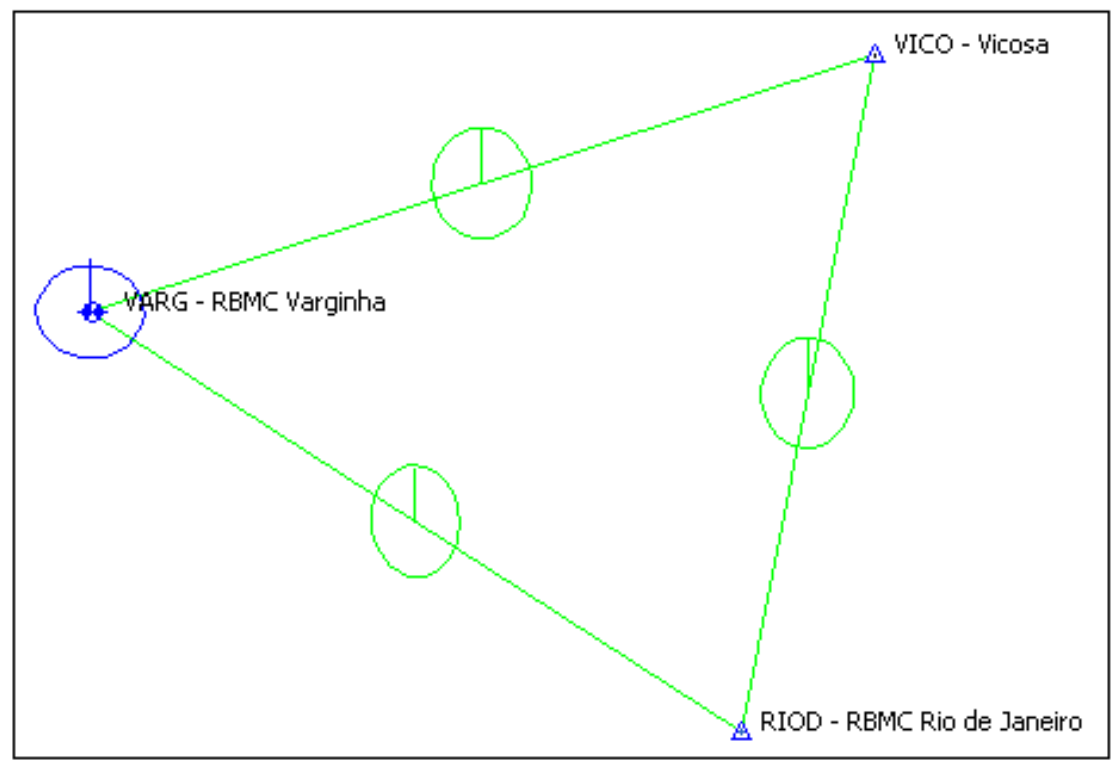

Coordenadas Ajustadas de VARG:

E (UTM): $454968.9426 \mathrm{~m}$

N (UTM): $7617727.3027 \mathrm{~m}$

\section{B.1.2.3 Inverno (Dias Julianos 193 a 196)}

- $193 / 2007$

A posteriori UWE: 1.2017892 , Bounds: ( $0.6770032,1.241639)$

TABELA B25: Resultado do Processamento

\begin{tabular}{|c|c|c|c|c|c|c|c|c|}
\hline \multicolumn{9}{|c|}{ GPS Obs Report } \\
\hline Name & $\mid \begin{array}{c}\text { Horizontal } \\
\text { Precision (m) }\end{array}$ & $\begin{array}{l}\text { Vertical } \\
\text { Precision } \\
\text { (m) }\end{array}$ & $\begin{array}{l}\text { Distance } \\
\text { (m) }\end{array}$ & $\begin{array}{c}\text { Solution } \\
\text { Type }\end{array}$ & $\begin{array}{c}\text { GPS } \\
\text { Satellites }\end{array}$ & PDOP & Status & RMS \\
\hline $\begin{array}{l}\text { RIOD - RBMC Rio de } \\
\text { Janeiro-VARG - } \\
\text { RBMC Varginha }\end{array}$ & 0.030 & 0.064 & 261011.679 & $\begin{array}{l}\text { Fixed,Wide } \\
\text { Lane }\end{array}$ & 29 & 3.003 & Adjusted & 0.077 \\
\hline $\begin{array}{l}\text { RIOD - RBMC Rio de } \\
\text { Janeiro-VICO - RBMC } \\
\text { Vicosa }\end{array}$ & $\mid 0.028$ & 0.066 & 232120.621 & $\begin{array}{l}\text { Fixed,Wide } \\
\text { Lane }\end{array}$ & 29 & 2.727 & Adjusted & 0.073 \\
\hline $\begin{array}{l}\text { VARG - RBMC } \\
\text { Varginha-VICO - } \\
\text { RBMC Vicosa }\end{array}$ & 0.037 & 0.073 & 280097.772 & $\begin{array}{l}\text { Fixed,Wide } \\
\text { Lane }\end{array}$ & 29 & 2.992 & Adjusted & 0.080 \\
\hline
\end{tabular}


Figura B25: Elipses de Erro

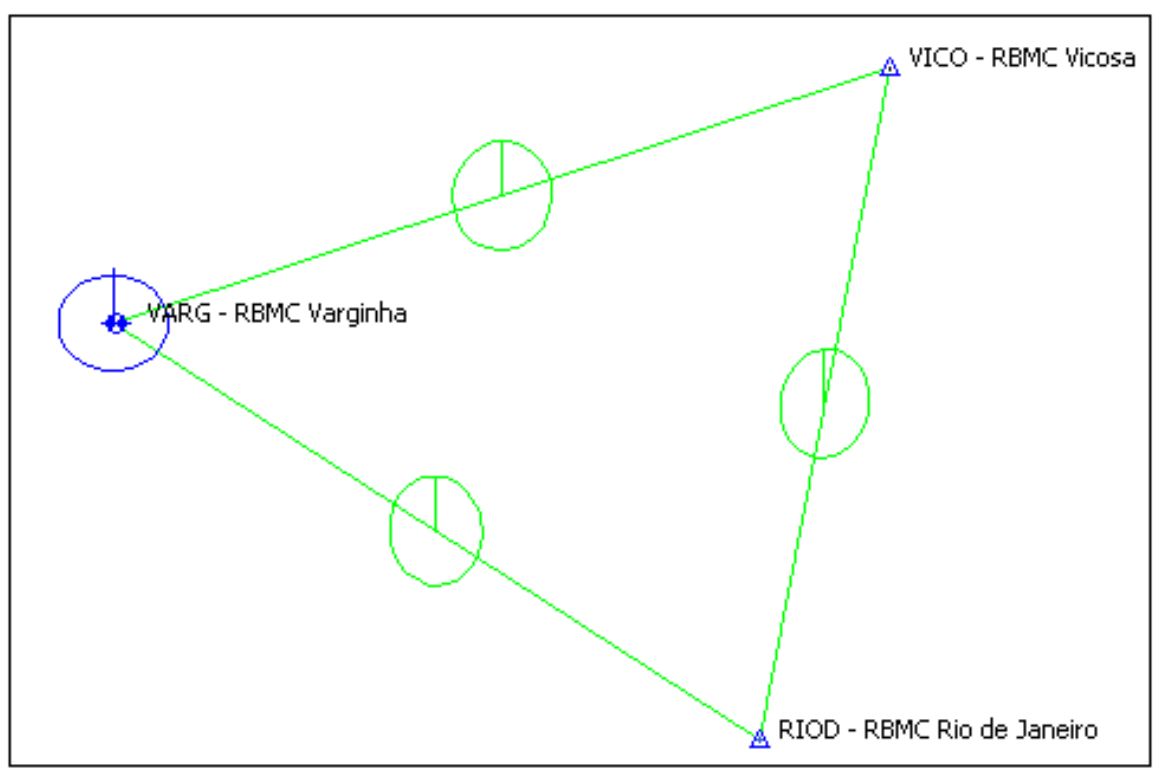

Coordenadas Ajustadas de VARG:

E (UTM): $454968.9671 \mathrm{~m}$

N (UTM): $7617727.3115 \mathrm{~m}$

- $194 / 2007$

A posteriori UWE: 0.8575785 , Bounds: ( $0.6770032,1.241639)$

TABELA B26: Resultado do Processamento

\begin{tabular}{|c|c|c|c|c|c|c|c|c|}
\hline \multicolumn{9}{|c|}{ GPS Obs Report } \\
\hline Name & $\begin{array}{c}\text { Horizontal } \\
\text { Precision (m) }\end{array}$ & $\begin{array}{c}\text { Vertical } \\
\text { Precision } \\
\text { (m) } \\
\end{array}$ & $\begin{array}{l}\text { Distance } \\
\text { (m) }\end{array}$ & $\begin{array}{l}\text { Solution } \\
\text { Type }\end{array}$ & $\begin{array}{c}\text { GPS } \\
\text { Satellites }\end{array}$ & PDOP & Status & RMS \\
\hline $\begin{array}{l}\text { RIOD - RBMC Rio de } \\
\text { Janeiro-VARG - } \\
\text { RBMC Varginha }\end{array}$ & 0.032 & 0.070 & 261011.688 & $\begin{array}{l}\text { Fixed,Wide } \\
\text { Lane }\end{array}$ & $\mid 30$ & 2.999 & Adjusted & 0.077 \\
\hline $\begin{array}{l}\text { RIOD - RBMC Rio de } \\
\text { Janeiro-VICO - RBMC } \\
\text { Vicosa }\end{array}$ & 0.032 & 0.065 & 232120.610 & $\begin{array}{l}\text { Fixed,Wide } \\
\text { Lane }\end{array}$ & 30 & 2.946 & Adjusted & 0.073 \\
\hline $\begin{array}{l}\text { VARG - RBMC } \\
\text { Varginha-VICO - } \\
\text { RBMC Vicosa }\end{array}$ & 0.034 & 0.072 & 280097.765 & $\begin{array}{l}\text { Fixed,Wide } \\
\text { Lane }\end{array}$ & 30 & 3.016 & Adjusted & 0.079 \\
\hline
\end{tabular}


Figura B26: Elipses de Erro

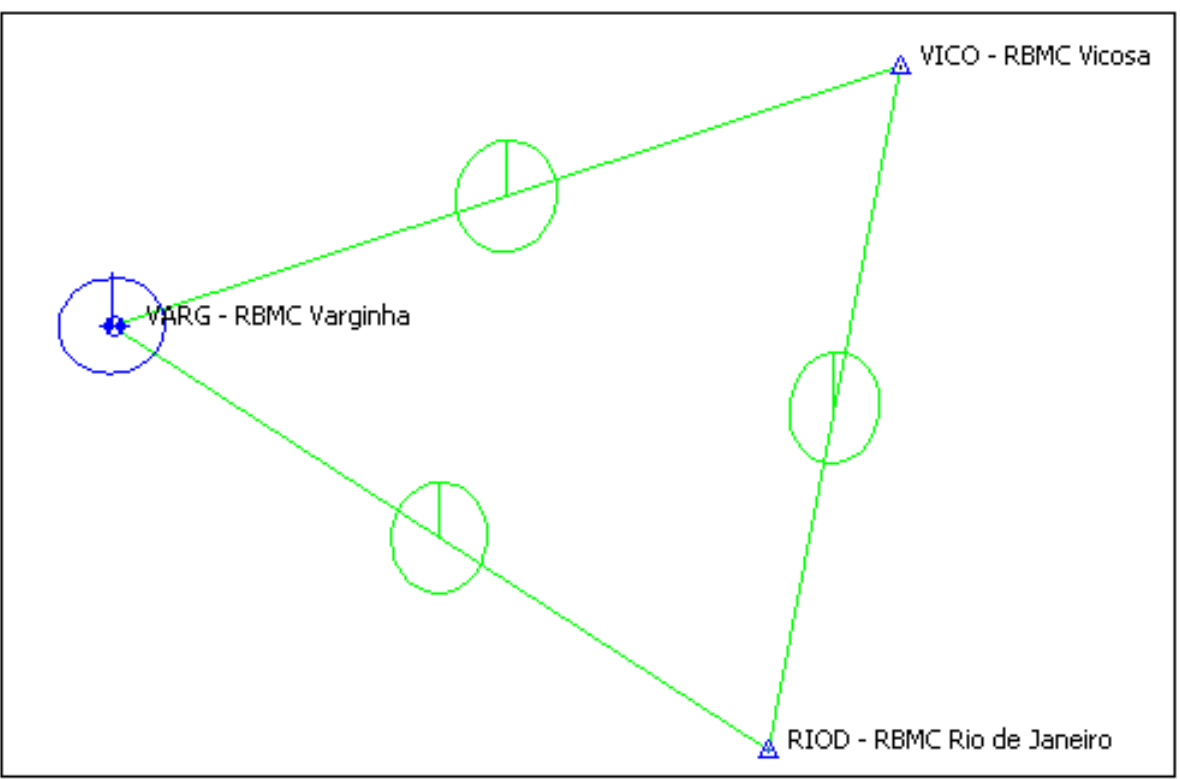

Coordenadas Ajustadas de VARG:

E (UTM): $454968.9521 \mathrm{~m}$

N (UTM): $7617727.3003 \mathrm{~m}$

- $195 / 2007$

A posteriori UWE: 0.8600458 , Bounds: $(0.6770032,1.241639)$

TABELA B27: Resultado do Processamento

\begin{tabular}{|c|c|c|c|c|c|c|c|c|}
\hline \multicolumn{9}{|c|}{ GPS Obs Report } \\
\hline Name & $\begin{array}{c}\text { Horizontal } \\
\text { Precision (m) }\end{array}$ & $\begin{array}{l}\text { Vertical } \\
\text { Precision } \\
(\mathbf{m}) \\
\end{array}$ & $\begin{array}{l}\text { Distance } \\
\text { (m) }\end{array}$ & $\begin{array}{l}\text { Solution } \\
\text { Type }\end{array}$ & $\begin{array}{c}\text { GPS } \\
\text { Satellites }\end{array}$ & PDOP & Status & RMS \\
\hline $\begin{array}{l}\text { RIOD - RBMC Rio de } \\
\text { Janeiro-VARG - } \\
\text { RBMC Varginha }\end{array}$ & 0.033 & 0.069 & 261011.676 & $\begin{array}{l}\text { Fixed,Wide } \\
\text { Lane }\end{array}$ & 30 & 2.994 & Adjusted & 0.077 \\
\hline $\begin{array}{l}\text { RIOD - RBMC Rio de } \\
\text { Janeiro-VICO - RBMC } \\
\text { Vicosa }\end{array}$ & 0.034 & 0.064 & 232120.606 & $\begin{array}{l}\text { Fixed,Wide } \\
\text { Lane }\end{array}$ & 30 & 2.950 & Adjusted & 0.072 \\
\hline $\begin{array}{l}\text { VARG - RBMC } \\
\text { Varginha-VICO - } \\
\text { RBMC Vicosa }\end{array}$ & 0.035 & 0.072 & 280097.764 & $\begin{array}{l}\text { Fixed,Wide } \\
\text { Lane }\end{array}$ & 30 & 3.009 & Adjusted & 0.080 \\
\hline
\end{tabular}


Figura B27: Elipses de Erro

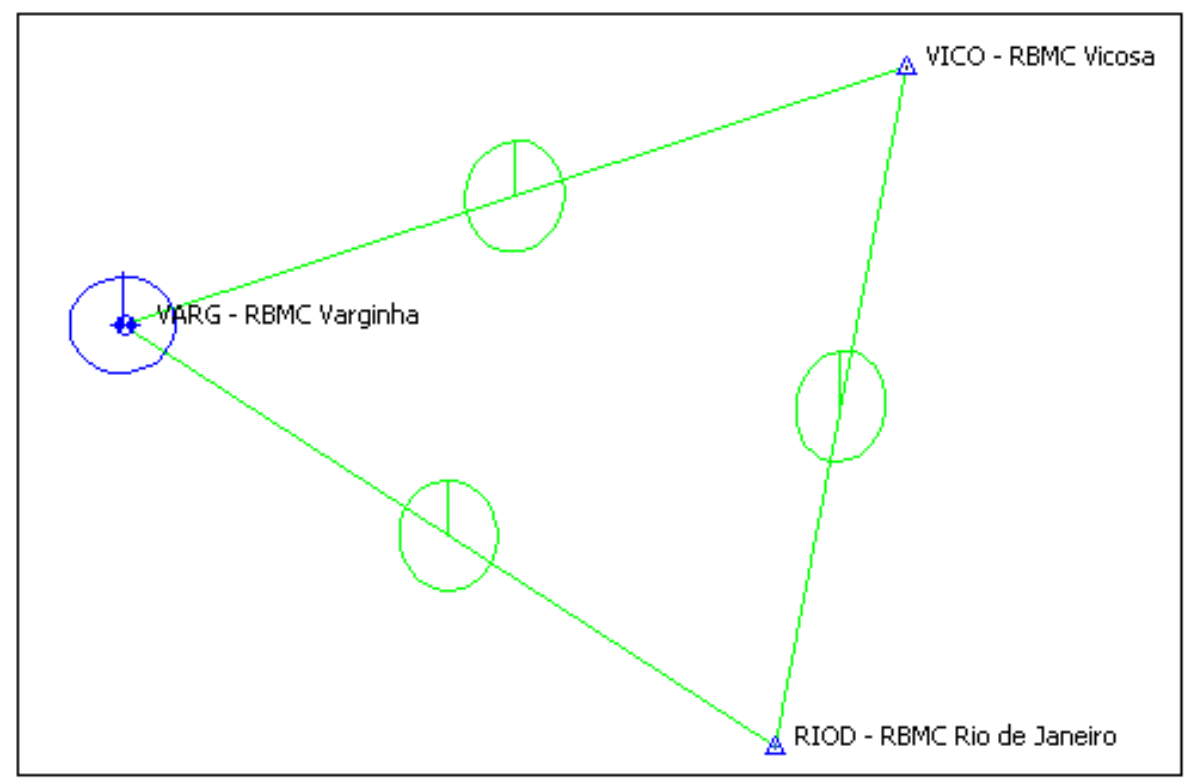

Coordenadas Ajustadas de VARG:

E (UTM): $454968.9564 \mathrm{~m}$

N (UTM): $7617727.2978 \mathrm{~m}$

- $196 / 2007$

A posteriori UWE: 1.116587 , Bounds: ( $0.6770032,1.241639$ )

TABELA B28: Resultado do Processamento

\begin{tabular}{|c|c|c|c|c|c|c|c|c|}
\hline \multicolumn{9}{|c|}{ GPS Obs Report } \\
\hline Name & $\begin{array}{c}\text { Horizontal } \\
\text { Precision }(\mathbf{m})\end{array}$ & $\begin{array}{l}\text { Vertical } \\
\text { Precision } \\
\text { (m) }\end{array}$ & $\begin{array}{c}\text { Distance } \\
\text { (m) }\end{array}$ & $\begin{array}{l}\text { Solution } \\
\text { Type }\end{array}$ & $\begin{array}{c}\text { GPS } \\
\text { Satellites }\end{array}$ & PDOP & Status & RMS \\
\hline $\begin{array}{l}\text { RIOD - RBMC Rio de } \\
\text { Janeiro-VARG - } \\
\text { RBMC Varginha }\end{array}$ & 0.037 & 0.068 & 261011.683 & $\begin{array}{l}\text { Fixed,Wide } \\
\text { Lane }\end{array}$ & 30 & 2.993 & Adjusted & 0.077 \\
\hline $\begin{array}{l}\text { RIOD - RBMC Rio de } \\
\text { Janeiro-VICO - RBMC } \\
\text { Vicosa }\end{array}$ & 0.034 & 0.065 & 232120.614 & $\begin{array}{l}\text { Fixed,Wide } \\
\text { Lane }\end{array}$ & 30 & 2.949 & Adjusted & 0.073 \\
\hline $\begin{array}{l}\text { VARG - RBMC } \\
\text { Varginha-VICO - } \\
\text { RBMC Vicosa }\end{array}$ & 0.037 & 0.070 & 280097.768 & $\begin{array}{l}\text { Fixed, Wide } \\
\text { Lane }\end{array}$ & 30 & 3.008 & Adjusted & 0.079 \\
\hline
\end{tabular}


Figura B28: Elipses de Erro

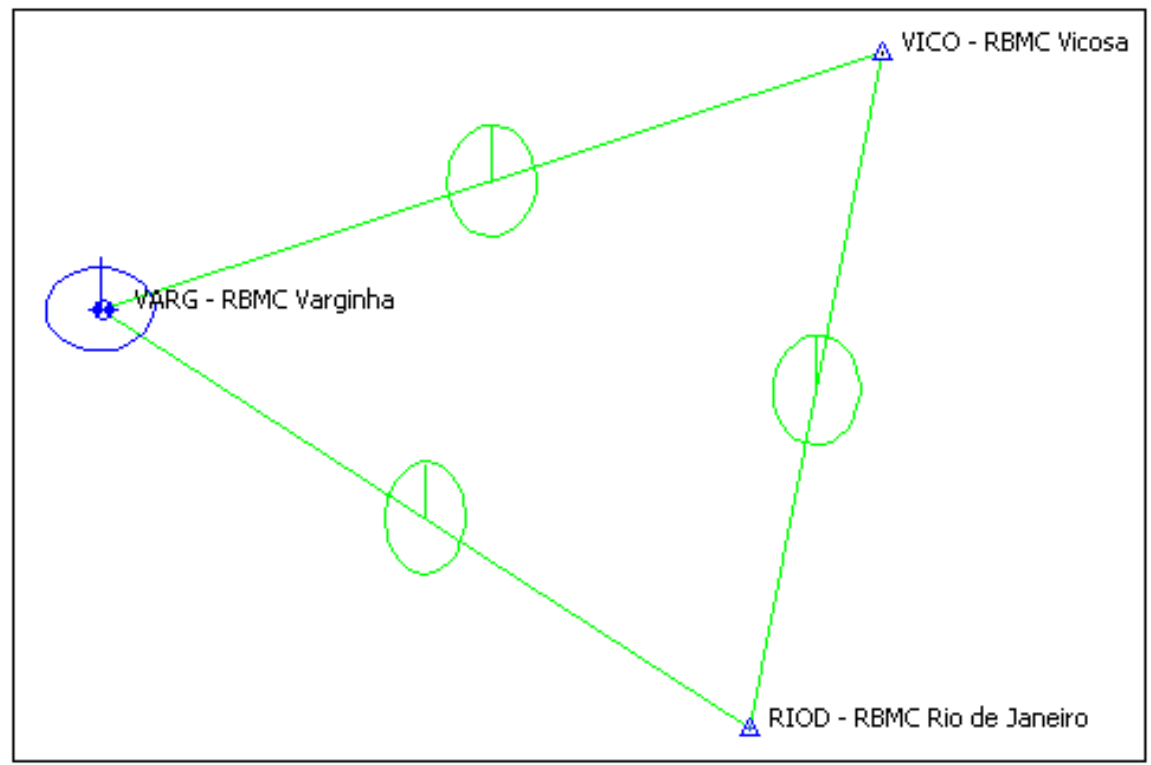

Coordenadas Ajustadas de VARG:

E (UTM): $454968.9498 \mathrm{~m}$

N (UTM): $7617727.2999 \mathrm{~m}$

\section{B.1.2.4 Primavera (Dias Julianos 286 a 289)}

- $286 / 2007$

A posteriori UWE: 0.8290749 , Bounds: ( $0.6770032,1.241639)$

TABELA B29: Resultado do Processamento

\begin{tabular}{|c|c|c|c|c|c|c|c|c|}
\hline \multicolumn{9}{|c|}{ GPS Obs Report } \\
\hline Name & $\begin{array}{c}\text { Horizontal } \\
\text { Precision (m) }\end{array}$ & $\begin{array}{l}\text { Vertical } \\
\text { Precision } \\
\text { (m) }\end{array}$ & $\begin{array}{c}\text { Distance } \\
\text { (m) }\end{array}$ & $\begin{array}{l}\text { Solution } \\
\text { Type }\end{array}$ & $\begin{array}{c}\text { GPS } \\
\text { Satellites }\end{array}$ & PDOP & Status & RMS \\
\hline $\begin{array}{l}\text { RIOD - Rio de } \\
\text { Janeiro-VARG - } \\
\text { Varginha } \\
\end{array}$ & 0.042 & 0.065 & 261011.688 & $\begin{array}{l}\text { Fixed,Wide } \\
\text { Lane }\end{array}$ & 30 & 2.992 & Adjusted & 0.077 \\
\hline $\begin{array}{l}\text { RIOD - Rio de } \\
\text { Janeiro-VICO - } \\
\text { Vicosa }\end{array}$ & 0.033 & 0.065 & 232120.621 & $\begin{array}{l}\text { Fixed,Wide } \\
\text { Lane }\end{array}$ & 30 & 2.913 & Adjusted & 0.073 \\
\hline $\begin{array}{l}\text { VARG - } \\
\text { Varginha-VICO - } \\
\text { Vicosa }\end{array}$ & 0.049 & 0.062 & 280097.777 & $\begin{array}{l}\text { Fixed,Wide } \\
\text { Lane }\end{array}$ & 30 & 2.977 & Adjusted & 0.079 \\
\hline
\end{tabular}


Figura B29: Elipses de Erro

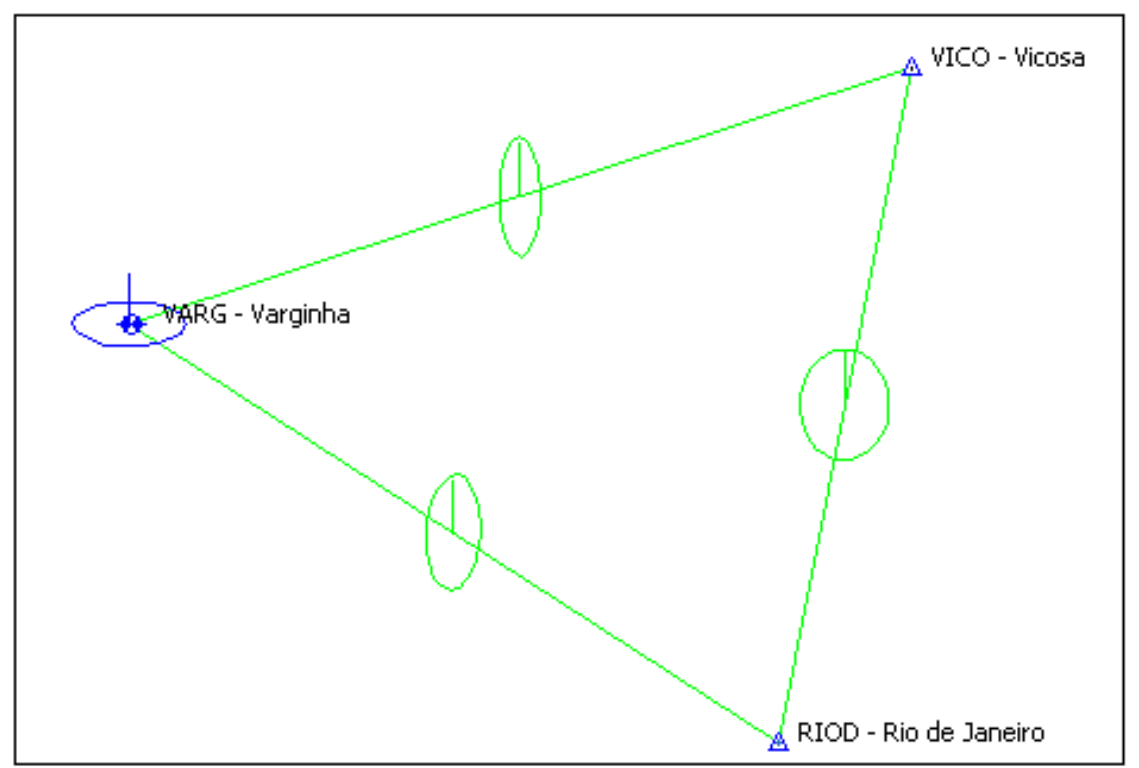

Coordenadas Ajustadas de VARG:

E (UTM): $454968.9469 \mathrm{~m}$

N (UTM): $7617727.3045 \mathrm{~m}$

- $\underline{287 / 2007}$

A posteriori UWE: 1.045234 , Bounds: ( $0.6770032,1.241639$ )

TABELA B30: Resultado do Processamento

\begin{tabular}{|c|c|c|c|c|c|c|c|c|}
\hline \multicolumn{9}{|c|}{ GPS Obs Report } \\
\hline Name & $\begin{array}{c}\text { Horizontal } \\
\text { Precision (m) }\end{array}$ & $\begin{array}{l}\text { Vertical } \\
\text { Precision } \\
\text { (m) }\end{array}$ & $\begin{array}{l}\text { Distance } \\
\text { (m) }\end{array}$ & $\begin{array}{c}\text { Solution } \\
\text { Type }\end{array}$ & $\begin{array}{c}\text { GPS } \\
\text { Satellites }\end{array}$ & PDOP & Status & RMS \\
\hline $\begin{array}{l}\text { RIOD - Rio de } \\
\text { Janeiro-VARG - } \\
\text { Varginha }\end{array}$ & 0.034 & 0.069 & 261011.693 & $\begin{array}{l}\text { Fixed, Wide } \\
\text { Lane }\end{array}$ & 30 & 2.991 & Adjusted & 0.077 \\
\hline $\begin{array}{l}\text { RIOD - Rio de } \\
\text { Janeiro-VICO - } \\
\text { Vicosa }\end{array}$ & 0.036 & 0.063 & 232120.632 & $\begin{array}{l}\text { Fixed,Wide } \\
\text { Lane }\end{array}$ & 30 & 2.913 & Adjusted & 0.072 \\
\hline $\begin{array}{l}\text { VARG - } \\
\text { Varginha-VICO - } \\
\text { Vicosa }\end{array}$ & 0.035 & 0.072 & 280097.794 & $\begin{array}{l}\text { Fixed,Wide } \\
\text { Lane }\end{array}$ & 30 & 2.975 & Adjusted & 0.080 \\
\hline
\end{tabular}


Figura B30: Elipses de Erro

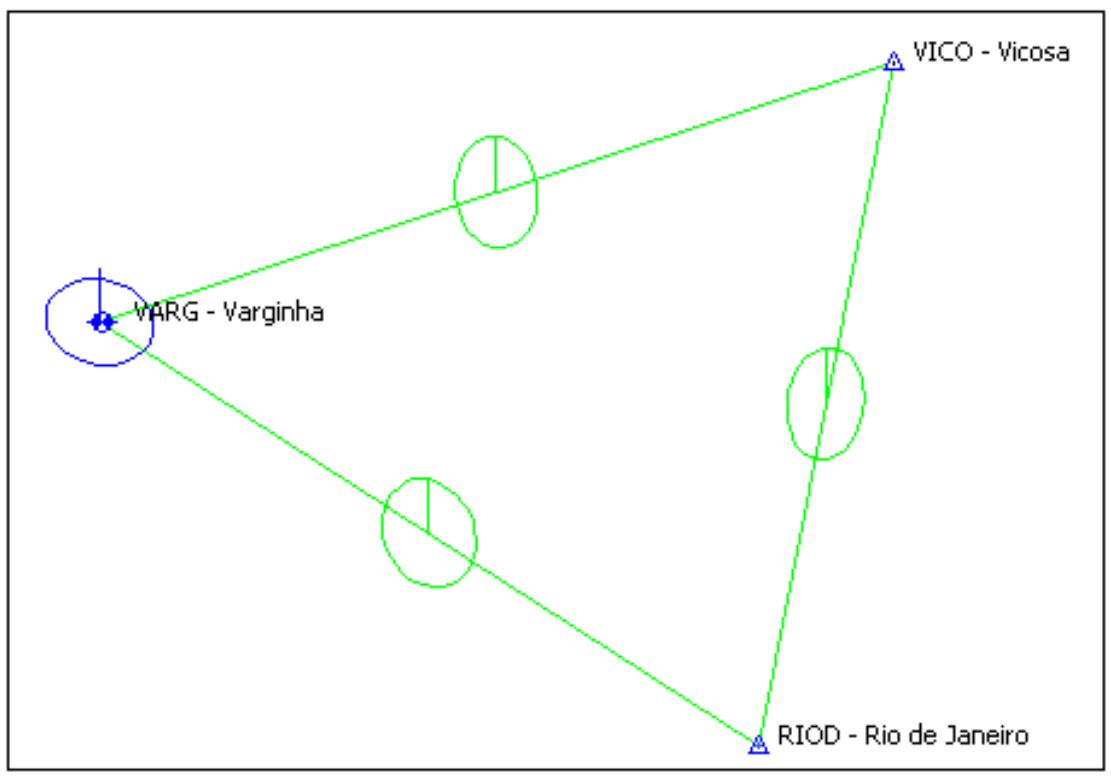

Coordenadas Ajustadas de VARG:

E (UTM): $454968.9394 \mathrm{~m}$

N (UTM): $7617727.2993 \mathrm{~m}$

- $\underline{288 / 2007}$

A posteriori UWE: 1.2246184 , Bounds: $(0.6770032,1.241639)$

TABELA B31: Resultado do Processamento

\begin{tabular}{|c|c|c|c|c|c|c|c|c|}
\hline \multicolumn{9}{|c|}{ GPS Obs Report } \\
\hline Name & $\begin{array}{c}\text { Horizontal } \\
\text { Precision (m) }\end{array}$ & $\begin{array}{c}\text { Vertical } \\
\text { Precision } \\
(\mathbf{m}) \\
\end{array}$ & $\begin{array}{c}\text { Distance } \\
\text { (m) }\end{array}$ & $\begin{array}{l}\text { Solution } \\
\text { Type }\end{array}$ & $\begin{array}{c}\text { GPS } \\
\text { Satellites }\end{array}$ & PDOP & Status & RMS \\
\hline $\begin{array}{l}\text { RIOD - Rio de } \\
\text { Janeiro-VARG - } \\
\text { Varginha } \\
\end{array}$ & 0.042 & 0.072 & 261011.690 & $\begin{array}{l}\text { Fixed,Wide } \\
\text { Lane }\end{array}$ & 29 & 2.921 & Adjusted & 0.076 \\
\hline $\begin{array}{l}\text { RIOD - Rio de } \\
\text { Janeiro-VICO - } \\
\text { Vicosa }\end{array}$ & 0.049 & 0.064 & 232120.635 & $\begin{array}{l}\text { Fixed,Wide } \\
\text { Lane }\end{array}$ & 27 & 2.821 & Adjusted & 0.070 \\
\hline $\begin{array}{l}\text { VARG - } \\
\text { Varginha-VICO - } \\
\text { Vicosa }\end{array}$ & 0.041 & 0.076 & $\mid 280097.790$ & $\begin{array}{l}\text { Fixed,Wide } \\
\text { Lane }\end{array}$ & 30 & 2.835 & Adjusted & 0.080 \\
\hline
\end{tabular}


Figura B31: Elipses de Erro

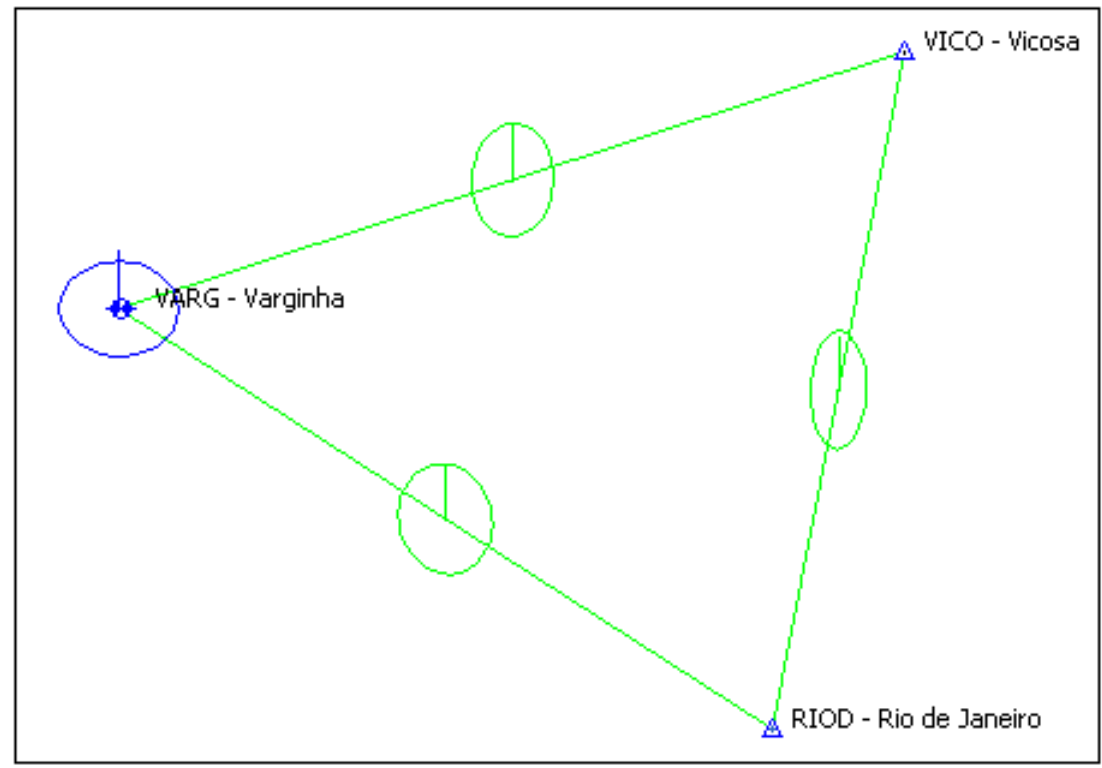

Coordenadas Ajustadas de VARG:

E (UTM): $454968.9458 \mathrm{~m}$

N (UTM): $7617727.2760 \mathrm{~m}$

- $\underline{289 / 2007}$

A posteriori UWE: 1.0128999 , Bounds: ( $0.6770032,1.241639)$

TABELA B32: Resultado do Processamento

\begin{tabular}{|c|c|c|c|c|c|c|c|c|}
\hline \multicolumn{9}{|c|}{ GPS Obs Report } \\
\hline Name & $\begin{array}{c}\text { Horizontal } \\
\text { Precision (m) }\end{array}$ & $\begin{array}{l}\text { Vertical } \\
\text { Precision } \\
\text { (m) }\end{array}$ & $\begin{array}{l}\text { Distance } \\
\text { (m) }\end{array}$ & $\begin{array}{c}\text { Solution } \\
\text { Type }\end{array}$ & $\begin{array}{c}\text { GPS } \\
\text { Satellites }\end{array}$ & PDOP & Status & RMS \\
\hline $\begin{array}{l}\text { RIOD - Rio de } \\
\text { Janeiro-VARG - } \\
\text { Varginha }\end{array}$ & 0.035 & 0.071 & 261011.688 & $\begin{array}{l}\text { Fixed, Wide } \\
\text { Lane }\end{array}$ & 29 & 2.809 & Adjusted & 0.078 \\
\hline $\begin{array}{l}\text { RIOD - Rio de } \\
\text { Janeiro-VICO - } \\
\text { Vicosa }\end{array}$ & 0.032 & 0.066 & 232120.636 & $\begin{array}{l}\text { Fixed,Wide } \\
\text { Lane }\end{array}$ & 29 & 2.986 & Adjusted & 0.074 \\
\hline $\begin{array}{l}\text { VARG - } \\
\text { Varginha-VICO - } \\
\text { Vicosa }\end{array}$ & 0.031 & 0.062 & 280097.789 & $\begin{array}{l}\text { Fixed,Wide } \\
\text { Lane }\end{array}$ & 30 & 2.775 & Adjusted & 0.080 \\
\hline
\end{tabular}

Figura B32: Elipses de Erro 


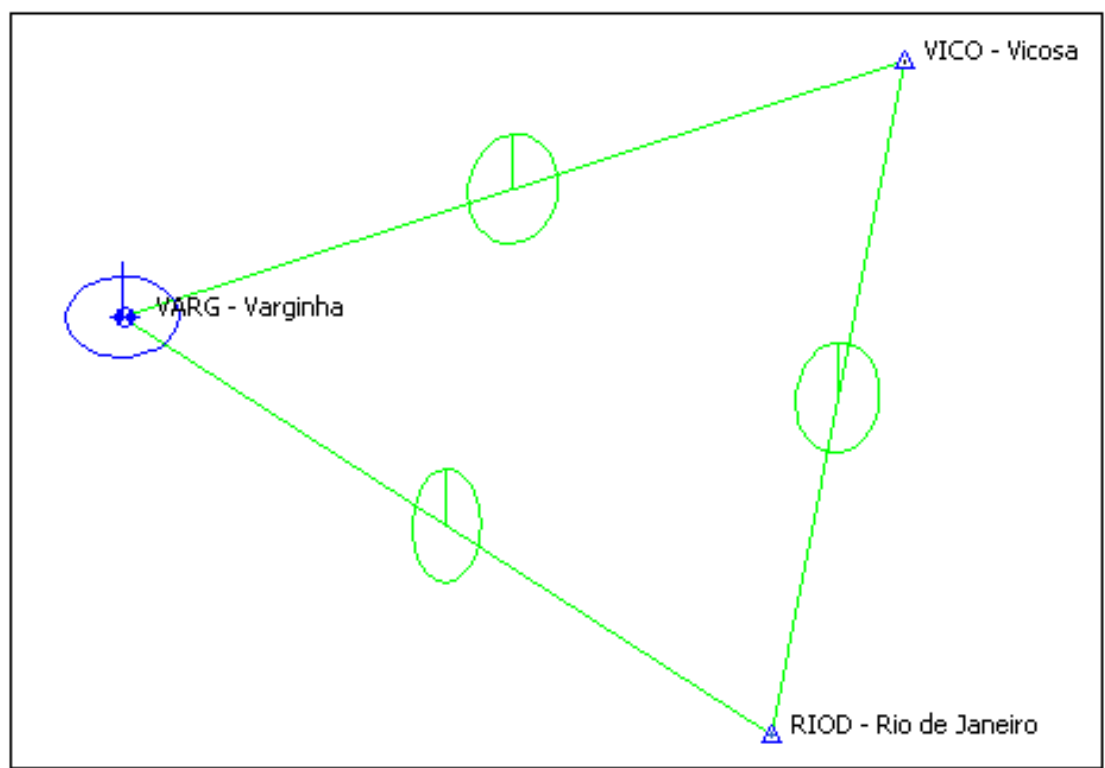

Coordenadas Ajustadas de VARG:

E (UTM): $454968.9567 \mathrm{~m}$

N (UTM): $7617727.3256 \mathrm{~m}$

\section{B.1.3 Ano de 2008}

\section{B.1.3.1 Verão (Dias Julianos 011 a 014)}

- $\underline{011 / 2008}$

A posteriori UWE: 1.05242 , Bounds: ( $0.6770032,1.241639$ )

TABELA B33: Resultado do Processamento

\begin{tabular}{|c|c|c|c|c|c|c|c|c|}
\hline \multicolumn{9}{|c|}{ GPS Obs Report } \\
\hline Name & $\begin{array}{c}\text { Horizontal } \\
\text { Precision }(\mathbf{m})\end{array}$ & $\begin{array}{l}\text { Vertical } \\
\text { Precision } \\
(\mathbf{m}) \\
\end{array}$ & $\begin{array}{l}\text { Distance } \\
\text { (m) }\end{array}$ & $\begin{array}{l}\text { Solution } \\
\text { Type }\end{array}$ & $\begin{array}{c}\text { GPS } \\
\text { Satellites }\end{array}$ & PDOP & Status & RMS \\
\hline $\begin{array}{l}\text { RIOD - Rio de } \\
\text { Janeiro-VARG - } \\
\text { Varginha }\end{array}$ & 0.037 & 0.068 & 261011.704 & $\begin{array}{l}\text { Fixed,Wide } \\
\text { Lane }\end{array}$ & 30 & 2.926 & Adjusted & 0.077 \\
\hline $\begin{array}{l}\text { RIOD - Rio de } \\
\text { Janeiro-VICO - } \\
\text { Vicosa }\end{array}$ & 0.041 & 0.062 & 232120.642 & $\begin{array}{l}\text { Fixed,Wide } \\
\text { Lane }\end{array}$ & 30 & 2.802 & Adjusted & 0.074 \\
\hline $\begin{array}{l}\text { VARG - } \\
\text { Varginha-VICO - } \\
\text { Vicosa }\end{array}$ & 0.037 & 0.071 & 280097.785 & $\begin{array}{l}\text { Fixed,Wide } \\
\text { Lane }\end{array}$ & 30 & 2.933 & Adjusted & 0.080 \\
\hline
\end{tabular}


Figura B33: Elipses de Erro

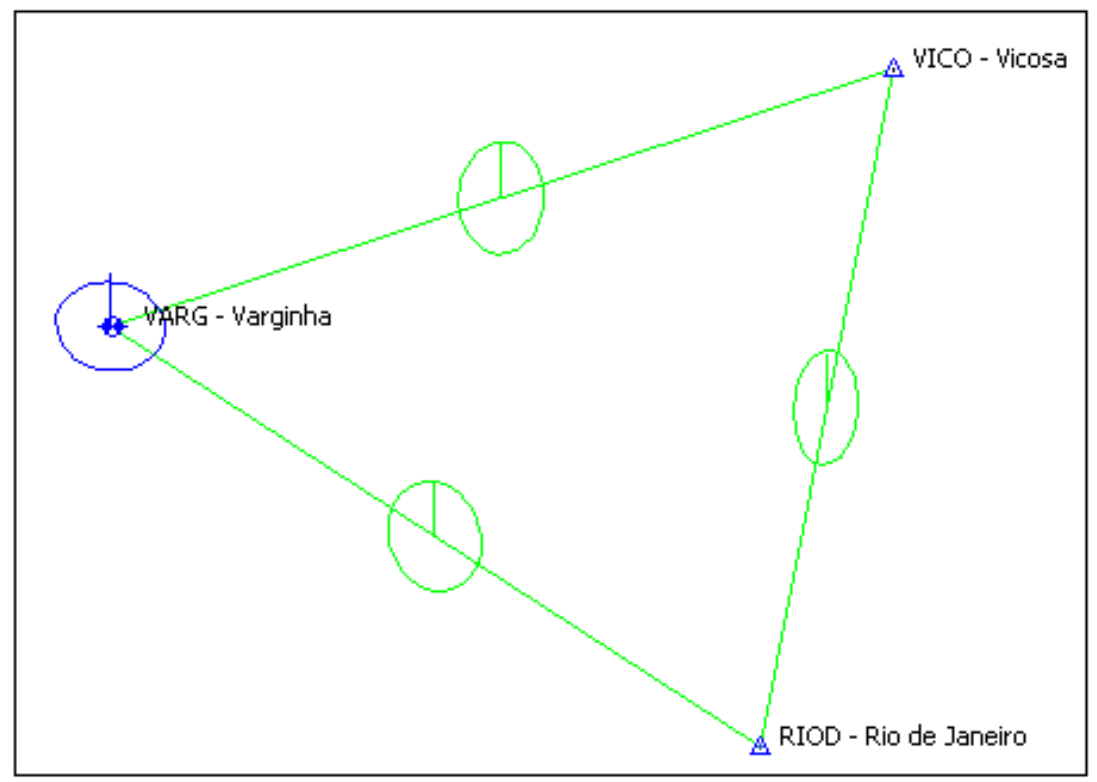

Coordenadas Ajustadas de VARG:

E (UTM): $454968.9397 \mathrm{~m}$

N (UTM): $7617727.3002 \mathrm{~m}$

- $\underline{012 / 2008}$

A posteriori UWE: 0.8080161 , Bounds: ( $0.6770032,1.241639$ )

TABELA B34: Resultado do Processamento

\begin{tabular}{|c|c|c|c|c|c|c|c|c|}
\hline \multicolumn{9}{|c|}{ GPS Obs Report } \\
\hline Name & \begin{tabular}{|c} 
Horizontal \\
Precision (m)
\end{tabular} & $\begin{array}{c}\text { Vertical } \\
\text { Precision } \\
\text { (m) }\end{array}$ & $\begin{array}{c}\text { Distance } \\
\text { (m) }\end{array}$ & $\begin{array}{c}\text { Solution } \\
\text { Type }\end{array}$ & $\begin{array}{c}\text { GPS } \\
\text { Satellites }\end{array}$ & PDOP & Status & RMS \\
\hline $\begin{array}{l}\text { RIOD - Rio de } \\
\text { Janeiro-VARG - } \\
\text { Varginha }\end{array}$ & 0.035 & 0.069 & 261011.707 & $\begin{array}{l}\text { Fixed,Wide } \\
\text { Lane }\end{array}$ & 30 & 2.900 & Adjusted & 0.077 \\
\hline $\begin{array}{l}\text { RIOD - Rio de } \\
\text { Janeiro-VICO - } \\
\text { Vicosa }\end{array}$ & 0.036 & 0.063 & 232120.634 & $\begin{array}{l}\text { Fixed,Wide } \\
\text { Lane }\end{array}$ & 30 & 2.801 & Adjusted & 0.073 \\
\hline $\begin{array}{l}\text { VARG - } \\
\text { Varginha-VICO - } \\
\text { Vicosa }\end{array}$ & 0.034 & 0.072 & 280097.791 & $\begin{array}{l}\text { Fixed,Wide } \\
\text { Lane }\end{array}$ & 30 & 2.904 & Adjusted & 0.080 \\
\hline
\end{tabular}


Figura B34: Elipses de Erro

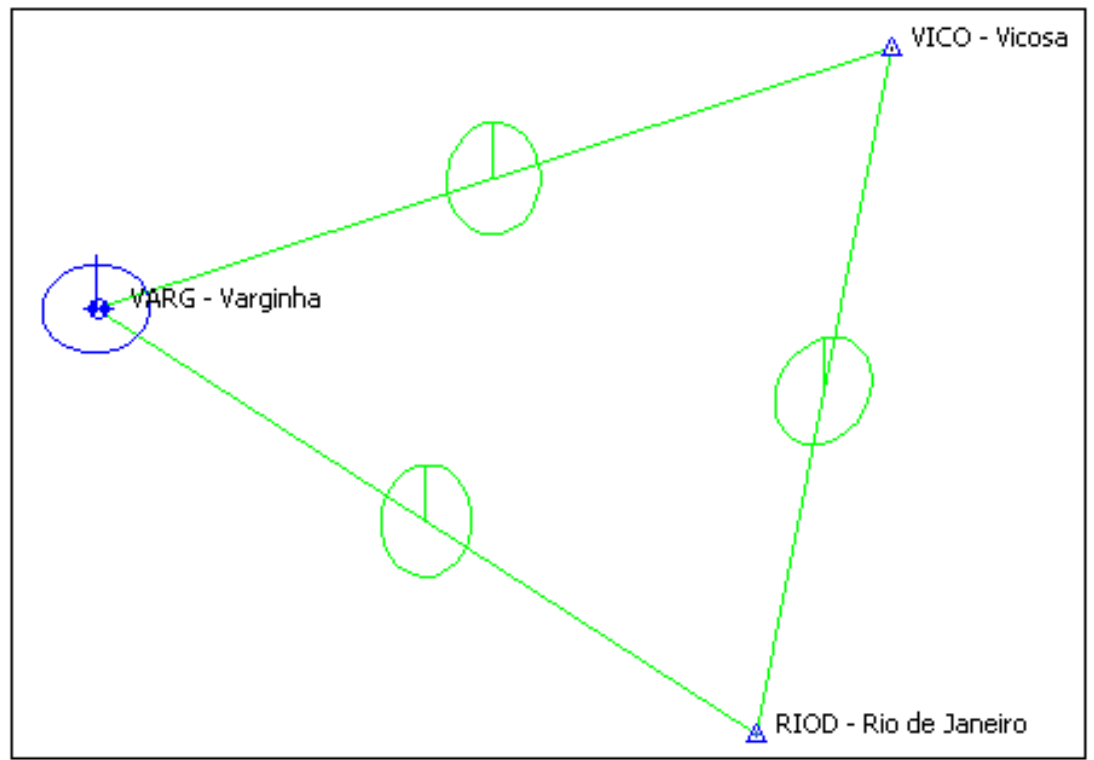

Coordenadas Ajustadas de VARG:

E (UTM): $454968.9322 \mathrm{~m}$

N (UTM): $7617727.3023 \mathrm{~m}$

- $\underline{013 / 2008}$

A posteriori UWE: 1.209917 , Bounds: ( $0.6770032,1.241639$ )

TABELA B35: Resultado do Processamento

\begin{tabular}{|c|c|c|c|c|c|c|c|c|}
\hline \multicolumn{9}{|c|}{ GPS Obs Report } \\
\hline Name & \begin{tabular}{|c} 
Horizontal \\
Precision (m)
\end{tabular} & $\begin{array}{l}\text { Vertical } \\
\text { Precision } \\
\text { (m) }\end{array}$ & $\begin{array}{c}\text { Distance } \\
\text { (m) }\end{array}$ & $\begin{array}{c}\text { Solution } \\
\text { Type }\end{array}$ & $\begin{array}{c}\text { GPS } \\
\text { Satellites }\end{array}$ & PDOP & Status & RMS \\
\hline $\begin{array}{l}\text { RIOD - Rio de } \\
\text { Janeiro-VARG - } \\
\text { Varginha } \\
\end{array}$ & 0.038 & 0.064 & 261011.721 & $\begin{array}{l}\text { Fixed,Wide } \\
\text { Lane }\end{array}$ & 28 & 2.876 & Adjusted & 0.080 \\
\hline $\begin{array}{l}\text { RIOD - Rio de } \\
\text { Janeiro-VICO - } \\
\text { Vicosa }\end{array}$ & 0.033 & 0.062 & 232120.640 & $\begin{array}{l}\text { Fixed,Wide } \\
\text { Lane }\end{array}$ & 28 & 2.887 & Adjusted & 0.076 \\
\hline $\begin{array}{l}\text { VARG - } \\
\text { Varginha-VICO - } \\
\text { Vicosa }\end{array}$ & 0.038 & 0.066 & 280097.787 & $\begin{array}{l}\text { Fixed,Wide } \\
\text { Lane }\end{array}$ & 29 & 2.432 & Adjusted & 0.080 \\
\hline
\end{tabular}


Figura B35: Elipses de Erro

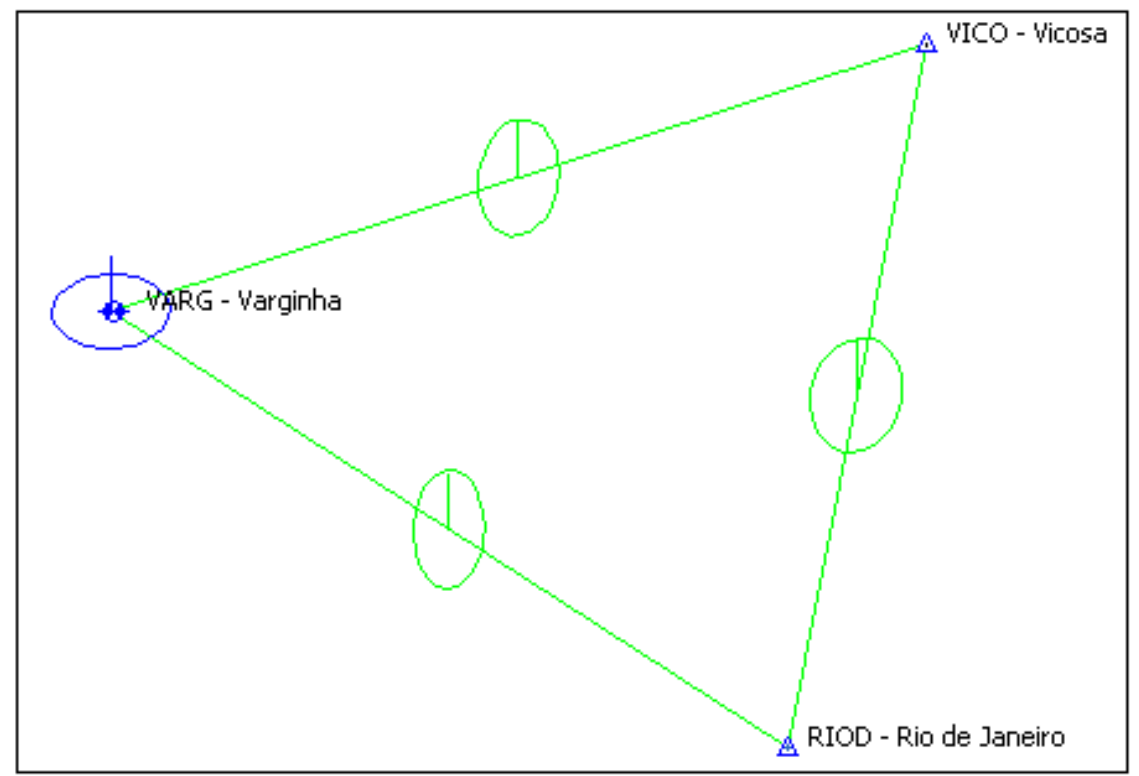

Coordenadas Ajustadas de VARG:

E (UTM): $454968.9421 \mathrm{~m}$

N (UTM): $7617727.3246 \mathrm{~m}$

- $\underline{014 / 2008}$

A posteriori UWE: 1.113214 , Bounds: ( $0.6770032,1.241639$ )

TABELA B36: Resultado do Processamento

\begin{tabular}{|c|c|c|c|c|c|c|c|c|}
\hline \multicolumn{9}{|c|}{ GPS Obs Report } \\
\hline Name & $\begin{array}{c}\text { Horizontal } \\
\text { Precision (m) }\end{array}$ & $\begin{array}{c}\text { Vertical } \\
\text { Precision } \\
\text { (m) } \\
\end{array}$ & $\begin{array}{c}\text { Distance } \\
\text { (m) }\end{array}$ & $\begin{array}{c}\text { Solution } \\
\text { Type }\end{array}$ & $\begin{array}{c}\text { GPS } \\
\text { Satellites }\end{array}$ & PDOP & Status & RMS \\
\hline $\begin{array}{l}\text { RIOD - Rio de } \\
\text { Janeiro-VARG - } \\
\text { Varginha } \\
\end{array}$ & 0.042 & 0.063 & 261011.687 & $\begin{array}{l}\text { Fixed,Wide } \\
\text { Lane }\end{array}$ & 28 & 2.569 & Adjusted & 0.080 \\
\hline \begin{tabular}{|l} 
RIOD - Rio de \\
Janeiro-VICO - \\
Vicosa \\
\end{tabular} & 0.032 & 0.060 & $\mid 232120.619$ & $\begin{array}{l}\text { Fixed,Wide } \\
\text { Lane }\end{array}$ & 30 & 2.996 & Adjusted & 0.074 \\
\hline $\begin{array}{l}\text { VARG - } \\
\text { Varginha-VICO - } \\
\text { Vicosa }\end{array}$ & 0.034 & 0.065 & 280097.782 & $\begin{array}{l}\text { Fixed,Wide } \\
\text { Lane }\end{array}$ & 25 & 2.321 & Adjusted & 0.080 \\
\hline
\end{tabular}

Figura B36: Elipses de Erro 


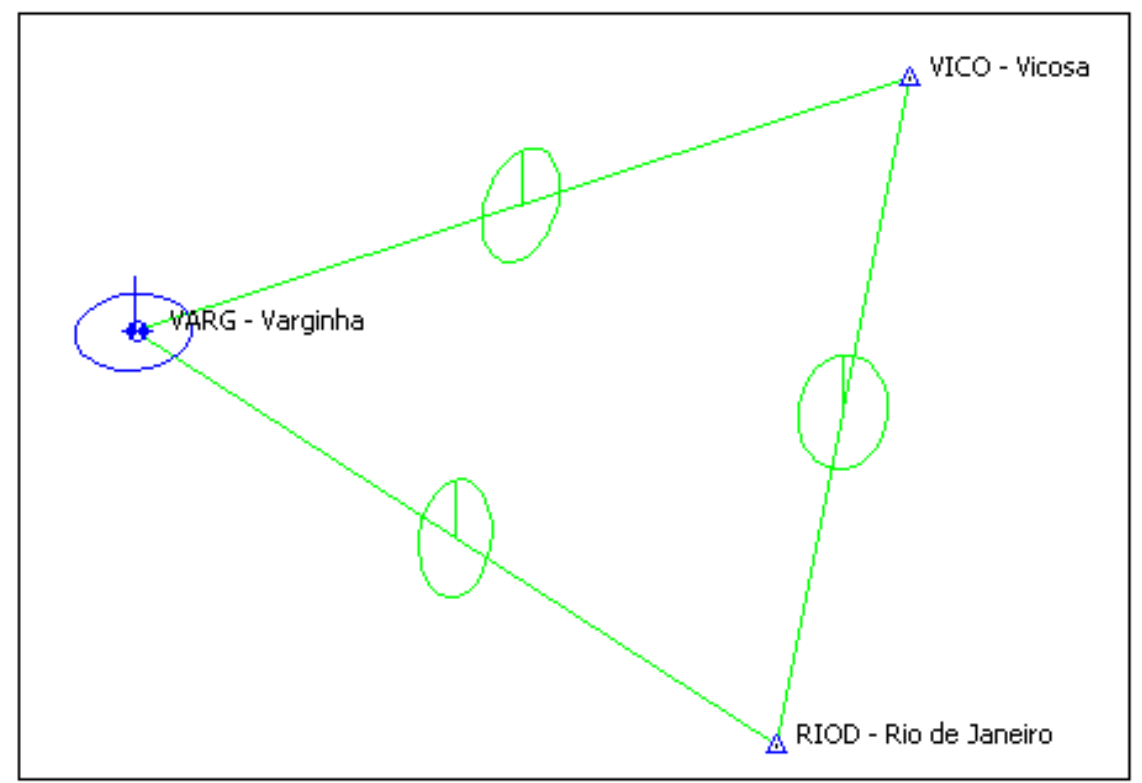

Coordenadas Ajustadas de VARG:

E (UTM): $454968.9546 \mathrm{~m}$

N (UTM): $7617727.2931 \mathrm{~m}$

\section{B.1.3.2 Outono (Dias Julianos 102 a 105)}

- $\underline{102 / 2008}$

A posteriori UWE: 0.7019208 , Bounds: ( $0.6770032,1.241639)$

TABELA B37: Resultado do Processamento

\begin{tabular}{|c|c|c|c|c|c|c|c|c|}
\hline \multicolumn{9}{|c|}{ GPS Obs Report } \\
\hline Name & $\begin{array}{c}\text { Horizontal } \\
\text { Precision (m) }\end{array}$ & $\begin{array}{l}\text { Vertical } \\
\text { Precision } \\
(\mathbf{m}) \\
\end{array}$ & $\begin{array}{l}\text { Distance } \\
\quad(\mathbf{m})\end{array}$ & $\begin{array}{l}\text { Solution } \\
\text { Type }\end{array}$ & $\begin{array}{c}\text { GPS } \\
\text { Satellites }\end{array}$ & PDOP & Status & RMS \\
\hline $\begin{array}{l}\text { RIOD - Rio de } \\
\text { Janeiro-VARG - } \\
\text { Varginha (CEMIG) }\end{array}$ & 0.042 & 0.065 & 261011.681 & $\begin{array}{l}\text { Fixed,Wide } \\
\text { Lane }\end{array}$ & 30 & 3.006 & Adjusted & 0.076 \\
\hline $\begin{array}{l}\text { RIOD - Rio de } \\
\text { Janeiro-VICO - Vicosa }\end{array}$ & 0.031 & 0.061 & 232120.632 & $\begin{array}{l}\text { Fixed,Wide } \\
\text { Lane }\end{array}$ & 31 & 2.986 & Adjusted & 0.073 \\
\hline $\begin{array}{l}\text { VARG - Varginha } \\
\text { (CEMIG)-VICO - } \\
\text { Vicosa } \\
\end{array}$ & 0.033 & 0.064 & 280097.777 & $\begin{array}{l}\text { Fixed,Wide } \\
\text { Lane }\end{array}$ & 29 & 3.041 & Adjusted & 0.080 \\
\hline
\end{tabular}

Figura B37: Elipses de Erro 


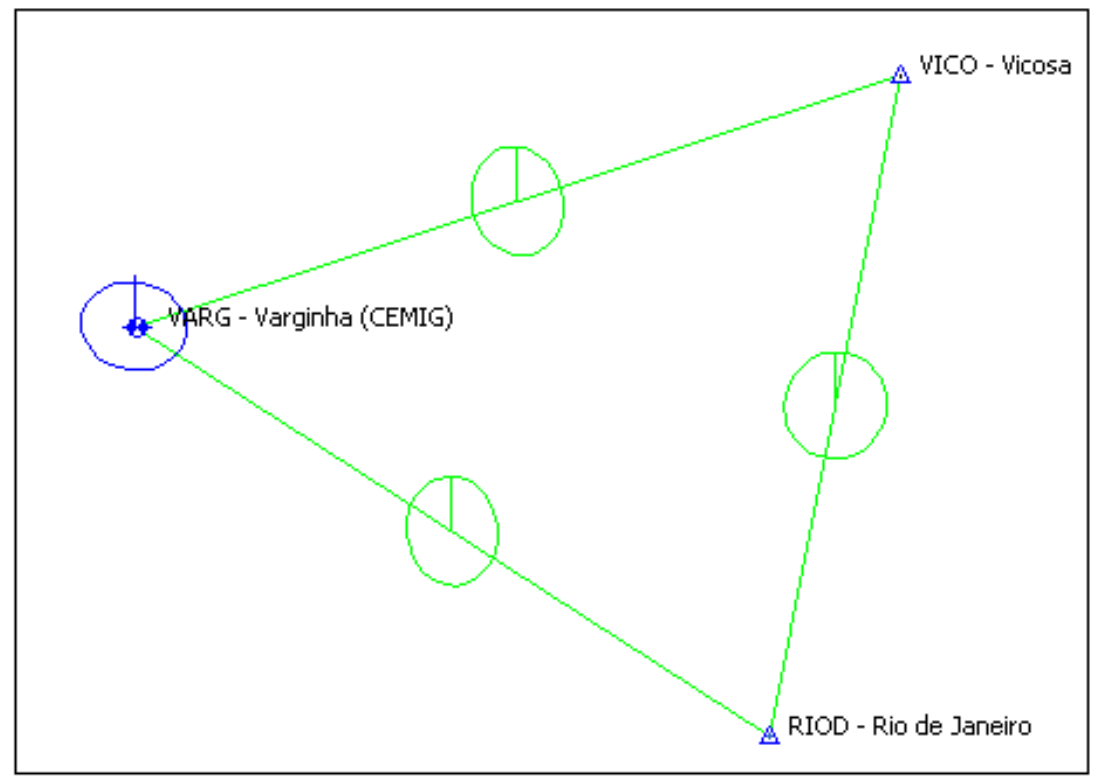

Coordenadas Ajustadas de VARG:

E (UTM): $454968.9682 \mathrm{~m}$

N (UTM): $7617727.2867 \mathrm{~m}$

- $103 / 2008$

A posteriori UWE: 0.6998219 , Bounds: ( $0.6770032,1.241639)$

TABELA B38: Resultado do Processamento

\begin{tabular}{|c|c|c|c|c|c|c|c|c|}
\hline \multicolumn{9}{|c|}{ GPS Obs Report } \\
\hline Name & $\begin{array}{c}\text { Horizontal } \\
\text { Precision }(\mathbf{m})\end{array}$ & $\begin{array}{c}\text { Vertical } \\
\text { Precision } \\
(\mathbf{m}) \\
\end{array}$ & $\begin{array}{l}\text { Distance } \\
\text { (m) }\end{array}$ & $\begin{array}{l}\text { Solution } \\
\text { Type }\end{array}$ & $\begin{array}{c}\text { GPS } \\
\text { Satellites }\end{array}$ & PDOP & Status & RMS \\
\hline $\begin{array}{l}\text { RIOD - Rio de } \\
\text { Janeiro-VARG - } \\
\text { Varginha (CEMIG) }\end{array}$ & 0.036 & 0.063 & 261011.688 & $\begin{array}{l}\text { Fixed,Wide } \\
\text { Lane }\end{array}$ & 28 & 3.011 & Adjusted & 0.078 \\
\hline $\begin{array}{l}\text { RIOD - Rio de } \\
\text { Janeiro-VICO - Vicosa }\end{array}$ & 0.034 & 0.061 & 232120.617 & $\begin{array}{l}\text { Fixed,Wide } \\
\text { Lane }\end{array}$ & 30 & 2.845 & Adjusted & 0.073 \\
\hline $\begin{array}{l}\text { VARG - Varginha } \\
\text { (CEMIG)-VICO - } \\
\text { Vicosa }\end{array}$ & 0.041 & 0.069 & 280097.763 & $\begin{array}{l}\text { Fixed,Wide } \\
\text { Lane }\end{array}$ & 26 & 3.055 & Adjusted & 0.080 \\
\hline
\end{tabular}


Figura B38: Elipses de Erro

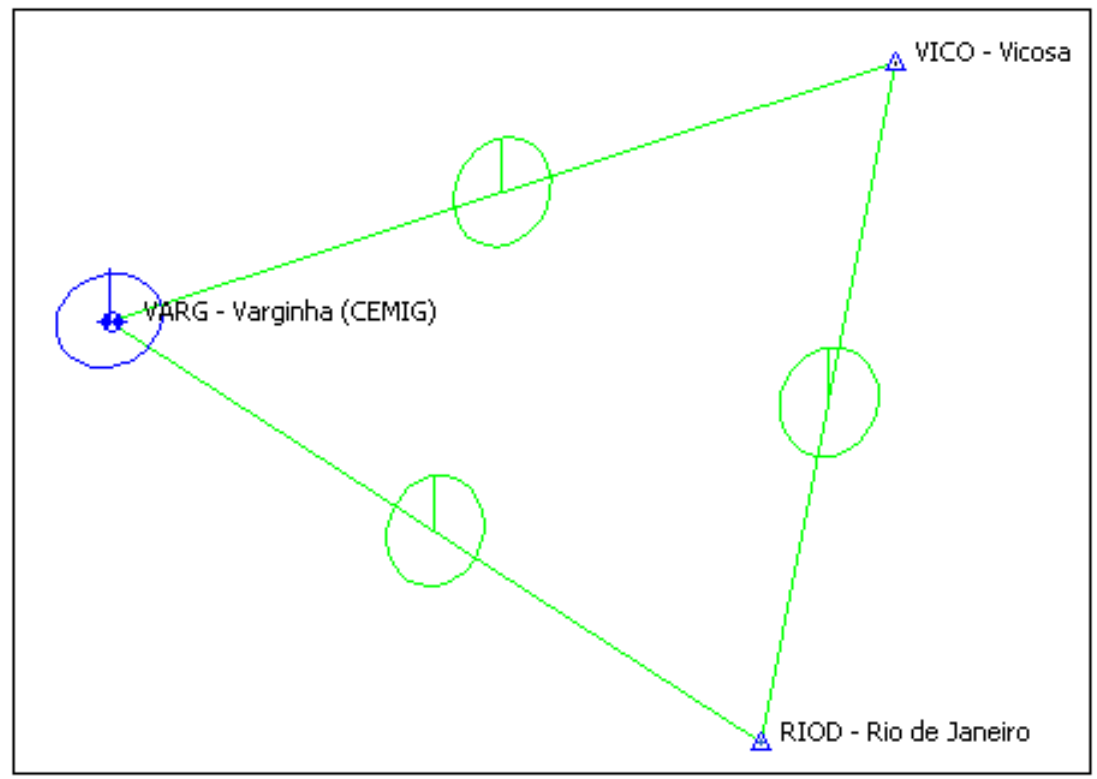

Coordenadas Ajustadas de VARG:

E (UTM): $454968.9620 \mathrm{~m}$

N (UTM): $7617727.3126 \mathrm{~m}$

- $104 / 2008$

A posteriori UWE: 0.7092813 , Bounds: ( $0.6770032,1.241639)$

TABELA B39: Resultado do Processamento

\begin{tabular}{|c|c|c|c|c|c|c|c|c|}
\hline \multicolumn{9}{|c|}{ GPS Obs Report } \\
\hline Name & $\begin{array}{c}\text { Horizontal } \\
\text { Precision }(\mathbf{m})\end{array}$ & $\begin{array}{l}\text { Vertical } \\
\text { Precision } \\
(\mathbf{m}) \\
\end{array}$ & $\begin{array}{l}\text { Distance } \\
\quad(\mathbf{m})\end{array}$ & $\begin{array}{l}\text { Solution } \\
\text { Type }\end{array}$ & $\begin{array}{c}\text { GPS } \\
\text { Satellites }\end{array}$ & PDOP & Status & RMS \\
\hline $\begin{array}{l}\text { RIOD - Rio de } \\
\text { Janeiro-VARG - } \\
\text { Varginha (CEMIG) }\end{array}$ & 0.038 & 0.064 & 261011.691 & $\begin{array}{l}\text { Fixed,Wide } \\
\text { Lane }\end{array}$ & 28 & 2.974 & Adjusted & 0.077 \\
\hline $\begin{array}{l}\text { RIOD - Rio de } \\
\text { Janeiro-VICO - Vicosa }\end{array}$ & 0.033 & 0.061 & 232120.630 & $\begin{array}{l}\text { Fixed,Wide } \\
\text { Lane }\end{array}$ & 31 & 2.835 & Adjusted & 0.072 \\
\hline $\begin{array}{l}\text { VARG - Varginha } \\
\text { (CEMIG)-VICO - } \\
\text { Vicosa }\end{array}$ & 0.032 & 0.072 & 280097.783 & $\begin{array}{l}\text { Fixed,Wide } \\
\text { Lane }\end{array}$ & 27 & 3.004 & Adjusted & 0.080 \\
\hline
\end{tabular}


Figura B39: Elipses de Erro

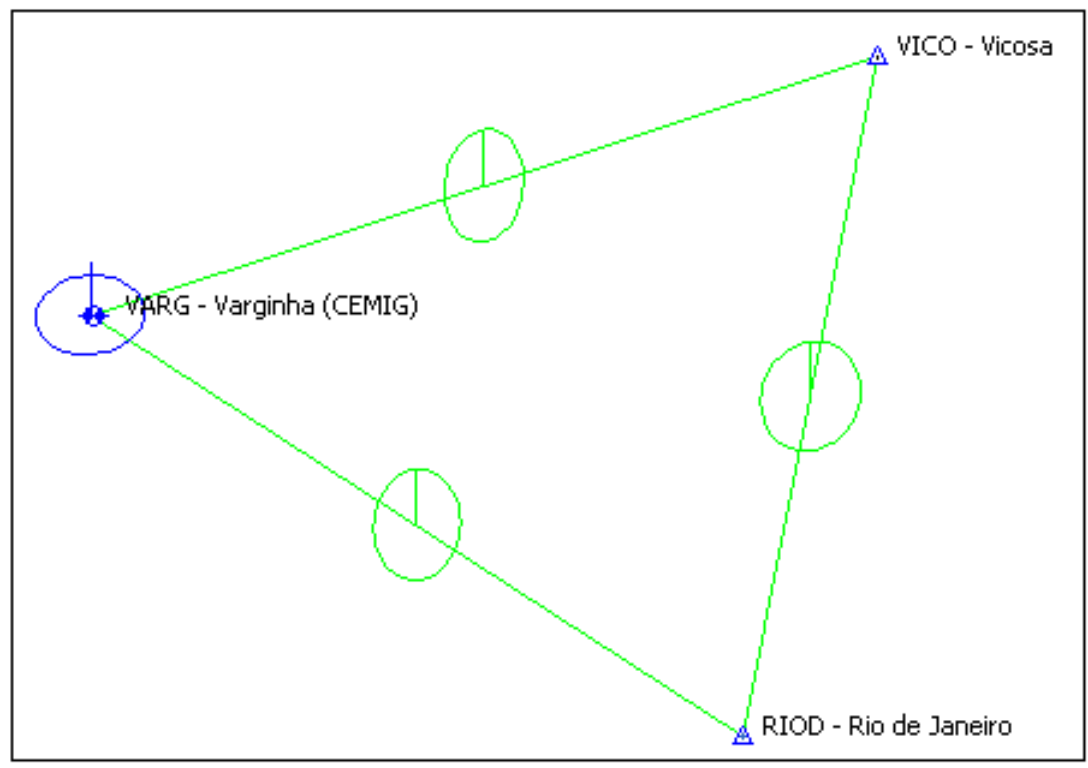

Coordenadas Ajustadas de VARG:

E (UTM): $454968.9683 \mathrm{~m}$

N (UTM): $7617727.2871 \mathrm{~m}$

- $105 / 2008$

A posteriori UWE: 0.7012431 , Bounds: ( $0.6770032,1.241639$ )

TABELA B40: Resultado do Processamento

\begin{tabular}{|c|c|c|c|c|c|c|c|c|}
\hline \multicolumn{9}{|c|}{ GPS Obs Report } \\
\hline Name & $\begin{array}{c}\text { Horizontal } \\
\text { Precision }(\mathbf{m})\end{array}$ & $\begin{array}{l}\text { Vertical } \\
\text { Precision } \\
(\mathbf{m}) \\
\end{array}$ & $\begin{array}{l}\text { Distance } \\
\quad(\mathbf{m})\end{array}$ & $\begin{array}{l}\text { Solution } \\
\text { Type }\end{array}$ & $\begin{array}{c}\text { GPS } \\
\text { Satellites }\end{array}$ & PDOP & Status & RMS \\
\hline $\begin{array}{l}\text { RIOD - Rio de } \\
\text { Janeiro-VARG - } \\
\text { Varginha (CEMIG) }\end{array}$ & 0.033 & 0.068 & 261011.694 & $\begin{array}{l}\text { Fixed,Wide } \\
\text { Lane }\end{array}$ & 31 & 2.954 & Adjusted & 0.077 \\
\hline $\begin{array}{l}\text { RIOD - Rio de } \\
\text { Janeiro-VICO - Vicosa }\end{array}$ & 0.032 & 0.064 & 232120.621 & $\begin{array}{l}\text { Fixed,Wide } \\
\text { Lane }\end{array}$ & 31 & 3.027 & Adjusted & 0.072 \\
\hline $\begin{array}{l}\text { VARG - Varginha } \\
\text { (CEMIG)-VICO - } \\
\text { Vicosa }\end{array}$ & 0.041 & 0.068 & 280097.790 & $\begin{array}{l}\text { Fixed,Wide } \\
\text { Lane }\end{array}$ & 30 & 2.989 & Adjusted & 0.080 \\
\hline
\end{tabular}


Figura B40: Elipses de Erro

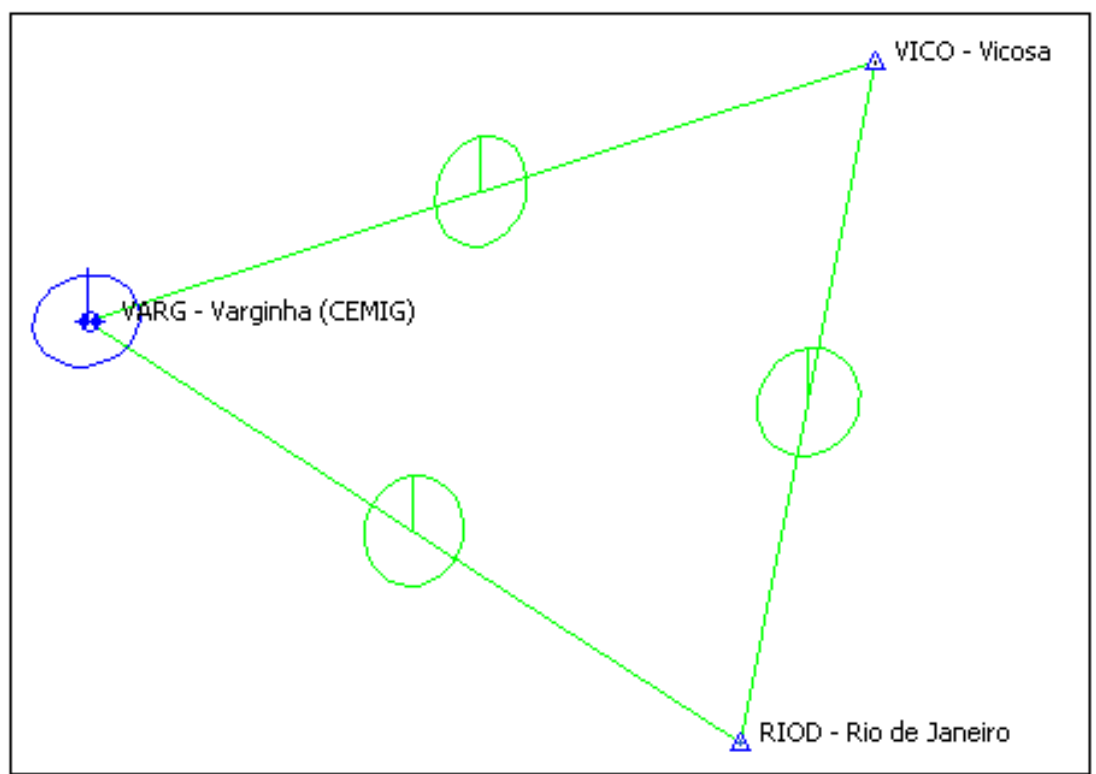

Coordenadas Ajustadas de VARG:

E (UTM): $454968.9492 \mathrm{~m}$

N (UTM): $7617727.2894 \mathrm{~m}$

\section{B.1.3.3 Inverno (Dias Julianos 194 a 197)}

- $194 / 2008$

A posteriori UWE: 0.8888385 , Bounds: ( $0.6770032,1.241639)$

TABELA B41: Resultado do Processamento

\begin{tabular}{|c|c|c|c|c|c|c|c|c|}
\hline \multicolumn{9}{|c|}{ GPS Obs Report } \\
\hline Name & $\begin{array}{c}\text { Horizontal } \\
\text { Precision (m) }\end{array}$ & $\begin{array}{l}\text { Vertical } \\
\text { Precision } \\
(\mathbf{m}) \\
\end{array}$ & $\begin{array}{l}\text { Distance } \\
\quad(\mathbf{m})\end{array}$ & $\begin{array}{l}\text { Solution } \\
\text { Type }\end{array}$ & $\begin{array}{c}\text { GPS } \\
\text { Satellites }\end{array}$ & PDOP & Status & RMS \\
\hline $\begin{array}{l}\text { RIOD - Rio de } \\
\text { Janeiro-VARG - } \\
\text { Varginha (CEMIG) }\end{array}$ & 0.034 & 0.069 & 261011.670 & $\begin{array}{l}\text { Fixed,Wide } \\
\text { Lane }\end{array}$ & 31 & 2.914 & Adjusted & 0.077 \\
\hline $\begin{array}{l}\text { RIOD - Rio de } \\
\text { Janeiro-VICO - Vicosa }\end{array}$ & 0.031 & 0.066 & 232120.617 & $\begin{array}{l}\text { Fixed,Wide } \\
\text { Lane }\end{array}$ & 31 & 2.843 & Adjusted & 0.073 \\
\hline $\begin{array}{l}\text { VARG - Varginha } \\
\text { (CEMIG)-VICO - } \\
\text { Vicosa }\end{array}$ & 0.034 & 0.072 & 280097.765 & $\begin{array}{l}\text { Fixed,Wide } \\
\text { Lane }\end{array}$ & 31 & 2.889 & Adjusted & 0.079 \\
\hline
\end{tabular}


Figura B41: Elipses de Erro

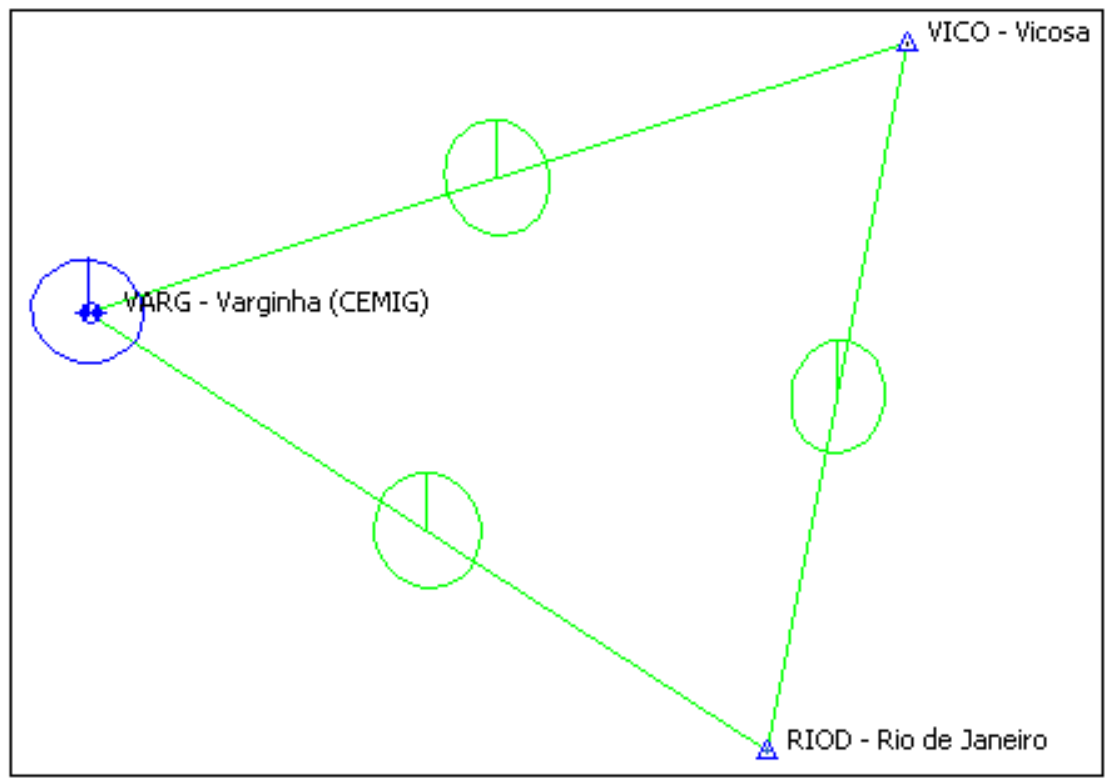

Coordenadas Ajustadas de VARG:

E (UTM): $454968.9578 \mathrm{~m}$

N (UTM): $7617727.2917 \mathrm{~m}$

- $195 / 2008$

A posteriori UWE: 0.6892901 , Bounds: ( $0.6770032,1.241639)$

TABELA B42: Resultado do Processamento

\begin{tabular}{|c|c|c|c|c|c|c|c|c|}
\hline \multicolumn{9}{|c|}{ GPS Obs Report } \\
\hline Name & $\begin{array}{c}\text { Horizontal } \\
\text { Precision (m) }\end{array}$ & $\begin{array}{l}\text { Vertical } \\
\text { Precision } \\
(\mathbf{m}) \\
\end{array}$ & $\begin{array}{l}\text { Distance } \\
\quad(\mathbf{m})\end{array}$ & $\begin{array}{l}\text { Solution } \\
\text { Type }\end{array}$ & $\begin{array}{c}\text { GPS } \\
\text { Satellites }\end{array}$ & PDOP & Status & RMS \\
\hline $\begin{array}{l}\text { RIOD - Rio de } \\
\text { Janeiro-VARG - } \\
\text { Varginha (CEMIG) }\end{array}$ & 0.033 & 0.071 & 261011.663 & $\begin{array}{l}\text { Fixed,Wide } \\
\text { Lane }\end{array}$ & 30 & 2.892 & Adjusted & 0.077 \\
\hline $\begin{array}{l}\text { RIOD - Rio de } \\
\text { Janeiro-VICO - Vicosa }\end{array}$ & 0.032 & 0.063 & 232120.610 & $\begin{array}{l}\text { Fixed,Wide } \\
\text { Lane }\end{array}$ & 30 & 2.857 & Adjusted & 0.073 \\
\hline $\begin{array}{l}\text { VARG - Varginha } \\
\text { (CEMIG)-VICO - } \\
\text { Vicosa }\end{array}$ & 0.033 & 0.074 & 280097.760 & $\begin{array}{l}\text { Fixed,Wide } \\
\text { Lane }\end{array}$ & 30 & 2.829 & Adjusted & 0.080 \\
\hline
\end{tabular}


Figura B42: Elipses de Erro

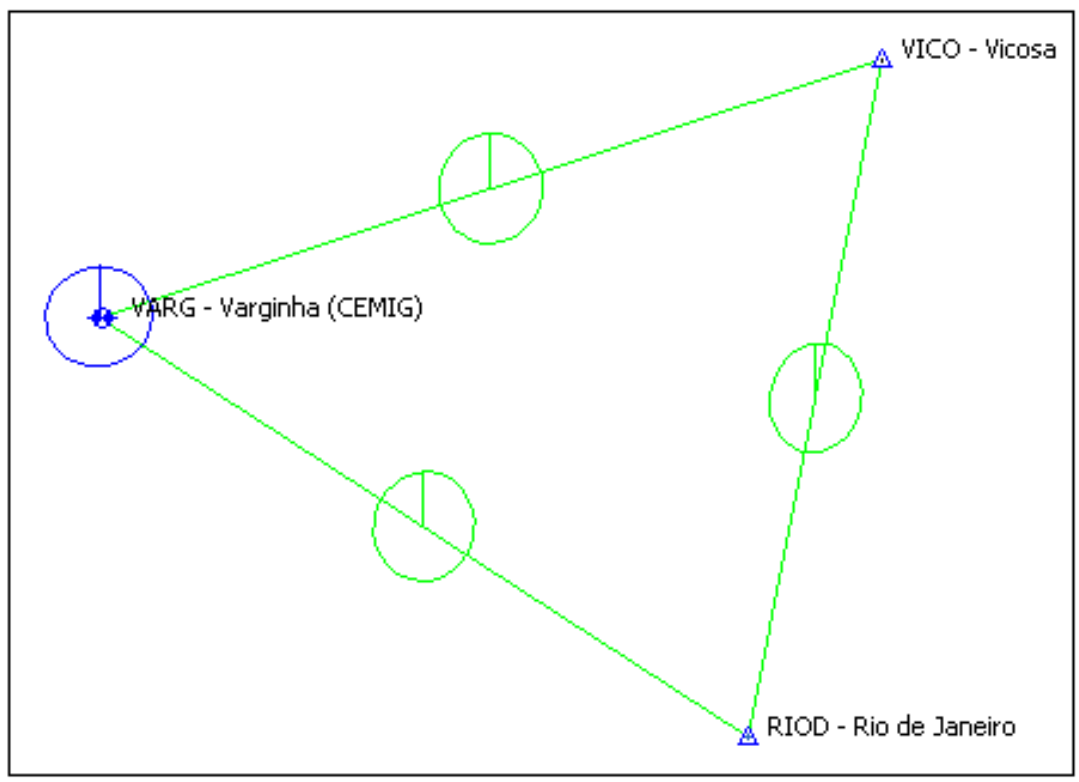

Coordenadas Ajustadas de VARG:

E (UTM): $454968.9658 \mathrm{~m}$

N (UTM): $7617727.2942 \mathrm{~m}$

- $196 / 2008$

A posteriori UWE: 0.6907199 , Bounds: ( $0.6770032,1.241639)$

TABELA B43: Resultado do Processamento

\begin{tabular}{|c|c|c|c|c|c|c|c|c|}
\hline \multicolumn{9}{|c|}{ GPS Obs Report } \\
\hline Name & $\begin{array}{c}\text { Horizontal } \\
\text { Precision (m) }\end{array}$ & $\begin{array}{l}\text { Vertical } \\
\text { Precision } \\
(\mathbf{m}) \\
\end{array}$ & $\begin{array}{l}\text { Distance } \\
\quad(\mathbf{m})\end{array}$ & $\begin{array}{l}\text { Solution } \\
\text { Type }\end{array}$ & $\begin{array}{c}\text { GPS } \\
\text { Satellites }\end{array}$ & PDOP & Status & RMS \\
\hline $\begin{array}{l}\text { RIOD - Rio de } \\
\text { Janeiro-VARG - } \\
\text { Varginha (CEMIG) }\end{array}$ & 0.030 & 0.066 & 261011.670 & $\begin{array}{l}\text { Fixed,Wide } \\
\text { Lane }\end{array}$ & 30 & 2.887 & Adjusted & 0.077 \\
\hline $\begin{array}{l}\text { RIOD - Rio de } \\
\text { Janeiro-VICO - Vicosa }\end{array}$ & 0.028 & 0.062 & 232120.611 & $\begin{array}{l}\text { Fixed,Wide } \\
\text { Lane }\end{array}$ & 31 & 2.832 & Adjusted & 0.073 \\
\hline $\begin{array}{l}\text { VARG - Varginha } \\
\text { (CEMIG)-VICO - } \\
\text { Vicosa }\end{array}$ & 0.033 & 0.068 & 280097.758 & $\begin{array}{l}\text { Fixed,Wide } \\
\text { Lane }\end{array}$ & 30 & 2.989 & Adjusted & 0.080 \\
\hline
\end{tabular}


Figura B43: Elipses de Erro

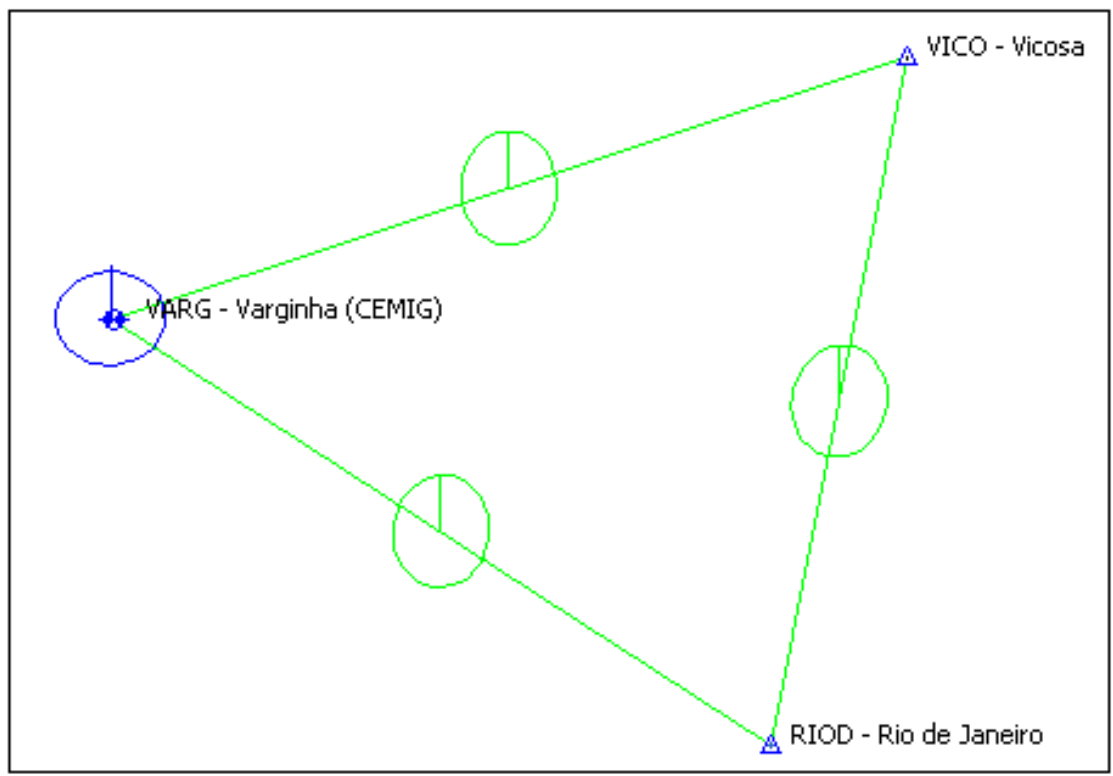

Coordenadas Ajustadas de VARG:

E (UTM): $454968.9548 \mathrm{~m}$

N (UTM): $7617727.3143 \mathrm{~m}$

- $197 / 2008$

A posteriori UWE: 0.9120472 , Bounds: ( $0.6770032,1.241639)$

TABELA B44: Resultado do Processamento

\begin{tabular}{|c|c|c|c|c|c|c|c|c|}
\hline \multicolumn{9}{|c|}{ GPS Obs Report } \\
\hline Name & $\begin{array}{c}\text { Horizontal } \\
\text { Precision (m) }\end{array}$ & $\begin{array}{l}\text { Vertical } \\
\text { Precision } \\
\text { (m) }\end{array}$ & $\begin{array}{l}\text { Distance } \\
\quad(\mathbf{m})\end{array}$ & $\begin{array}{l}\text { Solution } \\
\text { Type }\end{array}$ & $\begin{array}{c}\text { GPS } \\
\text { Satellites }\end{array}$ & PDOP & Status & RMS \\
\hline $\begin{array}{l}\text { RIOD - Rio de } \\
\text { Janeiro-VARG - } \\
\text { Varginha (CEMIG) }\end{array}$ & 0.031 & 0.067 & 261011.669 & $\begin{array}{l}\text { Fixed,Wide } \\
\text { Lane }\end{array}$ & 30 & 2.871 & Adjusted & 0.077 \\
\hline $\begin{array}{l}\text { RIOD - Rio de } \\
\text { Janeiro-VICO - Vicosa }\end{array}$ & 0.028 & 0.071 & 232120.608 & $\begin{array}{l}\text { Fixed,Wide } \\
\text { Lane }\end{array}$ & 29 & 2.646 & Adjusted & 0.073 \\
\hline $\begin{array}{l}\text { VARG - Varginha } \\
\text { (CEMIG)-VICO - } \\
\text { Vicosa }\end{array}$ & 0.032 & 0.068 & 280097.749 & $\begin{array}{l}\text { Fixed,Wide } \\
\text { Lane }\end{array}$ & 29 & 2.512 & Adjusted & 0.080 \\
\hline
\end{tabular}


Figura B44: Elipses de Erro

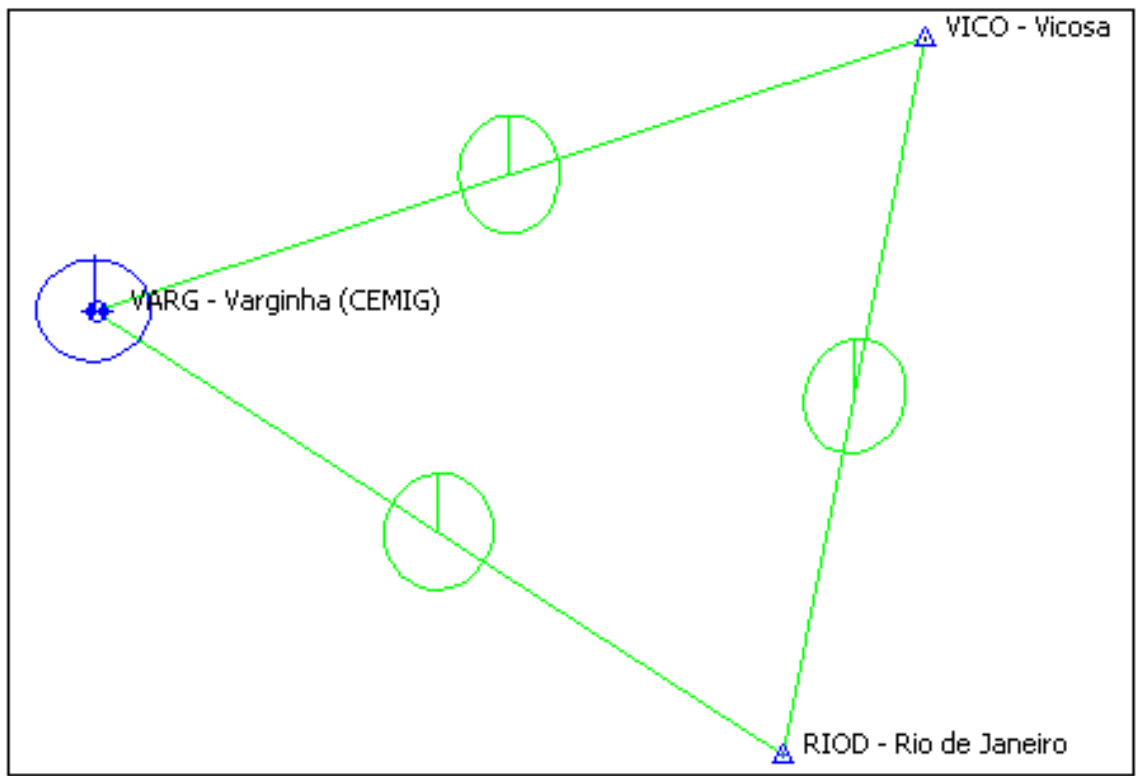

Coordenadas Ajustadas de VARG:

E (UTM): $454968.9626 \mathrm{~m}$

N (UTM): $7617727.2879 \mathrm{~m}$

B.1.3.4 Primavera (Dias Julianos 287 a 290)

- $287 / 2008$

A posteriori UWE: 0.7511296 , Bounds: ( $0.6770032,1.241639)$

TABELA B45: Resultado do Processamento

\begin{tabular}{|c|c|c|c|c|c|c|c|c|}
\hline \multicolumn{9}{|c|}{ GPS Obs Report } \\
\hline Name & $\begin{array}{c}\text { Horizontal } \\
\text { Precision (m) }\end{array}$ & $\begin{array}{c}\text { Vertical } \\
\text { Precision }(\mathbf{m})\end{array}$ & $\begin{array}{l}\text { Distance } \\
\text { (m) }\end{array}$ & $\begin{array}{c}\text { Solution } \\
\text { Type }\end{array}$ & $\begin{array}{c}\text { GPS } \\
\text { Satellites }\end{array}$ & PDOP & Status & RMS \\
\hline RIOD-VARG & 0.036 & 0.068 & 261011.690 & $\begin{array}{l}\text { Fixed,Wide } \\
\text { Lane }\end{array}$ & 31 & 2.724 & Adjusted & 0.077 \\
\hline RIOD-VICO & 0.033 & 0.064 & 232120.626 & $\begin{array}{l}\text { Fixed,Wide } \\
\text { Lane } \\
\end{array}$ & 31 & 2.697 & Adjusted & 0.073 \\
\hline VARG-VICO & 0.040 & 0.068 & 280097.780 & $\begin{array}{l}\text { Fixed,Wide } \\
\text { Lane }\end{array}$ & 31 & 2.709 & Adjusted & 0.079 \\
\hline
\end{tabular}


Figura B45: Elipses de Erro

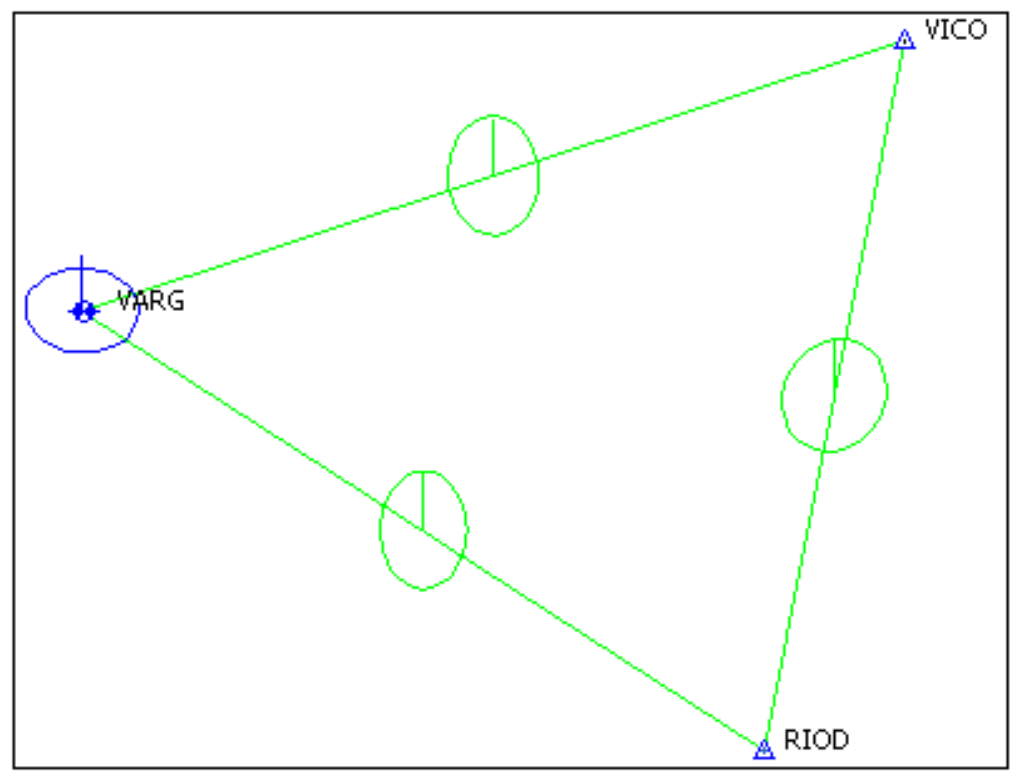

Coordenadas Ajustadas de VARG:

E (UTM): $454968.9391 \mathrm{~m}$

N (UTM): $7617727.2956 \mathrm{~m}$

- $\underline{288 / 2008}$

A posteriori UWE: 0.7046474 , Bounds: ( $0.6770032,1.241639)$

TABELA B46: Resultado do Processamento

\begin{tabular}{|c|c|c|c|c|c|c|c|c|}
\hline \multicolumn{9}{|c|}{ GPS Obs Report } \\
\hline Name & $\begin{array}{c}\text { Horizontal } \\
\text { Precision (m) }\end{array}$ & \begin{tabular}{|c|} 
Vertical \\
Precision $(\mathbf{m})$ \\
\end{tabular} & $\begin{array}{c}\text { Distance } \\
(\mathbf{m})\end{array}$ & $\begin{array}{c}\text { Solution } \\
\text { Type } \\
\end{array}$ & $\begin{array}{c}\text { GPS } \\
\text { Satellites } \\
\end{array}$ & PDOP & Status & RMS \\
\hline RIOD-VARG & 0.038 & 0.067 & 261011.688 & $\begin{array}{l}\text { Fixed,Wide } \\
\text { Lane }\end{array}$ & 31 & 2.723 & Adjusted & 0.077 \\
\hline RIOD-VICO & 0.033 & 0.065 & 232120.623 & $\begin{array}{l}\text { Fixed,Wide } \\
\text { Lane }\end{array}$ & 31 & 2.696 & Adjusted & 0.073 \\
\hline VARG-VICO & $\mid 0.038$ & 0.070 & 280097.785 & $\begin{array}{l}\text { Fixed,Wide } \\
\text { Lane }\end{array}$ & 31 & $\mid 2.708$ & Adjusted & 0.079 \\
\hline
\end{tabular}


Figura B46: Elipses de Erro

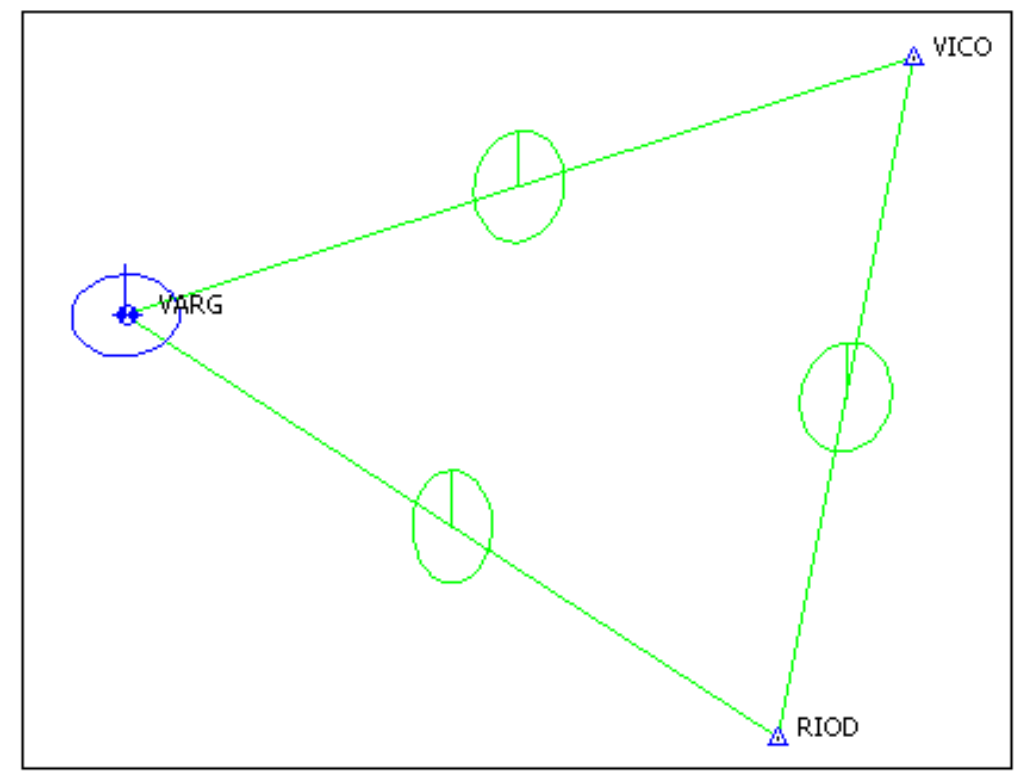

Coordenadas Ajustadas de VARG:

E (UTM): $454968.9403 \mathrm{~m}$

N (UTM): $7617727.2975 \mathrm{~m}$

- $289 / 2008$

A posteriori UWE: 0.998281 , Bounds: ( $0.6770032,1.241639$ )

TABELA B47: Resultado do Processamento

\begin{tabular}{|c|c|c|c|c|c|c|c|c|}
\hline \multicolumn{9}{|c|}{ GPS Obs Report } \\
\hline Name & $\begin{array}{c}\text { Horizontal } \\
\text { Precision }(\mathbf{m})\end{array}$ & $\begin{array}{c}\text { Vertical } \\
\text { Precision (m) }\end{array}$ & $\begin{array}{l}\text { Distance } \\
\text { (m) }\end{array}$ & $\begin{array}{c}\text { Solution } \\
\text { Type }\end{array}$ & $\begin{array}{c}\text { GPS } \\
\text { Satellites }\end{array}$ & PDOP & Status & RMS \\
\hline RIOD-VARG & 0.037 & 0.066 & 261011.692 & $\begin{array}{l}\text { Fixed,Wide } \\
\text { Lane }\end{array}$ & 30 & 2.555 & Adjusted & 0.077 \\
\hline RIOD-VICO & 0.036 & 0.058 & 232120.634 & $\begin{array}{l}\text { Fixed,Wide } \\
\text { Lane }\end{array}$ & 30 & 2.361 & Adjusted & 0.073 \\
\hline VARG-VICO & $\mid 0.041$ & 0.069 & 280097.787 & $\begin{array}{l}\text { Fixed,Wide } \\
\text { Lane } \\
\end{array}$ & 28 & 2.604 & Adjusted & 0.080 \\
\hline
\end{tabular}


Figura B47: Elipses de Erro

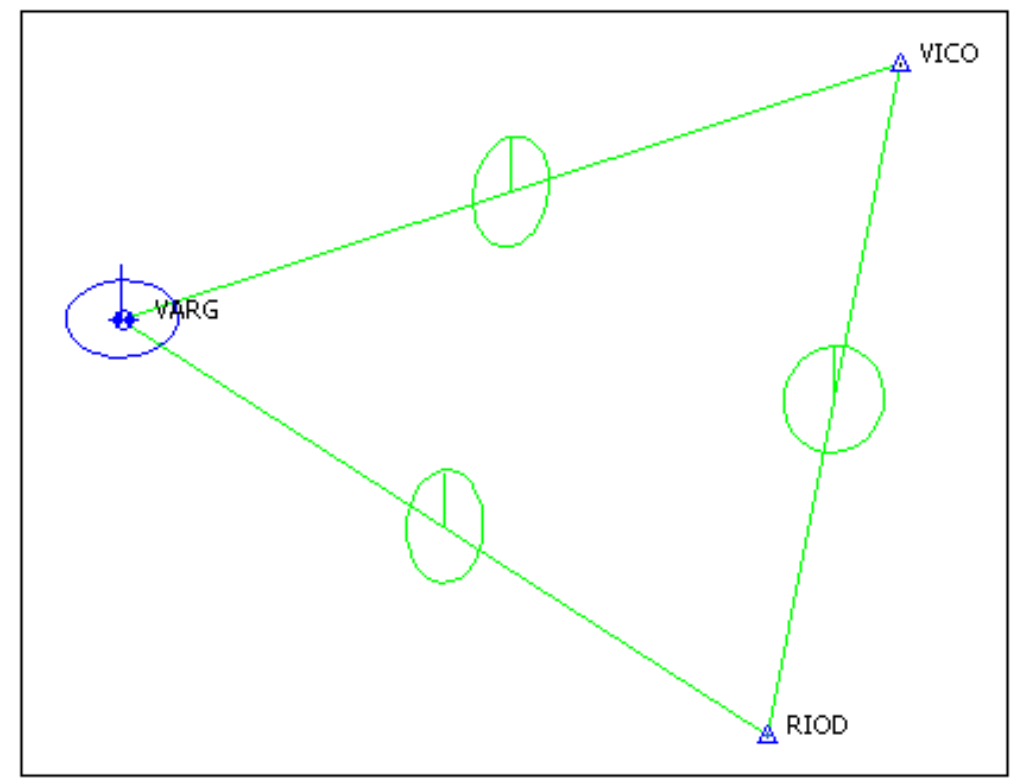

Coordenadas Ajustadas de VARG:

E (UTM): $454968.9456 \mathrm{~m}$

N (UTM): $7617727.2899 \mathrm{~m}$

- $\underline{290 / 2008}$

A posteriori UWE: 1.22893 , Bounds: ( $0.6770032,1.241639$ )

TABELA B48: Resultado do Processamento

\begin{tabular}{|c|c|c|c|c|c|c|c|c|}
\hline \multicolumn{9}{|c|}{ GPS Obs Report } \\
\hline Name & $\begin{array}{c}\text { Horizontal } \\
\text { Precision }(\mathrm{m})\end{array}$ & \begin{tabular}{|c|} 
Vertical \\
Precision (m)
\end{tabular} & $\begin{array}{c}\text { Distance } \\
(\mathbf{m})\end{array}$ & $\begin{array}{c}\text { Solution } \\
\text { Type }\end{array}$ & $\begin{array}{c}\text { GPS } \\
\text { Satellites }\end{array}$ & PDOP & Status & RMS \\
\hline RIOD-VARG & $\mid 0.036$ & 0.071 & 261011.688 & $\begin{array}{l}\text { Fixed,Wide } \\
\text { Lane }\end{array}$ & 30 & 2.809 & Adjusted & 0.077 \\
\hline RIOD-VICO & 0.029 & 0.058 & 232120.635 & $\begin{array}{l}\text { Fixed,Wide } \\
\text { Lane }\end{array}$ & 30 & 2.735 & Adjusted & 0.073 \\
\hline VARG-VICO & $\mid 0.042$ & 0.080 & 280097.790 & $\begin{array}{l}\text { Fixed,Wide } \\
\text { Lane }\end{array}$ & 26 & 2.981 & Adjusted & 0.080 \\
\hline
\end{tabular}


Figura B48: Elipses de Erro

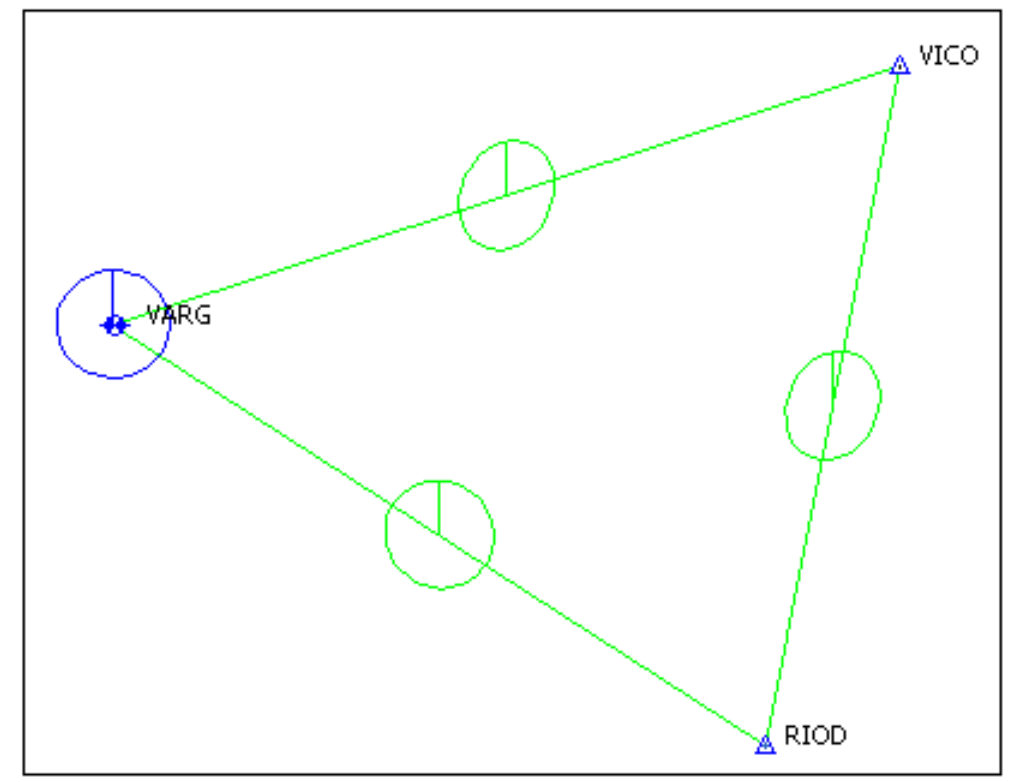

Coordenadas Ajustadas de VARG:

E (UTM): $454968.9518 \mathrm{~m}$

$>\mathrm{N}$ (UTM): $7617727.3119 \mathrm{~m}$

B.2 Distâncias Diferentes (com pelo menos uma menor que $300 \mathrm{~km}$ ) e Geometria Ruim entre as estações da RBMC (VARG-RIOD-UBER)

B.2.1 Ano de 2006

B.2.1.1 Verão (Dias Julianos 011 a 014)

- $\underline{011 / 2006}$

A posteriori UWE: 0.9074996 , Bounds: ( $0.6770032,1.241639)$ 
TABELA B49: Resultado do Processamento

\begin{tabular}{|c|c|c|c|c|c|c|c|c|}
\hline \multicolumn{9}{|c|}{ GPS Obs Report } \\
\hline Name & $\begin{array}{l}\text { Horizontal } \\
\text { Precision } \\
\text { (m) }\end{array}$ & $\begin{array}{l}\text { Vertical } \\
\text { Precision } \\
\text { (m) }\end{array}$ & $\begin{array}{c}\text { Distance } \\
\text { (m) }\end{array}$ & $\begin{array}{c}\text { Solution } \\
\text { Type }\end{array}$ & $\begin{array}{c}\text { GPS } \\
\text { Satellites }\end{array}$ & PDOP & Status & RMS \\
\hline \begin{tabular}{|l} 
RIOD - RBMC Rio de \\
Janeiro-UBER - \\
RBMC Uberlândia \\
\end{tabular} & 0.089 & 0.087 & 678629.082 & $\begin{array}{l}\text { Float, Wide } \\
\text { Lane }\end{array}$ & 26 & 3.004 & Adjusted & 0.122 \\
\hline $\begin{array}{l}\text { RIOD - RBMC Rio de } \\
\text { Janeiro-VARG - } \\
\text { RBMC Varginha }\end{array}$ & 0.041 & 0.063 & 261011.688 & $\begin{array}{l}\text { Fixed,Wide } \\
\text { Lane }\end{array}$ & | 26 & 2.885 & Adjusted & 0.076 \\
\hline \begin{tabular}{|l} 
UBER - RBMC \\
Uberlândia-VARG - \\
RBMC Varginha
\end{tabular} & 0.070 & 0.072 & 420650.795 & $\begin{array}{l}\text { Float,Wide } \\
\text { Lane }\end{array}$ & 29 & 3.034 & Adjusted & 0.098 \\
\hline
\end{tabular}

Figura B49: Elipses de Erro

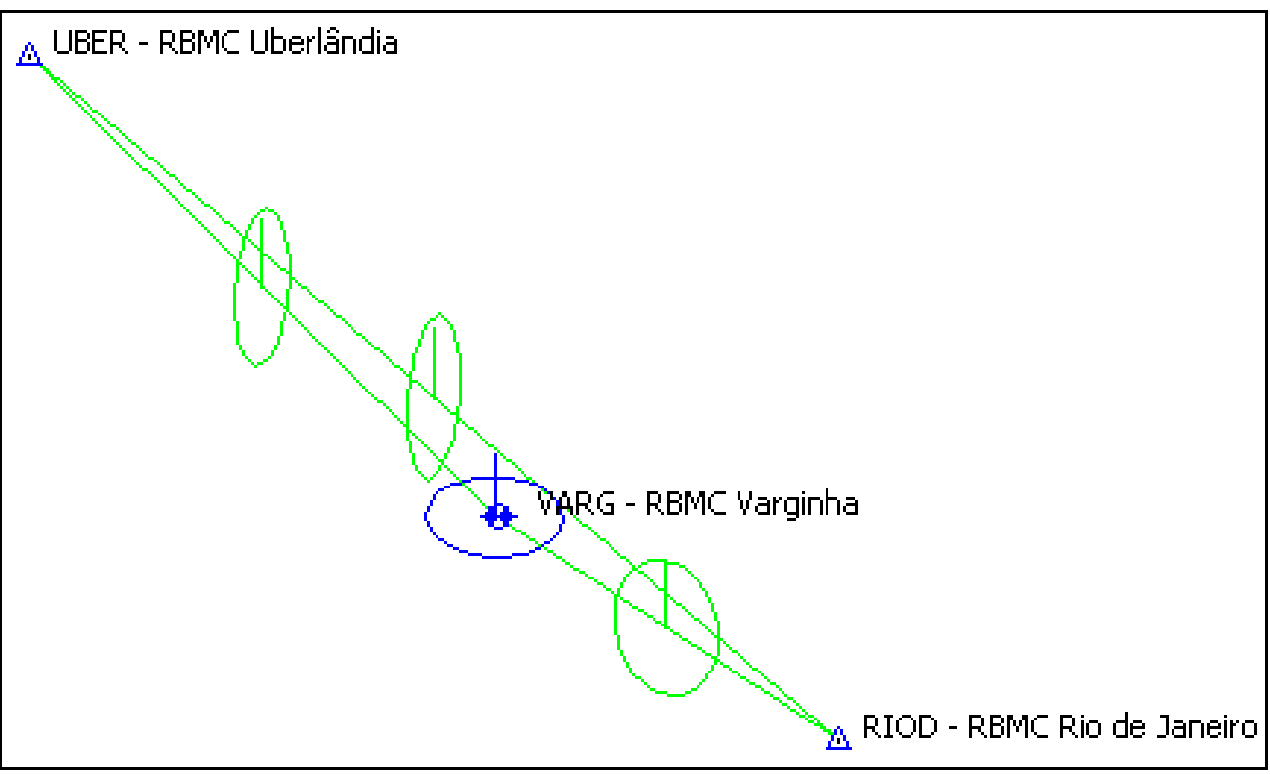

Coordenadas Ajustadas de VARG:

E (UTM): $454968.9476 \mathrm{~m}$

$>\mathrm{N}$ (UTM): $7617727.3013 \mathrm{~m}$

- $\underline{012 / 2006}$

A posteriori UWE: 0.8928756 , Bounds: ( $0.6770032,1.241639)$ 
TABELA B50: Resultado do Processamento

\begin{tabular}{|c|c|c|c|c|c|c|c|c|}
\hline \multicolumn{9}{|c|}{ GPS Obs Report } \\
\hline Name & $\begin{array}{l}\text { Horizontal } \\
\text { Precision } \\
\text { (m) }\end{array}$ & $\begin{array}{l}\text { Vertical } \\
\text { Precision } \\
\text { (m) }\end{array}$ & $\begin{array}{l}\text { Distance } \\
\text { (m) }\end{array}$ & $\begin{array}{l}\text { Solution } \\
\text { Type }\end{array}$ & $\begin{array}{c}\text { GPS } \\
\text { Satellites }\end{array}$ & |PDOP & Status & RMS \\
\hline $\begin{array}{l}\text { RIOD - RBMC Rio de } \\
\text { Janeiro-UBER - } \\
\text { RBMC Uberlândia } \\
\end{array}$ & 0.098 & 0.079 & 678629.129 & $\begin{array}{l}\text { Float,Wide } \\
\text { Lane }\end{array}$ & 24 & 3.009 & Adjusted & 0.124 \\
\hline $\begin{array}{l}\text { RIOD - RBMC Rio de } \\
\text { Janeiro-VARG - } \\
\text { RBMC Varginha } \\
\end{array}$ & 0.051 & 0.057 & 261011.715 & $\begin{array}{l}\text { Fixed,Wide } \\
\text { Lane }\end{array}$ & 23 & 3.001 & Adjusted & 0.075 \\
\hline $\begin{array}{l}\text { UBER - RBMC } \\
\text { Uberlândia-VARG - } \\
\text { RBMC Varginha }\end{array}$ & 0.061 & 0.077 & 420650.768 & $\begin{array}{l}\text { Fixed,Wide } \\
\text { Lane }\end{array}$ & 27 & 3.003 & Adjusted & 0.096 \\
\hline
\end{tabular}

Figura B50: Elipses de Erro

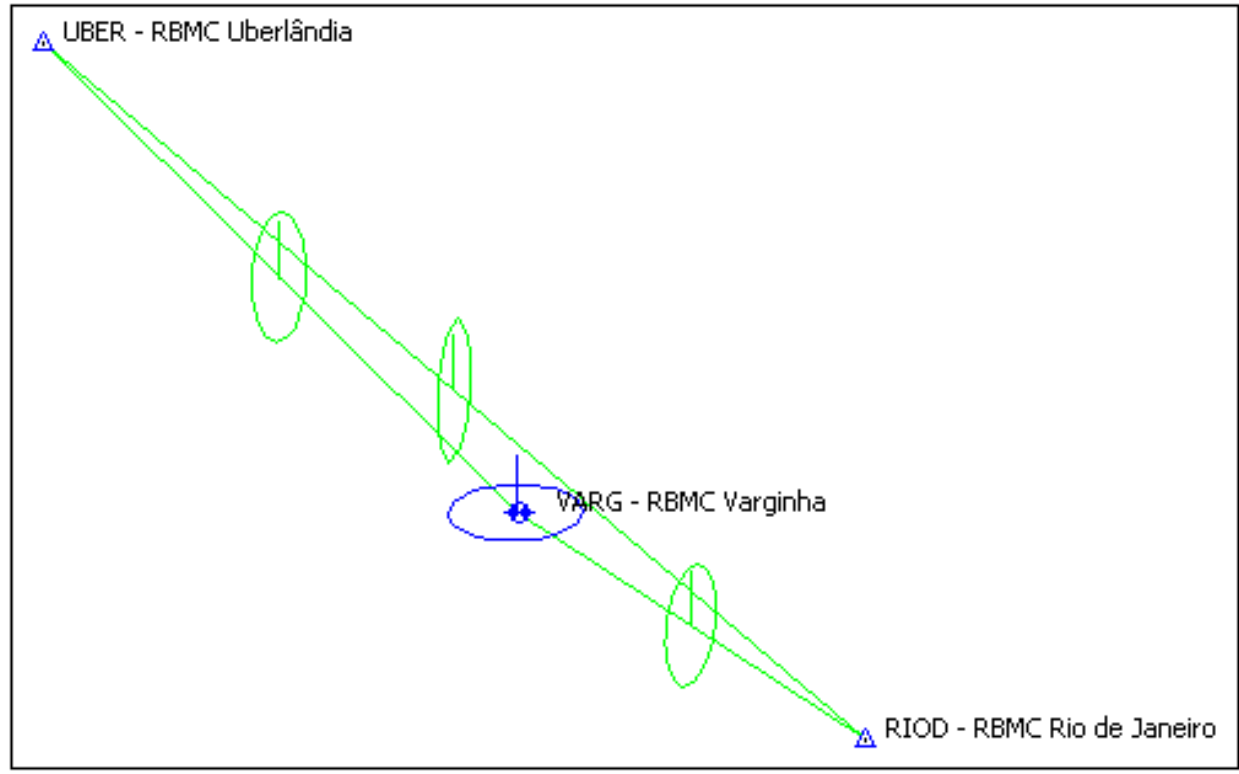

Coordenadas Ajustadas de VARG:

E (UTM): $454968.9516 \mathrm{~m}$

N (UTM): $7617727.3145 \mathrm{~m}$

- $\underline{013 / 2006}$

A posteriori UWE: 0.9873208 , Bounds: ( $0.6770032,1.241639)$ 
TABELA B51: Resultado do Processamento

\begin{tabular}{|c|c|c|c|c|c|c|c|c|}
\hline \multicolumn{9}{|c|}{ GPS Obs Report } \\
\hline Name & $\begin{array}{l}\text { Horizontal } \\
\text { Precision } \\
\text { (m) }\end{array}$ & \begin{tabular}{|c|} 
Vertical \\
Precision \\
(m)
\end{tabular} & $\begin{array}{l}\text { Distance } \\
\text { (m) }\end{array}$ & $\begin{array}{c}\text { Solution } \\
\text { Type }\end{array}$ & $\begin{array}{c}\text { GPS } \\
\text { Satellites }\end{array}$ & PDOP & Status & RMS \\
\hline $\begin{array}{l}\text { RIOD - RBMC Rio de } \\
\text { Janeiro-UBER - } \\
\text { RBMC Uberlândia }\end{array}$ & 0.087 & 0.092 & 678629.128 & $\begin{array}{l}\text { Float,Wide } \\
\text { Lane }\end{array}$ & 25 & 2.901 & Adjusted & $\mid 0.122$ \\
\hline $\begin{array}{l}\text { RIOD - RBMC Rio de } \\
\text { Janeiro-VARG - } \\
\text { RBMC Varginha }\end{array}$ & 0.043 & 0.062 & 261011.688 & $\begin{array}{l}\text { Fixed,Wide } \\
\text { Lane }\end{array}$ & 25 & 2.564 & Adjusted & 0.080 \\
\hline $\begin{array}{l}\text { UBER - RBMC } \\
\text { Uberlândia-VARG - } \\
\text { RBMC Varginha }\end{array}$ & 0.042 & 0.082 & 420650.771 & $\begin{array}{l}\text { Fixed,Wide } \\
\text { Lane }\end{array}$ & |24 & 3.029 & Adjusted & 0.096 \\
\hline
\end{tabular}

Figura B51: Elipses de Erro

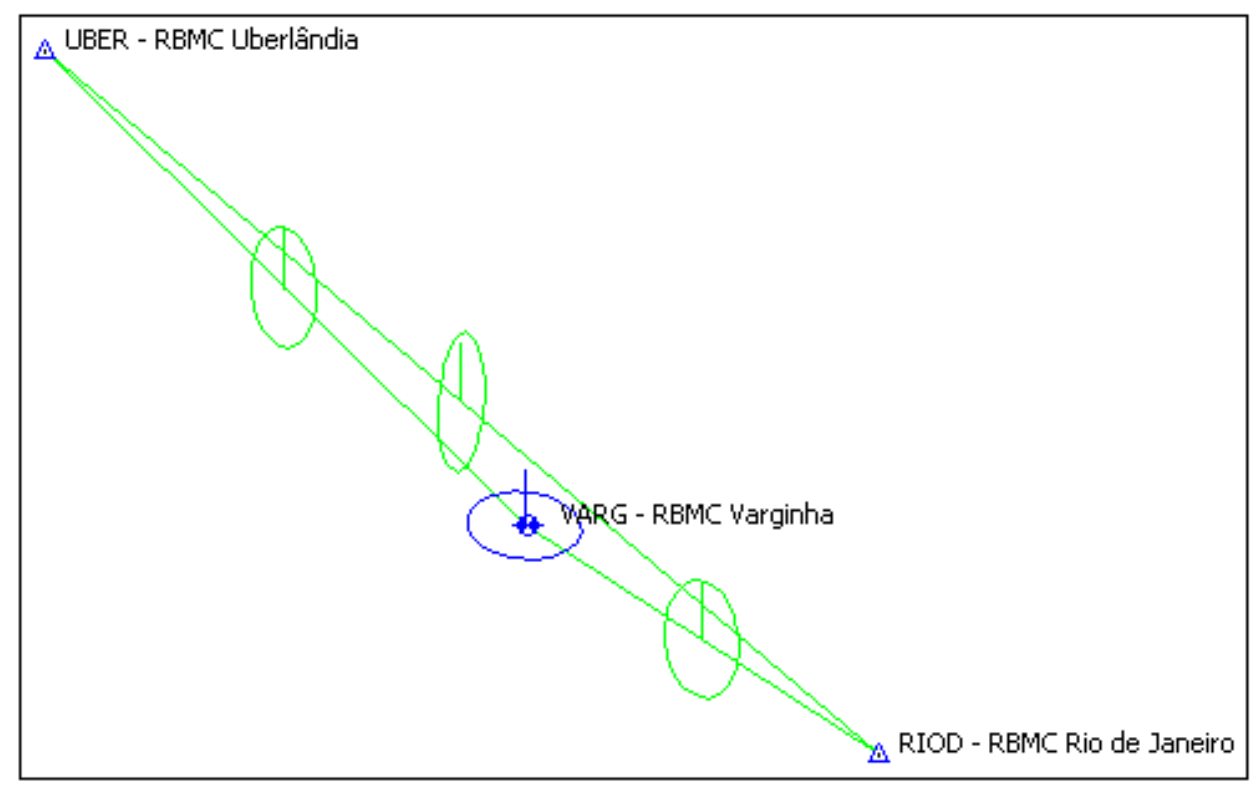

Coordenadas Ajustadas de VARG:

E (UTM): $454968.9328 \mathrm{~m}$

N (UTM): $7617727.2891 \mathrm{~m}$

- $\underline{014 / 2006}$

A posteriori UWE: 1.2351 , Bounds: ( $0.6770032,1.241639)$ 
TABELA B52: Resultado do Processamento

\begin{tabular}{|c|c|c|c|c|c|c|c|c|}
\hline \multicolumn{9}{|c|}{ GPS Obs Report } \\
\hline Name & $\begin{array}{l}\text { Horizontal } \\
\text { Precision } \\
\text { (m) }\end{array}$ & $\begin{array}{c}\text { Vertical } \\
\text { Precision } \\
(\mathbf{m})\end{array}$ & $\begin{array}{l}\text { Distance } \\
\text { (m) }\end{array}$ & $\begin{array}{l}\text { Solution } \\
\text { Type }\end{array}$ & $\begin{array}{c}\text { GPS } \\
\text { Satellites }\end{array}$ & PDOP & Status & RMS \\
\hline $\begin{array}{l}\text { RIOD - RBMC Rio de } \\
\text { Janeiro-UBER - } \\
\text { RBMC Uberlândia }\end{array}$ & 0.088 & 0.089 & 678629.087 & $\begin{array}{l}\text { Float,Wide } \\
\text { Lane }\end{array}$ & 26 & 3.007 & Adjusted & 0.122 \\
\hline $\begin{array}{l}\text { RIOD - RBMC Rio de } \\
\text { Janeiro-VARG - } \\
\text { RBMC Varginha }\end{array}$ & 0.042 & 0.067 & 261011.691 & $\begin{array}{l}\text { Fixed,Wide } \\
\text { Lane }\end{array}$ & 25 & 2.891 & Adjusted & 0.078 \\
\hline $\begin{array}{l}\text { UBER - RBMC } \\
\text { Uberlândia-VARG - } \\
\text { RBMC Varginha }\end{array}$ & 0.054 & 0.085 & 420650.788 & $\begin{array}{l}\text { Float,Wide } \\
\text { Lane }\end{array}$ & 29 & 3.003 & Adjusted & 0.096 \\
\hline
\end{tabular}

Figura B52: Elipses de Erro

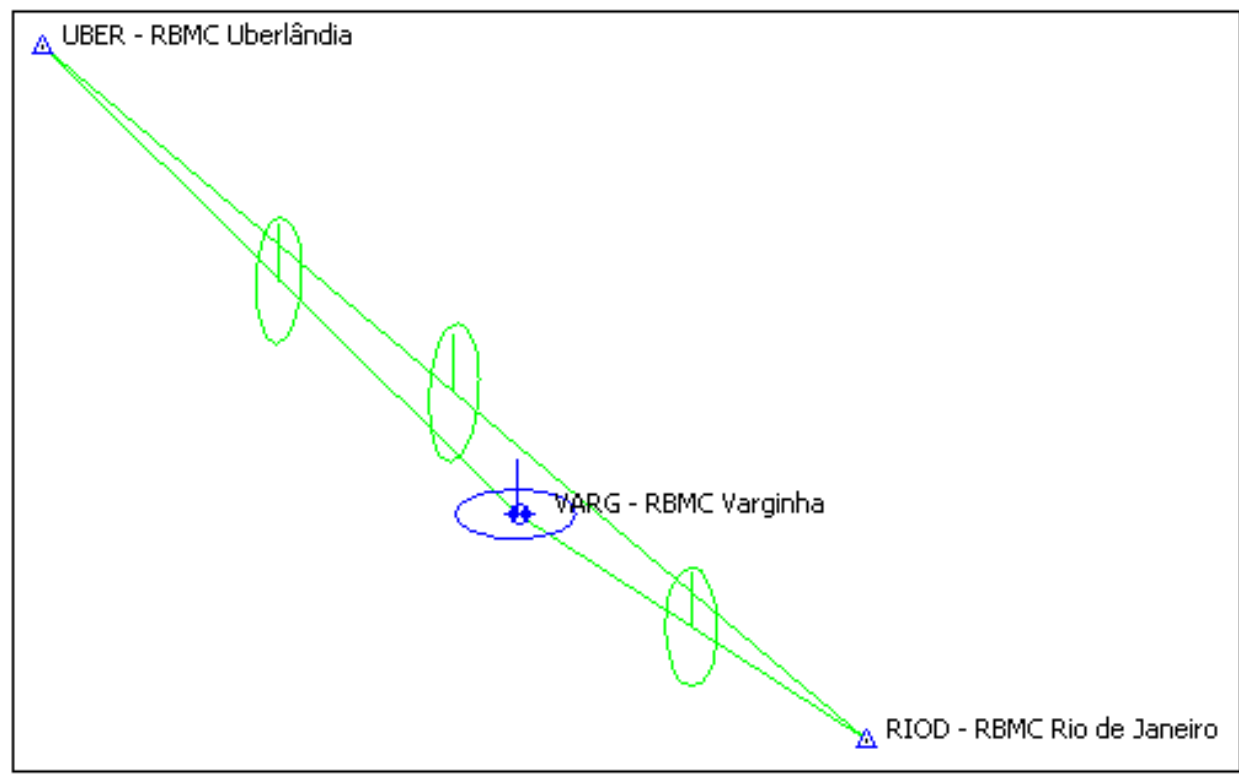

Coordenadas Ajustadas de VARG:

E (UTM): $454968.9789 \mathrm{~m}$

N (UTM): $7617727.2802 \mathrm{~m}$

\section{B.2.1.2 Outono (Dias Julianos 101 a 104)}

- $101 / 2006$

A posteriori UWE: 1.22689 , Bounds: ( $0.6770032,1.241639)$ 
TABELA B53: Resultado do Processamento

\begin{tabular}{|c|c|c|c|c|c|c|c|c|}
\hline \multicolumn{9}{|c|}{ GPS Obs Report } \\
\hline Name & $\begin{array}{l}\text { Horizontal } \\
\text { Precision } \\
\text { (m) }\end{array}$ & $\begin{array}{l}\text { Vertical } \\
\text { Precision } \\
\text { (m) }\end{array}$ & $\begin{array}{l}\text { Distance } \\
\text { (m) }\end{array}$ & $\begin{array}{l}\text { Solution } \\
\text { Type }\end{array}$ & $\begin{array}{c}\text { GPS } \\
\text { Satellites }\end{array}$ & |PDOP & Status & RMS \\
\hline $\begin{array}{l}\text { RIOD - RBMC Rio de } \\
\text { Janeiro-UBER - } \\
\text { RBMC Uberlândia } \\
\end{array}$ & 0.091 & 0.088 & 678629.114 & $\begin{array}{l}\text { Float,Wide } \\
\text { Lane }\end{array}$ & 27 & 2.801 & Adjusted & 0.124 \\
\hline $\begin{array}{l}\text { RIOD - RBMC Rio de } \\
\text { Janeiro-VARG - } \\
\text { RBMC Varginha } \\
\end{array}$ & 0.037 & 0.068 & 261011.686 & $\begin{array}{l}\text { Fixed,Wide } \\
\text { Lane }\end{array}$ & 27 & 3.045 & Adjusted & 0.078 \\
\hline $\begin{array}{l}\text { UBER - RBMC } \\
\text { Uberlândia-VARG - } \\
\text { RBMC Varginha }\end{array}$ & 0.072 & 0.066 & 420650.794 & $\begin{array}{l}\text { Float,Wide } \\
\text { Lane }\end{array}$ & 26 & 2.777 & Adjusted & 0.098 \\
\hline
\end{tabular}

Figura B53: Elipses de Erro

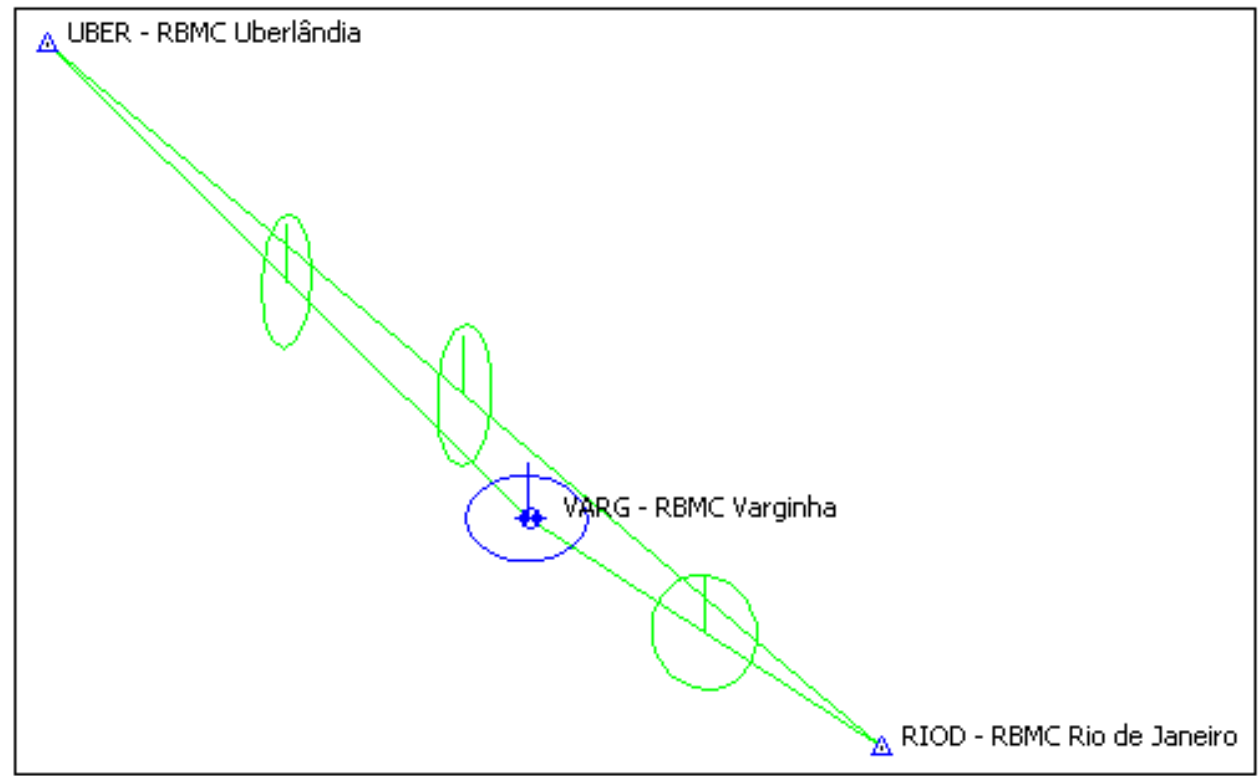

Coordenadas Ajustadas de VARG:

E (UTM): $454968.9417 \mathrm{~m}$

N (UTM): $7617727.2875 \mathrm{~m}$

- $102 / 2006$

A posteriori UWE: 0.788106 , Bounds: ( $0.6770032,1.241639$ ) 
TABELA B54: Resultado do Processamento

\begin{tabular}{|c|c|c|c|c|c|c|c|c|}
\hline \multicolumn{9}{|c|}{ GPS Obs Report } \\
\hline Name & $\begin{array}{l}\text { Horizontal } \\
\text { Precision } \\
\text { (m) }\end{array}$ & $\begin{array}{l}\text { Vertical } \\
\text { Precision } \\
\text { (m) }\end{array}$ & $\begin{array}{l}\text { Distance } \\
\text { (m) }\end{array}$ & $\begin{array}{l}\text { Solution } \\
\text { Type }\end{array}$ & $\begin{array}{c}\text { GPS } \\
\text { Satellites }\end{array}$ & |PDOP & Status & RMS \\
\hline $\begin{array}{l}\text { RIOD - RBMC Rio de } \\
\text { Janeiro-UBER - } \\
\text { RBMC Uberlândia } \\
\end{array}$ & 0.091 & 0.082 & 678629.087 & $\begin{array}{l}\text { Float,Wide } \\
\text { Lane }\end{array}$ & 24 & 2.886 & Adjusted & 0.124 \\
\hline $\begin{array}{l}\text { RIOD - RBMC Rio de } \\
\text { Janeiro-VARG - } \\
\text { RBMC Varginha } \\
\end{array}$ & 0.037 & 0.067 & 261011.677 & $\begin{array}{l}\text { Fixed,Wide } \\
\text { Lane }\end{array}$ & 26 & 2.364 & Adjusted & $\mid 0.078$ \\
\hline $\begin{array}{l}\text { UBER - RBMC } \\
\text { Uberlândia-VARG - } \\
\text { RBMC Varginha }\end{array}$ & 0.067 & 0.067 & 420650.763 & $\begin{array}{l}\text { Float,Wide } \\
\text { Lane }\end{array}$ & 26 & 3.007 & Adjusted & 0.098 \\
\hline
\end{tabular}

Figura B54: Elipses de Erro

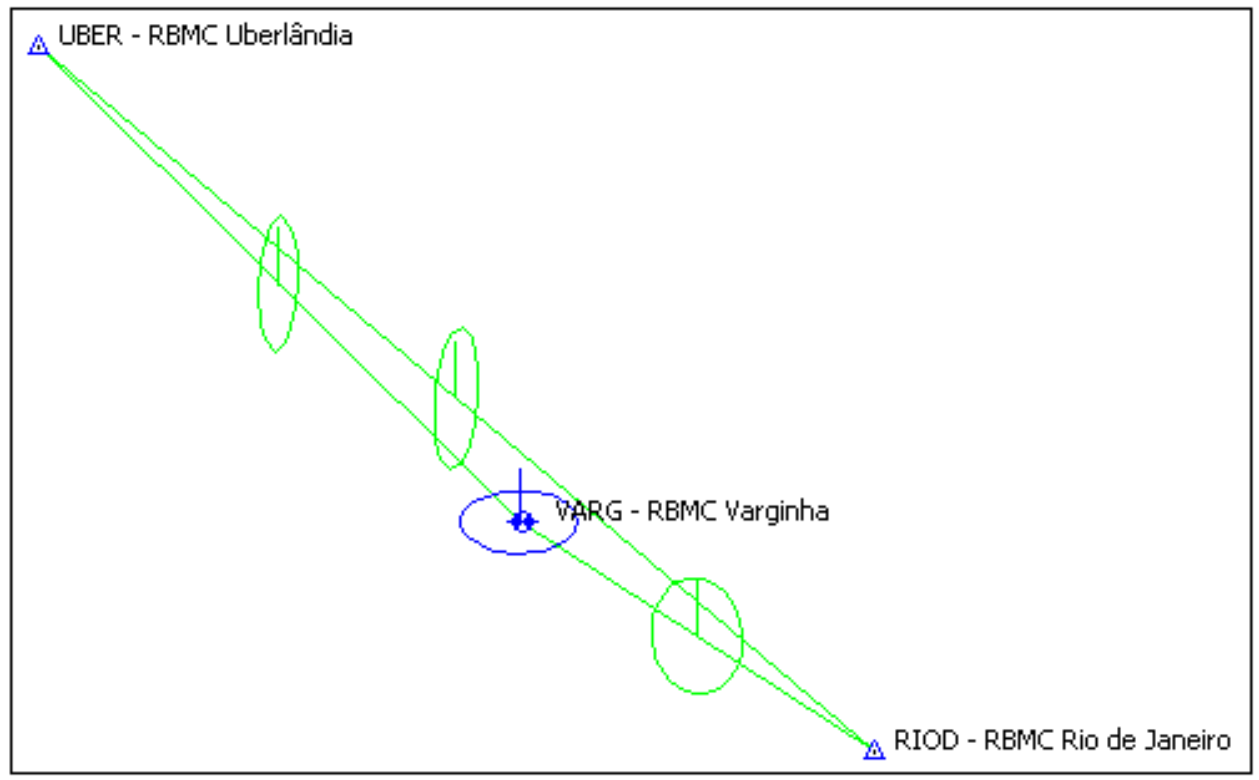

Coordenadas Ajustadas de VARG:

E (UTM): $454968.9768 \mathrm{~m}$

N (UTM): $7617727.2922 \mathrm{~m}$

- $103 / 2006$

A posteriori UWE: 0.8466732 , Bounds: ( $0.6770032,1.241639)$ 
TABELA B55: Resultado do Processamento

\begin{tabular}{|c|c|c|c|c|c|c|c|c|}
\hline \multicolumn{9}{|c|}{ GPS Obs Report } \\
\hline Name & $\begin{array}{l}\text { Horizontal } \\
\text { Precision } \\
\text { (m) }\end{array}$ & $\begin{array}{l}\text { Vertical } \\
\text { Precision } \\
\text { (m) }\end{array}$ & $\begin{array}{l}\text { Distance } \\
\text { (m) }\end{array}$ & $\begin{array}{l}\text { Solution } \\
\text { Type }\end{array}$ & $\begin{array}{c}\text { GPS } \\
\text { Satellites }\end{array}$ & |PDOP & Status & RMS \\
\hline $\begin{array}{l}\text { RIOD - RBMC Rio de } \\
\text { Janeiro-UBER - } \\
\text { RBMC Uberlândia } \\
\end{array}$ & 0.086 & 0.090 & 678629.102 & $\begin{array}{l}\text { Float,Wide } \\
\text { Lane }\end{array}$ & 29 & 4.348 & Adjusted & 0.124 \\
\hline $\begin{array}{l}\text { RIOD - RBMC Rio de } \\
\text { Janeiro-VARG - } \\
\text { RBMC Varginha } \\
\end{array}$ & 0.035 & 0.069 & 261011.686 & $\begin{array}{l}\text { Fixed,Wide } \\
\text { Lane }\end{array}$ & 29 & 3.002 & Adjusted & $\mid 0.077$ \\
\hline $\begin{array}{l}\text { UBER - RBMC } \\
\text { Uberlândia-VARG - } \\
\text { RBMC Varginha }\end{array}$ & 0.064 & 0.073 & 420650.776 & $\begin{array}{l}\text { Float,Wide } \\
\text { Lane }\end{array}$ & 29 & 3.009 & Adjusted & 0.097 \\
\hline
\end{tabular}

Figura B55: Elipses de Erro

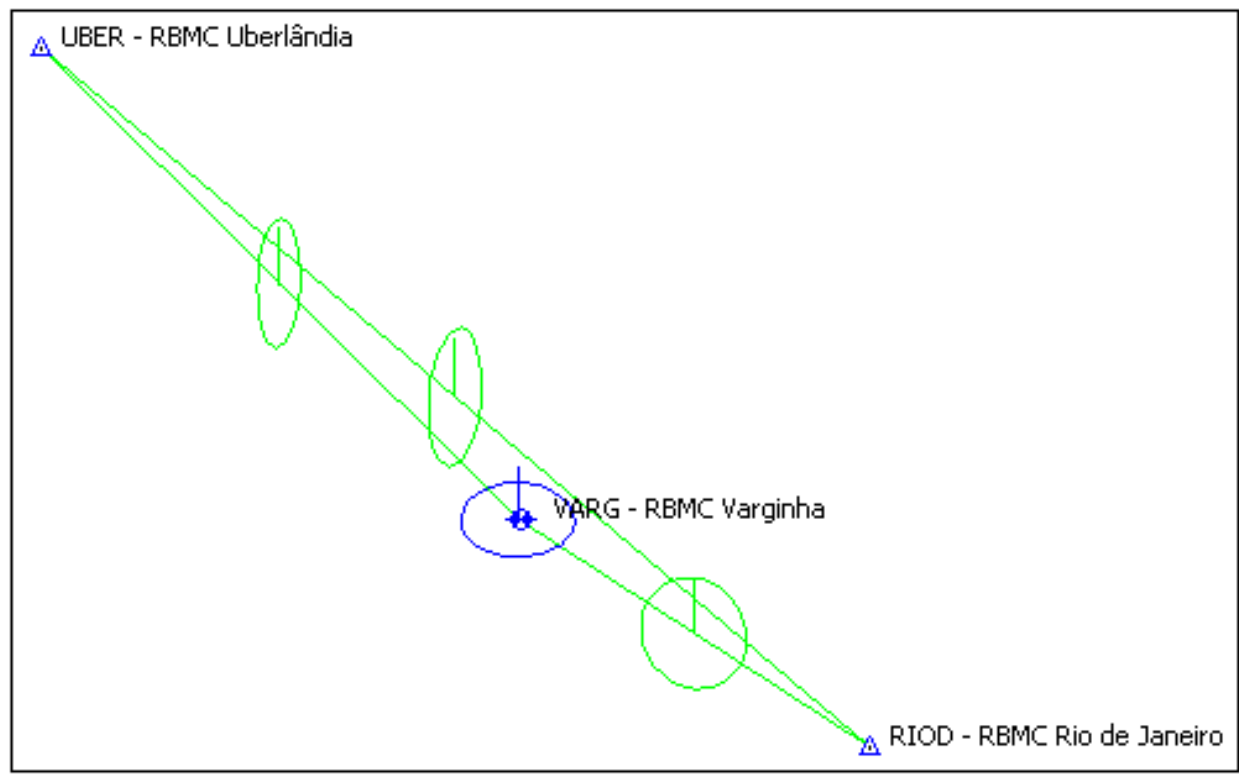

Coordenadas Ajustadas de VARG:

E (UTM): $454968.9561 \mathrm{~m}$

N (UTM): $7617727.2917 \mathrm{~m}$

- $104 / 2006$

A posteriori UWE: 0.9537787 , Bounds: ( $0.6770032,1.241639)$ 
TABELA B56: Resultado do Processamento

\begin{tabular}{|c|c|c|c|c|c|c|c|c|}
\hline \multicolumn{9}{|c|}{ GPS Obs Report } \\
\hline Name & $\begin{array}{l}\text { Horizontal } \\
\text { Precision } \\
\text { (m) }\end{array}$ & $\begin{array}{l}\text { Vertical } \\
\text { Precision } \\
\text { (m) }\end{array}$ & $\begin{array}{l}\text { Distance } \\
\text { (m) }\end{array}$ & $\begin{array}{l}\text { Solution } \\
\text { Type }\end{array}$ & $\begin{array}{c}\text { GPS } \\
\text { Satellites }\end{array}$ & |PDOP & Status & RMS \\
\hline $\begin{array}{l}\text { RIOD - RBMC Rio de } \\
\text { Janeiro-UBER - } \\
\text { RBMC Uberlândia } \\
\end{array}$ & 0.090 & 0.086 & 678629.121 & $\begin{array}{l}\text { Float,Wide } \\
\text { Lane }\end{array}$ & 29 & 4.544 & Adjusted & 0.124 \\
\hline $\begin{array}{l}\text { RIOD - RBMC Rio de } \\
\text { Janeiro-VARG - } \\
\text { RBMC Varginha } \\
\end{array}$ & 0.035 & 0.068 & 261011.684 & $\begin{array}{l}\text { Fixed,Wide } \\
\text { Lane }\end{array}$ & 29 & 6.339 & Adjusted & $\mid 0.077$ \\
\hline $\begin{array}{l}\text { UBER - RBMC } \\
\text { Uberlândia-VARG - } \\
\text { RBMC Varginha }\end{array}$ & 0.067 & 0.071 & 420650.775 & $\begin{array}{l}\text { Float,Wide } \\
\text { Lane }\end{array}$ & 29 & 5.861 & Adjusted & 0.098 \\
\hline
\end{tabular}

Figura B56: Elipses de Erro

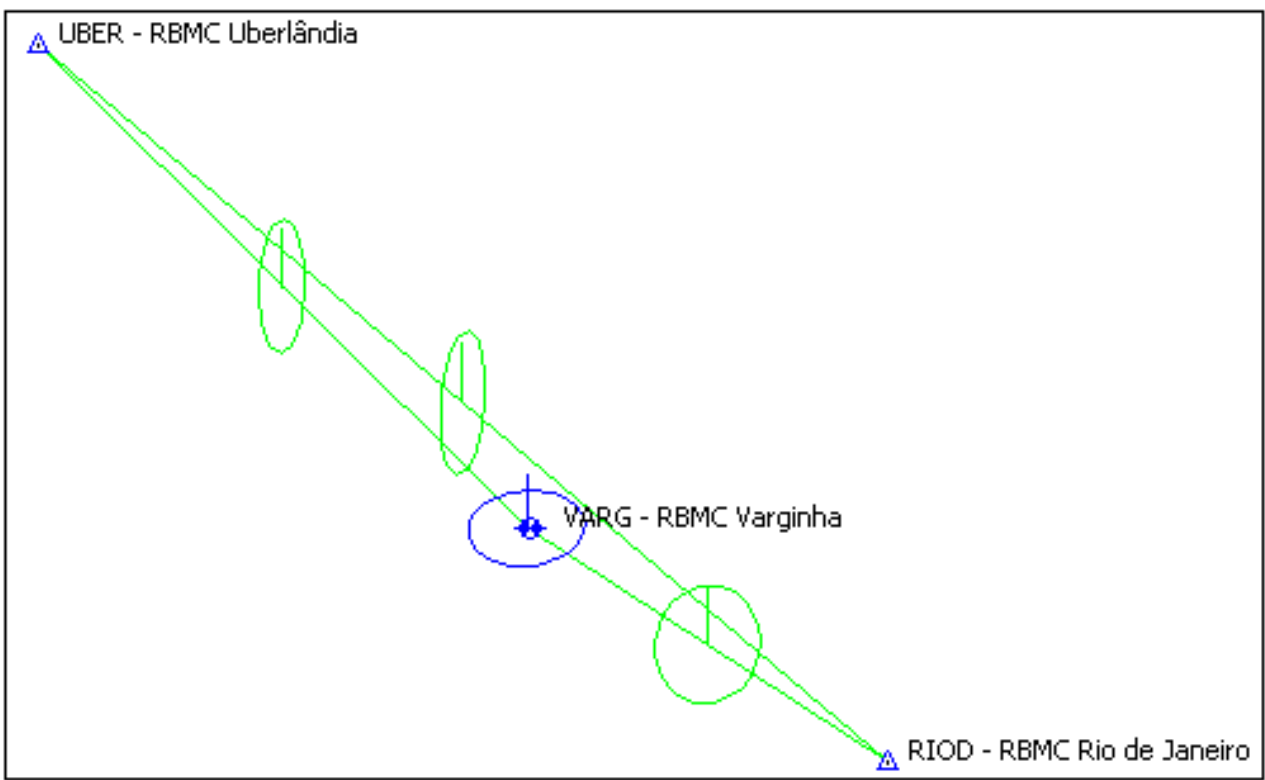

Coordenadas Ajustadas de VARG:

E (UTM): $454968.9533 \mathrm{~m}$

$>\mathrm{N}$ (UTM): $7617727.2910 \mathrm{~m}$

\section{B.2.1.3 Inverno (Dias Julianos 193 a 196)}

- $193 / 2006$

A posteriori UWE: 1.471061 , Bounds: ( $0.6770032,1.241639$ ) 
TABELA B57: Resultado do Processamento

\begin{tabular}{|c|c|c|c|c|c|c|c|c|}
\hline \multicolumn{9}{|c|}{ GPS Obs Report } \\
\hline Name & $\begin{array}{l}\text { Horizontal } \\
\text { Precision } \\
\text { (m) }\end{array}$ & $\begin{array}{l}\text { Vertical } \\
\text { Precision } \\
\text { (m) }\end{array}$ & $\begin{array}{l}\text { Distance } \\
\text { (m) }\end{array}$ & $\begin{array}{l}\text { Solution } \\
\text { Type }\end{array}$ & $\begin{array}{c}\text { GPS } \\
\text { Satellites }\end{array}$ & |PDOP & Status & RMS \\
\hline $\begin{array}{l}\text { RIOD - RBMC Rio de } \\
\text { Janeiro-UBER - } \\
\text { RBMC Uberlândia } \\
\end{array}$ & 0.074 & 0.099 & 678629.077 & $\begin{array}{l}\text { Fixed,Wide } \\
\text { Lane }\end{array}$ & 29 & 5.182 & Adjusted & 0.124 \\
\hline $\begin{array}{l}\text { RIOD - RBMC Rio de } \\
\text { Janeiro-VARG - } \\
\text { RBMC Varginha } \\
\end{array}$ & 0.034 & 0.069 & 261011.682 & $\begin{array}{l}\text { Fixed,Wide } \\
\text { Lane }\end{array}$ & 29 & 4.335 & Adjusted & $\mid 0.077$ \\
\hline $\begin{array}{l}\text { UBER - RBMC } \\
\text { Uberlândia-VARG - } \\
\text { RBMC Varginha }\end{array}$ & 0.044 & 0.087 & 420650.783 & $\begin{array}{l}\text { Fixed,Wide } \\
\text { Lane }\end{array}$ & 29 & 4.923 & Adjusted & 0.097 \\
\hline
\end{tabular}

Figura B57: Elipses de Erro

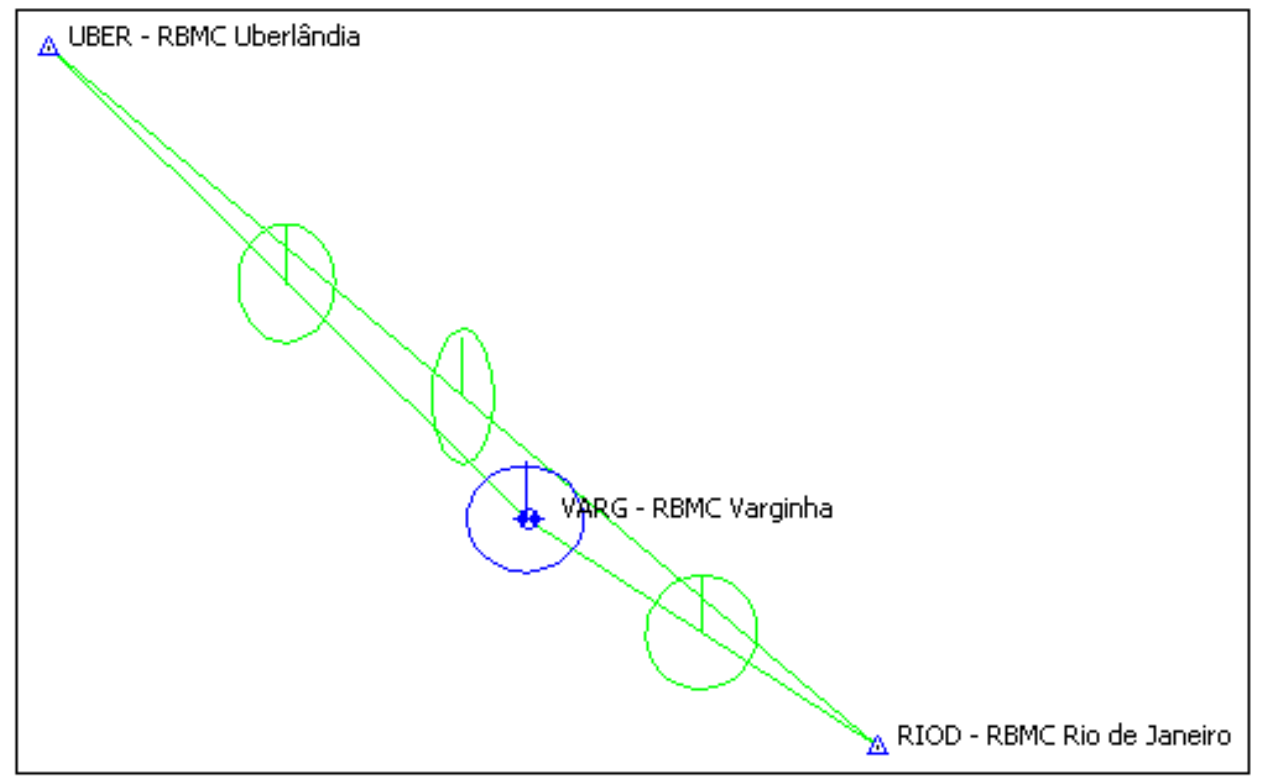

Coordenadas Ajustadas de VARG:

E (UTM): $454968.9581 \mathrm{~m}$

N (UTM): $7617727.2935 \mathrm{~m}$

- $194 / 2006$

A posteriori UWE: 0.7110671 , Bounds: ( $0.6770032,1.241639)$ 
TABELA B58: Resultado do Processamento

\begin{tabular}{|c|c|c|c|c|c|c|c|c|}
\hline \multicolumn{9}{|c|}{ GPS Obs Report } \\
\hline Name & $\begin{array}{l}\text { Horizontal } \\
\text { Precision } \\
\text { (m) }\end{array}$ & $\begin{array}{l}\text { Vertical } \\
\text { Precision } \\
\text { (m) }\end{array}$ & $\begin{array}{l}\text { Distance } \\
\text { (m) }\end{array}$ & $\begin{array}{l}\text { Solution } \\
\text { Type }\end{array}$ & $\begin{array}{c}\text { GPS } \\
\text { Satellites }\end{array}$ & |PDOP & Status & RMS \\
\hline $\begin{array}{l}\text { RIOD - RBMC Rio de } \\
\text { Janeiro-UBER - } \\
\text { RBMC Uberlândia } \\
\end{array}$ & 0.056 & 0.110 & 678629.067 & $\begin{array}{l}\text { Fixed,Wide } \\
\text { Lane }\end{array}$ & 29 & 3.001 & Adjusted & 0.124 \\
\hline $\begin{array}{l}\text { RIOD - RBMC Rio de } \\
\text { Janeiro-VARG - } \\
\text { RBMC Varginha } \\
\end{array}$ & 0.033 & 0.069 & 261011.677 & $\begin{array}{l}\text { Fixed,Wide } \\
\text { Lane }\end{array}$ & 29 & 2.983 & Adjusted & $\mid 0.077$ \\
\hline $\begin{array}{l}\text { UBER - RBMC } \\
\text { Uberlândia-VARG - } \\
\text { RBMC Varginha }\end{array}$ & 0.047 & 0.085 & 420650.777 & $\begin{array}{l}\text { Fixed,Wide } \\
\text { Lane }\end{array}$ & 29 & 3.022 & Adjusted & 0.097 \\
\hline
\end{tabular}

Figura B58: Elipses de Erro

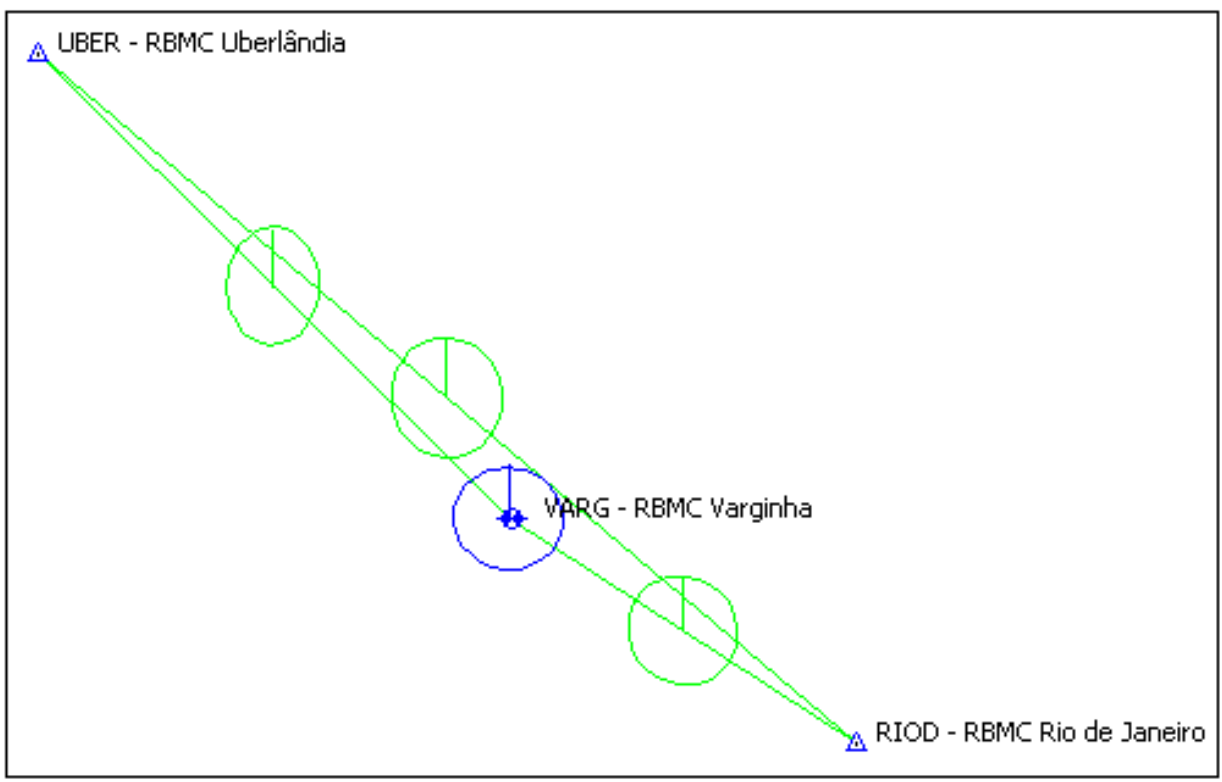

Coordenadas Ajustadas de VARG:

E (UTM): $454968.9615 \mathrm{~m}$

$>\mathrm{N}(\mathrm{UTM}): 7617727.2956 \mathrm{~m}$

- $195 / 2006$

A posteriori UWE: 0.6504965 , Bounds: ( $0.6770032,1.241639)$ 
TABELA B59: Resultado do Processamento

\begin{tabular}{|c|c|c|c|c|c|c|c|c|}
\hline \multicolumn{9}{|c|}{ GPS Obs Report } \\
\hline Name & $\begin{array}{l}\text { Horizontal } \\
\text { Precision } \\
(\mathbf{m})\end{array}$ & $\begin{array}{l}\text { Vertical } \\
\text { Precision } \\
\text { (m) }\end{array}$ & $\begin{array}{c}\text { Distance } \\
(\mathbf{m})\end{array}$ & $\begin{array}{l}\text { Solution } \\
\text { Type }\end{array}$ & $\begin{array}{c}\text { GPS } \\
\text { Satellites }\end{array}$ & PDOP & Status & RMS \\
\hline $\begin{array}{l}\text { RIOD - RBMC Rio de } \\
\text { Janeiro-UBER - } \\
\text { RBMC Uberlândia } \\
\end{array}$ & 0.051 & 0.113 & 678629.087 & $\begin{array}{l}\text { Fixed,Wide } \\
\text { Lane }\end{array}$ & 29 & 10.786 & Adjusted & 0.124 \\
\hline $\begin{array}{l}\text { RIOD - RBMC Rio de } \\
\text { Janeiro-VARG - } \\
\text { RBMC Varginha } \\
\end{array}$ & 0.033 & 0.069 & 261011.676 & $\begin{array}{l}\text { Fixed,Wide } \\
\text { Lane }\end{array}$ & $\mid 29$ & 4.179 & Adjusted & $\mid 0.077$ \\
\hline $\begin{array}{l}\text { UBER - RBMC } \\
\text { Uberlândia-VARG - } \\
\text { RBMC Varginha }\end{array}$ & 0.044 & 0.087 & 420650.775 & $\begin{array}{l}\text { Fixed,Wide } \\
\text { Lane }\end{array}$ & 29 & 10.503 & Adjusted & 0.097 \\
\hline
\end{tabular}

Figura B59: Elipses de Erro

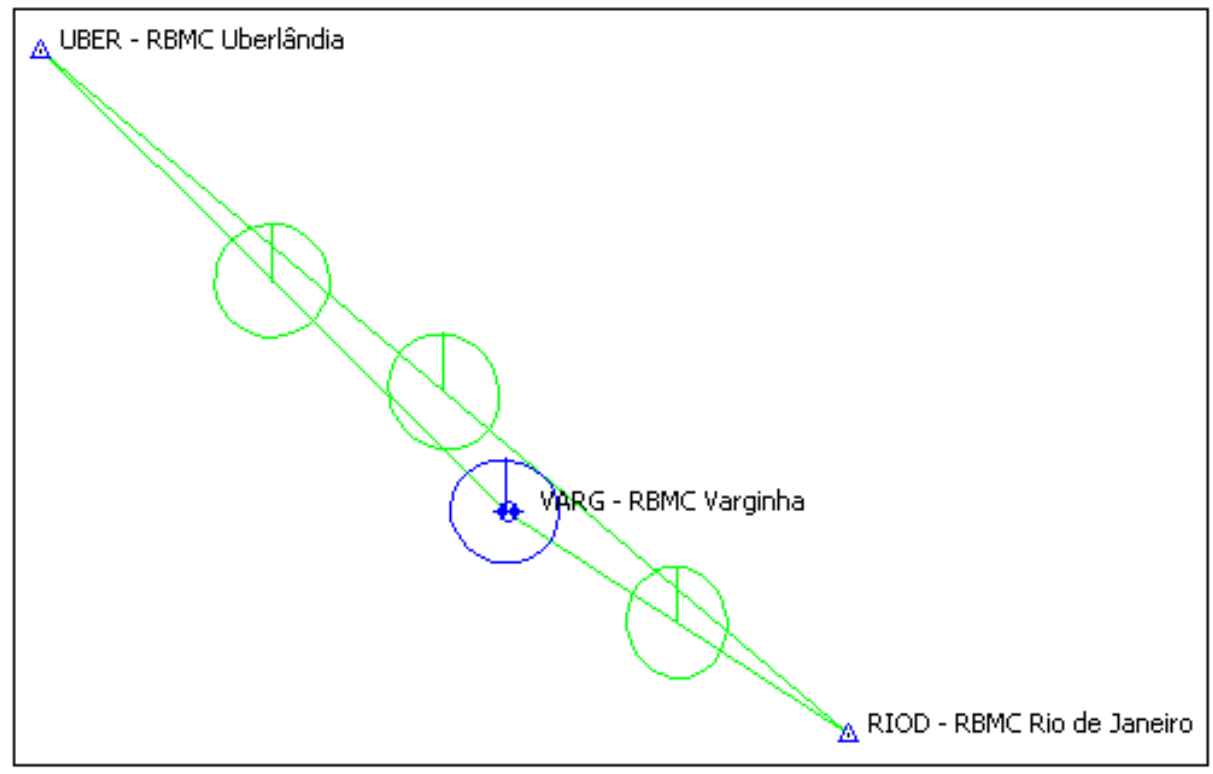

Coordenadas Ajustadas de VARG:

E (UTM): $454968.9627 \mathrm{~m}$

N (UTM): $7617727.3003 \mathrm{~m}$

- $196 / 2006$

A posteriori UWE: 1.05728 , Bounds: ( $0.6770032,1.241639$ ) 
TABELA B60: Resultado do Processamento

\begin{tabular}{|c|c|c|c|c|c|c|c|c|}
\hline \multicolumn{9}{|c|}{ GPS Obs Report } \\
\hline Name & \begin{tabular}{|c|} 
Horizontal \\
Precision \\
(m)
\end{tabular} & $\begin{array}{l}\text { Vertical } \\
\text { Precision } \\
\text { (m) }\end{array}$ & $\begin{array}{l}\text { Distance } \\
\quad(\mathbf{m})\end{array}$ & $\begin{array}{c}\text { Solution } \\
\text { Type }\end{array}$ & $\begin{array}{c}\text { GPS } \\
\text { Satellites }\end{array}$ & PDOP & Status & RMS \\
\hline $\begin{array}{l}\text { RIOD - RBMC Rio de } \\
\text { Janeiro-UBER - } \\
\text { RBMC Uberlândia }\end{array}$ & 0.057 & 0.111 & 678629.088 & $\begin{array}{l}\text { Fixed,Wide } \\
\text { Lane }\end{array}$ & 28 & 3.054 & Adjusted & 0.125 \\
\hline $\begin{array}{l}\text { RIOD - RBMC Rio de } \\
\text { Janeiro-VARG - } \\
\text { RBMC Varginha }\end{array}$ & 0.035 & 0.065 & 261011.667 & $\begin{array}{l}\text { Fixed,Wide } \\
\text { Lane }\end{array}$ & 26 & 3.021 & Adjusted & 0.078 \\
\hline \begin{tabular}{|l} 
UBER - RBMC \\
Uberlândia-VARG - \\
RBMC Varginha
\end{tabular} & 0.041 & 0.086 & 420650.780 & $\begin{array}{l}\text { Fixed,Wide } \\
\text { Lane }\end{array}$ & 27 & 2.897 & Adjusted & 0.098 \\
\hline
\end{tabular}

Figura B60: Elipses de Erro

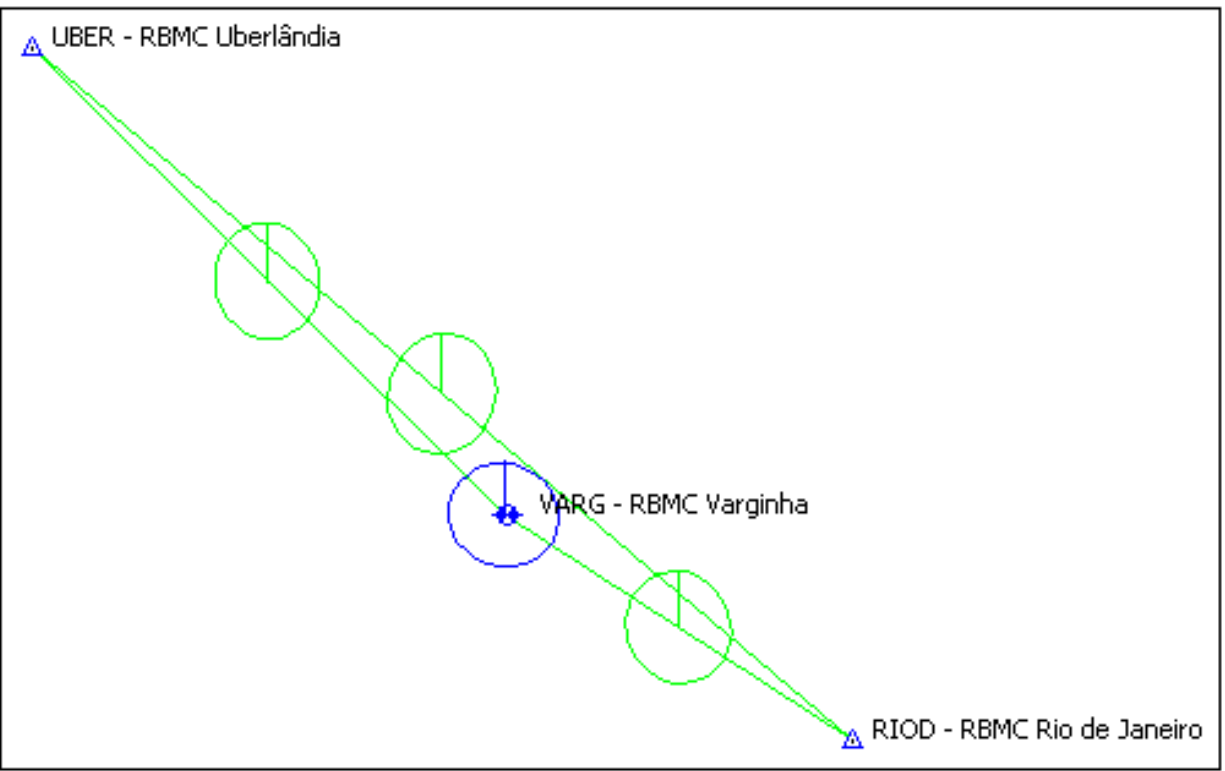

Coordenadas Ajustadas de VARG:

E (UTM): $454968.9670 \mathrm{~m}$

N (UTM): $7617727.3002 \mathrm{~m}$

\section{B.2.1.4 Primavera (Dias Julianos 286 a 289)}

- $286 / 2006$

A posteriori UWE: 1.09897 , Bounds: ( $0.6770032,1.241639$ ) 
TABELA B61: Resultado do Processamento

\begin{tabular}{|c|c|c|c|c|c|c|c|c|}
\hline \multicolumn{9}{|c|}{ GPS Obs Report } \\
\hline Name & \begin{tabular}{|c|} 
Horizontal \\
Precision \\
$(\mathbf{m})$
\end{tabular} & $\begin{array}{l}\text { Vertical } \\
\text { Precision } \\
\text { (m) }\end{array}$ & $\begin{array}{l}\text { Distance } \\
\text { (m) }\end{array}$ & $\begin{array}{c}\text { Solution } \\
\text { Type }\end{array}$ & $\begin{array}{c}\text { GPS } \\
\text { Satellites }\end{array}$ & PDOP & Status & RMS \\
\hline $\begin{array}{l}\text { RIOD - RBMC Rio de } \\
\text { Janeiro-UBER - } \\
\text { RBMC Uberlândia } \\
\end{array}$ & 0.095 & 0.084 & $\mid 678629.073$ & $\begin{array}{l}\text { Float, Wide } \\
\text { Lane }\end{array}$ & 24 & 2.584 & Adjusted & 0.124 \\
\hline $\begin{array}{l}\text { RIOD - RBMC Rio de } \\
\text { Janeiro-VARG - } \\
\text { RBMC Varginha }\end{array}$ & 0.039 & 0.066 & 261011.696 & $\begin{array}{l}\text { Fixed,Wide } \\
\text { Lane }\end{array}$ & $\mid 25$ & 3.028 & Adjusted & 0.078 \\
\hline \begin{tabular}{|l} 
UBER - RBMC \\
Uberlândia-VARG - \\
RBMC Varginha
\end{tabular} & 0.051 & 0.083 & 420650.811 & $\begin{array}{l}\text { Fixed,Wide } \\
\text { Lane }\end{array}$ & | 26 & 2.664 & Adjusted & 0.096 \\
\hline
\end{tabular}

Figura B61: Elipses de Erro

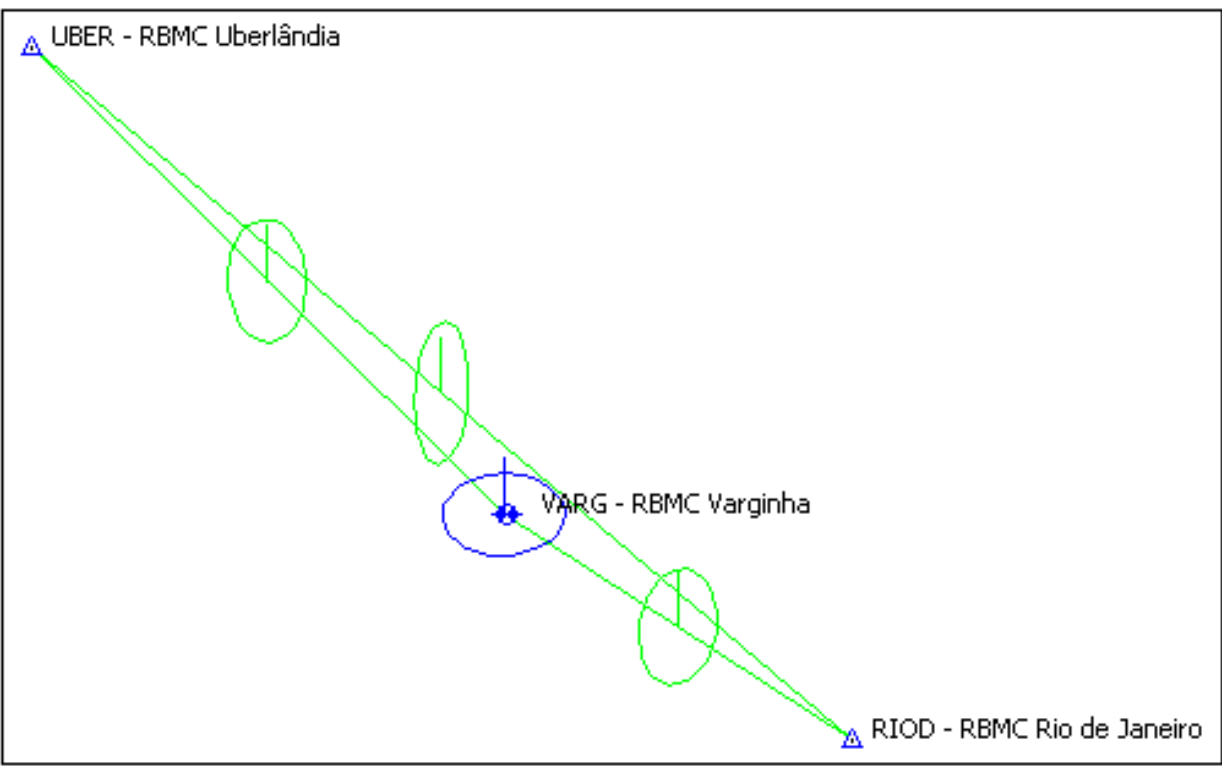

Coordenadas Ajustadas de VARG:

E (UTM): $454968.9326 \mathrm{~m}$

N (UTM): $7617727.3009 \mathrm{~m}$

- $\underline{287 / 2006}$

A posteriori UWE: 0.8671327 , Bounds: ( $0.6770032,1.241639)$ 
TABELA B62: Resultado do Processamento

\begin{tabular}{|c|c|c|c|c|c|c|c|c|}
\hline \multicolumn{9}{|c|}{ GPS Obs Report } \\
\hline Name & $\begin{array}{l}\text { Horizontal } \\
\text { Precision } \\
\text { (m) }\end{array}$ & $\begin{array}{l}\text { Vertical } \\
\text { Precision } \\
\text { (m) }\end{array}$ & $\begin{array}{c}\text { Distance } \\
\text { (m) }\end{array}$ & $\begin{array}{c}\text { Solution } \\
\text { Type }\end{array}$ & $\begin{array}{c}\text { GPS } \\
\text { Satellites }\end{array}$ & PDOP & Status & RMS \\
\hline \begin{tabular}{|l} 
RIOD - RBMC Rio de \\
Janeiro-UBER - \\
RBMC Uberlândia \\
\end{tabular} & 0.094 & 0.078 & 678629.145 & $\begin{array}{l}\text { Float, Wide } \\
\text { Lane }\end{array}$ & 28 & 3.004 & Adjusted & 0.124 \\
\hline $\begin{array}{l}\text { RIOD - RBMC Rio de } \\
\text { Janeiro-VARG - } \\
\text { RBMC Varginha }\end{array}$ & 0.038 & 0.064 & 261011.684 & $\begin{array}{l}\text { Fixed,Wide } \\
\text { Lane }\end{array}$ & | 27 & 2.783 & Adjusted & 0.078 \\
\hline \begin{tabular}{|l} 
UBER - RBMC \\
Uberlândia-VARG - \\
RBMC Varginha
\end{tabular} & 0.070 & 0.071 & 420650.813 & $\begin{array}{l}\text { Float,Wide } \\
\text { Lane }\end{array}$ & 29 & 2.986 & Adjusted & 0.098 \\
\hline
\end{tabular}

Figura B62: Elipses de Erro

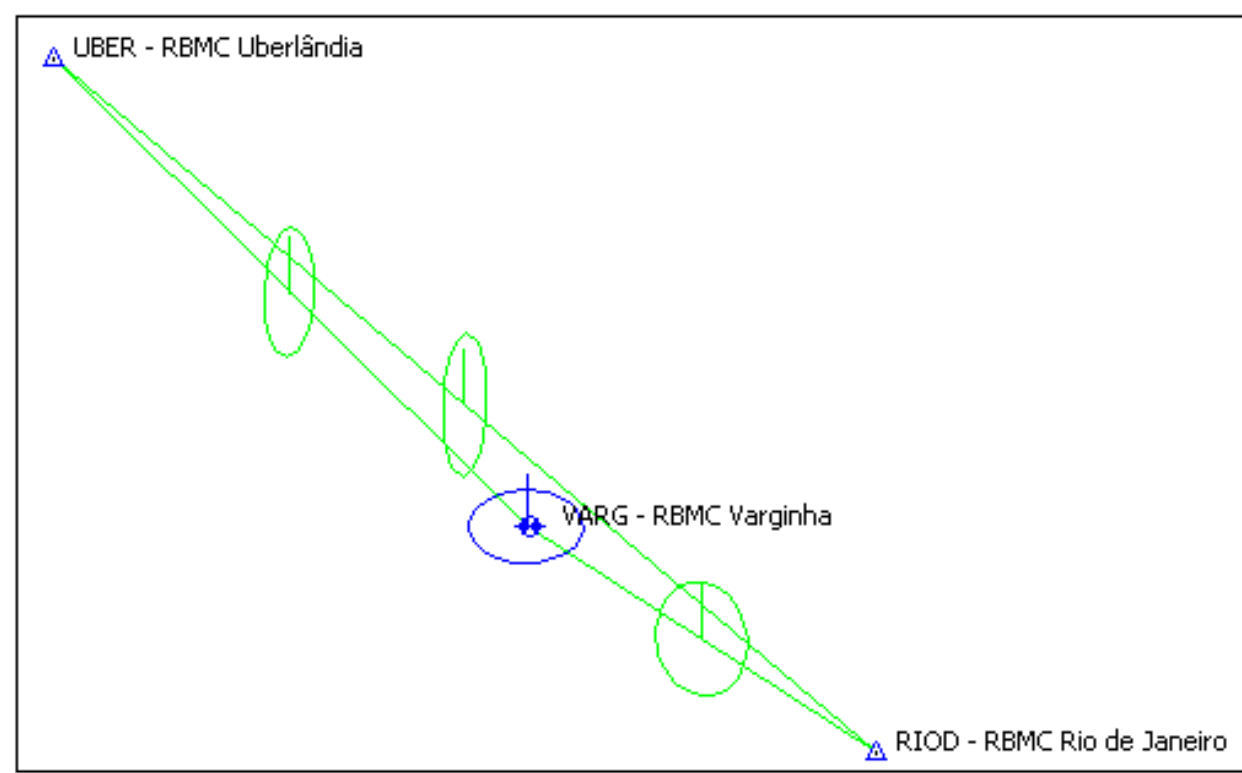

Coordenadas Ajustadas de VARG:

E (UTM): $454968.9581 \mathrm{~m}$

N (UTM): $7617727.2886 \mathrm{~m}$

- $\underline{288 / 2006}$

A posteriori UWE: 1.119375 , Bounds: ( $0.6770032,1.241639$ ) 
TABELA B63: Resultado do Processamento

\begin{tabular}{|c|c|c|c|c|c|c|c|c|}
\hline \multicolumn{9}{|c|}{ GPS Obs Report } \\
\hline Name & $\begin{array}{l}\text { Horizontal } \\
\text { Precision } \\
\text { (m) }\end{array}$ & $\begin{array}{l}\text { Vertical } \\
\text { Precision } \\
\text { (m) }\end{array}$ & $\begin{array}{l}\text { Distance } \\
\text { (m) }\end{array}$ & $\begin{array}{l}\text { Solution } \\
\text { Type }\end{array}$ & $\begin{array}{c}\text { GPS } \\
\text { Satellites }\end{array}$ & |PDOP & Status & RMS \\
\hline $\begin{array}{l}\text { RIOD - RBMC Rio de } \\
\text { Janeiro-UBER - } \\
\text { RBMC Uberlândia } \\
\end{array}$ & 0.093 & 0.083 & 678629.145 & $\begin{array}{l}\text { Float,Wide } \\
\text { Lane }\end{array}$ & 28 & 3.019 & Adjusted & 0.124 \\
\hline $\begin{array}{l}\text { RIOD - RBMC Rio de } \\
\text { Janeiro-VARG - } \\
\text { RBMC Varginha } \\
\end{array}$ & 0.036 & 0.067 & 261011.682 & $\begin{array}{l}\text { Fixed,Wide } \\
\text { Lane }\end{array}$ & 26 & 3.001 & Adjusted & $\mid 0.077$ \\
\hline $\begin{array}{l}\text { UBER - RBMC } \\
\text { Uberlândia-VARG - } \\
\text { RBMC Varginha }\end{array}$ & 0.076 & 0.062 & 420650.799 & $\begin{array}{l}\text { Float,Wide } \\
\text { Lane }\end{array}$ & 29 & 2.878 & Adjusted & 0.098 \\
\hline
\end{tabular}

Figura B63: Elipses de Erro

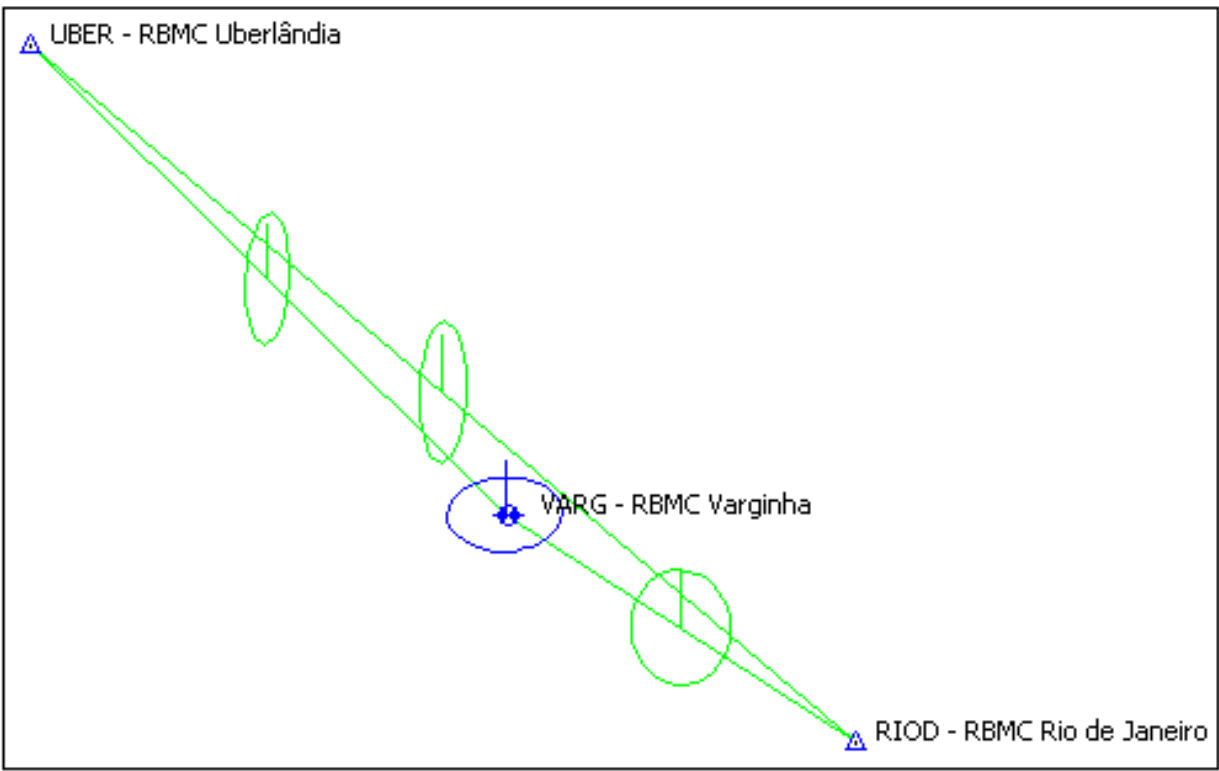

Coordenadas Ajustadas de VARG:

E (UTM): $454968.9672 \mathrm{~m}$

N (UTM): $7617727.2804 \mathrm{~m}$

- $\underline{289 / 2006}$

A posteriori UWE: 0.9324785 , Bounds: $(0.6770032,1.241639)$ 
TABELA B64: Resultado do Processamento

\begin{tabular}{|c|c|c|c|c|c|c|c|c|}
\hline \multicolumn{9}{|c|}{ GPS Obs Report } \\
\hline Name & $\begin{array}{l}\text { Horizontal } \\
\text { Precision } \\
\text { (m) }\end{array}$ & \begin{tabular}{|c|} 
Vertical \\
Precision \\
(m)
\end{tabular} & $\begin{array}{l}\text { Distance } \\
\text { (m) }\end{array}$ & $\begin{array}{c}\text { Solution } \\
\text { Type }\end{array}$ & $\begin{array}{c}\text { GPS } \\
\text { Satellites }\end{array}$ & PDOP & Status & RMS \\
\hline $\begin{array}{l}\text { RIOD - RBMC Rio de } \\
\text { Janeiro-UBER - } \\
\text { RBMC Uberlândia }\end{array}$ & 0.095 & 0.077 & 678629.134 & $\begin{array}{l}\text { Float,Wide } \\
\text { Lane }\end{array}$ & 27 & 3.004 & Adjusted & $\mid 0.124$ \\
\hline $\begin{array}{l}\text { RIOD - RBMC Rio de } \\
\text { Janeiro-VARG - } \\
\text { RBMC Varginha }\end{array}$ & 0.044 & 0.062 & 261011.685 & $\begin{array}{l}\text { Fixed,Wide } \\
\text { Lane }\end{array}$ & 26 & 2.983 & Adjusted & 0.078 \\
\hline $\begin{array}{l}\text { UBER - RBMC } \\
\text { Uberlândia-VARG - } \\
\text { RBMC Varginha }\end{array}$ & 0.061 & 0.075 & 420650.809 & $\begin{array}{l}\text { Fixed,Wide } \\
\text { Lane }\end{array}$ & $\mid 38$ & 2.776 & Adjusted & 0.096 \\
\hline
\end{tabular}

Figura B64: Elipses de Erro

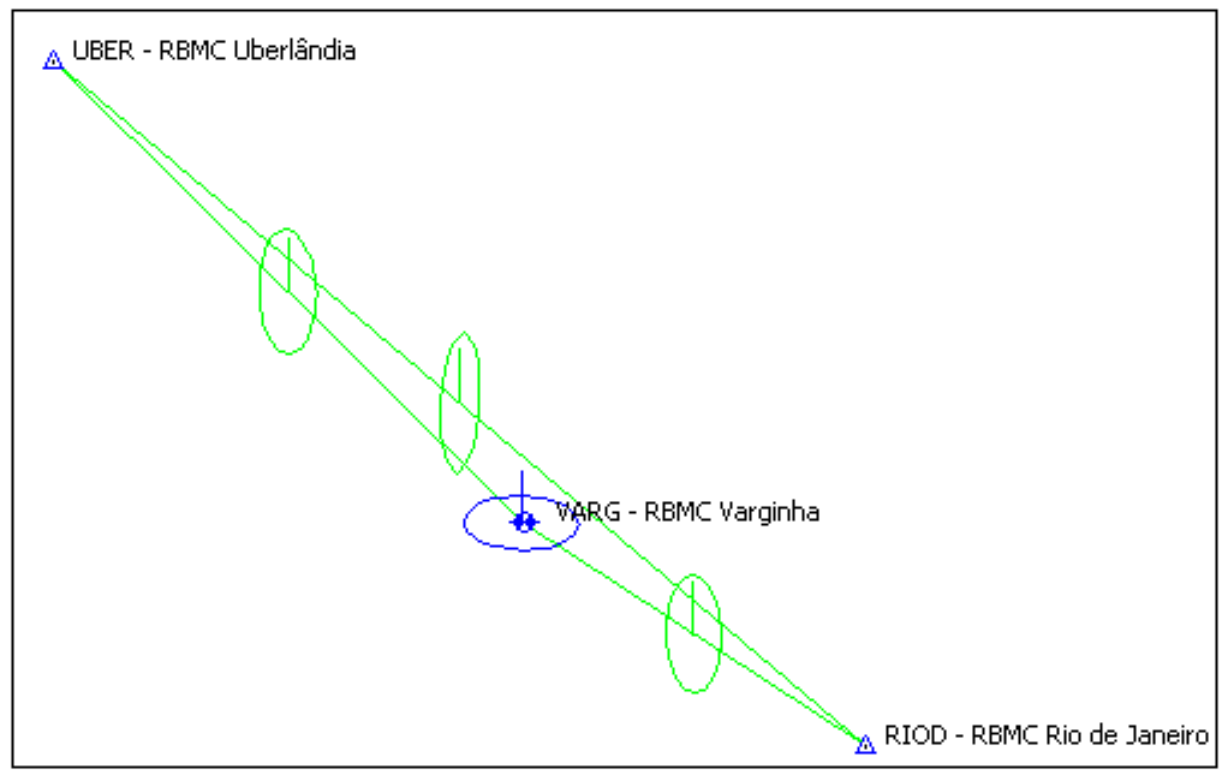

Coordenadas Ajustadas de VARG:

E (UTM): $454968.9701 \mathrm{~m}$

$>\mathrm{N}(\mathrm{UTM}): 7617727.2958 \mathrm{~m}$

\section{B.2.2 Ano de 2007}

\section{B.2.2.1 Verão (Dias Julianos 011 a 014)}

- $\underline{011 / 2007}$

A posteriori UWE: 1.002386 , Bounds: ( $0.6770032,1.241639$ ) 
TABELA B65: Resultado do Processamento

\begin{tabular}{|c|c|c|c|c|c|c|c|c|}
\hline \multicolumn{9}{|c|}{ GPS Obs Report } \\
\hline Name & \begin{tabular}{|c|} 
Horizontal \\
Precision \\
(m)
\end{tabular} & \begin{tabular}{|c|} 
Vertical \\
Precision \\
(m)
\end{tabular} & $\begin{array}{l}\text { Distance } \\
\quad(\mathbf{m})\end{array}$ & $\begin{array}{c}\text { Solution } \\
\text { Type }\end{array}$ & $\begin{array}{c}\text { GPS } \\
\text { Satellites }\end{array}$ & PDOP & Status & RMS \\
\hline $\begin{array}{l}\text { RIOD - RBMC Rio de } \\
\text { Janeiro-UBER - } \\
\text { RBMC Uberlândia }\end{array}$ & 0.088 & 0.085 & 678629.123 & $\begin{array}{l}\text { Float,Wide } \\
\text { Lane }\end{array}$ & 29 & 3.049 & Adjusted & 0.124 \\
\hline $\begin{array}{l}\text { RIOD - RBMC Rio de } \\
\text { Janeiro-VARG - } \\
\text { RBMC Varginha } \\
\end{array}$ & 0.037 & 0.066 & 261011.679 & $\begin{array}{l}\text { Fixed,Wide } \\
\text { Lane }\end{array}$ & 29 & 3.002 & Adjusted & 0.077 \\
\hline \begin{tabular}{|l|} 
UBER - RBMC \\
Uberlândia-VARG - \\
RBMC Varginha \\
\end{tabular} & 0.066 & 0.072 & 420650.829 & $\begin{array}{l}\text { Fixed,Wide } \\
\text { Lane }\end{array}$ & 30 & 2.981 & Adjusted & 0.098 \\
\hline
\end{tabular}

Figura B65: Elipses de Erro

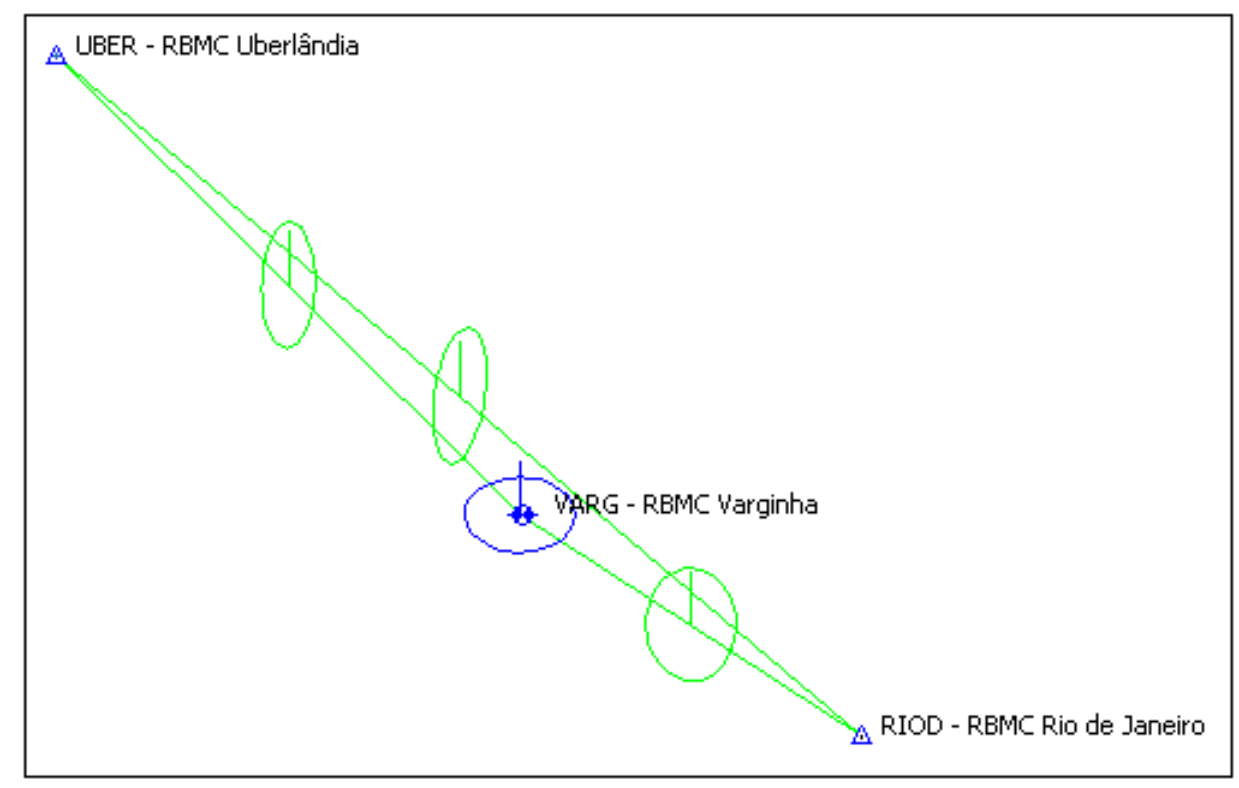

Coordenadas Ajustadas de VARG:

E (UTM): $454968.952 \mathrm{~m}$

N (UTM): $7617727.2972 \mathrm{~m}$

- $\underline{012 / 2007}$

A posteriori UWE: 0.9982019 , Bounds: ( $0.6770032,1.241639$ ) 
TABELA B66: Resultado do Processamento

\begin{tabular}{|c|c|c|c|c|c|c|c|c|}
\hline \multicolumn{9}{|c|}{ GPS Obs Report } \\
\hline Name & \begin{tabular}{|c} 
Horizontal \\
Precision (m)
\end{tabular} & $\begin{array}{l}\text { Vertical } \\
\text { Precision } \\
\text { (m) }\end{array}$ & $\begin{array}{c}\text { Distance } \\
\text { (m) }\end{array}$ & $\begin{array}{c}\text { Solution } \\
\text { Type }\end{array}$ & $\begin{array}{c}\text { GPS } \\
\text { Satellites }\end{array}$ & PDOP & Status & RMS \\
\hline $\begin{array}{l}\text { RIOD - RBMC Rio de } \\
\text { Janeiro-UBER - RBMC } \\
\text { Uberlândia }\end{array}$ & 0.085 & 0.090 & 678629.159 & \begin{tabular}{|l} 
Float,Wide \\
Lane
\end{tabular} & 26 & 2.389 & Adjusted & 0.124 \\
\hline $\begin{array}{l}\text { RIOD - RBMC Rio de } \\
\text { Janeiro-VARG - RBMC } \\
\text { Varginha } \\
\end{array}$ & 0.042 & 0.066 & 261011.699 & \begin{tabular}{|l} 
Fixed,Wide \\
Lane
\end{tabular} & 26 & 2.888 & Adjusted & 0.077 \\
\hline $\begin{array}{l}\text { UBER - RBMC } \\
\text { Uberlândia-VARG - } \\
\text { RBMC Varginha }\end{array}$ & 0.053 & 0.084 & 420650.818 & \begin{tabular}{|l} 
Fixed,Wide \\
Lane
\end{tabular} & 30 & 2.991 & Adjusted & 0.098 \\
\hline
\end{tabular}

Figura B66: Elipses de Erro

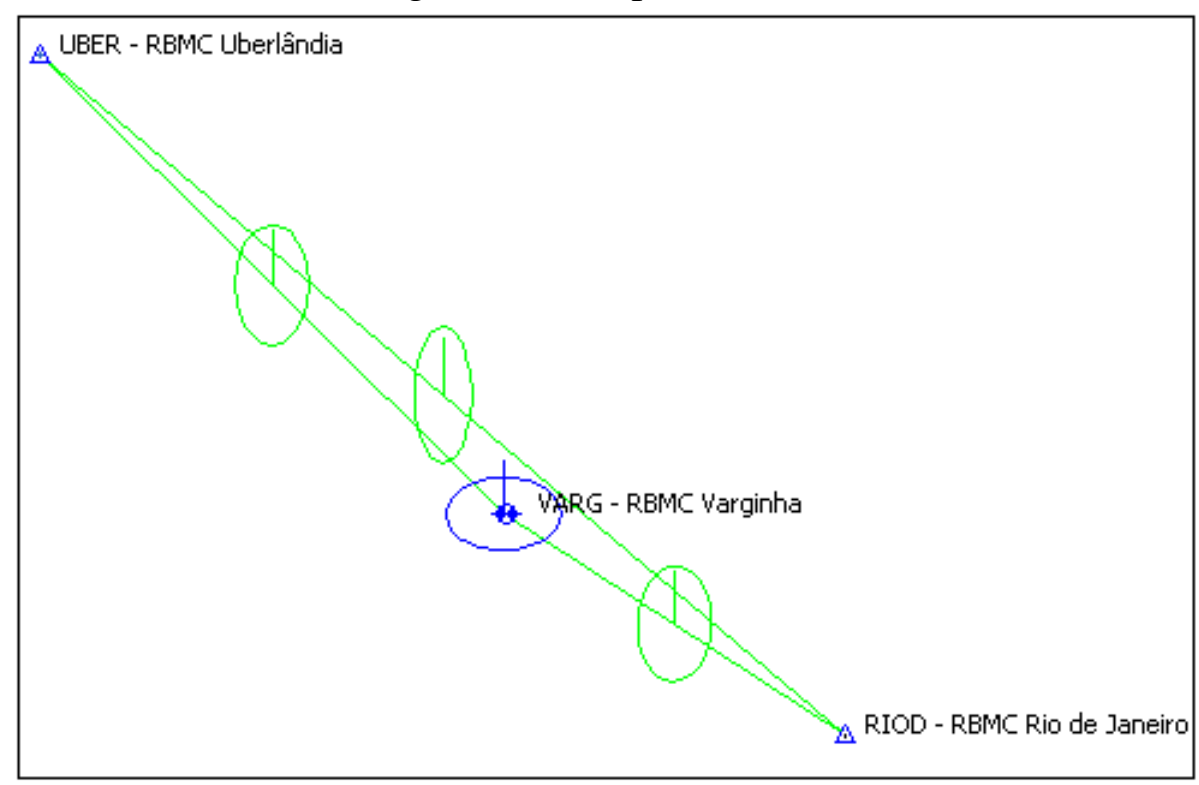

Coordenadas Ajustadas de VARG:

E (UTM): $454968.9889 \mathrm{~m}$

N (UTM): $7617727.2815 \mathrm{~m}$

- $\underline{013 / 2007}$

A posteriori UWE: 1.2391 , Bounds: ( $0.6770032,1.241639$ ) 
TABELA B67: Resultado do Processamento

\begin{tabular}{|c|c|c|c|c|c|c|c|c|}
\hline \multicolumn{9}{|c|}{ GPS Obs Report } \\
\hline Name & \begin{tabular}{|c} 
Horizontal \\
Precision (m)
\end{tabular} & $\begin{array}{c}\text { Vertical } \\
\text { Precision } \\
\text { (m) }\end{array}$ & $\begin{array}{c}\text { Distance } \\
\text { (m) }\end{array}$ & $\begin{array}{c}\text { Solution } \\
\text { Type }\end{array}$ & $\begin{array}{c}\text { GPS } \\
\text { Satellites }\end{array}$ & PDOP & Status & RMS \\
\hline $\begin{array}{l}\text { RIOD - RBMC Rio de } \\
\text { Janeiro-UBER - RBMC } \\
\text { Uberlândia }\end{array}$ & 0.093 & 0.089 & 678629.191 & $\begin{array}{l}\text { Float, Wide } \\
\text { Lane }\end{array}$ & 28 & $\mid 3.009$ & Adjusted & 0.125 \\
\hline $\begin{array}{l}\text { RIOD - RBMC Rio de } \\
\text { Janeiro-VARG - RBMC } \\
\text { Varginha } \\
\end{array}$ & 0.033 & 0.062 & 261011.725 & \begin{tabular}{|l} 
Fixed,Wide \\
Lane
\end{tabular} & 28 & |3.011 & Adjusted & 0.079 \\
\hline \begin{tabular}{|l|} 
UBER - RBMC \\
Uberlândia-VARG - \\
RBMC Varginha \\
\end{tabular} & 0.051 & 0.084 & 420650.821 & \begin{tabular}{|l} 
Fixed,Wide \\
Lane
\end{tabular} & 31 & 2.965 & Adjusted & 0.097 \\
\hline
\end{tabular}

Figura B67: Elipses de Erro

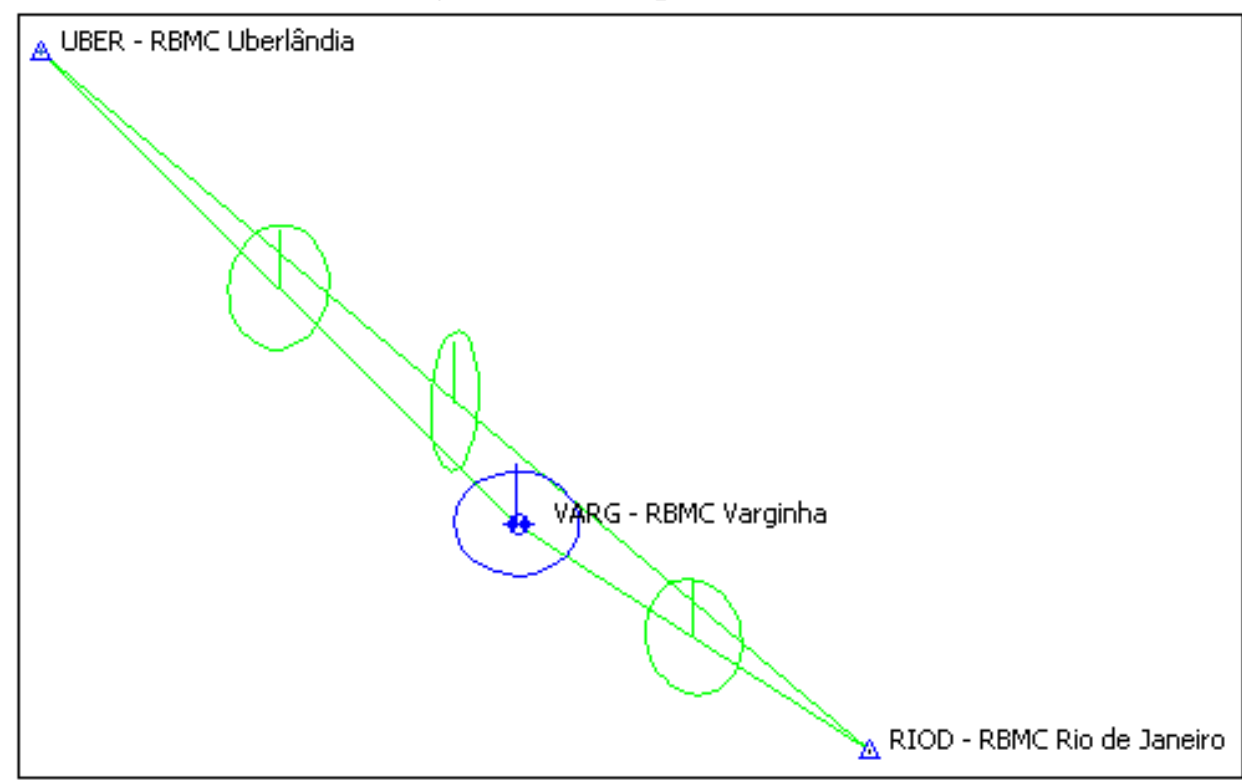

Coordenadas Ajustadas de VARG:

E (UTM): $454968.9552 \mathrm{~m}$

N (UTM): $7617727.3007 \mathrm{~m}$

- $\underline{014 / 2007}$

A posteriori UWE: 1.012961 , Bounds: ( $0.6770032,1.241639$ ) 
TABELA B68: Resultado do Processamento

\begin{tabular}{|c|c|c|c|c|c|c|c|c|}
\hline \multicolumn{9}{|c|}{ GPS Obs Report } \\
\hline Name & \begin{tabular}{|c} 
Horizontal \\
Precision (m)
\end{tabular} & $\begin{array}{l}\text { Vertical } \\
\text { Precision } \\
\text { (m) }\end{array}$ & $\begin{array}{c}\text { Distance } \\
\text { (m) }\end{array}$ & $\begin{array}{c}\text { Solution } \\
\text { Type }\end{array}$ & $\begin{array}{c}\text { GPS } \\
\text { Satellites }\end{array}$ & PDOP & Status & RMS \\
\hline $\begin{array}{l}\text { RIOD - RBMC Rio de } \\
\text { Janeiro-UBER - RBMC } \\
\text { Uberlândia }\end{array}$ & 0.081 & 0.092 & 678629.132 & \begin{tabular}{|l} 
Float,Wide \\
Lane
\end{tabular} & |29 & 3.006 & Adjusted & 0.124 \\
\hline $\begin{array}{l}\text { RIOD - RBMC Rio de } \\
\text { Janeiro-VARG - RBMC } \\
\text { Varginha } \\
\end{array}$ & 0.044 & 0.060 & 261011.713 & \begin{tabular}{|l} 
Fixed,Wide \\
Lane
\end{tabular} & 28 & 2.394 & Adjusted & 0.078 \\
\hline $\begin{array}{l}\text { UBER - RBMC } \\
\text { Uberlândia-VARG - } \\
\text { RBMC Varginha }\end{array}$ & 0.063 & 0.082 & 420650.860 & \begin{tabular}{|l} 
Float, Wide \\
Lane
\end{tabular} & 29 & 2.981 & Adjusted & 0.101 \\
\hline
\end{tabular}

Figura B68: Elipses de Erro

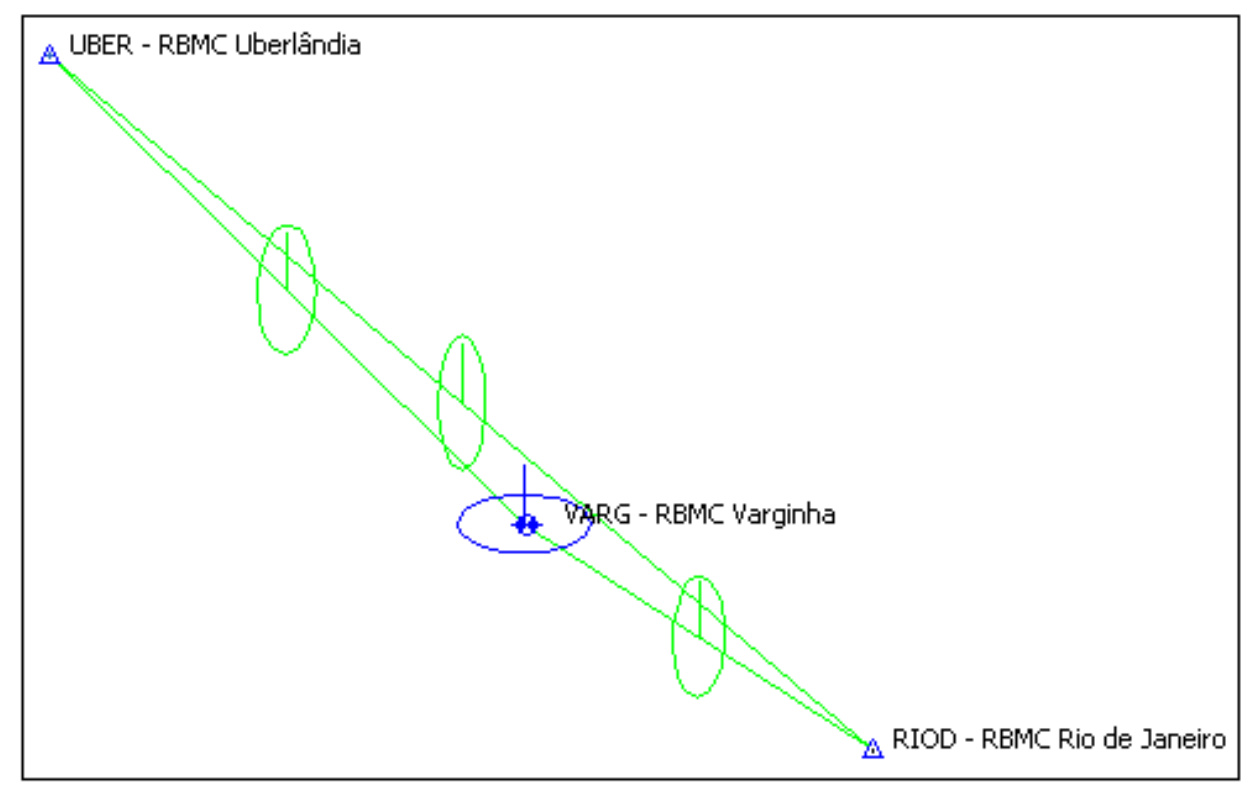

Coordenadas Ajustadas de VARG:

E (UTM): $454968.9492 \mathrm{~m}$

N (UTM): $7617727.2882 \mathrm{~m}$

\section{B.2.2.2 Outono (Dias Julianos 101 a 104)}

- $101 / 2007$

A posteriori UWE: 1.19482 , Bounds: ( $0.6770032,1.241639$ ) 
TABELA B69: Resultado do Processamento

\begin{tabular}{|c|c|c|c|c|c|c|c|c|}
\hline \multicolumn{9}{|c|}{ GPS Obs Report } \\
\hline Name & \begin{tabular}{|c} 
Horizontal \\
Precision (m)
\end{tabular} & $\begin{array}{l}\text { Vertical } \\
\text { Precision } \\
\text { (m) }\end{array}$ & $\begin{array}{l}\text { Distance } \\
\text { (m) }\end{array}$ & $\begin{array}{c}\text { Solution } \\
\text { Type }\end{array}$ & $\begin{array}{c}\text { GPS } \\
\text { Satellites }\end{array}$ & PDOP & Status & RMS \\
\hline $\begin{array}{l}\text { RIOD - RBMC Rio de } \\
\text { Janeiro-UBER - RBMC } \\
\text { Uberlï ¿1/2dia } \\
\end{array}$ & 0.085 & 0.084 & 678629.123 & $\begin{array}{l}\text { Float,Wide } \\
\text { Lane }\end{array}$ & 29 & 3.012 & Adjusted & $\mid 0.124$ \\
\hline \begin{tabular}{|l} 
RIOD - RBMC Rio de \\
Janeiro-VARG - RBMC \\
Varginha \\
\end{tabular} & 0.032 & 0.067 & 261011.687 & $\begin{array}{l}\text { Fixed,Wide } \\
\text { Lane }\end{array}$ & 28 & 2.592 & Adjusted & $\mid 0.077$ \\
\hline \begin{tabular}{|l|} 
UBER - RBMC \\
Uberli i $i^{1 / 2 d i a-V A R G ~-~}$ \\
RBMC Varginha \\
\end{tabular} & 0.065 & 0.067 & 420650.782 & $\begin{array}{l}\text { Float,Wide } \\
\text { Lane }\end{array}$ & 30 & 2.618 & Adjusted & 0.098 \\
\hline
\end{tabular}

Figura B69: Elipses de Erro

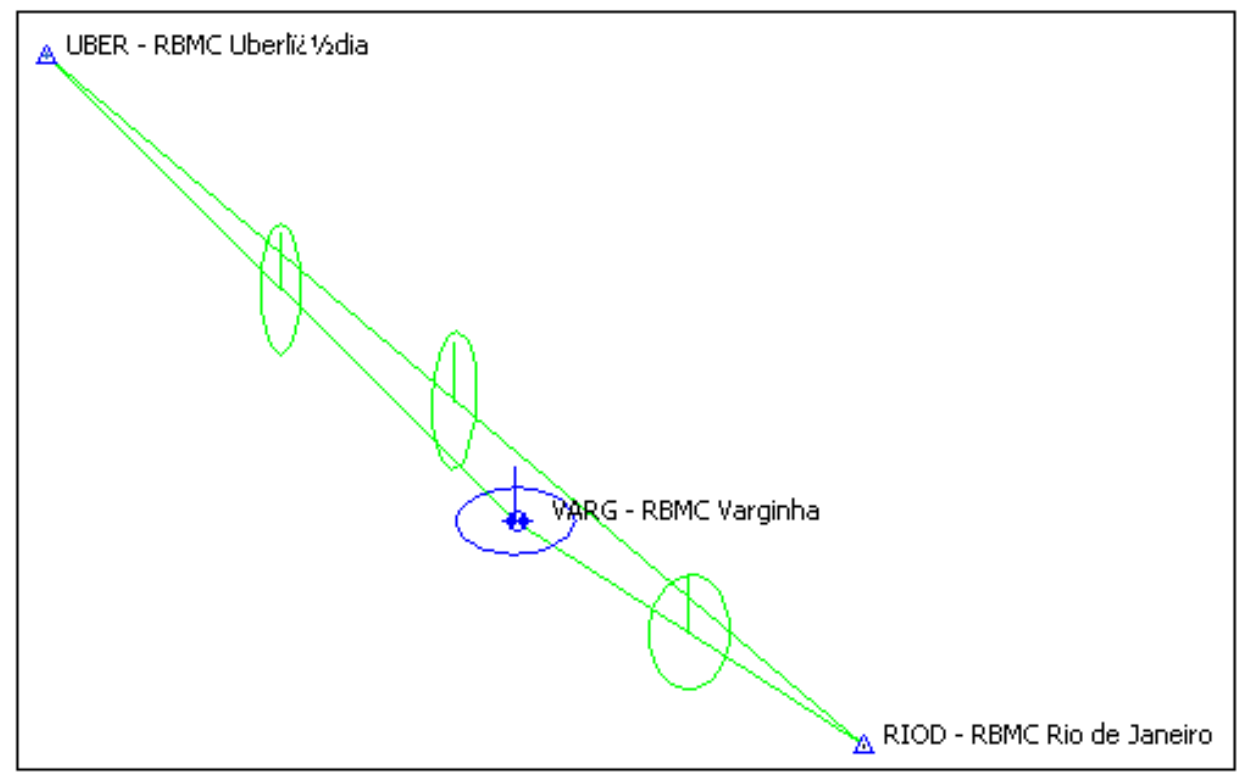

Coordenadas Ajustadas de VARG:

E (UTM): $454968.9496 \mathrm{~m}$

$>\mathrm{N}$ (UTM): $7617727.3028 \mathrm{~m}$

- $102 / 2007$

A posteriori UWE: 1.079876 , Bounds: ( $0.6770032,1.241639)$ 
TABELA B70: Resultado do Processamento

\begin{tabular}{|c|c|c|c|c|c|c|c|c|}
\hline \multicolumn{9}{|c|}{ GPS Obs Report } \\
\hline Name & $\mid \begin{array}{c}\text { Horizontal } \\
\text { Precision }(\mathbf{m})\end{array}$ & $\begin{array}{c}\text { Vertical } \\
\text { Precision } \\
\text { (m) }\end{array}$ & $\begin{array}{l}\text { Distance } \\
\text { (m) }\end{array}$ & $\begin{array}{c}\text { Solution } \\
\text { Type }\end{array}$ & \begin{tabular}{|c} 
GPS \\
Satellites
\end{tabular} & |PDOP & Status & RMS \\
\hline $\begin{array}{l}\text { RIOD - RBMC Rio de } \\
\text { Janeiro-UBER - RBMC } \\
\text { Uberlândia } \\
\end{array}$ & 0.086 & 0.092 & 678629.089 & $\begin{array}{l}\text { Float,Wide } \\
\text { Lane }\end{array}$ & 30 & 3.008 & Adjusted & 0.126 \\
\hline $\begin{array}{l}\text { RIOD - RBMC Rio de } \\
\text { Janeiro-VARG - RBMC } \\
\text { Varginha }\end{array}$ & 0.033 & 0.069 & 261011.676 & $\begin{array}{l}\text { Fixed,Wide } \\
\text { Lane }\end{array}$ & 30 & 2.745 & Adjusted & 0.077 \\
\hline $\begin{array}{l}\text { UBER - RBMC } \\
\text { Uberlândia-VARG - } \\
\text { RBMC Varginha }\end{array}$ & 0.064 & 0.074 & 420650.778 & $\begin{array}{l}\text { Float,Wide } \\
\text { Lane }\end{array}$ & 31 & 2.794 & Adjusted & 0.097 \\
\hline
\end{tabular}

Figura B70: Elipses de Erro

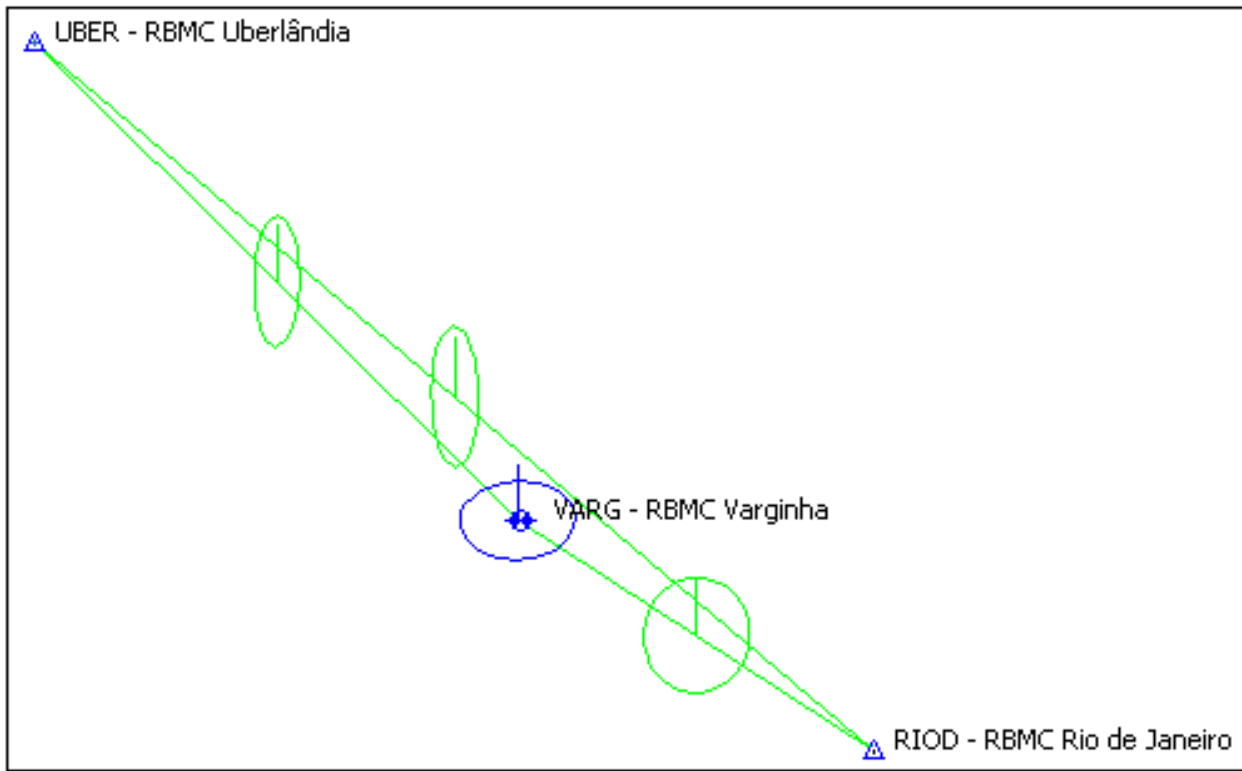

Coordenadas Ajustadas de VARG:

E (UTM): $454968.9625 \mathrm{~m}$

N (UTM): $7617727.2904 \mathrm{~m}$

- $\underline{103 / 2007}$

A posteriori UWE: 1.080554 , Bounds: ( $0.6770032,1.241639$ ) 
TABELA B71: Resultado do Processamento

\begin{tabular}{|c|c|c|c|c|c|c|c|c|}
\hline \multicolumn{9}{|c|}{ GPS Obs Report } \\
\hline Name & $\mid \begin{array}{c}\text { Horizontal } \\
\text { Precision }(\mathbf{m})\end{array}$ & $\begin{array}{l}\text { Vertical } \\
\text { Precision } \\
\text { (m) }\end{array}$ & $\begin{array}{l}\text { Distance } \\
\text { (m) }\end{array}$ & $\begin{array}{c}\text { Solution } \\
\text { Type }\end{array}$ & \begin{tabular}{|c} 
GPS \\
Satellites
\end{tabular} & |PDOP & Status & RMS \\
\hline $\begin{array}{l}\text { RIOD - RBMC Rio de } \\
\text { Janeiro-UBER - RBMC } \\
\text { Uberlândia } \\
\end{array}$ & 0.063 & 0.107 & 678629.096 & $\begin{array}{l}\text { Fixed,Wide } \\
\text { Lane }\end{array}$ & 30 & 2.989 & Adjusted & 0.124 \\
\hline $\begin{array}{l}\text { RIOD - RBMC Rio de } \\
\text { Janeiro-VARG - RBMC } \\
\text { Varginha }\end{array}$ & 0.034 & 0.069 & 261011.681 & $\begin{array}{l}\text { Fixed,Wide } \\
\text { Lane }\end{array}$ & 30 & 2.732 & Adjusted & 0.077 \\
\hline $\begin{array}{l}\text { UBER - RBMC } \\
\text { Uberlândia-VARG - } \\
\text { RBMC Varginha }\end{array}$ & 0.044 & 0.088 & 420650.770 & $\begin{array}{l}\text { Fixed,Wide } \\
\text { Lane }\end{array}$ & 31 & 2.779 & Adjusted & 0.099 \\
\hline
\end{tabular}

Figura B71: Elipses de Erro

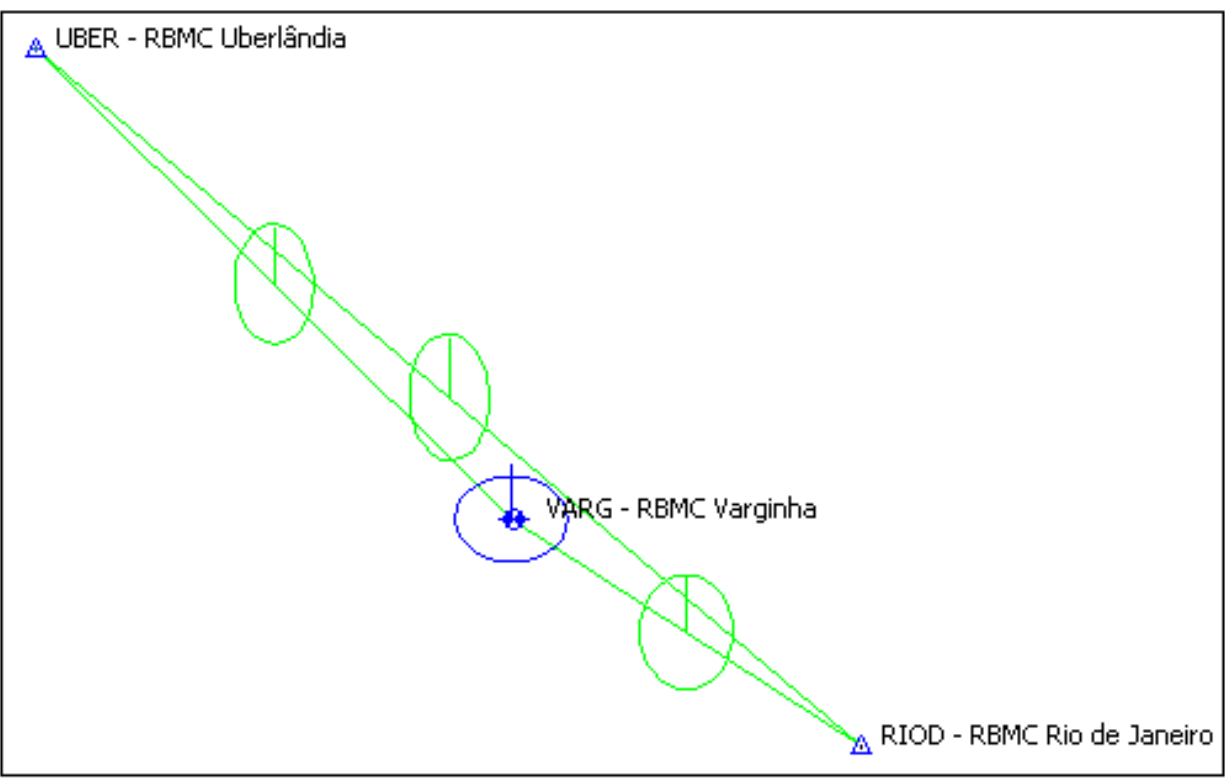

Coordenadas Ajustadas de VARG:

E (UTM): $454968.9578 \mathrm{~m}$

N (UTM): $7617727.2864 \mathrm{~m}$

- $104 / 2007$

A posteriori UWE: 1.13934 , Bounds: ( $0.6770032,1.241639$ ) 
TABELA B72: Resultado do Processamento

\begin{tabular}{|c|c|c|c|c|c|c|c|c|}
\hline \multicolumn{9}{|c|}{ GPS Obs Report } \\
\hline Name & \begin{tabular}{|c} 
Horizontal \\
Precision (m)
\end{tabular} & $\begin{array}{c}\text { Vertical } \\
\text { Precision } \\
\text { (m) }\end{array}$ & $\begin{array}{l}\text { Distance } \\
\quad(\mathbf{m})\end{array}$ & $\begin{array}{l}\text { Solution } \\
\text { Type }\end{array}$ & $\begin{array}{c}\text { GPS } \\
\text { Satellites }\end{array}$ & PDOP & Status & RMS \\
\hline $\begin{array}{l}\text { RIOD - RBMC Rio de } \\
\text { Janeiro-UBER - RBMC } \\
\text { Uberlândia }\end{array}$ & 0.088 & 0.088 & 678629.127 & $\begin{array}{l}\text { Float,Wide } \\
\text { Lane }\end{array}$ & 30 & 2.974 & Adjusted & 0.124 \\
\hline $\begin{array}{l}\text { RIOD - RBMC Rio de } \\
\text { Janeiro-VARG - RBMC } \\
\text { Varginha }\end{array}$ & 0.036 & 0.068 & 261011.692 & $\begin{array}{l}\text { Fixed,Wide } \\
\text { Lane }\end{array}$ & 30 & 2.721 & Adjusted & 0.077 \\
\hline $\begin{array}{l}\text { UBER - RBMC } \\
\text { Uberlândia-VARG - } \\
\text { RBMC Varginha } \\
\end{array}$ & 0.046 & 0.086 & 420650.794 & $\begin{array}{l}\text { Fixed,Wide } \\
\text { Lane }\end{array}$ & 31 & 2.771 & Adjusted & 0.097 \\
\hline
\end{tabular}

Figura B72: Elipses de Erro

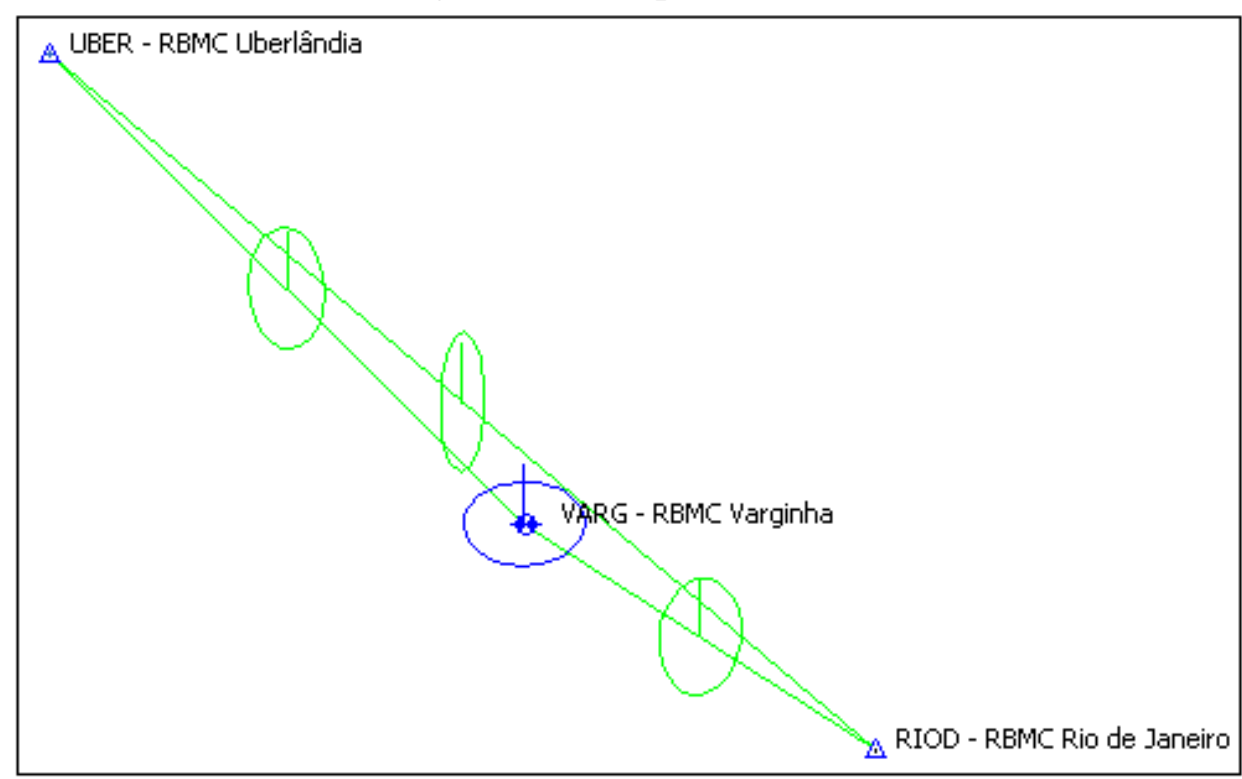

Coordenadas Ajustadas de VARG:

E (UTM): $454968.9498 \mathrm{~m}$

N (UTM): $7617727.2972 \mathrm{~m}$

\section{B.2.2.3 Inverno (Dias Julianos 193 a 196)}

- $193 / 2007$

A posteriori UWE: 1.22816 , Bounds: ( $0.6770032,1.241639)$ 
TABELA B73: Resultado do Processamento

\begin{tabular}{|c|c|c|c|c|c|c|c|c|}
\hline \multicolumn{9}{|c|}{ GPS Obs Report } \\
\hline Name & $\begin{array}{c}\text { Horizontal } \\
\text { Precision (m) }\end{array}$ & $\begin{array}{c}\text { Vertical } \\
\text { Precision } \\
\text { (m) }\end{array}$ & $\begin{array}{l}\text { Distance } \\
\text { (m) }\end{array}$ & $\begin{array}{c}\text { Solution } \\
\text { Type }\end{array}$ & $\begin{array}{c}\text { GPS } \\
\text { Satellites }\end{array}$ & PDOP & Status & RMS \\
\hline $\begin{array}{l}\text { RIOD - RBMC Rio de } \\
\text { Janeiro-UBER - RBMC } \\
\text { Uberlï ¿1/2dia } \\
\end{array}$ & 0.052 & 0.111 & 678629.109 & \begin{tabular}{|l} 
Fixed,Wide \\
Lane
\end{tabular} & 29 & 3.005 & Adjusted & 0.124 \\
\hline $\begin{array}{l}\text { RIOD - RBMC Rio de } \\
\text { Janeiro-VARG - RBMC } \\
\text { Varginha }\end{array}$ & 0.031 & 0.071 & 261011.682 & \begin{tabular}{|l} 
Fixed,Wide \\
Lane
\end{tabular} & 29 & 3.001 & Adjusted & 0.077 \\
\hline $\begin{array}{l}\text { UBER - RBMC } \\
\text { Uberlïi/1/2ia-VARG - } \\
\text { RBMC Varginha }\end{array}$ & 0.044 & 0.083 & 420650.761 & \begin{tabular}{l|l} 
Fixed,Wide \\
Lane
\end{tabular} & 28 & 2.629 & Adjusted & $\mid 0.098$ \\
\hline
\end{tabular}

Figura B73: Elipses de Erro

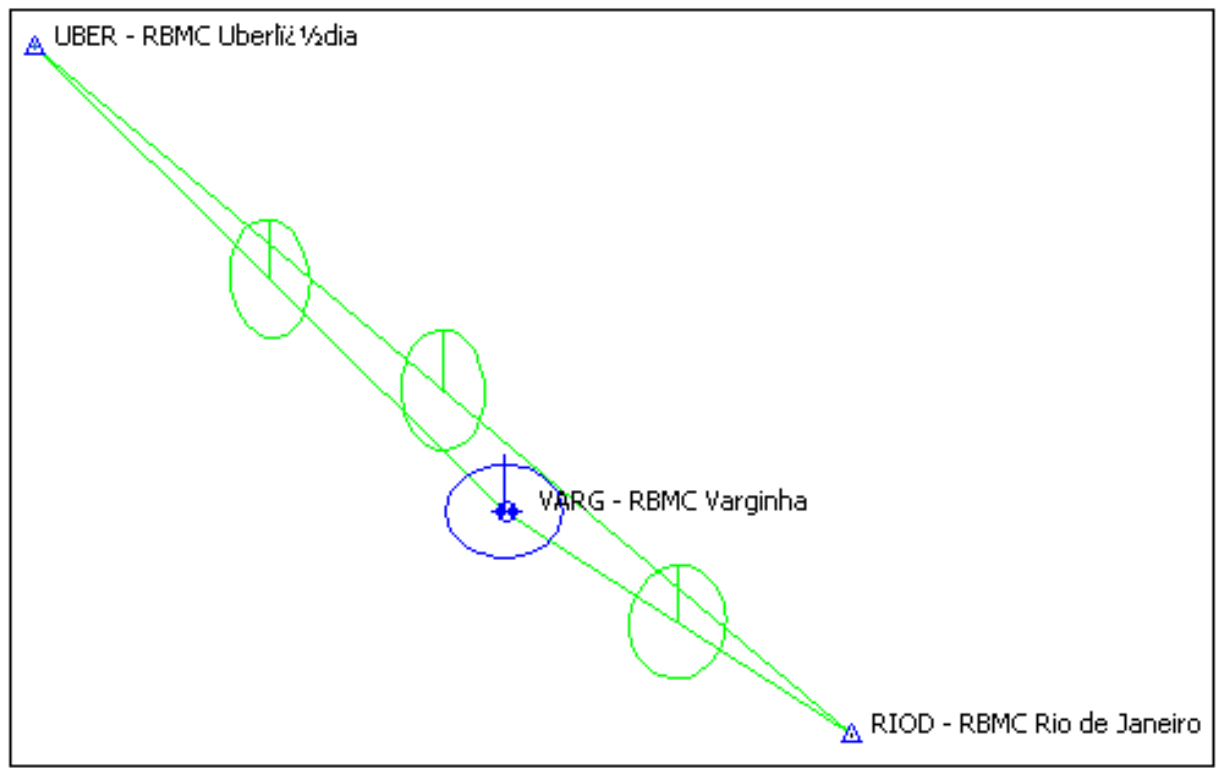

Coordenadas Ajustadas de VARG:

E (UTM): $454968.9572 \mathrm{~m}$

$>\mathrm{N}$ (UTM): $7617727.3024 \mathrm{~m}$

- $194 / 2007$

A posteriori UWE: 1.209817 , Bounds: ( $0.6770032,1.241639$ ) 
TABELA B74: Resultado do Processamento

\begin{tabular}{|c|c|c|c|c|c|c|c|c|}
\hline \multicolumn{9}{|c|}{ GPS Obs Report } \\
\hline Name & $\begin{array}{c}\text { Horizontal } \\
\text { Precision (m) }\end{array}$ & $\begin{array}{c}\text { Vertical } \\
\text { Precision } \\
\text { (m) }\end{array}$ & $\begin{array}{l}\text { Distance } \\
\text { (m) }\end{array}$ & $\begin{array}{c}\text { Solution } \\
\text { Type }\end{array}$ & $\begin{array}{c}\text { GPS } \\
\text { Satellites }\end{array}$ & PDOP & Status & RMS \\
\hline $\begin{array}{l}\text { RIOD - RBMC Rio de } \\
\text { Janeiro-UBER - RBMC } \\
\text { Uberlï ¿1/2dia } \\
\end{array}$ & 0.056 & 0.114 & 678629.103 & \begin{tabular}{|l} 
Fixed,Wide \\
Lane
\end{tabular} & 27 & 3.021 & Adjusted & 0.124 \\
\hline $\begin{array}{l}\text { RIOD - RBMC Rio de } \\
\text { Janeiro-VARG - RBMC } \\
\text { Varginha }\end{array}$ & 0.038 & 0.072 & 261011.696 & \begin{tabular}{|l} 
Fixed,Wide \\
Lane
\end{tabular} & 28 & 2.826 & Adjusted & 0.077 \\
\hline $\begin{array}{l}\text { UBER - RBMC } \\
\text { Uberlïi/1/2ia-VARG - } \\
\text { RBMC Varginha }\end{array}$ & 0.041 & 0.085 & 420650.777 & \begin{tabular}{l|l} 
Fixed,Wide \\
Lane
\end{tabular} & 29 & 2.764 & Adjusted & $\mid 0.098$ \\
\hline
\end{tabular}

Figura B74: Elipses de Erro

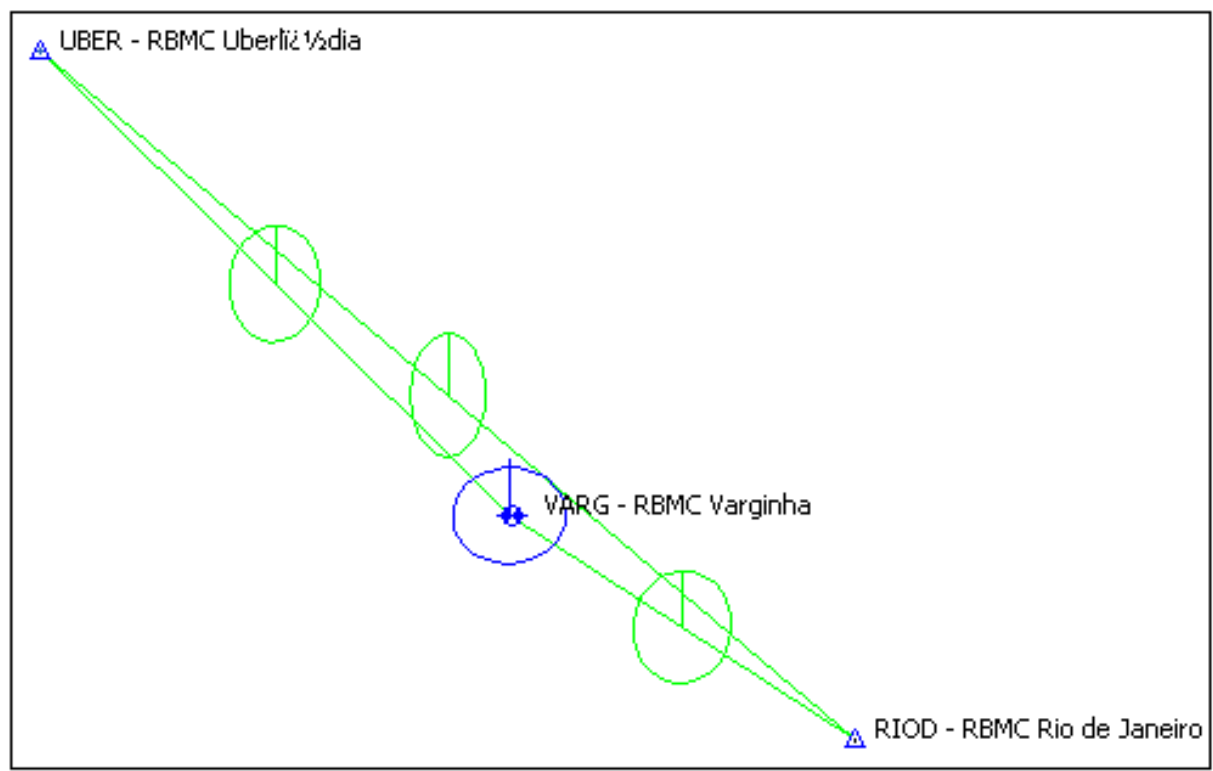

Coordenadas Ajustadas de VARG:

E (UTM): $454968.9658 \mathrm{~m}$

N (UTM): $7617727.3114 \mathrm{~m}$

- $195 / 2007$

A posteriori UWE: 0.7613588 , Bounds: $(0.6770032,1.241639)$ 
TABELA B75: Resultado do Processamento

\begin{tabular}{|c|c|c|c|c|c|c|c|c|}
\hline \multicolumn{9}{|c|}{ GPS Obs Report } \\
\hline Name & $\begin{array}{c}\text { Horizontal } \\
\text { Precision (m) }\end{array}$ & $\begin{array}{c}\text { Vertical } \\
\text { Precision } \\
\text { (m) }\end{array}$ & $\begin{array}{l}\text { Distance } \\
\text { (m) }\end{array}$ & $\begin{array}{c}\text { Solution } \\
\text { Type }\end{array}$ & $\begin{array}{c}\text { GPS } \\
\text { Satellites }\end{array}$ & PDOP & Status & RMS \\
\hline $\begin{array}{l}\text { RIOD - RBMC Rio de } \\
\text { Janeiro-UBER - RBMC } \\
\text { Uberlï ¿1/2dia } \\
\end{array}$ & 0.082 & 0.092 & 678629.074 & \begin{tabular}{|l} 
Float,Wide \\
Lane
\end{tabular} & 30 & 3.007 & Adjusted & 0.124 \\
\hline $\begin{array}{l}\text { RIOD - RBMC Rio de } \\
\text { Janeiro-VARG - RBMC } \\
\text { Varginha }\end{array}$ & 0.033 & 0.069 & 261011.677 & \begin{tabular}{|l} 
Fixed,Wide \\
Lane
\end{tabular} & 30 & 2.994 & Adjusted & 0.077 \\
\hline $\begin{array}{l}\text { UBER - RBMC } \\
\text { Uberlïi/1/2ia-VARG - } \\
\text { RBMC Varginha }\end{array}$ & 0.049 & 0.084 & 420650.773 & \begin{tabular}{l|l} 
Fixed,Wide \\
Lane
\end{tabular} & 31 & 2.869 & Adjusted & 0.097 \\
\hline
\end{tabular}

Figura B75: Elipses de Erro

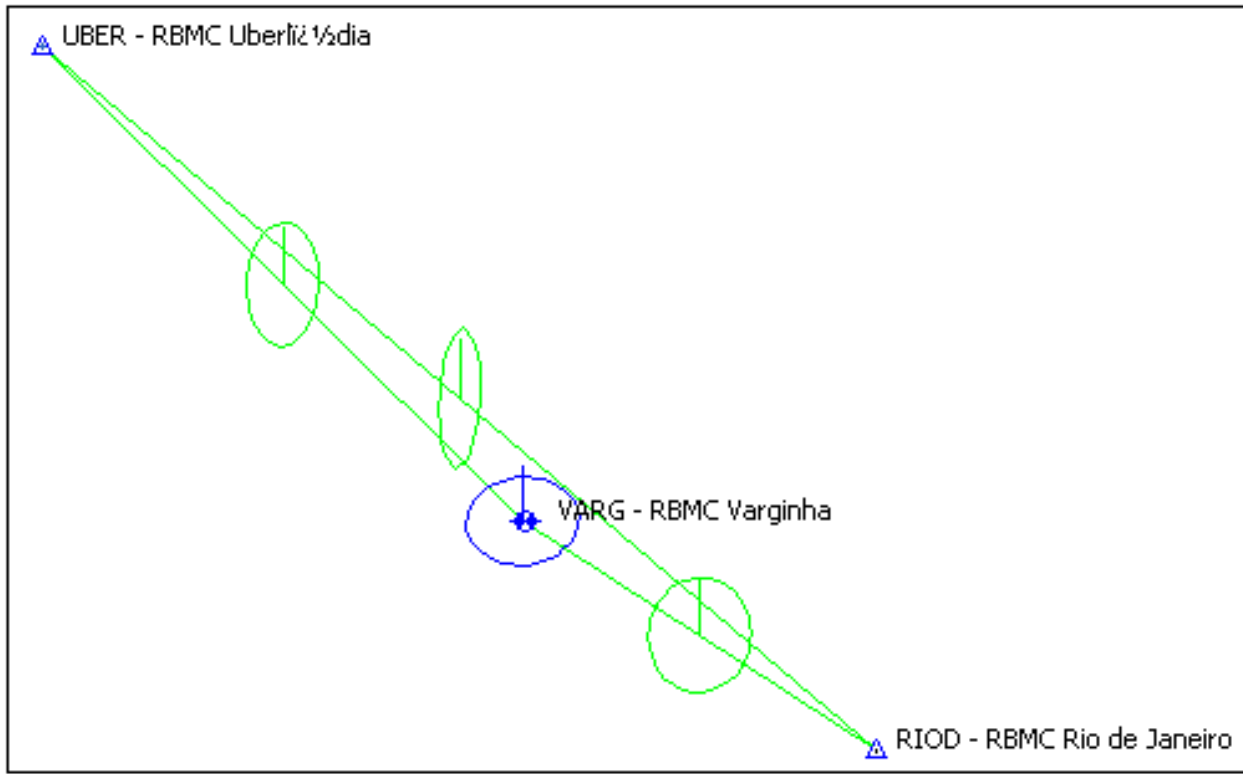

Coordenadas Ajustadas de VARG:

E (UTM): $454968.9555 \mathrm{~m}$

N (UTM): $7617727.2919 \mathrm{~m}$

- $196 / 2007$

A posteriori UWE: 0.972181 , Bounds: ( $0.6770032,1.241639$ ) 
TABELA B76: Resultado do Processamento

\begin{tabular}{|c|c|c|c|c|c|c|c|c|}
\hline \multicolumn{9}{|c|}{ GPS Obs Report } \\
\hline Name & \begin{tabular}{|} 
Horizontal \\
Precision (m)
\end{tabular} & $\begin{array}{l}\text { Vertical } \\
\text { Precision } \\
\text { (m) }\end{array}$ & $\begin{array}{l}\text { Distance } \\
\text { (m) }\end{array}$ & $\begin{array}{l}\text { Solution } \\
\text { Type }\end{array}$ & $\begin{array}{c}\text { GPS } \\
\text { Satellites }\end{array}$ & PDOP & Status & RMS \\
\hline $\begin{array}{l}\text { RIOD - RBMC Rio de } \\
\text { Janeiro-UBER - RBMC } \\
\text { Uberlï }{ }^{1 / 2 \text { dia }} \\
\end{array}$ & 0.052 & 0.112 & 678629.090 & $\begin{array}{l}\text { Fixed,Wide } \\
\text { Lane }\end{array}$ & 30 & 2.789 & Adjusted & 0.124 \\
\hline $\begin{array}{l}\text { RIOD - RBMC Rio de } \\
\text { Janeiro-VARG - RBMC } \\
\text { Varginha }\end{array}$ & 0.034 & 0.069 & 261011.687 & $\begin{array}{l}\text { Fixed,Wide } \\
\text { Lane }\end{array}$ & 30 & 2.993 & Adjusted & 0.077 \\
\hline $\begin{array}{l}\text { UBER - RBMC } \\
\text { Uberlïi/2dia-VARG - } \\
\text { RBMC Varginha }\end{array}$ & 0.041 & 0.088 & 420650.791 & $\begin{array}{l}\text { Fixed,Wide } \\
\text { Lane }\end{array}$ & 31 & 2.880 & Adjusted & 0.097 \\
\hline
\end{tabular}

Figura B76: Elipses de Erro

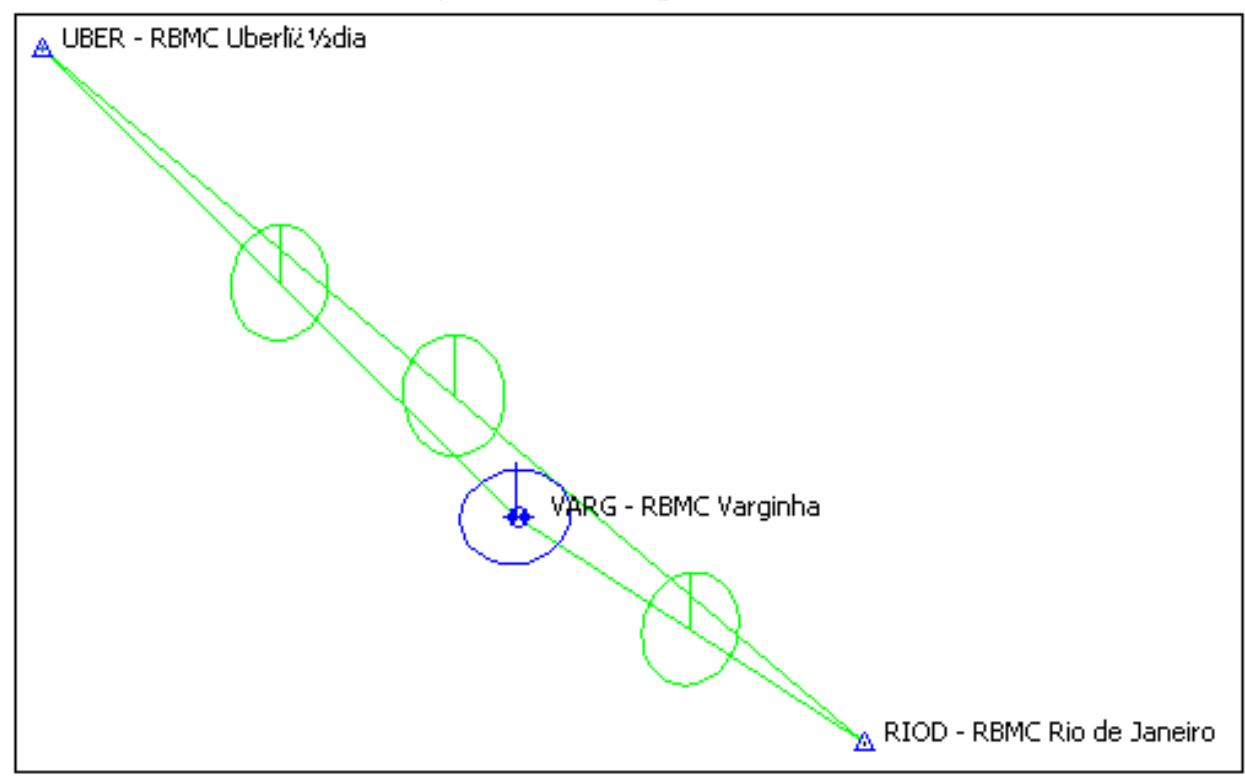

Coordenadas Ajustadas de VARG:

E (UTM): $454968.9596 \mathrm{~m}$

N (UTM): $7617727.2938 \mathrm{~m}$

\section{B.2.2.4 Primavera (Dias Julianos 286 a 289)}

- $\underline{286 / 2007}$

A posteriori UWE: 2.036222 , Bounds: ( $0.6770032,1.241639$ ) 
TABELA B77: Resultado do Processamento

\begin{tabular}{|c|c|c|c|c|c|c|c|c|}
\hline \multicolumn{9}{|c|}{ GPS Obs Report } \\
\hline Name & $\begin{array}{c}\text { Horizontal } \\
\text { Precision } \\
\text { (m) }\end{array}$ & \begin{tabular}{|c|} 
Vertical \\
Precision \\
$(\mathbf{m})$
\end{tabular} & $\begin{array}{l}\text { Distance } \\
\text { (m) }\end{array}$ & $\begin{array}{c}\text { Solution } \\
\text { Type }\end{array}$ & $\begin{array}{c}\text { GPS } \\
\text { Satellites }\end{array}$ & PDOP & Status & RMS \\
\hline \begin{tabular}{|l} 
RIOD - Rio de \\
Janeiro-UBER - \\
Uberlandia(CEMIG)
\end{tabular} & 0.083 & 0.091 & 678629.058 & $\begin{array}{l}\text { Float,Wide } \\
\text { Lane }\end{array}$ & 30 & 3.183 & Adjusted & 0.124 \\
\hline $\begin{array}{l}\text { RIOD - Rio de } \\
\text { Janeiro-VARG - Varginha }\end{array}$ & 0.036 & 0.068 & 261011.671 & \begin{tabular}{|l} 
Fixed,Wide \\
Lane
\end{tabular} & 30 & 2.992 & Adjusted & 0.077 \\
\hline $\begin{array}{l}\text { UBER - } \\
\text { Uberlandia(CEMIG)-VARG } \\
\text { - Varginha }\end{array}$ & 0.068 & 0.069 & 420650.754 & $\begin{array}{l}\text { Float, Wide } \\
\text { Lane }\end{array}$ & 31 & 2.906 & Adjusted & 0.097 \\
\hline
\end{tabular}

Figura B77: Elipses de Erro

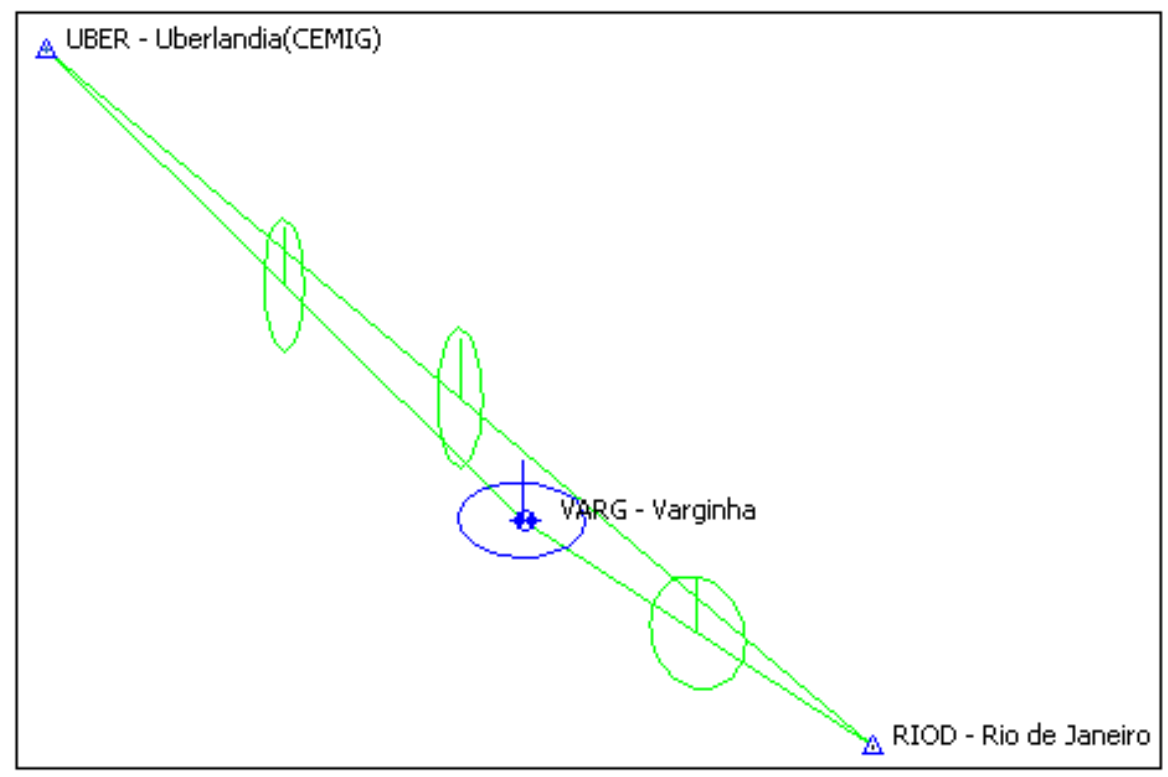

Coordenadas Ajustadas de VARG:

E (UTM): $454968.5137 \mathrm{~m}$

N (UTM): $7617727.5616 \mathrm{~m}$

- $\underline{287 / 2007}$

A posteriori UWE: 1.218713 , Bounds: ( $0.6770032,1.241639$ ) 
TABELA B78: Resultado do Processamento

\begin{tabular}{|c|c|c|c|c|c|c|c|c|}
\hline \multicolumn{9}{|c|}{ GPS Obs Report } \\
\hline Name & $\begin{array}{l}\text { Horizontal } \\
\text { Precision (m) }\end{array}$ & $\begin{array}{l}\text { Vertical } \\
\text { Precision } \\
\text { (m) }\end{array}$ & $\begin{array}{l}\text { Distance } \\
\text { (m) }\end{array}$ & $\begin{array}{l}\text { Solution } \\
\text { Type }\end{array}$ & $\begin{array}{c}\text { GPS } \\
\text { Satellites }\end{array}$ & PDOP & Status & RMS \\
\hline $\begin{array}{l}\text { RIOD - Rio de } \\
\text { Janeiro-UBER }\end{array}$ & 0.080 & 0.092 & 678629.120 & $\begin{array}{l}\text { Float,Wide } \\
\text { Lane }\end{array}$ & 29 & 2.619 & Adjusted & 0.124 \\
\hline $\begin{array}{l}\text { RIOD - Rio de } \\
\text { Janeiro-VARG - } \\
\text { Varginha }\end{array}$ & 0.030 & 0.066 & 261011.759 & $\begin{array}{l}\text { Fixed,Wide } \\
\text { Lane }\end{array}$ & 29 & 2.991 & Adjusted & 0.076 \\
\hline $\begin{array}{l}\text { UBER-VARG - } \\
\text { Varginha }\end{array}$ & 0.054 & 0.082 & 420650.796 & \begin{tabular}{|l} 
Fixed,Wide \\
Lane
\end{tabular} & 30 & 2.881 & Adjusted & 0.098 \\
\hline
\end{tabular}

Figura B78: Elipses de Erro

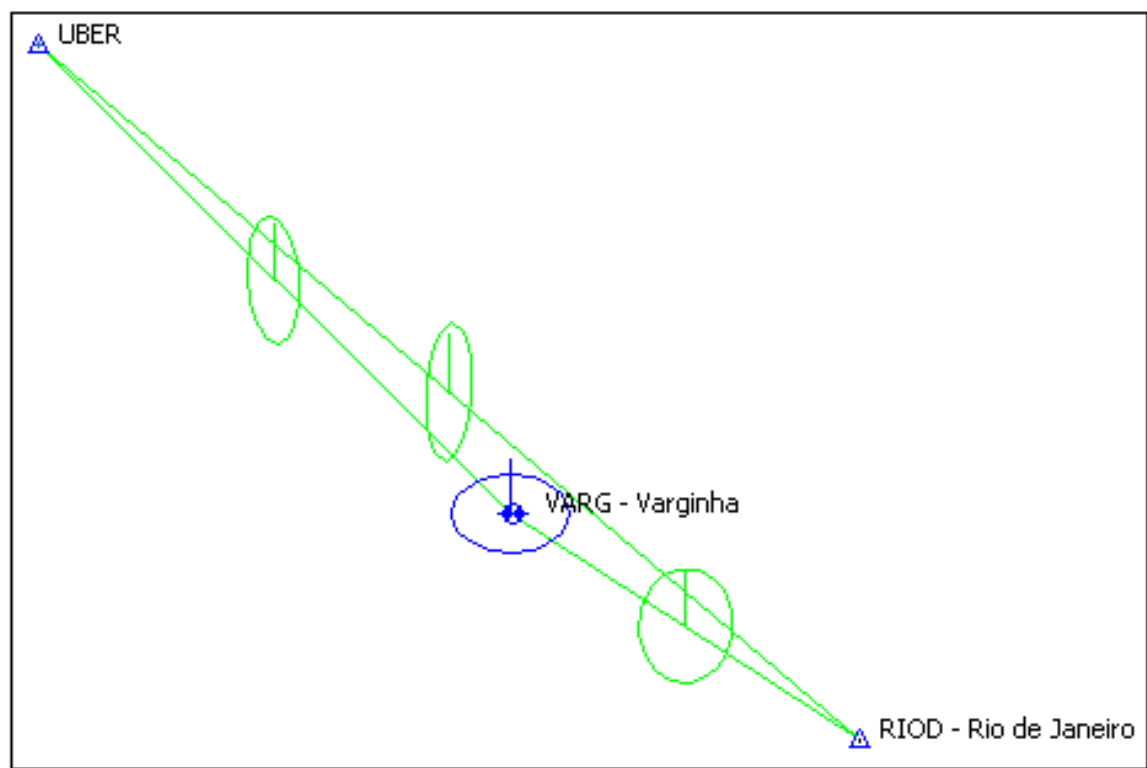

Coordenadas Ajustadas de VARG:

E (UTM): $454968.9103 \mathrm{~m}$

N (UTM): $7617727.2769 \mathrm{~m}$

- $\underline{288 / 2007}$

A posteriori UWE: 0.971937 , Bounds: ( $0.6770032,1.241639)$ 
TABELA B79: Resultado do Processamento

\begin{tabular}{|c|c|c|c|c|c|c|c|c|}
\hline \multicolumn{9}{|c|}{ GPS Obs Report } \\
\hline Name & $\begin{array}{c}\text { Horizontal } \\
\text { Precision (m) }\end{array}$ & $\begin{array}{c}\text { Vertical } \\
\text { Precision } \\
\text { (m) }\end{array}$ & $\begin{array}{l}\text { Distance } \\
\text { (m) }\end{array}$ & $\begin{array}{c}\text { Solution } \\
\text { Type }\end{array}$ & $\begin{array}{c}\text { GPS } \\
\text { Satellites }\end{array}$ & | PDOP & Status & RMS \\
\hline \begin{tabular}{|l|} 
RIOD - Rio de \\
Janeiro-UBER - \\
Uberlandia \\
\end{tabular} & $\mid 0.071$ & 0.095 & |678629.109 & $\begin{array}{l}\text { Float,Wide } \\
\text { Lane }\end{array}$ & 28 & 3.029 & Adjusted & 0.124 \\
\hline \begin{tabular}{|l} 
RIOD - Rio de \\
Janeiro-VARG - \\
Varginha
\end{tabular} & 0.050 & 0.061 & |261011.701 & \begin{tabular}{|l} 
Fixed,Wide \\
Lane
\end{tabular} & 30 & 2.993 & Adjusted & 0.077 \\
\hline $\begin{array}{l}\text { UBER - } \\
\text { Uberlandia-VARG - } \\
\text { Varginha }\end{array}$ & 0.060 & 0.078 & 420650.773 & \begin{tabular}{|l} 
Float,Wide \\
Lane
\end{tabular} & 31 & 2.884 & Adjusted & 0.098 \\
\hline
\end{tabular}

Figura B79: Elipses de Erro

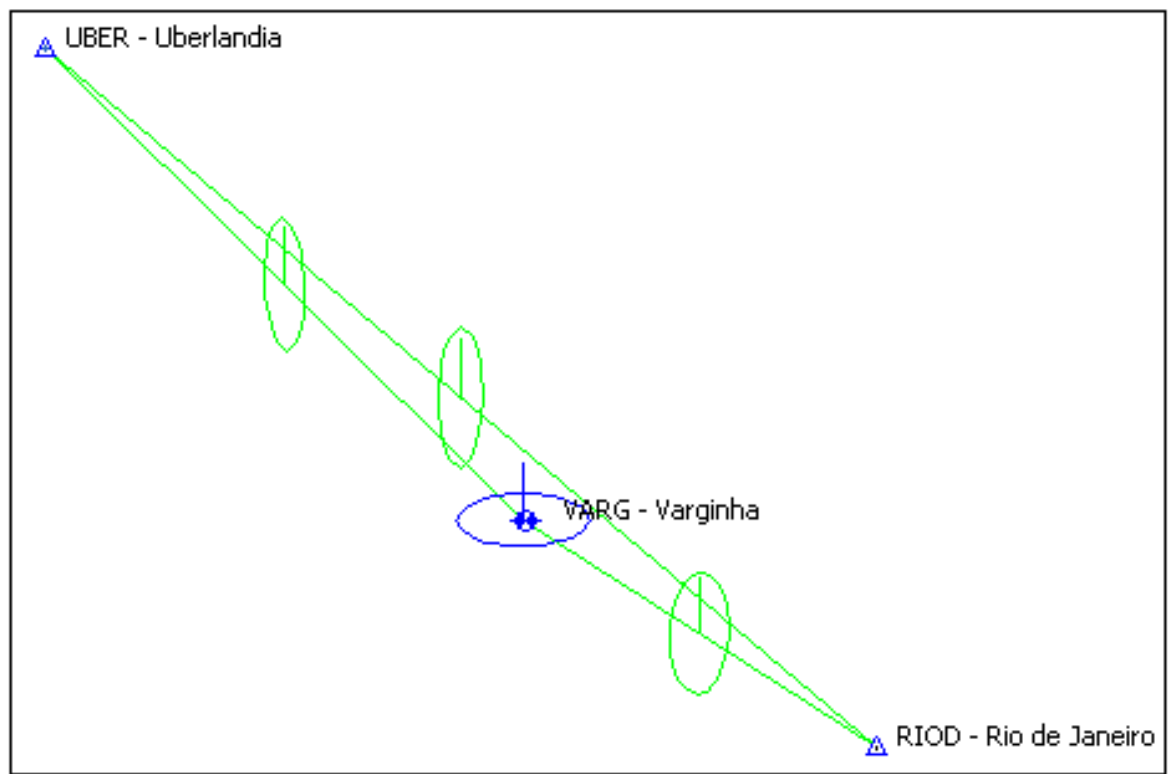

Coordenadas Ajustadas de VARG:

E (UTM): $454968.9447 \mathrm{~m}$

N (UTM): $7617727.3076 \mathrm{~m}$

- $289 / 2007$

A posteriori UWE: 1.023952 , Bounds: ( $0.6770032,1.241639$ ) 
TABELA B80: Resultado do Processamento

\begin{tabular}{|c|c|c|c|c|c|c|c|c|}
\hline \multicolumn{9}{|c|}{ GPS Obs Report } \\
\hline Name & $\begin{array}{c}\text { Horizontal } \\
\text { Precision (m) }\end{array}$ & $\begin{array}{c}\text { Vertical } \\
\text { Precision } \\
\text { (m) }\end{array}$ & $\begin{array}{l}\text { Distance } \\
\text { (m) }\end{array}$ & $\begin{array}{c}\text { Solution } \\
\text { Type }\end{array}$ & $\begin{array}{c}\text { GPS } \\
\text { Satellites }\end{array}$ & | PDOP & Status & RMS \\
\hline \begin{tabular}{|l|} 
RIOD - Rio de \\
Janeiro-UBER - \\
Uberlandia \\
\end{tabular} & $\mid 0.087$ & 0.081 & |678629.138 & $\begin{array}{l}\text { Float,Wide } \\
\text { Lane }\end{array}$ & 27 & 2.756 & Adjusted & 0.125 \\
\hline $\begin{array}{l}\text { RIOD - Rio de } \\
\text { Janeiro-VARG - } \\
\text { Varginha }\end{array}$ & $\mid 0.031$ & 0.065 & |261011.688 & \begin{tabular}{|l} 
Fixed,Wide \\
Lane
\end{tabular} & 30 & 2.872 & Adjusted & 0.077 \\
\hline $\begin{array}{l}\text { UBER - } \\
\text { Uberlandia-VARG - } \\
\text { Varginha }\end{array}$ & 0.060 & 0.064 & |420650.798 & \begin{tabular}{|l} 
Float,Wide \\
Lane
\end{tabular} & 31 & 2.913 & Adjusted & 0.097 \\
\hline
\end{tabular}

Figura B80: Elipses de Erro

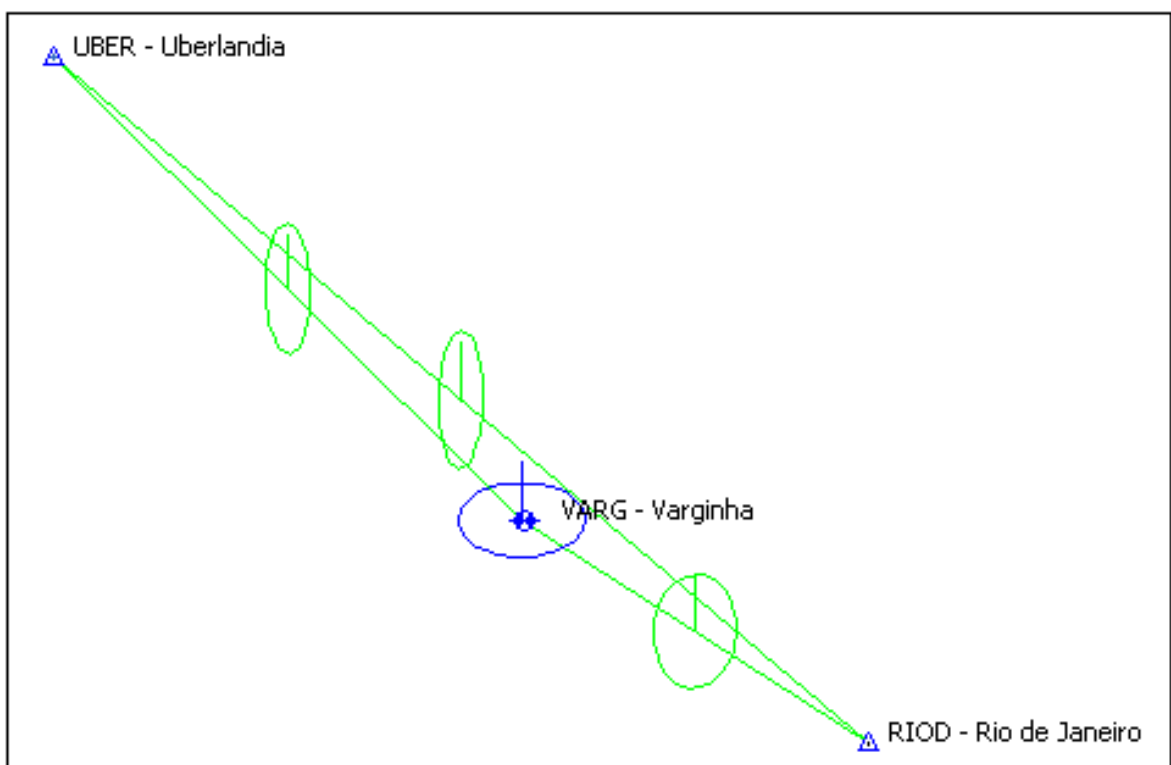

Coordenadas Ajustadas de VARG:

E (UTM): $454968.9572 \mathrm{~m}$

N (UTM): $7617727.3026 \mathrm{~m}$

\section{B.2.3 Ano de 2008}

\section{B.2.3.1 Verão (Dias Julianos 011 a 014)}

- $\underline{011 / 2008}$

A posteriori UWE: 0.9849429 , Bounds: ( $0.6770032,1.241639)$ 
TABELA B81: Resultado do Processamento

\begin{tabular}{|c|c|c|c|c|c|c|c|c|}
\hline \multicolumn{9}{|c|}{ GPS Obs Report } \\
\hline Name & $\begin{array}{c}\text { Horizontal } \\
\text { Precision (m) }\end{array}$ & $\begin{array}{l}\text { Vertical } \\
\text { Precision } \\
\quad(m)\end{array}$ & $\begin{array}{l}\text { Distance } \\
\text { (m) }\end{array}$ & $\begin{array}{c}\text { Solution } \\
\text { Type }\end{array}$ & $\begin{array}{c}\text { GPS } \\
\text { Satellites }\end{array}$ & PDOP & Status & RMS \\
\hline $\begin{array}{l}\text { RIOD - Rio de } \\
\text { Janeiro-UBER - } \\
\text { Uberlandia }\end{array}$ & 0.094 & 0.081 & 678629.134 & $\begin{array}{l}\text { Float,Wide } \\
\text { Lane }\end{array}$ & 30 & 3.053 & Adjusted & 0.124 \\
\hline $\begin{array}{l}\text { RIOD - Rio de } \\
\text { Janeiro-VARG - } \\
\text { Varginha }\end{array}$ & 0.034 & 0.069 & 261011.700 & $\begin{array}{l}\text { Fixed,Wide } \\
\text { Lane }\end{array}$ & 30 & 2.926 & Adjusted & 0.077 \\
\hline $\begin{array}{l}\text { UBER - } \\
\text { Uberlandia-VARG - } \\
\text { Varginha }\end{array}$ & 0.061 & 0.076 & 420650.814 & $\begin{array}{l}\text { Fixed,Wide } \\
\text { Lane }\end{array}$ & 32 & 2.889 & Adjusted & 0.097 \\
\hline
\end{tabular}

Figura B81: Elipses de Erro

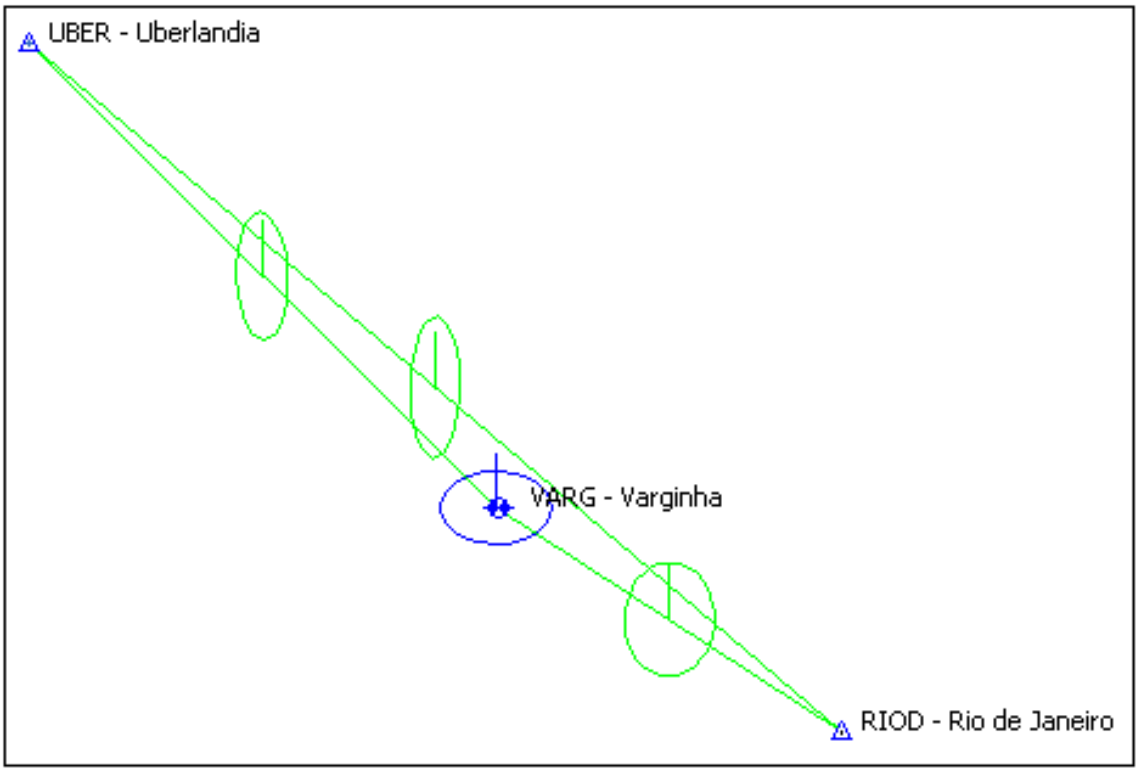

Coordenadas Ajustadas de VARG:

E (UTM): $454968.9475 \mathrm{~m}$

N (UTM): $7617727.2904 \mathrm{~m}$

- $\underline{012 / 2008}$

A posteriori UWE: 1.241243 , Bounds: ( $0.6770032,1.241639$ ) 
TABELA B82: Resultado do Processamento

\begin{tabular}{|c|c|c|c|c|c|c|c|c|}
\hline \multicolumn{9}{|c|}{ GPS Obs Report } \\
\hline Name & $\begin{array}{c}\text { Horizontal } \\
\text { Precision (m) }\end{array}$ & $\begin{array}{c}\text { Vertical } \\
\text { Precision } \\
\text { (m) }\end{array}$ & $\begin{array}{l}\text { Distance } \\
\text { (m) }\end{array}$ & $\begin{array}{c}\text { Solution } \\
\text { Type }\end{array}$ & $\begin{array}{c}\text { GPS } \\
\text { Satellites }\end{array}$ & PDOP & Status & RMS \\
\hline \begin{tabular}{|l|} 
RIOD - Rio de \\
Janeiro-UBER - \\
Uberlandia \\
\end{tabular} & $\mid 0.092$ & 0.083 & |678629.151 & \begin{tabular}{|l} 
Fixed,Wide \\
Lane
\end{tabular} & 31 & 2.982 & Adjusted & 0.124 \\
\hline \begin{tabular}{|l} 
RIOD - Rio de \\
Janeiro-VARG - \\
Varginha
\end{tabular} & 0.035 & 0.070 & |261011.711 & \begin{tabular}{|l} 
Fixed,Wide \\
Lane
\end{tabular} & 30 & 2.900 & Adjusted & 0.078 \\
\hline $\begin{array}{l}\text { UBER - } \\
\text { Uberlandia-VARG - } \\
\text { Varginha }\end{array}$ & 0.050 & 0.084 & 420650.815 & $\begin{array}{l}\text { Fixed,Wide } \\
\text { Lane }\end{array}$ & 32 & 2.917 & Adjusted & 0.098 \\
\hline
\end{tabular}

Figura B82: Elipses de Erro

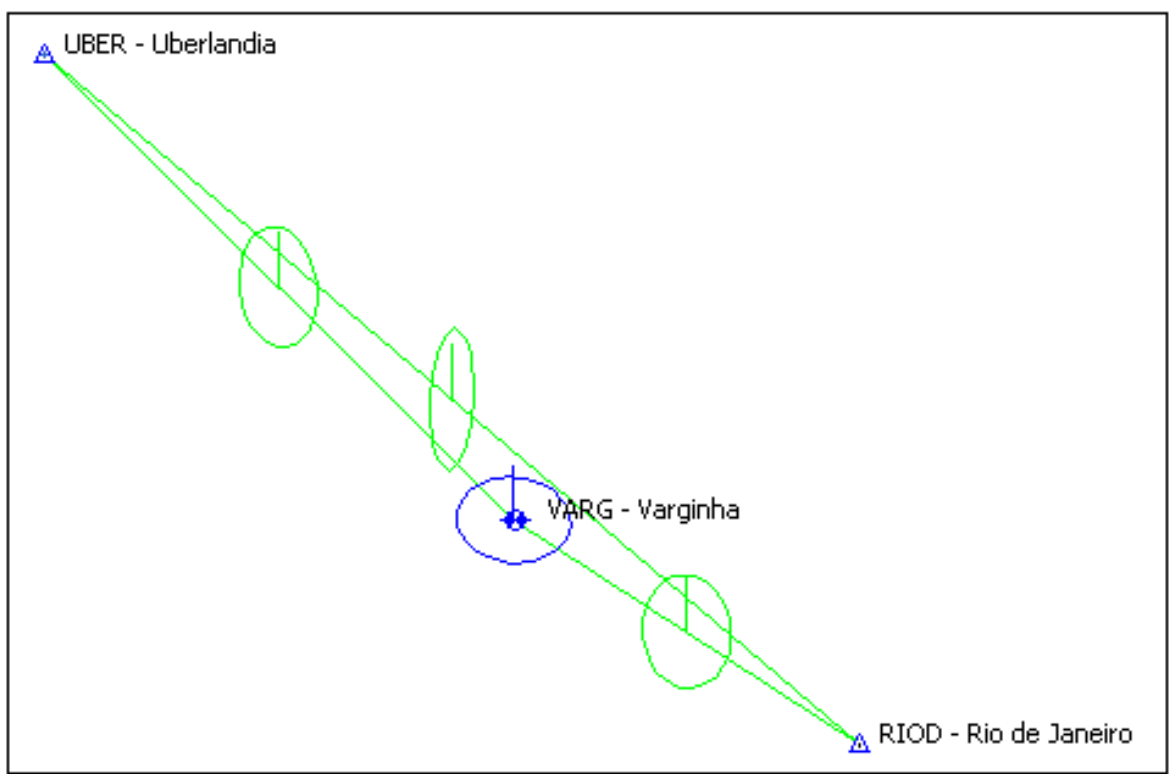

Coordenadas Ajustadas de VARG:

E (UTM): $454968.9435 \mathrm{~m}$

N (UTM): $7617727.2944 \mathrm{~m}$

- $\underline{013 / 2008}$

A posteriori UWE: 1.23619 , Bounds: ( $0.6770032,1.241639$ ) 
TABELA B83: Resultado do Processamento

\begin{tabular}{|c|c|c|c|c|c|c|c|c|}
\hline \multicolumn{9}{|c|}{ GPS Obs Report } \\
\hline Name & $\begin{array}{c}\text { Horizontal } \\
\text { Precision (m) }\end{array}$ & $\begin{array}{c}\text { Vertical } \\
\text { Precision } \\
\text { (m) }\end{array}$ & $\begin{array}{l}\text { Distance } \\
\text { (m) }\end{array}$ & $\begin{array}{c}\text { Solution } \\
\text { Type }\end{array}$ & $\begin{array}{c}\text { GPS } \\
\text { Satellites }\end{array}$ & | PDOP & Status & RMS \\
\hline \begin{tabular}{|l|} 
RIOD - Rio de \\
Janeiro-UBER - \\
Uberlandia \\
\end{tabular} & $\mid 0.082$ & 0.090 & |678629.140 & $\begin{array}{l}\mid \begin{array}{l}\text { Float,Wide } \\
\text { Lane }\end{array} \\
\text { late }\end{array}$ & 30 & 2.510 & Adjusted & 0.124 \\
\hline $\begin{array}{l}\text { RIOD - Rio de } \\
\text { Janeiro-VARG - } \\
\text { Varginha }\end{array}$ & 0.032 & 0.065 & |261011.689 & \begin{tabular}{|l} 
Fixed,Wide \\
Lane
\end{tabular} & 30 & 2.889 & Adjusted & 0.077 \\
\hline $\begin{array}{l}\text { UBER - } \\
\text { Uberlandia-VARG - } \\
\text { Varginha }\end{array}$ & 0.066 & 0.073 & |420650.820 & \begin{tabular}{|l} 
Float,Wide \\
Lane
\end{tabular} & 32 & 2.851 & Adjusted & 0.098 \\
\hline
\end{tabular}

Figura B83: Elipses de Erro

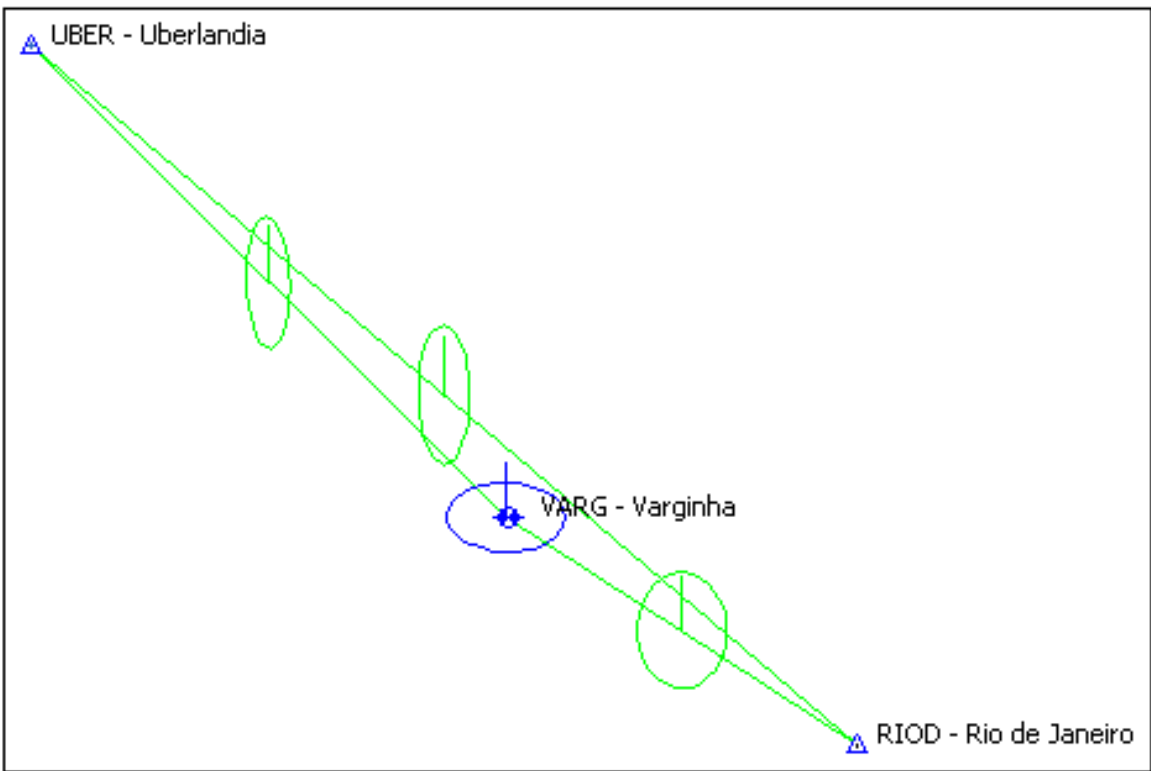

Coordenadas Ajustadas de VARG:

E (UTM): $454968.9582 \mathrm{~m}$

N (UTM): $7617727.2798 \mathrm{~m}$

- $\underline{014 / 2008}$

A posteriori UWE: 1.06255 , Bounds: ( $0.6770032,1.241639$ ) 
TABELA B84: Resultado do Processamento

\begin{tabular}{|c|c|c|c|c|c|c|c|c|}
\hline \multicolumn{9}{|c|}{ GPS Obs Report } \\
\hline Name & $\begin{array}{c}\text { Horizontal } \\
\text { Precision (m) }\end{array}$ & $\begin{array}{l}\text { Vertical } \\
\text { Precision } \\
\quad(m)\end{array}$ & $\begin{array}{l}\text { Distance } \\
\text { (m) }\end{array}$ & $\begin{array}{c}\text { Solution } \\
\text { Type }\end{array}$ & $\begin{array}{c}\text { GPS } \\
\text { Satellites }\end{array}$ & PDOP & Status & RMS \\
\hline $\begin{array}{l}\text { RIOD - Rio de } \\
\text { Janeiro-UBER - } \\
\text { Uberlandia }\end{array}$ & 0.084 & 0.090 & 678629.133 & $\begin{array}{l}\text { Float,Wide } \\
\text { Lane }\end{array}$ & 30 & 3.004 & Adjusted & 0.124 \\
\hline $\begin{array}{l}\text { RIOD - Rio de } \\
\text { Janeiro-VARG - } \\
\text { Varginha }\end{array}$ & 0.033 & 0.069 & 261011.697 & $\begin{array}{l}\text { Fixed,Wide } \\
\text { Lane }\end{array}$ & 30 & 2.888 & Adjusted & 0.077 \\
\hline $\begin{array}{l}\text { UBER - } \\
\text { Uberlandia-VARG - } \\
\text { Varginha }\end{array}$ & 0.051 & 0.083 & 420650.814 & $\begin{array}{l}\text { Fixed,Wide } \\
\text { Lane }\end{array}$ & 32 & 2.853 & Adjusted & 0.098 \\
\hline
\end{tabular}

Figura B84: Elipses de Erro

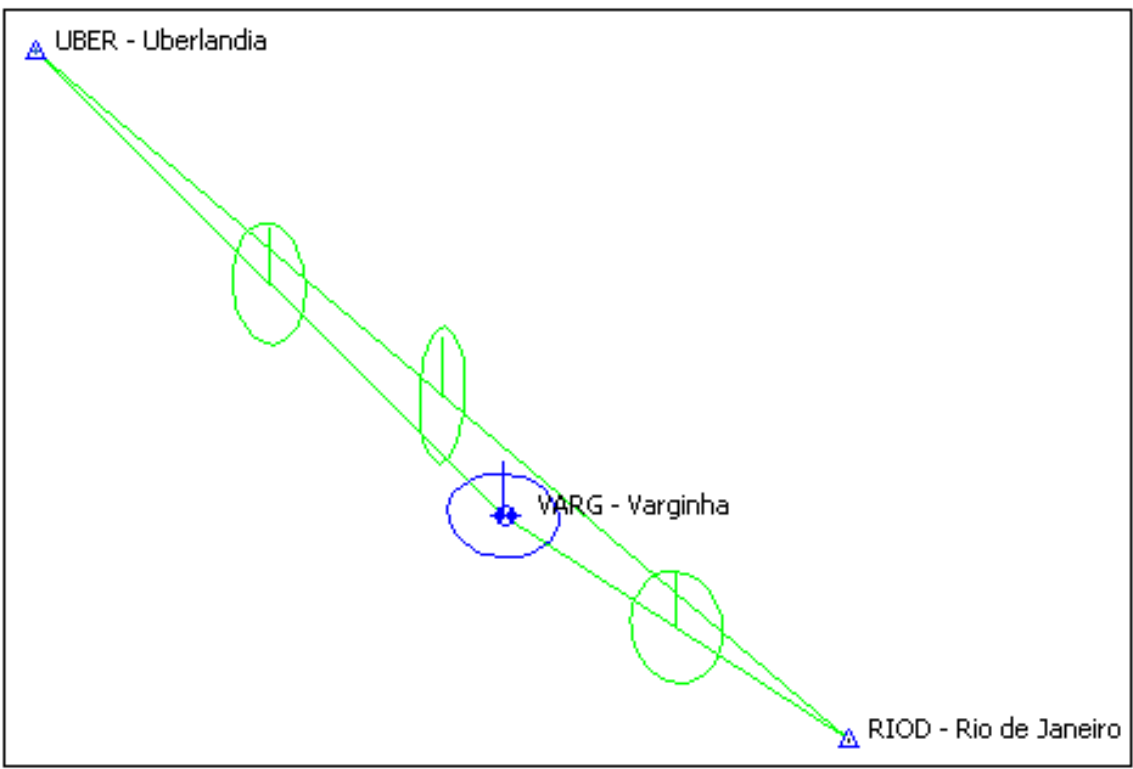

Coordenadas Ajustadas de VARG:

E (UTM): $454968.9581 \mathrm{~m}$

N (UTM): $7617727.2950 \mathrm{~m}$

B.2.3.2 Outono (Dias Julianos 102 a 105)

- $\underline{102 / 2008}$

A posteriori UWE: 0.9651859 , Bounds: ( $0.6770032,1.241639)$ 
TABELA B85: Resultado do Processamento

\begin{tabular}{|c|c|c|c|c|c|c|c|c|}
\hline \multicolumn{9}{|c|}{ GPS Obs Report } \\
\hline Name & $\begin{array}{c}\text { Horizontal } \\
\text { Precision (m) }\end{array}$ & $\begin{array}{c}\text { Vertical } \\
\text { Precision } \\
(\mathbf{m})\end{array}$ & $\begin{array}{l}\text { Distance } \\
\text { (m) }\end{array}$ & $\begin{array}{c}\text { Solution } \\
\text { Type }\end{array}$ & $\begin{array}{c}\text { GPS } \\
\text { Satellites }\end{array}$ & PDOP & Status & RMS \\
\hline \begin{tabular}{|l|} 
RIOD - Rio de \\
Janeiro-UBER - \\
Uberlandia \\
\end{tabular} & 0.082 & 0.090 & 678629.092 & $\begin{array}{l}\text { Float,Wide } \\
\text { Lane }\end{array}$ & 31 & 2.999 & Adjusted & 0.124 \\
\hline $\begin{array}{l}\text { RIOD - Rio de } \\
\text { Janeiro-VARG - Varginha } \\
\text { (CEMIG) }\end{array}$ & 0.036 & 0.065 & 261011.686 & $\begin{array}{l}\text { Fixed,Wide } \\
\text { Lane }\end{array}$ & 30 & 2.761 & Adjusted & 0.077 \\
\hline $\begin{array}{l}\text { UBER - } \\
\text { Uberlandia-VARG - } \\
\text { Varginha (CEMIG) }\end{array}$ & 0.064 & 0.071 & 420650.762 & $\begin{array}{l}\text { Float,Wide } \\
\text { Lane }\end{array}$ & 31 & 3.053 & Adjusted & 0.098 \\
\hline
\end{tabular}

Figura B85: Elipses de Erro

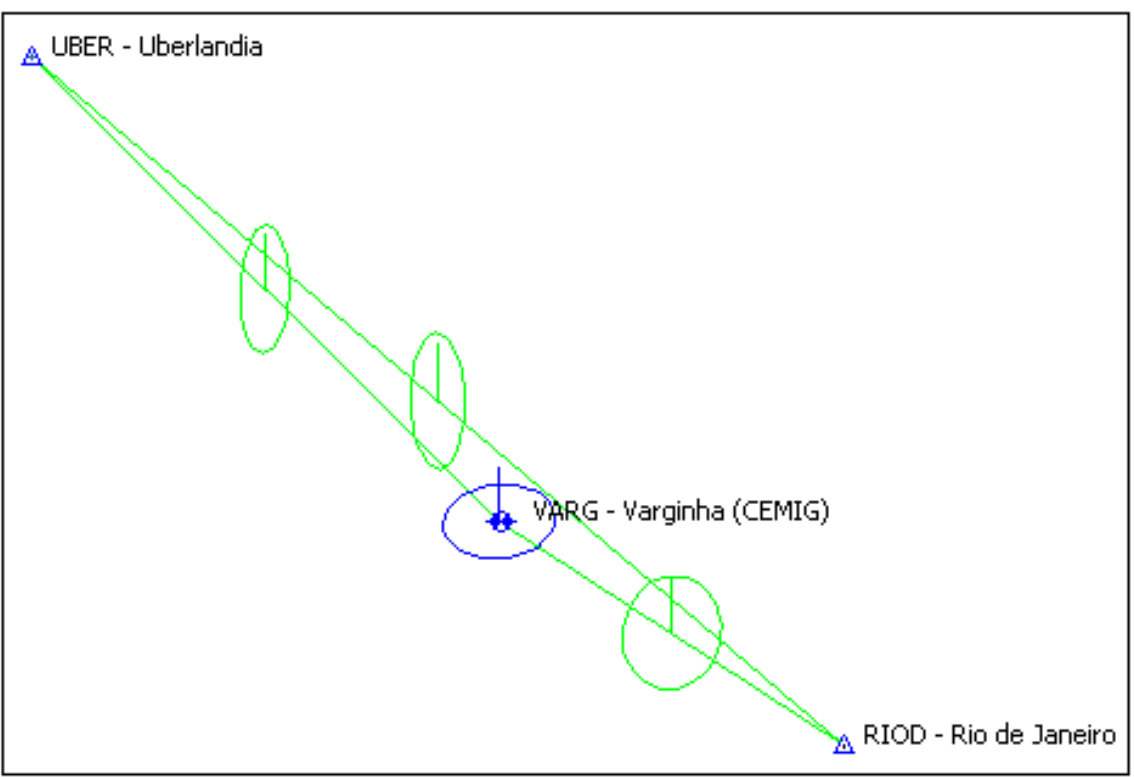

Coordenadas Ajustadas de VARG:

E (UTM): $454968.9562 \mathrm{~m}$

N (UTM): $7617727.2935 \mathrm{~m}$

- $\underline{103 / 2008}$

A posteriori UWE: 0.6872091 , Bounds: ( $0.6770032,1.241639)$ 
TABELA B86: Resultado do Processamento

\begin{tabular}{|c|c|c|c|c|c|c|c|c|}
\hline \multicolumn{9}{|c|}{ GPS Obs Report } \\
\hline Name & $\begin{array}{c}\text { Horizontal } \\
\text { Precision (m) }\end{array}$ & $\begin{array}{l}\text { Vertical } \\
\text { Precision } \\
\text { (m) }\end{array}$ & $\begin{array}{l}\text { Distance } \\
\text { (m) }\end{array}$ & $\begin{array}{c}\text { Solution } \\
\text { Type }\end{array}$ & $\begin{array}{c}\text { GPS } \\
\text { Satellites }\end{array}$ & PDOP & Status & RMS \\
\hline \begin{tabular}{|l|} 
RIOD - Rio de \\
Janeiro-UBER - \\
Uberlandia \\
\end{tabular} & 0.080 & 0.091 & 678629.103 & $\begin{array}{l}\text { Fixed,Wide } \\
\text { Lane }\end{array}$ & 29 & 2.882 & Adjusted & 0.124 \\
\hline $\begin{array}{l}\text { RIOD - Rio de } \\
\text { Janeiro-VARG - Varginha } \\
\text { (CEMIG) }\end{array}$ & 0.037 & 0.064 & 261011.688 & $\begin{array}{l}\text { Fixed,Wide } \\
\text { Lane }\end{array}$ & 28 & 3.008 & Adjusted & 0.077 \\
\hline $\begin{array}{l}\text { UBER - } \\
\text { Uberlandia-VARG - } \\
\text { Varginha (CEMIG) }\end{array}$ & 0.045 & 0.080 & 420650.759 & $\begin{array}{l}\text { Fixed,Wide } \\
\text { Lane }\end{array}$ & 28 & 2.879 & Adjusted & 0.097 \\
\hline
\end{tabular}

Figura B86: Elipses de Erro

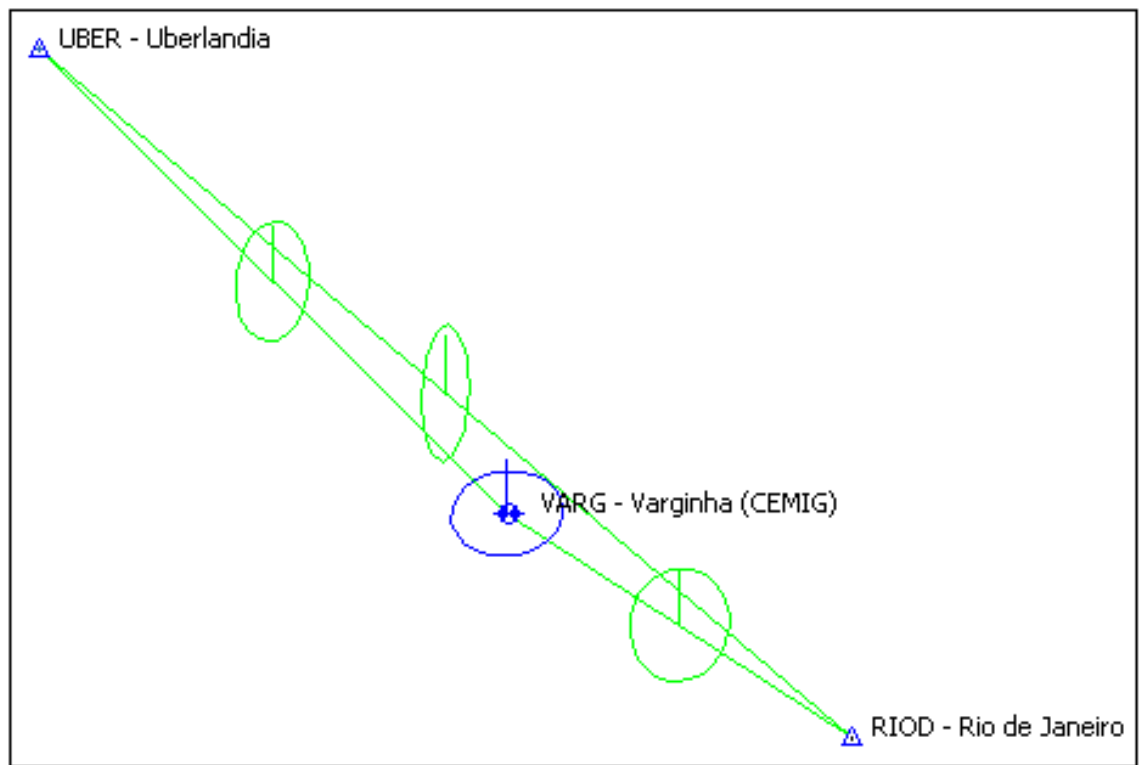

Coordenadas Ajustadas de VARG:

E (UTM): $454968.9671 \mathrm{~m}$

N (UTM): $7617727.2988 \mathrm{~m}$

- $\underline{104 / 2008}$

A posteriori UWE: 1.182035 , Bounds: ( $0.6770032,1.241639$ ) 
TABELA B87: Resultado do Processamento

\begin{tabular}{|c|c|c|c|c|c|c|c|c|}
\hline \multicolumn{9}{|c|}{ GPS Obs Report } \\
\hline Name & $\begin{array}{c}\text { Horizontal } \\
\text { Precision (m) }\end{array}$ & $\begin{array}{c}\text { Vertical } \\
\text { Precision } \\
(\mathbf{m})\end{array}$ & $\begin{array}{l}\text { Distance } \\
\text { (m) }\end{array}$ & $\begin{array}{c}\text { Solution } \\
\text { Type }\end{array}$ & $\begin{array}{c}\text { GPS } \\
\text { Satellites }\end{array}$ & | PDOP & Status & RMS \\
\hline \begin{tabular}{|l|} 
RIOD - Rio de \\
Janeiro-UBER - \\
Uberlandia \\
\end{tabular} & 0.076 & 0.094 & 678629.100 & $\begin{array}{l}\text { Float,Wide } \\
\text { Lane }\end{array}$ & 28 & 3.002 & Adjusted & 0.124 \\
\hline $\begin{array}{l}\text { RIOD - Rio de } \\
\text { Janeiro-VARG - Varginha } \\
\text { (CEMIG) }\end{array}$ & 0.034 & 0.065 & 261011.682 & $\begin{array}{l}\text { Fixed,Wide } \\
\text { Lane }\end{array}$ & 28 & 2.991 & Adjusted & 0.077 \\
\hline $\begin{array}{l}\text { UBER - } \\
\text { Uberlandia-VARG - } \\
\text { Varginha (CEMIG) }\end{array}$ & 0.054 & 0.081 & 420650.796 & $\begin{array}{l}\text { Fixed,Wide } \\
\text { Lane }\end{array}$ & 29 & 3.006 & Adjusted & 0.097 \\
\hline
\end{tabular}

Figura B87: Elipses de Erro

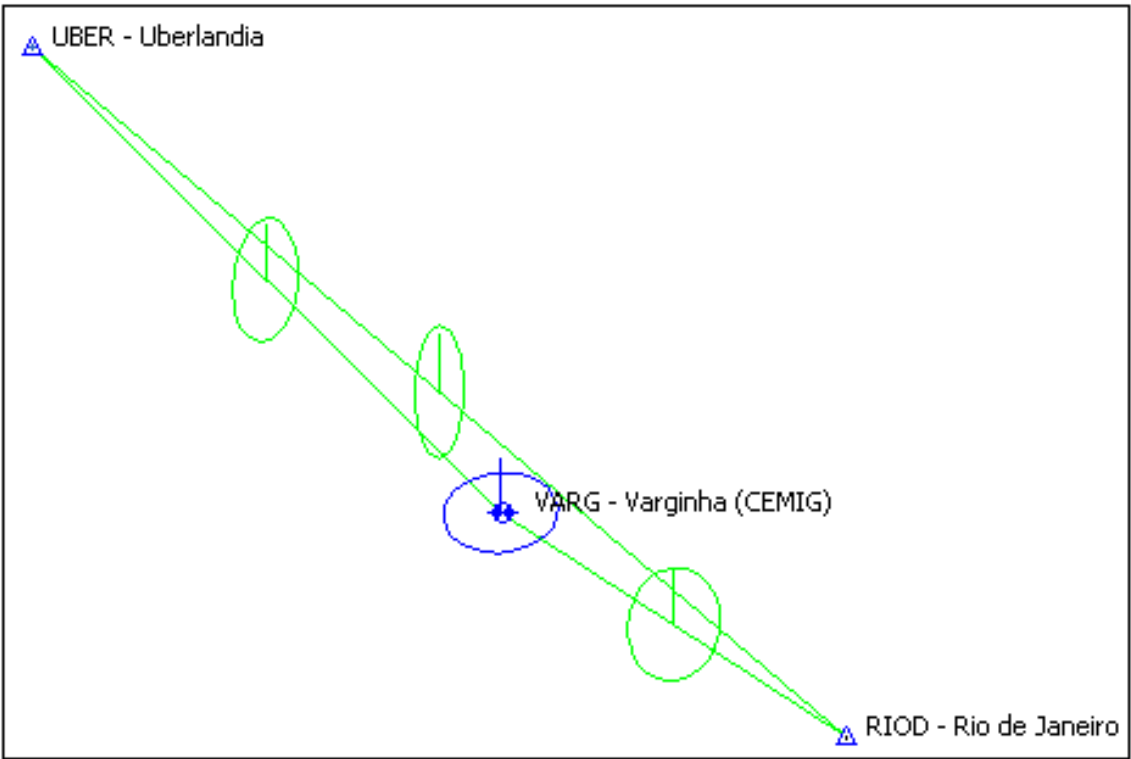

Coordenadas Ajustadas de VARG:

E (UTM): $454968.9781 \mathrm{~m}$

N (UTM): $7617727.3002 \mathrm{~m}$

- $\underline{105 / 2008}$

A posteriori UWE: 1.223448 , Bounds: ( $0.6770032,1.241639$ ) 
TABELA B88: Resultado do Processamento

\begin{tabular}{|c|c|c|c|c|c|c|c|c|}
\hline \multicolumn{9}{|c|}{ GPS Obs Report } \\
\hline Name & $\begin{array}{c}\text { Horizontal } \\
\text { Precision (m) }\end{array}$ & $\begin{array}{c}\text { Vertical } \\
\text { Precision } \\
(\mathbf{m})\end{array}$ & $\begin{array}{l}\text { Distance } \\
\text { (m) }\end{array}$ & $\begin{array}{c}\text { Solution } \\
\text { Type }\end{array}$ & $\begin{array}{c}\text { GPS } \\
\text { Satellites }\end{array}$ & PDOP & Status & RMS \\
\hline \begin{tabular}{|l|} 
RIOD - Rio de \\
Janeiro-UBER - \\
Uberlandia \\
\end{tabular} & 0.080 & 0.095 & 678629.140 & $\begin{array}{l}\text { Float,Wide } \\
\text { Lane }\end{array}$ & 29 & 3.014 & Adjusted & 0.124 \\
\hline $\begin{array}{l}\text { RIOD - Rio de } \\
\text { Janeiro-VARG - Varginha } \\
\text { (CEMIG) }\end{array}$ & 0.039 & 0.067 & 261011.695 & $\begin{array}{l}\text { Fixed,Wide } \\
\text { Lane }\end{array}$ & 31 & 2.954 & Adjusted & 0.077 \\
\hline $\begin{array}{l}\text { UBER - } \\
\text { Uberlandia-VARG - } \\
\text { Varginha (CEMIG) }\end{array}$ & 0.066 & 0.073 & 420650.800 & $\begin{array}{l}\text { Float,Wide } \\
\text { Lane }\end{array}$ & 32 & 2.787 & Adjusted & 0.098 \\
\hline
\end{tabular}

Figura B88: Elipses de Erro

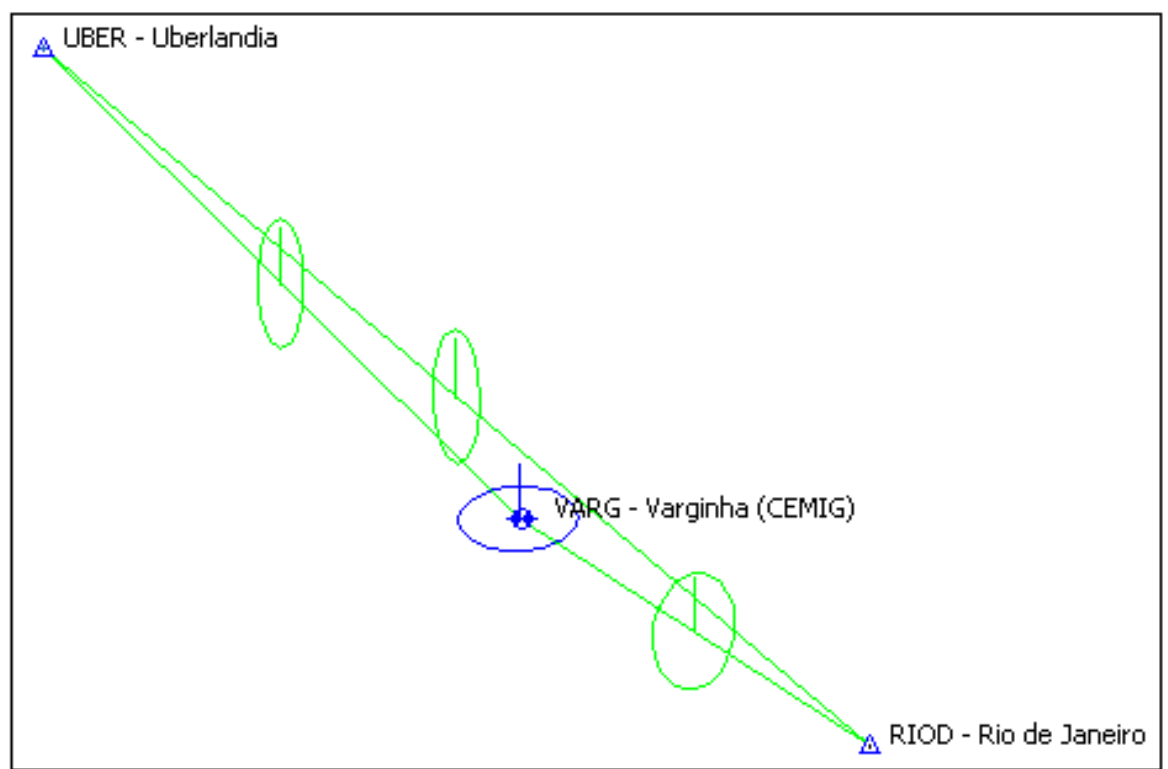

Coordenadas Ajustadas de VARG:

E (UTM): $454968.9411 \mathrm{~m}$

N (UTM): $7617727.2981 \mathrm{~m}$

\section{B.2.3.3 Inverno (Dias Julianos 194 a 197)}

- $194 / 2008$

A posteriori UWE: 1.23519 , Bounds: ( $0.6770032,1.241639$ ) 
TABELA B89: Resultado do Processamento

\begin{tabular}{|c|c|c|c|c|c|c|c|c|}
\hline \multicolumn{9}{|c|}{ GPS Obs Report } \\
\hline Name & $\begin{array}{c}\text { Horizontal } \\
\text { Precision (m) }\end{array}$ & $\begin{array}{c}\text { Vertical } \\
\text { Precision } \\
(\mathbf{m})\end{array}$ & $\begin{array}{l}\text { Distance } \\
\text { (m) }\end{array}$ & $\begin{array}{c}\text { Solution } \\
\text { Type }\end{array}$ & $\begin{array}{c}\text { GPS } \\
\text { Satellites }\end{array}$ & PDOP & Status & RMS \\
\hline \begin{tabular}{|l|} 
RIOD - Rio de \\
Janeiro-UBER - \\
Uberlandia \\
\end{tabular} & 0.055 & 0.111 & 678629.095 & $\begin{array}{l}\text { Fixed,Wide } \\
\text { Lane }\end{array}$ & 30 & 3.002 & Adjusted & 0.124 \\
\hline $\begin{array}{l}\text { RIOD - Rio de } \\
\text { Janeiro-VARG - Varginha } \\
\text { (CEMIG) }\end{array}$ & 0.032 & 0.070 & 261011.675 & $\begin{array}{l}\text { Fixed,Wide } \\
\text { Lane }\end{array}$ & 30 & 2.871 & Adjusted & 0.077 \\
\hline $\begin{array}{l}\text { UBER - } \\
\text { Uberlandia-VARG - } \\
\text { Varginha (CEMIG) }\end{array}$ & 0.045 & 0.088 & 420650.773 & $\begin{array}{l}\text { Fixed,Wide } \\
\text { Lane }\end{array}$ & 30 & 2.897 & Adjusted & 0.097 \\
\hline
\end{tabular}

Figura B89: Elipses de Erro

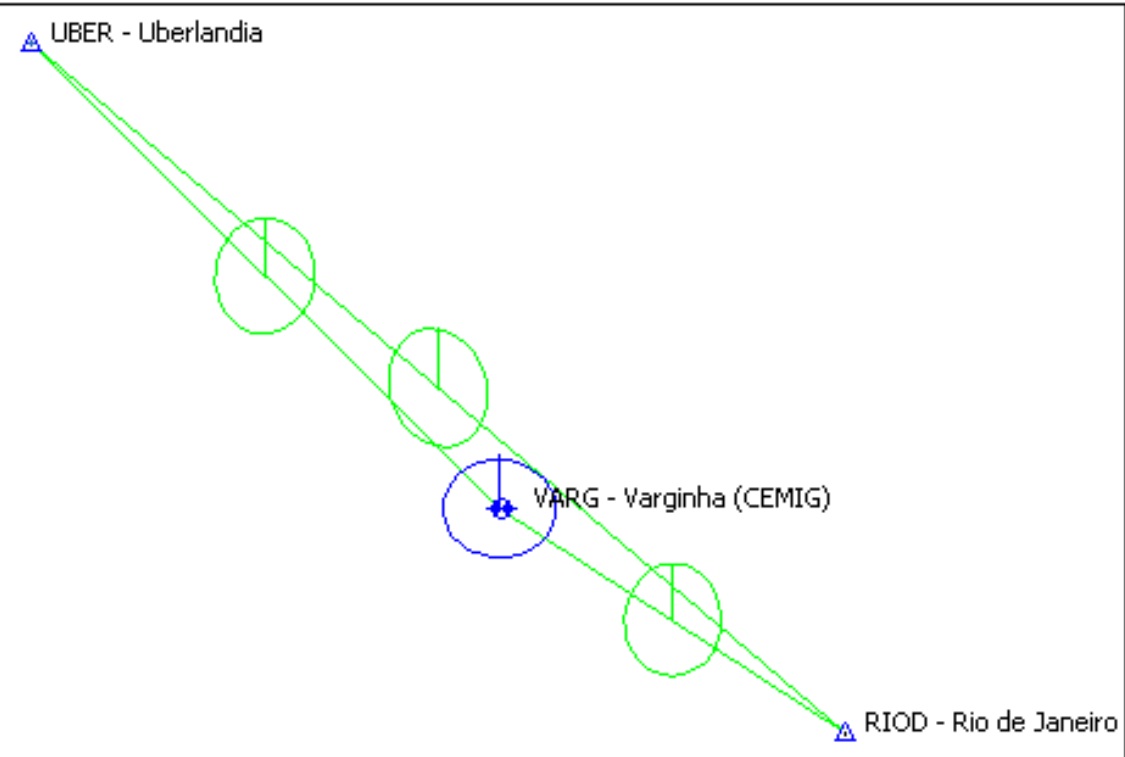

Coordenadas Ajustadas de VARG:

E (UTM): $454968.9321 \mathrm{~m}$

N (UTM): $7617727.3081 \mathrm{~m}$

- $\underline{195 / 2008}$

A posteriori UWE: 1.004648 , Bounds: ( $0.6770032,1.241639$ ) 
TABELA B90: Resultado do Processamento

\begin{tabular}{|c|c|c|c|c|c|c|c|c|}
\hline \multicolumn{9}{|c|}{ GPS Obs Report } \\
\hline Name & $\begin{array}{c}\text { Horizontal } \\
\text { Precision (m) }\end{array}$ & $\begin{array}{c}\text { Vertical } \\
\text { Precision } \\
(\mathbf{m})\end{array}$ & $\begin{array}{l}\text { Distance } \\
\text { (m) }\end{array}$ & $\begin{array}{c}\text { Solution } \\
\text { Type }\end{array}$ & $\begin{array}{c}\text { GPS } \\
\text { Satellites }\end{array}$ & PDOP & Status & RMS \\
\hline \begin{tabular}{|l|} 
RIOD - Rio de \\
Janeiro-UBER - \\
Uberlandia \\
\end{tabular} & 0.079 & 0.096 & 678629.069 & $\begin{array}{l}\text { Float,Wide } \\
\text { Lane }\end{array}$ & 29 & 3.022 & Adjusted & 0.124 \\
\hline $\begin{array}{l}\text { RIOD - Rio de } \\
\text { Janeiro-VARG - Varginha } \\
\text { (CEMIG) }\end{array}$ & 0.033 & 0.069 & 261011.665 & $\begin{array}{l}\text { Fixed,Wide } \\
\text { Lane }\end{array}$ & 31 & 2.890 & Adjusted & 0.077 \\
\hline $\begin{array}{l}\text { UBER - } \\
\text { Uberlandia-VARG - } \\
\text { Varginha (CEMIG) }\end{array}$ & 0.051 & 0.083 & 420650.746 & $\begin{array}{l}\text { Fixed,Wide } \\
\text { Lane }\end{array}$ & 31 & 2.787 & Adjusted & 0.097 \\
\hline
\end{tabular}

Figura B90: Elipses de Erro

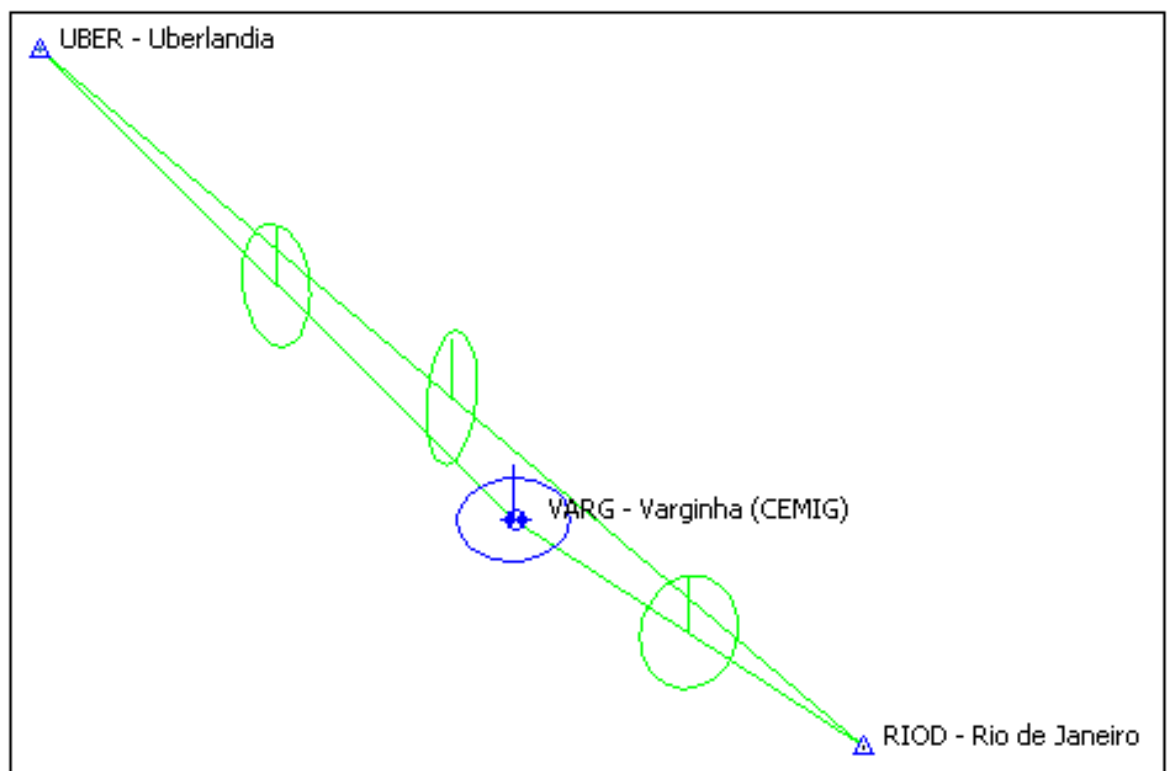

Coordenadas Ajustadas de VARG:

E (UTM): $454968.9578 \mathrm{~m}$

N (UTM): $7617727.2933 \mathrm{~m}$

- $\underline{196 / 2008}$

A posteriori UWE: 0.8593838 , Bounds: ( $0.6770032,1.241639)$ 
TABELA B91: Resultado do Processamento

\begin{tabular}{|c|c|c|c|c|c|c|c|c|}
\hline \multicolumn{9}{|c|}{ GPS Obs Report } \\
\hline Name & $\begin{array}{c}\text { Horizontal } \\
\text { Precision (m) }\end{array}$ & $\begin{array}{c}\text { Vertical } \\
\text { Precision } \\
(\mathbf{m})\end{array}$ & $\begin{array}{l}\text { Distance } \\
\text { (m) }\end{array}$ & $\begin{array}{c}\text { Solution } \\
\text { Type }\end{array}$ & $\begin{array}{c}\text { GPS } \\
\text { Satellites }\end{array}$ & PDOP & Status & RMS \\
\hline \begin{tabular}{|l|} 
RIOD - Rio de \\
Janeiro-UBER - \\
Uberlandia \\
\end{tabular} & 0.052 & 0.112 & 678629.066 & $\begin{array}{l}\text { Fixed,Wide } \\
\text { Lane }\end{array}$ & 31 & 3.044 & Adjusted & 0.124 \\
\hline $\begin{array}{l}\text { RIOD - Rio de } \\
\text { Janeiro-VARG - Varginha } \\
\text { (CEMIG) }\end{array}$ & 0.033 & 0.070 & 261011.678 & $\begin{array}{l}\text { Fixed,Wide } \\
\text { Lane }\end{array}$ & 31 & 2.890 & Adjusted & 0.077 \\
\hline $\begin{array}{l}\text { UBER - } \\
\text { Uberlandia-VARG - } \\
\text { Varginha (CEMIG) }\end{array}$ & 0.043 & 0.088 & 420650.759 & $\begin{array}{l}\text { Fixed,Wide } \\
\text { Lane }\end{array}$ & 31 & 2.807 & Adjusted & 0.097 \\
\hline
\end{tabular}

Figura B91: Elipses de Erro

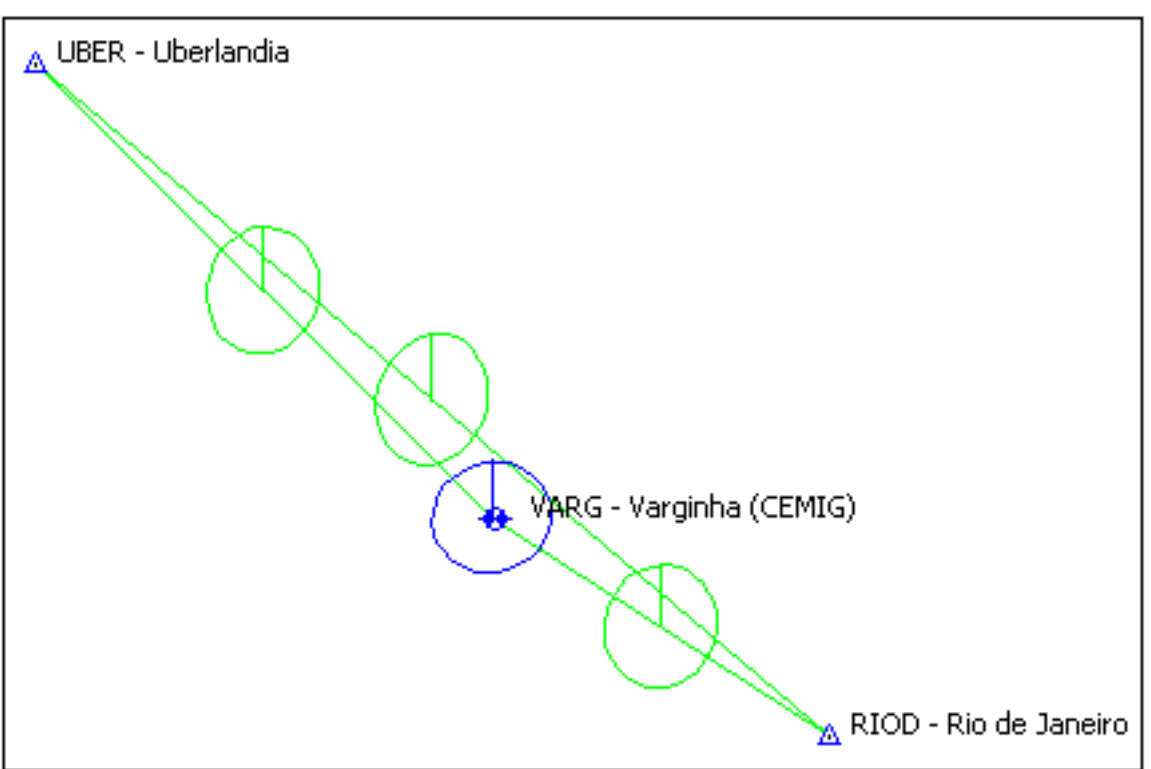

Coordenadas Ajustadas de VARG:

E (UTM): $454968.9535 \mathrm{~m}$

N (UTM): $7617727.2984 \mathrm{~m}$

- $197 / 2008$

A posteriori UWE: 0.8153326 , Bounds: ( $0.6770032,1.241639)$ 
TABELA B92: Resultado do Processamento

\begin{tabular}{|c|c|c|c|c|c|c|c|c|}
\hline \multicolumn{9}{|c|}{ GPS Obs Report } \\
\hline Name & \begin{tabular}{|c} 
Horizontal \\
Precision (m)
\end{tabular} & $\begin{array}{c}\text { Vertical } \\
\text { Precision } \\
(\mathbf{m})\end{array}$ & $\begin{array}{l}\text { Distance } \\
\quad(\mathbf{m})\end{array}$ & $\begin{array}{c}\text { Solution } \\
\text { Type }\end{array}$ & $\begin{array}{c}\text { GPS } \\
\text { Satellites }\end{array}$ & |PDOP & Status & RMS \\
\hline \begin{tabular}{|l|} 
RIOD - Rio de \\
Janeiro-UBER - \\
Uberlandia \\
\end{tabular} & 0.054 & 0.112 & 678629.075 & $\begin{array}{l}\text { Fixed,Wide } \\
\text { Lane }\end{array}$ & 31 & 3.049 & Adjusted & 0.124 \\
\hline $\begin{array}{l}\text { RIOD - Rio de } \\
\text { Janeiro-VARG - Varginha } \\
\text { (CEMIG) }\end{array}$ & 0.033 & 0.069 & 261011.671 & $\begin{array}{l}\text { Fixed,Wide } \\
\text { Lane }\end{array}$ & 31 & 2.906 & Adjusted & 0.077 \\
\hline $\begin{array}{l}\text { UBER - } \\
\text { Uberlandia-VARG - } \\
\text { Varginha (CEMIG) }\end{array}$ & 0.043 & 0.087 & 420650.761 & $\begin{array}{l}\text { Fixed,Wide } \\
\text { Lane }\end{array}$ & 31 & 2.786 & Adjusted & 0.097 \\
\hline
\end{tabular}

Figura B92: Elipses de Erro

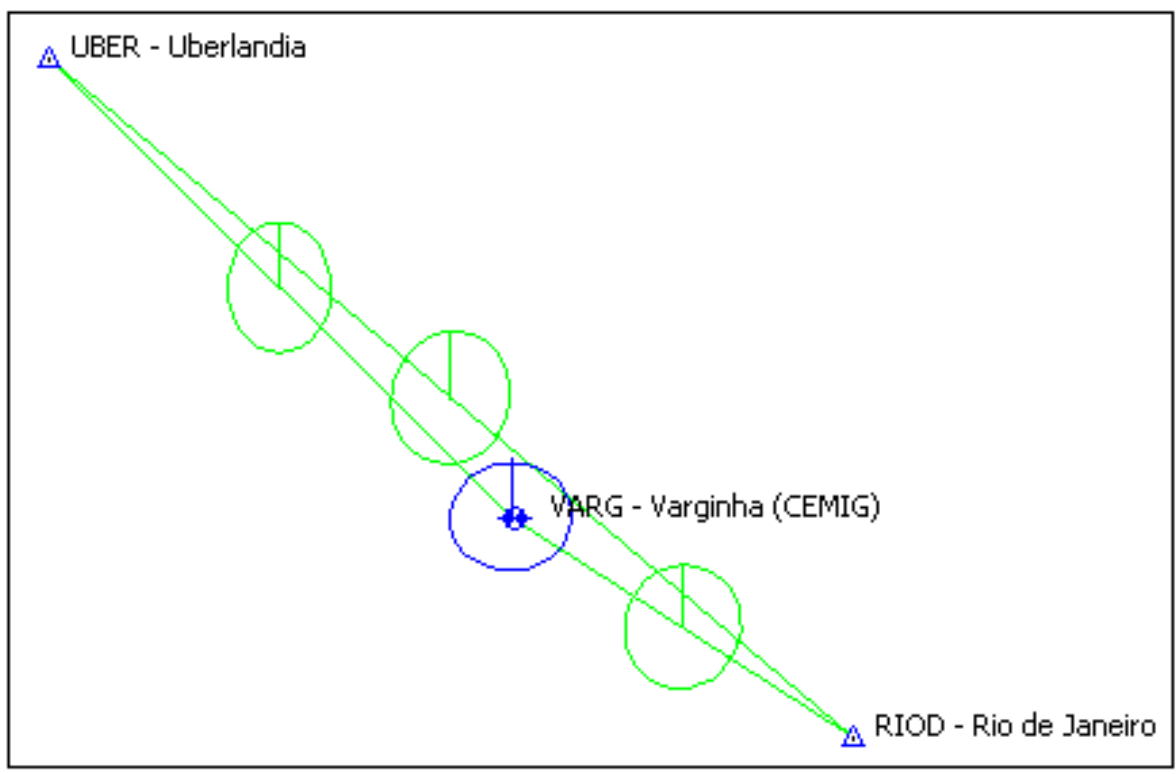

Coordenadas Ajustadas de VARG:

E (UTM): $454968.9601 \mathrm{~m}$

N (UTM): $7617727.2966 \mathrm{~m}$

\section{B.2.3.4 Primavera (Dias Julianos 287 a 290)}

- $287 / 2008$

A posteriori UWE: 1.2194626 , Bounds: ( $0.6770032,1.241639)$ 
TABELA B93: Resultado do Processamento

\begin{tabular}{|c|c|c|c|c|c|c|c|c|}
\hline \multicolumn{9}{|c|}{ GPS Obs Report } \\
\hline Name & $\begin{array}{c}\text { Horizontal } \\
\text { Precision (m) }\end{array}$ & $\begin{array}{c}\text { Vertical } \\
\text { Precision (m) }\end{array}$ & \begin{tabular}{|c|}
$\begin{array}{c}\text { Distance } \\
(\mathrm{m})\end{array}$ \\
\end{tabular} & $\begin{array}{c}\text { Solution } \\
\text { Type }\end{array}$ & $\begin{array}{c}\text { GPS } \\
\text { Satellites }\end{array}$ & PDOP & Status & RMS \\
\hline RIOD-UBER & $\mid 0.081$ & 0.090 & ||678629.122 & $\begin{array}{l}\text { Float,Wide } \\
\text { Lane }\end{array}$ & 30 & 2.894 & Adjusted & 0.124 \\
\hline RIOD-VARG & 0.045 & 0.062 & 261011.701 & $\begin{array}{l}\text { Fixed,Wide } \\
\text { Lane }\end{array}$ & 30 & 2.724 & Adjusted & 0.077 \\
\hline UBER-VARG & 0.066 & 0.073 & 420650.792 & $\begin{array}{l}\text { Float,Wide } \\
\text { Lane }\end{array}$ & 30 & 2.630 & Adjusted & 0.099 \\
\hline
\end{tabular}

Figura B93: Elipses de Erro

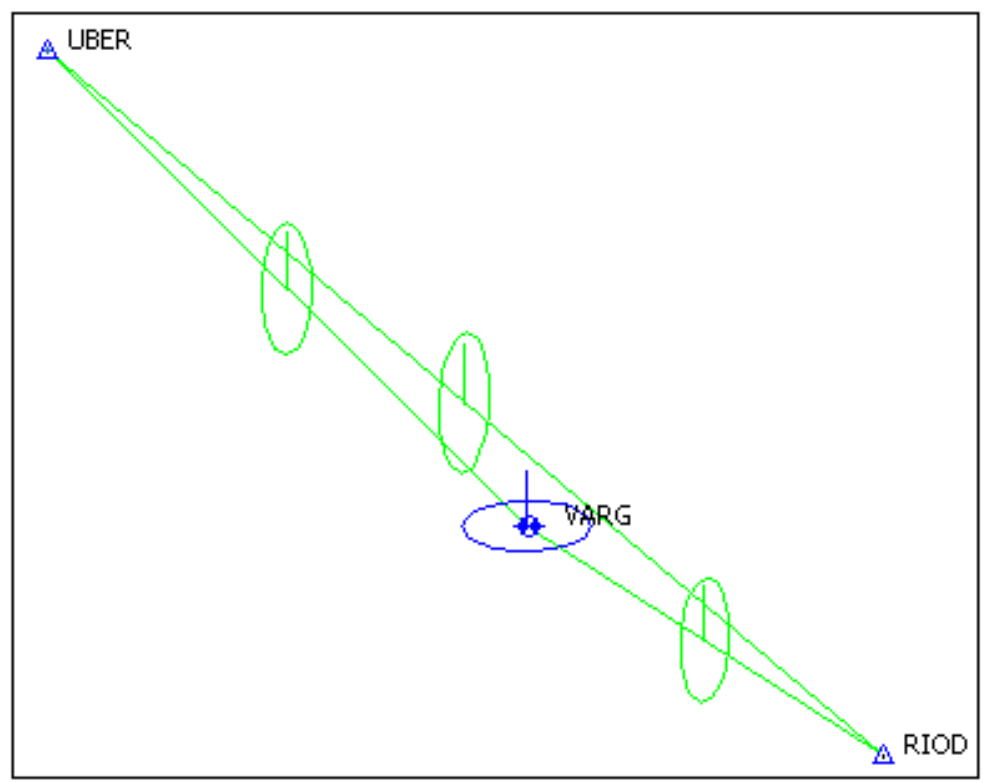

Coordenadas Ajustadas de VARG:

E (UTM): $454968.9561 \mathrm{~m}$

N (UTM): $7617727.2870 \mathrm{~m}$

- $\underline{288 / 2008}$

A posteriori UWE: 1.156297 , Bounds: ( $0.6770032,1.241639$ ) 
TABELA B94: Resultado do Processamento

\begin{tabular}{|c|c|c|c|c|c|c|c|c|}
\hline \multicolumn{9}{|c|}{ GPS Obs Report } \\
\hline Name & $\begin{array}{c}\text { Horizontal } \\
\text { Precision (m) }\end{array}$ & $\begin{array}{c}\text { Vertical } \\
\text { Precision (m) }\end{array}$ & \begin{tabular}{|c|} 
Distance \\
$(\mathrm{m})$
\end{tabular} & $\begin{array}{c}\text { Solution } \\
\text { Type }\end{array}$ & $\begin{array}{c}\text { GPS } \\
\text { Satellites }\end{array}$ & PDOP & Status & RMS \\
\hline RIOD-UBER & $\mid 0.082$ & 0.092 & 678629.100 & $\begin{array}{l}\text { Float,Wide } \\
\text { Lane }\end{array}$ & 30 & 2.772 & Adjusted & 0.124 \\
\hline RIOD-VARG & 0.033 & 0.067 & 261011.687 & $\begin{array}{l}\text { Fixed,Wide } \\
\text { Lane }\end{array}$ & 30 & 2.893 & Adjusted & 0.078 \\
\hline UBER-VARG & 0.066 & 0.071 & 420650.783 & $\begin{array}{l}\text { Float,Wide } \\
\text { Lane }\end{array}$ & 29 & 2.598 & Adjusted & 0.096 \\
\hline
\end{tabular}

Figura B94: Elipses de Erro

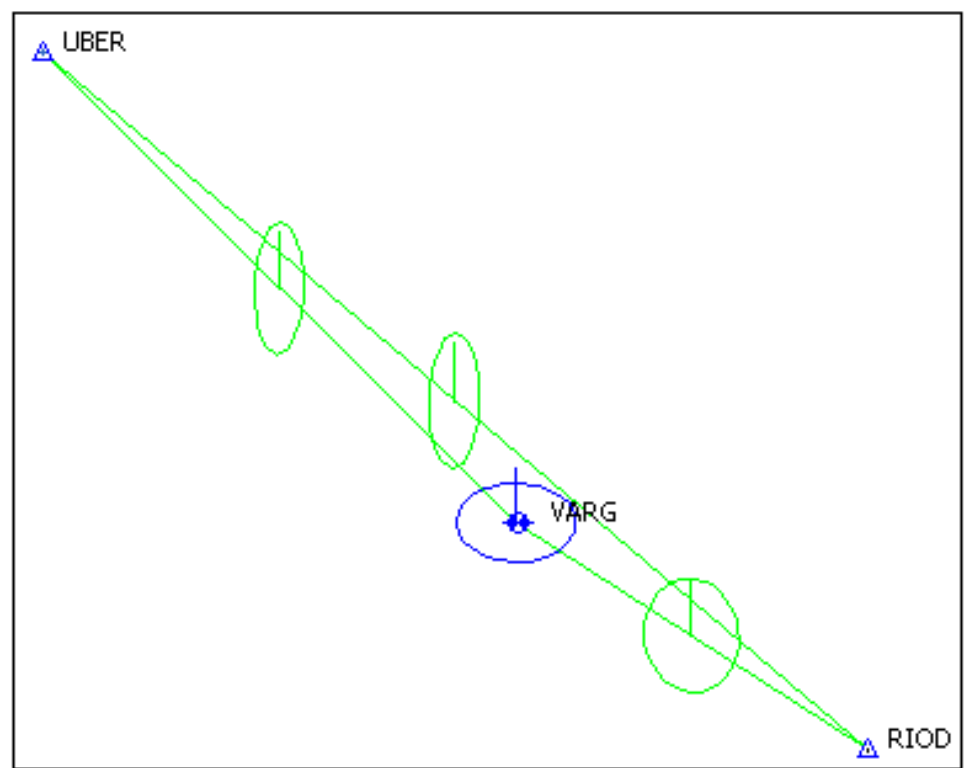

Coordenadas Ajustadas de VARG:

E (UTM): $454968.9662 \mathrm{~m}$

N (UTM): $7617727.2996 \mathrm{~m}$

- $\underline{289 / 2008}$

A posteriori UWE: 1.164652 , Bounds: ( $0.6770032,1.241639$ ) 
TABELA B95: Resultado do Processamento

\begin{tabular}{|c|c|c|c|c|c|c|c|c|}
\hline \multicolumn{9}{|c|}{ GPS Obs Report } \\
\hline Name & $\begin{array}{c}\text { Horizontal } \\
\text { Precision (m) }\end{array}$ & $\begin{array}{c}\text { Vertical } \\
\text { Precision (m) }\end{array}$ & $\begin{array}{c}\text { Distance } \\
\text { (m) }\end{array}$ & $\begin{array}{c}\text { Solution } \\
\text { Type }\end{array}$ & $\begin{array}{c}\text { GPS } \\
\text { Satellites }\end{array}$ & PDOP & Status & RMS \\
\hline RIOD-UBER & 0.080 & 0.091 & 678629.085 & $\begin{array}{l}\text { Float,Wide } \\
\text { Lane }\end{array}$ & 29 & 2.301 & Adjusted & 0.124 \\
\hline RIOD-VARG & 0.032 & 0.067 & 261011.686 & $\begin{array}{l}\text { Fixed,Wide } \\
\text { Lane }\end{array}$ & 29 & 2.820 & Adjusted & 0.078 \\
\hline UBER-VARG & 0.065 & 0.072 & 420650.771 & $\begin{array}{l}\text { Float,Wide } \\
\text { Lane }\end{array}$ & 30 & 2.918 & Adjusted & 0.096 \\
\hline
\end{tabular}

Figura B95: Elipses de Erro

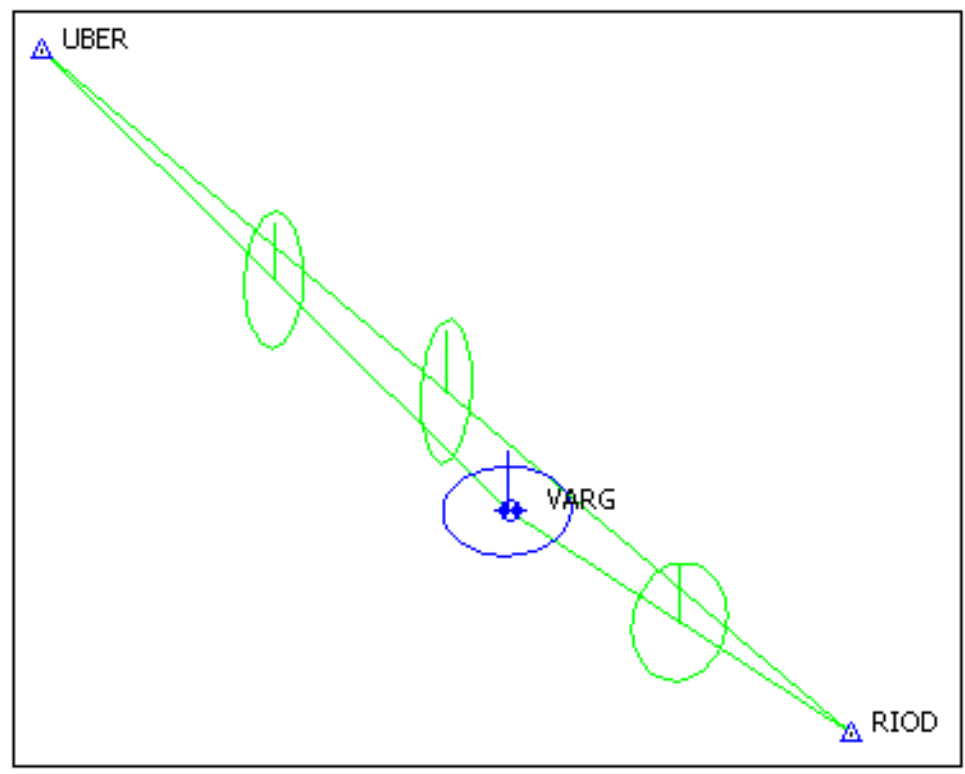

Coordenadas Ajustadas de VARG:

E (UTM): $454968.9465 \mathrm{~m}$

N (UTM): $7617727.2997 \mathrm{~m}$

- $\underline{290 / 2008}$

A posteriori UWE: 0.9983762 , Bounds: ( $0.6770032,1.241639)$ 
TABELA B96: Resultado do Processamento

\begin{tabular}{|c|c|c|c|c|c|c|c|c|}
\hline \multicolumn{9}{|c|}{ GPS Obs Report } \\
\hline Name & $\begin{array}{c}\text { Horizontal } \\
\text { Precision (m) }\end{array}$ & $\begin{array}{c}\text { Vertical } \\
\text { Precision (m) }\end{array}$ & $\begin{array}{c}\text { Distance } \\
\text { (m) }\end{array}$ & $\begin{array}{c}\text { Solution } \\
\text { Type }\end{array}$ & $\begin{array}{c}\text { GPS } \\
\text { Satellites }\end{array}$ & PDOP & Status & RMS \\
\hline RIOD-UBER & 0.083 & 0.085 & 678629.106 & $\begin{array}{l}\text { Float,Wide } \\
\text { Lane }\end{array}$ & 29 & 3.041 & Adjusted & 0.124 \\
\hline RIOD-VARG & 0.031 & 0.067 & 261011.693 & $\begin{array}{l}\text { Fixed,Wide } \\
\text { Lane }\end{array}$ & 29 & 2.674 & Adjusted & 0.078 \\
\hline UBER-VARG & 0.065 & 0.068 & 420650.794 & $\begin{array}{l}\text { Float,Wide } \\
\text { Lane }\end{array}$ & 31 & 2.652 & Adjusted & 0.097 \\
\hline
\end{tabular}

Figura B96: Elipses de Erro

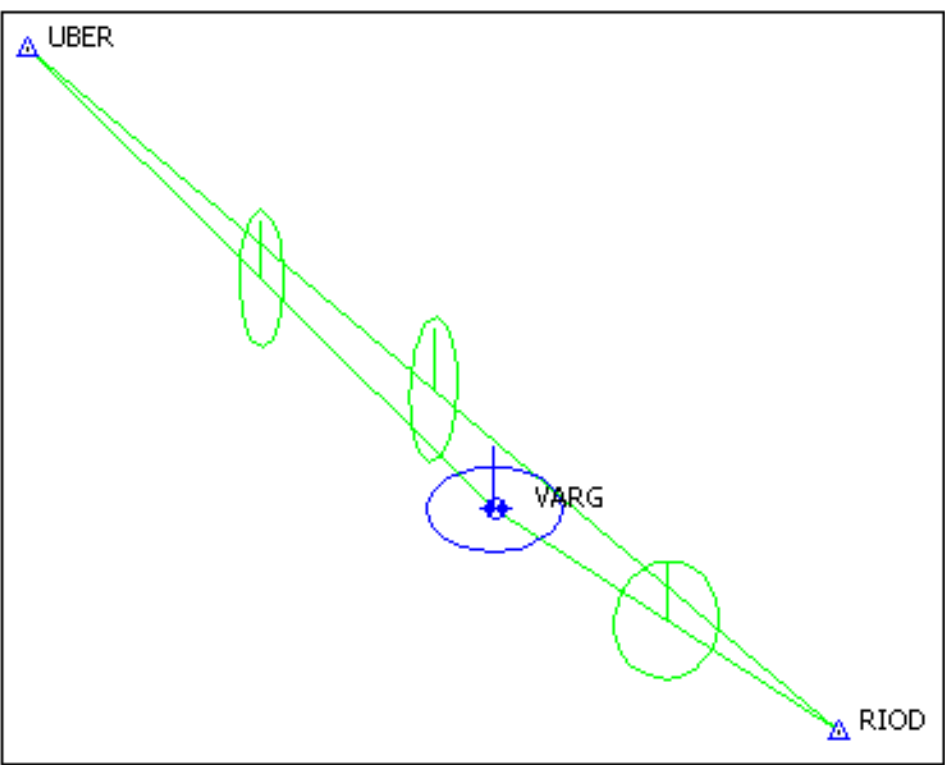

Coordenadas Ajustadas de VARG:

E (UTM): $454968.9566 \mathrm{~m}$

N (UTM): $7617727.3112 \mathrm{~m}$ 


\title{
B.3 Distâncias maiores que 700 km e Geometria Ideal entre as estações da RBMC
}

\author{
B.3.1 2006
}

B.3.1.1 Verão (Dias Julianos 011 a 014)

- $\underline{011 / 2006}$

A posteriori UWE: 1.153691 , Bounds: ( $0.6770032,1.241639)$

TABELA B97: Resultado do Processamento

\begin{tabular}{|c|c|c|c|c|c|c|c|c|}
\hline \multicolumn{9}{|c|}{ GPS Obs Report } \\
\hline Name & $\begin{array}{l}\text { Horizontal } \\
\text { Precision } \\
(\mathbf{m}) \\
\end{array}$ & $\begin{array}{l}\text { Vertical } \\
\text { Precision } \\
(\mathbf{m}) \\
\end{array}$ & $\begin{array}{l}\text { Distance } \\
\text { (m) }\end{array}$ & $\begin{array}{c}\text { Solution } \\
\text { Type }\end{array}$ & $\begin{array}{c}\text { GPS } \\
\text { Satellites }\end{array}$ & PDOP & Status & RMS \\
\hline $\begin{array}{l}\text { BRAZ - RBMC } \\
\text { Brasilia-CUIB - } \\
\text { RBMC Cuiaba }\end{array}$ & 0.092 & 0.103 & 878314.419 & $\begin{array}{l}\text { Float,Wide } \\
\text { Lane }\end{array}$ & 26 & 3.027 & Adjusted & 0.143 \\
\hline $\begin{array}{l}\text { BRAZ - RBMC } \\
\text { Brasilia-PPTE - } \\
\text { RBMC Presidente } \\
\text { Prudente }\end{array}$ & 0.090 & 0.102 & 777286.945 & $\begin{array}{l}\text { Float,Wide } \\
\text { Lane }\end{array}$ & 26 & 3.012 & Adjusted & 0.133 \\
\hline $\begin{array}{l}\text { CUIB - RBMC } \\
\text { Cuiaba-PPTE - } \\
\text { RBMC Presidente } \\
\text { Prudente }\end{array}$ & 0.106 & 0.096 & 876276.068 & $\begin{array}{l}\text { Float, Wide } \\
\text { Lane }\end{array}$ & 26 & 3.002 & Adjusted & 0.143 \\
\hline
\end{tabular}

Figura B97: Elipses de Erro

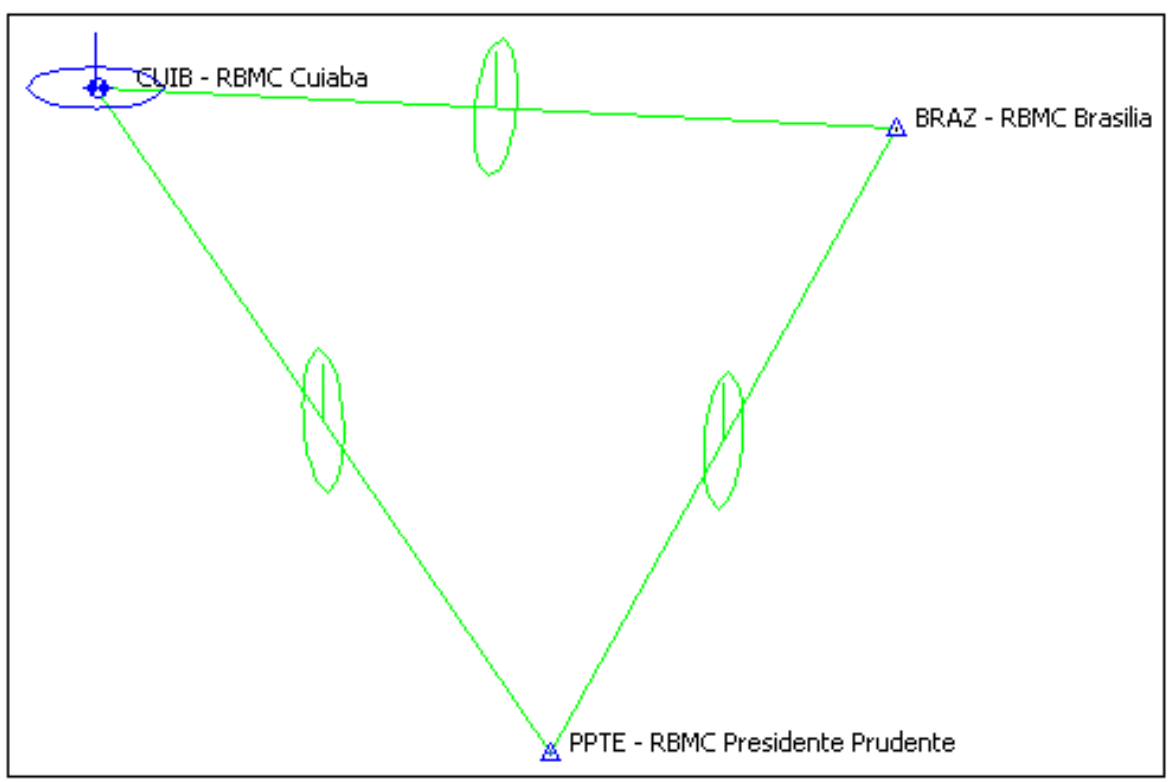


Coordenadas Ajustadas de CUIB:

E (UTM): $599737.3235 \mathrm{~m}$

$\mathrm{N}(\mathrm{UTM}): 8280040.8291 \mathrm{~m}$

- $\underline{012 / 2006}$

A posteriori UWE: 1.2310946 , Bounds: ( $0.6770032,1.241639)$

TABELA B98: Resultado do Processamento

\begin{tabular}{|c|c|c|c|c|c|c|c|c|}
\hline \multicolumn{9}{|c|}{ GPS Obs Report } \\
\hline Name & $\begin{array}{c}\text { Horizontal } \\
\text { Precision (m) }\end{array}$ & $\begin{array}{l}\text { Vertical } \\
\text { Precision } \\
\text { (m) }\end{array}$ & $\begin{array}{l}\text { Distance } \\
\text { (m) }\end{array}$ & $\begin{array}{c}\text { Solution } \\
\text { Type }\end{array}$ & $\begin{array}{c}\text { GPS } \\
\text { Satellites }\end{array}$ & PDOP & Status & RMS \\
\hline $\begin{array}{l}\text { BRAZ - RBMC } \\
\text { Brasilia-CUIB - } \\
\text { RBMC Cuiaba } \\
\end{array}$ & 0.092 & 0.100 & 878314.415 & $\begin{array}{l}\text { Float,Wide } \\
\text { Lane }\end{array}$ & 27 & 3.086 & Adjusted & 0.141 \\
\hline $\begin{array}{l}\text { BRAZ - RBMC } \\
\text { Brasilia-PPTE - } \\
\text { RBMC Presidente } \\
\text { Prudente }\end{array}$ & 0.067 & 0.110 & 777286.925 & $\begin{array}{l}\text { Fixed,Wide } \\
\text { Lane }\end{array}$ & 27 & 3.072 & Adjusted & 0.133 \\
\hline $\begin{array}{l}\text { CUIB - RBMC } \\
\text { Cuiaba-PPTE - } \\
\text { RBMC Presidente } \\
\text { Prudente }\end{array}$ & 0.081 & 0.111 & 876276.096 & $\begin{array}{l}\text { Float,Wide } \\
\text { Lane }\end{array}$ & 27 & 3.189 & Adjusted & 0.141 \\
\hline
\end{tabular}

Figura B98: Elipses de Erro

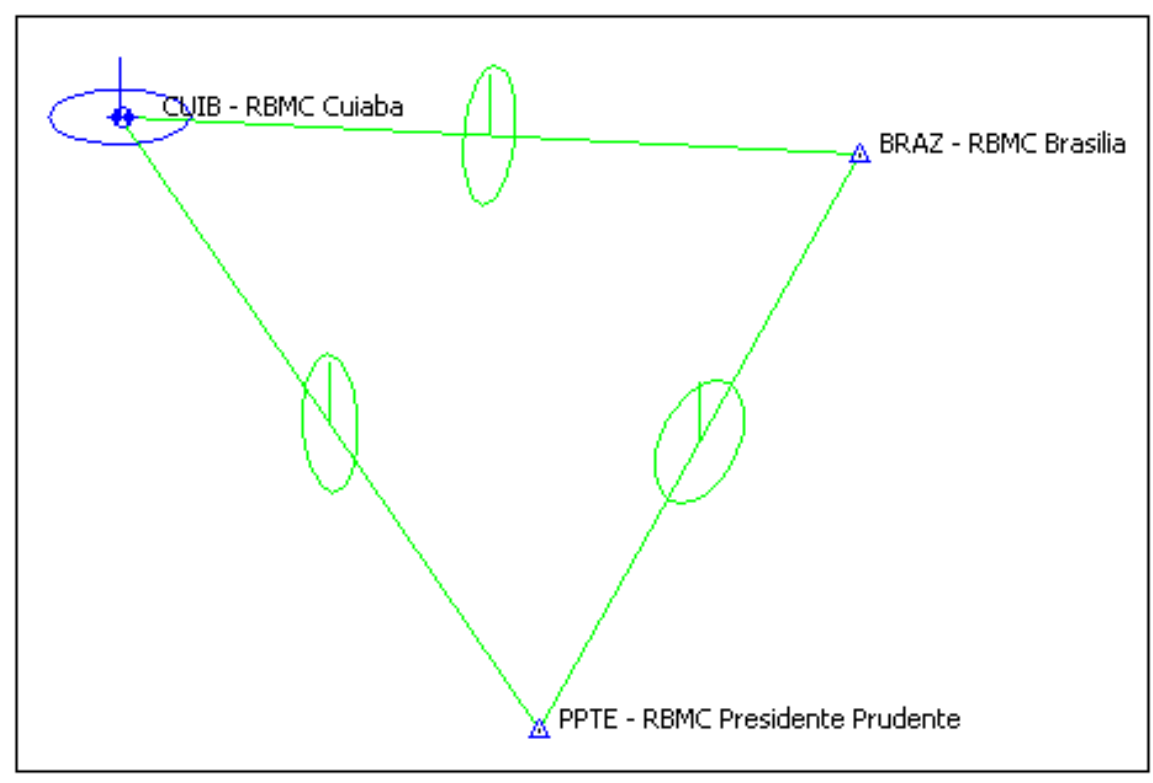


Coordenadas Ajustadas de CUIB:

E (UTM): $599737.3018 \mathrm{~m}$

N (UTM): $8280040.8126 \mathrm{~m}$

- $\underline{013 / 2006}$

A posteriori UWE: 0.8986484 , Bounds: ( $0.6770032,1.241639)$

TABELA B99: Resultado do Processamento

\begin{tabular}{|c|c|c|c|c|c|c|c|c|}
\hline \multicolumn{9}{|c|}{ GPS Obs Report } \\
\hline Name & $\begin{array}{c}\text { Horizontal } \\
\text { Precision } \\
\text { (m) }\end{array}$ & $\begin{array}{c}\text { Vertical } \\
\text { Precision } \\
\text { (m) }\end{array}$ & $\begin{array}{l}\text { Distance } \\
\text { (m) }\end{array}$ & $\begin{array}{c}\text { Solution } \\
\text { Type }\end{array}$ & $\begin{array}{c}\text { GPS } \\
\text { Satellites }\end{array}$ & PDOP & Status & RMS \\
\hline $\begin{array}{l}\text { BRAZ - RBMC } \\
\text { Brasilia-CUIB - } \\
\text { RBMC Cuiaba } \\
\end{array}$ & 0.103 & 0.096 & 878314.364 & $\begin{array}{l}\text { Float,Wide } \\
\text { Lane }\end{array}$ & 28 & 3.075 & Adjusted & 0.141 \\
\hline $\begin{array}{l}\text { BRAZ - RBMC } \\
\text { Brasilia-PPTE - } \\
\text { RBMC Presidente } \\
\text { Prudente } \\
\end{array}$ & 0.086 & 0.101 & 777286.915 & $\begin{array}{l}\text { Float,Wide } \\
\text { Lane }\end{array}$ & 28 & 3.076 & Adjusted & 0.132 \\
\hline $\begin{array}{l}\text { CUIB - RBMC } \\
\text { Cuiaba-PPTE - } \\
\text { RBMC Presidente } \\
\text { Prudente }\end{array}$ & 0.088 & 0.111 & 876276.044 & $\begin{array}{l}\text { Float,Wide } \\
\text { Lane }\end{array}$ & 28 & 3.142 & Adjusted & 0.142 \\
\hline
\end{tabular}

Figura B99: Elipses de Erro

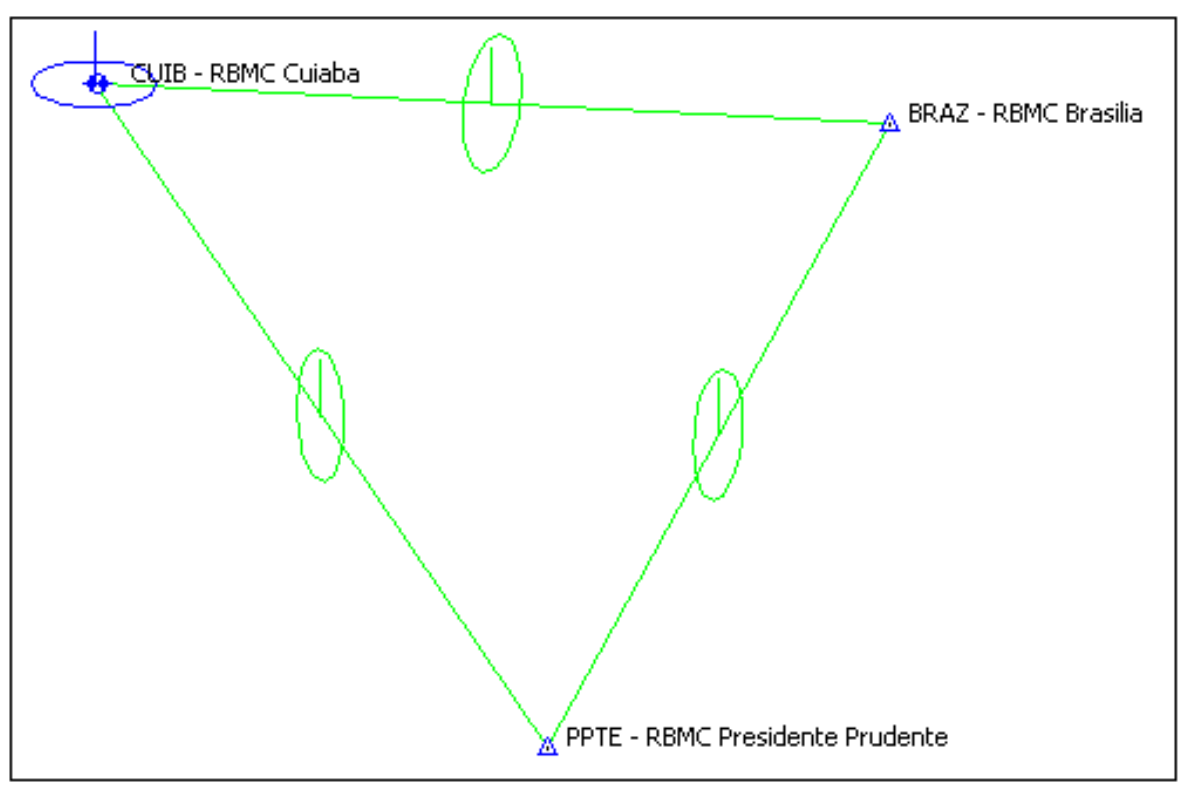


Coordenadas Ajustadas de CUIB:

E (UTM): $599737.3427 \mathrm{~m}$

N (UTM): $8280040.8325 \mathrm{~m}$

- $\underline{014 / 2006}$

A posteriori UWE: 0.9477072 , Bounds: ( $0.5291502,1.312758)$

TABELA B100: Resultado do Processamento

\begin{tabular}{|c|c|c|c|c|c|c|c|c|}
\hline \multicolumn{9}{|c|}{ GPS Obs Report } \\
\hline Name & \begin{tabular}{|c} 
Horizontal \\
Precision \\
(m)
\end{tabular} & \begin{tabular}{|c|} 
Vertical \\
Precision \\
(m)
\end{tabular} & $\begin{array}{l}\text { Distance } \\
\text { (m) }\end{array}$ & $\begin{array}{c}\text { Solution } \\
\text { Type }\end{array}$ & $\begin{array}{c}\text { GPS } \\
\text { Satellites }\end{array}$ & PDOP & Status & RMS \\
\hline $\begin{array}{l}\text { BRAZ - RBMC } \\
\text { Brasilia-CUIB - } \\
\text { RBMC Cuiaba } \\
\end{array}$ & & & & $\begin{array}{l}\text { Failed,No } \\
\text { Ephemeris }\end{array}$ & 28 & & $\begin{array}{l}\text { PostProcessed } \\
\text { Failed }\end{array}$ & \\
\hline $\begin{array}{l}\text { BRAZ - RBMC } \\
\text { Brasilia-PPTE - } \\
\text { RBMC Presidente } \\
\text { Prudente }\end{array}$ & 0.079 & 0.106 & 777286.898 & $\begin{array}{l}\text { Float,Wide } \\
\text { Lane }\end{array}$ & 28 & 3.071 & Adjusted & 0.133 \\
\hline $\begin{array}{l}\text { CUIB - RBMC } \\
\text { Cuiaba-PPTE - } \\
\text { RBMC Presidente } \\
\text { Prudente }\end{array}$ & & & & $\begin{array}{l}\text { Failed,No } \\
\text { Ephemeris }\end{array}$ & 28 & & $\begin{array}{l}\text { PostProcessed } \\
\text { Failed }\end{array}$ & \\
\hline
\end{tabular}

Figura B100: Elipses de Erro

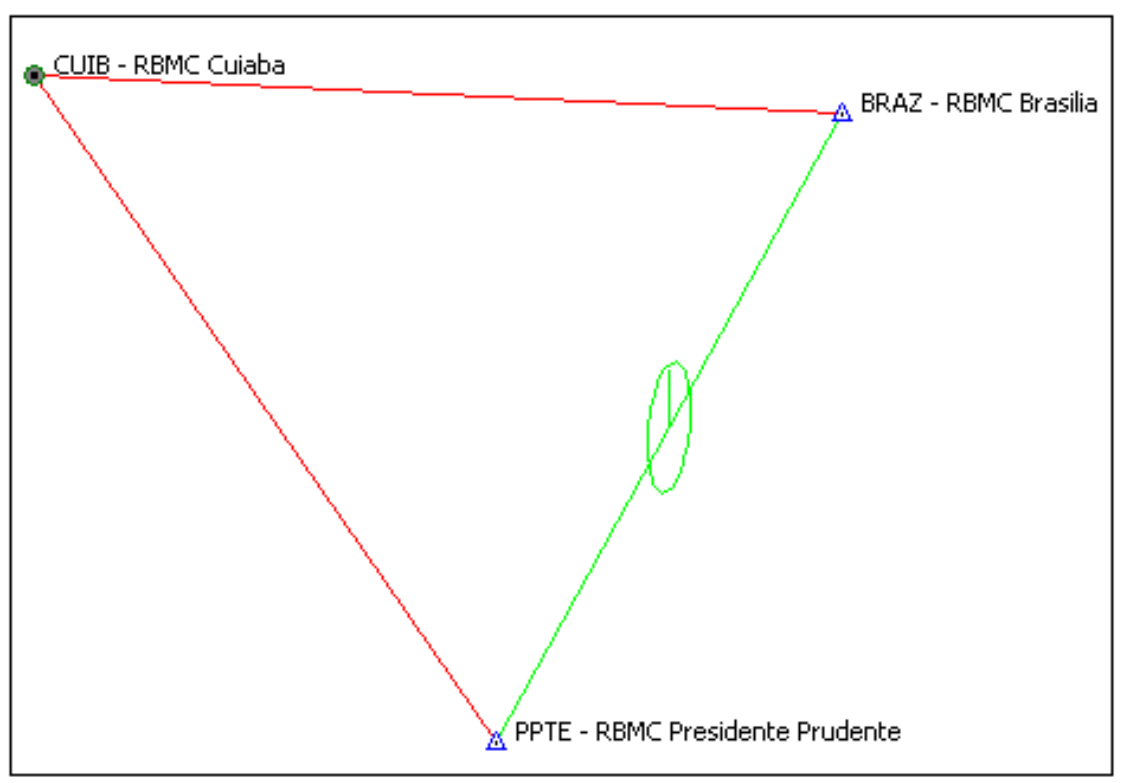


B.3.1.2 Outono (Dias Julianos 101 a 104)

- $101 / 2006$

A posteriori UWE: 1, Bounds: $(1,1)$

TABELA B101: Resultado do Processamento

\begin{tabular}{|c|c|c|c|c|c|c|c|c|}
\hline \multicolumn{9}{|c|}{ GPS Obs Report } \\
\hline Name & $\begin{array}{c}\text { Horizontal } \\
\text { Precision } \\
\text { (m) }\end{array}$ & $\begin{array}{l}\text { Vertical } \\
\text { Precision } \\
(\mathbf{m}) \\
\end{array}$ & $\begin{array}{c}\text { Distance } \\
\text { (m) }\end{array}$ & $\begin{array}{l}\text { Solution } \\
\text { Type }\end{array}$ & $\begin{array}{c}\text { GPS } \\
\text { Satellites }\end{array}$ & PDOP & Status & RMS \\
\hline $\begin{array}{l}\text { BRAZ - RBMC } \\
\text { Brasilia-CUIB - } \\
\text { RBMC Cuiaba }\end{array}$ & & & & $\begin{array}{l}\text { Failed,No } \\
\text { Ephemeris }\end{array}$ & 29 & & $\begin{array}{l}\text { PostProcessed } \\
\text { Failed }\end{array}$ & \\
\hline $\begin{array}{l}\text { BRAZ - RBMC } \\
\text { Brasilia-PPTE - } \\
\text { RBMC Presidente } \\
\text { Prudente }\end{array}$ & & & & $\begin{array}{l}\text { Failed,No } \\
\text { Ephemeris }\end{array}$ & 29 & & $\begin{array}{l}\text { PostProcessed } \\
\text { Failed }\end{array}$ & \\
\hline $\begin{array}{l}\text { CUIB - RBMC } \\
\text { Cuiaba-PPTE - } \\
\text { RBMC Presidente } \\
\text { Prudente }\end{array}$ & 0.094 & 0.105 & 876276.032 & $\begin{array}{l}\text { Float, Wide } \\
\text { Lane }\end{array}$ & 29 & 3.024 & Adjusted & 0.141 \\
\hline
\end{tabular}

Figura B101: Elipses de Erro

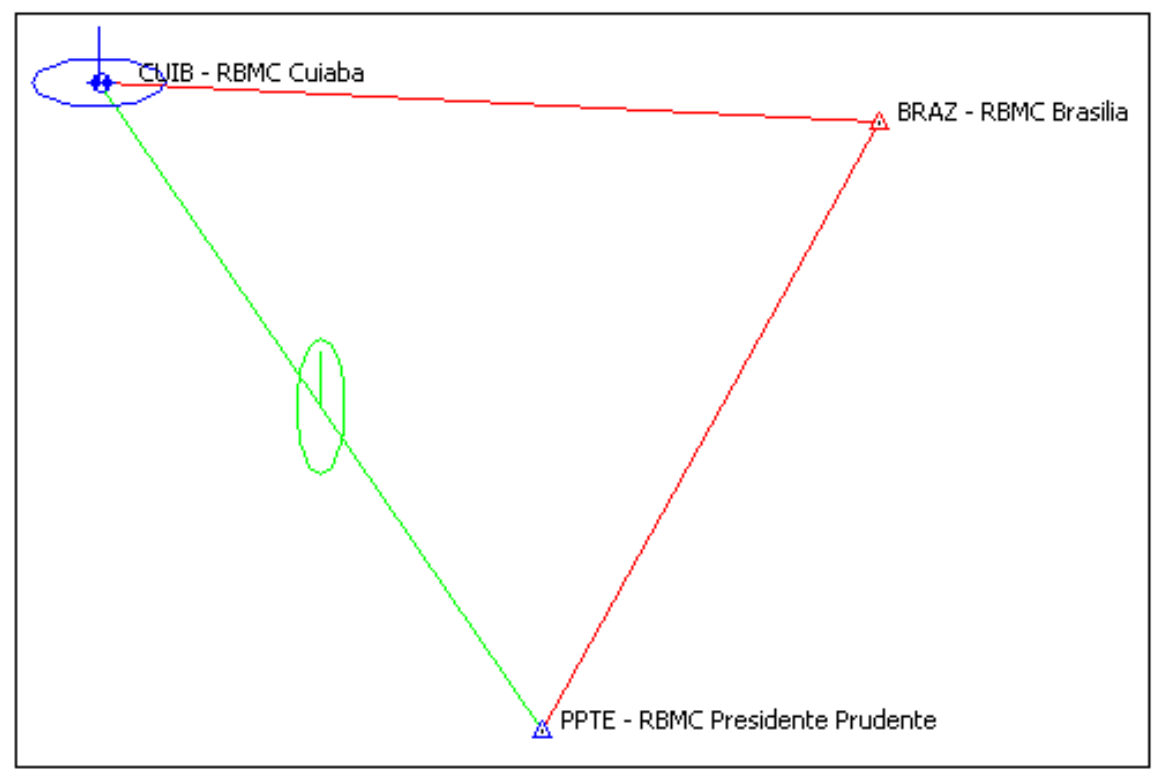

- $102 / 2006$

A posteriori UWE: 0.602021 , Bounds: ( $0.6770032,1.241639)$ 
TABELA B102: Resultado do Processamento

\begin{tabular}{|c|c|c|c|c|c|c|c|c|}
\hline \multicolumn{9}{|c|}{ GPS Obs Report } \\
\hline Name & \begin{tabular}{|c} 
Horizontal \\
Precision (m)
\end{tabular} & $\begin{array}{l}\text { Vertical } \\
\text { Precision } \\
\text { (m) }\end{array}$ & $\begin{array}{l}\text { Distance } \\
\text { (m) }\end{array}$ & $\begin{array}{c}\text { Solution } \\
\text { Type }\end{array}$ & $\begin{array}{c}\text { GPS } \\
\text { Satellites }\end{array}$ & PDOP & Status & RMS \\
\hline \begin{tabular}{|l} 
BRAZ - RBMC \\
Brasilia-CUIB - \\
RBMC Cuiaba \\
\end{tabular} & 0.101 & 0.100 & 878314.337 & $\begin{array}{l}\text { Float,Wide } \\
\text { Lane }\end{array}$ & 29 & & Adjusted & 0.142 \\
\hline $\begin{array}{l}\text { BRAZ - RBMC } \\
\text { Brasilia-PPTE - } \\
\text { RBMC Presidente } \\
\text { Prudente }\end{array}$ & 0.066 & 0.117 & 777286.914 & $\begin{array}{l}\text { Fixed,Wide } \\
\text { Lane }\end{array}$ & 29 & & Adjusted & 0.134 \\
\hline $\begin{array}{l}\text { CUIB - RBMC } \\
\text { Cuiaba-PPTE - } \\
\text { RBMC Presidente } \\
\text { Prudente }\end{array}$ & 0.095 & 0.104 & 876276.024 & $\begin{array}{l}\text { Float,Wide } \\
\text { Lane }\end{array}$ & 29 & 2.938 & Adjusted & 0.141 \\
\hline
\end{tabular}

Figura B102: Elipses de Erro

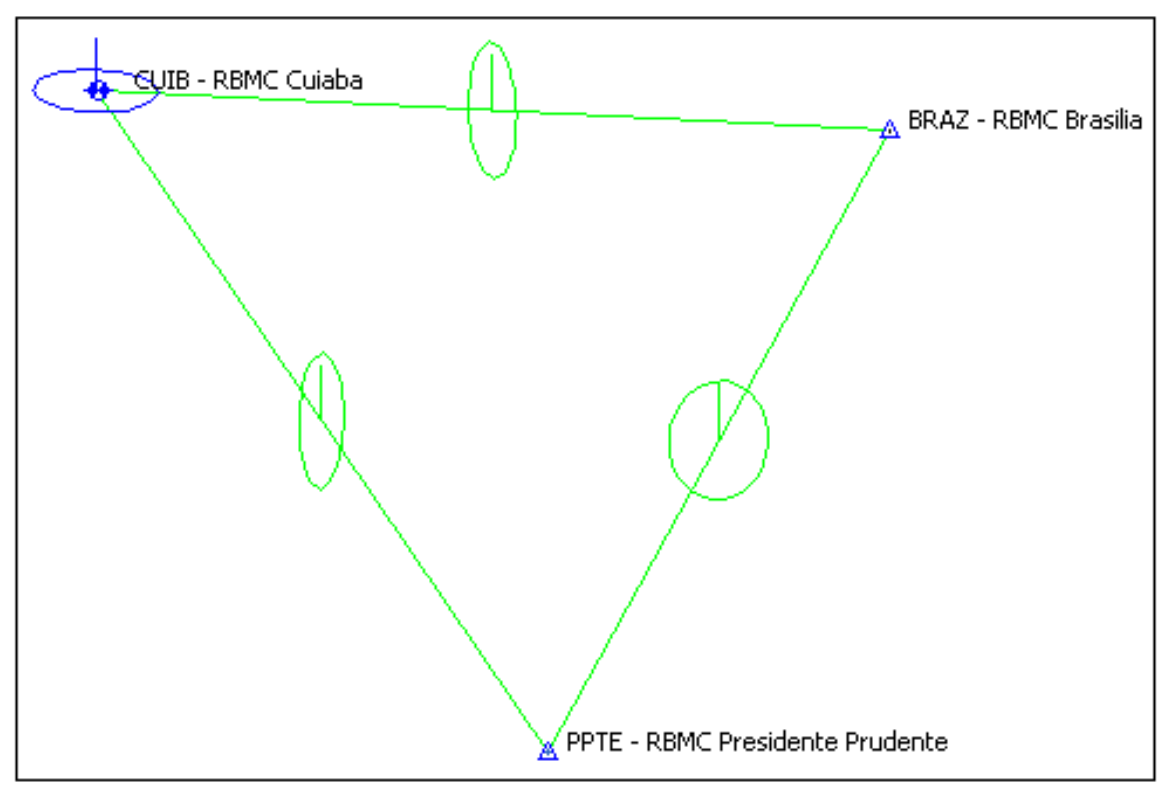

Coordenadas Ajustadas de CUIB:

E (UTM): $599737.3743 \mathrm{~m}$

N (UTM): $8280040.8446 \mathrm{~m}$

- $103 / 2006$

A posteriori UWE: 1.117514 , Bounds: ( $0.6770032,1.241639$ ) 
TABELA B103: Resultado do Processamento

\begin{tabular}{|c|c|c|c|c|c|c|c|c|}
\hline \multicolumn{9}{|c|}{ GPS Obs Report } \\
\hline Name & $\begin{array}{l}\text { Horizontal } \\
\text { Precision } \\
\text { (m) }\end{array}$ & $\begin{array}{l}\text { Vertical } \\
\text { Precision } \\
\text { (m) }\end{array}$ & $\begin{array}{l}\text { Distance } \\
\text { (m) }\end{array}$ & $\begin{array}{c}\text { Solution } \\
\text { Type }\end{array}$ & $\begin{array}{c}\text { GPS } \\
\text { Satellites }\end{array}$ & PDOP & Status & RMS \\
\hline $\begin{array}{l}\text { BRAZ - RBMC } \\
\text { Brasilia-CUIB - } \\
\text { RBMC Cuiaba } \\
\end{array}$ & 0.103 & 0.090 & 878314.362 & \begin{tabular}{|l} 
Float,Wide \\
Lane
\end{tabular} & 23 & 3.021 & Adjusted & 0.141 \\
\hline $\begin{array}{l}\text { BRAZ - RBMC } \\
\text { Brasilia-PPTE - } \\
\text { RBMC Presidente } \\
\text { Prudente }\end{array}$ & 0.092 & 0.100 & 777286.917 & $\begin{array}{l}\text { Float,Wide } \\
\text { Lane }\end{array}$ & 29 & 3.015 & Adjusted & 0.136 \\
\hline $\begin{array}{l}\text { CUIB - RBMC } \\
\text { Cuiaba-PPTE - } \\
\text { RBMC Presidente } \\
\text { Prudente }\end{array}$ & 0.096 & 0.103 & 876276.040 & $\begin{array}{l}\text { Float,Wide } \\
\text { Lane }\end{array}$ & 29 & 2.938 & Adjusted & 0.141 \\
\hline
\end{tabular}

Figura B103: Elipses de Erro

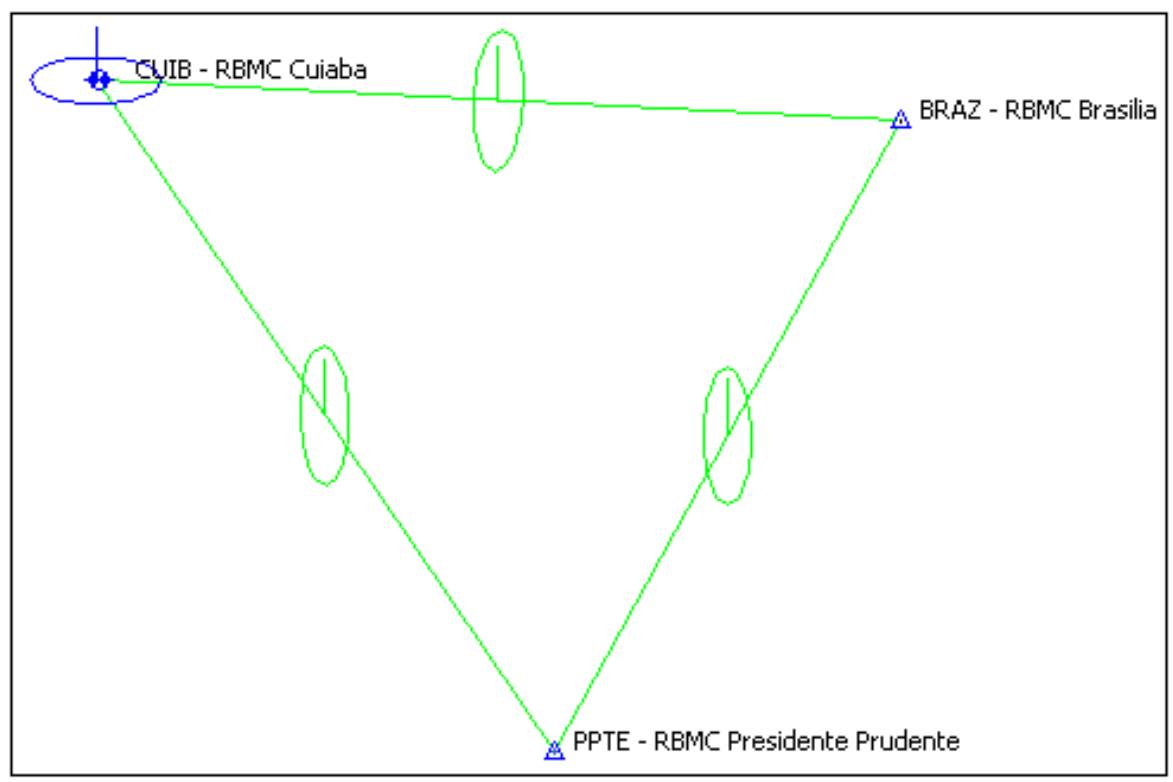

Coordenadas Ajustadas de CUIB:

E (UTM): $599737.3356 \mathrm{~m}$

N (UTM): $8280040.8474 \mathrm{~m}$

- $\underline{104 / 2006}$

A posteriori UWE: 0.8894302 , Bounds: ( $0.6770032,1.241639)$ 
TABELA B104: Resultado do Processamento

\begin{tabular}{|c|c|c|c|c|c|c|c|c|}
\hline \multicolumn{9}{|c|}{ GPS Obs Report } \\
\hline Name & $\begin{array}{c}\text { Horizontal } \\
\text { Precision } \\
\text { (m) }\end{array}$ & $\begin{array}{l}\text { Vertical } \\
\text { Precision } \\
\text { (m) }\end{array}$ & $\begin{array}{l}\text { Distance } \\
\text { (m) }\end{array}$ & $\begin{array}{c}\text { Solution } \\
\text { Type }\end{array}$ & $\begin{array}{c}\text { GPS } \\
\text { Satellites }\end{array}$ & PDOP & Status & RMS \\
\hline $\begin{array}{l}\text { BRAZ - RBMC } \\
\text { Brasilia-CUIB - } \\
\text { RBMC Cuiaba }\end{array}$ & 0.108 & 0.094 & 878314.384 & $\begin{array}{l}\text { Float,Wide } \\
\text { Lane }\end{array}$ & 29 & 2.967 & Adjusted & 0.143 \\
\hline $\begin{array}{l}\text { BRAZ - RBMC } \\
\text { Brasilia-PPTE - } \\
\text { RBMC Presidente } \\
\text { Prudente }\end{array}$ & 0.099 & 0.090 & 777286.930 & $\begin{array}{l}\text { Float,Wide } \\
\text { Lane }\end{array}$ & 29 & 2.912 & Adjusted & 0.134 \\
\hline $\begin{array}{l}\text { CUIB - RBMC } \\
\text { Cuiaba-PPTE - } \\
\text { RBMC Presidente } \\
\text { Prudente }\end{array}$ & 0.101 & 0.098 & 876276.062 & $\begin{array}{l}\text { Float,Wide } \\
\text { Lane }\end{array}$ & 29 & 2.937 & Adjusted & 0.141 \\
\hline
\end{tabular}

Figura B104: Elipses de Erro

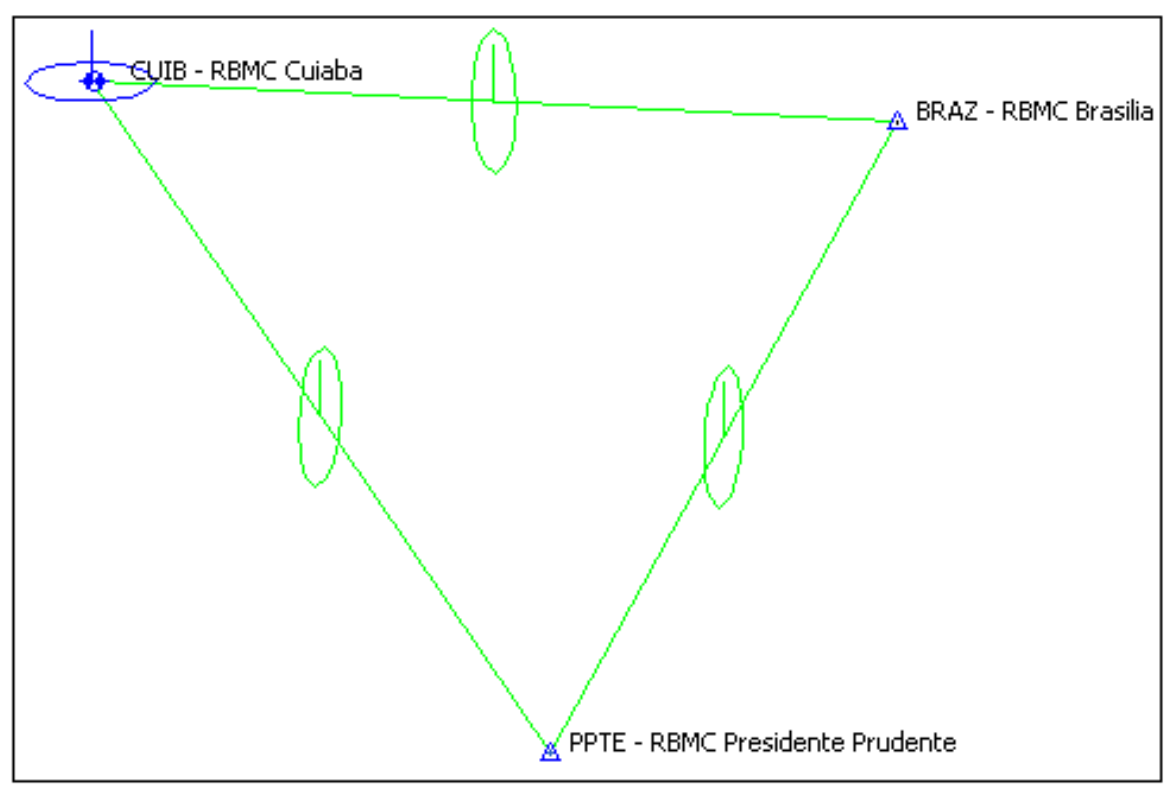

Coordenadas Ajustadas de CUIB:

E (UTM): $599737.3401 \mathrm{~m}$

N (UTM): $8280040.8666 \mathrm{~m}$

\section{B.3.1.3 Inverno (Dias Julianos 193 a 196)}

- $193 / 2006$

A posteriori UWE: 0.4383219 , Bounds: ( $0.6770032,1.241639)$ 
TABELA B105: Resultado do Processamento

\begin{tabular}{|c|c|c|c|c|c|c|c|c|}
\hline \multicolumn{9}{|c|}{ GPS Obs Report } \\
\hline Name & \begin{tabular}{|c} 
Horizontal \\
Precision (m)
\end{tabular} & $\begin{array}{c}\text { Vertical } \\
\text { Precision } \\
\text { (m) }\end{array}$ & $\begin{array}{l}\text { Distance } \\
\text { (m) }\end{array}$ & $\begin{array}{c}\text { Solution } \\
\text { Type }\end{array}$ & $\begin{array}{c}\text { GPS } \\
\text { Satellites }\end{array}$ & PDOP & Status & RMS \\
\hline \begin{tabular}{|l|} 
BRAZ - RBMC \\
Brasilia-CUIB - \\
RBMC Cuiaba \\
\end{tabular} & 0.101 & 0.098 & 878314.350 & $\begin{array}{l}\text { Float,Wide } \\
\text { Lane }\end{array}$ & 28 & 3.192 & Adjusted & $\mid 0.141$ \\
\hline $\begin{array}{l}\text { BRAZ - RBMC } \\
\text { Brasilia-PPTE - } \\
\text { RBMC Presidente } \\
\text { Prudente }\end{array}$ & $\mid 0.068$ & 0.114 & 777286.885 & $\begin{array}{l}\text { Fixed,Wide } \\
\text { Lane }\end{array}$ & 28 & 18.239 & Adjusted & 0.132 \\
\hline \begin{tabular}{|l|} 
CUIB - RBMC \\
Cuiaba-PPTE - RBMC \\
Presidente Prudente
\end{tabular} & 0.094 & 0.105 & 876276.009 & $\begin{array}{l}\text { Fixed,Wide } \\
\text { Lane }\end{array}$ & 28 & 3.119 & Adjusted & $\mid 0.141$ \\
\hline
\end{tabular}

Figura B105: Elipses de Erro

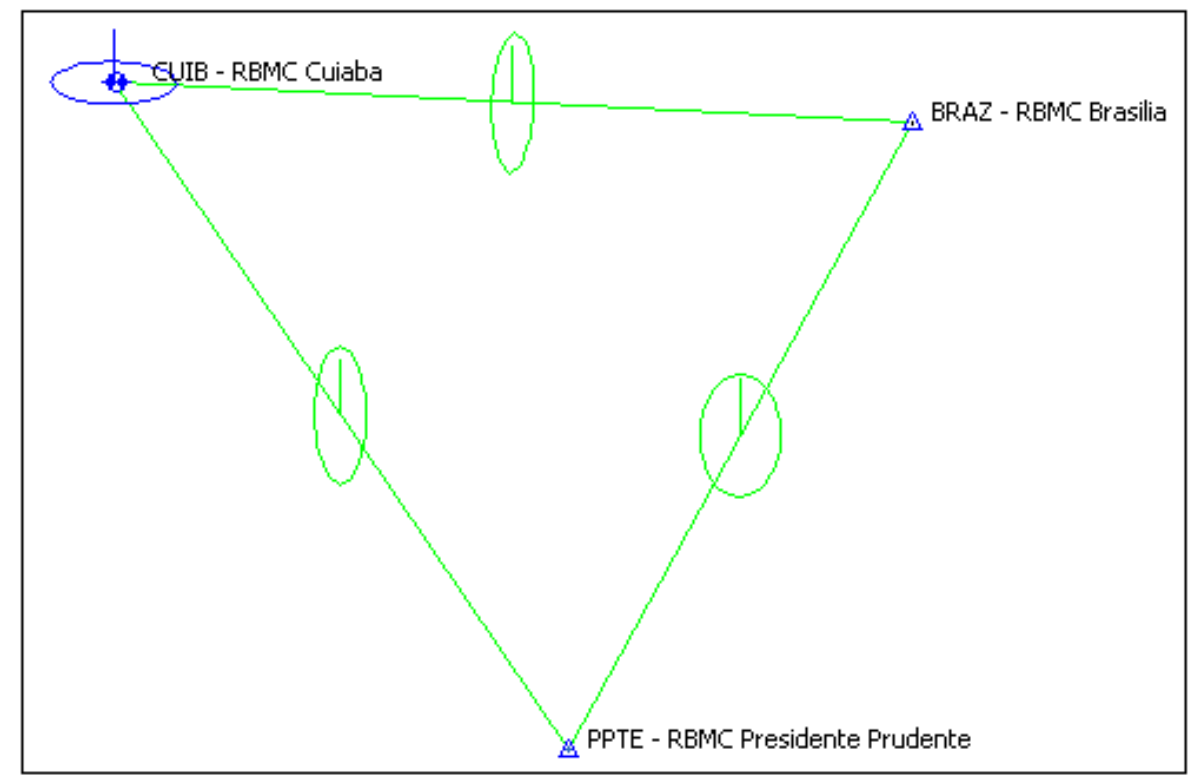

Coordenadas Ajustadas de CUIB:

E (UTM): $599737.3675 \mathrm{~m}$

N (UTM): $8280040.8548 \mathrm{~m}$

- $194 / 2006$

A posteriori UWE: 0.6820169 , Bounds: ( $0.6770032,1.241639$ ) 
TABELA B106: Resultado do Processamento

\begin{tabular}{|c|c|c|c|c|c|c|c|c|}
\hline \multicolumn{9}{|c|}{ GPS Obs Report } \\
\hline Name & \begin{tabular}{|c} 
Horizontal \\
Precision (m)
\end{tabular} & $\begin{array}{c}\text { Vertical } \\
\text { Precision } \\
\text { (m) }\end{array}$ & $\begin{array}{l}\text { Distance } \\
\text { (m) }\end{array}$ & $\begin{array}{c}\text { Solution } \\
\text { Type }\end{array}$ & $\begin{array}{c}\text { GPS } \\
\text { Satellites }\end{array}$ & PDOP & Status & RMS \\
\hline \begin{tabular}{|l} 
BRAZ - RBMC \\
Brasilia-CUIB - \\
RBMC Cuiaba \\
\end{tabular} & 0.116 & 0.076 & 878314.402 & $\begin{array}{l}\text { Float,Wide } \\
\text { Lane }\end{array}$ & 26 & 3.000 & Adjusted & 0.141 \\
\hline $\begin{array}{l}\text { BRAZ - RBMC } \\
\text { Brasilia-PPTE - } \\
\text { RBMC Presidente } \\
\text { Prudente }\end{array}$ & 0.060 & 0.113 & 777286.900 & $\begin{array}{l}\text { Fixed,Wide } \\
\text { Lane }\end{array}$ & 25 & 2.988 & Adjusted & 0.133 \\
\hline $\begin{array}{l}\text { CUIB - RBMC } \\
\text { Cuiaba-PPTE - } \\
\text { RBMC Presidente } \\
\text { Prudente }\end{array}$ & 0.102 & 0.096 & 876275.993 & $\begin{array}{l}\text { Float,Wide } \\
\text { Lane }\end{array}$ & 27 & 3.011 & Adjusted & 0.141 \\
\hline
\end{tabular}

Figura B106: Elipses de Erro

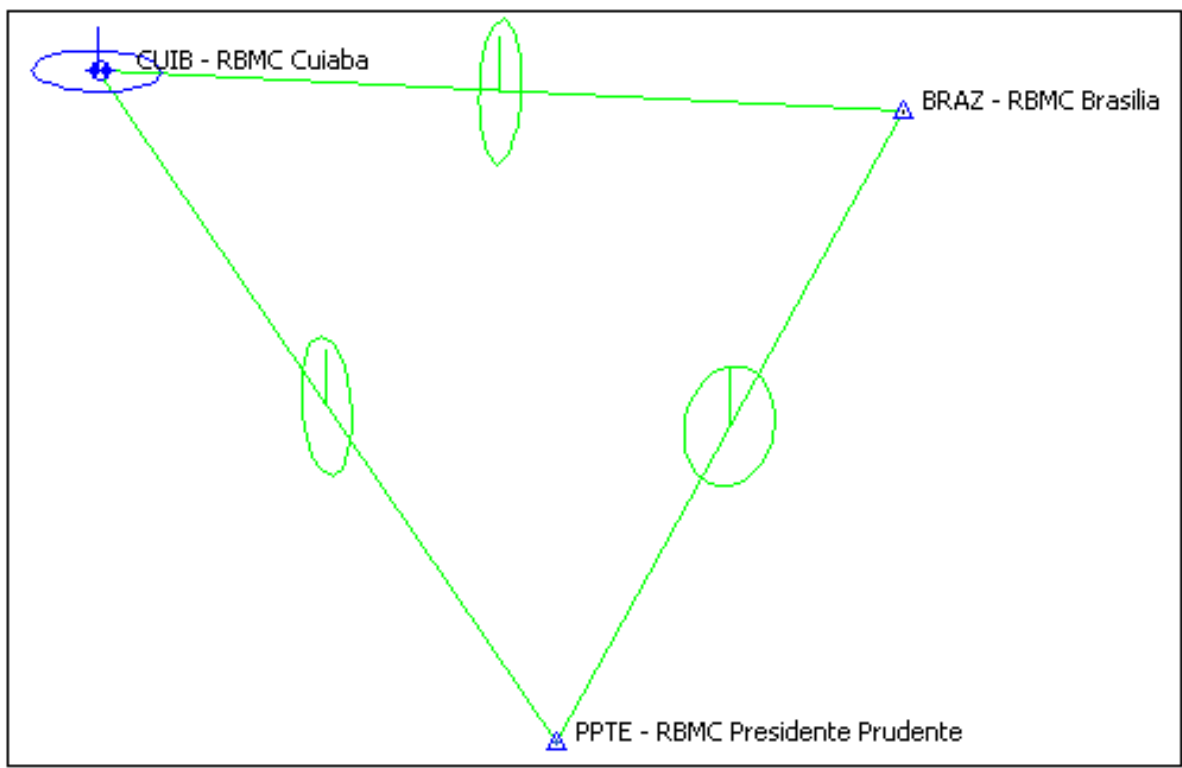

Coordenadas Ajustadas de CUIB:

E (UTM): $599737.3574 \mathrm{~m}$

N (UTM): $8280040.8440 \mathrm{~m}$

- $195 / 2006$

A posteriori UWE: 1, Bounds: $(1,1)$ 
TABELA B107: Resultado do Processamento

\begin{tabular}{|c|c|c|c|c|c|c|c|c|}
\hline \multicolumn{9}{|c|}{ GPS Obs Report } \\
\hline Name & \begin{tabular}{|c|} 
Horizontal \\
Precision \\
$(\mathbf{m})$
\end{tabular} & \begin{tabular}{|c|} 
Vertical \\
Precision \\
(m) \\
\end{tabular} & $\begin{array}{l}\text { Distance } \\
\text { (m) }\end{array}$ & $\begin{array}{c}\text { Solution } \\
\text { Type }\end{array}$ & \begin{tabular}{|c} 
GPS \\
Satellites
\end{tabular} & PDOP & Status & RMS \\
\hline \begin{tabular}{|l} 
BRAZ - RBMC \\
Brasilia-CUIB - \\
RBMC Cuiaba \\
\end{tabular} & & & & \begin{tabular}{|l} 
Failed,No \\
Ephemeris
\end{tabular} & 28 & & $\begin{array}{l}\text { PostProcessed } \\
\text { Failed }\end{array}$ & \\
\hline $\begin{array}{l}\text { BRAZ - RBMC } \\
\text { Brasilia-PPTE - } \\
\text { RBMC Presidente } \\
\text { Prudente }\end{array}$ & & & & $\begin{array}{l}\text { Failed,No } \\
\text { Ephemeris }\end{array}$ & 28 & & $\begin{array}{l}\text { PostProcessed } \\
\text { Failed }\end{array}$ & \\
\hline $\begin{array}{l}\text { CUIB - RBMC } \\
\text { Cuiaba-PPTE - } \\
\text { RBMC Presidente } \\
\text { Prudente }\end{array}$ & 0.063 & 0.126 & 876276.028 & $\begin{array}{l}\text { Fixed,Wide } \\
\text { Lane }\end{array}$ & 28 & 3.121 & Adjusted & $\mid 0.141$ \\
\hline
\end{tabular}

Figura B107: Elipses de Erro

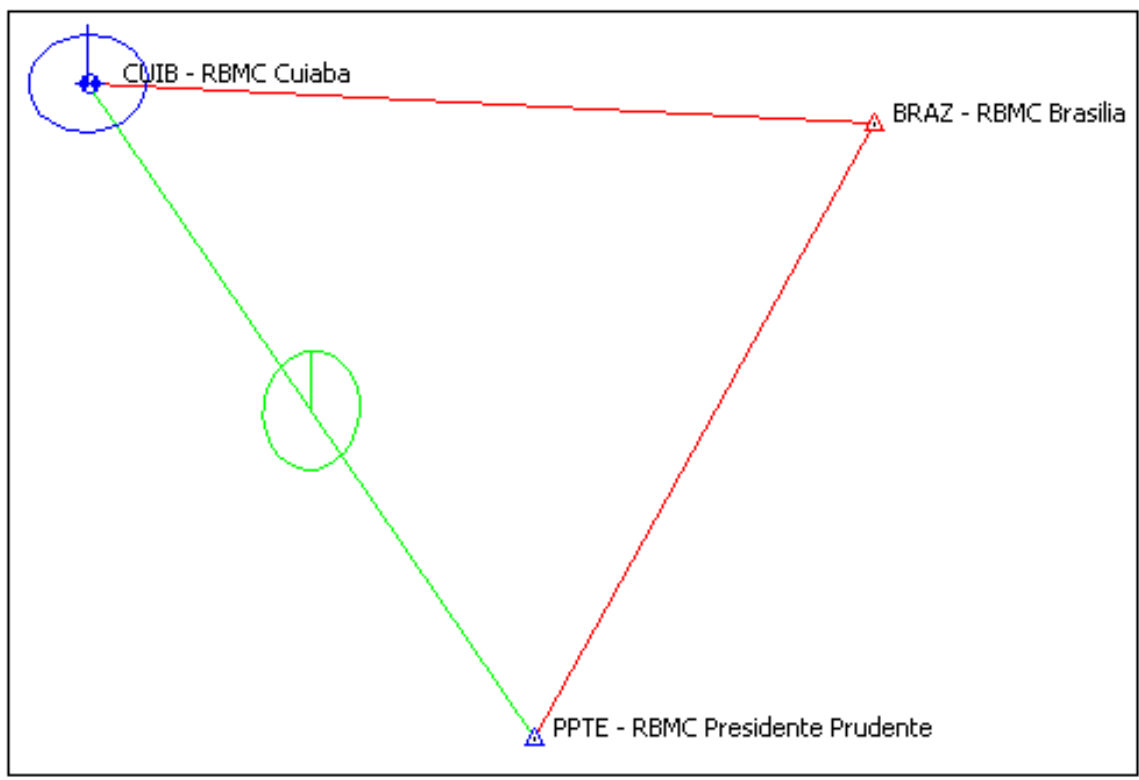

- $196 / 2006$

A posteriori UWE: 1.123710 , Bounds: ( $0.6770032,1.241639$ ) 
TABELA B108: Resultado do Processamento

\begin{tabular}{|c|c|c|c|c|c|c|c|c|}
\hline \multicolumn{9}{|c|}{ GPS Obs Report } \\
\hline Name & \begin{tabular}{|c} 
Horizontal \\
Precision (m)
\end{tabular} & $\begin{array}{c}\text { Vertical } \\
\text { Precision } \\
\text { (m) }\end{array}$ & $\begin{array}{l}\text { Distance } \\
\text { (m) }\end{array}$ & $\begin{array}{c}\text { Solution } \\
\text { Type }\end{array}$ & $\begin{array}{c}\text { GPS } \\
\text { Satellites }\end{array}$ & PDOP & Status & RMS \\
\hline \begin{tabular}{|l|} 
BRAZ - RBMC \\
Brasilia-CUIB - \\
RBMC Cuiaba \\
\end{tabular} & 0.102 & 0.094 & 878314.368 & $\begin{array}{l}\text { Float,Wide } \\
\text { Lane }\end{array}$ & 27 & 3.000 & Adjusted & 0.141 \\
\hline $\begin{array}{l}\text { BRAZ - RBMC } \\
\text { Brasilia-PPTE - } \\
\text { RBMC Presidente } \\
\text { Prudente } \\
\end{array}$ & 0.054 & 0.124 & 777286.889 & $\begin{array}{l}\text { Fixed,Wide } \\
\text { Lane }\end{array}$ & 24 & 2.996 & Adjusted & 0.132 \\
\hline $\begin{array}{l}\text { CUIB - RBMC } \\
\text { Cuiaba-PPTE - } \\
\text { RBMC Presidente } \\
\text { Prudente }\end{array}$ & 0.068 & 0.122 & 876276.039 & $\begin{array}{l}\text { Fixed,Wide } \\
\text { Lane }\end{array}$ & 27 & 3.022 & Adjusted & 0.141 \\
\hline
\end{tabular}

Figura B108: Elipses de Erro

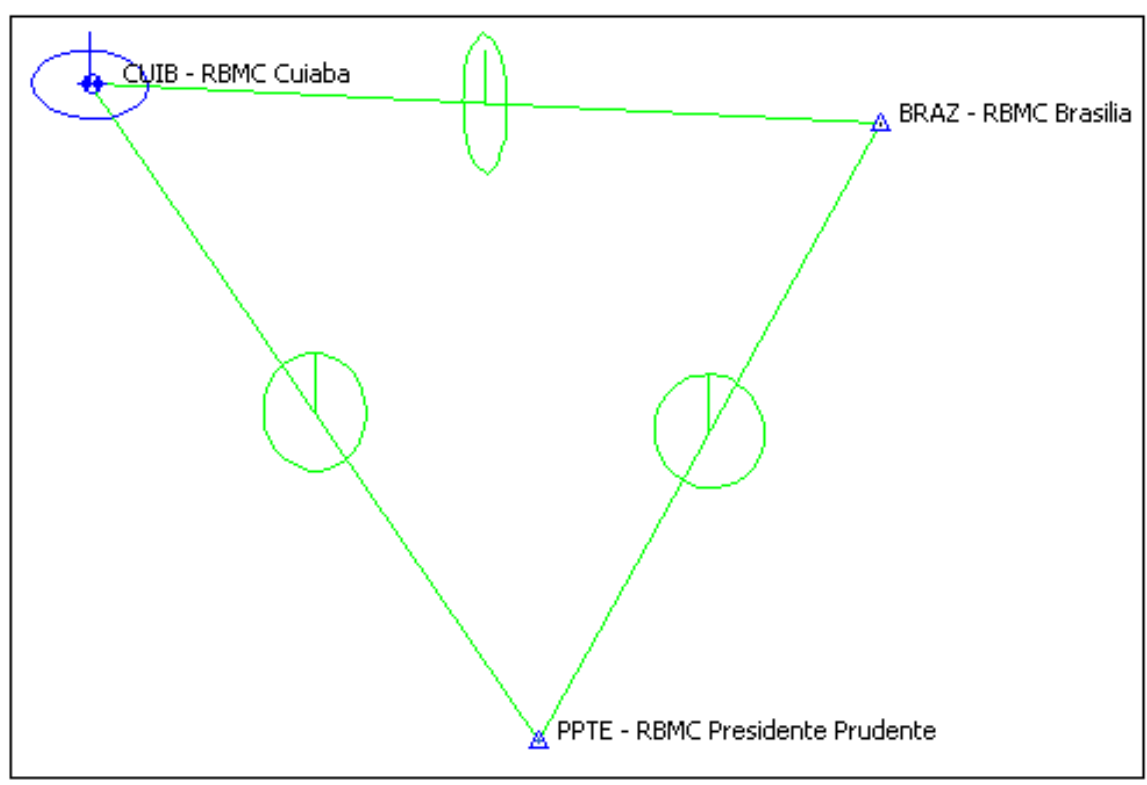

Coordenadas Ajustadas de CUIB:

E (UTM): $599737.3275 \mathrm{~m}$

N (UTM): $8280040.8517 \mathrm{~m}$

\section{B.3.1.4 Primavera (Dias Julianos 011 a 014)}

- $286 / 2006$

A posteriori UWE: 1.093013 , Bounds: ( $0.6770032,1.241639$ ) 
TABELA B109: Resultado do Processamento

\begin{tabular}{|c|c|c|c|c|c|c|c|c|}
\hline \multicolumn{9}{|c|}{ GPS Obs Report } \\
\hline Name & \begin{tabular}{|c} 
Horizontal \\
Precision (m)
\end{tabular} & $\begin{array}{c}\text { Vertical } \\
\text { Precision } \\
\text { (m) }\end{array}$ & $\begin{array}{l}\text { Distance } \\
\text { (m) }\end{array}$ & $\begin{array}{c}\text { Solution } \\
\text { Type }\end{array}$ & $\begin{array}{c}\text { GPS } \\
\text { Satellites }\end{array}$ & PDOP & Status & RMS \\
\hline \begin{tabular}{|l|} 
BRAZ - RBMC \\
Brasilia-CUIB - \\
RBMC Cuiaba \\
\end{tabular} & 0.092 & 0.106 & 878314.407 & $\begin{array}{l}\text { Fixed,Wide } \\
\text { Lane }\end{array}$ & 27 & 3.040 & Adjusted & 0.141 \\
\hline $\begin{array}{l}\text { BRAZ - RBMC } \\
\text { Brasilia-PPTE - } \\
\text { RBMC Presidente } \\
\text { Prudente } \\
\end{array}$ & 0.088 & 0.099 & 777286.932 & $\begin{array}{l}\text { Float,Wide } \\
\text { Lane }\end{array}$ & 28 & 2.956 & Adjusted & 0.133 \\
\hline $\begin{array}{l}\text { CUIB - RBMC } \\
\text { Cuiaba-PPTE - } \\
\text { RBMC Presidente } \\
\text { Prudente }\end{array}$ & 0.087 & 0.111 & 876276.072 & $\begin{array}{l}\text { Float,Wide } \\
\text { Lane }\end{array}$ & 27 & 3.016 & Adjusted & 0.141 \\
\hline
\end{tabular}

Figura B109: Elipses de Erro

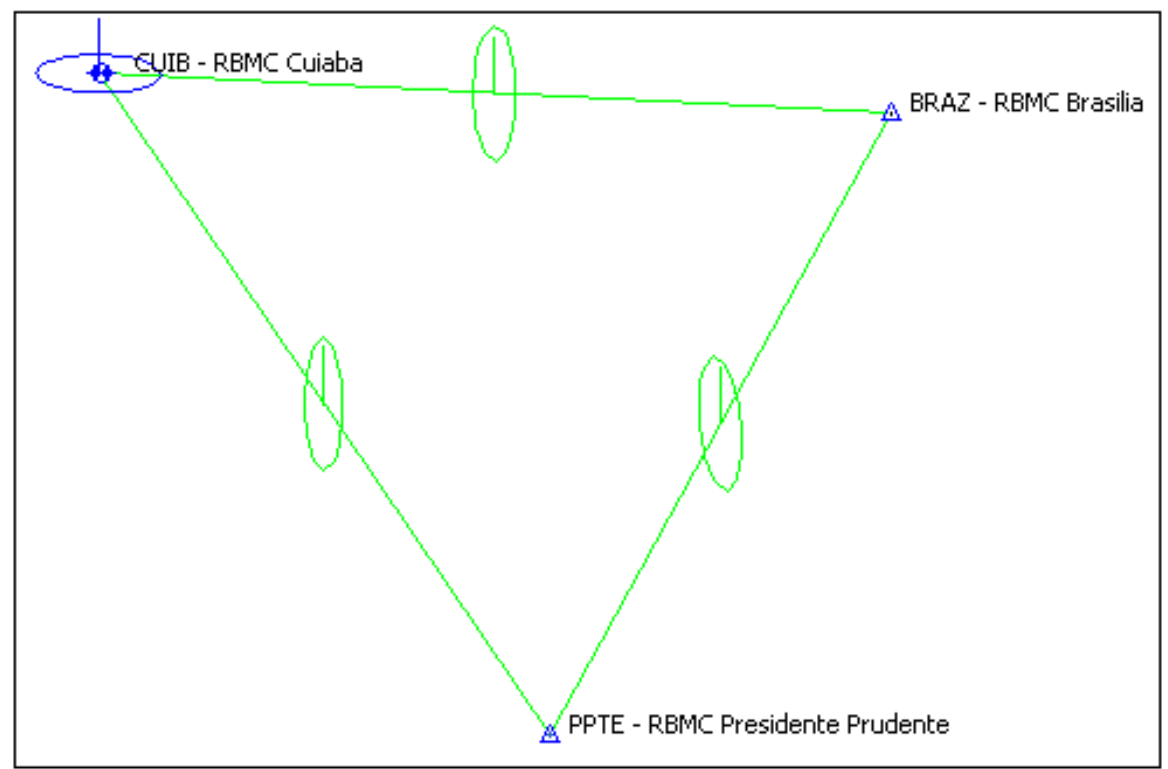

Coordenadas Ajustadas de CUIB:

E (UTM): $599737.3028 \mathrm{~m}$

N (UTM): $8280040.8526 \mathrm{~m}$

- $287 / 2006$

A posteriori UWE: 0.9276355 , Bounds: $(0.6770032,1.241639)$ 
TABELA B110: Resultado do Processamento

\begin{tabular}{|c|c|c|c|c|c|c|c|c|}
\hline \multicolumn{9}{|c|}{ GPS Obs Report } \\
\hline Name & \begin{tabular}{|c|} 
Horizontal \\
Precision \\
(m)
\end{tabular} & $\begin{array}{c}\text { Vertical } \\
\text { Precision } \\
\text { (m) }\end{array}$ & $\begin{array}{l}\text { Distance } \\
\text { (m) }\end{array}$ & $\begin{array}{c}\text { Solution } \\
\text { Type }\end{array}$ & $\begin{array}{c}\text { GPS } \\
\text { Satellites }\end{array}$ & PDOP & Status & RMS \\
\hline \begin{tabular}{|l|} 
BRAZ - RBMC \\
Brasilia-CUIB - \\
RBMC Cuiaba \\
\end{tabular} & 0.101 & 0.099 & 878314.412 & \begin{tabular}{|l} 
Float,Wide \\
Lane
\end{tabular} & 27 & 3.044 & Adjusted & 0.141 \\
\hline $\begin{array}{l}\text { BRAZ - RBMC } \\
\text { Brasilia-PPTE - } \\
\text { RBMC Presidente } \\
\text { Prudente }\end{array}$ & 0.084 & 0.103 & 777286.919 & $\begin{array}{l}\text { Float,Wide } \\
\text { Lane }\end{array}$ & 25 & 3.002 & Adjusted & 0.133 \\
\hline $\begin{array}{l}\text { CUIB - RBMC } \\
\text { Cuiaba-PPTE - } \\
\text { RBMC Presidente } \\
\text { Prudente }\end{array}$ & 0.095 & 0.105 & 876276.042 & $\begin{array}{l}\text { Float,Wide } \\
\text { Lane }\end{array}$ & 27 & 3.009 & Adjusted & 0.141 \\
\hline
\end{tabular}

Figura B110: Elipses de Erro

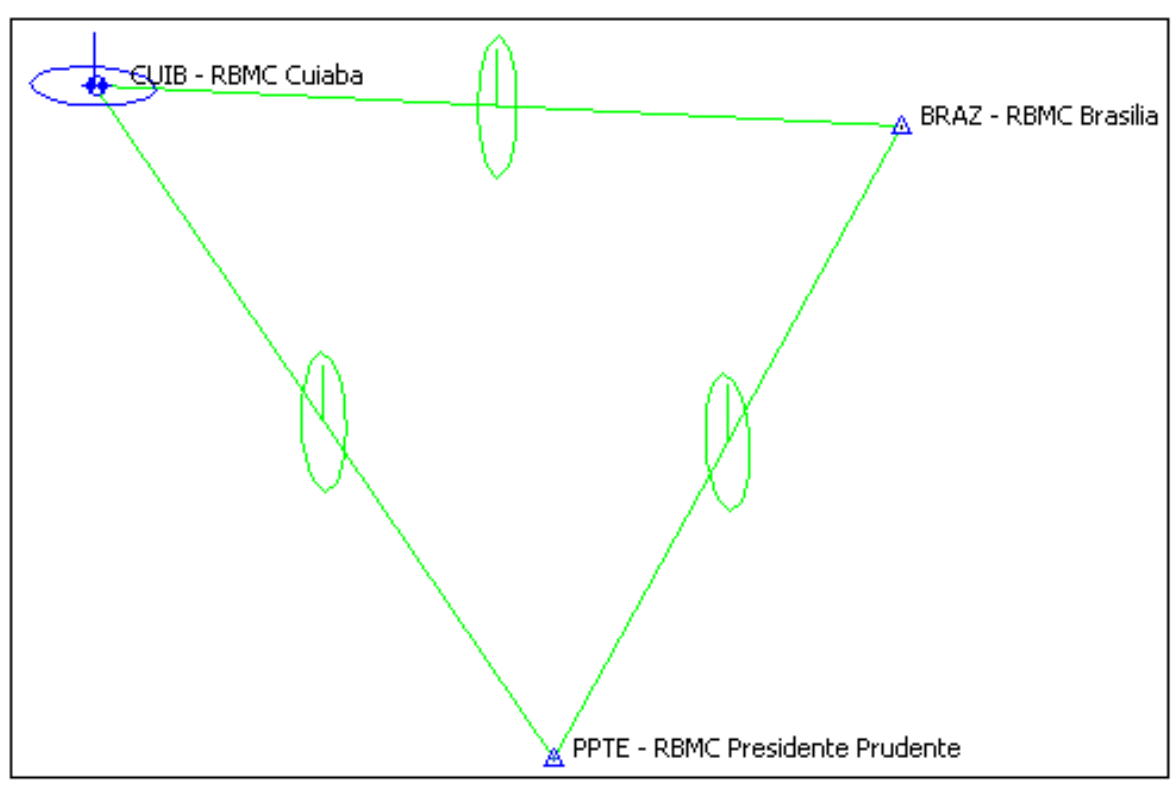

Coordenadas Ajustadas de CUIB:

E (UTM): $599737.3325 \mathrm{~m}$

N (UTM): $8280040.8401 \mathrm{~m}$

- $\underline{288 / 2006}$

A posteriori UWE: 1.133716 , Bounds: ( $0.6770032,1.241639)$ 
TABELA B111: Resultado do Processamento

\begin{tabular}{|c|c|c|c|c|c|c|c|c|}
\hline \multicolumn{9}{|c|}{ GPS Obs Report } \\
\hline Name & \begin{tabular}{|c} 
Horizontal \\
Precision (m)
\end{tabular} & $\begin{array}{l}\text { Vertical } \\
\text { Precision } \\
\text { (m) }\end{array}$ & $\begin{array}{l}\text { Distance } \\
\text { (m) }\end{array}$ & $\begin{array}{c}\text { Solution } \\
\text { Type }\end{array}$ & $\begin{array}{c}\text { GPS } \\
\text { Satellites }\end{array}$ & PDOP & Status & RMS \\
\hline \begin{tabular}{|l} 
BRAZ - RBMC \\
Brasilia-CUIB - \\
RBMC Cuiaba \\
\end{tabular} & 0.098 & 0.101 & 878314.420 & $\begin{array}{l}\text { Float,Wide } \\
\text { Lane }\end{array}$ & 27 & 2.798 & Adjusted & 0.141 \\
\hline $\begin{array}{l}\text { BRAZ - RBMC } \\
\text { Brasilia-PPTE - } \\
\text { RBMC Presidente } \\
\text { Prudente }\end{array}$ & 0.060 & 0.118 & 777286.955 & $\begin{array}{l}\text { Fixed,Wide } \\
\text { Lane }\end{array}$ & 28 & 3.041 & Adjusted & 0.133 \\
\hline $\begin{array}{l}\text { CUIB - RBMC } \\
\text { Cuiaba-PPTE - } \\
\text { RBMC Presidente } \\
\text { Prudente }\end{array}$ & 0.088 & 0.110 & 876276.057 & $\begin{array}{l}\text { Float,Wide } \\
\text { Lane }\end{array}$ & 27 & 3.008 & Adjusted & 0.141 \\
\hline
\end{tabular}

Figura B111: Elipses de Erro

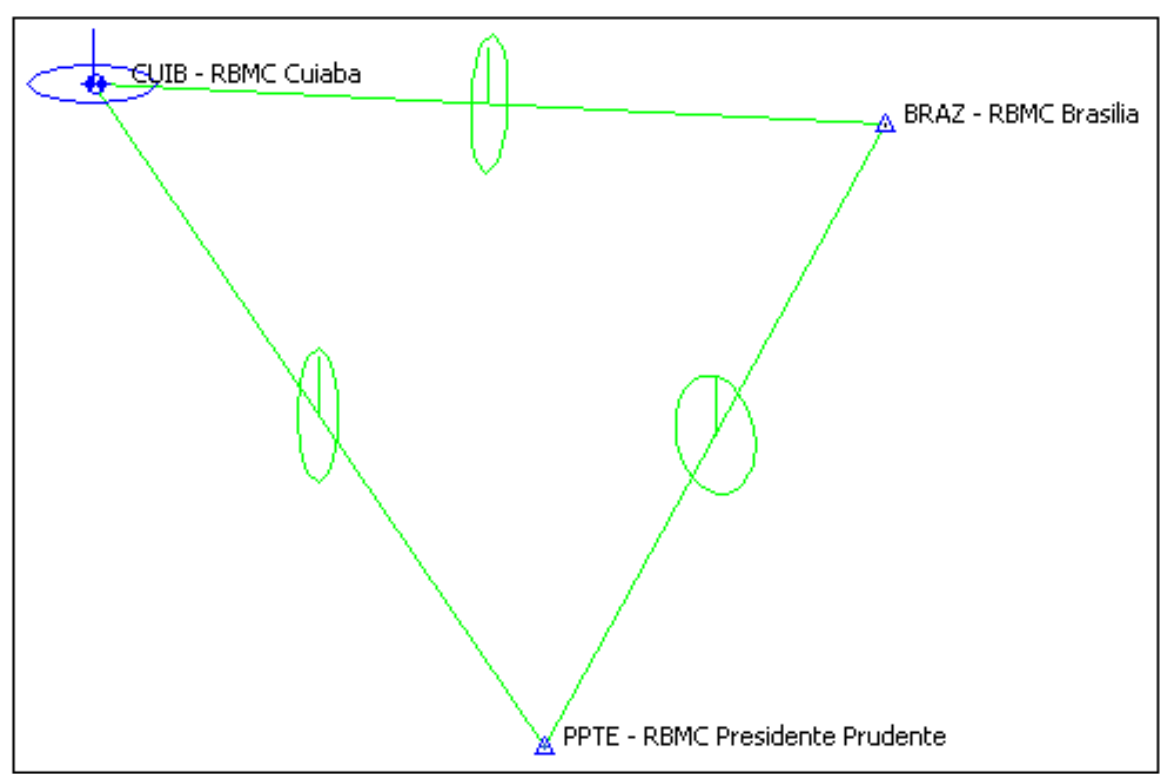

Coordenadas Ajustadas de CUIB:

E (UTM): $599737.3220 \mathrm{~m}$

> N (UTM): $8280040.8682 \mathrm{~m}$

- $\underline{289 / 2006}$

A posteriori UWE: 1.20184 , Bounds: ( $0.6770032,1.241639$ ) 
TABELA B112: Resultado do Processamento

\begin{tabular}{|c|c|c|c|c|c|c|c|c|}
\hline \multicolumn{9}{|c|}{ GPS Obs Report } \\
\hline Name & $\begin{array}{l}\text { Horizontal } \\
\text { Precision } \\
\text { (m) }\end{array}$ & $\begin{array}{l}\text { Vertical } \\
\text { Precision } \\
\text { (m) }\end{array}$ & $\begin{array}{c}\text { Distance } \\
\text { (m) }\end{array}$ & $\begin{array}{l}\text { Solution } \\
\text { Type }\end{array}$ & $\begin{array}{c}\text { GPS } \\
\text { Satellites }\end{array}$ & PDOP & Status & RMS \\
\hline $\begin{array}{l}\text { BRAZ - RBMC } \\
\text { Brasilia-CUIB - } \\
\text { RBMC Cuiaba } \\
\end{array}$ & 0.073 & 0.120 & 878314.410 & \begin{tabular}{|l} 
Fixed,Wide \\
Lane
\end{tabular} & 25 & 3.034 & Adjusted & $\mid 0.141$ \\
\hline $\begin{array}{l}\text { BRAZ - RBMC } \\
\text { Brasilia-PPTE - } \\
\text { RBMC Presidente } \\
\text { Prudente }\end{array}$ & 0.077 & 0.115 & 777286.969 & \begin{tabular}{|l} 
Fixed,Wide \\
Lane
\end{tabular} & 23 & 2.708 & Adjusted & $\mid 0.133$ \\
\hline $\begin{array}{l}\text { CUIB - RBMC } \\
\text { Cuiaba-PPTE - } \\
\text { RBMC Presidente } \\
\text { Prudente }\end{array}$ & 0.089 & 0.109 & 876276.066 & \begin{tabular}{|l} 
Float,Wide \\
Lane
\end{tabular} & 27 & 3.007 & Adjusted & $\mid 0.141$ \\
\hline
\end{tabular}

Figura B112: Elipses de Erro

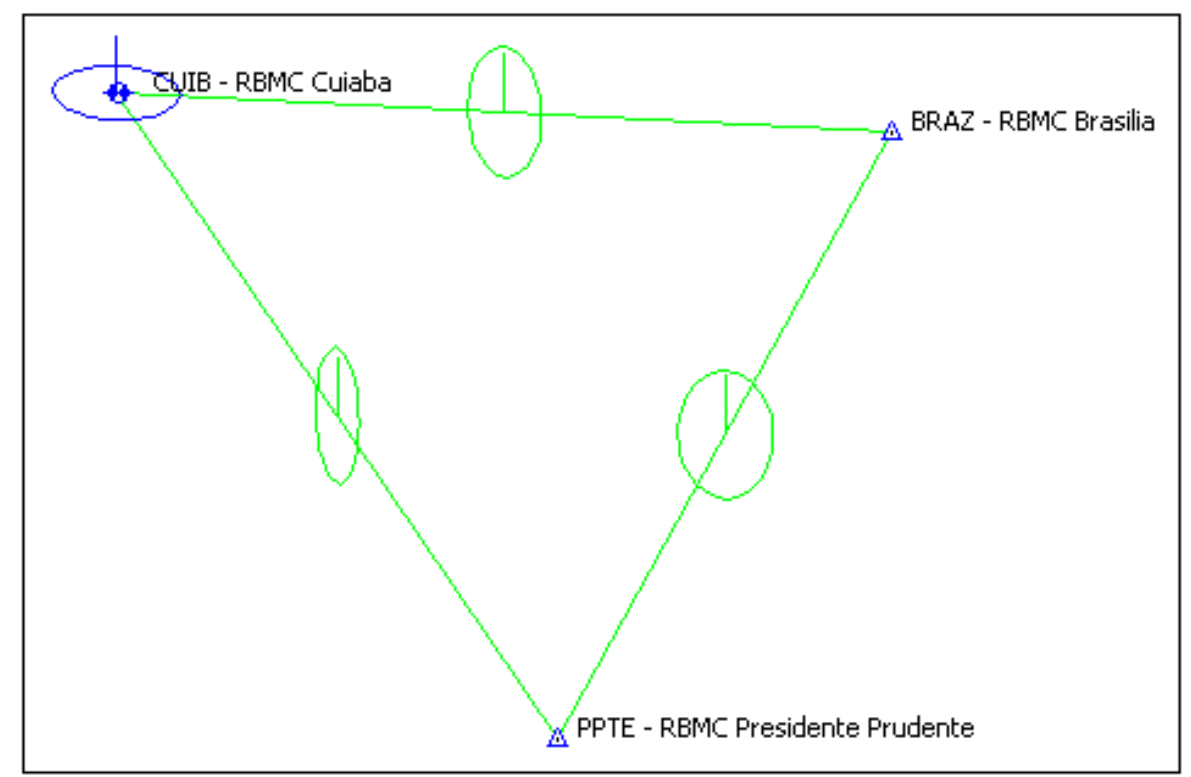

Coordenadas Ajustadas de CUIB:

E (UTM): $599737.3024 \mathrm{~m}$

N (UTM): $8280040.8679 \mathrm{~m}$

\section{B.3.2 2007}

B.3.2.1 Verão (Dias Julianos 011 a 014)

- $\underline{011 / 2007}$

A posteriori UWE: 1.577039 , Bounds: ( $0.6770032,1.241639$ ) 
TABELA B113: Resultado do Processamento

\begin{tabular}{|c|c|c|c|c|c|c|c|c|}
\hline \multicolumn{9}{|c|}{ GPS Obs Report } \\
\hline Name & $\begin{array}{c}\text { Horizontal } \\
\text { Precision (m) }\end{array}$ & $\begin{array}{l}\text { Vertical } \\
\text { Precision } \\
\text { (m) }\end{array}$ & $\begin{array}{l}\text { Distance } \\
\text { (m) }\end{array}$ & $\begin{array}{l}\text { Solution } \\
\text { Type }\end{array}$ & $\begin{array}{c}\text { GPS } \\
\text { Satellites }\end{array}$ & PDOP & Status & RMS \\
\hline $\begin{array}{l}\text { BRAZ - RBMC } \\
\text { Brasilia-CUIB - } \\
\text { RBMC Cuiaba } \\
\end{array}$ & 0.085 & 0.113 & 878314.414 & $\begin{array}{l}\text { Fixed,Wide } \\
\text { Lane }\end{array}$ & 28 & 6.658 & Adjusted & 0.141 \\
\hline $\begin{array}{l}\text { BRAZ - RBMC } \\
\text { Brasilia-PPTE - } \\
\text { RBMC Presidente } \\
\text { Prudente }\end{array}$ & 0.103 & 0.089 & 777286.966 & $\begin{array}{l}\text { Float,Wide } \\
\text { Lane }\end{array}$ & 28 & 53.121 & Adjusted & 0.136 \\
\hline $\begin{array}{l}\text { CUIB - RBMC } \\
\text { Cuiaba-PPTE - RBMC } \\
\text { Presidente Prudente }\end{array}$ & $\mid 0.099$ & 0.104 & 876276.087 & $\begin{array}{l}\text { Float,Wide } \\
\text { Lane }\end{array}$ & 28 & 3.499 & Adjusted & 0.144 \\
\hline
\end{tabular}

Figura B113: Elipses de Erro

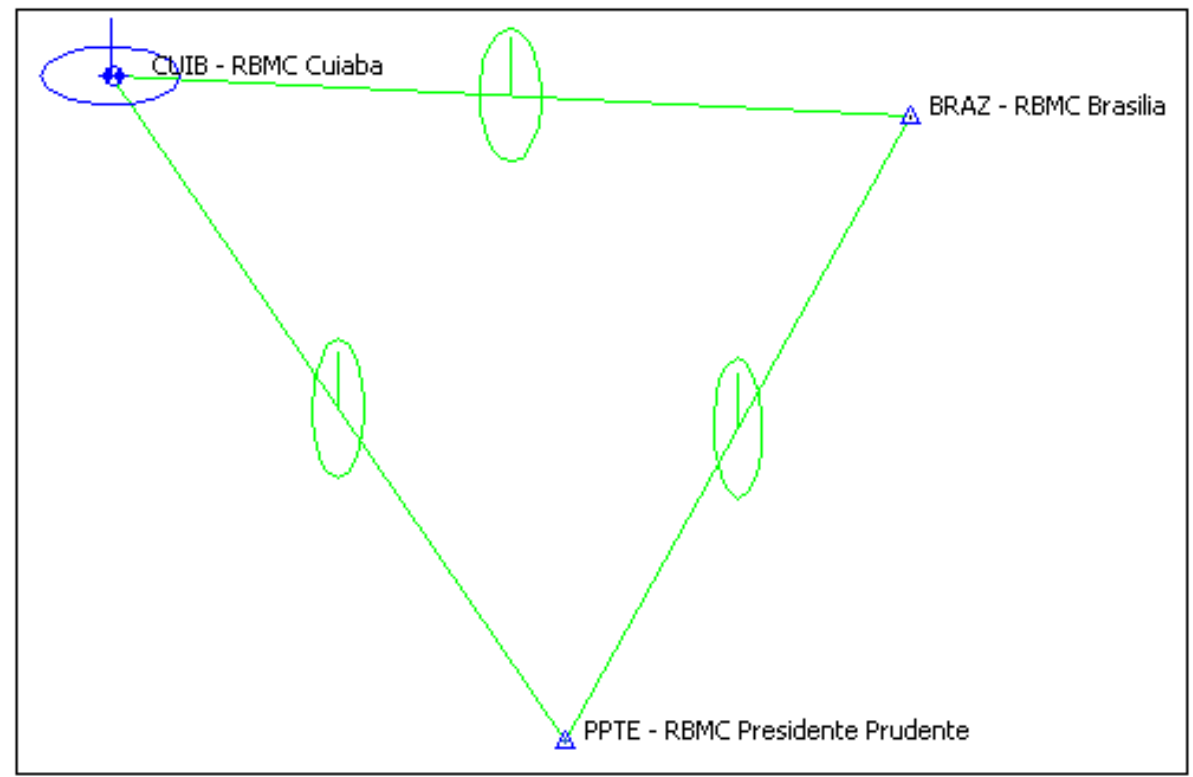

Coordenadas Ajustadas de CUIB:

E (UTM): $599737.3039 \mathrm{~m}$

N (UTM): $8280040.8775 \mathrm{~m}$

- $\underline{012 / 2007}$

A posteriori UWE: 1.032919 , Bounds: ( $0.6770032,1.241639)$ 
TABELA B114: Resultado do Processamento

\begin{tabular}{|c|c|c|c|c|c|c|c|c|}
\hline \multicolumn{9}{|c|}{ GPS Obs Report } \\
\hline Name & \begin{tabular}{|c} 
Horizontal \\
Precision (m)
\end{tabular} & $\begin{array}{l}\text { Vertical } \\
\text { Precision } \\
\text { (m) }\end{array}$ & $\begin{array}{l}\text { Distance } \\
\text { (m) }\end{array}$ & $\begin{array}{l}\text { Solution } \\
\text { Type }\end{array}$ & $\begin{array}{c}\text { GPS } \\
\text { Satellites }\end{array}$ & PDOP & Status & RMS \\
\hline $\begin{array}{l}\text { BRAZ - RBMC } \\
\text { Brasilia-CUIB - } \\
\text { RBMC Cuiaba } \\
\end{array}$ & 0.103 & 0.093 & 878314.446 & $\begin{array}{l}\text { Float,Wide } \\
\text { Lane }\end{array}$ & 26 & 3.003 & Adjusted & 0.141 \\
\hline $\begin{array}{l}\text { BRAZ - RBMC } \\
\text { Brasilia-PPTE - } \\
\text { RBMC Presidente } \\
\text { Prudente }\end{array}$ & 0.066 & 0.114 & 777286.943 & $\begin{array}{l}\text { Fixed,Wide } \\
\text { Lane }\end{array}$ & 28 & 2.898 & Adjusted & 0.133 \\
\hline $\begin{array}{l}\text { CUIB - RBMC } \\
\text { Cuiaba-PPTE - } \\
\text { RBMC Presidente } \\
\text { Prudente }\end{array}$ & 0.101 & 0.101 & 876276.106 & $\begin{array}{l}\text { Float,Wide } \\
\text { Lane }\end{array}$ & 25 & 3.053 & Adjusted & 0.142 \\
\hline
\end{tabular}

Figura B114: Elipses de Erro

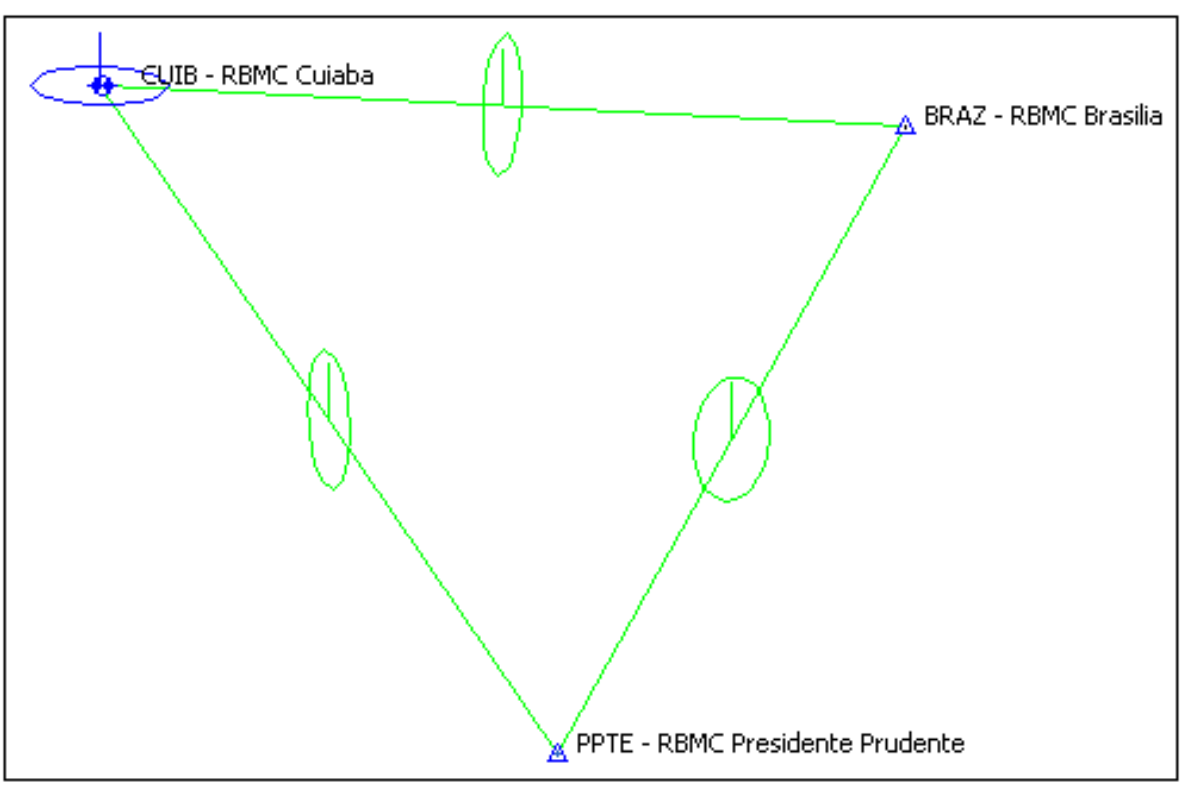

Coordenadas Ajustadas de CUIB:

E (UTM): $599737.2820 \mathrm{~m}$

N (UTM): $8280040.8542 \mathrm{~m}$

- $\underline{013 / 2007}$

A posteriori UWE: 1.119285 , Bounds: ( $0.6770032,1.241639$ ) 
TABELA B115: Resultado do Processamento

\begin{tabular}{|c|c|c|c|c|c|c|c|c|}
\hline \multicolumn{9}{|c|}{ GPS Obs Report } \\
\hline Name & $\begin{array}{c}\text { Horizontal } \\
\text { Precision } \\
\text { (m) }\end{array}$ & $\begin{array}{l}\text { Vertical } \\
\text { Precision } \\
\text { (m) }\end{array}$ & $\begin{array}{l}\text { Distance } \\
\text { (m) }\end{array}$ & $\begin{array}{c}\text { Solution } \\
\text { Type }\end{array}$ & $\begin{array}{c}\text { GPS } \\
\text { Satellites }\end{array}$ & PDOP & Status & RMS \\
\hline $\begin{array}{l}\text { BRAZ - RBMC } \\
\text { Brasilia-CUIB - } \\
\text { RBMC Cuiaba }\end{array}$ & 0.100 & 0.096 & 878314.423 & $\begin{array}{l}\text { Float,Wide } \\
\text { Lane }\end{array}$ & 25 & 3.007 & Adjusted & 0.141 \\
\hline $\begin{array}{l}\text { BRAZ - RBMC } \\
\text { Brasilia-PPTE - } \\
\text { RBMC Presidente } \\
\text { Prudente }\end{array}$ & 0.091 & 0.093 & 777286.944 & $\begin{array}{l}\text { Float,Wide } \\
\text { Lane }\end{array}$ & 27 & 2.966 & Adjusted & 0.132 \\
\hline $\begin{array}{l}\text { CUIB - RBMC } \\
\text { Cuiaba-PPTE - } \\
\text { RBMC Presidente } \\
\text { Prudente }\end{array}$ & 0.093 & 0.106 & 876276.106 & $\begin{array}{l}\text { Float,Wide } \\
\text { Lane }\end{array}$ & 26 & 2.765 & Adjusted & 0.144 \\
\hline
\end{tabular}

Figura B115: Elipses de Erro

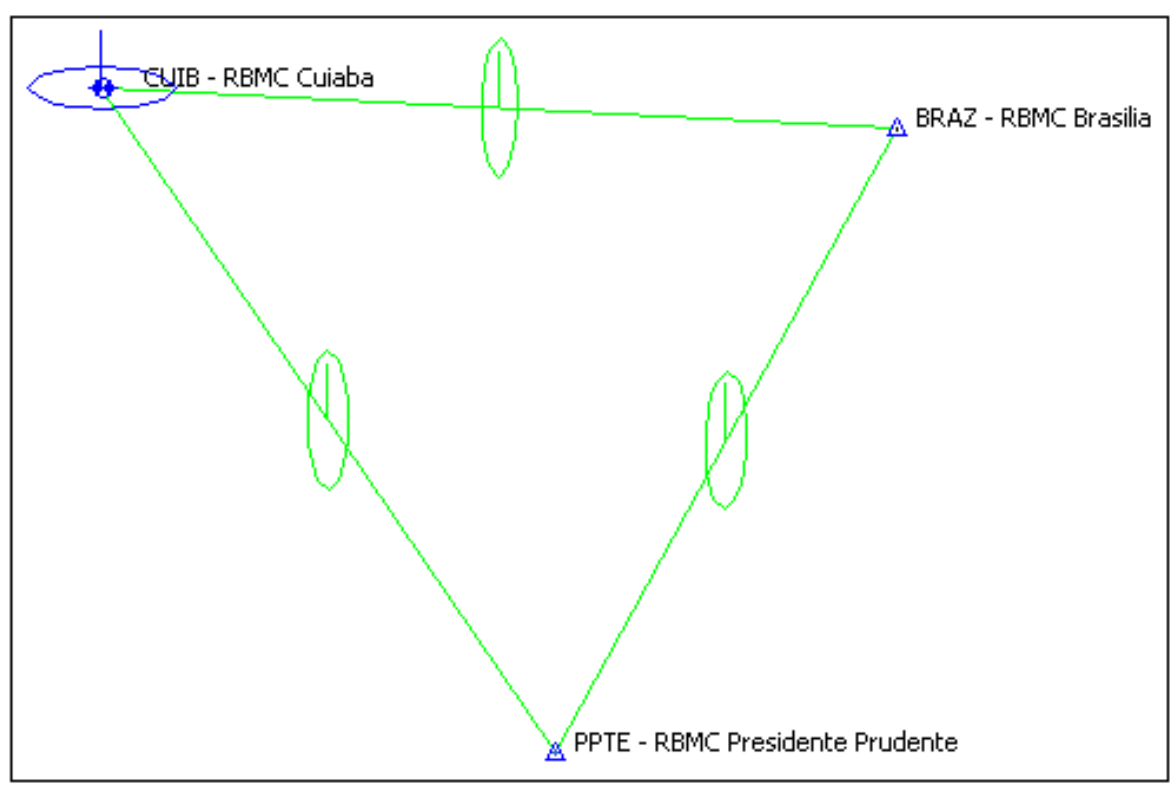

Coordenadas Ajustadas de CUIB:

E (UTM): $599737.2856 \mathrm{~m}$

$>\mathrm{N}$ (UTM): $8280040.8628 \mathrm{~m}$

- $\underline{014 / 2007}$

A posteriori UWE: 1.176204 , Bounds: ( $0.6770032,1.241639)$ 
TABELA B116: Resultado do Processamento

\begin{tabular}{|c|c|c|c|c|c|c|c|c|}
\hline \multicolumn{9}{|c|}{ GPS Obs Report } \\
\hline Name & $\begin{array}{l}\text { Horizontal } \\
\text { Precision } \\
\text { (m) }\end{array}$ & $\begin{array}{l}\text { Vertical } \\
\text { Precision } \\
\text { (m) }\end{array}$ & $\begin{array}{l}\text { Distance } \\
\text { (m) }\end{array}$ & $\begin{array}{c}\text { Solution } \\
\text { Type }\end{array}$ & $\begin{array}{c}\text { GPS } \\
\text { Satellites }\end{array}$ & PDOP & Status & RMS \\
\hline $\begin{array}{l}\text { BRAZ - RBMC } \\
\text { Brasilia-CUIB - } \\
\text { RBMC Cuiaba }\end{array}$ & 0.115 & 0.082 & 878314.462 & $\begin{array}{l}\text { Float,Wide } \\
\text { Lane }\end{array}$ & 25 & 3.001 & Adjusted & 0.141 \\
\hline $\begin{array}{l}\text { BRAZ - RBMC } \\
\text { Brasilia-PPTE - } \\
\text { RBMC Presidente } \\
\text { Prudente }\end{array}$ & 0.089 & 0.098 & 777286.950 & $\begin{array}{l}\text { Float,Wide } \\
\text { Lane }\end{array}$ & 25 & 2.958 & Adjusted & 0.133 \\
\hline $\begin{array}{l}\text { CUIB - RBMC } \\
\text { Cuiaba-PPTE - } \\
\text { RBMC Presidente } \\
\text { Prudente }\end{array}$ & 0.092 & 0.109 & 876276.113 & $\begin{array}{l}\text { Float,Wide } \\
\text { Lane }\end{array}$ & 24 & 3.002 & Adjusted & 0.142 \\
\hline
\end{tabular}

Figura B116: Elipses de Erro

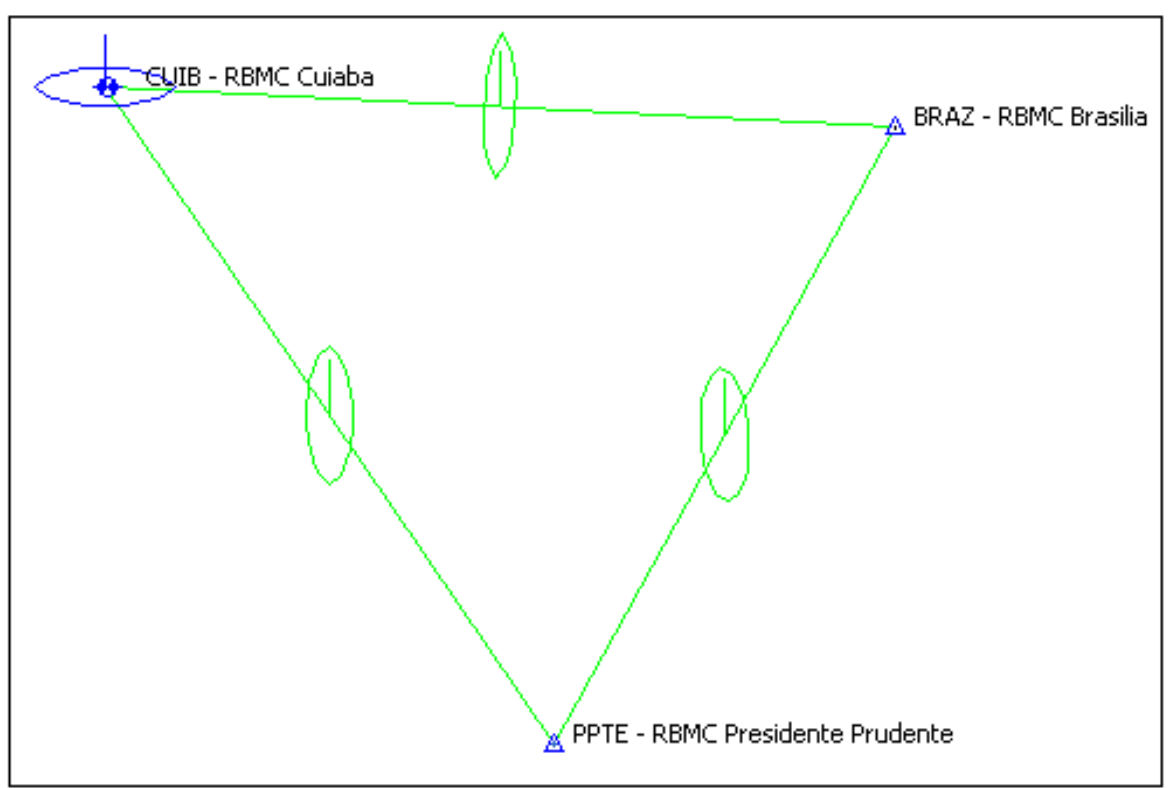

Coordenadas Ajustadas de CUIB:

E (UTM): $599737.2928 \mathrm{~m}$

N (UTM): $8280040.8695 \mathrm{~m}$

\section{B.3.2.2 Outono (Dias Julianos 101 a 104)}

- $\underline{101 / 2007}$

A posteriori UWE: 0.7526265 , Bounds: ( 0.6770032, 1.241639) 
TABELA B117: Resultado do Processamento

\begin{tabular}{|c|c|c|c|c|c|c|c|c|}
\hline \multicolumn{9}{|c|}{ GPS Obs Report } \\
\hline Name & $\begin{array}{c}\text { Horizontal } \\
\text { Precision (m) }\end{array}$ & $\begin{array}{l}\text { Vertical } \\
\text { Precision } \\
\text { (m) }\end{array}$ & $\begin{array}{l}\text { Distance } \\
(\mathbf{m})\end{array}$ & $\begin{array}{l}\text { Solution } \\
\text { Type }\end{array}$ & $\begin{array}{c}\text { GPS } \\
\text { Satellites }\end{array}$ & PDOP & Status & RMS \\
\hline $\begin{array}{l}\text { BRAZ - } \\
\text { Brasilia-CUIB - } \\
\text { Cuiaba } \\
\end{array}$ & 0.099 & 0.100 & 878314.415 & $\begin{array}{l}\text { Float, Wide } \\
\text { Lane }\end{array}$ & 30 & 2.918 & Adjusted & 0.141 \\
\hline $\begin{array}{l}\text { BRAZ - } \\
\text { Brasilia-PPTE - } \\
\text { Presidente Prudente }\end{array}$ & 0.086 & 0.102 & 777286.897 & $\begin{array}{l}\text { Float,Wide } \\
\text { Lane }\end{array}$ & 30 & 2.795 & Adjusted & 0.133 \\
\hline $\begin{array}{l}\text { CUIB - } \\
\text { Cuiaba-PPTE - } \\
\text { Presidente Prudente }\end{array}$ & 0.094 & 0.105 & 876276.035 & $\begin{array}{l}\text { Float, Wide } \\
\text { Lane }\end{array}$ & 30 & 2.920 & Adjusted & 0.141 \\
\hline
\end{tabular}

Figura B117: Elipses de Erro

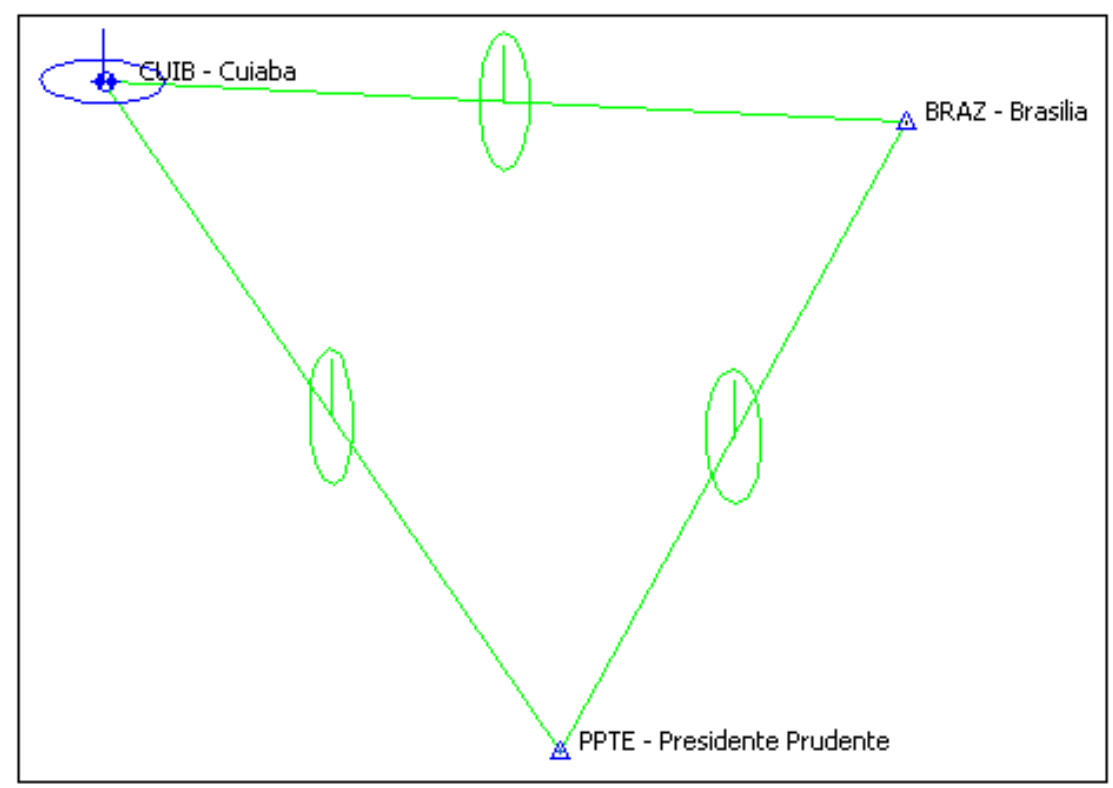

Coordenadas Ajustadas de CUIB:

E (UTM): $599737.2992 \mathrm{~m}$

N (UTM): $8280040.8296 \mathrm{~m}$

- $\underline{102 / 2007}$

A posteriori UWE: 0.6939436 , Bounds: ( $0.6770032,1.241639)$ 
TABELA B118: Resultado do Processamento

\begin{tabular}{|c|c|c|c|c|c|c|c|c|}
\hline \multicolumn{9}{|c|}{ GPS Obs Report } \\
\hline Name & $\begin{array}{c}\text { Horizontal } \\
\text { Precision } \\
\text { (m) }\end{array}$ & $\begin{array}{l}\text { Vertical } \\
\text { Precision } \\
\text { (m) }\end{array}$ & $\begin{array}{l}\text { Distance } \\
\text { (m) }\end{array}$ & $\begin{array}{c}\text { Solution } \\
\text { Type }\end{array}$ & $\begin{array}{c}\text { GPS } \\
\text { Satellites }\end{array}$ & PDOP & Status & RMS \\
\hline $\begin{array}{l}\text { BRAZ - RBMC } \\
\text { Brasilia-CUIB - } \\
\text { RBMC Cuiaba }\end{array}$ & 0.101 & 0.099 & 878314.383 & $\begin{array}{l}\text { Float,Wide } \\
\text { Lane }\end{array}$ & 30 & 2.919 & Adjusted & 0.141 \\
\hline $\begin{array}{l}\text { BRAZ - RBMC } \\
\text { Brasilia-PPTE - } \\
\text { RBMC Presidente } \\
\text { Prudente }\end{array}$ & 0.092 & 0.095 & 777286.872 & $\begin{array}{l}\text { Float,Wide } \\
\text { Lane }\end{array}$ & 30 & 2.797 & Adjusted & 0.133 \\
\hline $\begin{array}{l}\text { CUIB - RBMC } \\
\text { Cuiaba-PPTE - } \\
\text { RBMC Presidente } \\
\text { Prudente }\end{array}$ & 0.099 & 0.101 & 876276.069 & $\begin{array}{l}\text { Float,Wide } \\
\text { Lane }\end{array}$ & 30 & 2.922 & Adjusted & 0.141 \\
\hline
\end{tabular}

Figura B118: Elipses de Erro

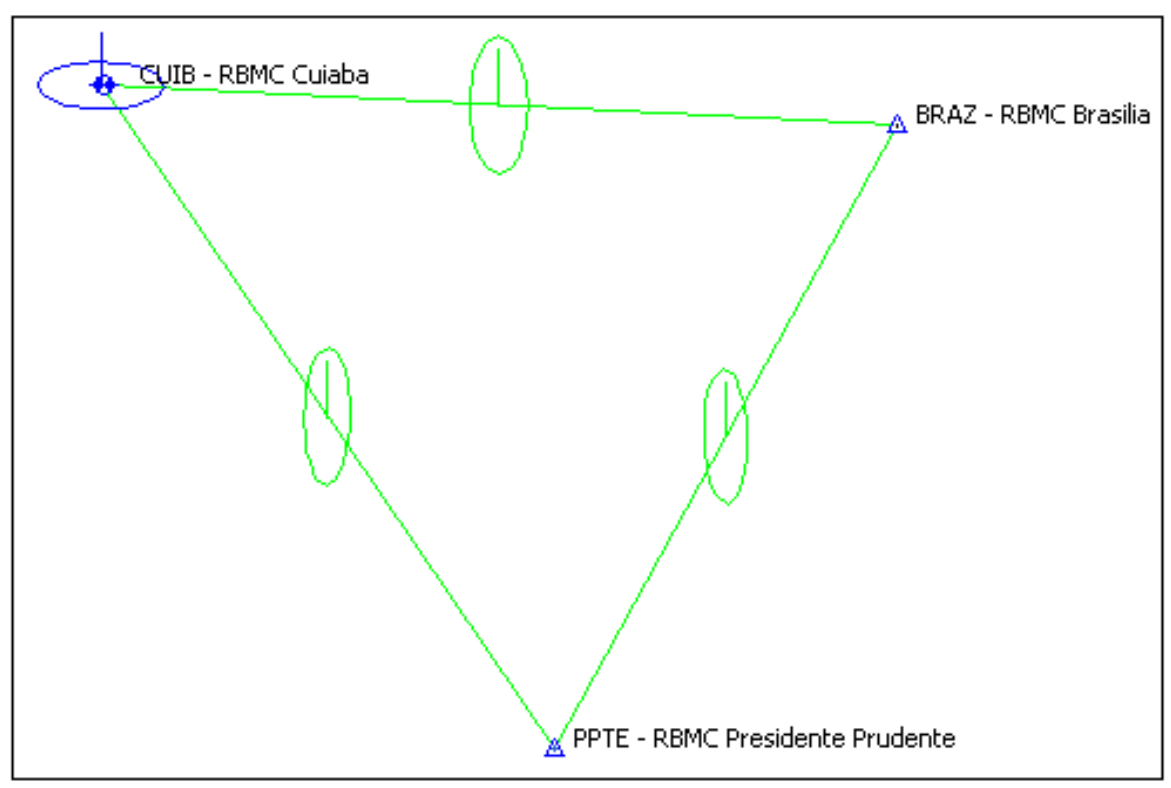

Coordenadas Ajustadas de CUIB:

E (UTM): $599737.3046 \mathrm{~m}$

N (UTM): $8280040.8406 \mathrm{~m}$

- $103 / 2007$

A posteriori UWE: 1.12392 , Bounds: ( $0.6770032,1.241639$ ) 
TABELA B119: Resultado do Processamento

\begin{tabular}{|c|c|c|c|c|c|c|c|c|}
\hline \multicolumn{9}{|c|}{ GPS Obs Report } \\
\hline Name & $\begin{array}{c}\text { Horizontal } \\
\text { Precision } \\
\text { (m) }\end{array}$ & $\begin{array}{l}\text { Vertical } \\
\text { Precision } \\
\text { (m) }\end{array}$ & $\begin{array}{l}\text { Distance } \\
\text { (m) }\end{array}$ & $\begin{array}{c}\text { Solution } \\
\text { Type }\end{array}$ & $\begin{array}{c}\text { GPS } \\
\text { Satellites }\end{array}$ & PDOP & Status & RMS \\
\hline $\begin{array}{l}\text { BRAZ - RBMC } \\
\text { Brasilia-CUIB - } \\
\text { RBMC Cuiaba }\end{array}$ & 0.097 & 0.103 & 878314.409 & $\begin{array}{l}\text { Float,Wide } \\
\text { Lane }\end{array}$ & 30 & 2.918 & Adjusted & 0.141 \\
\hline $\begin{array}{l}\text { BRAZ - RBMC } \\
\text { Brasilia-PPTE - } \\
\text { RBMC Presidente } \\
\text { Prudente }\end{array}$ & 0.092 & 0.095 & 777286.896 & $\begin{array}{l}\text { Float,Wide } \\
\text { Lane }\end{array}$ & 30 & 2.794 & Adjusted & 0.133 \\
\hline $\begin{array}{l}\text { CUIB - RBMC } \\
\text { Cuiaba-PPTE - } \\
\text { RBMC Presidente } \\
\text { Prudente }\end{array}$ & 0.098 & 0.104 & 876276.054 & $\begin{array}{l}\text { Float,Wide } \\
\text { Lane }\end{array}$ & 30 & 2.921 & Adjusted & 0.143 \\
\hline
\end{tabular}

Figura B119: Elipses de Erro

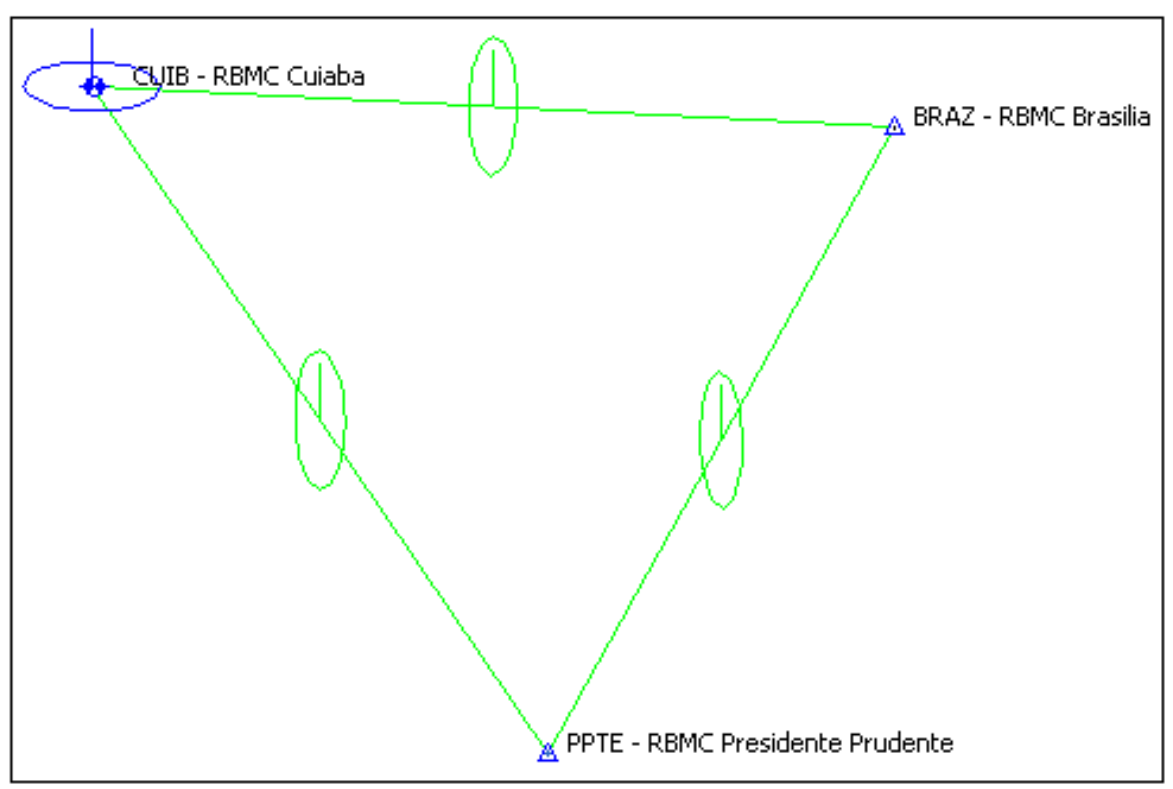

Coordenadas Ajustadas de CUIB:

E (UTM): $599737.3070 \mathrm{~m}$

N (UTM): $8280040.8492 \mathrm{~m}$

- $104 / 2007$

A posteriori UWE: 1.026571 , Bounds: ( $0.6770032,1.241639)$ 
TABELA B120: Resultado do Processamento

\begin{tabular}{|c|c|c|c|c|c|c|c|c|}
\hline \multicolumn{9}{|c|}{ GPS Obs Report } \\
\hline Name & $\begin{array}{l}\text { Horizontal } \\
\text { Precision } \\
\text { (m) }\end{array}$ & $\begin{array}{l}\text { Vertical } \\
\text { Precision } \\
\text { (m) }\end{array}$ & $\begin{array}{l}\text { Distance } \\
\text { (m) }\end{array}$ & $\begin{array}{c}\text { Solution } \\
\text { Type }\end{array}$ & $\begin{array}{c}\text { GPS } \\
\text { Satellites }\end{array}$ & PDOP & Status & RMS \\
\hline $\begin{array}{l}\text { BRAZ - RBMC } \\
\text { Brasilia-CUIB - } \\
\text { RBMC Cuiaba }\end{array}$ & 0.100 & 0.100 & 878314.344 & $\begin{array}{l}\text { Float,Wide } \\
\text { Lane }\end{array}$ & 30 & 2.918 & Adjusted & 0.141 \\
\hline $\begin{array}{l}\text { BRAZ - RBMC } \\
\text { Brasilia-PPTE - } \\
\text { RBMC Presidente } \\
\text { Prudente }\end{array}$ & 0.096 & 0.092 & 777286.890 & $\begin{array}{l}\text { Float,Wide } \\
\text { Lane }\end{array}$ & 30 & 2.794 & Adjusted & 0.133 \\
\hline $\begin{array}{l}\text { CUIB - RBMC } \\
\text { Cuiaba-PPTE - } \\
\text { RBMC Presidente } \\
\text { Prudente }\end{array}$ & 0.106 & 0.095 & 876276.053 & $\begin{array}{l}\text { Float,Wide } \\
\text { Lane }\end{array}$ & 30 & 2.921 & Adjusted & 0.142 \\
\hline
\end{tabular}

Figura B120: Elipses de Erro

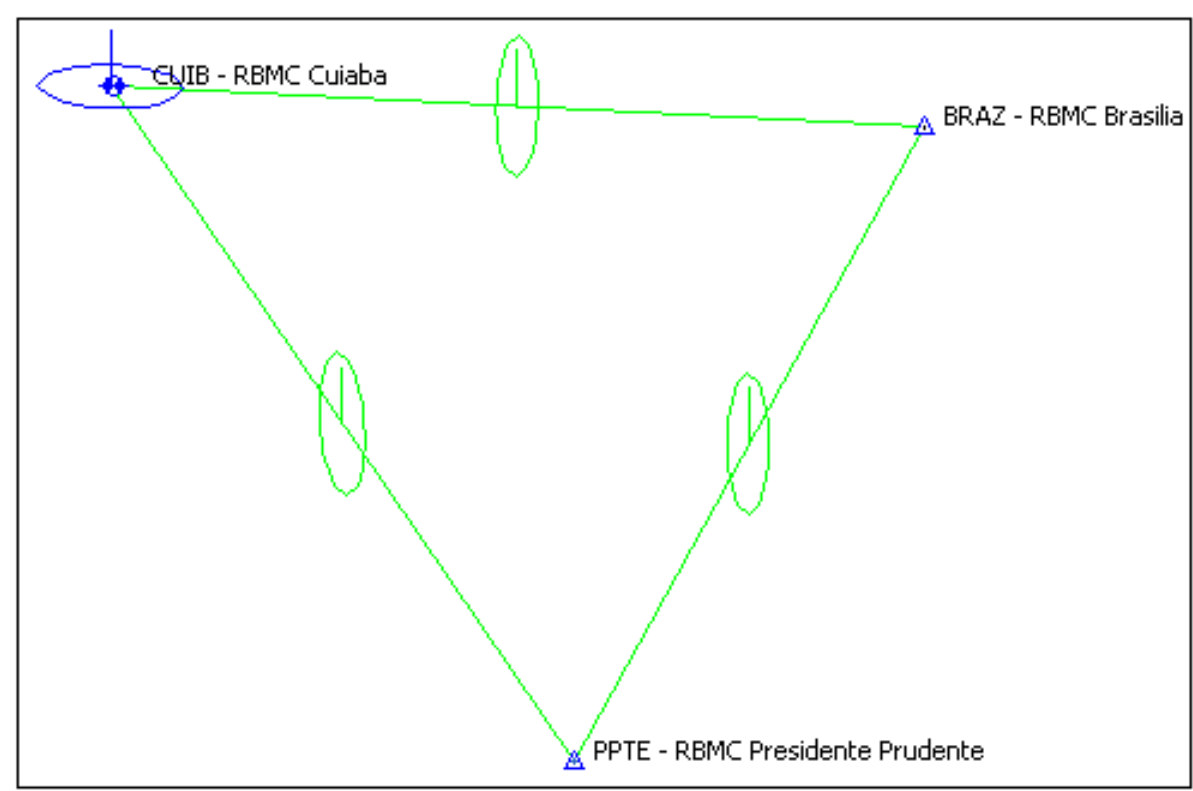

Coordenadas Ajustadas de CUIB:

E (UTM): $599737.3520 \mathrm{~m}$

N (UTM): $8280040.8438 \mathrm{~m}$

\section{B.3.2.3 Inverno (Dias Julianos 193 a 196)}

- $193 / 2007$

A posteriori UWE: 1.004317 , Bounds: ( $0.6770032,1.241639$ ) 
TABELA B121: Resultado do Processamento

\begin{tabular}{|c|c|c|c|c|c|c|c|c|}
\hline \multicolumn{9}{|c|}{ GPS Obs Report } \\
\hline Name & \begin{tabular}{|c} 
Horizontal \\
Precision (m)
\end{tabular} & $\begin{array}{c}\text { Vertical } \\
\text { Precision } \\
\text { (m) }\end{array}$ & $\begin{array}{l}\text { Distance } \\
\text { (m) }\end{array}$ & $\begin{array}{c}\text { Solution } \\
\text { Type }\end{array}$ & $\begin{array}{c}\text { GPS } \\
\text { Satellites }\end{array}$ & PDOP & Status & RMS \\
\hline \begin{tabular}{|l} 
BRAZ - RBMC \\
Brasilia-CUIB - \\
RBMC Cuiaba \\
\end{tabular} & 0.100 & 0.099 & 878314.349 & $\begin{array}{l}\text { Float,Wide } \\
\text { Lane }\end{array}$ & 30 & 2.863 & Adjusted & 0.141 \\
\hline $\begin{array}{l}\text { BRAZ - RBMC } \\
\text { Brasilia-PPTE - } \\
\text { RBMC Presidente } \\
\text { Prudente }\end{array}$ & 0.056 & 0.121 & 777286.871 & $\begin{array}{l}\text { Fixed,Wide } \\
\text { Lane }\end{array}$ & 30 & 2.887 & Adjusted & 0.134 \\
\hline $\begin{array}{l}\text { CUIB - RBMC } \\
\text { Cuiaba-PPTE - } \\
\text { RBMC Presidente } \\
\text { Prudente }\end{array}$ & 0.095 & 0.104 & 876276.029 & $\begin{array}{l}\text { Fixed,Wide } \\
\text { Lane }\end{array}$ & 30 & 2.918 & Adjusted & 0.141 \\
\hline
\end{tabular}

Figura B121: Elipses de Erro

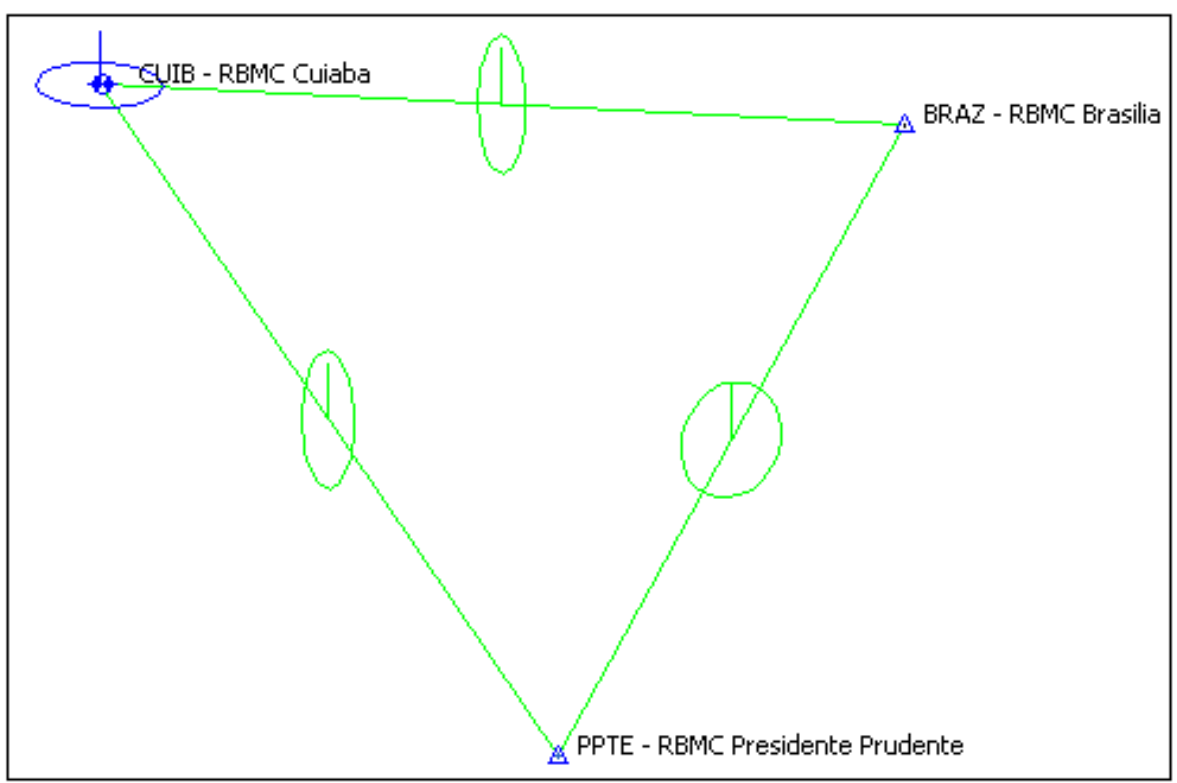

Coordenadas Ajustadas de CUIB:

E (UTM): $599737.3546 \mathrm{~m}$

N (UTM): $8280040.8407 \mathrm{~m}$

- $194 / 2007$

A posteriori UWE: 1.179601 , Bounds: ( $0.6770032,1.241639$ ) 
TABELA B122: Resultado do Processamento

\begin{tabular}{|c|c|c|c|c|c|c|c|c|}
\hline \multicolumn{9}{|c|}{ GPS Obs Report } \\
\hline Name & \begin{tabular}{|c} 
Horizontal \\
Precision (m)
\end{tabular} & $\begin{array}{l}\text { Vertical } \\
\text { Precision } \\
\text { (m) }\end{array}$ & $\begin{array}{l}\text { Distance } \\
\text { (m) }\end{array}$ & $\begin{array}{l}\text { Solution } \\
\text { Type }\end{array}$ & $\begin{array}{c}\text { GPS } \\
\text { Satellites }\end{array}$ & PDOP & Status & RMS \\
\hline $\begin{array}{l}\text { BRAZ - RBMC } \\
\text { Brasilia-CUIB - } \\
\text { RBMC Cuiaba } \\
\end{array}$ & 0.106 & 0.093 & 878314.359 & $\begin{array}{l}\text { Float,Wide } \\
\text { Lane }\end{array}$ & 30 & 2.864 & Adjusted & 0.141 \\
\hline $\begin{array}{l}\text { BRAZ - RBMC } \\
\text { Brasilia-PPTE - } \\
\text { RBMC Presidente } \\
\text { Prudente }\end{array}$ & 0.064 & 0.116 & 777286.890 & $\begin{array}{l}\text { Fixed,Wide } \\
\text { Lane }\end{array}$ & 30 & 2.890 & Adjusted & 0.132 \\
\hline $\begin{array}{l}\text { CUIB - RBMC } \\
\text { Cuiaba-PPTE - } \\
\text { RBMC Presidente } \\
\text { Prudente }\end{array}$ & 0.063 & 0.126 & 876276.046 & $\begin{array}{l}\text { Fixed,Wide } \\
\text { Lane }\end{array}$ & 30 & 2.921 & Adjusted & 0.141 \\
\hline
\end{tabular}

Figura B122: Elipses de Erro

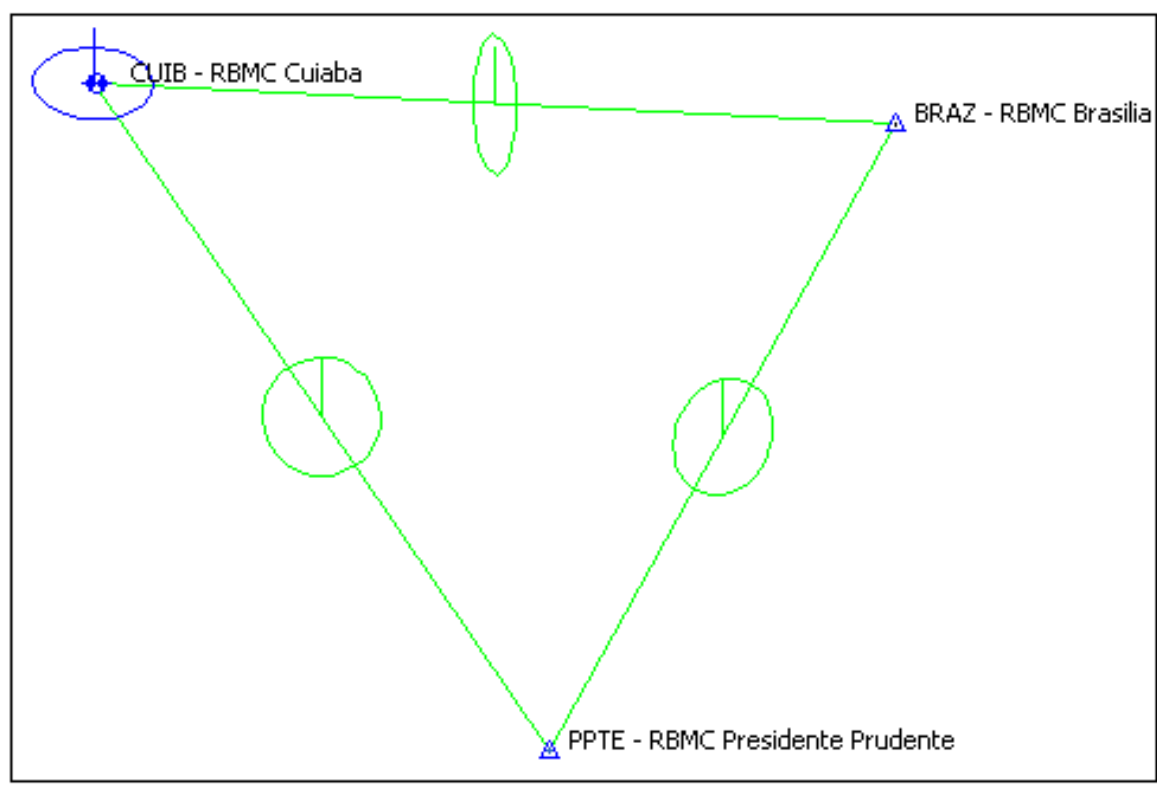

Coordenadas Ajustadas de CUIB:

E (UTM): $599737.3254 \mathrm{~m}$

N (UTM): $8280040.8289 \mathrm{~m}$

- $195 / 2007$

A posteriori UWE: 0.9244521 , Bounds: ( $0.6770032,1.241639)$ 
TABELA B123: Resultado do Processamento

\begin{tabular}{|c|c|c|c|c|c|c|c|c|}
\hline \multicolumn{9}{|c|}{ GPS Obs Report } \\
\hline Name & \begin{tabular}{|c} 
Horizontal \\
Precision (m)
\end{tabular} & $\begin{array}{c}\text { Vertical } \\
\text { Precision } \\
\text { (m) }\end{array}$ & $\begin{array}{l}\text { Distance } \\
\text { (m) }\end{array}$ & $\begin{array}{c}\text { Solution } \\
\text { Type }\end{array}$ & $\begin{array}{c}\text { GPS } \\
\text { Satellites }\end{array}$ & PDOP & Status & RMS \\
\hline \begin{tabular}{|l|} 
BRAZ - RBMC \\
Brasilia-CUIB - \\
RBMC Cuiaba \\
\end{tabular} & 0.105 & 0.094 & 878314.370 & $\begin{array}{l}\text { Float,Wide } \\
\text { Lane }\end{array}$ & 30 & 2.863 & Adjusted & 0.141 \\
\hline $\begin{array}{l}\text { BRAZ - RBMC } \\
\text { Brasilia-PPTE - } \\
\text { RBMC Presidente } \\
\text { Prudente } \\
\end{array}$ & 0.064 & 0.116 & 777286.901 & $\begin{array}{l}\text { Fixed,Wide } \\
\text { Lane }\end{array}$ & 30 & 2.891 & Adjusted & 0.132 \\
\hline $\begin{array}{l}\text { CUIB - RBMC } \\
\text { Cuiaba-PPTE - } \\
\text { RBMC Presidente } \\
\text { Prudente }\end{array}$ & 0.066 & 0.124 & 876276.025 & $\begin{array}{l}\text { Fixed,Wide } \\
\text { Lane }\end{array}$ & 30 & 2.922 & Adjusted & 0.141 \\
\hline
\end{tabular}

Figura B123: Elipses de Erro

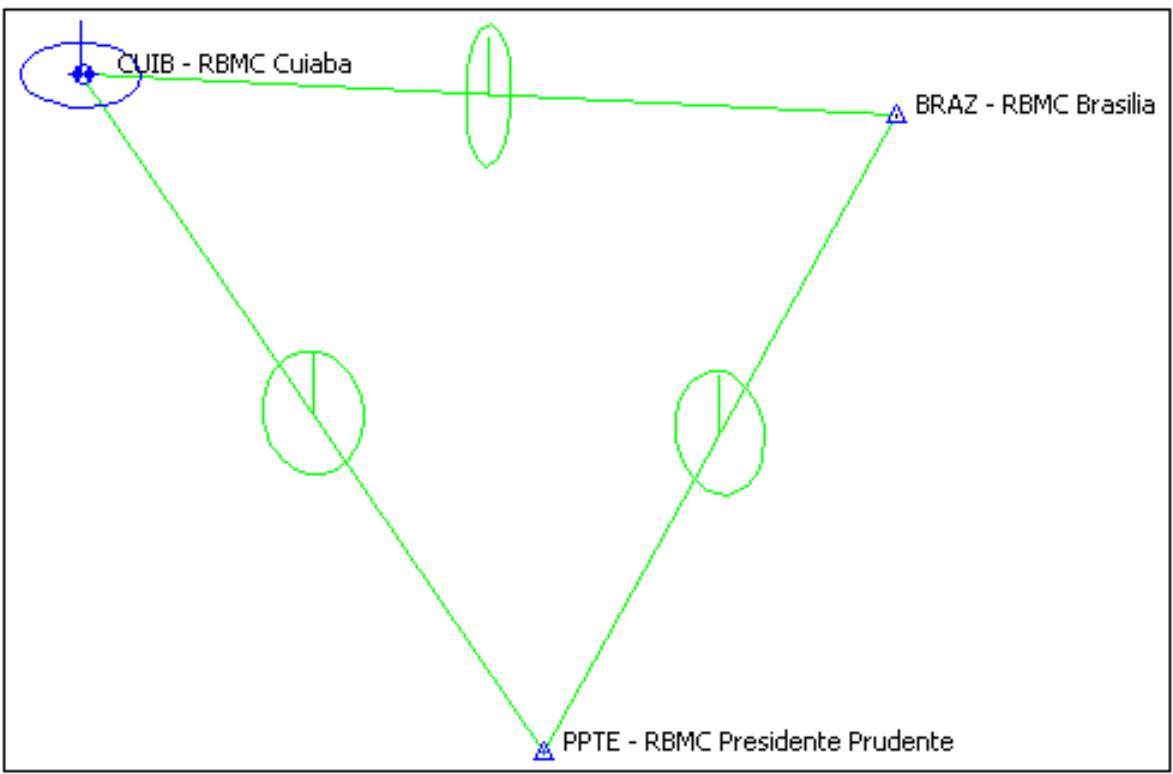

Coordenadas Ajustadas de CUIB:

E (UTM): $599737.3474 \mathrm{~m}$

N (UTM): $8280040.8322 \mathrm{~m}$

- $196 / 2007$

A posteriori UWE: 1.2209181 , Bounds: ( $0.6770032,1.241639$ ) 
TABELA B124: Resultado do Processamento

\begin{tabular}{|c|c|c|c|c|c|c|c|c|}
\hline \multicolumn{9}{|c|}{ GPS Obs Report } \\
\hline Name & \begin{tabular}{|c} 
Horizontal \\
Precision (m)
\end{tabular} & $\begin{array}{c}\text { Vertical } \\
\text { Precision } \\
\text { (m) }\end{array}$ & $\begin{array}{l}\text { Distance } \\
\text { (m) }\end{array}$ & $\begin{array}{c}\text { Solution } \\
\text { Type }\end{array}$ & $\begin{array}{c}\text { GPS } \\
\text { Satellites }\end{array}$ & PDOP & Status & RMS \\
\hline \begin{tabular}{|l|} 
BRAZ - RBMC \\
Brasilia-CUIB - \\
RBMC Cuiaba \\
\end{tabular} & 0.104 & 0.096 & 878314.358 & $\begin{array}{l}\text { Float,Wide } \\
\text { Lane }\end{array}$ & 30 & 2.862 & Adjusted & 0.141 \\
\hline $\begin{array}{l}\text { BRAZ - RBMC } \\
\text { Brasilia-PPTE - } \\
\text { RBMC Presidente } \\
\text { Prudente } \\
\end{array}$ & 0.068 & 0.114 & 777286.886 & $\begin{array}{l}\text { Fixed,Wide } \\
\text { Lane }\end{array}$ & 30 & 2.890 & Adjusted & 0.133 \\
\hline $\begin{array}{l}\text { CUIB - RBMC } \\
\text { Cuiaba-PPTE - } \\
\text { RBMC Presidente } \\
\text { Prudente }\end{array}$ & 0.075 & 0.119 & 876276.037 & $\begin{array}{l}\text { Fixed,Wide } \\
\text { Lane }\end{array}$ & 30 & 2.920 & Adjusted & 0.141 \\
\hline
\end{tabular}

Figura B124: Elipses de Erro

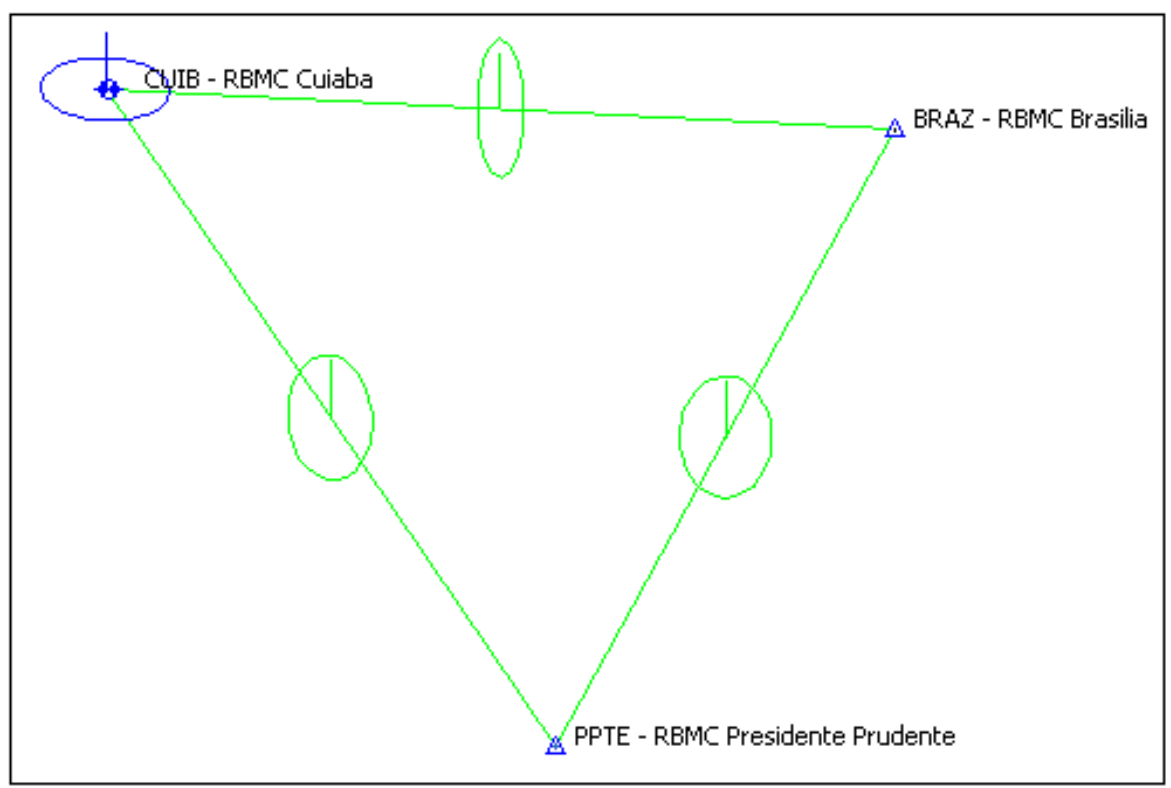

Coordenadas Ajustadas de CUIB:

E (UTM): $599737.3373 \mathrm{~m}$

N (UTM): $8280040.8341 \mathrm{~m}$

\section{B.3.2.4 Primavera (Dias Julianos 286 a 289)}

- $286 / 2007$

A posteriori UWE: 0.8597406 , Bounds: $(0.6770032,1.241639)$ 
TABELA B125: Resultado do Processamento

\begin{tabular}{|c|c|c|c|c|c|c|c|c|}
\hline \multicolumn{9}{|c|}{ GPS Obs Report } \\
\hline Name & $\begin{array}{c}\text { Horizontal } \\
\text { Precision (m) }\end{array}$ & $\begin{array}{l}\text { Vertical } \\
\text { Precision } \\
\text { (m) }\end{array}$ & $\begin{array}{l}\text { Distance } \\
\text { (m) }\end{array}$ & $\begin{array}{l}\text { Solution } \\
\text { Type }\end{array}$ & $\begin{array}{c}\text { GPS } \\
\text { Satellites }\end{array}$ & PDOP & Status & RMS \\
\hline $\begin{array}{l}\text { BRAZ - } \\
\text { Brasilia-CUIB - } \\
\text { Cuiaba } \\
\end{array}$ & 0.105 & 0.094 & 878314.394 & $\begin{array}{l}\text { Fixed,Wide } \\
\text { Lane }\end{array}$ & 30 & 2.839 & Adjusted & 0.141 \\
\hline $\begin{array}{l}\text { BRAZ - } \\
\text { Brasilia-PPTE - } \\
\text { Presidente Prudente }\end{array}$ & 0.093 & 0.095 & 777286.941 & $\begin{array}{l}\text { Float,Wide } \\
\text { Lane }\end{array}$ & 30 & 2.933 & Adjusted & 0.133 \\
\hline $\begin{array}{l}\text { CUIB - } \\
\text { Cuiaba-PPTE - } \\
\text { Presidente Prudente }\end{array}$ & 0.101 & 0.101 & 876276.076 & $\begin{array}{l}\text { Float,Wide } \\
\text { Lane }\end{array}$ & 30 & 2.969 & Adjusted & 0.142 \\
\hline
\end{tabular}

Figura B125: Elipses de Erro

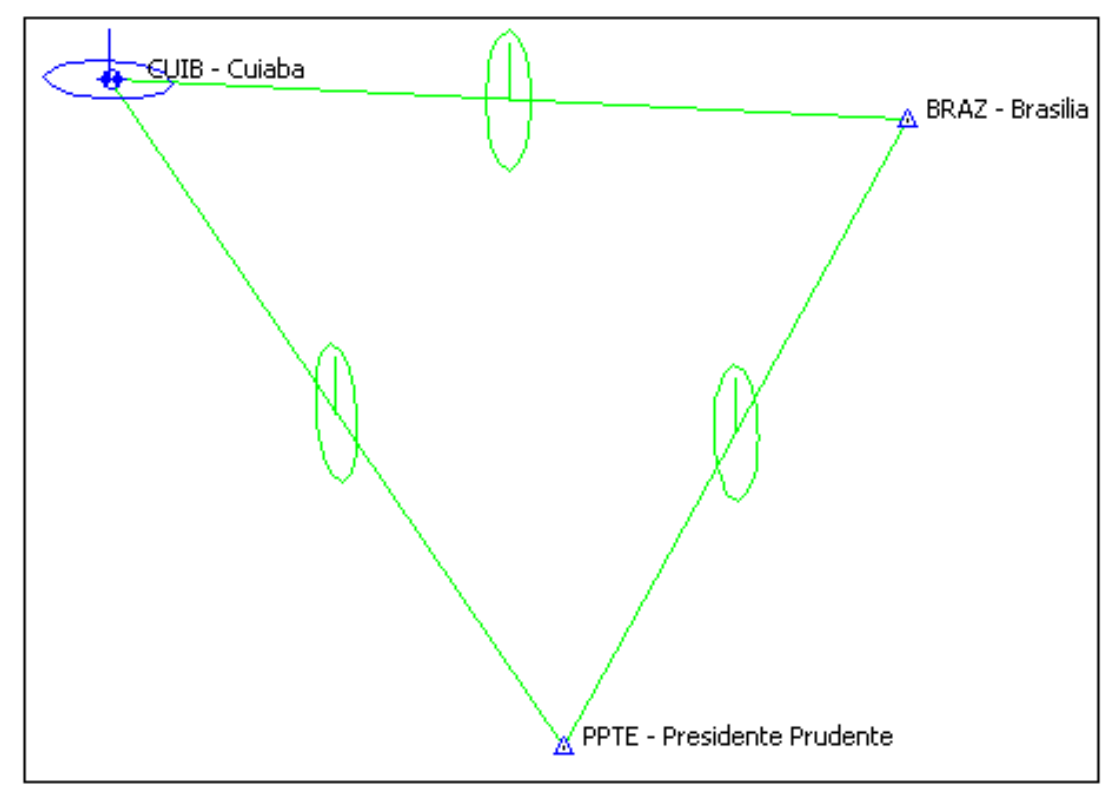

Coordenadas Ajustadas de CUIB:

E (UTM): $599737.3495 \mathrm{~m}$

N (UTM): $8280040.8838 \mathrm{~m}$

- $\underline{287 / 2007}$

A posteriori UWE: 0.9445755 , Bounds: ( $0.6770032,1.241639)$ 
TABELA B126: Resultado do Processamento

\begin{tabular}{|c|c|c|c|c|c|c|c|c|}
\hline \multicolumn{9}{|c|}{ GPS Obs Report } \\
\hline Name & $\begin{array}{c}\text { Horizontal } \\
\text { Precision (m) }\end{array}$ & $\begin{array}{l}\text { Vertical } \\
\text { Precision } \\
\text { (m) }\end{array}$ & $\begin{array}{l}\text { Distance } \\
\text { (m) }\end{array}$ & $\begin{array}{c}\text { Solution } \\
\text { Type }\end{array}$ & $\begin{array}{c}\text { GPS } \\
\text { Satellites }\end{array}$ & PDOP & Status & RMS \\
\hline $\begin{array}{l}\text { BRAZ - } \\
\text { Brasilia-CUIB - } \\
\text { Cuiaba } \\
\end{array}$ & 0.107 & 0.092 & 878314.436 & $\begin{array}{l}\text { Float,Wide } \\
\text { Lane }\end{array}$ & 30 & 2.839 & Adjusted & 0.141 \\
\hline $\begin{array}{l}\text { BRAZ - } \\
\text { Brasilia-PPTE - } \\
\text { Presidente Prudente }\end{array}$ & 0.097 & 0.091 & 777286.935 & $\begin{array}{l}\text { Float,Wide } \\
\text { Lane }\end{array}$ & 30 & 2.935 & Adjusted & 0.132 \\
\hline $\begin{array}{l}\text { CUIB - } \\
\text { Cuiaba-PPTE - } \\
\text { Presidente Prudente }\end{array}$ & 0.091 & 0.111 & 876276.066 & $\begin{array}{l}\text { Fixed,Wide } \\
\text { Lane }\end{array}$ & 30 & 2.970 & Adjusted & 0.143 \\
\hline
\end{tabular}

Figura B126: Elipses de Erro

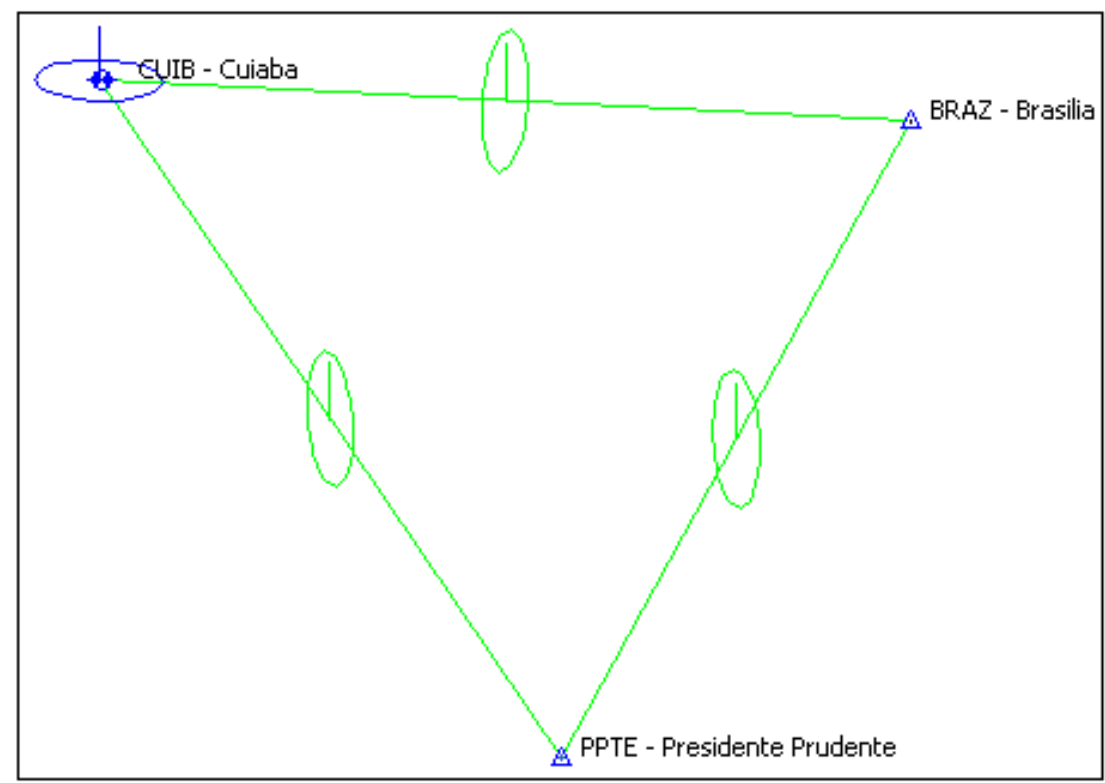

Coordenadas Ajustadas de CUIB:

E (UTM): $599737.3214 \mathrm{~m}$

N (UTM): $8280040.8630 \mathrm{~m}$

- $\underline{288 / 2007}$

A posteriori UWE: 0.9975834 , Bounds: ( $0.6770032,1.241639$ ) 
TABELA B127: Resultado do Processamento

\begin{tabular}{|c|c|c|c|c|c|c|c|c|}
\hline \multicolumn{9}{|c|}{ GPS Obs Report } \\
\hline Name & $\begin{array}{c}\text { Horizontal } \\
\text { Precision (m) }\end{array}$ & $\begin{array}{l}\text { Vertical } \\
\text { Precision } \\
\text { (m) }\end{array}$ & $\begin{array}{l}\text { Distance } \\
\text { (m) }\end{array}$ & $\begin{array}{l}\text { Solution } \\
\text { Type }\end{array}$ & $\begin{array}{c}\text { GPS } \\
\text { Satellites }\end{array}$ & PDOP & Status & RMS \\
\hline $\begin{array}{l}\text { BRAZ - } \\
\text { Brasilia-CUIB - } \\
\text { Cuiaba } \\
\end{array}$ & 0.090 & 0.109 & 878314.394 & $\begin{array}{l}\text { Fixed,Wide } \\
\text { Lane }\end{array}$ & 30 & 2.840 & Adjusted & 0.141 \\
\hline $\begin{array}{l}\text { BRAZ - } \\
\text { Brasilia-PPTE - } \\
\text { Presidente Prudente }\end{array}$ & 0.093 & 0.095 & 777286.914 & $\begin{array}{l}\text { Float,Wide } \\
\text { Lane }\end{array}$ & 30 & 2.934 & Adjusted & 0.133 \\
\hline $\begin{array}{l}\text { CUIB - } \\
\text { Cuiaba-PPTE - } \\
\text { Presidente Prudente }\end{array}$ & 0.100 & 0.101 & 876276.071 & $\begin{array}{l}\text { Float,Wide } \\
\text { Lane }\end{array}$ & 30 & 2.968 & Adjusted & 0.142 \\
\hline
\end{tabular}

Figura B127: Elipses de Erro

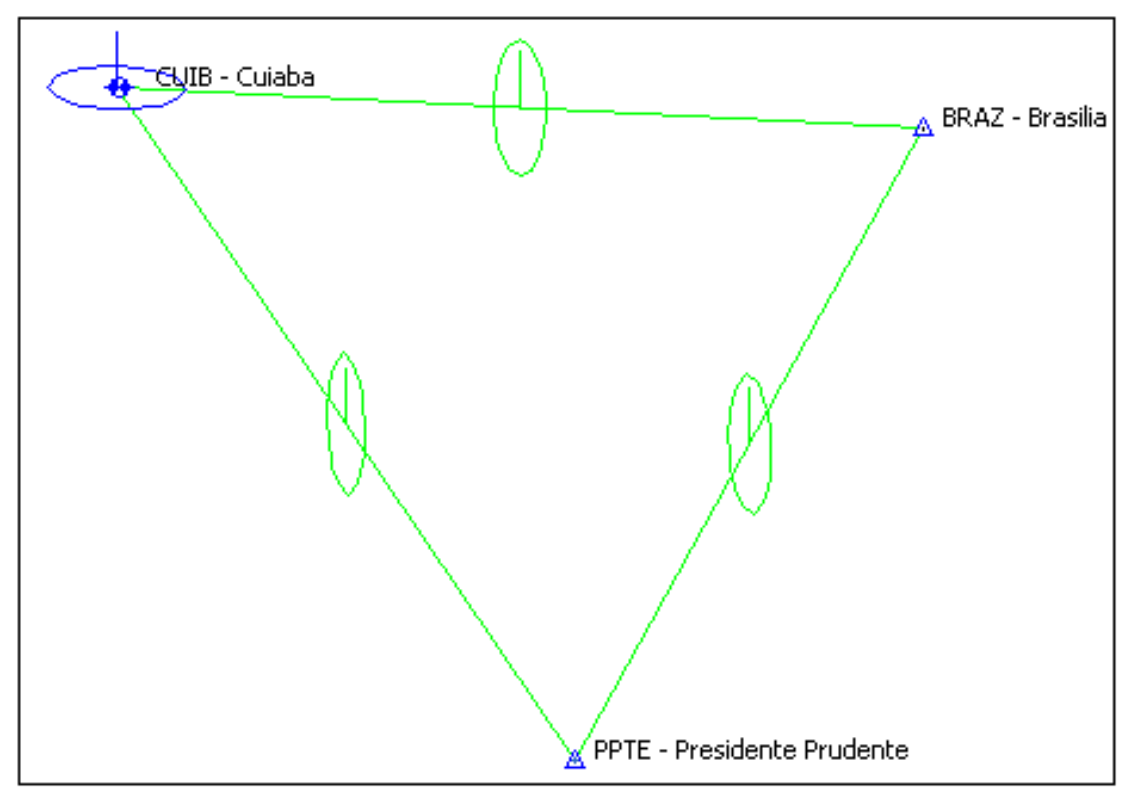

Coordenadas Ajustadas de CUIB:

E (UTM): $599737.3225 \mathrm{~m}$

N (UTM): $8280040.8507 \mathrm{~m}$

- $289 / 2007$

A posteriori UWE: 1.1776875 , Bounds: ( $0.6770032,1.241639)$ 
TABELA B128: Resultado do Processamento

\begin{tabular}{|c|c|c|c|c|c|c|c|c|}
\hline \multicolumn{9}{|c|}{ GPS Obs Report } \\
\hline Name & $\begin{array}{l}\text { Horizontal } \\
\text { Precision (m) }\end{array}$ & $\begin{array}{c}\text { Vertical } \\
\text { Precision } \\
\text { (m) }\end{array}$ & $\begin{array}{l}\text { Distance } \\
\text { (m) }\end{array}$ & $\begin{array}{c}\text { Solution } \\
\text { Type }\end{array}$ & $\begin{array}{c}\text { GPS } \\
\text { Satellites }\end{array}$ & PDOP & Status & RMS \\
\hline $\begin{array}{l}\text { BRAZ - } \\
\text { Brasilia-CUIB - } \\
\text { Cuiaba }\end{array}$ & 0.101 & 0.099 & 878314.410 & $\begin{array}{l}\text { Float,Wide } \\
\text { Lane }\end{array}$ & 30 & 2.840 & Adjusted & 0.141 \\
\hline $\begin{array}{l}\text { BRAZ - } \\
\text { Brasilia-PPTE - } \\
\text { Presidente Prudente }\end{array}$ & 0.097 & 0.093 & 777286.935 & \begin{tabular}{l|l} 
Float,Wide \\
Lane
\end{tabular} & 30 & 2.934 & Adjusted & 0.135 \\
\hline $\begin{array}{l}\text { CUIB - } \\
\text { Cuiaba-PPTE - } \\
\text { Presidente Prudente }\end{array}$ & 0.101 & 0.100 & 876276.073 & $\begin{array}{l}\text { Float,Wide } \\
\text { Lane }\end{array}$ & 30 & 2.966 & Adjusted & 0.142 \\
\hline
\end{tabular}

Figura B128: Elipses de Erro

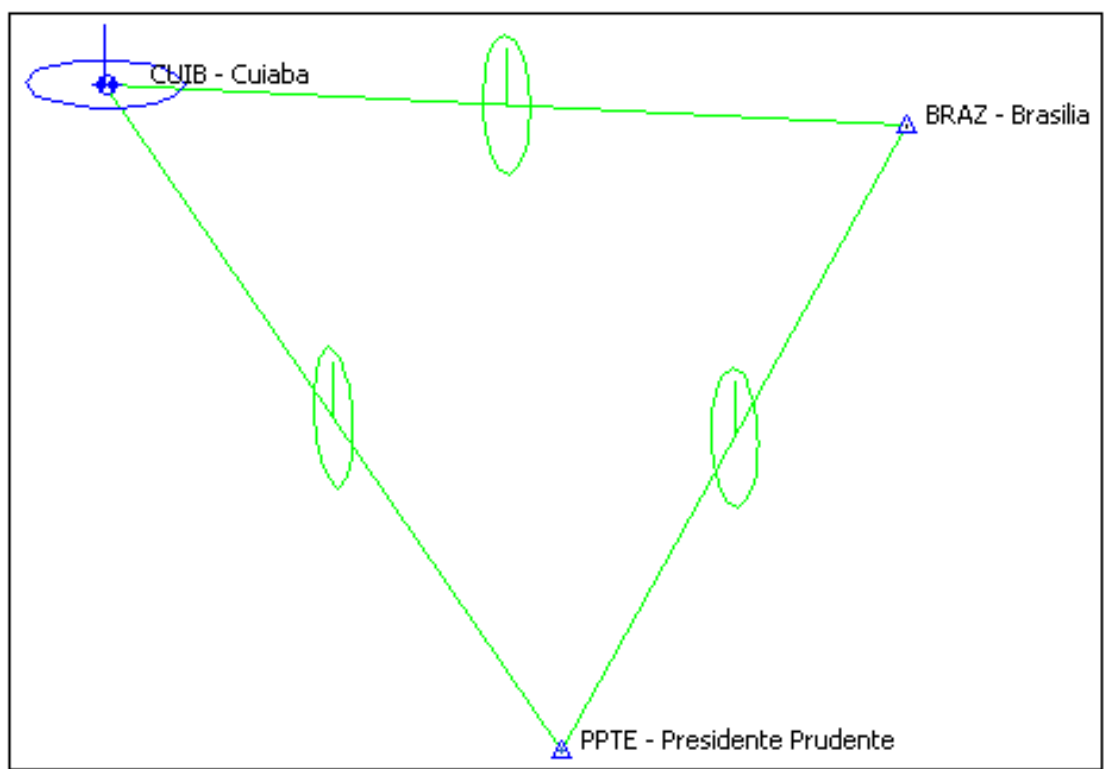

Coordenadas Ajustadas de CUIB:

E (UTM): $599737.3208 \mathrm{~m}$

N (UTM): $8280040.8649 \mathrm{~m}$

\section{B.3.3 2008}

B.3.3.1 Verão (Dias Julianos 011 a 014) 
- $\underline{011 / 2008}$

A posteriori UWE: 1.1967204 , Bounds: ( $0.6770032,1.241639$ )

TABELA B129: Resultado do Processamento

\begin{tabular}{|c|c|c|c|c|c|c|c|c|}
\hline \multicolumn{9}{|c|}{ GPS Obs Report } \\
\hline Name & $\begin{array}{c}\text { Horizontal } \\
\text { Precision (m) }\end{array}$ & $\begin{array}{c}\text { Vertical } \\
\text { Precision } \\
(\mathbf{m}) \\
\end{array}$ & $\begin{array}{c}\text { Distance } \\
\text { (m) }\end{array}$ & $\begin{array}{l}\text { Solution } \\
\text { Type }\end{array}$ & $\begin{array}{c}\text { GPS } \\
\text { Satellites }\end{array}$ & PDOP & Status & RMS \\
\hline $\begin{array}{l}\text { BRAZ - } \\
\text { Brasilia-CUIB - } \\
\text { Cuiaba }\end{array}$ & 0.090 & 0.109 & 878314.415 & $\begin{array}{l}\text { Fixed,Wide } \\
\text { Lane }\end{array}$ & 30 & 2.893 & Adjusted & 0.141 \\
\hline $\begin{array}{l}\text { BRAZ - } \\
\text { Brasilia-PPTE - } \\
\text { Presidente Prudente }\end{array}$ & 0.090 & 0.098 & 777286.973 & $\begin{array}{l}\text { Float,Wide } \\
\text { Lane }\end{array}$ & 30 & 2.890 & Adjusted & 0.133 \\
\hline $\begin{array}{l}\text { CUIB - } \\
\text { Cuiaba-PPTE - } \\
\text { Presidente Prudente }\end{array}$ & 0.095 & 0.105 & 876276.106 & $\begin{array}{l}\text { Float,Wide } \\
\text { Lane }\end{array}$ & 30 & 2.961 & Adjusted & 0.141 \\
\hline
\end{tabular}

Figura B129: Elipses de Erro

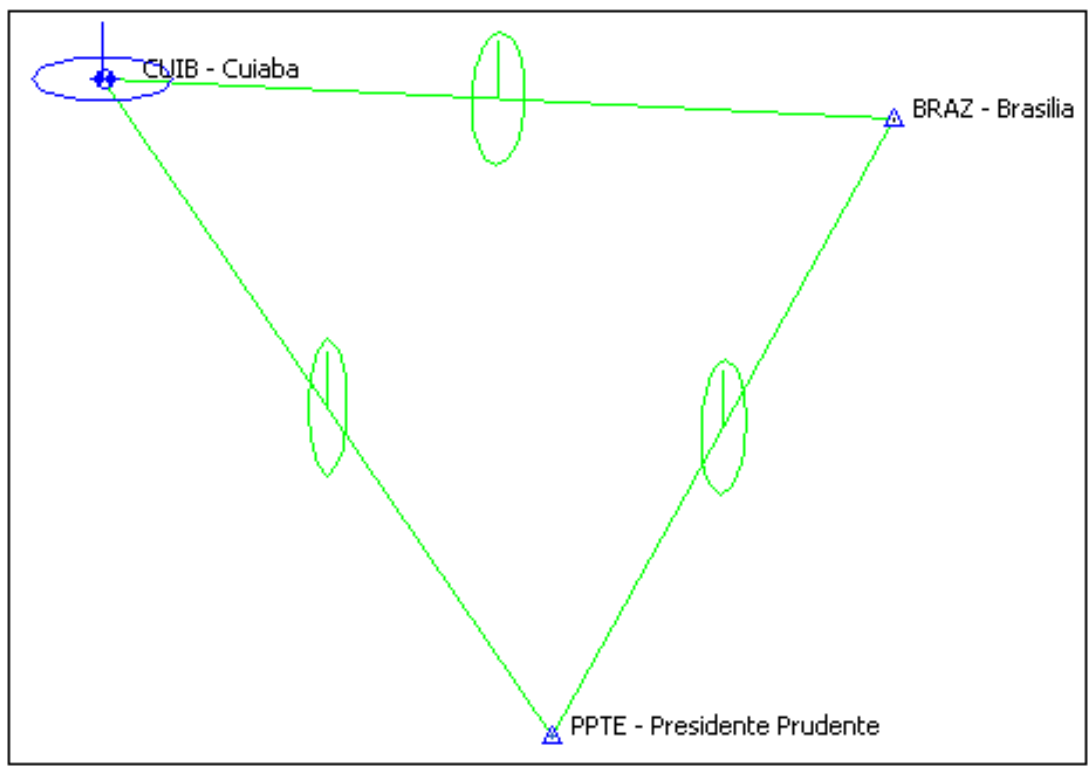

Coordenadas Ajustadas de CUIB:

E (UTM): $599737.2866 \mathrm{~m}$ 
N (UTM): $8280040.8755 \mathrm{~m}$

- $\underline{012 / 2008}$

A posteriori UWE: 0.8657473 , Bounds: ( $0.6770032,1.241639)$

TABELA B130: Resultado do Processamento

\begin{tabular}{|c|c|c|c|c|c|c|c|c|}
\hline \multicolumn{9}{|c|}{ GPS Obs Report } \\
\hline Name & \begin{tabular}{|c} 
Horizontal \\
Precision (m)
\end{tabular} & $\begin{array}{l}\text { Vertical } \\
\text { Precision } \\
\text { (m) }\end{array}$ & $\begin{array}{l}\text { Distance } \\
\text { (m) }\end{array}$ & $\begin{array}{c}\text { Solution } \\
\text { Type }\end{array}$ & $\begin{array}{c}\text { GPS } \\
\text { Satellites }\end{array}$ & PDOP & Status & RMS \\
\hline $\begin{array}{l}\text { BRAZ - } \\
\text { Brasilia-CUIB - } \\
\text { Cuiaba }\end{array}$ & 0.096 & 0.104 & 878314.426 & $\begin{array}{l}\text { Fixed,Wide } \\
\text { Lane }\end{array}$ & 30 & 2.896 & Adjusted & 0.141 \\
\hline $\begin{array}{l}\text { BRAZ - } \\
\text { Brasilia-PPTE - } \\
\text { Presidente Prudente }\end{array}$ & 0.088 & 0.101 & 777286.950 & $\begin{array}{l}\text { Float,Wide } \\
\text { Lane }\end{array}$ & 30 & 2.892 & Adjusted & 0.134 \\
\hline $\begin{array}{l}\text { CUIB - } \\
\text { Cuiaba-PPTE - } \\
\text { Presidente Prudente }\end{array}$ & 0.092 & 0.107 & 876276.091 & $\begin{array}{l}\text { Float,Wide } \\
\text { Lane }\end{array}$ & 30 & 2.962 & Adjusted & 0.141 \\
\hline
\end{tabular}

Figura B130: Elipses de Erro

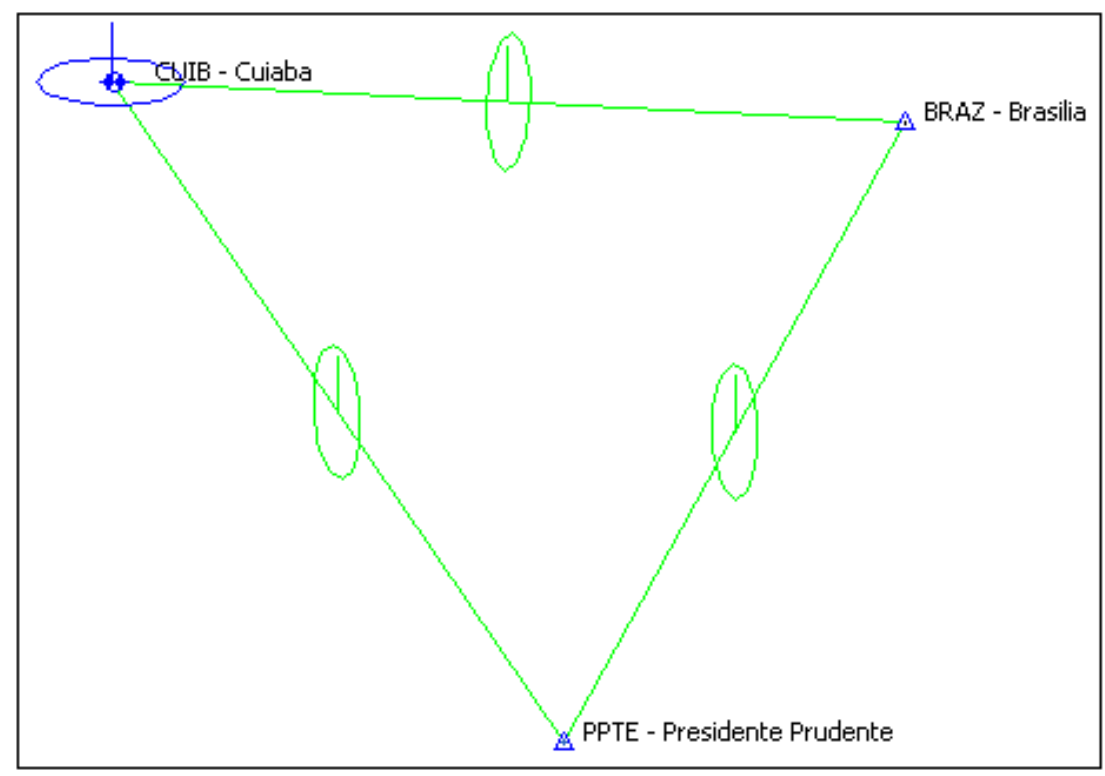

Coordenadas Ajustadas de CUIB:

E (UTM): $599737.3097 \mathrm{~m}$ 
N (UTM): $8280040.8502 \mathrm{~m}$

- $\underline{013 / 2008}$

A posteriori UWE: 1.2378761 , Bounds: ( $0.6770032,1.241639$ )

TABELA B131: Resultado do Processamento

\begin{tabular}{|c|c|c|c|c|c|c|c|c|}
\hline \multicolumn{9}{|c|}{ GPS Obs Report } \\
\hline Name & \begin{tabular}{|c} 
Horizontal \\
Precision (m)
\end{tabular} & $\begin{array}{l}\text { Vertical } \\
\text { Precision } \\
\text { (m) }\end{array}$ & $\begin{array}{l}\text { Distance } \\
\text { (m) }\end{array}$ & $\begin{array}{c}\text { Solution } \\
\text { Type }\end{array}$ & $\begin{array}{c}\text { GPS } \\
\text { Satellites }\end{array}$ & PDOP & Status & RMS \\
\hline $\begin{array}{l}\text { BRAZ - } \\
\text { Brasilia-CUIB - } \\
\text { Cuiaba }\end{array}$ & 0.106 & 0.094 & 878314.432 & $\begin{array}{l}\text { Float, Wide } \\
\text { Lane }\end{array}$ & 30 & 2.901 & Adjusted & 0.141 \\
\hline $\begin{array}{l}\text { BRAZ - } \\
\text { Brasilia-PPTE - } \\
\text { Presidente Prudente }\end{array}$ & 0.092 & 0.097 & 777286.927 & $\begin{array}{l}\text { Float, Wide } \\
\text { Lane }\end{array}$ & 30 & 2.895 & Adjusted & 0.134 \\
\hline $\begin{array}{l}\text { CUIB - } \\
\text { Cuiaba-PPTE - } \\
\text { Presidente Prudente }\end{array}$ & 0.098 & 0.112 & 876276.083 & $\begin{array}{l}\text { Float,Wide } \\
\text { Lane }\end{array}$ & 30 & 2.966 & Adjusted & 0.149 \\
\hline
\end{tabular}

Figura B131: Elipses de Erro

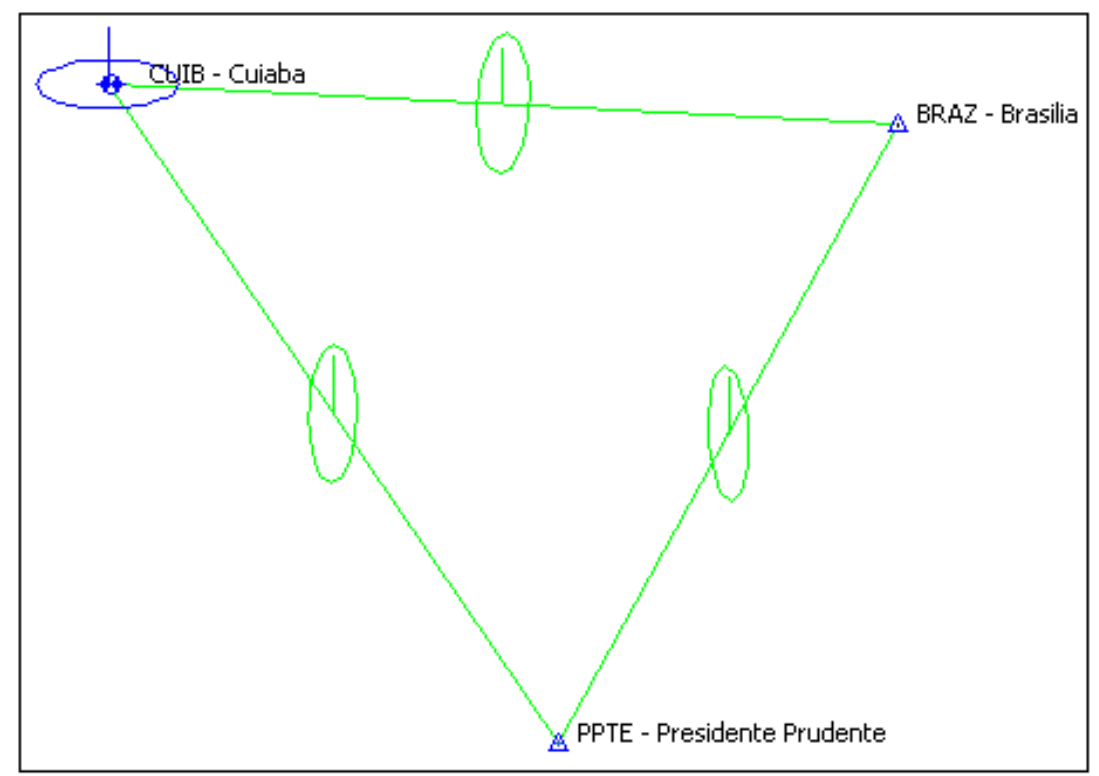

Coordenadas Ajustadas de CUIB:

E (UTM): $599737.2832 \mathrm{~m}$ 
N (UTM): $8280040.8540 \mathrm{~m}$

- $\underline{014 / 2008}$

A posteriori UWE: 1.225202 , Bounds: ( $0.6770032,1.241639$ )

TABELA B132: Resultado do Processamento

\begin{tabular}{|c|c|c|c|c|c|c|c|c|}
\hline \multicolumn{9}{|c|}{ GPS Obs Report } \\
\hline Name & \begin{tabular}{|c} 
Horizontal \\
Precision (m)
\end{tabular} & $\begin{array}{l}\text { Vertical } \\
\text { Precision } \\
\text { (m) }\end{array}$ & $\begin{array}{l}\text { Distance } \\
\text { (m) }\end{array}$ & $\begin{array}{c}\text { Solution } \\
\text { Type }\end{array}$ & $\begin{array}{c}\text { GPS } \\
\text { Satellites }\end{array}$ & PDOP & Status & RMS \\
\hline $\begin{array}{l}\text { BRAZ - } \\
\text { Brasilia-CUIB - } \\
\text { Cuiaba }\end{array}$ & 0.101 & 0.099 & 878314.438 & $\begin{array}{l}\mid \begin{array}{l}\text { Float,Wide } \\
\text { Lane }\end{array} \\
\text { lan }\end{array}$ & 30 & 2.905 & Adjusted & 0.142 \\
\hline $\begin{array}{l}\text { BRAZ - } \\
\text { Brasilia-PPTE - } \\
\text { Presidente Prudente }\end{array}$ & 0.073 & 0.110 & 777286.947 & \begin{tabular}{|l} 
Fixed,Wide \\
Lane
\end{tabular} & 30 & 2.898 & Adjusted & 0.133 \\
\hline $\begin{array}{l}\text { CUIB - } \\
\text { Cuiaba-PPTE - } \\
\text { Presidente Prudente }\end{array}$ & 0.093 & 0.109 & 876276.091 & \begin{tabular}{|l}
$\mid \begin{array}{l}\text { Float,Wide } \\
\text { Lane }\end{array}$ \\
lat
\end{tabular} & 30 & 2.969 & Adjusted & 0.143 \\
\hline
\end{tabular}

Figura B132: Elipses de Erro

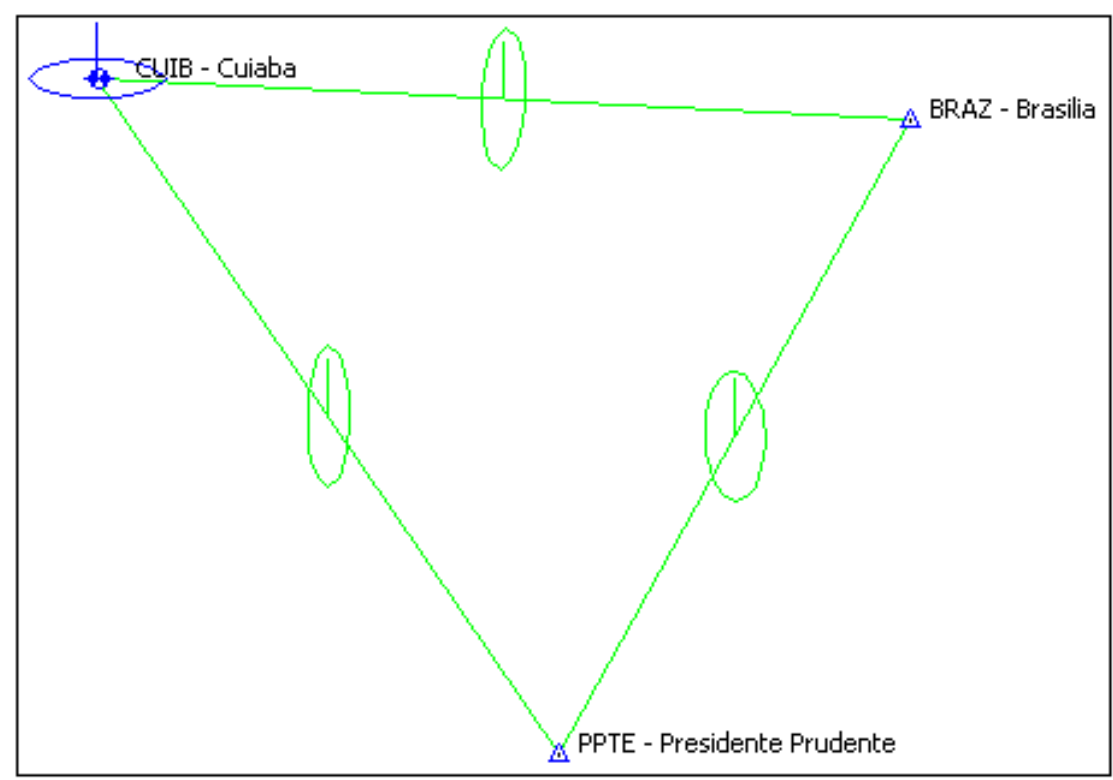

Coordenadas Ajustadas de CUIB:

E (UTM): $599737.3032 \mathrm{~m}$ 
N (UTM): $8280040.8745 \mathrm{~m}$

\section{B.3.3.2 Outono (Dias Julianos 102 a 105)}

- $102 / 2008$

A posteriori UWE: 0.859926 , Bounds: ( $0.6770032,1.241639$ )

TABELA B133: Resultado do Processamento

\begin{tabular}{|c|c|c|c|c|c|c|c|c|}
\hline \multicolumn{9}{|c|}{ GPS Obs Report } \\
\hline Name & $\mid \begin{array}{c}\text { Horizontal } \\
\text { Precision }(\mathbf{m})\end{array}$ & $\begin{array}{c}\text { Vertical } \\
\text { Precision } \\
(\mathbf{m})\end{array}$ & $\begin{array}{l}\text { Distance } \\
\text { (m) }\end{array}$ & $\begin{array}{l}\text { Solution } \\
\text { Type }\end{array}$ & $\begin{array}{c}\text { GPS } \\
\text { Satellites }\end{array}$ & PDOP & Status & RMS \\
\hline $\begin{array}{l}\text { BRAZ - } \\
\text { Brasilia-CUIB - } \\
\text { Cuiaba }\end{array}$ & 0.100 & 0.100 & 878314.408 & \begin{tabular}{l|l} 
Float,Wide \\
Lane
\end{tabular} & 31 & 2.961 & Adjusted & 0.141 \\
\hline $\begin{array}{l}\text { BRAZ - } \\
\text { Brasilia-PPTE - } \\
\text { Presidente Prudente }\end{array}$ & 0.093 & 0.096 & 777286.917 & $\begin{array}{l}\mid \begin{array}{l}\text { Float,Wide } \\
\text { Lane }\end{array} \\
\text { | }\end{array}$ & 31 & 2.848 & Adjusted & 0.133 \\
\hline $\begin{array}{l}\text { CUIB - } \\
\text { Cuiaba-PPTE - } \\
\text { Presidente Prudente }\end{array}$ & 0.093 & 0.106 & 876276.057 & \begin{tabular}{l|l} 
& Float,Wide \\
Lane
\end{tabular} & |31 & 2.905 & Adjusted & 0.141 \\
\hline
\end{tabular}

Figura B133: Elipses de Erro

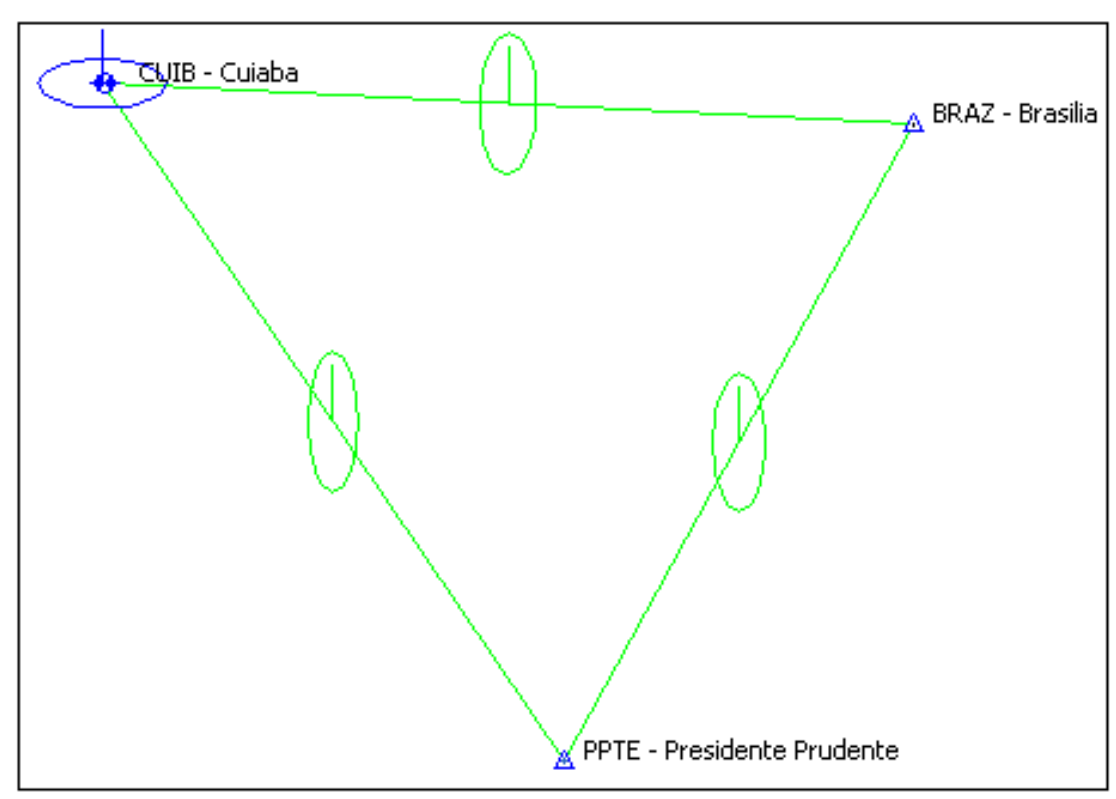

Coordenadas Ajustadas de CUIB:

E (UTM): $599737.3249 \mathrm{~m}$ 
N (UTM): $8280040.8565 \mathrm{~m}$

- $103 / 2008$

A posteriori UWE: 0.7947232 , Bounds: ( $0.6770032,1.241639)$

TABELA B134: Resultado do Processamento

\begin{tabular}{|c|c|c|c|c|c|c|c|c|}
\hline \multicolumn{9}{|c|}{ GPS Obs Report } \\
\hline Name & \begin{tabular}{|c} 
Horizontal \\
Precision (m)
\end{tabular} & $\begin{array}{l}\text { Vertical } \\
\text { Precision } \\
\text { (m) }\end{array}$ & $\begin{array}{l}\text { Distance } \\
\text { (m) }\end{array}$ & $\begin{array}{c}\text { Solution } \\
\text { Type }\end{array}$ & $\begin{array}{c}\text { GPS } \\
\text { Satellites }\end{array}$ & PDOP & Status & RMS \\
\hline $\begin{array}{l}\text { BRAZ - } \\
\text { Brasilia-CUIB - } \\
\text { Cuiaba }\end{array}$ & 0.100 & 0.098 & 878314.382 & $\begin{array}{l}\text { Float, Wide } \\
\text { Lane }\end{array}$ & 31 & 2.954 & Adjusted & 0.141 \\
\hline $\begin{array}{l}\text { BRAZ - } \\
\text { Brasilia-PPTE - } \\
\text { Presidente Prudente }\end{array}$ & 0.090 & 0.098 & 777286.908 & $\begin{array}{l}\text { Float, Wide } \\
\text { Lane }\end{array}$ & 31 & 2.855 & Adjusted & 0.133 \\
\hline $\begin{array}{l}\text { CUIB - } \\
\text { Cuiaba-PPTE - } \\
\text { Presidente Prudente }\end{array}$ & 0.090 & 0.109 & 876276.058 & $\begin{array}{l}\text { Float,Wide } \\
\text { Lane }\end{array}$ & 31 & 2.909 & Adjusted & 0.141 \\
\hline
\end{tabular}

Figura B134: Elipses de Erro

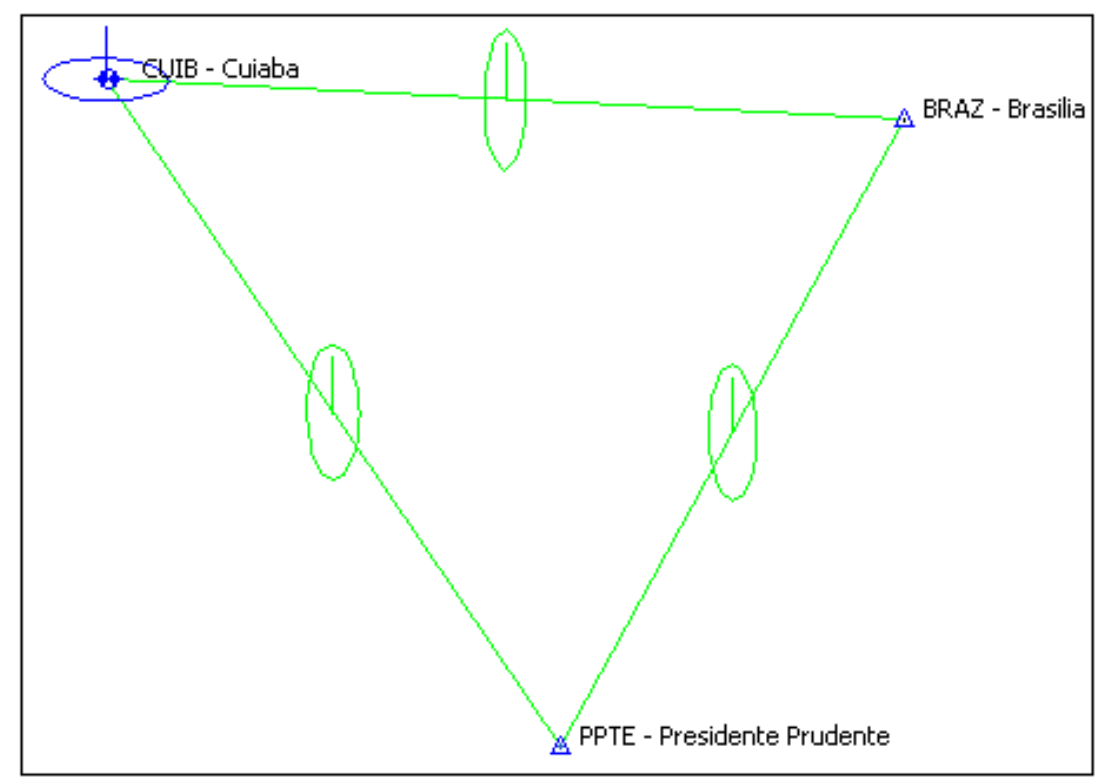

Coordenadas Ajustadas de CUIB:

E (UTM): $599737.3482 \mathrm{~m}$ 
- $104 / 2008$

A posteriori UWE: 0.695451 , Bounds: ( $0.6770032,1.241639$ )

TABELA B135: Resultado do Processamento

\begin{tabular}{|c|c|c|c|c|c|c|c|c|}
\hline \multicolumn{9}{|c|}{ GPS Obs Report } \\
\hline Name & \begin{tabular}{|c} 
Horizontal \\
Precision (m)
\end{tabular} & $\begin{array}{l}\text { Vertical } \\
\text { Precision } \\
\text { (m) }\end{array}$ & $\begin{array}{l}\text { Distance } \\
\text { (m) }\end{array}$ & $\begin{array}{c}\text { Solution } \\
\text { Type }\end{array}$ & $\begin{array}{c}\text { GPS } \\
\text { Satellites }\end{array}$ & PDOP & Status & RMS \\
\hline $\begin{array}{l}\text { BRAZ - } \\
\text { Brasilia-CUIB - } \\
\text { Cuiaba }\end{array}$ & 0.101 & 0.099 & 878314.398 & $\begin{array}{l}\text { Float, Wide } \\
\text { Lane }\end{array}$ & 31 & 2.945 & Adjusted & 0.141 \\
\hline $\begin{array}{l}\text { BRAZ - } \\
\text { Brasilia-PPTE - } \\
\text { Presidente Prudente }\end{array}$ & 0.089 & 0.098 & 777286.922 & $\begin{array}{l}\text { Float, Wide } \\
\text { Lane }\end{array}$ & 31 & 2.848 & Adjusted & 0.132 \\
\hline $\begin{array}{l}\text { CUIB - } \\
\text { Cuiaba-PPTE - } \\
\text { Presidente Prudente }\end{array}$ & 0.094 & 0.106 & 876276.065 & $\begin{array}{l}\text { Float,Wide } \\
\text { Lane }\end{array}$ & 31 & 2.904 & Adjusted & 0.142 \\
\hline
\end{tabular}

Figura B135: Elipses de Erro

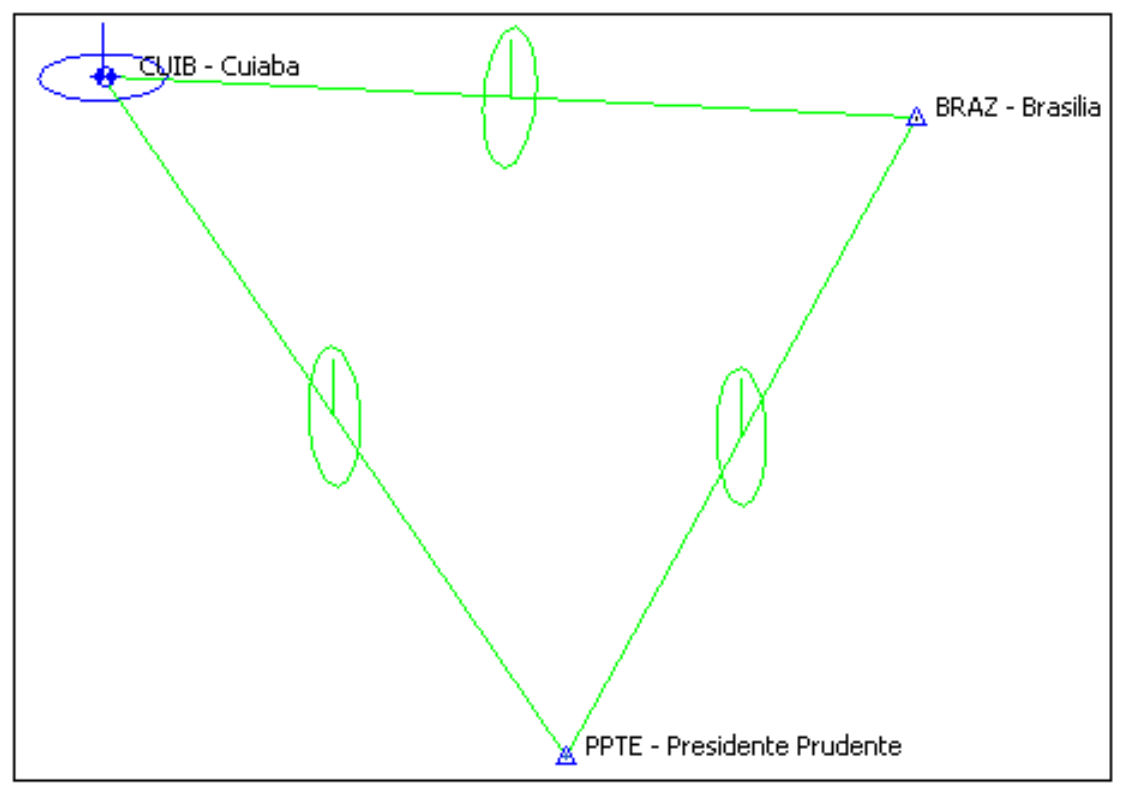

Coordenadas Ajustadas de CUIB:

E (UTM): $599737.3383 \mathrm{~m}$ 
N (UTM): $8280040.8583 \mathrm{~m}$

- $105 / 2008$

A posteriori UWE: 1.225202 , Bounds: ( $0.6770032,1.241639)$

TABELA B136: Resultado do Processamento

\begin{tabular}{|c|c|c|c|c|c|c|c|c|}
\hline \multicolumn{9}{|c|}{ GPS Obs Report } \\
\hline Name & \begin{tabular}{|c} 
Horizontal \\
Precision (m)
\end{tabular} & $\begin{array}{l}\text { Vertical } \\
\text { Precision } \\
\text { (m) }\end{array}$ & $\begin{array}{l}\text { Distance } \\
\text { (m) }\end{array}$ & $\begin{array}{c}\text { Solution } \\
\text { Type }\end{array}$ & $\begin{array}{c}\text { GPS } \\
\text { Satellites }\end{array}$ & PDOP & Status & RMS \\
\hline $\begin{array}{l}\text { BRAZ - } \\
\text { Brasilia-CUIB - } \\
\text { Cuiaba }\end{array}$ & 0.101 & 0.099 & 878314.438 & $\begin{array}{l}\mid \begin{array}{l}\text { Float,Wide } \\
\text { Lane }\end{array} \\
\text { lan }\end{array}$ & 30 & 2.905 & Adjusted & 0.142 \\
\hline $\begin{array}{l}\text { BRAZ - } \\
\text { Brasilia-PPTE - } \\
\text { Presidente Prudente }\end{array}$ & 0.073 & 0.110 & 777286.947 & \begin{tabular}{|l} 
Fixed,Wide \\
Lane
\end{tabular} & 30 & 2.898 & Adjusted & 0.133 \\
\hline $\begin{array}{l}\text { CUIB - } \\
\text { Cuiaba-PPTE - } \\
\text { Presidente Prudente }\end{array}$ & 0.093 & 0.109 & 876276.091 & \begin{tabular}{|l}
$\mid \begin{array}{l}\text { Float,Wide } \\
\text { Lane }\end{array}$ \\
lat
\end{tabular} & 30 & 2.969 & Adjusted & 0.143 \\
\hline
\end{tabular}

Figura B136: Elipses de Erro

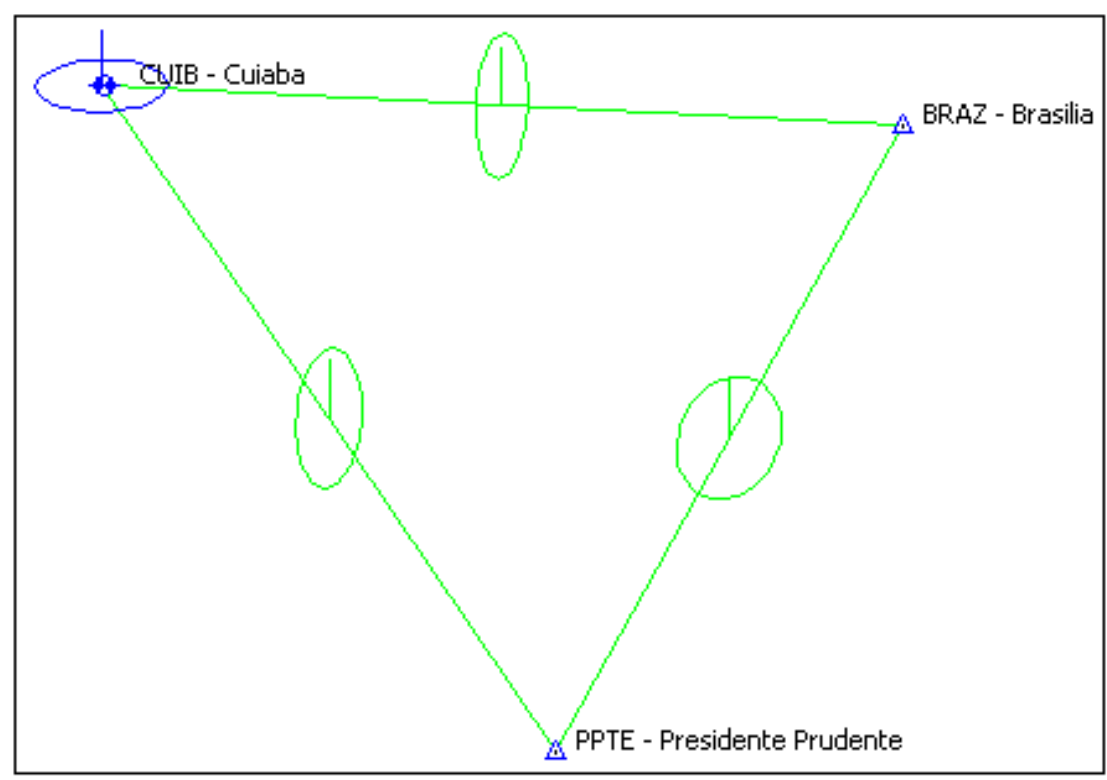

Coordenadas Ajustadas de CUIB:

E (UTM): $599737.3032 \mathrm{~m}$ 


\section{B.3.3.3 Inverno (Dias Julianos 194 a 197)}

- $\underline{194 / 2008}$

A posteriori UWE: 1.072395 , Bounds: ( $0.6770032,1.241639$ )

TABELA B137: Resultado do Processamento

\begin{tabular}{|c|c|c|c|c|c|c|c|c|}
\hline \multicolumn{9}{|c|}{ GPS Obs Report } \\
\hline Name & $\begin{array}{c}\text { Horizontal } \\
\text { Precision (m) }\end{array}$ & $\begin{array}{l}\text { Vertical } \\
\text { Precision } \\
\text { (m) }\end{array}$ & $\begin{array}{c}\text { Distance } \\
\text { (m) }\end{array}$ & $\begin{array}{c}\text { Solution } \\
\text { Type }\end{array}$ & $\begin{array}{c}\text { GPS } \\
\text { Satellites }\end{array}$ & PDOP & Status & RMS \\
\hline $\begin{array}{l}\text { BRAZ - } \\
\text { Brasilia-CUIB - } \\
\text { Cuiaba } \\
\end{array}$ & 0.068 & 0.123 & 878314.366 & $\begin{array}{l}\text { Fixed,Wide } \\
\text { Lane }\end{array}$ & 31 & 2.771 & Adjusted & 0.141 \\
\hline $\begin{array}{l}\text { BRAZ - } \\
\text { Brasilia-PPTE - } \\
\text { Presidente Prudente }\end{array}$ & 0.060 & 0.120 & 777286.891 & $\begin{array}{l}\text { Fixed,Wide } \\
\text { Lane }\end{array}$ & 31 & 2.747 & Adjusted & 0.134 \\
\hline $\begin{array}{l}\text { CUIB - } \\
\text { Cuiaba-PPTE - } \\
\text { Presidente Prudente }\end{array}$ & 0.063 & 0.125 & 876275.997 & $\begin{array}{l}\text { Fixed,Wide } \\
\text { Lane }\end{array}$ & 31 & 2.752 & Adjusted & 0.141 \\
\hline
\end{tabular}

Figura B137: Elipses de Erro

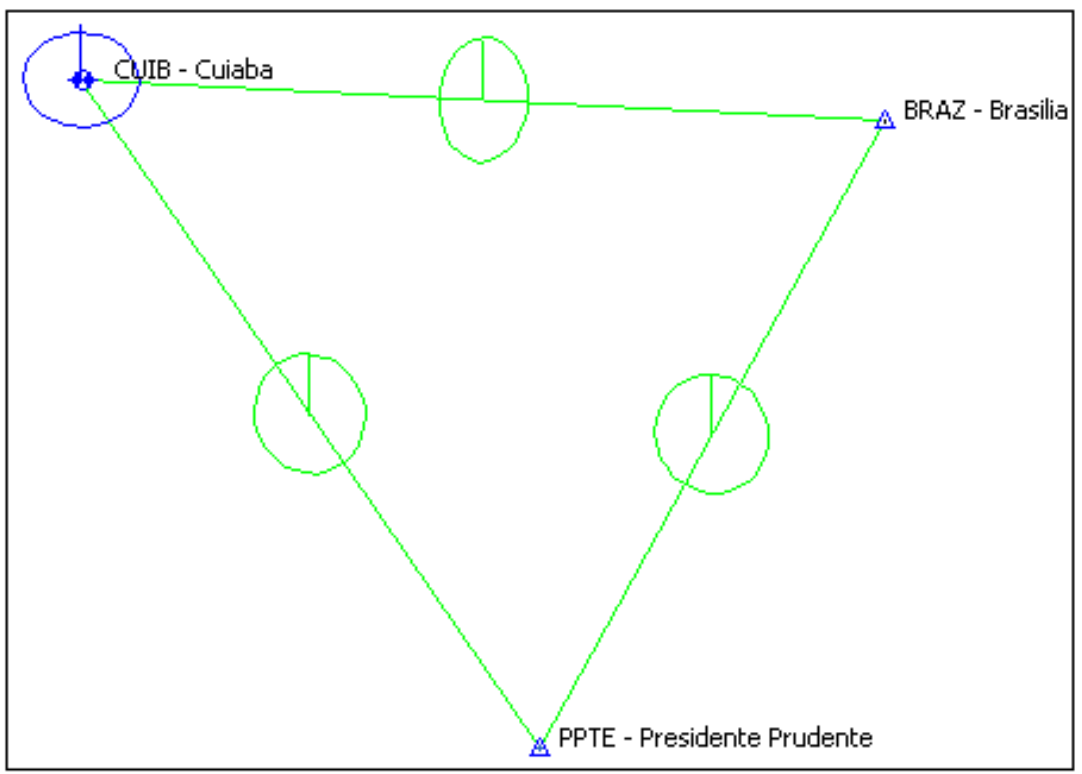

Coordenadas Ajustadas de CUIB:

E (UTM): $599737.3373 \mathrm{~m}$ 
N (UTM): $8280040.8301 \mathrm{~m}$

- $195 / 2008$

A posteriori UWE: 0.6845205 , Bounds: ( $0.6770032,1.241639)$

TABELA B138: Resultado do Processamento

\begin{tabular}{|c|c|c|c|c|c|c|c|c|}
\hline \multicolumn{9}{|c|}{ GPS Obs Report } \\
\hline Name & \begin{tabular}{|c} 
Horizontal \\
Precision (m)
\end{tabular} & $\begin{array}{l}\text { Vertical } \\
\text { Precision } \\
\text { (m) }\end{array}$ & $\begin{array}{l}\text { Distance } \\
\text { (m) }\end{array}$ & $\begin{array}{c}\text { Solution } \\
\text { Type }\end{array}$ & $\begin{array}{c}\text { GPS } \\
\text { Satellites }\end{array}$ & PDOP & Status & RMS \\
\hline $\begin{array}{l}\text { BRAZ - } \\
\text { Brasilia-CUIB - } \\
\text { Cuiaba }\end{array}$ & 0.098 & 0.101 & 878314.362 & $\begin{array}{l}\mid \begin{array}{l}\text { Float,Wide } \\
\text { Lane }\end{array} \\
\text { lan }\end{array}$ & 31 & 2.771 & Adjusted & 0.141 \\
\hline $\begin{array}{l}\text { BRAZ - } \\
\text { Brasilia-PPTE - } \\
\text { Presidente Prudente }\end{array}$ & 0.066 & 0.115 & 777286.874 & \begin{tabular}{|l} 
Fixed,Wide \\
Lane
\end{tabular} & 31 & 2.760 & Adjusted & 0.133 \\
\hline $\begin{array}{l}\text { CUIB - } \\
\text { Cuiaba-PPTE - } \\
\text { Presidente Prudente }\end{array}$ & 0.096 & 0.102 & 876275.973 & \begin{tabular}{|l}
$\mid \begin{array}{l}\text { Float,Wide } \\
\text { Lane }\end{array}$ \\
lat
\end{tabular} & 31 & 2.781 & Adjusted & 0.141 \\
\hline
\end{tabular}

Figura B138: Elipses de Erro

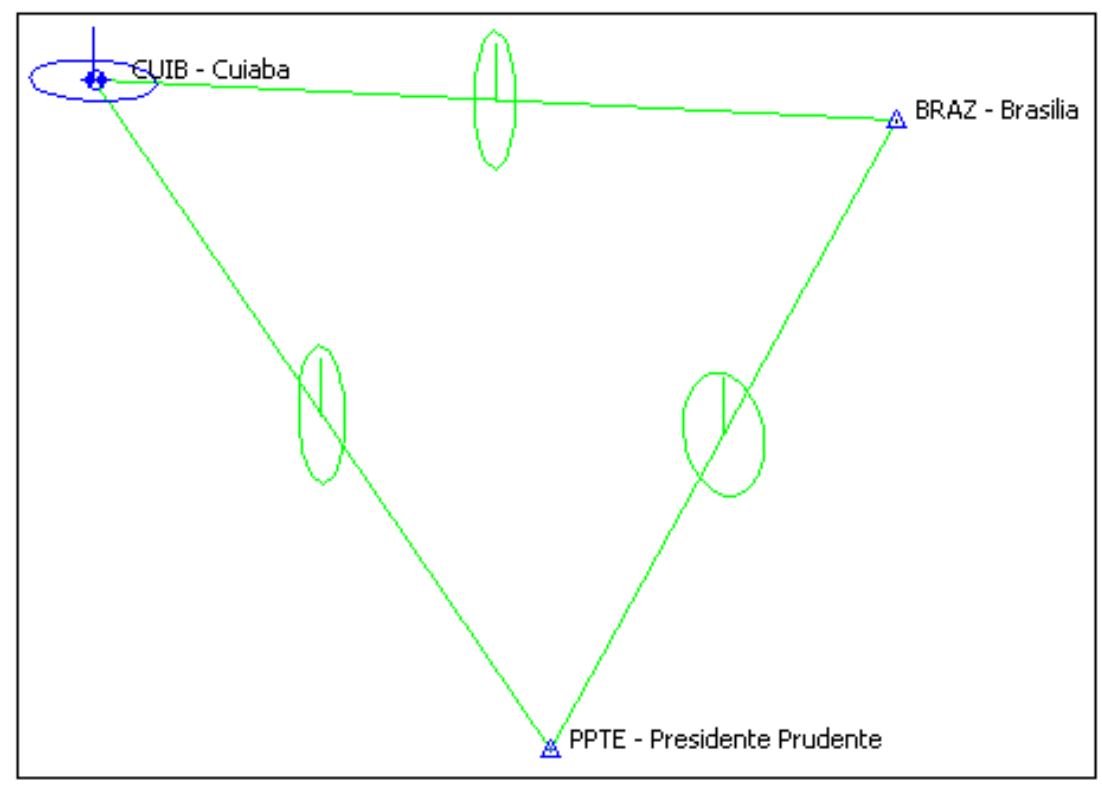

Coordenadas Ajustadas de CUIB:

E (UTM): $599737.3758 \mathrm{~m}$ 
N (UTM): $8280040.8360 \mathrm{~m}$

- $196 / 2008$

A posteriori UWE: 1.005475 , Bounds: ( $0.6770032,1.241639$ )

TABELA B139: Resultado do Processamento

\begin{tabular}{|c|c|c|c|c|c|c|c|c|}
\hline \multicolumn{9}{|c|}{ GPS Obs Report } \\
\hline Name & \begin{tabular}{|c} 
Horizontal \\
Precision (m)
\end{tabular} & $\begin{array}{l}\text { Vertical } \\
\text { Precision } \\
\text { (m) }\end{array}$ & $\begin{array}{l}\text { Distance } \\
\text { (m) }\end{array}$ & $\begin{array}{c}\text { Solution } \\
\text { Type }\end{array}$ & $\begin{array}{c}\text { GPS } \\
\text { Satellites }\end{array}$ & PDOP & Status & RMS \\
\hline $\begin{array}{l}\text { BRAZ - } \\
\text { Brasilia-CUIB - } \\
\text { Cuiaba }\end{array}$ & 0.088 & 0.110 & 878314.373 & $\begin{array}{l}\text { Fixed,Wide } \\
\text { Lane }\end{array}$ & 31 & 2.771 & Adjusted & 0.141 \\
\hline $\begin{array}{l}\text { BRAZ - } \\
\text { Brasilia-PPTE - } \\
\text { Presidente Prudente }\end{array}$ & 0.065 & 0.116 & 777286.857 & $\begin{array}{l}\text { Fixed,Wide } \\
\text { Lane }\end{array}$ & 31 & 2.758 & Adjusted & 0.132 \\
\hline $\begin{array}{l}\text { CUIB - } \\
\text { Cuiaba-PPTE - } \\
\text { Presidente Prudente }\end{array}$ & 0.065 & 0.125 & 876275.996 & $\begin{array}{l}\text { Fixed,Wide } \\
\text { Lane }\end{array}$ & 31 & 2.778 & Adjusted & 0.141 \\
\hline
\end{tabular}

Figura B139: Elipses de Erro

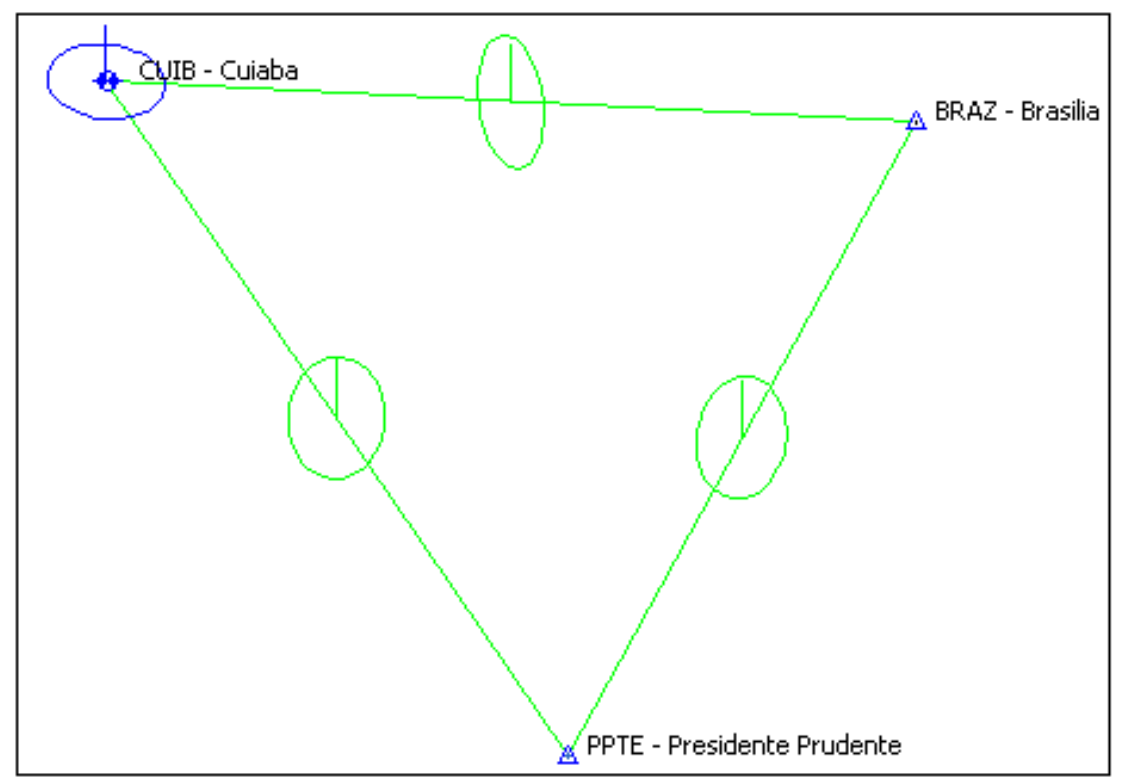

Coordenadas Ajustadas de CUIB:

E (UTM): $599737.3441 \mathrm{~m}$ 
N (UTM): $8280040.8236 \mathrm{~m}$

- $197 / 2008$

A posteriori UWE: 1.2167854 , Bounds: ( $0.6770032,1.241639$ )

TABELA B140: Resultado do Processamento

\begin{tabular}{|c|c|c|c|c|c|c|c|c|}
\hline \multicolumn{9}{|c|}{ GPS Obs Report } \\
\hline Name & \begin{tabular}{|c} 
Horizontal \\
Precision (m)
\end{tabular} & $\begin{array}{l}\text { Vertical } \\
\text { Precision } \\
\text { (m) }\end{array}$ & $\begin{array}{l}\text { Distance } \\
\text { (m) }\end{array}$ & $\begin{array}{c}\text { Solution } \\
\text { Type }\end{array}$ & $\begin{array}{c}\text { GPS } \\
\text { Satellites }\end{array}$ & PDOP & Status & RMS \\
\hline $\begin{array}{l}\text { BRAZ - } \\
\text { Brasilia-CUIB - } \\
\text { Cuiaba }\end{array}$ & 0.101 & 0.098 & 878314.352 & $\begin{array}{l}\text { Float,Wide } \\
\text { Lane }\end{array}$ & 31 & 2.771 & Adjusted & 0.141 \\
\hline $\begin{array}{l}\text { BRAZ - } \\
\text { Brasilia-PPTE - } \\
\text { Presidente Prudente }\end{array}$ & 0.057 & 0.122 & 777286.869 & $\begin{array}{l}\text { Fixed,Wide } \\
\text { Lane }\end{array}$ & 31 & 2.758 & Adjusted & 0.134 \\
\hline $\begin{array}{l}\text { CUIB - } \\
\text { Cuiaba-PPTE - } \\
\text { Presidente Prudente }\end{array}$ & 0.064 & 0.125 & 876275.993 & $\begin{array}{l}\text { Fixed,Wide } \\
\text { Lane }\end{array}$ & 31 & 2.778 & Adjusted & 0.141 \\
\hline
\end{tabular}

Figura B140: Elipses de Erro

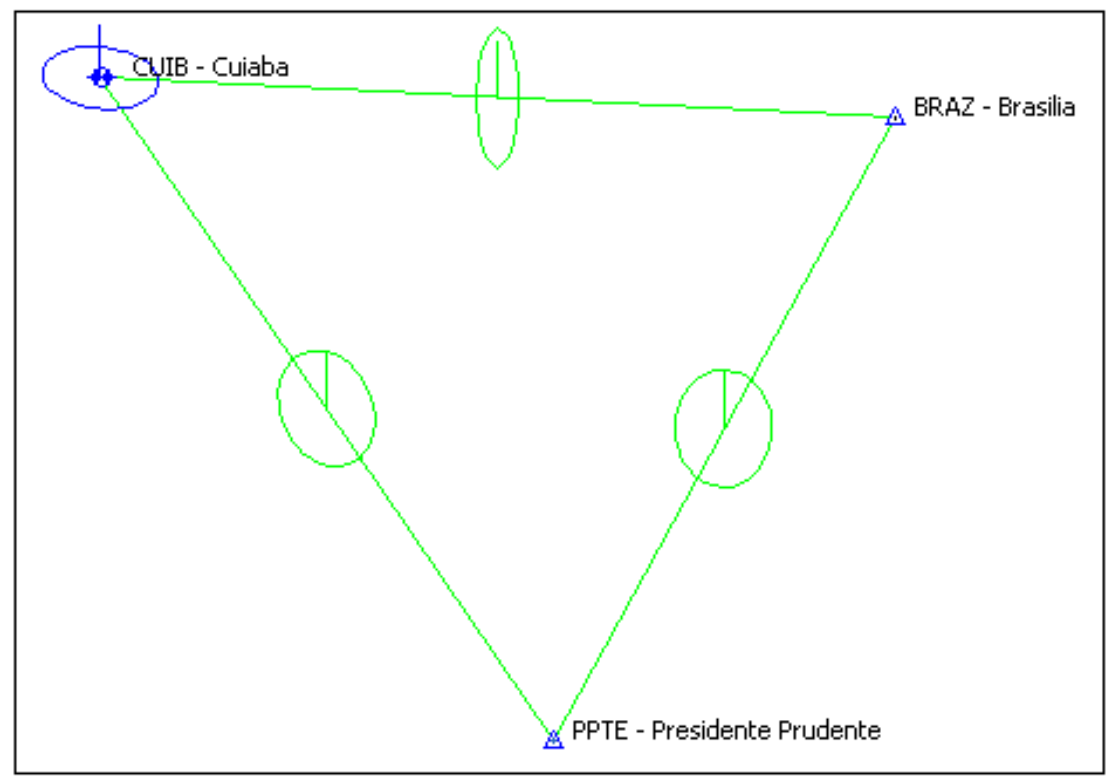

Coordenadas Ajustadas de CUIB:

E (UTM): $599737.3423 \mathrm{~m}$ 
N (UTM): $8280040.8242 \mathrm{~m}$

\section{B.3.3.4 Primavera (Dias Julianos 287 a 290)}

- $287 / 2008$

A posteriori UWE: 0.6974601 , Bounds: ( $0.6770032,1.241639)$

TABELA B141: Resultado do Processamento

\begin{tabular}{|c|c|c|c|c|c|c|c|c|}
\hline \multicolumn{9}{|c|}{ GPS Obs Report } \\
\hline Name & $\begin{array}{c}\text { Horizontal } \\
\text { Precision (m) } \\
\end{array}$ & \begin{tabular}{|c|} 
Vertical \\
Precision $(m)$ \\
\end{tabular} & \begin{tabular}{|c|}
$\begin{array}{c}\text { Distance } \\
(\mathbf{m})\end{array}$ \\
\end{tabular} & $\begin{array}{c}\text { Solution } \\
\text { Type }\end{array}$ & $\begin{array}{c}\text { GPS } \\
\text { Satellites } \\
\end{array}$ & PDOP & Status & RMS \\
\hline BRAZ-CUIB & 0.099 & 0.101 & 878314.416 & $\begin{array}{l}\text { Float,Wide } \\
\text { Lane }\end{array}$ & 31 & 2.740 & Adjusted & 0.141 \\
\hline BRAZ-PPTE & 0.092 & 0.096 & 777286.912 & $\begin{array}{l}\text { Float,Wide } \\
\text { Lane }\end{array}$ & 31 & 2.717 & Adjusted & 0.133 \\
\hline CUIB-PPTE & $\mid 0.092$ & 0.106 & 876276.054 & $\begin{array}{l}\text { Float,Wide } \\
\text { Lane }\end{array}$ & 31 & 2.727 & Adjusted & 0.141 \\
\hline
\end{tabular}

Figura B141: Elipses de Erro

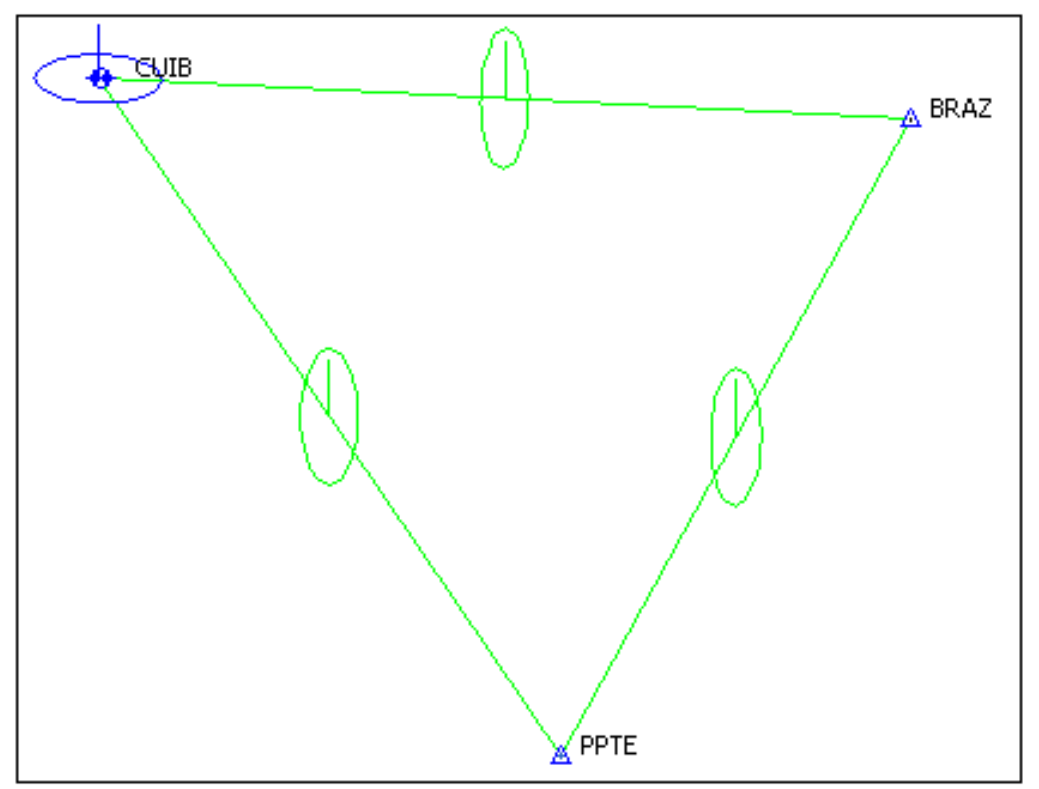

Coordenadas Ajustadas de CUIB:

E (UTM): $599737.3159 \mathrm{~m}$ 
N (UTM): $8280040.8492 \mathrm{~m}$

- $\underline{288 / 2008}$

A posteriori UWE: 1.058914 , Bounds: ( $0.6770032,1.241639$ )

TABELA B142: Resultado do Processamento

\begin{tabular}{|c|c|c|c|c|c|c|c|c|}
\hline \multicolumn{9}{|c|}{ GPS Obs Report } \\
\hline Name & $\begin{array}{c}\text { Horizontal } \\
\text { Precision (m) }\end{array}$ & \begin{tabular}{|c|} 
Vertical \\
Precision $(m)$
\end{tabular} & \begin{tabular}{|c|} 
Distance \\
(m)
\end{tabular} & \begin{tabular}{|c} 
Solution \\
Type
\end{tabular} & $\begin{array}{c}\text { GPS } \\
\text { Satellites }\end{array}$ & PDOP & Status & RMS \\
\hline BRAZ-CUIB & 0.094 & 0.105 & 878314.384 & $\begin{array}{l}\text { Float, Wide } \\
\text { Lane }\end{array}$ & 31 & 2.740 & Adjusted & 0.141 \\
\hline BRAZ-PPTE & 0.089 & 0.098 & 777286.904 & $\begin{array}{l}\text { Float,Wide } \\
\text { Lane }\end{array}$ & 31 & 2.720 & Adjusted & 0.132 \\
\hline CUIB-PPTE & 0.096 & 0.103 & 876276.045 & $\begin{array}{l}\text { Float,Wide } \\
\text { Lane }\end{array}$ & 31 & 2.728 & Adjusted & 0.141 \\
\hline
\end{tabular}

Figura B142: Elipses de Erro

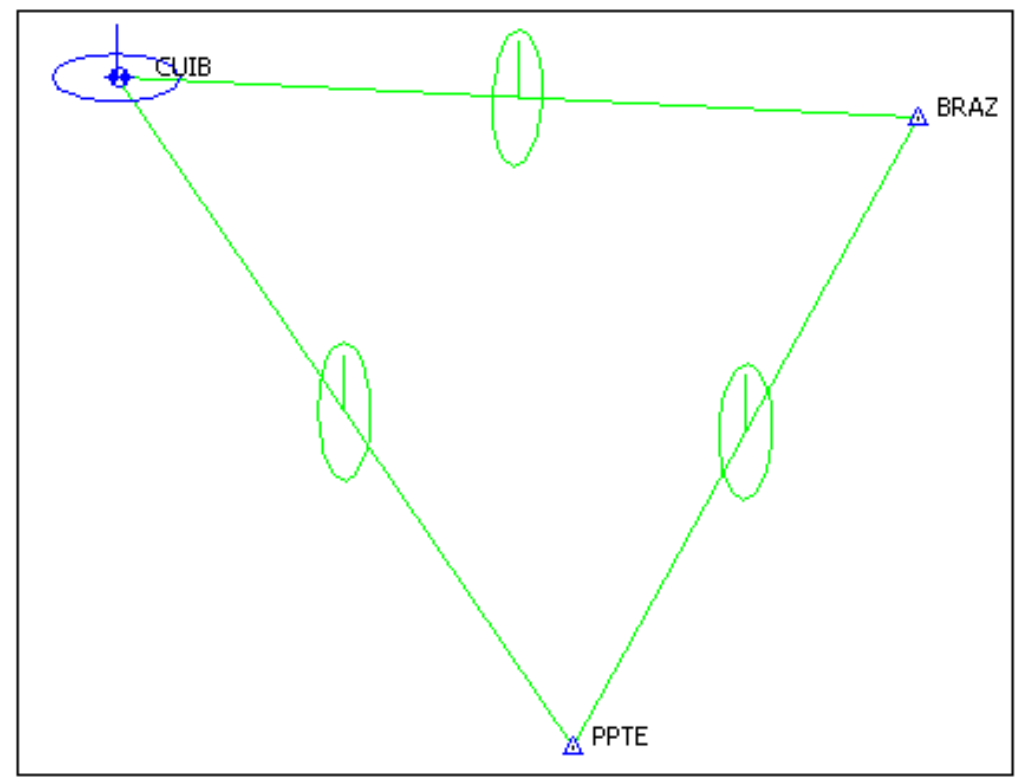

Coordenadas Ajustadas de CUIB:

E (UTM): $599737.3332 \mathrm{~m}$

N (UTM): $8280040.8476 \mathrm{~m}$

- $\underline{289 / 2008}$

A posteriori UWE: 0.6928103 , Bounds: ( 0.6770032, 1.241639) 
TABELA B143: Resultado do Processamento

\begin{tabular}{|c|c|c|c|c|c|c|c|c|}
\hline \multicolumn{9}{|c|}{ GPS Obs Report } \\
\hline Name & $\begin{array}{c}\text { Horizontal } \\
\text { Precision (m) }\end{array}$ & $\begin{array}{c}\text { Vertical } \\
\text { Precision (m) }\end{array}$ & \begin{tabular}{|c|} 
Distance \\
$(\mathrm{m})$
\end{tabular} & $\begin{array}{c}\text { Solution } \\
\text { Type }\end{array}$ & $\begin{array}{c}\text { GPS } \\
\text { Satellites }\end{array}$ & PDOP & Status & RMS \\
\hline BRAZ-CUIB & 0.099 & 0.100 & 878314.372 & $\begin{array}{l}\text { Float,Wide } \\
\text { Lane }\end{array}$ & 31 & 2.739 & Adjusted & 0.141 \\
\hline BRAZ-PPTE & 0.096 & 0.091 & 777286.911 & $\begin{array}{l}\text { Float,Wide } \\
\text { Lane }\end{array}$ & 31 & 2.727 & Adjusted & 0.132 \\
\hline CUIB-PPTE & 0.102 & 0.096 & 876276.028 & $\begin{array}{l}\text { Float,Wide } \\
\text { Lane }\end{array}$ & 31 & 2.734 & Adjusted & 0.141 \\
\hline
\end{tabular}

Figura B143: Elipses de Erro

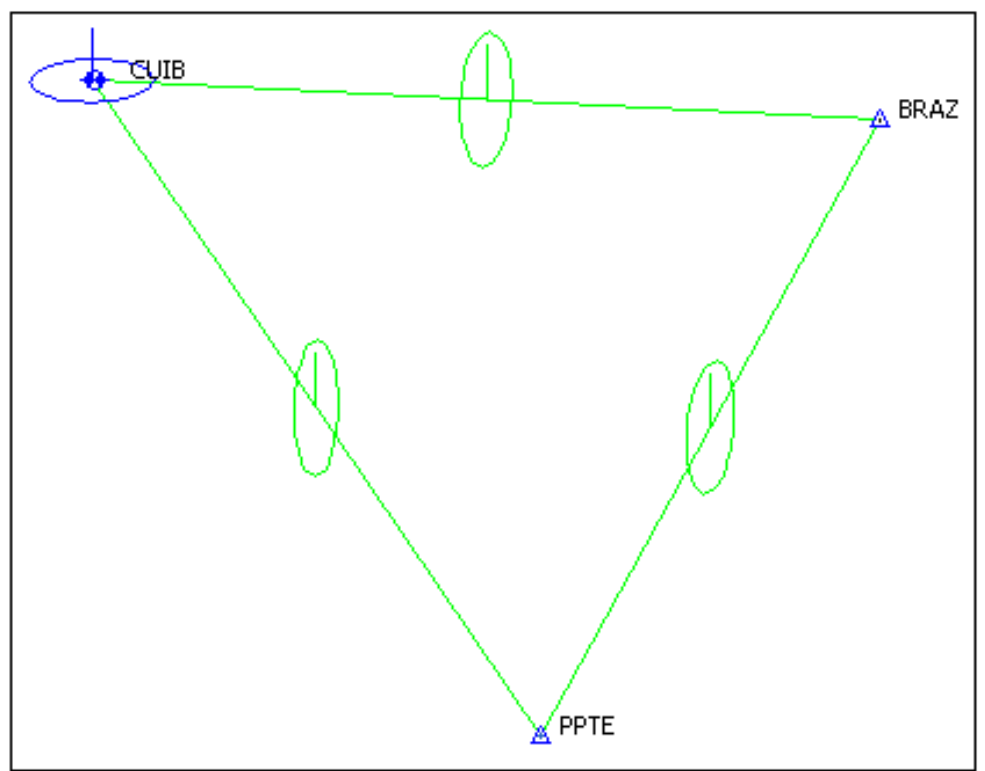

Coordenadas Ajustadas de CUIB:

E (UTM): $599737.3404 \mathrm{~m}$

N (UTM): $8280040.8519 \mathrm{~m}$

- $290 / 2008$

A posteriori UWE: 0.6867104 , Bounds: ( $0.6770032,1.241639)$

TABELA B144: Resultado do Processamento

\begin{tabular}{|c|c|c|c|c|c|c|c|c|}
\hline \multicolumn{9}{|c|}{ GPS Obs Report } \\
\hline Name & Horizontal & Vertical & Distance & Solution & GPS & PDOP & Status & RMS \\
\hline
\end{tabular}




\begin{tabular}{|c|c|c|c|c|c|c|c|c|}
\hline & Precision (m) & Precision (m) & (m) & Type & Satellites & & & \\
\hline BRAZ-CUIB & 0.101 & 0.098 & 878314.388 & \begin{tabular}{|l} 
Float,Wide \\
Lane
\end{tabular} & 30 & 2.802 & Adjusted & 0.141 \\
\hline BRAZ-PPTE & 0.093 & 0.096 & |777286.909 & $\begin{array}{l}\text { Float,Wide } \\
\text { Lane }\end{array}$ & 30 & 2.890 & Adjusted & $\mid 0.134$ \\
\hline CUIB-PPTE & 0.093 & 0.106 & 876276.022 & $\begin{array}{l}\text { Fixed,Wide } \\
\text { Lane }\end{array}$ & 30 & 2.892 & Adjusted & $\mid 0.141$ \\
\hline
\end{tabular}

Figura B144: Elipses de Erro

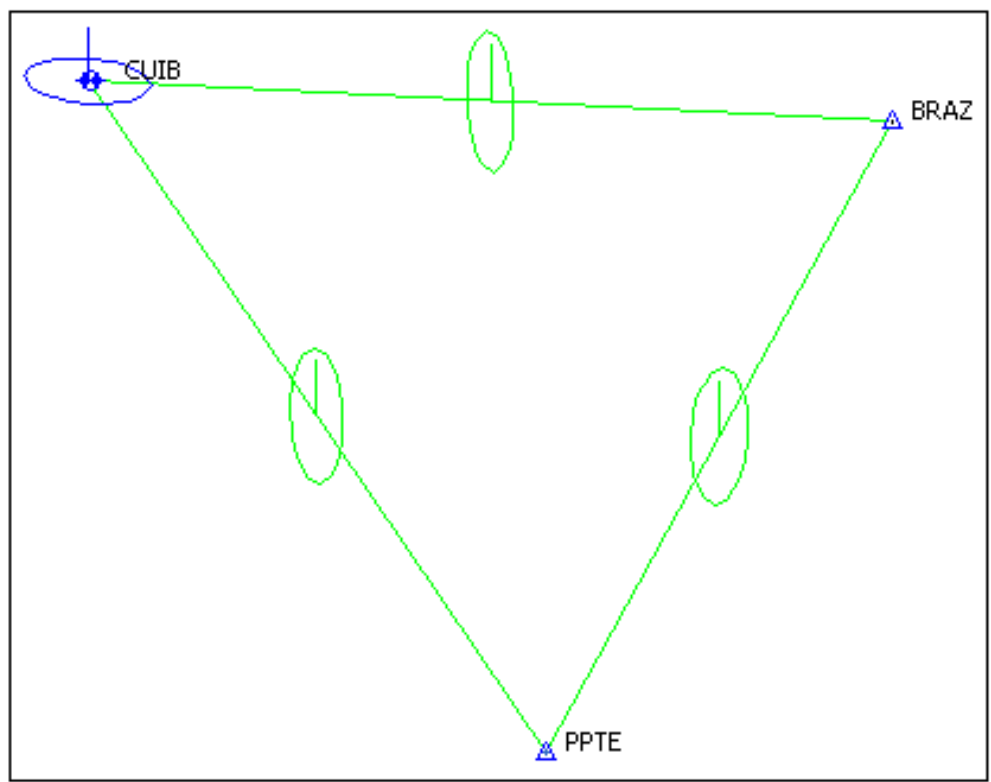

Coordenadas Ajustadas de CUIB:

E (UTM): $599737.3394 \mathrm{~m}$

N (UTM): $8280040.8426 \mathrm{~m}$

B.4 Distâncias diferentes (com pelo menos uma maior que $700 \mathrm{~km}$ ) e Geometria Ruim entre as estações da RBMC 


\section{B.4.1 2006}

\section{B.4.1.1 Verão (Dias Julianos 011 a 014)}

- $\underline{011 / 2006}$

A posteriori UWE: 0.6776848 , Bounds: ( $0.6770032,1.241639)$

TABELA B145: Resultado do Processamento

\begin{tabular}{|c|c|c|c|c|c|c|c|c|}
\hline \multicolumn{9}{|c|}{ GPS Obs Report } \\
\hline Name & $\begin{array}{c}\text { Horizontal } \\
\text { Precision }(\mathbf{m})\end{array}$ & $\begin{array}{l}\text { Vertical } \\
\text { Precision } \\
\text { (m) }\end{array}$ & $\begin{array}{l}\text { Distance } \\
\text { (m) }\end{array}$ & $\begin{array}{l}\text { Solution } \\
\text { Type }\end{array}$ & $\begin{array}{c}\text { GPS } \\
\text { Satellites }\end{array}$ & PDOP & Status & RMS \\
\hline $\begin{array}{l}\text { BRAZ - RBMC } \\
\text { Brasilia-CUIB - RBMC } \\
\text { Cuiaba }\end{array}$ & 0.098 & 0.102 & 878314.391 & $\begin{array}{l}\text { Float,Wide } \\
\text { Lane }\end{array}$ & 27 & 3.079 & Adjusted & 0.141 \\
\hline $\begin{array}{l}\text { BRAZ - RBMC } \\
\text { Brasilia-MCLA - } \\
\text { RBMC Montes Claros }\end{array}$ & 0.061 & 0.078 & 435497.372 & $\begin{array}{l}\text { Fixed,Wide } \\
\text { Lane }\end{array}$ & 27 & 3.507 & Adjusted & 0.099 \\
\hline $\begin{array}{l}\text { CUIB - RBMC } \\
\text { Cuiaba-MCLA - } \\
\text { RBMC Montes Claros }\end{array}$ & 0.111 & 0.132 & 1307630.572 & $\begin{array}{l}\text { Float,Wide } \\
\text { Lane }\end{array}$ & 27 & 3.869 & Adjusted & 0.172 \\
\hline
\end{tabular}

Figura B145: Elipses de Erro

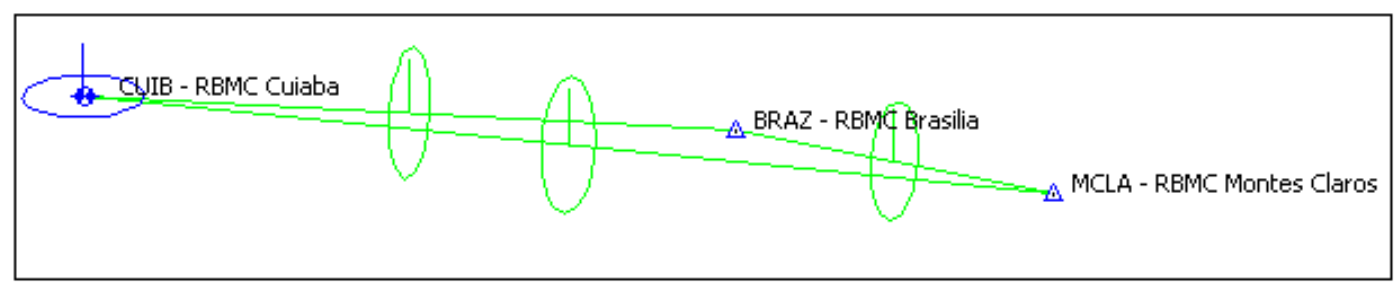

Coordenadas Ajustadas de CUIB:

E (UTM): $599737.3229 \mathrm{~m}$

N (UTM): $8280040.8031 \mathrm{~m}$

- $012 / 2006$

A posteriori UWE: 1.0323 , Bounds: ( $0.6770032,1.241639$ )

TABELA B146: Resultado do Processamento 


\begin{tabular}{|c|c|c|c|c|c|c|c|c|}
\hline Name & $\begin{array}{c}\text { Horizontal } \\
\text { Precision }(\mathbf{m})\end{array}$ & $\begin{array}{c}\text { Vertical } \\
\text { Precision } \\
(\mathbf{m})\end{array}$ & $\begin{array}{l}\text { Distance } \\
\text { (m) }\end{array}$ & $\begin{array}{c}\text { Solution } \\
\text { Type }\end{array}$ & $\begin{array}{c}\text { GPS } \\
\text { Satellites }\end{array}$ & | PDOP & Status & RMS \\
\hline $\begin{array}{l}\text { BRAZ - RBMC } \\
\text { Brasilia-CUIB - RBMC } \\
\text { Cuiaba }\end{array}$ & 0.095 & 0.104 & 878314.400 & $\begin{array}{l}\text { Float,Wide } \\
\text { Lane }\end{array}$ & 28 & 3.078 & Adjusted & 0.141 \\
\hline $\begin{array}{l}\text { BRAZ - RBMC } \\
\text { Brasilia-MCLA - } \\
\text { RBMC Montes Claros } \\
\end{array}$ & 0.064 & 0.079 & 435497.462 & $\begin{array}{l}\text { Fixed,Wide } \\
\text { Lane }\end{array}$ & 28 & 4.572 & Adjusted & | 0.101 \\
\hline $\begin{array}{l}\text { CUIB - RBMC } \\
\text { Cuiaba-MCLA - } \\
\text { RBMC Montes Claros }\end{array}$ & 0.116 & 0.128 & 1307630.532 & $\begin{array}{l}\text { Float,Wide } \\
\text { Lane }\end{array}$ & 28 & 4.604 & Adjusted & 0.173 \\
\hline
\end{tabular}

Figura B146: Elipses de Erro

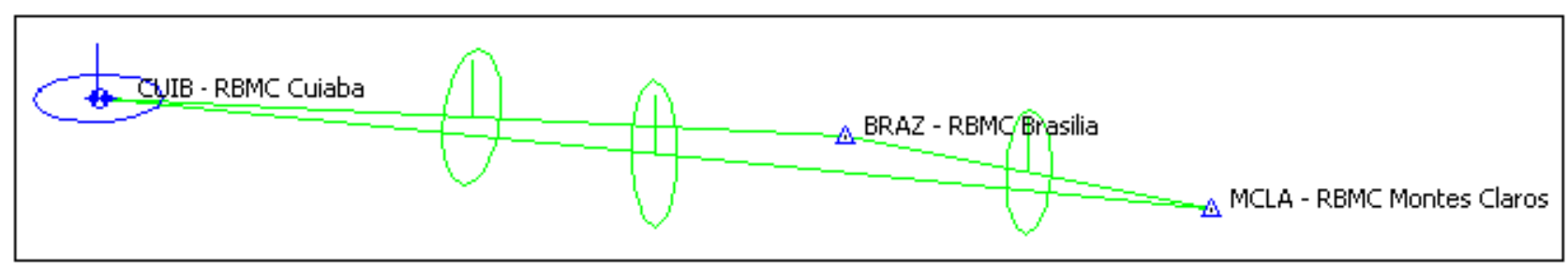

Coordenadas Ajustadas de CUIB:

E (UTM): $599737.3366 \mathrm{~m}$

N (UTM): $8280040.7944 \mathrm{~m}$

- $\underline{013 / 2006}$

A posteriori UWE: 0.7894436 , Bounds: ( $0.6770032,1.241639)$

TABELA B147: Resultado do Processamento 


\begin{tabular}{|c|c|c|c|c|c|c|c|c|}
\hline Name & $\begin{array}{c}\text { Horizontal } \\
\text { Precision }(\mathbf{m})\end{array}$ & $\begin{array}{c}\text { Vertical } \\
\text { Precision } \\
(\mathbf{m})\end{array}$ & $\begin{array}{l}\text { Distance } \\
\text { (m) }\end{array}$ & $\begin{array}{c}\text { Solution } \\
\text { Type }\end{array}$ & $\begin{array}{c}\text { GPS } \\
\text { Satellites }\end{array}$ & | PDOP & Status & RMS \\
\hline $\begin{array}{l}\text { BRAZ - RBMC } \\
\text { Brasilia-CUIB - RBMC } \\
\text { Cuiaba }\end{array}$ & 0.093 & 0.107 & 878314.407 & $\begin{array}{l}\text { Float,Wide } \\
\text { Lane }\end{array}$ & 28 & 3.075 & Adjusted & 0.142 \\
\hline $\begin{array}{l}\text { BRAZ - RBMC } \\
\text { Brasilia-MCLA - } \\
\text { RBMC Montes Claros } \\
\end{array}$ & 0.060 & 0.080 & 435497.414 & $\begin{array}{l}\text { Fixed,Wide } \\
\text { Lane }\end{array}$ & 28 & |3.971 & Adjusted & 0.100 \\
\hline $\begin{array}{l}\text { CUIB - RBMC } \\
\text { Cuiaba-MCLA - } \\
\text { RBMC Montes Claros }\end{array}$ & 0.115 & 0.128 & 1307630.553 & $\begin{array}{l}\text { Float,Wide } \\
\text { Lane }\end{array}$ & 28 & 4.478 & Adjusted & 0.172 \\
\hline
\end{tabular}

Figura B147: Elipses de Erro

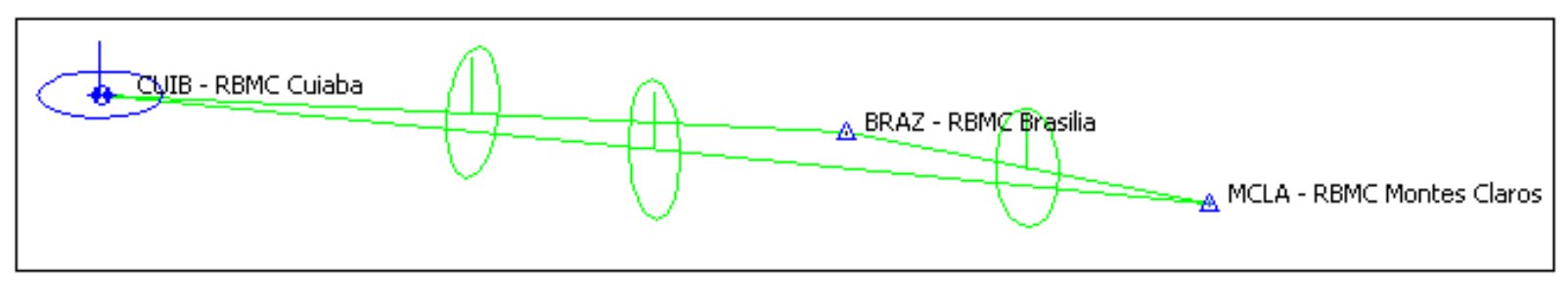

Coordenadas Ajustadas de CUIB:

E (UTM): $599737.3205 \mathrm{~m}$

N (UTM): $8280040.8055 \mathrm{~m}$

- $\underline{014 / 2006}$

A posteriori UWE: 0.4745827 , Bounds: ( $0.5291502,1.312758$ )

TABELA B148: Resultado do Processamento 


\begin{tabular}{|c|c|c|c|c|c|c|c|c|}
\hline Name & \begin{tabular}{|c}
$\begin{array}{c}\text { Horizontal } \\
\text { Precision } \\
\text { (m) }\end{array}$ \\
\end{tabular} & \begin{tabular}{|c|} 
Vertical \\
Precision \\
(m)
\end{tabular} & $\begin{array}{l}\text { Distance } \\
\quad(\mathbf{m})\end{array}$ & $\begin{array}{l}\text { Solution } \\
\text { Type }\end{array}$ & $\begin{array}{c}\text { GPS } \\
\text { Satellites }\end{array}$ & PDOP & Status & RMS \\
\hline $\begin{array}{l}\text { BRAZ - RBMC } \\
\text { Brasilia-CUIB - } \\
\text { RBMC Cuiaba }\end{array}$ & & & & \begin{tabular}{|l} 
Failed,No \\
Ephemeris
\end{tabular} & 28 & & $\begin{array}{l}\text { PostProcessed } \\
\text { Failed }\end{array}$ & \\
\hline $\begin{array}{l}\text { BRAZ - RBMC } \\
\text { Brasilia-MCLA - } \\
\text { RBMC Montes } \\
\text { Claros }\end{array}$ & 0.045 & 0.088 & 435497.357 & $\begin{array}{l}\text { Fixed,Wide } \\
\text { Lane }\end{array}$ & 28 & 4.193 & Adjusted & 0.099 \\
\hline $\begin{array}{l}\text { CUIB - RBMC } \\
\text { Cuiaba-MCLA - } \\
\text { RBMC Montes } \\
\text { Claros }\end{array}$ & & & & $\begin{array}{l}\text { Failed,No } \\
\text { Ephemeris }\end{array}$ & 28 & & $\begin{array}{l}\text { PostProcessed } \\
\text { Failed }\end{array}$ & \\
\hline
\end{tabular}

Figura B148: Elipses de Erro

CSUIB - REMC Cuiaba

\section{B.4.1.2 Outono (Dias Julianos 101 a 104)}

- $101 / 2006$

A posteriori UWE: 1, Bounds: $(1,1)$

TABELA B149: Resultado do Processamento

\begin{tabular}{|c|c|c|c|c|c|c|c|c|}
\hline \multicolumn{9}{|c|}{ GPS Obs Report } \\
\hline Name & $\begin{array}{l}\text { Horizontal } \\
\text { Precision } \\
\text { (m) }\end{array}$ & $\begin{array}{l}\text { Vertical } \\
\text { Precision } \\
\text { (m) }\end{array}$ & $\begin{array}{l}\text { Distance } \\
\text { (m) }\end{array}$ & $\begin{array}{c}\text { Solution } \\
\text { Type }\end{array}$ & $\begin{array}{c}\text { GPS } \\
\text { Satellites }\end{array}$ & PDOP & Status & RMS \\
\hline $\begin{array}{l}\text { BRAZ - RBMC } \\
\text { Brasilia-CUIB - } \\
\text { RBMC Cuiaba }\end{array}$ & & & & $\begin{array}{l}\text { Failed,No } \\
\text { Ephemeris }\end{array}$ & 29 & & $\begin{array}{l}\text { PostProcessed } \\
\text { Failed }\end{array}$ & \\
\hline $\begin{array}{l}\text { BRAZ - RBMC } \\
\text { Brasilia-MCLA - } \\
\text { RBMC Montes } \\
\text { Claros }\end{array}$ & & & & $\begin{array}{l}\text { Failed,No } \\
\text { Ephemeris }\end{array}$ & 29 & & $\begin{array}{l}\text { PostProcessed } \\
\text { Failed }\end{array}$ & \\
\hline $\begin{array}{l}\text { CUIB - RBMC } \\
\text { Cuiaba-MCLA - } \\
\text { RBMC Montes } \\
\text { Claros }\end{array}$ & 0.125 & 0.118 & 1307630.558 & $\begin{array}{l}\text { Float, Wide } \\
\text { Lane }\end{array}$ & 29 & 4.418 & Adjusted & 0.172 \\
\hline
\end{tabular}

Figura B149: Elipses de Erro 


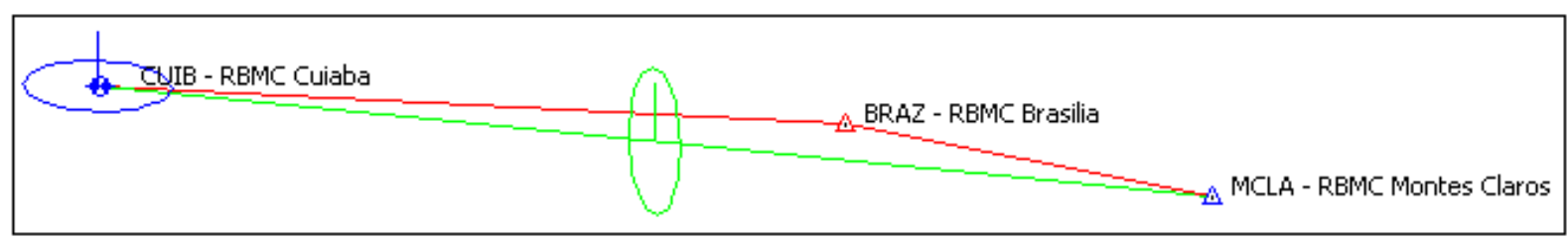

- $102 / 2006$

A posteriori UWE: 0.6873889 , Bounds: ( $0.6770032,1.241639)$

TABELA B150: Resultado do Processamento

\begin{tabular}{|c|c|c|c|c|c|c|c|c|}
\hline \multicolumn{9}{|c|}{ GPS Obs Report } \\
\hline Name & $\begin{array}{c}\text { Horizontal } \\
\text { Precision (m) }\end{array}$ & $\begin{array}{l}\text { Vertical } \\
\text { Precision } \\
\quad(\mathbf{m})\end{array}$ & $\begin{array}{l}\text { Distance } \\
\text { (m) }\end{array}$ & $\begin{array}{l}\text { Solution } \\
\text { Type }\end{array}$ & \begin{tabular}{|c|} 
GPS \\
Satellites
\end{tabular} & PDOP & Status & RMS \\
\hline $\begin{array}{l}\text { BRAZ - RBMC } \\
\text { Brasilia-CUIB - RBMC } \\
\text { Cuiaba }\end{array}$ & 0.106 & 0.092 & 878314.331 & $\begin{array}{l}\text { Float,Wide } \\
\text { Lane }\end{array}$ & 29 & 3.629 & Adjusted & 0.141 \\
\hline $\begin{array}{l}\text { BRAZ - RBMC } \\
\text { Brasilia-MCLA - } \\
\text { RBMC Montes Claros }\end{array}$ & 0.070 & 0.070 & 435497.377 & $\begin{array}{l}\text { Float,Wide } \\
\text { Lane }\end{array}$ & 29 & 4.581 & Adjusted & 0.099 \\
\hline $\begin{array}{l}\text { CUIB - RBMC } \\
\text { Cuiaba-MCLA - } \\
\text { RBMC Montes Claros }\end{array}$ & 0.123 & 0.120 & 1307630.558 & $\begin{array}{l}\text { Float,Wide } \\
\text { Lane }\end{array}$ & 29 & 4.740 & Adjusted & 0.172 \\
\hline
\end{tabular}

Figura B150: Elipses de Erro

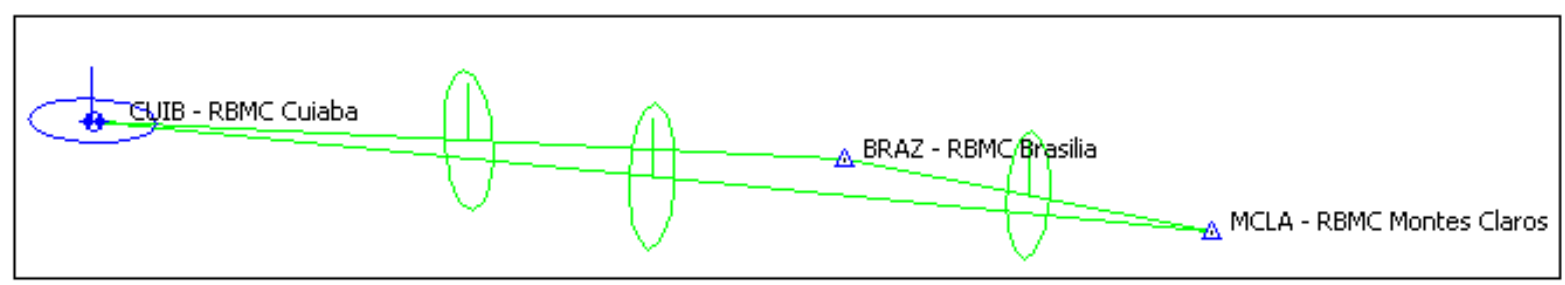

Coordenadas Ajustadas de CUIB:

E (UTM): $599737.3651 \mathrm{~m}$

N (UTM): $8280040.8432 \mathrm{~m}$

- $103 / 2006$

A posteriori UWE: 1.2354191 , Bounds: ( $0.6770032,1.241639)$

TABELA B151: Resultado do Processamento 


\begin{tabular}{|c|c|c|c|c|c|c|c|c|}
\hline \multicolumn{9}{|c|}{ GPS Obs Report } \\
\hline Name & $\begin{array}{c}\text { Horizontal } \\
\text { Precision (m) }\end{array}$ & $\begin{array}{c}\text { Vertical } \\
\text { Precision } \\
\text { (m) }\end{array}$ & $\begin{array}{l}\text { Distance } \\
\text { (m) }\end{array}$ & $\begin{array}{l}\text { Solution } \\
\text { Type }\end{array}$ & $\begin{array}{c}\text { GPS } \\
\text { Satellites }\end{array}$ & PDOP & Status & RMS \\
\hline $\begin{array}{l}\text { BRAZ - RBMC } \\
\text { Brasilia-CUIB - RBMC } \\
\text { Cuiaba }\end{array}$ & 0.101 & 0.100 & 878314.390 & $\begin{array}{l}\text { Float,Wide } \\
\text { Lane }\end{array}$ & 29 & 3.029 & Adjusted & 0.143 \\
\hline $\begin{array}{l}\text { BRAZ - RBMC } \\
\text { Brasilia-MCLA - } \\
\text { RBMC Montes Claros }\end{array}$ & 0.059 & 0.080 & 435497.342 & $\begin{array}{l}\text { Fixed,Wide } \\
\text { Lane }\end{array}$ & 29 & 4.477 & Adjusted & 0.099 \\
\hline $\begin{array}{l}\text { CUIB - RBMC } \\
\text { Cuiaba-MCLA - } \\
\text { RBMC Montes Claros }\end{array}$ & 0.127 & 0.116 & 1307630.520 & $\begin{array}{l}\text { Float, Wide } \\
\text { Lane }\end{array}$ & 29 & 4.085 & Adjusted & 0.172 \\
\hline
\end{tabular}

Figura B151: Elipses de Erro

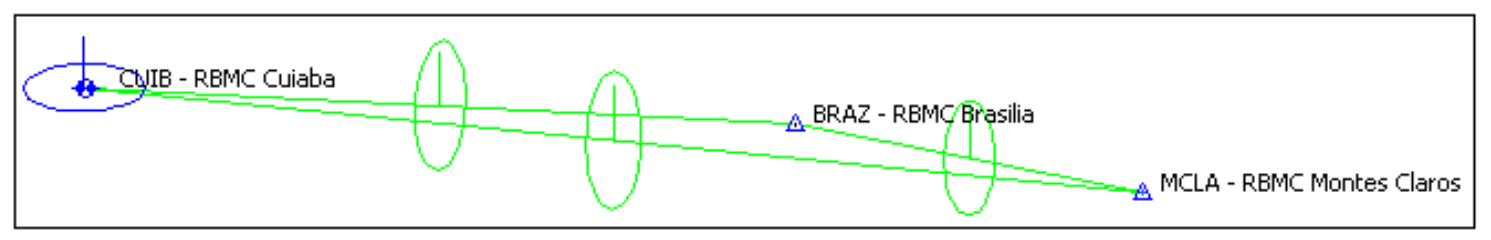

Coordenadas Ajustadas de CUIB:

E (UTM): $599737.3346 \mathrm{~m}$

N (UTM): $8280040.8307 \mathrm{~m}$

- $\underline{104 / 2006}$

A posteriori UWE: 0.3925854 , Bounds: ( $0.6770032,1.241639$ )

TABELA B152: Resultado do Processamento

\begin{tabular}{|c|c|c|c|c|c|c|c|c|}
\hline \multicolumn{9}{|c|}{ GPS Obs Report } \\
\hline Name & \begin{tabular}{|} 
Horizontal \\
Precision (m)
\end{tabular} & $\begin{array}{c}\text { Vertical } \\
\text { Precision } \\
\text { (m) }\end{array}$ & $\begin{array}{l}\text { Distance } \\
\text { (m) }\end{array}$ & $\begin{array}{l}\text { Solution } \\
\text { Type }\end{array}$ & $\begin{array}{c}\text { GPS } \\
\text { Satellites }\end{array}$ & PDOP & Status & RMS \\
\hline $\begin{array}{l}\text { BRAZ - RBMC } \\
\text { Brasilia-CUIB - RBMC } \\
\text { Cuiaba }\end{array}$ & 0.097 & 0.103 & 878314.379 & $\begin{array}{l}\text { Float,Wide } \\
\text { Lane }\end{array}$ & 29 & 2.967 & Adjusted & $\mid 0.141$ \\
\hline \begin{tabular}{|l|} 
BRAZ - RBMC \\
Brasilia-MCLA - \\
RBMC Montes Claros
\end{tabular} & 0.072 & 0.069 & 435497.390 & $\begin{array}{l}\text { Float, Wide } \\
\text { Lane }\end{array}$ & 29 & 3.861 & Adjusted & || 0.099 \\
\hline $\begin{array}{l}\text { CUIB - RBMC } \\
\text { Cuiaba-MCLA - } \\
\text { RBMC Montes Claros }\end{array}$ & 0.125 & 0.123 & 1307630.528 & $\begin{array}{l}\text { Float,Wide } \\
\text { Lane }\end{array}$ & 29 & 8.565 & Adjusted & $\mid 0.176$ \\
\hline
\end{tabular}

Figura B152: Elipses de Erro 


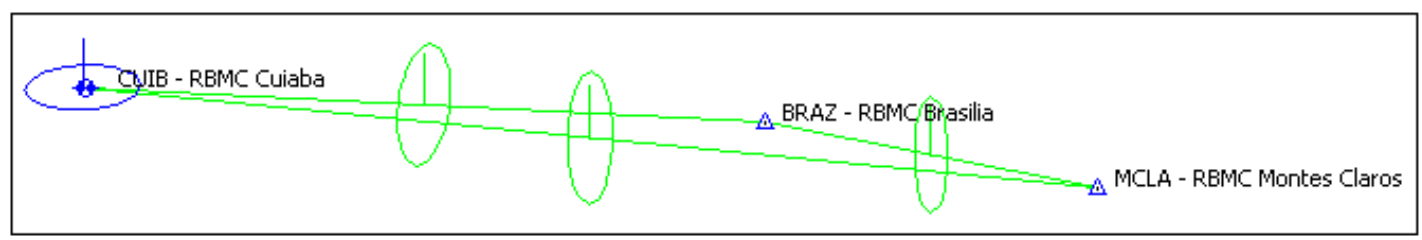

Coordenadas Ajustadas de CUIB:

E (UTM): $599737.3538 \mathrm{~m}$

N (UTM): $8280040.8527 \mathrm{~m}$

B.4.1.3 Inverno (Dias Julianos 193 a 196)

- $193 / 2006$

A posteriori UWE: 0.6915812 , Bounds: $(0.6770032,1.241639)$

TABELA B153: Resultado do Processamento

\begin{tabular}{|c|c|c|c|c|c|c|c|c|}
\hline \multicolumn{9}{|c|}{ GPS Obs Report } \\
\hline Name & $\begin{array}{c}\text { Horizontal } \\
\text { Precision (m) }\end{array}$ & $\begin{array}{l}\text { Vertical } \\
\text { Precision } \\
(\mathbf{m}) \\
\end{array}$ & $\begin{array}{c}\text { Distance } \\
\text { (m) }\end{array}$ & $\begin{array}{c}\text { Solution } \\
\text { Type }\end{array}$ & $\begin{array}{c}\text { GPS } \\
\text { Satellites }\end{array}$ & PDOP & Status & RMS \\
\hline $\begin{array}{l}\text { BRAZ - RBMC } \\
\text { Brasilia-CUIB - RBMC } \\
\text { Cuiaba } \\
\end{array}$ & 0.123 & 0.068 & 878314.362 & $\begin{array}{l}\text { Float,Wide } \\
\text { Lane }\end{array}$ & 28 & 3.038 & Adjusted & 0.141 \\
\hline $\begin{array}{l}\text { BRAZ - RBMC } \\
\text { Brasilia-MCLA - } \\
\text { RBMC Montes Claros }\end{array}$ & 0.047 & 0.087 & 435497.339 & $\begin{array}{l}\text { Fixed,Wide } \\
\text { Lane }\end{array}$ & 28 & 2.961 & Adjusted & 0.099 \\
\hline $\begin{array}{l}\text { CUIB - RBMC } \\
\text { Cuiaba-MCLA - } \\
\text { RBMC Montes Claros }\end{array}$ & 0.126 & 0.117 & 1307630.516 & $\begin{array}{l}\text { Float,Wide } \\
\text { Lane }\end{array}$ & 28 & 3.527 & Adjusted & 0.172 \\
\hline
\end{tabular}

Figura B153: Elipses de Erro

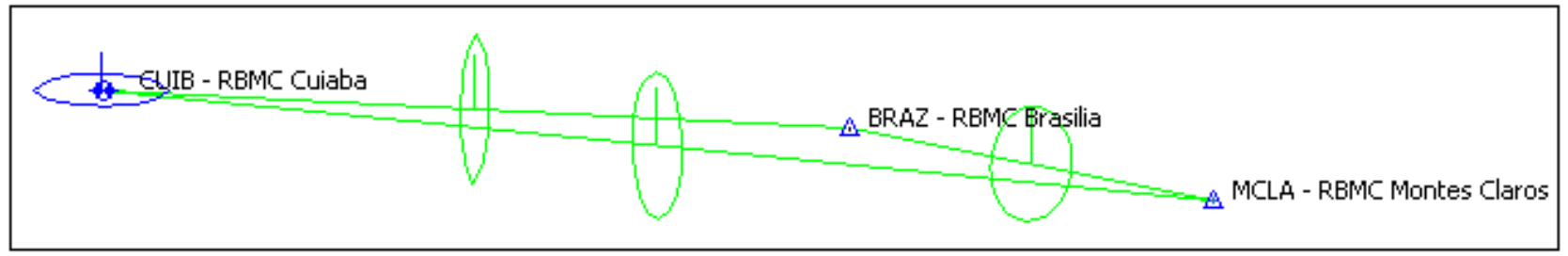

Coordenadas Ajustadas de CUIB: 
E (UTM): $599737.3535 \mathrm{~m}$

N (UTM): $8280040.8543 \mathrm{~m}$

- $194 / 2006$

A posteriori UWE: 0.9281472 , Bounds: ( $0.6770032,1.241639)$

TABELA B154: Resultado do Processamento

\begin{tabular}{|c|c|c|c|c|c|c|c|c|}
\hline \multicolumn{9}{|c|}{ GPS Obs Report } \\
\hline Name & $\begin{array}{c}\text { Horizontal } \\
\text { Precision }(\mathbf{m})\end{array}$ & $\begin{array}{l}\text { Vertical } \\
\text { Precision } \\
\quad(\mathbf{m})\end{array}$ & $\begin{array}{l}\text { Distance } \\
\text { (m) }\end{array}$ & $\begin{array}{l}\text { Solution } \\
\text { Type }\end{array}$ & $\begin{array}{c}\text { GPS } \\
\text { Satellites }\end{array}$ & PDOP & Status & RMS \\
\hline $\begin{array}{l}\text { BRAZ - RBMC } \\
\text { Brasilia-CUIB - RBMC } \\
\text { Cuiaba }\end{array}$ & 0.111 & 0.101 & 878314.380 & $\begin{array}{l}\text { Float,Wide } \\
\text { Lane }\end{array}$ & 28 & 3.200 & Adjusted & 0.150 \\
\hline $\begin{array}{l}\text { BRAZ - RBMC } \\
\text { Brasilia-MCLA - } \\
\text { RBMC Montes Claros }\end{array}$ & 0.056 & 0.082 & 435497.328 & $\begin{array}{l}\text { Fixed,Wide } \\
\text { Lane }\end{array}$ & 28 & 2.985 & Adjusted & 0.100 \\
\hline $\begin{array}{l}\text { CUIB - RBMC } \\
\text { Cuiaba-MCLA - } \\
\text { RBMC Montes Claros }\end{array}$ & 0.123 & 0.120 & 1307630.507 & $\begin{array}{l}\text { Float,Wide } \\
\text { Lane }\end{array}$ & 28 & 3.528 & Adjusted & 0.172 \\
\hline
\end{tabular}

Figura B154: Elipses de Erro

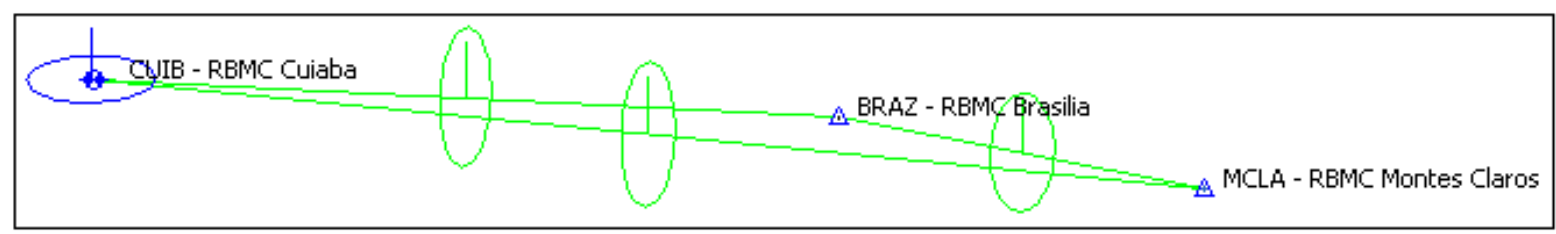

Coordenadas Ajustadas de CUIB:

E (UTM): $599737.3428 \mathrm{~m}$

N (UTM): $8280040.8537 \mathrm{~m}$

- $195 / 2006$

A posteriori UWE: 1 , Bounds: $(1,1)$

TABELA B155: Resultado do Processamento 


\begin{tabular}{|c|c|c|c|c|c|c|c|c|}
\hline \multicolumn{9}{|c|}{ GPS Obs Report } \\
\hline Name & \begin{tabular}{|c}
$\begin{array}{c}\text { Horizontal } \\
\text { Precision } \\
(\mathrm{m})\end{array}$ \\
\end{tabular} & $\begin{array}{l}\text { Vertical } \\
\text { Precision } \\
\text { (m) }\end{array}$ & $\begin{array}{l}\text { Distance } \\
\quad(\mathbf{m})\end{array}$ & $\begin{array}{l}\text { Solution } \\
\text { Type }\end{array}$ & $\begin{array}{c}\text { GPS } \\
\text { Satellites }\end{array}$ & PDOP & Status & RMS \\
\hline $\begin{array}{l}\text { BRAZ - RBMC } \\
\text { Brasilia-CUIB - } \\
\text { RBMC Cuiaba }\end{array}$ & & & & $\begin{array}{l}\text { Failed,No } \\
\text { Ephemeris }\end{array}$ & 28 & & \begin{tabular}{|l|} 
PostProcessed \\
Failed
\end{tabular} & \\
\hline $\begin{array}{l}\text { BRAZ - RBMC } \\
\text { Brasilia-MCLA - } \\
\text { RBMC Montes } \\
\text { Claros } \\
\end{array}$ & & & & \begin{tabular}{||l} 
Failed,No \\
Ephemeris
\end{tabular} & 28 & & \begin{tabular}{|l|l} 
PostProcessed \\
Failed
\end{tabular} & \\
\hline $\begin{array}{l}\text { CUIB - RBMC } \\
\text { Cuiaba-MCLA - } \\
\text { RBMC Montes } \\
\text { Claros } \\
\end{array}$ & 0.123 & 0.119 & 1307630.509 & $\begin{array}{l}\text { Float,Wide } \\
\text { Lane }\end{array}$ & 28 & 3.522 & Adjusted & 0.172 \\
\hline
\end{tabular}

Figura B155: Elipses de Erro

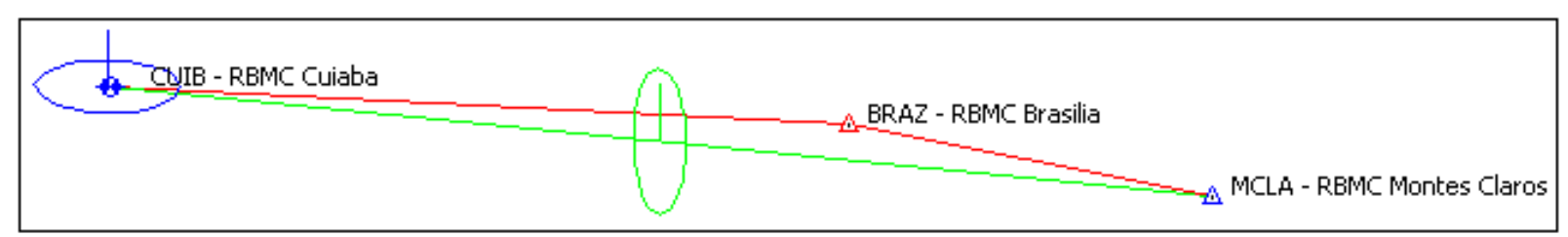

- $196 / 2006$

A posteriori UWE: 0.6793016 , Bounds: ( $0.6770032,1.241639)$

TABELA B156: Resultado do Processamento

\begin{tabular}{|c|c|c|c|c|c|c|c|c|}
\hline \multicolumn{9}{|c|}{ GPS Obs Report } \\
\hline Name & \begin{tabular}{|} 
Horizontal \\
Precision (m)
\end{tabular} & $\begin{array}{l}\text { Vertical } \\
\text { Precision } \\
\text { (m) }\end{array}$ & $\begin{array}{l}\text { Distance } \\
\text { (m) }\end{array}$ & $\begin{array}{l}\text { Solution } \\
\text { Type }\end{array}$ & $\begin{array}{c}\text { GPS } \\
\text { Satellites }\end{array}$ & PDOP & Status & RMS \\
\hline $\begin{array}{l}\text { BRAZ - RBMC } \\
\text { Brasilia-CUIB - RBMC } \\
\text { Cuiaba }\end{array}$ & 0.116 & 0.079 & 878314.369 & $\begin{array}{l}\text { Float,Wide } \\
\text { Lane }\end{array}$ & 28 & 3.202 & Adjusted & $\mid 0.141$ \\
\hline \begin{tabular}{|l} 
BRAZ - RBMC \\
Brasilia-MCLA - \\
RBMC Montes Claros
\end{tabular} & 0.071 & 0.070 & 435497.385 & $\begin{array}{l}\text { Float, Wide } \\
\text { Lane }\end{array}$ & 28 & 2.977 & Adjusted & || 0.099 \\
\hline $\begin{array}{l}\text { CUIB - RBMC } \\
\text { Cuiaba-MCLA - } \\
\text { RBMC Montes Claros }\end{array}$ & 0.126 & 0.121 & 1307630.525 & $\begin{array}{l}\text { Float,Wide } \\
\text { Lane }\end{array}$ & 28 & 3.521 & Adjusted & $\mid 0.175$ \\
\hline
\end{tabular}

Figura B156: Elipses de Erro 


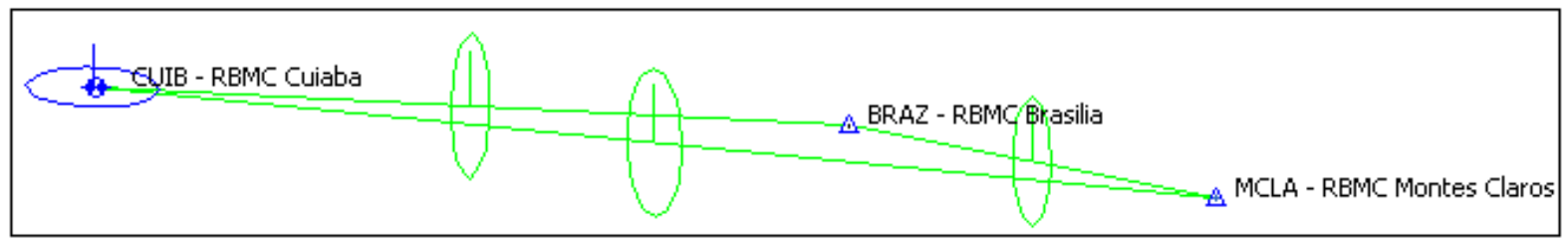

Coordenadas Ajustadas de CUIB:

E (UTM): $599737.3419 \mathrm{~m}$

N (UTM): $8280040.8565 \mathrm{~m}$

B.4.1.4 Primavera (Dias Julianos 286 a 289)

- $286 / 2006$

A posteriori UWE: 0.7554716 , Bounds: ( $0.6770032,1.241639)$

TABELA B157: Resultado do Processamento

\begin{tabular}{|c|c|c|c|c|c|c|c|c|}
\hline \multicolumn{9}{|c|}{ GPS Obs Report } \\
\hline Name & $\begin{array}{c}\text { Horizontal } \\
\text { Precision (m) }\end{array}$ & $\begin{array}{l}\text { Vertical } \\
\text { Precision } \\
\text { (m) }\end{array}$ & $\begin{array}{l}\text { Distance } \\
\text { (m) }\end{array}$ & $\begin{array}{l}\text { Solution } \\
\text { Type }\end{array}$ & $\begin{array}{c}\text { GPS } \\
\text { Satellites }\end{array}$ & PDOP & Status & RMS \\
\hline $\begin{array}{l}\text { BRAZ - RBMC } \\
\text { Brasilia-CUIB - RBMC } \\
\text { Cuiaba }\end{array}$ & 0.099 & 0.102 & 878314.411 & $\begin{array}{l}\text { Fixed,Wide } \\
\text { Lane }\end{array}$ & 27 & 3.040 & Adjusted & 0.142 \\
\hline $\begin{array}{l}\text { BRAZ - RBMC } \\
\text { Brasilia-MCLA - } \\
\text { RBMC Montes Claros }\end{array}$ & 0.047 & 0.087 & 435497.404 & $\begin{array}{l}\text { Fixed,Wide } \\
\text { Lane }\end{array}$ & 28 & 2.910 & Adjusted & 0.099 \\
\hline $\begin{array}{l}\text { CUIB - RBMC } \\
\text { Cuiaba-MCLA - } \\
\text { RBMC Montes Claros }\end{array}$ & 0.108 & 0.133 & 1307630.601 & $\begin{array}{l}\text { Fixed,Wide } \\
\text { Lane }\end{array}$ & 27 & 3.417 & Adjusted & 0.172 \\
\hline
\end{tabular}

Figura B157: Elipses de Erro

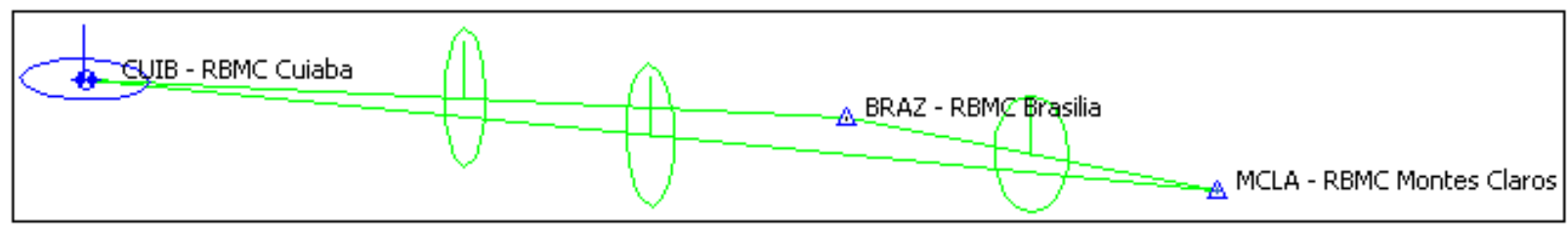

Coordenadas Ajustadas de CUIB: 
E (UTM): $599737.2854 \mathrm{~m}$

N (UTM): $8280040.8177 \mathrm{~m}$

- $\underline{287 / 2006}$

A posteriori UWE: 0.8917967 , Bounds: ( $0.6770032,1.241639)$

TABELA B158: Resultado do Processamento

\begin{tabular}{|c|c|c|c|c|c|c|c|c|}
\hline \multicolumn{9}{|c|}{ GPS Obs Report } \\
\hline Name & $\begin{array}{c}\text { Horizontal } \\
\text { Precision }(\mathbf{m})\end{array}$ & $\begin{array}{l}\text { Vertical } \\
\text { Precision } \\
\quad(\mathbf{m})\end{array}$ & $\begin{array}{c}\text { Distance } \\
\text { (m) }\end{array}$ & $\begin{array}{c}\text { Solution } \\
\text { Type }\end{array}$ & $\begin{array}{c}\text { GPS } \\
\text { Satellites }\end{array}$ & PDOP & Status & RMS \\
\hline $\begin{array}{l}\text { BRAZ - RBMC } \\
\text { Brasilia-CUIB - RBMC } \\
\text { Cuiaba }\end{array}$ & 0.102 & 0.097 & 878314.410 & $\begin{array}{l}\text { Float,Wide } \\
\text { Lane }\end{array}$ & 27 & 3.044 & Adjusted & 0.141 \\
\hline $\begin{array}{l}\text { BRAZ - RBMC } \\
\text { Brasilia-MCLA - } \\
\text { RBMC Montes Claros }\end{array}$ & 0.055 & 0.084 & 435497.422 & $\begin{array}{l}\text { Fixed,Wide } \\
\text { Lane }\end{array}$ & 28 & 2.911 & Adjusted & 0.101 \\
\hline $\begin{array}{l}\text { CUIB - RBMC } \\
\text { Cuiaba-MCLA - } \\
\text { RBMC Montes Claros }\end{array}$ & 0.128 & 0.115 & 1307630.596 & $\begin{array}{l}\text { Float,Wide } \\
\text { Lane }\end{array}$ & 27 & 3.415 & Adjusted & 0.173 \\
\hline
\end{tabular}

Figura B158: Elipses de Erro

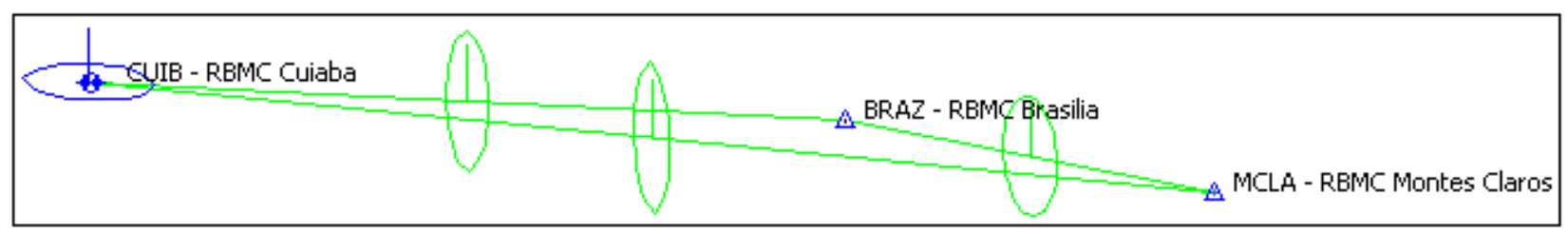

Coordenadas Ajustadas de CUIB:

E (UTM): $599737.2845 \mathrm{~m}$

N (UTM): $8280040.8072 \mathrm{~m}$

- $288 / 2006$

A posteriori UWE: 0.8911267 , Bounds: ( $0.6770032,1.241639)$

TABELA B159: Resultado do Processamento 


\begin{tabular}{|c|c|c|c|c|c|c|c|c|}
\hline \multicolumn{9}{|c|}{ GPS Obs Report } \\
\hline Name & $\begin{array}{c}\text { Horizontal } \\
\text { Precision (m) }\end{array}$ & $\begin{array}{c}\text { Vertical } \\
\text { Precision } \\
\text { (m) }\end{array}$ & $\begin{array}{l}\text { Distance } \\
\text { (m) }\end{array}$ & $\begin{array}{l}\text { Solution } \\
\text { Type }\end{array}$ & $\begin{array}{c}\text { GPS } \\
\text { Satellites }\end{array}$ & PDOP & Status & RMS \\
\hline $\begin{array}{l}\text { BRAZ - RBMC } \\
\text { Brasilia-CUIB - RBMC } \\
\text { Cuiaba }\end{array}$ & 0.095 & 0.104 & 878314.426 & $\begin{array}{l}\text { Float,Wide } \\
\text { Lane }\end{array}$ & 27 & 3.001 & Adjusted & 0.141 \\
\hline $\begin{array}{l}\text { BRAZ - RBMC } \\
\text { Brasilia-MCLA - } \\
\text { RBMC Montes Claros }\end{array}$ & 0.053 & 0.084 & 435497.374 & $\begin{array}{l}\text { Fixed,Wide } \\
\text { Lane }\end{array}$ & 28 & 4.523 & Adjusted & 0.099 \\
\hline $\begin{array}{l}\text { CUIB - RBMC } \\
\text { Cuiaba-MCLA - } \\
\text { RBMC Montes Claros }\end{array}$ & 0.124 & 0.119 & 1307630.596 & $\begin{array}{l}\text { Float, Wide } \\
\text { Lane }\end{array}$ & 27 & 3.436 & Adjusted & 0.172 \\
\hline
\end{tabular}

Figura B159: Elipses de Erro

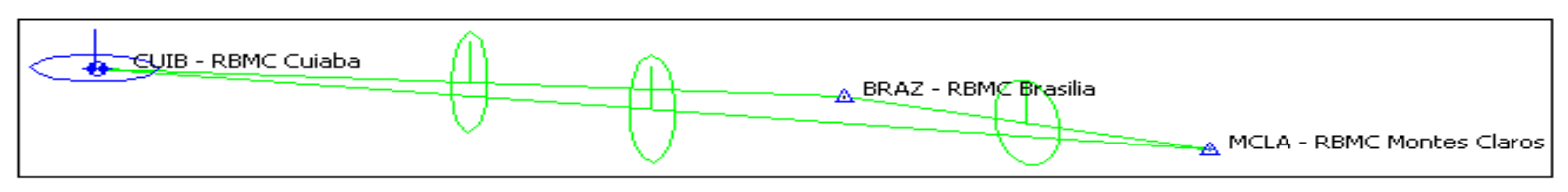

Coordenadas Ajustadas de CUIB:

E (UTM): $599737.2771 \mathrm{~m}$

N (UTM): $8280040.8337 \mathrm{~m}$

- $\underline{289 / 2006}$

Number of used GPS vectors: 5

A posteriori UWE: 0.9749595 , Bounds: ( $0.7778175,1.180748$ )

TABELA B160: Resultado do Processamento 


\begin{tabular}{|c|c|c|c|c|c|c|c|c|}
\hline Name & $\begin{array}{c}\text { Horizontal } \\
\text { Precision (m) }\end{array}$ & $\begin{array}{c}\text { Vertical } \\
\text { Precision } \\
\text { (m) }\end{array}$ & $\begin{array}{l}\text { Distance } \\
\text { (m) }\end{array}$ & $\begin{array}{c}\text { Solution } \\
\text { Type }\end{array}$ & $\begin{array}{c}\text { GPS } \\
\text { Satellites }\end{array}$ & PDOP & Status & RMS \\
\hline $\begin{array}{l}\text { BRAZ - RBMC } \\
\text { Brasilia-CUIB - RBMC } \\
\text { Cuiaba } \\
\end{array}$ & 0.123 & 0.069 & 878314.463 & $\begin{array}{l}\text { Float,Wide } \\
\text { Lane }\end{array}$ & 21 & 2.984 & Adjusted & 0.141 \\
\hline $\begin{array}{l}\text { BRAZ - RBMC } \\
\text { Brasilia-CUIB - RBMC } \\
\text { Cuiaba } \\
\end{array}$ & 0.065 & 0.125 & 878314.393 & \begin{tabular}{|l} 
Fixed,Wide \\
Lane
\end{tabular} & 25 & 3.034 & Adjusted & 0.141 \\
\hline \begin{tabular}{|l|} 
BRAZ - RBMC \\
Brasilia-MCLA - \\
RBMC Montes Claros \\
\end{tabular} & 0.049 & 0.086 & 435497.378 & \begin{tabular}{|l} 
Fixed,Wide \\
Lane
\end{tabular} & 26 & 2.835 & Adjusted & 0.099 \\
\hline \begin{tabular}{|l|} 
BRAZ - RBMC \\
Brasilia-MCLA - \\
RBMC Montes Claros \\
\end{tabular} & 0.072 & 0.069 & 435497.389 & $\begin{array}{l}\text { Float,Wide } \\
\text { Lane }\end{array}$ & 21 & 3.019 & Adjusted & 0.099 \\
\hline \begin{tabular}{|l|} 
CUIB - RBMC \\
Cuiaba-MCLA - \\
RBMC Montes Claros
\end{tabular} & 0.123 & 0.120 & 1307630.604 & \begin{tabular}{|l} 
Float,Wide \\
Lane
\end{tabular} & 27 & 3.436 & Adjusted & 0.172 \\
\hline
\end{tabular}

Figura B160: Elipses de Erro

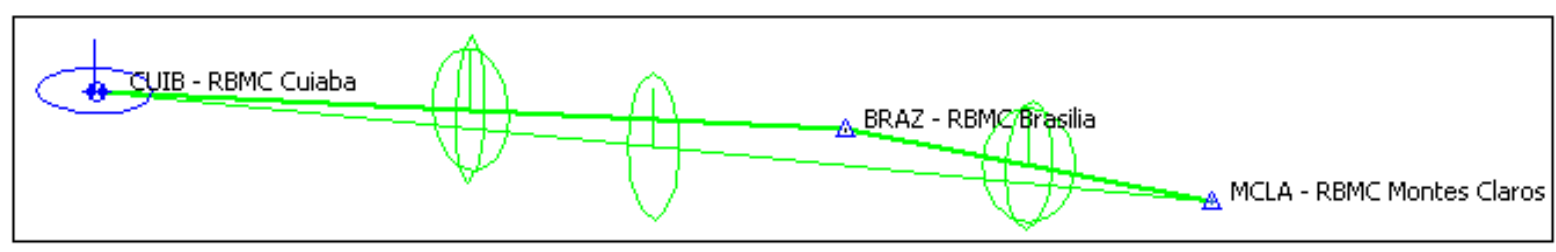

Coordenadas Ajustadas de CUIB:

E (UTM): $599737.3045 \mathrm{~m}$

N (UTM): $8280040.8191 \mathrm{~m}$

\section{B.4.2 2007}

\section{B.4.2.1 Verão (Dias Julianos 011 a 014)}

- $\underline{011 / 2007}$

A posteriori UWE: 0.6096848 , Bounds: ( $0.6770032,1.241639)$

TABELA B161: Resultado do Processamento 


\begin{tabular}{|c|c|c|c|c|c|c|c|c|}
\hline \multicolumn{9}{|c|}{ GPS Obs Report } \\
\hline Name & $\begin{array}{c}\text { Horizontal } \\
\text { Precision (m) }\end{array}$ & $\begin{array}{c}\text { Vertical } \\
\text { Precision } \\
\text { (m) }\end{array}$ & $\begin{array}{l}\text { Distance } \\
\text { (m) }\end{array}$ & $\begin{array}{l}\text { Solution } \\
\text { Type }\end{array}$ & \begin{tabular}{|c} 
GPS \\
Satellites
\end{tabular} & PDOP & Status & RMS \\
\hline $\begin{array}{l}\text { BRAZ - RBMC } \\
\text { Brasilia-CUIB - RBMC } \\
\text { Cuiaba }\end{array}$ & 0.096 & 0.103 & 878314.351 & $\begin{array}{l}\text { Fixed,Wide } \\
\text { Lane }\end{array}$ & 28 & 6.658 & Adjusted & 0.141 \\
\hline $\begin{array}{l}\text { BRAZ - RBMC } \\
\text { Brasilia-MCLA - } \\
\text { RBMC Montes Claros }\end{array}$ & 0.053 & 0.084 & 435497.393 & $\begin{array}{l}\text { Fixed,Wide } \\
\text { Lane }\end{array}$ & 28 & 51.956 & Adjusted & 0.099 \\
\hline $\begin{array}{l}\text { CUIB - RBMC } \\
\text { Cuiaba-MCLA - } \\
\text { RBMC Montes Claros }\end{array}$ & 0.125 & 0.119 & 1307630.541 & $\begin{array}{l}\text { Float, Wide } \\
\text { Lane }\end{array}$ & 28 & 35.660 & Adjusted & 0.173 \\
\hline
\end{tabular}

Figura B161: Elipses de Erro

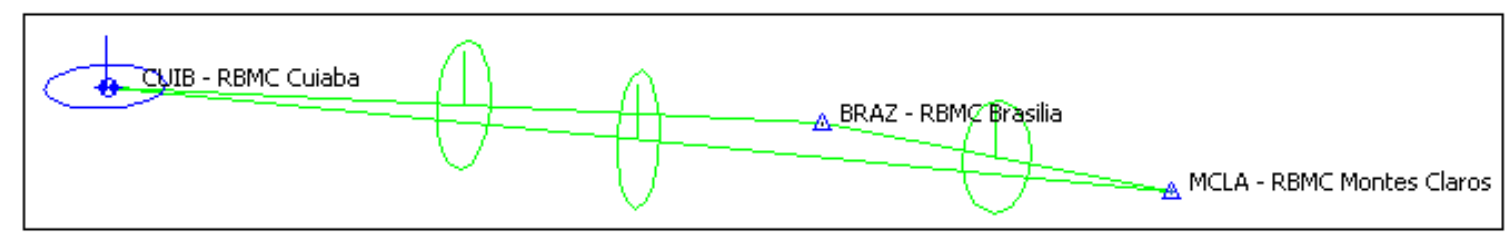

Coordenadas Ajustadas de CUIB:

E (UTM): $599737.3481 \mathrm{~m}$

N (UTM): $8280040.8426 \mathrm{~m}$

- $\underline{012 / 2007}$

A posteriori UWE: 0.6806499 , Bounds: ( $0.6770032,1.241639)$

TABELA B162: Resultado do Processamento 


\begin{tabular}{|c|c|c|c|c|c|c|c|c|}
\hline \multicolumn{9}{|c|}{ GPS Obs Report } \\
\hline Name & $\begin{array}{c}\text { Horizontal } \\
\text { Precision (m) }\end{array}$ & $\begin{array}{c}\text { Vertical } \\
\text { Precision } \\
\text { (m) }\end{array}$ & $\begin{array}{l}\text { Distance } \\
\text { (m) }\end{array}$ & $\begin{array}{l}\text { Solution } \\
\text { Type }\end{array}$ & $\begin{array}{c}\text { GPS } \\
\text { Satellites }\end{array}$ & PDOP & Status & RMS \\
\hline $\begin{array}{l}\text { BRAZ - RBMC } \\
\text { Brasilia-CUIB - RBMC } \\
\text { Cuiaba }\end{array}$ & 0.104 & 0.095 & 878314.442 & $\begin{array}{l}\text { Float,Wide } \\
\text { Lane }\end{array}$ & 27 & 3.033 & Adjusted & 0.141 \\
\hline $\begin{array}{l}\text { BRAZ - RBMC } \\
\text { Brasilia-MCLA - } \\
\text { RBMC Montes Claros }\end{array}$ & 0.047 & 0.087 & 435497.387 & $\begin{array}{l}\text { Fixed,Wide } \\
\text { Lane }\end{array}$ & 29 & 4.282 & Adjusted & 0.099 \\
\hline $\begin{array}{l}\text { CUIB - RBMC } \\
\text { Cuiaba-MCLA - } \\
\text { RBMC Montes Claros }\end{array}$ & 0.125 & 0.119 & 1307630.678 & $\begin{array}{l}\text { Float, Wide } \\
\text { Lane }\end{array}$ & 27 & 4.755 & Adjusted & 0.173 \\
\hline
\end{tabular}

Figura B162: Elipses de Erro

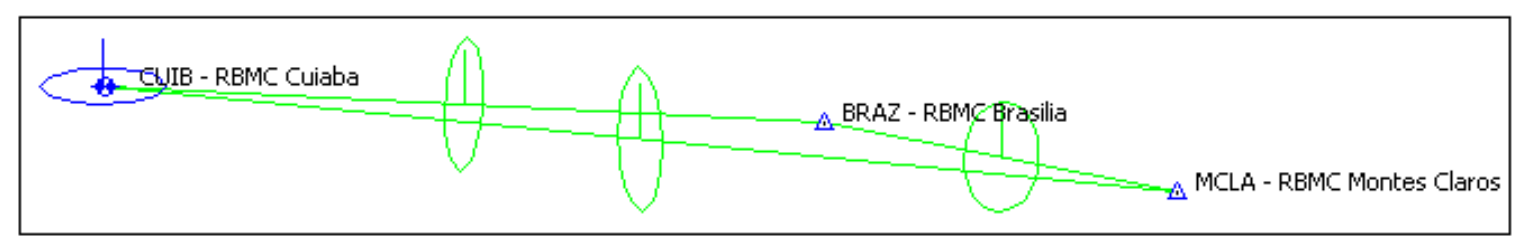

Coordenadas Ajustadas de CUIB:

E (UTM): $599737.2419 \mathrm{~m}$

N (UTM): $8280040.8185 \mathrm{~m}$

- $\underline{013 / 2007}$

A posteriori UWE: 0.6797143 , Bounds: ( $0.6770032,1.241639$ )

TABELA B163: Resultado do Processamento

\begin{tabular}{|c|c|c|c|c|c|c|c|c|}
\hline \multicolumn{9}{|c|}{ GPS Obs Report } \\
\hline Name & $\begin{array}{c}\text { Horizontal } \\
\text { Precision (m) }\end{array}$ & $\begin{array}{c}\text { Vertical } \\
\text { Precision } \\
\text { (m) }\end{array}$ & $\begin{array}{l}\text { Distance } \\
\text { (m) }\end{array}$ & $\begin{array}{l}\text { Solution } \\
\text { Type }\end{array}$ & $\begin{array}{c}\text { GPS } \\
\text { Satellites }\end{array}$ & PDOP & Status & RMS \\
\hline $\begin{array}{l}\text { BRAZ - RBMC } \\
\text { Brasilia-CUIB - RBMC } \\
\text { Cuiaba }\end{array}$ & 0.103 & 0.097 & 878314.462 & \begin{tabular}{|l} 
Float,Wide \\
Lane
\end{tabular} & 27 & 3.197 & Adjusted & $\mid 0.141$ \\
\hline $\begin{array}{l}\text { BRAZ - RBMC } \\
\text { Brasilia-MCLA - } \\
\text { RBMC Montes Claros }\end{array}$ & 0.049 & 0.087 & 435497.400 & $\begin{array}{l}\text { Fixed,Wide } \\
\text { Lane }\end{array}$ & 29 & 2.873 & Adjusted & 0.100 \\
\hline $\begin{array}{l}\text { CUIB - RBMC } \\
\text { Cuiaba-MCLA - } \\
\text { RBMC Montes Claros }\end{array}$ & 0.129 & 0.114 & 1307630.634 & $\begin{array}{l}\text { Float,Wide } \\
\text { Lane }\end{array}$ & 27 & 4.798 & Adjusted & $\mid 0.172$ \\
\hline
\end{tabular}

Figura B163: Elipses de Erro 


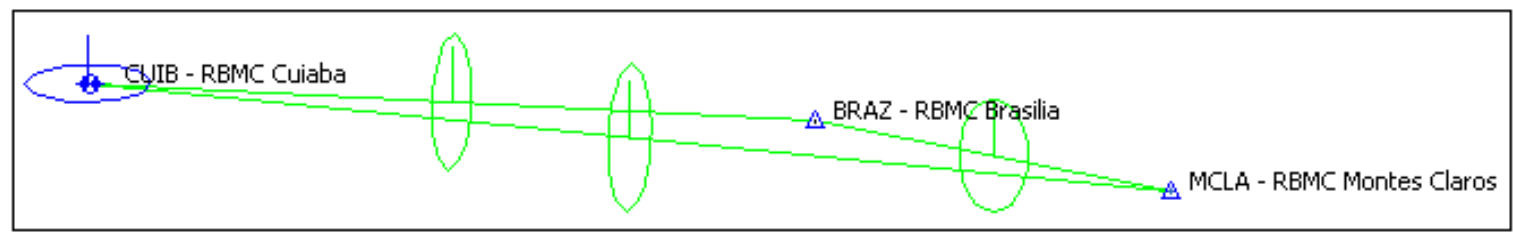

Coordenadas Ajustadas de CUIB:

E (UTM): $599737.2418 \mathrm{~m}$

N (UTM): $8280040.8465 \mathrm{~m}$

- $\underline{014 / 2007}$

A posteriori UWE: 0.8217363 , Bounds: $(0.6770032,1.241639)$

TABELA B164: Resultado do Processamento

\begin{tabular}{|c|c|c|c|c|c|c|c|c|}
\hline \multicolumn{9}{|c|}{ GPS Obs Report } \\
\hline Name & $\mid \begin{array}{c}\text { Horizontal } \\
\text { Precision (m) }\end{array}$ & $\begin{array}{l}\text { Vertical } \\
\text { Precision } \\
\text { (m) }\end{array}$ & $\begin{array}{l}\text { Distance } \\
\text { (m) }\end{array}$ & $\begin{array}{l}\text { Solution } \\
\text { Type }\end{array}$ & $\begin{array}{c}\text { GPS } \\
\text { Satellites }\end{array}$ & PDOP & Status & RMS \\
\hline $\begin{array}{l}\text { BRAZ - RBMC } \\
\text { Brasilia-CUIB - RBMC } \\
\text { Cuiaba }\end{array}$ & 0.104 & 0.096 & 878314.466 & $\begin{array}{l}\text { Float,Wide } \\
\text { Lane }\end{array}$ & 27 & 3.140 & Adjusted & 0.141 \\
\hline $\begin{array}{l}\text { BRAZ - RBMC } \\
\text { Brasilia-MCLA - } \\
\text { RBMC Montes Claros }\end{array}$ & 0.047 & 0.087 & 435497.382 & $\begin{array}{l}\text { Fixed,Wide } \\
\text { Lane }\end{array}$ & 29 & 2.867 & Adjusted & 0.099 \\
\hline $\begin{array}{l}\text { CUIB - RBMC } \\
\text { Cuiaba-MCLA - } \\
\text { RBMC Montes Claros }\end{array}$ & 0.131 & 0.112 & 1307630.627 & $\begin{array}{l}\text { Float,Wide } \\
\text { Lane }\end{array}$ & 27 & 3.442 & Adjusted & 0.172 \\
\hline
\end{tabular}

Figura B164: Elipses de Erro

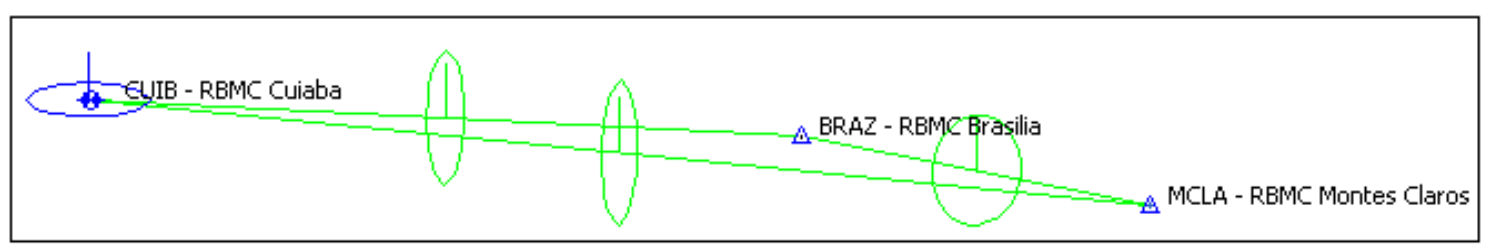

Coordenadas Ajustadas de CUIB: 
E (UTM): $599737.2435 \mathrm{~m}$

N (UTM): $8280040.8289 \mathrm{~m}$

\section{B.4.2.2 Outono (Dias Julianos 101 a 104)}

- $101 / 2007$

A posteriori UWE: 0.9275951 , Bounds: ( $0.6770032,1.241639)$

TABELA B165: Resultado do Processamento

\begin{tabular}{|c|c|c|c|c|c|c|c|c|}
\hline \multicolumn{9}{|c|}{ GPS Obs Report } \\
\hline Name & $\begin{array}{c}\text { Horizontal } \\
\text { Precision }(\mathbf{m})\end{array}$ & $\begin{array}{l}\text { Vertical } \\
\text { Precision } \\
\quad(\mathbf{m}) \\
\end{array}$ & $\begin{array}{l}\text { Distance } \\
\text { (m) }\end{array}$ & $\begin{array}{l}\text { Solution } \\
\text { Type }\end{array}$ & $\begin{array}{c}\text { GPS } \\
\text { Satellites }\end{array}$ & PDOP & Status & RMS \\
\hline $\begin{array}{l}\text { BRAZ - } \\
\text { Brasilia-CUIB - } \\
\text { Cuiaba }\end{array}$ & 0.101 & 0.099 & 878314.401 & $\begin{array}{l}\text { Float,Wide } \\
\text { Lane }\end{array}$ & 30 & 2.918 & Adjusted & 0.141 \\
\hline $\begin{array}{l}\text { BRAZ - } \\
\text { Brasilia-MCLA - } \\
\text { RBMC Montes Claros }\end{array}$ & 0.074 & 0.066 & 435497.372 & $\begin{array}{l}\text { Float,Wide } \\
\text { Lane }\end{array}$ & 30 & 2.891 & Adjusted & 0.099 \\
\hline $\begin{array}{l}\text { CUIB - Cuiaba-MCLA } \\
\text { - RBMC Montes } \\
\text { Claros }\end{array}$ & 0.122 & 0.122 & 1307630.562 & $\begin{array}{l}\text { Float, Wide } \\
\text { Lane }\end{array}$ & 30 & 3.051 & Adjusted & 0.172 \\
\hline
\end{tabular}

Figura B165: Elipses de Erro

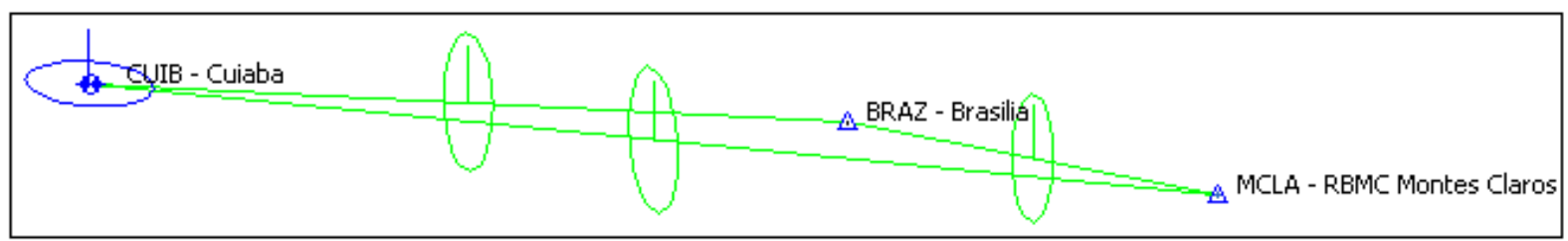

Coordenadas Ajustadas de CUIB:

E (UTM): $599737.3108 \mathrm{~m}$

N (UTM): $8280040.8213 \mathrm{~m}$

- $102 / 2007$

A posteriori UWE: 0.6925558 , Bounds: $(0.6770032,1.241639)$

TABELA B166: Resultado do Processamento 


\begin{tabular}{|c|c|c|c|c|c|c|c|c|}
\hline \multicolumn{9}{|c|}{ GPS Obs Report } \\
\hline Name & \begin{tabular}{|l} 
Horizontal \\
Precision (m)
\end{tabular} & $\begin{array}{c}\text { Vertical } \\
\text { Precision } \\
\text { (m) }\end{array}$ & $\begin{array}{l}\text { Distance } \\
\text { (m) }\end{array}$ & $\begin{array}{l}\text { Solution } \\
\text { Type }\end{array}$ & $\begin{array}{c}\text { GPS } \\
\text { Satellites }\end{array}$ & PDOP & Status & RMS \\
\hline $\begin{array}{l}\text { BRAZ - RBMC } \\
\text { Brasilia-CUIB - RBMC } \\
\text { Cuiaba }\end{array}$ & 0.096 & 0.104 & 878314.382 & $\begin{array}{l}\text { Float,Wide } \\
\text { Lane }\end{array}$ & 30 & 2.919 & Adjusted & $\mid 0.142$ \\
\hline $\begin{array}{l}\text { BRAZ - RBMC } \\
\text { Brasilia-MCLA - } \\
\text { RBMC Montes Claros }\end{array}$ & 0.076 & 0.064 & 435497.390 & $\begin{array}{l}\text { Float, Wide } \\
\text { Lane }\end{array}$ & 30 & 2.898 & Adjusted & $\mid 0.100$ \\
\hline $\begin{array}{l}\text { CUIB - RBMC } \\
\text { Cuiaba-MCLA - } \\
\text { RBMC Montes Claros }\end{array}$ & 0.124 & 0.119 & 1307630.522 & $\begin{array}{l}\text { Float,Wide } \\
\text { Lane }\end{array}$ & 30 & 3.351 & Adjusted & $\mid 0.172$ \\
\hline
\end{tabular}

Figura B166: Elipses de Erro

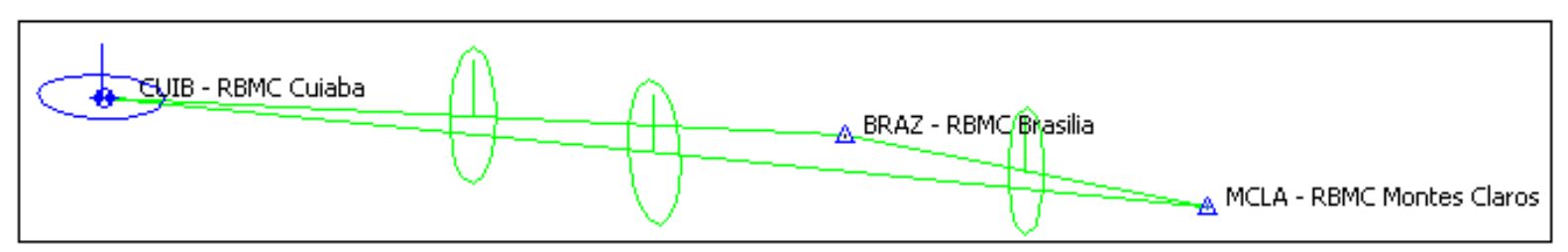

Coordenadas Ajustadas de CUIB:

E (UTM): $599737.3513 \mathrm{~m}$

N (UTM): $8280040.8297 \mathrm{~m}$

- $103 / 2007$

A posteriori UWE: 1.1435913 , Bounds: ( $0.6770032,1.241639$ )

TABELA B167: Resultado do Processamento 


\begin{tabular}{|c|c|c|c|c|c|c|c|c|}
\hline \multicolumn{9}{|c|}{ GPS Obs Report } \\
\hline Name & \begin{tabular}{|l} 
Horizontal \\
Precision (m)
\end{tabular} & $\begin{array}{c}\text { Vertical } \\
\text { Precision } \\
\text { (m) }\end{array}$ & $\begin{array}{l}\text { Distance } \\
\text { (m) }\end{array}$ & $\begin{array}{l}\text { Solution } \\
\text { Type }\end{array}$ & $\begin{array}{c}\text { GPS } \\
\text { Satellites }\end{array}$ & PDOP & Status & RMS \\
\hline $\begin{array}{l}\text { BRAZ - RBMC } \\
\text { Brasilia-CUIB - RBMC } \\
\text { Cuiaba }\end{array}$ & 0.108 & 0.098 & 878314.344 & $\begin{array}{l}\text { Float,Wide } \\
\text { Lane }\end{array}$ & 30 & 2.918 & Adjusted & $\mid 0.146$ \\
\hline \begin{tabular}{|l|} 
BRAZ - RBMC \\
Brasilia-MCLA - \\
RBMC Montes Claros \\
\end{tabular} & 0.071 & 0.070 & 435497.371 & $\begin{array}{l}\text { Float,Wide } \\
\text { Lane }\end{array}$ & 30 & 2.870 & Adjusted & $\mid 0.099$ \\
\hline $\begin{array}{l}\text { CUIB - RBMC } \\
\text { Cuiaba-MCLA - } \\
\text { RBMC Montes Claros }\end{array}$ & 0.128 & 0.116 & 1307630.509 & $\begin{array}{l}\text { Float,Wide } \\
\text { Lane }\end{array}$ & 30 & 3.377 & Adjusted & $\mid 0.173$ \\
\hline
\end{tabular}

Figura B167: Elipses de Erro

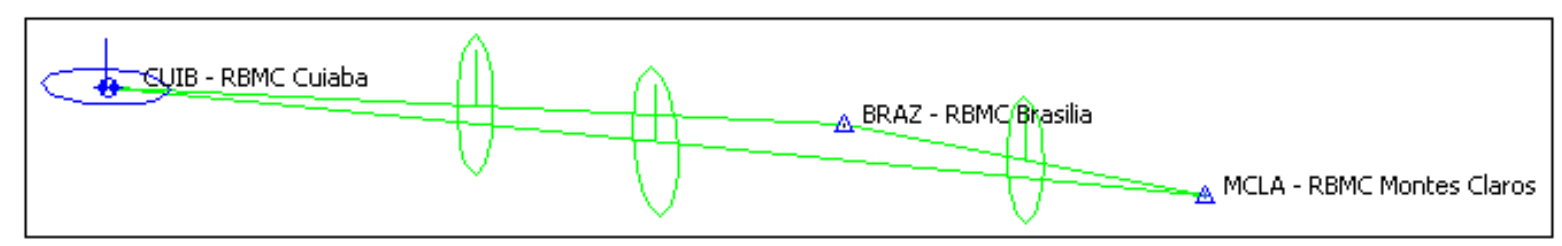

Coordenadas Ajustadas de CUIB:

E (UTM): $599737.3814 \mathrm{~m}$

N (UTM): $8280040.8289 \mathrm{~m}$

- $104 / 2007$

A posteriori UWE: 0.698205 , Bounds: ( $0.6770032,1.241639$ )

TABELA B168: Resultado do Processamento 


\begin{tabular}{|c|c|c|c|c|c|c|c|c|}
\hline \multicolumn{9}{|c|}{ GPS Obs Report } \\
\hline Name & $\begin{array}{c}\text { Horizontal } \\
\text { Precision (m) }\end{array}$ & $\begin{array}{c}\text { Vertical } \\
\text { Precision } \\
\text { (m) }\end{array}$ & $\begin{array}{l}\text { Distance } \\
\text { (m) }\end{array}$ & $\begin{array}{l}\text { Solution } \\
\text { Type }\end{array}$ & $\begin{array}{c}\text { GPS } \\
\text { Satellites }\end{array}$ & PDOP & Status & RMS \\
\hline $\begin{array}{l}\text { BRAZ - RBMC } \\
\text { Brasilia-CUIB - RBMC } \\
\text { Cuiaba }\end{array}$ & 0.100 & 0.099 & 878314.382 & $\begin{array}{l}\text { Float,Wide } \\
\text { Lane }\end{array}$ & 30 & 2.926 & Adjusted & 0.141 \\
\hline $\begin{array}{l}\text { BRAZ - RBMC } \\
\text { Brasilia-MCLA - } \\
\text { RBMC Montes Claros }\end{array}$ & 0.046 & 0.088 & 435497.350 & $\begin{array}{l}\text { Fixed,Wide } \\
\text { Lane }\end{array}$ & 30 & 2.807 & Adjusted & 0.099 \\
\hline $\begin{array}{l}\text { CUIB - RBMC } \\
\text { Cuiaba-MCLA - } \\
\text { RBMC Montes Claros }\end{array}$ & 0.125 & 0.119 & 1307630.501 & $\begin{array}{l}\text { Float, Wide } \\
\text { Lane }\end{array}$ & 30 & 3.382 & Adjusted & 0.173 \\
\hline
\end{tabular}

Figura B168: Elipses de Erro

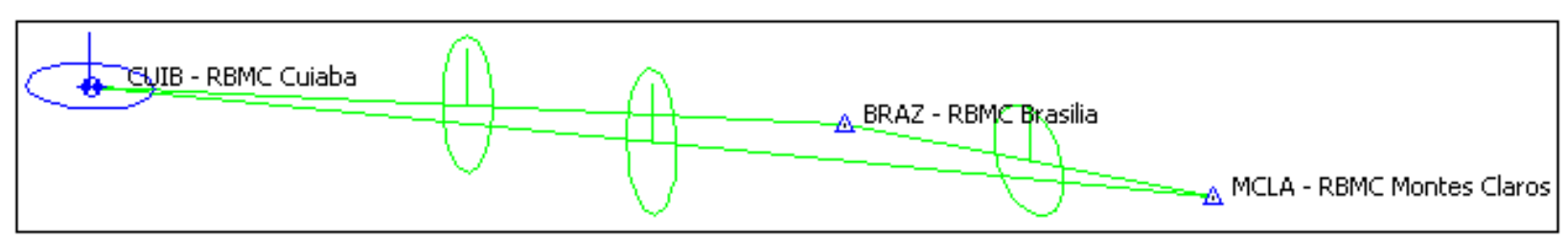

Coordenadas Ajustadas de CUIB:

E (UTM): $599737.3552 \mathrm{~m}$

N (UTM): $8280040.8315 \mathrm{~m}$

\section{B.4.2.3 Inverno (Dias Julianos 193 a 196)}

- $193 / 2007$

A posteriori UWE: 0.9986103 , Bounds: $(0.6770032,1.241639)$

TABELA B169: Resultado do Processamento 


\begin{tabular}{|c|c|c|c|c|c|c|c|c|}
\hline \multicolumn{9}{|c|}{ GPS Obs Report } \\
\hline Name & $\begin{array}{c}\text { Horizontal } \\
\text { Precision (m) }\end{array}$ & $\begin{array}{c}\text { Vertical } \\
\text { Precision } \\
\text { (m) }\end{array}$ & $\begin{array}{l}\text { Distance } \\
\text { (m) }\end{array}$ & $\begin{array}{l}\text { Solution } \\
\text { Type }\end{array}$ & $\begin{array}{c}\text { GPS } \\
\text { Satellites }\end{array}$ & PDOP & Status & RMS \\
\hline $\begin{array}{l}\text { BRAZ - RBMC } \\
\text { Brasilia-CUIB - RBMC } \\
\text { Cuiaba }\end{array}$ & 0.105 & 0.094 & 878314.352 & $\begin{array}{l}\text { Float,Wide } \\
\text { Lane }\end{array}$ & 30 & 2.863 & Adjusted & 0.141 \\
\hline $\begin{array}{l}\text { BRAZ - RBMC } \\
\text { Brasilia-MCLA - } \\
\text { RBMC Montes Claros }\end{array}$ & 0.066 & 0.075 & 435497.394 & $\begin{array}{l}\text { Fixed,Wide } \\
\text { Lane }\end{array}$ & 30 & 2.895 & Adjusted & 0.100 \\
\hline $\begin{array}{l}\text { CUIB - RBMC } \\
\text { Cuiaba-MCLA - } \\
\text { RBMC Montes Claros }\end{array}$ & 0.128 & 0.115 & 1307630.494 & $\begin{array}{l}\text { Float, Wide } \\
\text { Lane }\end{array}$ & 30 & 3.289 & Adjusted & 0.172 \\
\hline
\end{tabular}

Figura B169: Elipses de Erro

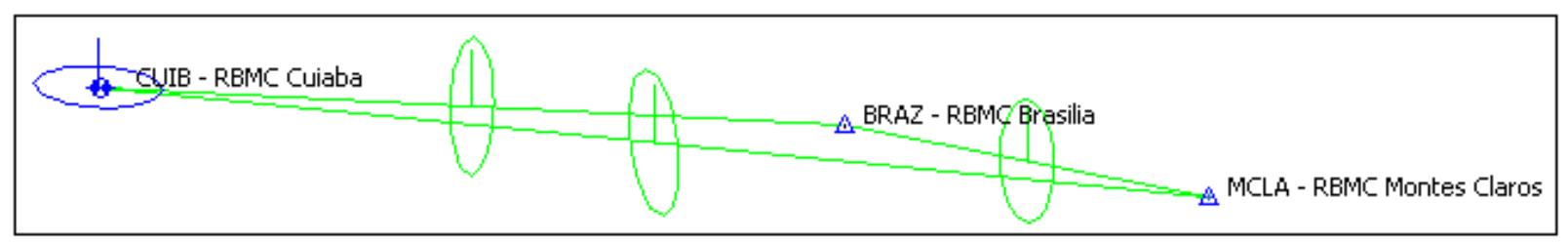

Coordenadas Ajustadas de CUIB:

E (UTM): $599737.3626 \mathrm{~m}$

N (UTM): $8280040.8247 \mathrm{~m}$

- $194 / 2007$

A posteriori UWE: 1.2294835 , Bounds: ( $0.6770032,1.241639$ )

TABELA B170: Resultado do Processamento

\begin{tabular}{|c|c|c|c|c|c|c|c|c|}
\hline \multicolumn{9}{|c|}{ GPS Obs Report } \\
\hline Name & $\begin{array}{c}\text { Horizontal } \\
\text { Precision (m) }\end{array}$ & $\begin{array}{l}\text { Vertical } \\
\text { Precision } \\
\text { (m) }\end{array}$ & $\begin{array}{l}\text { Distance } \\
\quad(\mathbf{m})\end{array}$ & $\begin{array}{l}\text { Solution } \\
\text { Type }\end{array}$ & $\begin{array}{c}\text { GPS } \\
\text { Satellites }\end{array}$ & PDOP & Status & RMS \\
\hline $\begin{array}{l}\text { BRAZ - RBMC } \\
\text { Brasilia-CUIB - RBMC } \\
\text { Cuiaba }\end{array}$ & 0.108 & 0.091 & 878314.363 & $\begin{array}{l}\text { Float,Wide } \\
\text { Lane }\end{array}$ & 30 & 2.864 & Adjusted & 0.141 \\
\hline $\begin{array}{l}\text { BRAZ - RBMC } \\
\text { Brasilia-MCLA - } \\
\text { RBMC Montes Claros }\end{array}$ & 0.046 & 0.088 & 435497.367 & $\begin{array}{l}\text { Fixed,Wide } \\
\text { Lane }\end{array}$ & 30 & 2.870 & Adjusted & 0.099 \\
\hline $\begin{array}{l}\text { CUIB - RBMC } \\
\text { Cuiaba-MCLA }\end{array}$ & 0.130 & 0.114 & 1307630.517 & $\begin{array}{l}\text { Float,Wide } \\
\text { Lane }\end{array}$ & 30 & 3.259 & Adjusted & 0.173 \\
\hline
\end{tabular}


Figura B170: Elipses de Erro

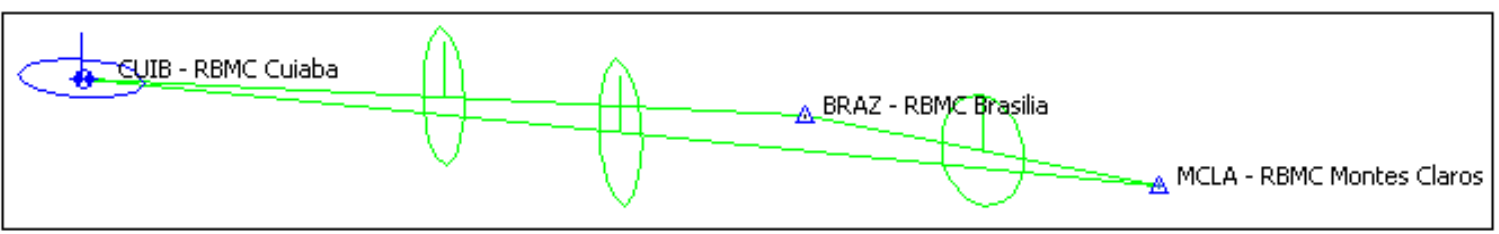

Coordenadas Ajustadas de CUIB:

E (UTM): $599737.3509 \mathrm{~m}$

N (UTM): $8280040.8162 \mathrm{~m}$

- $\underline{195 / 2007}$

A posteriori UWE: 0.7897375 , Bounds: ( $0.6770032,1.241639)$

TABELA B171: Resultado do Processamento

\begin{tabular}{|c|c|c|c|c|c|c|c|c|}
\hline \multicolumn{9}{|c|}{ GPS Obs Report } \\
\hline Name & \begin{tabular}{|c|} 
Horizontal \\
Precision (m)
\end{tabular} & $\begin{array}{l}\text { Vertical } \\
\text { Precision } \\
\text { (m) }\end{array}$ & $\begin{array}{l}\text { Distance } \\
\text { (m) }\end{array}$ & $\begin{array}{l}\text { Solution } \\
\text { Type }\end{array}$ & $\begin{array}{c}\text { GPS } \\
\text { Satellites }\end{array}$ & PDOP & Status & RMS \\
\hline $\begin{array}{l}\text { BRAZ - RBMC } \\
\text { Brasilia-CUIB - RBMC } \\
\text { Cuiaba } \\
\end{array}$ & 0.102 & 0.098 & 878314.355 & $\begin{array}{l}\text { Float,Wide } \\
\text { Lane }\end{array}$ & 30 & 2.863 & Adjusted & 0.141 \\
\hline $\begin{array}{l}\text { BRAZ - RBMC } \\
\text { Brasilia-MCLA - } \\
\text { RBMC Montes Claros }\end{array}$ & 0.047 & 0.087 & 435497.366 & $\begin{array}{l}\text { Fixed,Wide } \\
\text { Lane }\end{array}$ & 30 & 2.892 & Adjusted & 0.099 \\
\hline $\begin{array}{l}\text { CUIB - RBMC } \\
\text { Cuiaba-MCLA }\end{array}$ & 0.130 & 0.114 & 1307630.488 & \begin{tabular}{|l} 
Float,Wide \\
Lane
\end{tabular} & 30 & 3.286 & Adjusted & 0.173 \\
\hline
\end{tabular}

Figura B171: Elipses de Erro

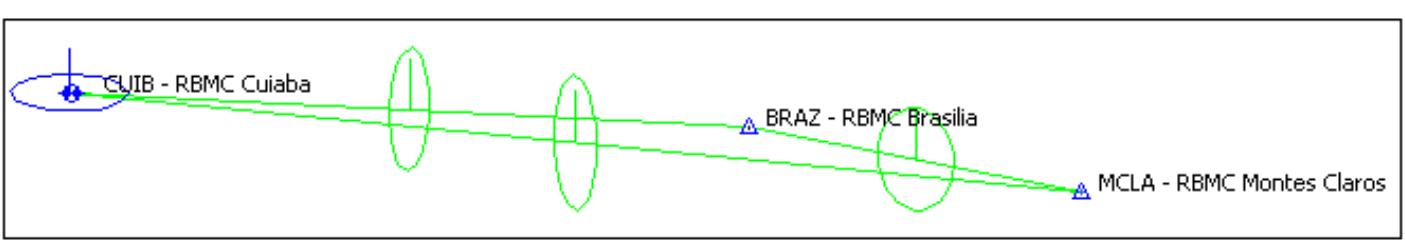

Coordenadas Ajustadas de CUIB:

E (UTM): $599737.3739 \mathrm{~m}$

N (UTM): $8280040.8213 \mathrm{~m}$ 
- $196 / 2007$

A posteriori UWE: 0.728103 , Bounds: ( $0.6770032,1.241639$ )

TABELA B172: Resultado do Processamento

\begin{tabular}{|c|c|c|c|c|c|c|c|c|}
\hline \multicolumn{9}{|c|}{ GPS Obs Report } \\
\hline Name & $\mid \begin{array}{c}\text { Horizontal } \\
\text { Precision }(\mathrm{m})\end{array}$ & $\begin{array}{l}\text { Vertical } \\
\text { Precision } \\
\text { (m) }\end{array}$ & $\begin{array}{c}\text { Distance } \\
\text { (m) }\end{array}$ & $\begin{array}{c}\text { Solution } \\
\text { Type }\end{array}$ & $\begin{array}{c}\text { GPS } \\
\text { Satellites }\end{array}$ & PDOP & Status & RMS \\
\hline \begin{tabular}{|l|} 
BRAZ - RBMC \\
Brasilia-CUIB - RBMC \\
Cuiaba
\end{tabular} & 0.103 & $\mid 0.096$ & 878314.359 & $\begin{array}{l}\text { Float,Wide } \\
\text { Lane }\end{array}$ & 30 & $\mid 2.862$ & Adjusted & 0.141 \\
\hline $\begin{array}{l}\text { BRAZ - RBMC } \\
\text { Brasilia-MCLA - } \\
\text { RBMC Montes Claros }\end{array}$ & $\mid 0.073$ & 0.067 & $\mid 435497.342$ & $\begin{array}{l}\text { Float, Wide } \\
\text { Lane }\end{array}$ & 30 & 2.866 & Adjusted & 0.099 \\
\hline $\begin{array}{l}\text { CUIB - RBMC } \\
\text { Cuiaba-MCLA - } \\
\text { RBMC Montes Claros }\end{array}$ & $\mid 0.126$ & $\mid 0.117$ & 1307630.509 & $\begin{array}{l}\text { Float, Wide } \\
\text { Lane }\end{array}$ & 30 & $\mid 3.258$ & Adjusted & 0.172 \\
\hline
\end{tabular}

Figura B172: Elipses de Erro

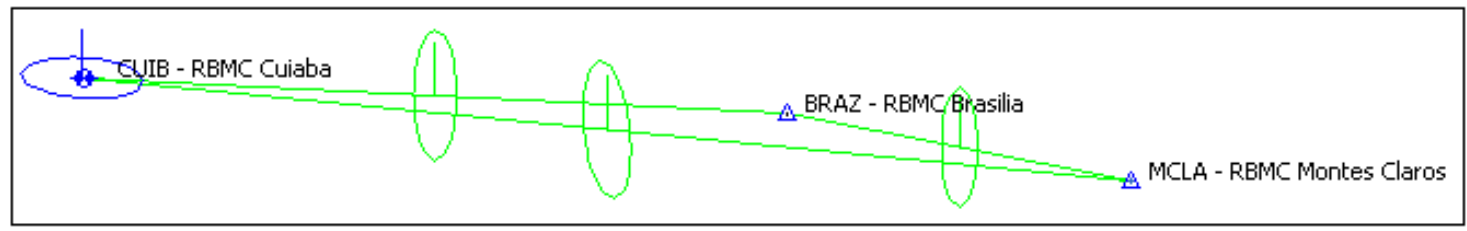

Coordenadas Ajustadas de CUIB:

E (UTM): $599737.3626 \mathrm{~m}$

N (UTM): $8280040.8223 \mathrm{~m}$

\section{B.4.2.4 Primavera (Dias Julianos 286 a 289)}

- $\underline{286 / 2007}$

A posteriori UWE: 1.044449 , Bounds: ( $0.6770032,1.241639)$ 
TABELA B173: Resultado do Processamento

\begin{tabular}{|c|c|c|c|c|c|c|c|c|}
\hline \multicolumn{9}{|c|}{ GPS Obs Report } \\
\hline Name & $\begin{array}{c}\text { Horizontal } \\
\text { Precision (m) }\end{array}$ & $\begin{array}{c}\text { Vertical } \\
\text { Precision } \\
\text { (m) }\end{array}$ & $\begin{array}{l}\text { Distance } \\
\text { (m) }\end{array}$ & $\begin{array}{c}\text { Solution } \\
\text { Type }\end{array}$ & $\begin{array}{c}\text { GPS } \\
\text { Satellites }\end{array}$ & PDOP & Status & RMS \\
\hline $\begin{array}{l}\text { BRAZ - } \\
\text { Brasilia-CUIB - } \\
\text { Cuiaba } \\
\end{array}$ & 0.102 & 0.097 & 878314.428 & $\begin{array}{l}\text { Float, Wide } \\
\text { Lane }\end{array}$ & 30 & 2.839 & Adjusted & 0.141 \\
\hline $\begin{array}{l}\text { BRAZ - } \\
\text { Brasilia-MCLA - } \\
\text { Montes Claros }\end{array}$ & 0.073 & 0.067 & 435497.355 & $\begin{array}{l}\text { Float,Wide } \\
\text { Lane }\end{array}$ & 30 & 2.797 & Adjusted & 0.099 \\
\hline $\begin{array}{l}\text { CUIB - } \\
\text { Cuiaba-MCLA - } \\
\text { Montes Claros }\end{array}$ & 0.125 & 0.118 & 1307630.557 & $\begin{array}{l}\text { Float,Wide } \\
\text { Lane }\end{array}$ & 30 & 3.199 & Adjusted & 0.172 \\
\hline
\end{tabular}

Figura B173: Elipses de Erro

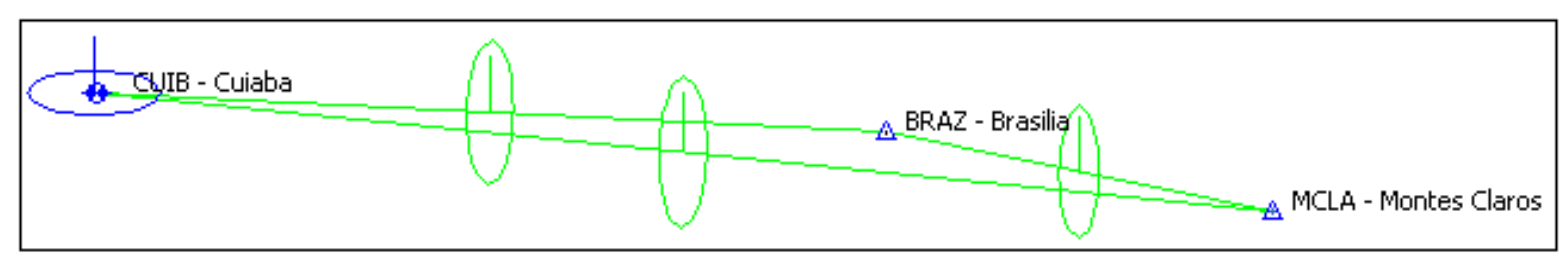

Coordenadas Ajustadas de CUIB:

E (UTM): $599737.3184 \mathrm{~m}$

N (UTM): $8280040.8695 \mathrm{~m}$

- $287 / 2007$

A posteriori UWE: 1.218302 , Bounds: ( $0.6770032,1.241639$ )

TABELA B174: Resultado do Processamento

\begin{tabular}{|c|c|c|c|c|c|c|c|c|}
\hline \multicolumn{9}{|c|}{ GPS Obs Report } \\
\hline Name & $\begin{array}{c}\text { Horizontal } \\
\text { Precision (m) }\end{array}$ & $\begin{array}{l}\text { Vertical } \\
\text { Precision } \\
\text { (m) }\end{array}$ & $\begin{array}{l}\text { Distance } \\
\text { (m) }\end{array}$ & $\begin{array}{l}\text { Solution } \\
\text { Type }\end{array}$ & $\begin{array}{c}\text { GPS } \\
\text { Satellites }\end{array}$ & PDOP & Status & RMS \\
\hline $\begin{array}{l}\text { BRAZ - } \\
\text { Brasilia-CUIB - } \\
\text { Cuiaba }\end{array}$ & 0.100 & 0.100 & 878314.420 & $\begin{array}{l}\text { Float,Wide } \\
\text { Lane }\end{array}$ & 30 & 2.839 & Adjusted & 0.141 \\
\hline $\begin{array}{l}\text { BRAZ - } \\
\text { Brasilia-MCLA - } \\
\text { Montes Claros }\end{array}$ & 0.075 & 0.064 & 435497.386 & $\begin{array}{l}\text { Float,Wide } \\
\text { Lane }\end{array}$ & 30 & 2.819 & Adjusted & 0.099 \\
\hline $\begin{array}{l}\text { CUIB - } \\
\text { Cuiaba-MCLA - } \\
\text { Montes Claros }\end{array}$ & 0.134 & 0.113 & 1307630.642 & $\begin{array}{l}\text { Float,Wide } \\
\text { Lane }\end{array}$ & 30 & 3.221 & Adjusted & 0.176 \\
\hline
\end{tabular}


Figura B174: Elipses de Erro

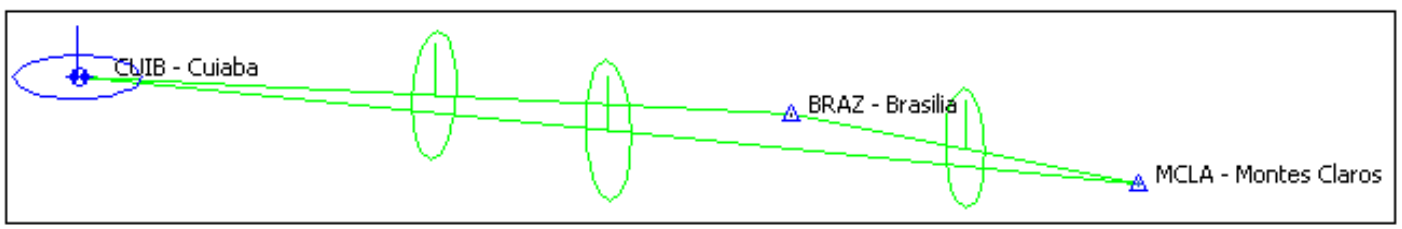

Coordenadas Ajustadas de CUIB:

E (UTM): $599737.2894 \mathrm{~m}$

N (UTM): $8280040.8321 \mathrm{~m}$

- $288 / 2007$

A posteriori UWE: 1.128544 , Bounds: ( $0.6770032,1.241639$ )

TABELA B175: Resultado do Processamento

\begin{tabular}{|c|c|c|c|c|c|c|c|c|}
\hline \multicolumn{9}{|c|}{ GPS Obs Report } \\
\hline Name & $\begin{array}{c}\text { Horizontal } \\
\text { Precision (m) }\end{array}$ & $\begin{array}{l}\text { Vertical } \\
\text { Precision } \\
\text { (m) }\end{array}$ & $\begin{array}{l}\text { Distance } \\
\text { (m) }\end{array}$ & $\begin{array}{l}\text { Solution } \\
\text { Type }\end{array}$ & $\begin{array}{c}\text { GPS } \\
\text { Satellites }\end{array}$ & PDOP & Status & RMS \\
\hline $\begin{array}{l}\text { BRAZ - } \\
\text { Brasilia-CUIB - } \\
\text { Cuiaba }\end{array}$ & 0.100 & 0.100 & 878314.409 & $\begin{array}{l}\text { Float,Wide } \\
\text { Lane }\end{array}$ & 30 & 2.840 & Adjusted & 0.141 \\
\hline $\begin{array}{l}\text { BRAZ - } \\
\text { Brasilia-MCLA - } \\
\text { Montes Claros } \\
\end{array}$ & 0.075 & 0.064 & 435497.342 & $\begin{array}{l}\text { Float,Wide } \\
\text { Lane }\end{array}$ & 30 & 2.821 & Adjusted & 0.099 \\
\hline $\begin{array}{l}\text { CUIB - } \\
\text { Cuiaba-MCLA }\end{array}$ & 0.137 & 0.104 & 1307630.532 & \begin{tabular}{|l} 
Float,Wide \\
Lane \\
\end{tabular} & 30 & 3.226 & Adjusted & 0.172 \\
\hline
\end{tabular}

Figura B175: Elipses de Erro

Coordenadas Ajustadas de CUIB:

E (UTM): $599737.3495 \mathrm{~m}$

N (UTM): $8280040.8226 \mathrm{~m}$ 
- $289 / 2007$

A posteriori UWE: 0.8591033 , Bounds: ( $0.6770032,1.241639)$

TABELA B176: Resultado do Processamento

\begin{tabular}{|c|c|c|c|c|c|c|c|c|}
\hline \multicolumn{9}{|c|}{ GPS Obs Report } \\
\hline Name & $\begin{array}{c}\text { Horizontal } \\
\text { Precision (m) }\end{array}$ & $\begin{array}{l}\text { Vertical } \\
\text { Precision } \\
\text { (m) }\end{array}$ & $\begin{array}{l}\text { Distance } \\
\text { (m) }\end{array}$ & $\begin{array}{l}\text { Solution } \\
\text { Type }\end{array}$ & $\begin{array}{c}\text { GPS } \\
\text { Satellites }\end{array}$ & PDOP & Status & RMS \\
\hline $\begin{array}{l}\text { BRAZ - } \\
\text { Brasilia-CUIB - } \\
\text { Cuiaba }\end{array}$ & 0.106 & 0.093 & 878314.399 & $\begin{array}{l}\text { Float,Wide } \\
\text { Lane }\end{array}$ & 30 & 2.840 & Adjusted & 0.141 \\
\hline $\begin{array}{l}\text { BRAZ - } \\
\text { Brasilia-MCLA - } \\
\text { Montes Claros }\end{array}$ & 0.073 & 0.067 & 435497.362 & $\begin{array}{l}\text { Float,Wide } \\
\text { Lane }\end{array}$ & 30 & 2.797 & Adjusted & 0.099 \\
\hline $\begin{array}{l}\text { CUIB - } \\
\text { Cuiaba-MCLA - } \\
\text { Montes Claros }\end{array}$ & 0.123 & 0.120 & 1307630.550 & $\begin{array}{l}\text { Float,Wide } \\
\text { Lane }\end{array}$ & 30 & 3.197 & Adjusted & 0.172 \\
\hline
\end{tabular}

Figura B176: Elipses de Erro

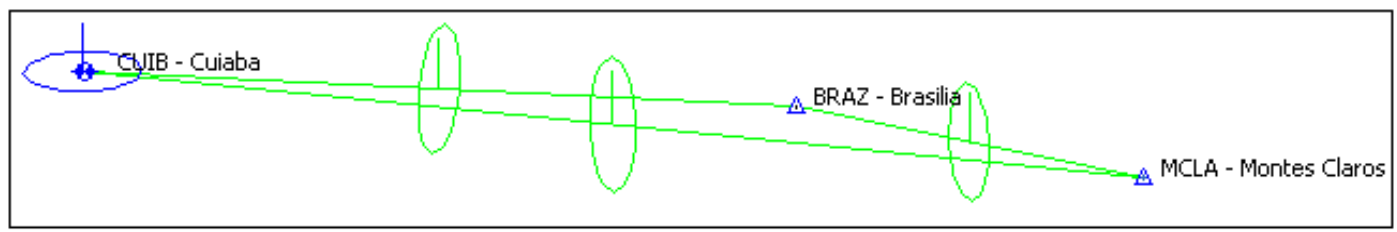

Coordenadas Ajustadas de CUIB:

E (UTM): $599737.3373 \mathrm{~m}$

$\mathrm{N}$ (UTM): $8280040.8350 \mathrm{~m}$

\section{B.4.32008}

\section{B.4.3.1 Verão (Dias Julianos 011 a 014)}

- $\underline{011 / 2008}$

A posteriori UWE: 0.7239017 , Bounds: ( $0.6770032,1.241639)$ 
TABELA B177: Resultado do Processamento

\begin{tabular}{|c|c|c|c|c|c|c|c|c|}
\hline \multicolumn{9}{|c|}{ GPS Obs Report } \\
\hline Name & \begin{tabular}{|c} 
Horizontal \\
Precision (m)
\end{tabular} & $\begin{array}{l}\text { Vertical } \\
\text { Precision } \\
\text { (m) }\end{array}$ & $\begin{array}{c}\text { Distance } \\
\text { (m) }\end{array}$ & $\begin{array}{c}\text { Solution } \\
\text { Type }\end{array}$ & $\begin{array}{c}\text { GPS } \\
\text { Satellites }\end{array}$ & PDOP & Status & RMS \\
\hline $\begin{array}{l}\text { BRAZ - } \\
\text { Brasilia-CUIB - } \\
\text { Cuiaba } \\
\end{array}$ & 0.096 & 0.104 & 878314.455 & $\begin{array}{l}\text { Float,Wide } \\
\text { Lane }\end{array}$ & 30 & 2.893 & Adjusted & 0.141 \\
\hline \begin{tabular}{|l} 
BRAZ - \\
Brasilia-MCLA - \\
Montes Claros \\
\end{tabular} & 0.057 & 0.081 & 435497.379 & $\begin{array}{l}\text { Fixed,Wide } \\
\text { Lane }\end{array}$ & 30 & 2.879 & Adjusted & 0.099 \\
\hline $\begin{array}{l}\text { CUIB - } \\
\text { Cuiaba-MCLA - } \\
\text { Montes Claros }\end{array}$ & 0.119 & 0.125 & 1307630.637 & $\begin{array}{l}\text { Float,Wide } \\
\text { Lane }\end{array}$ & 30 & 3.359 & Adjusted & 0.172 \\
\hline
\end{tabular}

Figura B177: Elipses de Erro

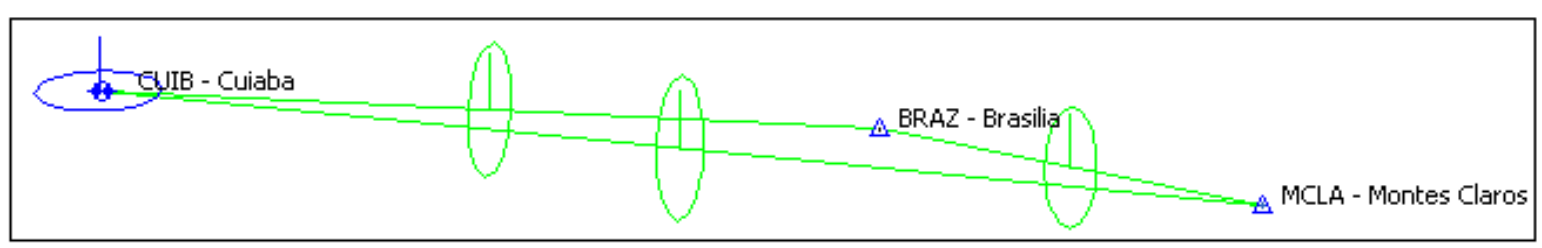

Coordenadas Ajustadas de CUIB:

E (UTM): $599737.2524 \mathrm{~m}$

N (UTM): $8280040.8249 \mathrm{~m}$

- $\underline{012 / 2008}$

A posteriori UWE: 0.7084365 , Bounds: ( $0.6770032,1.241639)$

TABELA B178: Resultado do Processamento

\begin{tabular}{|c|c|c|c|c|c|c|c|c|}
\hline \multicolumn{9}{|c|}{ GPS Obs Report } \\
\hline Name & $\begin{array}{c}\text { Horizontal } \\
\text { Precision (m) }\end{array}$ & $\begin{array}{l}\text { Vertical } \\
\text { Precision } \\
\text { (m) }\end{array}$ & $\begin{array}{l}\text { Distance } \\
\text { (m) }\end{array}$ & $\begin{array}{l}\text { Solution } \\
\text { Type }\end{array}$ & $\begin{array}{c}\text { GPS } \\
\text { Satellites }\end{array}$ & PDOP & Status & RMS \\
\hline \begin{tabular}{|l|} 
BRAZ - \\
Brasilia-CUIB - \\
Cuiaba \\
\end{tabular} & 0.103 & 0.096 & 878314.440 & $\begin{array}{l}\text { Float,Wide } \\
\text { Lane }\end{array}$ & 30 & 2.896 & Adjusted & 0.141 \\
\hline \begin{tabular}{|l|} 
BRAZ - \\
Brasilia-MCLA - \\
Montes Claros \\
\end{tabular} & 0.059 & 0.080 & 435497.396 & $\begin{array}{l}\text { Fixed,Wide } \\
\text { Lane }\end{array}$ & 30 & 2.905 & Adjusted & 0.100 \\
\hline $\begin{array}{l}\text { CUIB - } \\
\text { Cuiaba-MCLA }\end{array}$ & 0.120 & 0.124 & 1307630.616 & $\begin{array}{l}\text { Float,Wide } \\
\text { Lane }\end{array}$ & 30 & 3.393 & Adjusted & 0.172 \\
\hline
\end{tabular}


Figura B178: Elipses de Erro

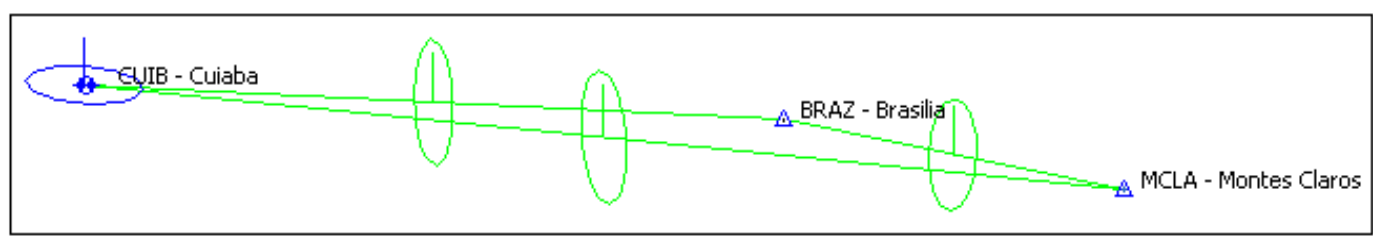

Coordenadas Ajustadas de CUIB:

E (UTM): $599737.2690 \mathrm{~m}$

N (UTM): $8280040.8131 \mathrm{~m}$

- $\underline{013 / 2008}$

A posteriori UWE: 1.052049 , Bounds: ( $0.6770032,1.241639$ )

TABELA B179: Resultado do Processamento

\begin{tabular}{|c|c|c|c|c|c|c|c|c|}
\hline \multicolumn{9}{|c|}{ GPS Obs Report } \\
\hline Name & $\begin{array}{c}\text { Horizontal } \\
\text { Precision (m) }\end{array}$ & $\begin{array}{l}\text { Vertical } \\
\text { Precision } \\
\text { (m) }\end{array}$ & $\begin{array}{l}\text { Distance } \\
\text { (m) }\end{array}$ & $\begin{array}{l}\text { Solution } \\
\text { Type }\end{array}$ & $\begin{array}{c}\text { GPS } \\
\text { Satellites }\end{array}$ & PDOP & Status & RMS \\
\hline \begin{tabular}{|l|} 
BRAZ - \\
Brasilia-CUIB - \\
Cuiaba \\
\end{tabular} & 0.106 & 0.093 & 878314.399 & $\begin{array}{l}\text { Float,Wide } \\
\text { Lane }\end{array}$ & 30 & 2.901 & Adjusted & 0.141 \\
\hline \begin{tabular}{|l|} 
BRAZ - \\
Brasilia-MCLA - \\
Montes Claros
\end{tabular} & 0.065 & 0.075 & 435497.390 & $\begin{array}{l}\text { Fixed,Wide } \\
\text { Lane }\end{array}$ & 30 & 2.899 & Adjusted & 0.099 \\
\hline $\begin{array}{l}\text { CUIB - } \\
\text { Cuiaba-MCLA }\end{array}$ & 0.129 & 0.114 & 1307630.593 & $\begin{array}{l}\text { Float,Wide } \\
\text { Lane }\end{array}$ & 30 & 3.379 & Adjusted & 0.172 \\
\hline
\end{tabular}

Figura B179: Elipses de Erro

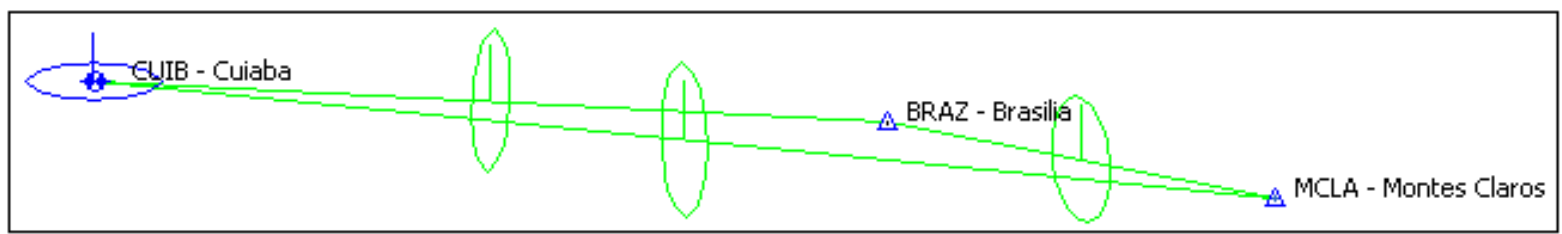

Coordenadas Ajustadas de CUIB:

E (UTM): $599737.3044 \mathrm{~m}$

N (UTM): $8280040.8019 \mathrm{~m}$ 
- $\underline{014 / 2008}$

A posteriori UWE: 1.0582321 , Bounds: ( $0.6770032,1.241639)$

TABELA B180: Resultado do Processamento

\begin{tabular}{|c|c|c|c|c|c|c|c|c|}
\hline \multicolumn{9}{|c|}{ GPS Obs Report } \\
\hline Name & $\begin{array}{c}\text { Horizontal } \\
\text { Precision (m) }\end{array}$ & $\begin{array}{l}\text { Vertical } \\
\text { Precision } \\
(\mathbf{m}) \\
\end{array}$ & $\begin{array}{l}\text { Distance } \\
\text { (m) }\end{array}$ & $\begin{array}{c}\text { Solution } \\
\text { Type }\end{array}$ & $\begin{array}{c}\text { GPS } \\
\text { Satellites }\end{array}$ & PDOP & Status & RMS \\
\hline $\begin{array}{l}\text { BRAZ - } \\
\text { Brasilia-CUIB - } \\
\text { Cuiaba }\end{array}$ & 0.103 & 0.097 & 878314.442 & $\begin{array}{l}\text { Float,Wide } \\
\text { Lane }\end{array}$ & 30 & 2.905 & Adjusted & 0.141 \\
\hline $\begin{array}{l}\text { BRAZ - } \\
\text { Brasilia-MCLA - } \\
\text { Montes Claros } \\
\end{array}$ & 0.068 & 0.072 & 435497.374 & $\begin{array}{l}\text { Fixed,Wide } \\
\text { Lane }\end{array}$ & 30 & 2.880 & Adjusted & 0.099 \\
\hline $\begin{array}{l}\text { CUIB - } \\
\text { Cuiaba-MCLA - } \\
\text { Montes Claros } \\
\end{array}$ & 0.122 & 0.123 & 1307630.517 & $\begin{array}{l}\text { Float,Wide } \\
\text { Lane }\end{array}$ & 30 & 3.358 & Adjusted & 0.173 \\
\hline
\end{tabular}

Figura B180: Elipses de Erro

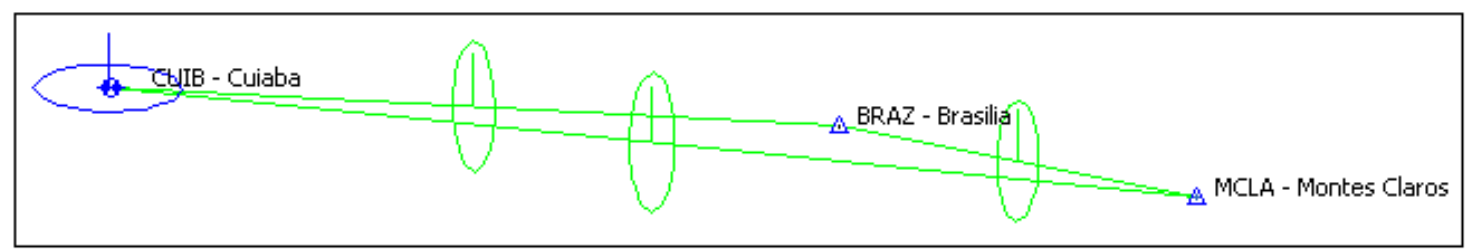

Coordenadas Ajustadas de CUIB:

E (UTM): $599737.3149 \mathrm{~m}$

N (UTM): $8280040.8237 \mathrm{~m}$

\section{B.4.3.2 Outono (Dias Julianos 102 a 105)}

- $\underline{102 / 2008}$

A posteriori UWE: 1.1209387 , Bounds: ( $0.6770032,1.241639)$ 
TABELA B181: Resultado do Processamento

\begin{tabular}{|c|c|c|c|c|c|c|c|c|}
\hline \multicolumn{9}{|c|}{ GPS Obs Report } \\
\hline Name & $\begin{array}{c}\text { Horizontal } \\
\text { Precision (m) }\end{array}$ & $\begin{array}{c}\text { Vertical } \\
\text { Precision } \\
\text { (m) }\end{array}$ & $\begin{array}{l}\text { Distance } \\
\text { (m) }\end{array}$ & $\begin{array}{c}\text { Solution } \\
\text { Type }\end{array}$ & $\begin{array}{c}\text { GPS } \\
\text { Satellites }\end{array}$ & PDOP & Status & RMS \\
\hline $\begin{array}{l}\text { BRAZ - } \\
\text { Brasilia-CUIB - } \\
\text { Cuiaba } \\
\end{array}$ & 0.110 & 0.088 & 878314.387 & $\begin{array}{l}\text { Float, Wide } \\
\text { Lane }\end{array}$ & 31 & 2.961 & Adjusted & 0.141 \\
\hline $\begin{array}{l}\text { BRAZ - } \\
\text { Brasilia-MCLA - } \\
\text { Montes Claros }\end{array}$ & 0.067 & 0.073 & 435497.366 & $\begin{array}{l}\text { Float,Wide } \\
\text { Lane }\end{array}$ & 31 & 2.883 & Adjusted & 0.099 \\
\hline $\begin{array}{l}\text { CUIB - } \\
\text { Cuiaba-MCLA - } \\
\text { Montes Claros }\end{array}$ & 0.122 & 0.122 & 1307630.563 & $\begin{array}{l}\text { Float,Wide } \\
\text { Lane }\end{array}$ & 31 & 3.320 & Adjusted & 0.172 \\
\hline
\end{tabular}

Figura B181: Elipses de Erro

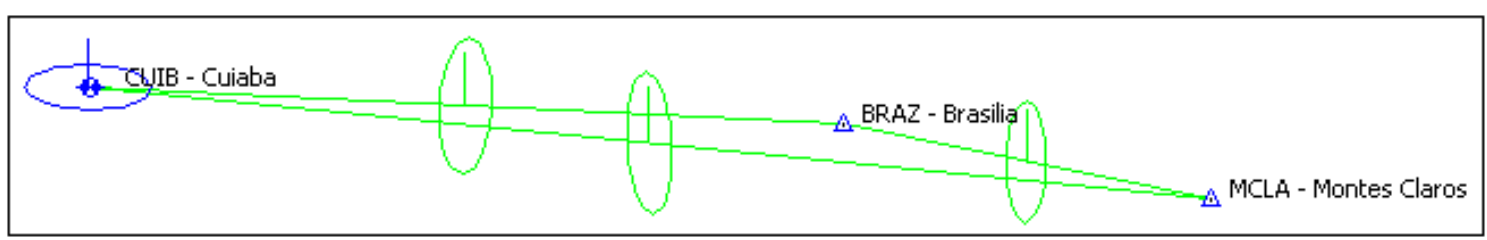

Coordenadas Ajustadas de CUIB:

E (UTM): $599737.3246 \mathrm{~m}$

N (UTM): $8280040.8442 \mathrm{~m}$

- $103 / 2008$

A posteriori UWE: 1.244564 , Bounds: ( $0.5291502,1.312758$ )

TABELA B182: Resultado do Processamento

\begin{tabular}{|c|c|c|c|c|c|c|c|c|}
\hline \multicolumn{9}{|c|}{ GPS Obs Report } \\
\hline Name & $\begin{array}{c}\text { Horizontal } \\
\text { Precision }(\mathbf{m})\end{array}$ & $\begin{array}{l}\text { Vertical } \\
\text { Precision } \\
\text { (m) }\end{array}$ & $\begin{array}{c}\text { Distance } \\
\text { (m) }\end{array}$ & $\begin{array}{l}\text { Solution } \\
\text { Type }\end{array}$ & $\begin{array}{c}\text { GPS } \\
\text { Satellites }\end{array}$ & PDOP & Status & RMS \\
\hline $\begin{array}{l}\text { BRAZ - } \\
\text { Brasilia-CUIB - } \\
\text { Cuiaba }\end{array}$ & 0.097 & 0.102 & 878314.402 & $\begin{array}{l}\text { Float,Wide } \\
\text { Lane }\end{array}$ & 31 & 2.954 & Adjusted & 0.141 \\
\hline $\begin{array}{l}\text { BRAZ - } \\
\text { Brasilia-MCLA - } \\
\text { Montes Claros }\end{array}$ & 0.069 & 0.092 & $\mid 435497.469$ & $\begin{array}{l}\text { Float,Wide } \\
\text { Lane }\end{array}$ & 31 & 2.859 & Adjusted & 0.116 \\
\hline CUIB-MCLA & & & & Failed & 31 & & $\begin{array}{l}\text { PostProcessed } \\
\text { Failed } \\
\end{array}$ & \\
\hline
\end{tabular}


Figura B182: Elipses de Erro

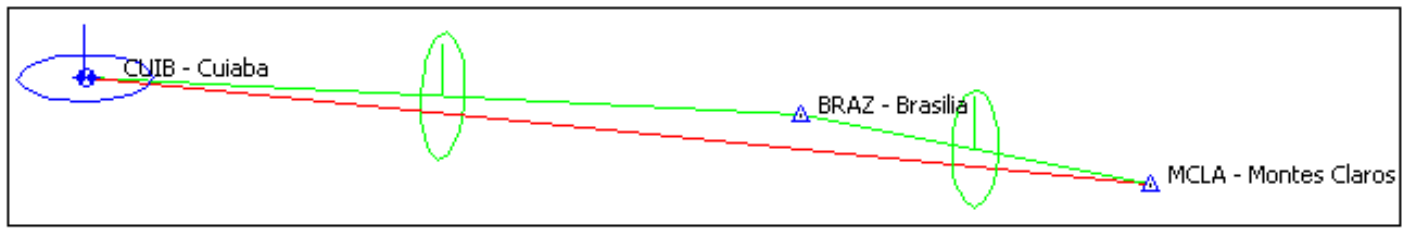

Coordenadas Ajustadas de CUIB:

E (UTM): $599737.3162 \mathrm{~m}$

N (UTM): $8280040.8412 \mathrm{~m}$

- $104 / 2008$

A posteriori UWE: 1.234934 , Bounds: ( $0.6770032,1.241639$ )

TABELA B183: Resultado do Processamento

\begin{tabular}{|c|c|c|c|c|c|c|c|c|}
\hline \multicolumn{9}{|c|}{ GPS Obs Report } \\
\hline Name & $\begin{array}{c}\text { Horizontal } \\
\text { Precision (m) }\end{array}$ & $\begin{array}{c}\text { Vertical } \\
\text { Precision (m) }\end{array}$ & \begin{tabular}{|c|} 
Distance \\
$(\mathrm{m})$
\end{tabular} & \begin{tabular}{|c|} 
Solution \\
Type
\end{tabular} & $\begin{array}{c}\text { GPS } \\
\text { Satellites }\end{array}$ & PDOP & Status & RMS \\
\hline BRAZ - CUIB & 0.102 & 0.098 & 878314.404 & $\begin{array}{l}\text { Float,Wide } \\
\text { Lane }\end{array}$ & 31 & 2.945 & Adjusted & 0.141 \\
\hline $\begin{array}{l}\text { BRAZ - } \\
\text { MCLA }\end{array}$ & 0.067 & 0.073 & 435497.354 & \begin{tabular}{|l|} 
Float,Wide \\
Lane \\
\end{tabular} & 31 & 2.849 & Adjusted & 0.099 \\
\hline CUIB-MCLA & 0.127 & 0.116 & 1307630.520 & $\begin{array}{l}\text { Float,Wide } \\
\text { Lane }\end{array}$ & 31 & 3.281 & Adjusted & 0.172 \\
\hline
\end{tabular}

Figura B183: Elipses de Erro

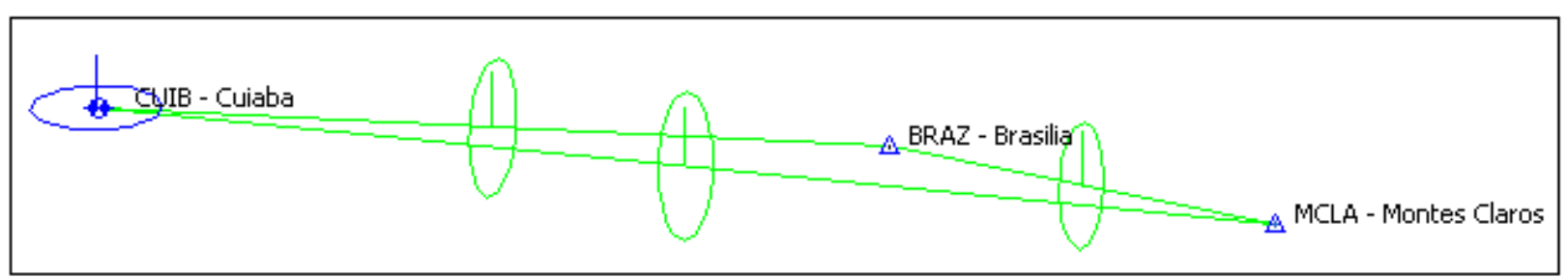

Coordenadas Ajustadas de CUIB:

E (UTM): $599737.3352 \mathrm{~m}$

N (UTM): $8280040.8359 \mathrm{~m}$ 
- $105 / 2008$

A posteriori UWE: 0.6982043 , Bounds: ( $0.6770032,1.241639)$

TABELA B184: Resultado do Processamento

\begin{tabular}{|c|c|c|c|c|c|c|c|c|}
\hline \multicolumn{9}{|c|}{ GPS Obs Report } \\
\hline Name & $\begin{array}{c}\text { Horizontal } \\
\text { Precision }(\mathbf{m})\end{array}$ & $\begin{array}{c}\text { Vertical } \\
\text { Precision } \\
\text { (m) }\end{array}$ & $\begin{array}{l}\text { Distance } \\
\text { (m) }\end{array}$ & $\begin{array}{l}\text { Solution } \\
\text { Type }\end{array}$ & $\begin{array}{c}\text { GPS } \\
\text { Satellites }\end{array}$ & PDOP & Status & RMS \\
\hline $\begin{array}{l}\text { BRAZ - } \\
\text { Brasilia-CUIB - } \\
\text { Cuiaba }\end{array}$ & 0.102 & 0.098 & 878314.400 & $\begin{array}{l}\text { Float,Wide } \\
\text { Lane }\end{array}$ & 31 & 2.938 & Adjusted & 0.142 \\
\hline $\begin{array}{l}\text { BRAZ - } \\
\text { Brasilia-MCLA - } \\
\text { Montes Claros }\end{array}$ & 0.067 & 0.073 & 435497.362 & $\begin{array}{l}\text { Float,Wide } \\
\text { Lane }\end{array}$ & 31 & 2.832 & Adjusted & 0.099 \\
\hline $\begin{array}{l}\text { CUIB - } \\
\text { Cuiaba-MCLA - } \\
\text { Montes Claros }\end{array}$ & 0.119 & 0.124 & 1307630.566 & $\begin{array}{l}\text { Float, Wide } \\
\text { Lane }\end{array}$ & 31 & 3.259 & Adjusted & 0.172 \\
\hline
\end{tabular}

Figura B184: Elipses de Erro

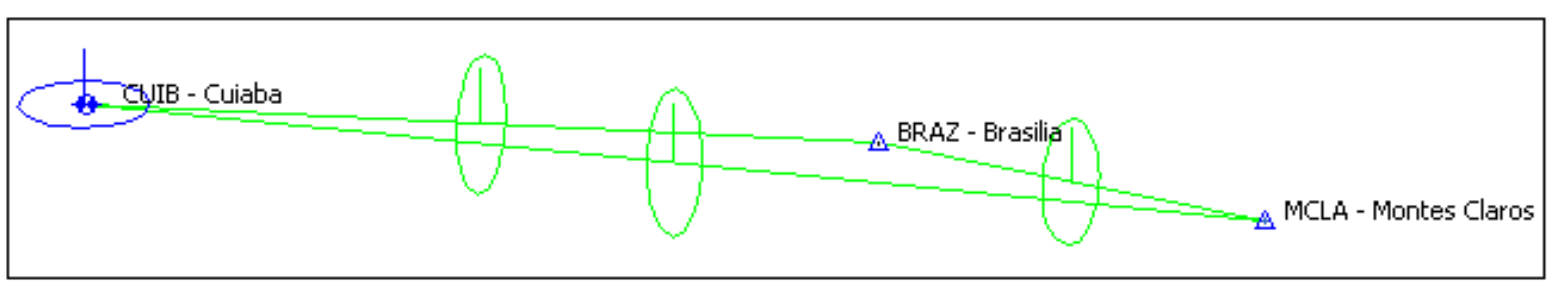

Coordenadas Ajustadas de CUIB:

E (UTM): $599737.3120 \mathrm{~m}$

N (UTM): $8280040.8292 \mathrm{~m}$

\section{B.4.3.3 Inverno (Dias Julianos 194 a 197)}

- $194 / 2008$

A posteriori UWE: 0.6891834 , Bounds: ( $0.6770032,1.241639)$ 
TABELA B185: Resultado do Processamento

\begin{tabular}{|c|c|c|c|c|c|c|c|c|}
\hline \multicolumn{9}{|c|}{ GPS Obs Report } \\
\hline Name & $\begin{array}{c}\text { Horizontal } \\
\text { Precision (m) }\end{array}$ & $\begin{array}{l}\text { Vertical } \\
\text { Precision } \\
\text { (m) }\end{array}$ & $\begin{array}{l}\text { Distance } \\
\text { (m) }\end{array}$ & $\begin{array}{c}\text { Solution } \\
\text { Type }\end{array}$ & $\begin{array}{c}\text { GPS } \\
\text { Satellites }\end{array}$ & PDOP & Status & RMS \\
\hline $\begin{array}{l}\text { BRAZ - } \\
\text { Brasilia-CUIB - } \\
\text { Cuiaba } \\
\end{array}$ & 0.065 & 0.125 & 878314.368 & $\begin{array}{l}\text { Fixed,Wide } \\
\text { Lane }\end{array}$ & 31 & 2.771 & Adjusted & 0.141 \\
\hline $\begin{array}{l}\text { BRAZ - } \\
\text { Brasilia-MCLA - } \\
\text { Montes Claros }\end{array}$ & 0.042 & 0.090 & 435497.358 & $\begin{array}{l}\text { Fixed,Wide } \\
\text { Lane }\end{array}$ & 28 & 2.921 & Adjusted & 0.099 \\
\hline $\begin{array}{l}\text { CUIB - } \\
\text { Cuiaba-MCLA - } \\
\text { Montes Claros }\end{array}$ & 0.075 & 0.155 & 1307630.535 & $\begin{array}{l}\text { Fixed,Wide } \\
\text { Lane }\end{array}$ & 28 & 3.270 & Adjusted & 0.172 \\
\hline
\end{tabular}

Figura B185: Elipses de Erro

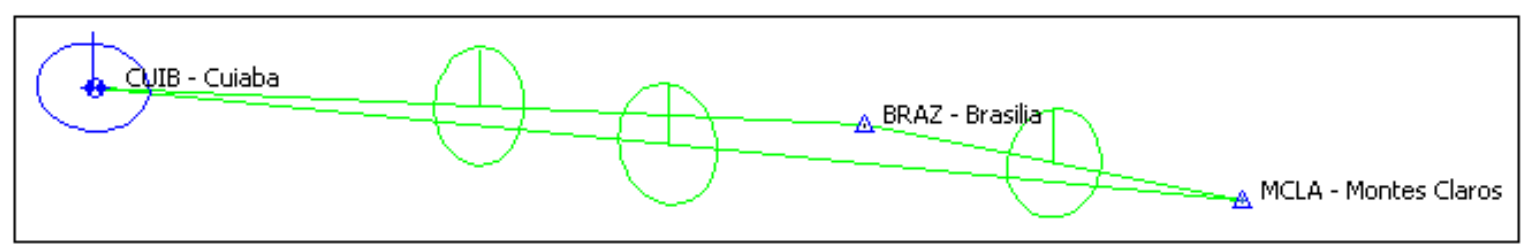

Coordenadas Ajustadas de CUIB:

E (UTM): $599737.3221 \mathrm{~m}$

N (UTM): $8280040.8329 \mathrm{~m}$

- $195 / 2008$

A posteriori UWE: 1.00294 , Bounds: ( $0.6770032,1.241639)$

TABELA B186: Resultado do Processamento

\begin{tabular}{|c|c|c|c|c|c|c|c|c|}
\hline \multicolumn{9}{|c|}{ GPS Obs Report } \\
\hline Name & $\begin{array}{c}\text { Horizontal } \\
\text { Precision (m) }\end{array}$ & $\begin{array}{l}\text { Vertical } \\
\text { Precision } \\
\text { (m) }\end{array}$ & $\begin{array}{l}\text { Distance } \\
\text { (m) }\end{array}$ & $\begin{array}{l}\text { Solution } \\
\text { Type }\end{array}$ & $\begin{array}{c}\text { GPS } \\
\text { Satellites }\end{array}$ & PDOP & Status & RMS \\
\hline $\begin{array}{l}\text { BRAZ - } \\
\text { Brasilia-CUIB - } \\
\text { Cuiaba }\end{array}$ & 0.099 & 0.100 & 878314.359 & $\begin{array}{l}\text { Float,Wide } \\
\text { Lane }\end{array}$ & 31 & 2.771 & Adjusted & 0.141 \\
\hline $\begin{array}{l}\text { BRAZ - } \\
\text { Brasilia-MCLA - } \\
\text { Montes Claros }\end{array}$ & 0.049 & 0.086 & 435497.336 & $\begin{array}{l}\text { Fixed,Wide } \\
\text { Lane }\end{array}$ & 31 & 2.799 & Adjusted & 0.099 \\
\hline $\begin{array}{l}\text { CUIB - } \\
\text { Cuiaba-MCLA - } \\
\text { Montes Claros }\end{array}$ & 0.122 & 0.120 & 1307630.490 & $\begin{array}{l}\text { Float,Wide } \\
\text { Lane }\end{array}$ & 31 & 3.167 & Adjusted & 0.172 \\
\hline
\end{tabular}


Figura B186: Elipses de Erro

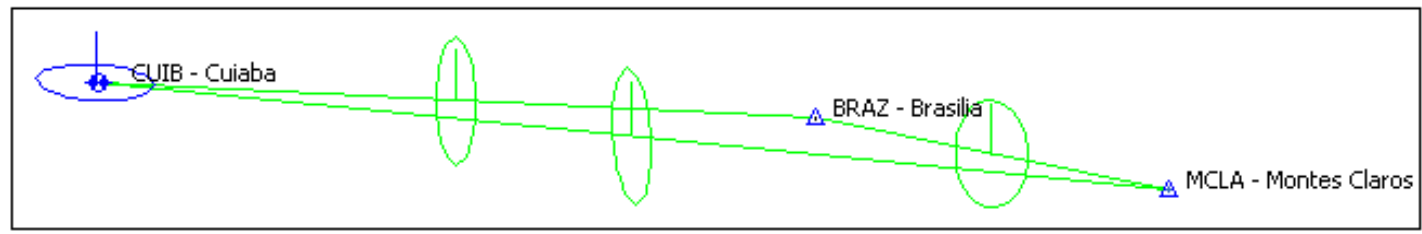

Coordenadas Ajustadas de CUIB:

E (UTM): $599737.3677 \mathrm{~m}$

N (UTM): $8280040.8342 \mathrm{~m}$

- $196 / 2008$

A posteriori UWE: 0.829071 , Bounds: ( $0.6770032,1.241639$ )

TABELA B187: Resultado do Processamento

\begin{tabular}{|c|c|c|c|c|c|c|c|c|}
\hline \multicolumn{9}{|c|}{ GPS Obs Report } \\
\hline Name & $\begin{array}{c}\text { Horizontal } \\
\text { Precision (m) }\end{array}$ & $\begin{array}{c}\text { Vertical } \\
\text { Precision (m) }\end{array}$ & \begin{tabular}{|c|} 
Distance \\
$(\mathrm{m})$
\end{tabular} & $\begin{array}{c}\text { Solution } \\
\text { Type }\end{array}$ & $\begin{array}{c}\text { GPS } \\
\text { Satellites }\end{array}$ & PDOP & Status & RMS \\
\hline BRAZ -CUIB & 0.068 & 0.123 & 878314.351 & $\begin{array}{l}\text { Fixed,Wide } \\
\text { Lane }\end{array}$ & 31 & 2.771 & Adjusted & 0.141 \\
\hline \begin{tabular}{|l} 
BRAZ \\
-MCLA
\end{tabular} & 0.044 & 0.089 & 435497.346 & $\begin{array}{l}\text { Fixed,Wide } \\
\text { Lane }\end{array}$ & 31 & 2.798 & Adjusted & 0.099 \\
\hline CUIB-MCLA & 0.119 & 0.130 & 1307630.532 & $\begin{array}{l}\text { Float,Wide } \\
\text { Lane }\end{array}$ & 31 & 3.174 & Adjusted & 0.176 \\
\hline
\end{tabular}

Figura B187: Elipses de Erro

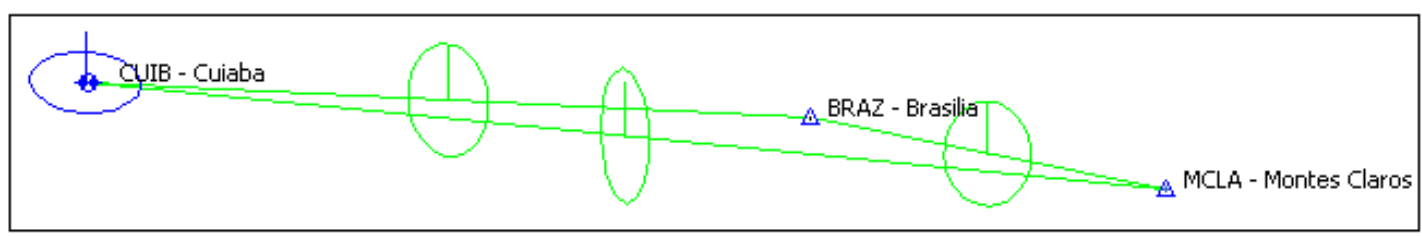

Coordenadas Ajustadas de CUIB:

E (UTM): $599737.3572 \mathrm{~m}$

N (UTM): $8280040.8223 \mathrm{~m}$ 
- $197 / 2008$

A posteriori UWE: 0.9875043 , Bounds: ( $0.6770032,1.241639)$

TABELA B188: Resultado do Processamento

\begin{tabular}{|c|c|c|c|c|c|c|c|c|}
\hline \multicolumn{9}{|c|}{ GPS Obs Report } \\
\hline Name & $\begin{array}{c}\text { Horizontal } \\
\text { Precision (m) }\end{array}$ & $\begin{array}{c}\text { Vertical } \\
\text { Precision } \\
\text { (m) }\end{array}$ & $\begin{array}{l}\text { Distance } \\
\text { (m) }\end{array}$ & $\begin{array}{c}\text { Solution } \\
\text { Type }\end{array}$ & $\begin{array}{c}\text { GPS } \\
\text { Satellites }\end{array}$ & PDOP & Status & RMS \\
\hline $\begin{array}{l}\text { BRAZ - } \\
\text { Brasilia-CUIB - } \\
\text { Cuiaba }\end{array}$ & 0.069 & 0.122 & 878314.347 & $\begin{array}{l}\text { Fixed,Wide } \\
\text { Lane }\end{array}$ & 31 & 2.771 & Adjusted & 0.141 \\
\hline $\begin{array}{l}\text { BRAZ - } \\
\text { Brasilia-MCLA - } \\
\text { Montes Claros } \\
\end{array}$ & 0.047 & 0.087 & 435497.343 & $\begin{array}{l}\text { Fixed,Wide } \\
\text { Lane }\end{array}$ & 31 & 2.796 & Adjusted & 0.099 \\
\hline $\begin{array}{l}\text { CUIB - } \\
\text { Cuiaba-MCLA - } \\
\text { Montes Claros } \\
\end{array}$ & 0.118 & 0.125 & 1307630.469 & $\begin{array}{l}\text { Float, Wide } \\
\text { Lane }\end{array}$ & 31 & 3.174 & Adjusted & 0.172 \\
\hline
\end{tabular}

Figura B188: Elipses de Erro

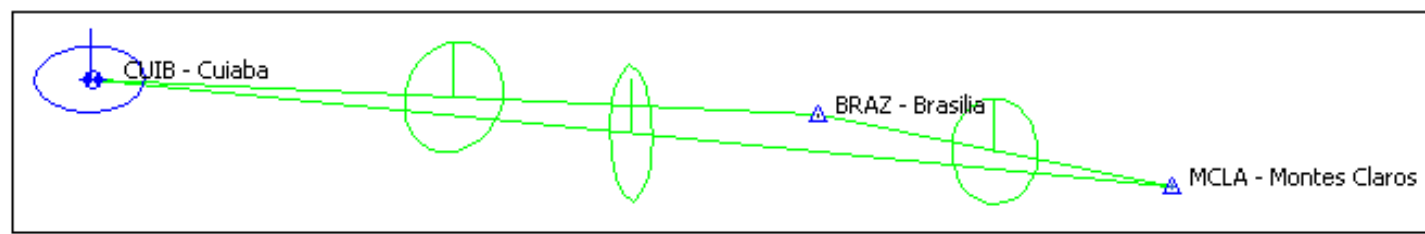

Coordenadas Ajustadas de CUIB:

E (UTM): $599737.3671 \mathrm{~m}$

N (UTM): $8280040.8241 \mathrm{~m}$

B.4.3.4 Primavera (Dias Julianos 287 a 290)

- $287 / 2008$

A posteriori UWE: 0.9794471 , Bounds: ( $0.6770032,1.241639)$ 
TABELA B189: Resultado do Processamento

\begin{tabular}{|c|c|c|c|c|c|c|c|c|}
\hline \multicolumn{9}{|c|}{ GPS Obs Report } \\
\hline Name & $\begin{array}{c}\text { Horizontal } \\
\text { Precision (m) }\end{array}$ & $\begin{array}{c}\text { Vertical } \\
\text { Precision (m) }\end{array}$ & $\begin{array}{c}\text { Distance } \\
(\mathbf{m})\end{array}$ & $\begin{array}{c}\text { Solution } \\
\text { Type }\end{array}$ & $\begin{array}{c}\text { GPS } \\
\text { Satellites }\end{array}$ & PDOP & Status & RMS \\
\hline BRAZ-CUIB & 0.096 & 0.103 & 878314.422 & $\begin{array}{l}\text { Float,Wide } \\
\text { Lane }\end{array}$ & 31 & 2.740 & Adjusted & 0.141 \\
\hline BRAZ-MCLA & $\mid 0.064$ & 0.076 & 435497.385 & $\begin{array}{l}\text { Fixed,Wide } \\
\text { Lane }\end{array}$ & 31 & 2.740 & Adjusted & 0.099 \\
\hline CUIB-MCLA & 0.111 & 0.131 & 1307630.599 & $\begin{array}{l}\text { Float,Wide } \\
\text { Lane }\end{array}$ & 31 & 3.211 & Adjusted & 0.172 \\
\hline
\end{tabular}

Figura B189: Elipses de Erro

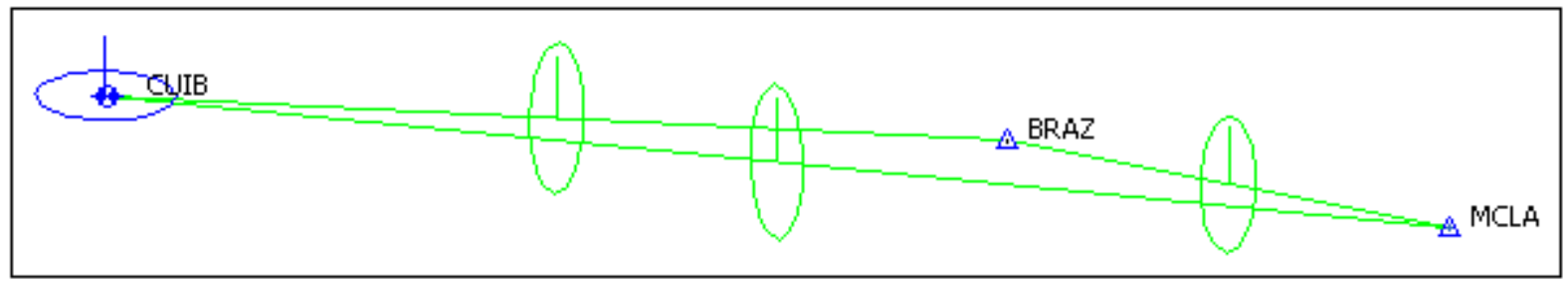

Coordenadas Ajustadas de CUIB:

E (UTM): $599737.2927 \mathrm{~m}$

N (UTM): $8280040.8410 \mathrm{~m}$

- $288 / 2008$

A posteriori UWE: 0.8016529 , Bounds: ( $0.6770032,1.241639)$

TABELA B190: Resultado do Processamento

\begin{tabular}{|c|c|c|c|c|c|c|c|c|}
\hline \multicolumn{9}{|c|}{ GPS Obs Report } \\
\hline Name & $\begin{array}{c}\text { Horizontal } \\
\text { Precision }(\mathrm{m})\end{array}$ & \begin{tabular}{|c|} 
Vertical \\
Precision (m)
\end{tabular} & $\begin{array}{c}\text { Distance } \\
(\mathrm{m})\end{array}$ & $\begin{array}{c}\text { Solution } \\
\text { Type }\end{array}$ & $\begin{array}{c}\text { GPS } \\
\text { Satellites } \\
\end{array}$ & PDOP & Status & RMS \\
\hline BRAZ-CUIB & $\mid 0.098$ & $\mid 0.101$ & 878314.381 & $\begin{array}{l}\text { Float,Wide } \\
\text { Lane }\end{array}$ & 31 & 2.740 & Adjusted & 0.141 \\
\hline BRAZ-MCLA & 0.045 & 0.088 & 435497.332 & $\begin{array}{l}\text { Fixed,Wide } \\
\text { Lane }\end{array}$ & 31 & 2.724 & Adjusted & 0.099 \\
\hline CUIB-MCLA & 0.103 & $\mid 0.137$ & 1307630.547 & $\begin{array}{l}\text { Fixed,Wide } \\
\text { Lane }\end{array}$ & 31 & 3.198 & Adjusted & 0.172 \\
\hline
\end{tabular}


Figura B190: Elipses de Erro

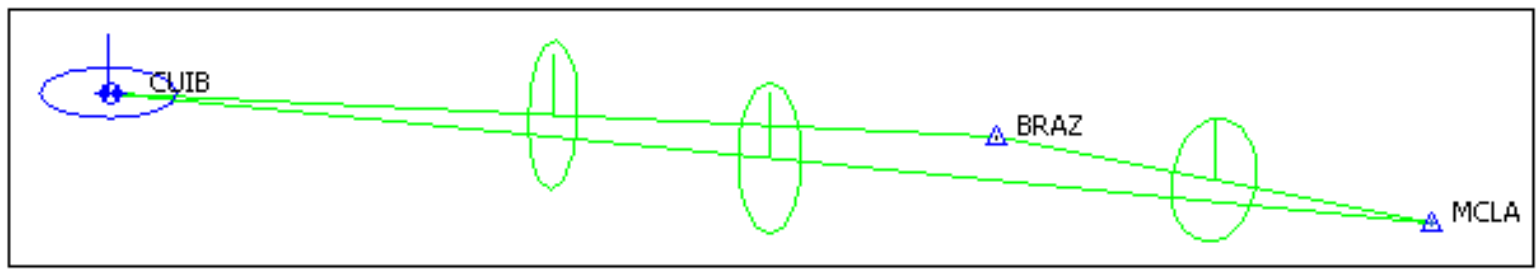

Coordenadas Ajustadas de CUIB:

E (UTM): $599737.3328 \mathrm{~m}$

N (UTM): $8280040.8258 \mathrm{~m}$

- $\underline{289 / 2008}$

A posteriori UWE: 0.7539261 , Bounds: ( $0.6770032,1.241639)$

TABELA B191: Resultado do Processamento

\begin{tabular}{|c|c|c|c|c|c|c|c|c|}
\hline \multicolumn{9}{|c|}{ GPS Obs Report } \\
\hline Name & $\begin{array}{c}\text { Horizontal } \\
\text { Precision }(\mathbf{m})\end{array}$ & $\begin{array}{c}\text { Vertical } \\
\text { Precision (m) }\end{array}$ & $\begin{array}{l}\text { Distance } \\
\text { (m) }\end{array}$ & $\begin{array}{c}\text { Solution } \\
\text { Type }\end{array}$ & $\begin{array}{c}\text { GPS } \\
\text { Satellites }\end{array}$ & PDOP & Status & RMS \\
\hline BRAZ-CUIB & $\mid 0.097$ & 0.102 & 878314.403 & \begin{tabular}{|l} 
Float,Wide \\
Lane \\
\end{tabular} & 31 & 2.739 & Adjusted & 0.141 \\
\hline BRAZ-MCLA & 0.053 & $\mid 0.084$ & 435497.346 & $\begin{array}{l}\text { Fixed,Wide } \\
\text { Lane } \\
\end{array}$ & 31 & 2.582 & Adjusted & 0.099 \\
\hline CUIB-MCLA & $\mid 0.114$ & $\mid 0.131$ & 1307630.542 & $\begin{array}{l}\text { Float,Wide } \\
\text { Lane }\end{array}$ & 31 & 3.138 & Adjusted & 0.173 \\
\hline
\end{tabular}

Figura B191: Elipses de Erro

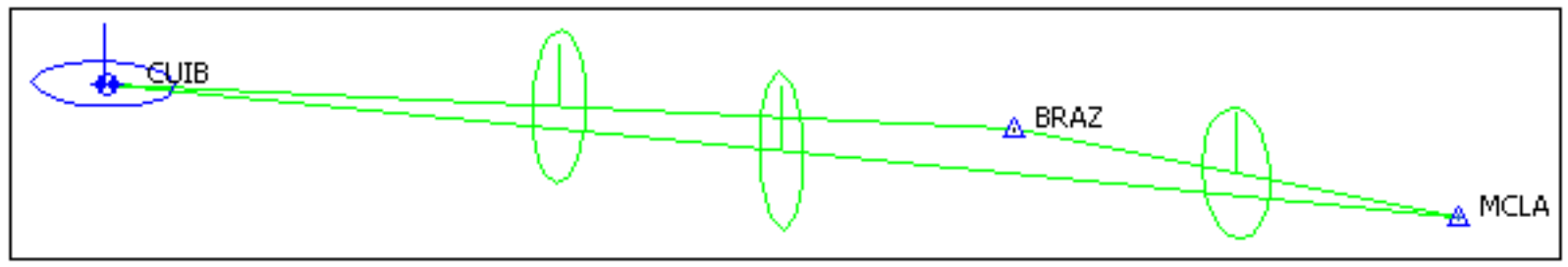

Coordenadas Ajustadas de CUIB:

E (UTM): $599737.3156 \mathrm{~m}$

N (UTM): $8280040.8461 \mathrm{~m}$ 
- $290 / 2008$

A posteriori UWE: 0.7012276 , Bounds: ( $0.6770032,1.241639)$

TABELA B192: Resultado do Processamento

\begin{tabular}{|c|c|c|c|c|c|c|c|c|}
\hline \multicolumn{9}{|c|}{ GPS Obs Report } \\
\hline Name & $\begin{array}{c}\text { Horizontal } \\
\text { Precision }(\mathbf{m})\end{array}$ & \begin{tabular}{|c|} 
Vertical \\
Precision $(\mathrm{m})$ \\
\end{tabular} & $\begin{array}{c}\text { Distance } \\
(\mathbf{m})\end{array}$ & $\begin{array}{c}\text { Solution } \\
\text { Type }\end{array}$ & $\begin{array}{c}\text { GPS } \\
\text { Satellites }\end{array}$ & PDOP & Status & RMS \\
\hline BRAZ-CUIB & 0.102 & 0.096 & 878314.406 & $\begin{array}{l}\text { Float,Wide } \\
\text { Lane }\end{array}$ & 30 & 2.802 & Adjusted & 0.141 \\
\hline BRAZ-MCLA & 0.075 & 0.066 & 435497.451 & $\begin{array}{l}\text { Float,Wide } \\
\text { Lane }\end{array}$ & 30 & 2.783 & Adjusted & $\mid 0.100$ \\
\hline CUIB-MCLA & 0.120 & 0.123 & 1307630.569 & $\begin{array}{l}\text { Float,Wide } \\
\text { Lane }\end{array}$ & 30 & 3.272 & Adjusted & $\mid 0.172$ \\
\hline
\end{tabular}

Figura B192: Elipses de Erro

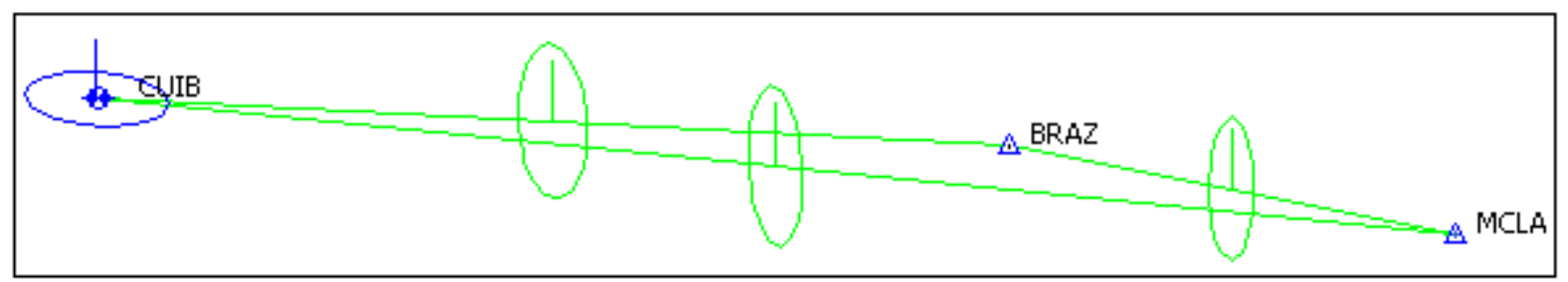

Coordenadas Ajustadas de CUIB:

E (UTM): $599737.3118 \mathrm{~m}$

N (UTM): $8280040.8471 \mathrm{~m}$ 


\section{$\underline{\text { ANEXO C - Monografias das estacões RBMC }}$}

\section{C.1 Estação BRAZ}

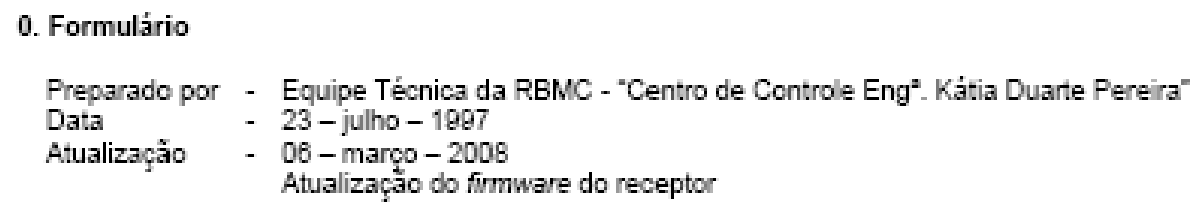

1. Identificação do local da estação GPS

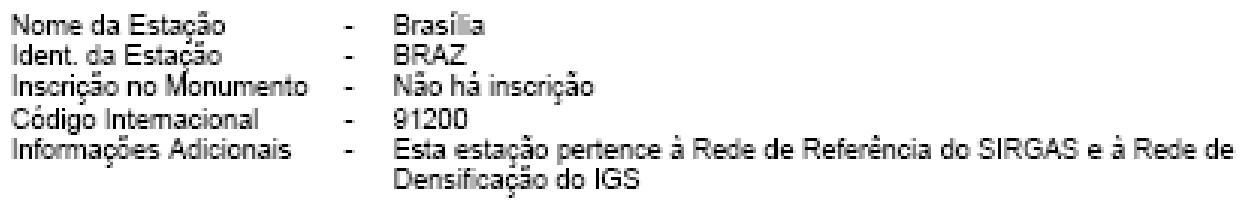

\section{Informação sobre a localizaçäo}

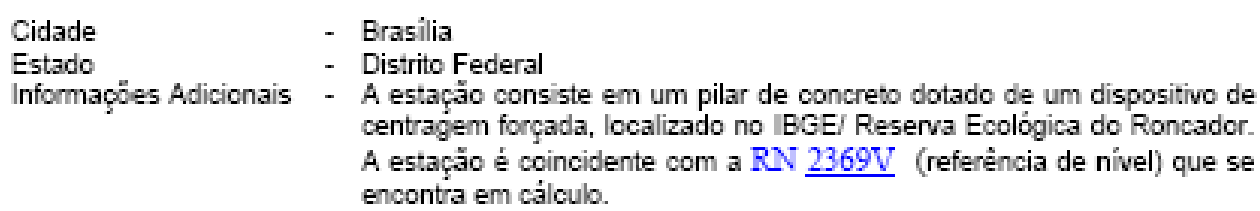
centragem forçada, localizado no IBGE/ Reserva Ecológica do Roncador. A estaçăo é coincidente com a RN $\underline{2369 \mathrm{~V}}$ (referência de nivel) que se encontra em cálculo.

\section{Coordenadas oficiais}

3.1) SIRGAS2000 (Época 2000,4)

\begin{tabular}{|l|r|r|l|}
\hline \multicolumn{5}{|c|}{ Coordenadas Geodésicas } \\
\hline Lattude: & $15^{\circ} 56^{\prime} 50,8112^{\prime \prime} \mathrm{S}$ & Sigma: & $0,001 \mathrm{~m}$ \\
\hline Longitude: & $47^{\circ} 52^{\prime} 40,3283^{\prime \prime} \mathrm{W}$ & Sigma: & $0,001 \mathrm{~m}$ \\
\hline Alt.Elip.: & $1106,02 \mathrm{~m}$ & Sigma: & $0,001 \mathrm{~m}$ \\
\hline Alt.Orto.: & $1118,73 \mathrm{~m}$ & Fonte: & GPS/ MAPGEO2004 \\
\hline \multicolumn{5}{|c|}{ Coordenadas Cartesianas } \\
\hline $\mathrm{X}$ & $4.115 .014,085 \mathrm{~m}$ & Sigma: & 0,001 \\
\hline $\mathrm{Y}$ & $-4.550 .641,549 \mathrm{~m}$ & Sigma: & 0,001 \\
\hline$Z$ & $-1.741 .444,019 \mathrm{~m}$ & Sigma: & 0,001 \\
\hline \multicolumn{5}{|c|}{ Coordenadas Planas (UTM) } \\
\hline UTM (N): & $8.234 .747,341 \mathrm{~m}$ & \\
\hline UTM (E): & $191.801,220 \mathrm{~m}$ & \\
\hline MC: & -45 & & \\
\hline
\end{tabular}




\begin{tabular}{|c|c|c|}
\hline IROE & $\begin{array}{l}\text { Diretoria de Geociëncias } \\
\text { Coordenaçăo de Geodesta }\end{array}$ & 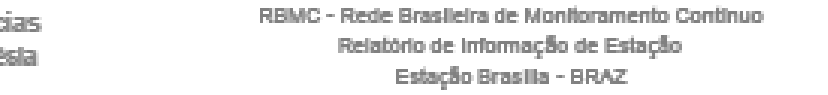 \\
\hline \multicolumn{3}{|c|}{ 4. Informações sobre o equipamento GPS } \\
\hline \multicolumn{3}{|c|}{ 4.1 Receptor } \\
\hline 4.1 .1 & $\begin{array}{l}\text { Tipo do Receptor } \\
\text { Número de Série } \\
\text { Versáo do Firmware } \\
\text { Data de Instalaçăo } \\
\text { Atualizaçáo do Firmware }\end{array}$ & $\begin{array}{l}- \text { NetRS } \\
=4644124503 \\
=1.2-0 \\
=13-\text { março-2007 } \\
=06-\text { março }-2008\end{array}$ \\
\hline 4.1.2 & $\begin{array}{l}\text { Tipo do Receptor } \\
\text { Número de Série } \\
\text { Versáo do Firmware } \\
\text { Data de Instalaçăo } \\
\text { Data de Alteração }\end{array}$ & $\begin{array}{l}- \text { NetRS } \\
=4644124503 \\
=1.1-5 \\
=13-\text { março }-2007 \\
=06-\text { março-2008 }\end{array}$ \\
\hline 4.1 .3 & $\begin{array}{l}\text { Tipo do Receptor } \\
\text { Número de Série } \\
\text { Versáo do Firmware } \\
\text { Data de Atualizaçäo } \\
\text { Data da Remoçáo }\end{array}$ & $\begin{array}{ll}- & \text { Trimble } 4000 S S I \\
- & 16594 \\
- & 7.29 \\
- & 21-\text { agosto }-1988 \\
- & 12-\text { março }-2007\end{array}$ \\
\hline 4.1 .4 & $\begin{array}{l}\text { Tipo do Receptor } \\
\text { Numero de Série } \\
\text { Versáo do Firmware } \\
\text { Data de Instalaçăo } \\
\text { Data da Remoçẵo }\end{array}$ & $\begin{array}{ll}- & \text { Trimble } 4000 S S I \\
- & 16594 \\
- & 7.22 \\
- & 28-\text { abril }-1988 \\
- & 12-\text { março }-2007\end{array}$ \\
\hline 4.1 .5 & $\begin{array}{l}\text { Tipo do Receptor } \\
\text { Numero de Série } \\
\text { Versáo do Firmware } \\
\text { Data de Instalaçẵo } \\
\text { Data da Remoçāo }\end{array}$ & $\begin{array}{ll}- & \text { ROGUE SNR-8000 } \\
- & 253 \\
- & 3.2 \text { link } \\
- & 26-\text { maio }-1995 \\
- & 28-\text { abril }-1988\end{array}$ \\
\hline \multicolumn{3}{|c|}{4.2 Antena } \\
\hline 4.2 .1 & $\begin{array}{l}\text { Tipo de Antena } \\
\text { Número de Série } \\
\text { Altura da Antena (m) } \\
\text { Data de Instalação }\end{array}$ & $\begin{array}{l}\text { - ZEPHYR GEODETIC (TRM 41249.00) } \\
\text { - } 60183651 \\
\text { - } 0,0080 \text { (distáncia do topo do dispositivo de centragem forçada à } \\
\text { base da antena, conforme figura abaixo). } \\
\text { - } 13-\text { março }-2007\end{array}$ \\
\hline 4.2 .2 & $\begin{array}{l}\text { Tipo de Antena } \\
\text { Numero de Série } \\
\text { Altura da Antena (m) } \\
\text { Data de Instalação } \\
\text { Data de Remoçảo }\end{array}$ & $\begin{array}{l}\text { - DORNE MARGOLIN T } \\
\text { - } 71001 \\
\text { - } 00,0080 \text { (distáncia do topo do dispositivo de centragem forçada à } \\
\text { base da antena, conforme figura abaixo). } \\
\text { - } 28-\text { abril - } 1998 \\
\text { - } 12 \text { - março }-2007\end{array}$ \\
\hline 4.2 .3 & $\begin{array}{l}\text { Tipo de Antena } \\
\text { Número de Série } \\
\text { Altura da Antena (m) } \\
\text { Data de Instalação } \\
\text { Data de Remoçầo }\end{array}$ & $\begin{array}{l}\text { - DORNE MARGOLIN T } \\
\text { - } 407 \\
\text { - } 0,0070 \text { (distáncia do topo do dispositivo de centragem forçada à } \\
\text { base da antena, conforme figura abaixo). } \\
\text { - } 26-\text { maio - } 1995 \\
\text { - } 28 \text { - abril - } 1998\end{array}$ \\
\hline
\end{tabular}




\subsection{Esquema da Altura da Antena}

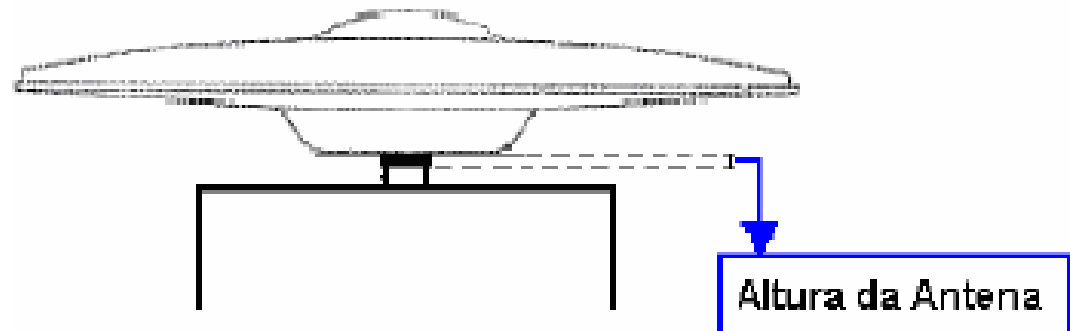

\subsection{Esquema da Antena}

4.4.1 Esquema da Antena ZEPHYR GEODETIC (TRM 41249.00)

Diagrama do plano de referência da antena ZEPHYR $_{\text {TM }}$ GEODETIC Identificação IGS: TRM $\mathbf{4 1 2 4 9 . 0 0}$

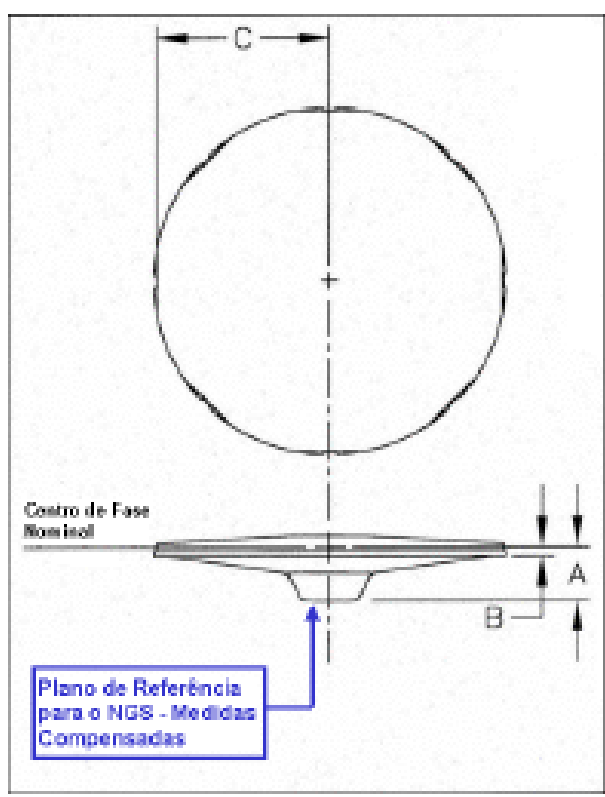

identincaçăo Dimensăo (m)

Distäncla

\begin{tabular}{|c|c|l|}
\hline A & 0,0532 & Distancla da base da antena ao centro de fase nominal. \\
\hline B & 0,0089 & Distancla entre o centro de fase nominal e a marca do gancho. \\
\hline C & 0,1698 & Distancla do centro radlal da antena a extremidade exterior do gancho. \\
\hline
\end{tabular}




\subsubsection{Esquema da Antena Dome Margolin T (TRM 28659.00)}

Diagrama do plano de referéncia da antena Dorne Margolin T Identificação IGS: TRM 29659.00
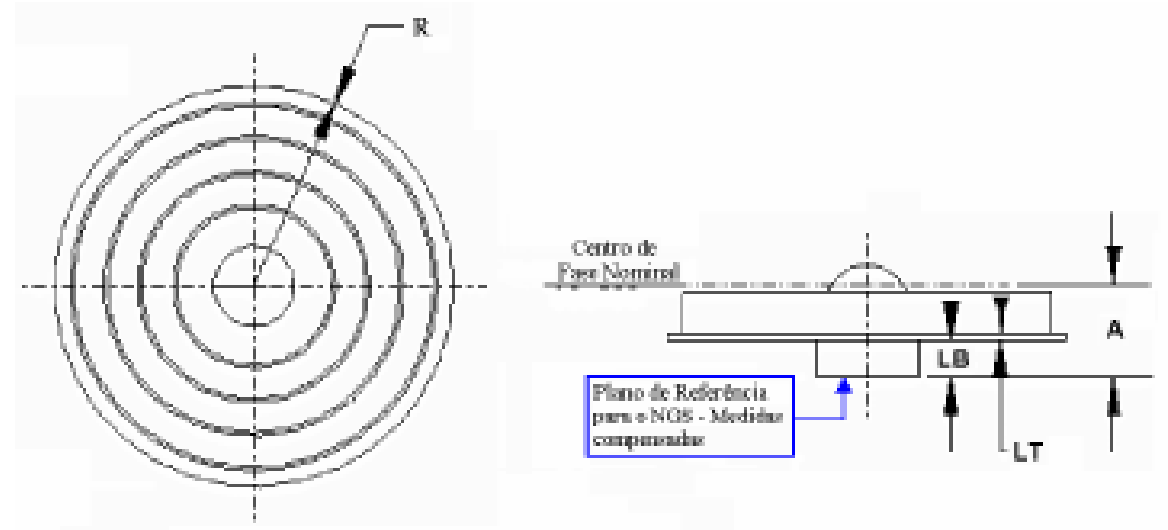

\begin{tabular}{|c|c|c|}
\hline Iden:ttcaçâ & Dimensฎ́o (m) & Distäncla \\
\hline A & 0,1100 & $\begin{array}{l}\text { Distancla do plano de referencla da antena ao centro de fase nominal da } \\
\text { freguencla L1 }\end{array}$ \\
\hline LB & 0,0350 & $\begin{array}{l}\text { Distàncla do plano de referencla da antena ao plano de refertncla Choke } \\
\text { Ring }\end{array}$ \\
\hline LT & 0,0031 & Espessura da antena \\
\hline $\mathbf{R}$ & 0,1905 & Distáncla do centro radlal da antena a extrenidade exterior do prato. \\
\hline
\end{tabular}

Observaça:

1. O certro de tase nominal e o plano de referencla uallzado para corigli a fase nas tabelas Trimble.

2. O fabricante infoma que valor do centro de fase nominal nấo esta relacionado com 05 valores de calbraçăo relativa da antena estimado pelo NGS.

3. O NGS possul um proleto com o objetivo de fornecer um procedinnento padrâo e consistente na determinaçato dos valores do centro de fase e da varlaçăo do centro de tase (puc).

4. Calbraçbes de outras fontes năo devem ser misturadas com os resulatas do NGS.

\section{Rede Local}

Nâo estabelecida

\section{Informações Complementares}

6.1 - Para informaçôes técnicas contatar:
Nome - BGEI DGCI Coordenação de Geodésia
Endereco - Av. Brasi, 15671, CEP21241-051, Rio de Janeiro, RJ
Telefone - (21) 21424928
Fax - (21) 21424850
Home Page - wwibge govibr
Contato - itmoüibge gov.br

6.2 - Para infomaçỏes sobre comercializaçăo e aquisiçâo de dados contatar.
Nome - Centro de Documentação e Disseminação de Informações - CDDUBGE
Endereco - Rua General Canabarro, 706, CEP 20271-201, Rio de Janeiro, RJ
Telefones - 0600218181
Fax - (21) 21424933
Contatos - Ibgeruibge govlbr 
6.3 -Instituiçôes participantes

A RBMC conta com o apoio das seguintes instituições:

CEFET/ UNEDI - Centro Federal de Educaçâo Tecnológica/ Imperatriz

CEMIG - Companhia Energética de Minas Gerais

CONDER - Companhia de Desenvolvimento Urbano do Estado da Bahia

DTCEA - Destacamento de Controle do Espaço Aéreo

EAFI - Escola Agrotécrica Federal de Inconfidentes

EPUSP - Escola Politécnica da Universidade de São Paulo

Exército Brasileiro - Diretoria do Serviço Geográfico do Exército/ 4a. DL - Manaus

FNMA - Fundo Nacional do Meio Ambiente

IME - Instituto M tar de Engenharia

INCRA - Instituto Nacional de Colonizaçăo e Reforma Agrária

INPE - Instituto Nacional de Pesquisas Espaciais/ Cuiabá e Euzébio

Marinha do Brasil - Capitania dos Portos/Bom Jesus da Lapa

Pró Guaiba - Fundo Pró-Guába, Govemo do estado do Rio Grande do Sul

SIPAM - Sistema de Proteçăo da Amazónia

UFPE - Universidade Federal de Pemambuco

UFPR - Universidade Federal do Paraná

UFRGS - Universidade Federal do Rio Grande do Sul

UFSM - Universidade Federal de Santa Maria

UFU - Universidade Federal de Uberlândia

UFV - Universidade Federal de Vicosa

UNESP - Universidade Estadual Paufista/ Campus de Presidente Prudente

UNIDERP - Universidade para o Desenvolvimento do Estado e da Região do Pantanal

URCA - Fundação Universidade Regional do Cariri 


\section{C.2 Estação CUIB}

\section{Formulário}

Preparado por - Equipe Técnica da RBMC - "Centro de Controle Eng". Kátia Duarte Pereira"

Data - 23-julho-1997

Atualização - $06-$ março- 2008

Atual zaçăo do fimware do receptor

\section{Identificação da estação GPS}

$\begin{array}{lll}\text { Nome da Estação } & - & \text { Cuiabá } \\ \text { Ident. da Estaçăo } & - & \text { CUIB } \\ \text { Inscriçăo no Monumento } & - & \text { Nấo há inscrição } \\ \text { Código Intemacional } & - & 92583 \\ \text { Informaçóes Adicionais } & - & \text { Esta estação pertence à Rede de Referéncia do SIRGAS e à Rede de } \\ & & \text { Densificaçăo do IGS }\end{array}$

2. Informação sobre localização

Cidade - Cuiabá

Estado - Mato Grosso

Informaçōes Adicionais - A estaçăo consiste em um dispositivo de centragem forçada cravado no topo de um reservatório de água, na Estacăo Terrena de Cuiabá, do Centro de Rastreio e Controle de Satélites do INPE.

\section{Coordenadas oficiais}

3.1) SIRGAS2000 (Época 2000,4)

\begin{tabular}{|c|c|c|c|}
\hline \multicolumn{4}{|c|}{ Coordenadas Geodésicas } \\
\hline Latitude: & $15^{\circ} 33^{\prime} 18,9468^{\prime} \mathrm{S}$ & Sigma: & $0,001 \mathrm{~m}$ \\
\hline Langitude: & $56^{\circ} 04^{\prime} 11,5196^{*} \mathrm{~W}$ & Sigma: & $0,001 \mathrm{~m}$ \\
\hline AltElip.: & $237,44 \mathrm{~m}$ & Sigma: & $0,002 \mathrm{~m}$ \\
\hline Altorto: & $236,32 \mathrm{~m}$ & Fonte: & GPS/ MAPGEO2004 \\
\hline \multicolumn{4}{|c|}{ Coordenadas Cartesianas } \\
\hline $\mathrm{x}$ & $3.430 .711 .406 \mathrm{~m}$ & Sigma: & $0,001 \mathrm{~m}$ \\
\hline $\mathrm{Y}$ & $-5.099 .641 .565 \mathrm{~m}$ & Sigma: & $0,002 \mathrm{~m}$ \\
\hline $\bar{z}$ & $-1.690 .432 .831 \mathrm{~m}$ & Sigma: & $0,001 \mathrm{~m}$ \\
\hline \multicolumn{4}{|c|}{ Coordenadas Planas (UTM) } \\
\hline UTM (N): & $8.280 .040,831 \mathrm{~m}$ & & \\
\hline UTM (E): & $599.737,357 \mathrm{~m}$ & & \\
\hline MC: & -57 & & \\
\hline
\end{tabular}


4. Informaçoes do equipamento GPS

4.1 Receptor

$$
\begin{aligned}
& \text { 4.1.1 Tipo do Receptor } \\
& \text { Numero de Serle } \\
& \text { Versado do FIrmware } \\
& \text { Data de Instalaçăo } \\
& \text { Atuallzaçăo do Flmmare } \\
& \text { - trimble NetRS } \\
& \text { - 4643124418 } \\
& \text { - } 1.2-0 \\
& \text { - 31-março-2007 }
\end{aligned}
$$

\subsection{Antena}

4.2.1 Tipo de Anten

Número de Serle

Altura da Antena (m)

- ZEPHYR GEODETIC (TRM 41249.00)

- 60183385

- 0.0080 (distancla vertical do topo do dispositivo de centragem

Data de instalação: forçada a base da antena, conforme figura ababxo)

4.22 Tipo de Antena Numero de Serle Atura da Antena $(\mathrm{m})$ :

- $31-\operatorname{março-2007}$

Data de instalaçâo:

- DORNE MARGOLIN T

- 070176

- 0.0080 (distancla vertical do topo do dispositivo de centragem forçada a base da antena, conforme figura ababo)

- 18 - Junho - 1997

\subsection{Esquema da Altura da Antena}

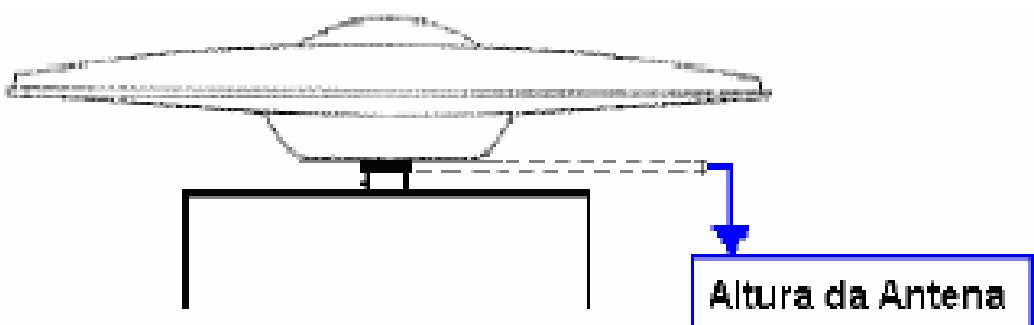




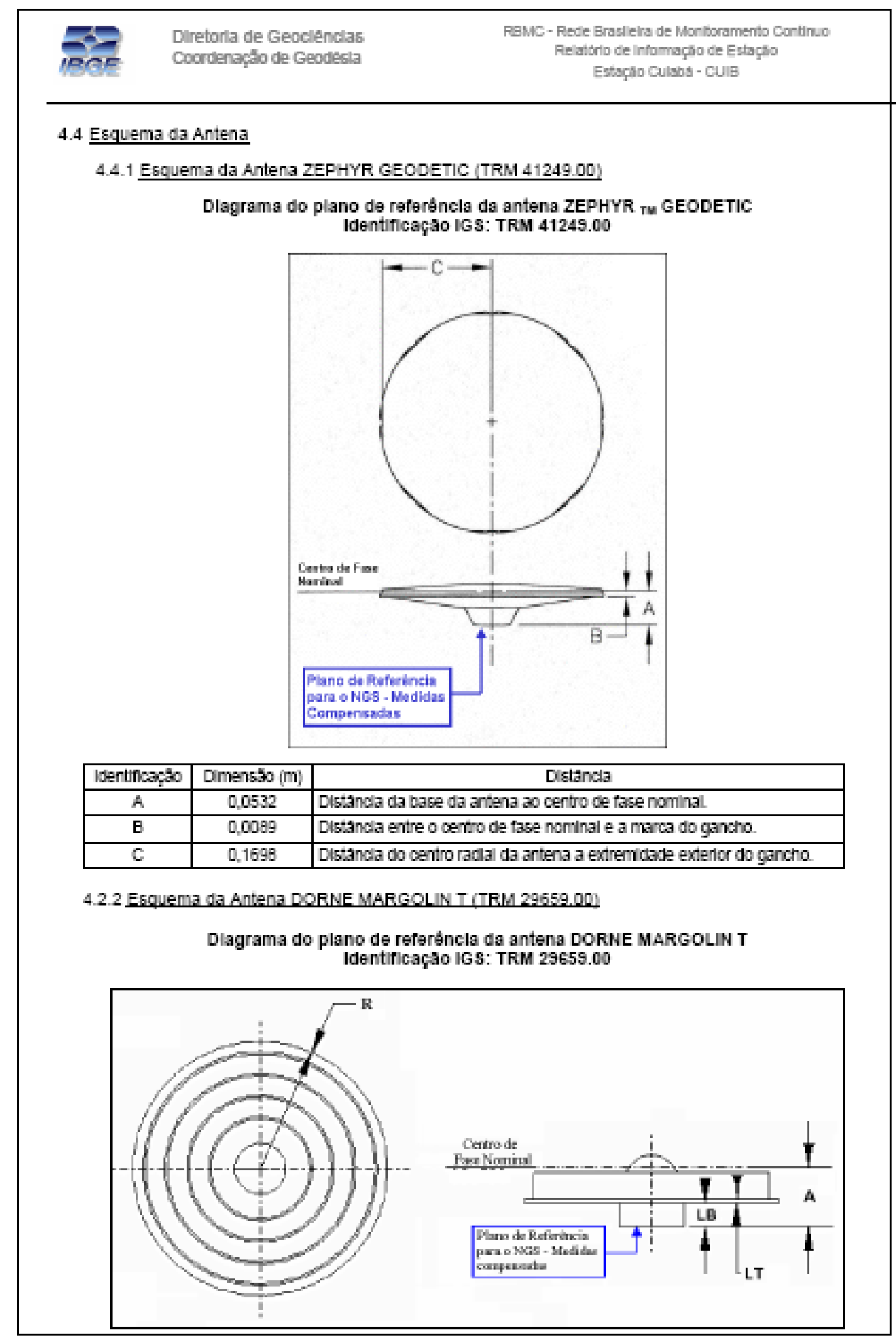




\begin{tabular}{|c|c|l|}
\hline Idenifícaçăo & Dimensăo (m) & \multicolumn{1}{|c|}{ Distäncla } \\
\hline A & 0,1100 & $\begin{array}{l}\text { Distancla do plano de referencla da antena as centro de fase nominal da } \\
\text { frequencla L1 }\end{array}$ \\
\hline LB & 0,0350 & $\begin{array}{l}\text { Distancla do plano de referencla da antena ao plano de referencla Choke } \\
\text { Fung }\end{array}$ \\
\hline LT & 0,0031 & Espessura da antena \\
\hline R & 0,1905 & Distancla do centro raclal da antena a extrenicdade exterior do prato. \\
\hline
\end{tabular}

Coservacjo:

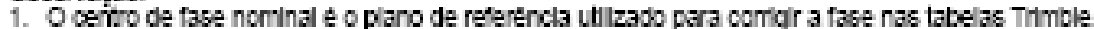

2. O fabricante informa que valor do centro de fase nominal näo estä relacionado com os valores de calbraç5̆o relattva da antena estinado pelo NGS.

3. O NGS possul um projeto con o objeilwo de fornecer um procedimento padrăo e consisterte na deleminaçắ dos valores do centro de fase e da varlaçăo do centro de fase (Dvc).

4. Calbraçbes de outras fortes náo devem ser misturadas com os resultados do NGS.

\title{
5. Rede local
}

\author{
Estap̧es $\quad$ - $92584,92585,92586,92587,92588,92589$ \\ Data de Observaç̧o - 26 - malo- 1995
}

\section{InformaçOes Complementares}

6.1- Para Informaçdes tecolcas contatar:

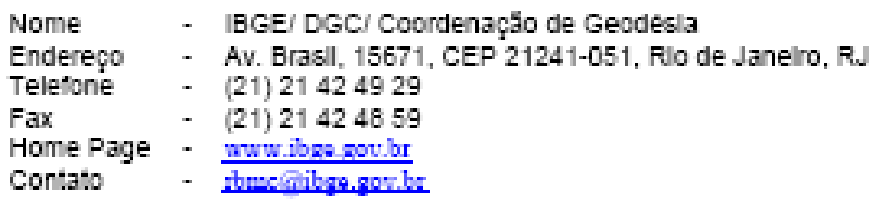

6.2 - Para informaçठ̀es sobre comerclallzaçăo e aquls/çăo de dados contatar:

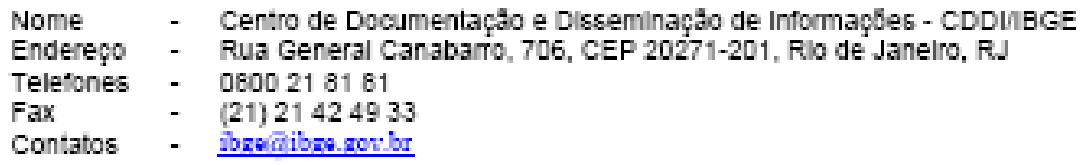

\section{3 -institulęofes participantes}

A RBMC conta com o apolo das segulntes Instituloples:

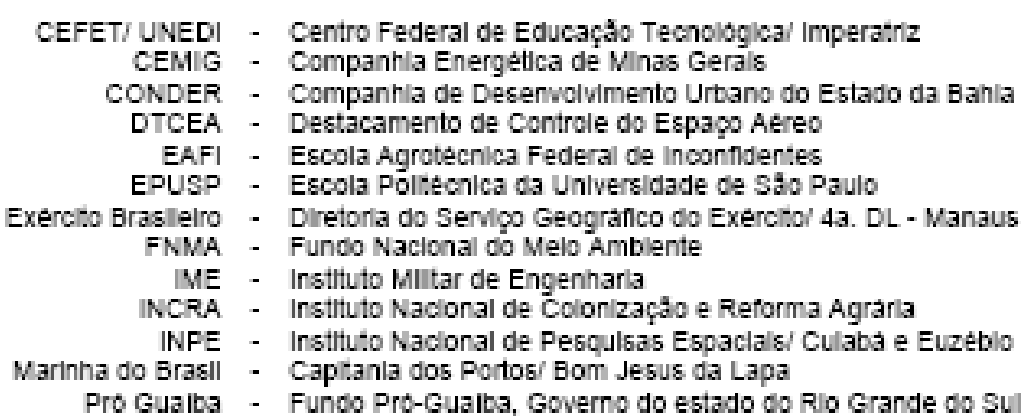




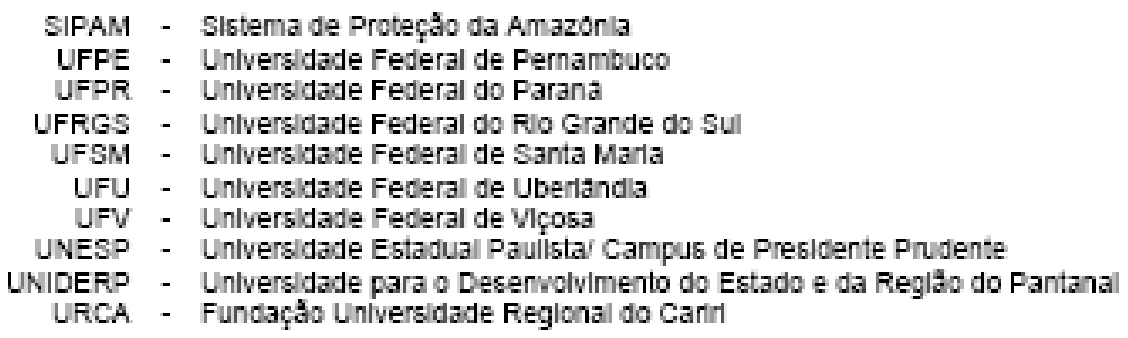




\section{C.3 Estação MCLA}

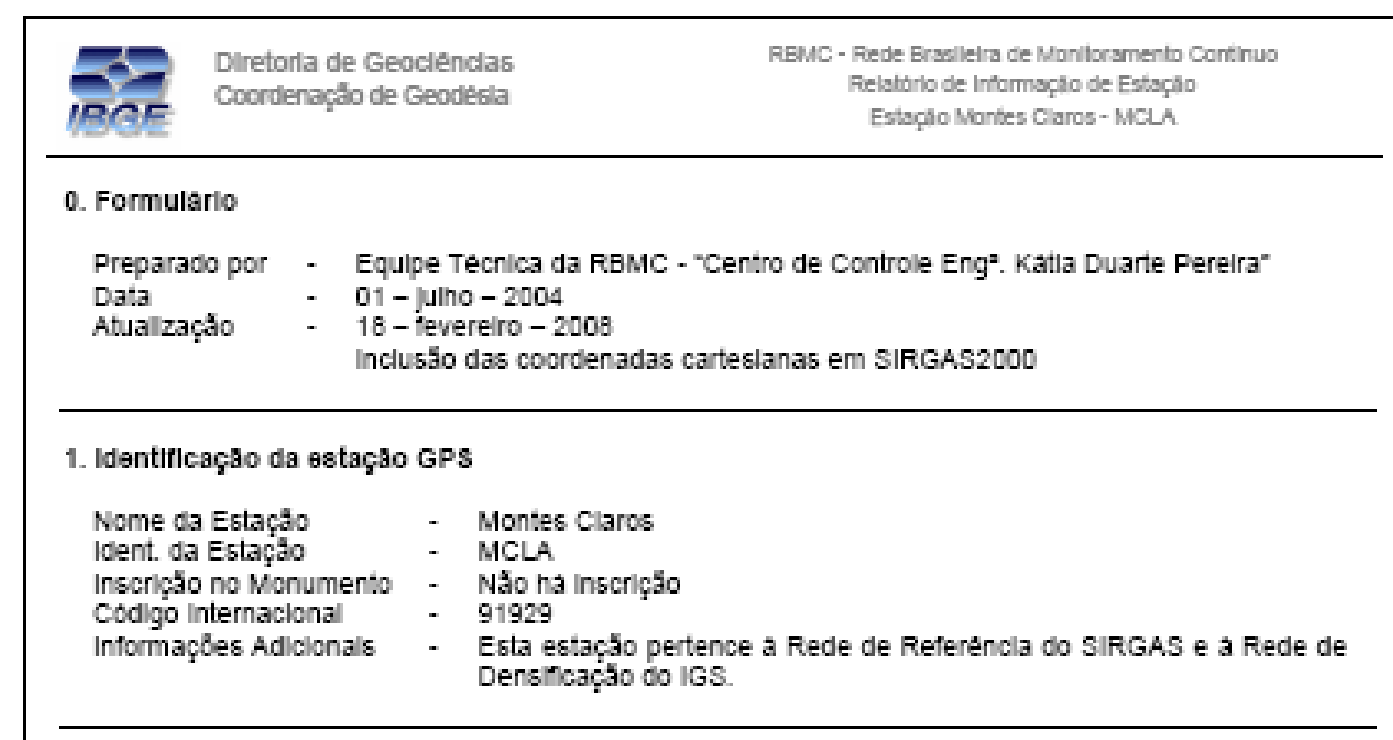

2. Informaça aobre a locallzaçåo

Cldade - Montes Claros

Estado - Minas Gerals

Informaçdes Adlcionals - A estaçåo consiste de un tudo de concreto, com $1.80 \mathrm{~m}$ de altura e dotada de um dlsposit:wo de centragem forçada cravado no seu topo. Esta siluada na calxa d'agua principal da Sub-estaçåo MOC1, pertencente a CEMIG.

\section{Coordenadas oficlals}

3.1) SIRGAS2000 (Epoca 2000,4)

\begin{tabular}{|c|c|c|c|}
\hline \multicolumn{4}{|c|}{ Coordenadas Geodesicas } \\
\hline Lattude: & $16^{\circ} 43^{\prime} 13,4226^{\circ} \mathrm{S}$ & Sigma: & $0,002 \mathrm{~m}$ \\
\hline Longltude: & $43^{\circ} 52^{\circ} 52,7383^{\circ} \mathrm{W}$ & Sigma: & $0,002 \mathrm{~m}$ \\
\hline Alt.Elp.: & $656,54 \mathrm{~m}$ & Sigma: & $0,014 \mathrm{~m}$ \\
\hline Alt.Orto.: & $669,27 \mathrm{~m}$ & Fonte & GPS/ MAPGEO2004 \\
\hline \multicolumn{4}{|c|}{ Coordenadas Carteslanas } \\
\hline $\mathrm{x}$ & $4.404 .519,580 \mathrm{~m}$ & Sigma: & $0,010 \mathrm{~m}$ \\
\hline Y & $-4.235 .798,388 \mathrm{~m}$ & Sigma: & $0,009 \mathrm{~m}$ \\
\hline$z$ & $-1.823 .409,174 \mathrm{~m}$ & Sigma: & $0,004 \mathrm{~m}$ \\
\hline \multicolumn{4}{|c|}{ Coordenadas Planas (UTM) } \\
\hline UTM (N): & $8.151 .040,841 \mathrm{~m}$ & & \\
\hline UTM (E): & $619.257,849 \mathrm{~m}$ & & \\
\hline MC: & -45 & & \\
\hline
\end{tabular}

\section{Informaç๐es do equipamento GPS}

\subsection{Receptor}

\begin{tabular}{|c|c|c|}
\hline 4.1.1 & $\begin{array}{l}\text { Tlpo do Receptor } \\
\text { Numero de Serle } \\
\text { Versăo do FIrmware } \\
\text { Data de Instalaç̧ăo }\end{array}$ & $\begin{array}{ll}= & \text { Ashtech Z-FX } \\
- & \text { UX220000803 } \\
- & \text { UD00 } \\
- & 18-\text { abrll - } 2001\end{array}$ \\
\hline
\end{tabular}




\subsection{Antena}

4.2.1 Tipo de Antena - Thales/Ashtech Marine III L1/22 (ASH 700700.B) Nümero de Serle $\quad$ - 6411

Altura da Antena (m) - 0.0600 (distancla vertical do topo do disposltivo de centragem

Data de instalaçăo: forçada a base da antena, conforme flgura abalxo)

- $18-a b r l l-2001$

4.3 Esquema da Altura da Antena

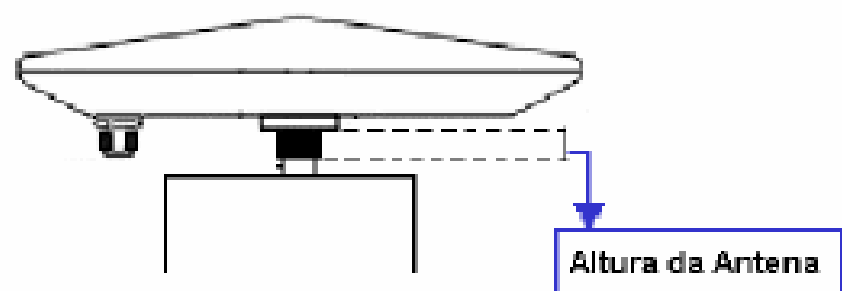

\subsection{Esquema da Antena}

Dlagrama do plano de referencla da antena Thales/Ashtech Marine III L1/L2 Identıflcaçâ IGS: ASH 700700.B
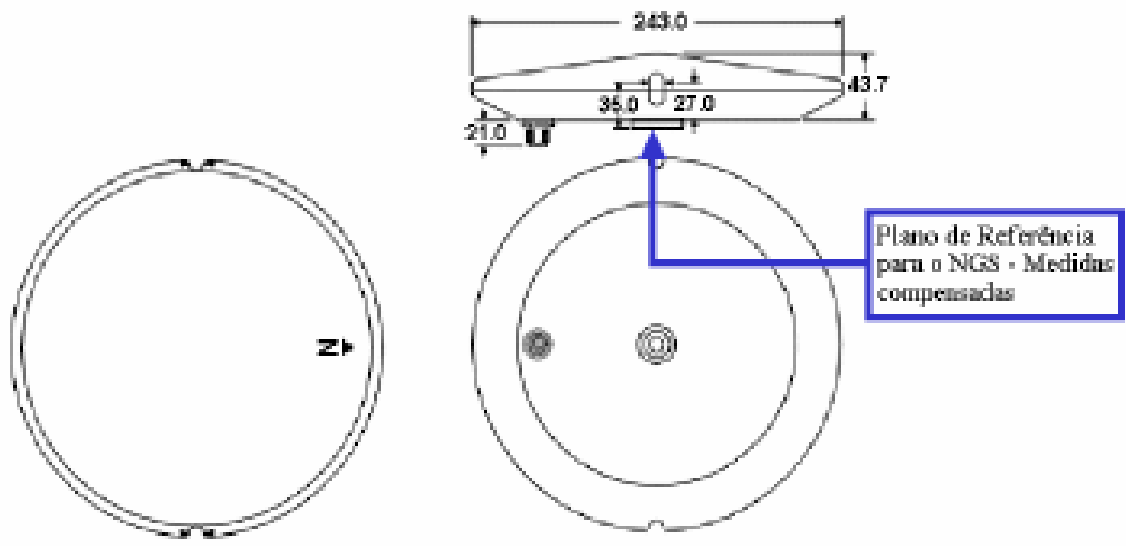

Obs. Todas as medidas em milimetros

\section{Rede local}

Năo estabelecida 


\section{Informaçסes Complementares}

6.1 - Para informą̧øes tecricas contatar:

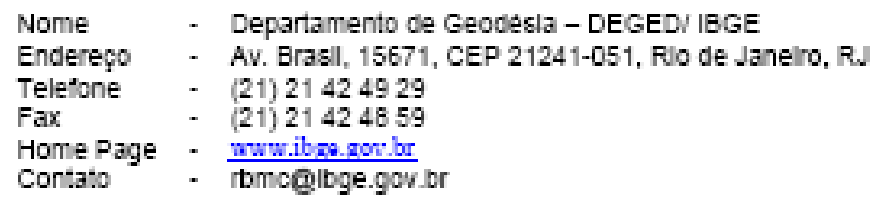

6.2 - Para informaçठes sobre comerclallzaçăo e aquls/çăo de dados contatar.

Nome - Centro de Documentaçăo e Disseninaçăo de Informaçbes - CDDV IBGE

Endereço - Rua General Canabarro, 706, CEP 20271-201, Rlo de Janelro, R.

Teletones - 0800218181

Fax - (21) 21424933

Contatos - ibreâibas.gorbr

\section{3 -Institulęర్tes participantes}

A RBMC conta com o apoio das seguintes Institulpôes:

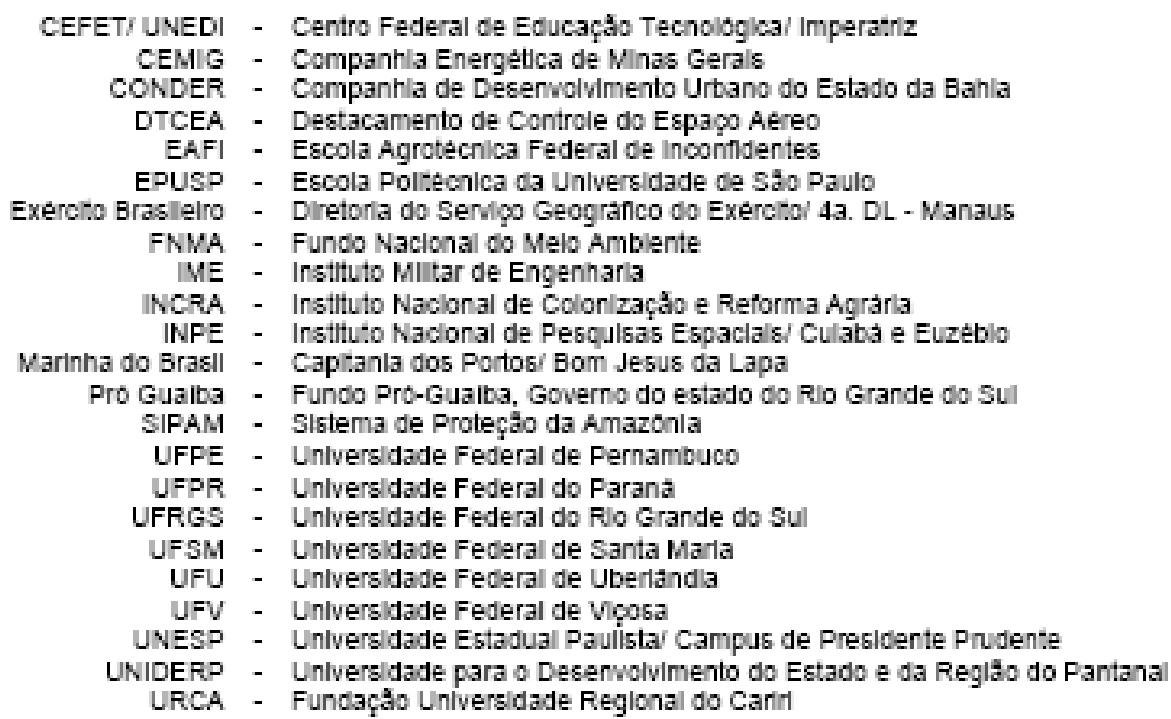




\section{C.4 Estação PPTE}

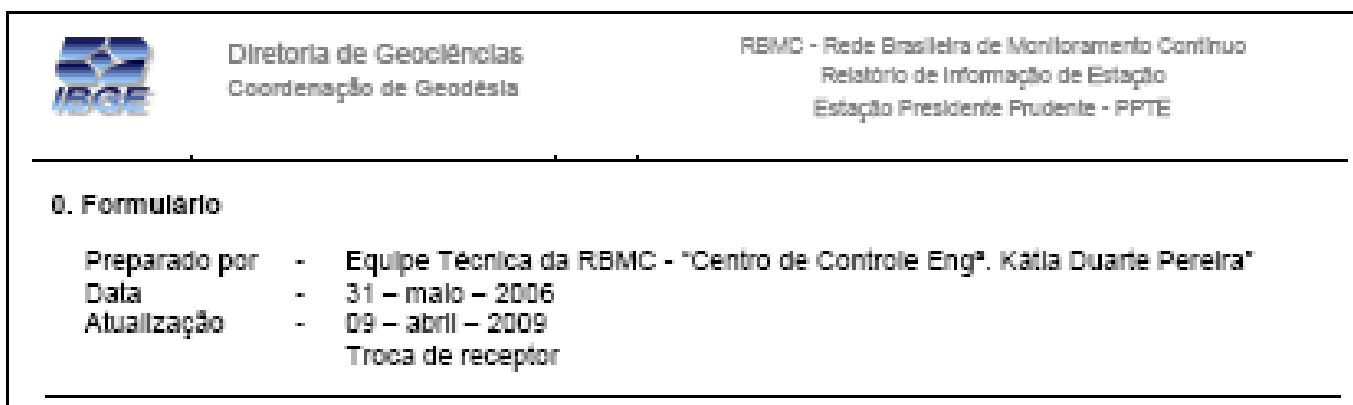

\section{Identiflcaçà da estaçăo GPS}

Nome da Estaç̧ăo

Ident. da Estaçăo

Presidente Prudente

- PPTE

Inscriçăo no Mionumento - Chapa de Identincaçåo padråo IBGE cravada na lateral do pllar com a Inscriçăo SAT 91559 . A Inscriçăo sera alterada para SAT 93900 na proxima manutençăo a ser reallzada na estaçăo.

Codigo Internacional - 93900

Informaçbes Adicionals -

\section{Informaçào aobre a locallzaçao}

Cldade - Presidente Prudente

Estado - Să Paulo

Informaçסes Adiclonals - A estaçấo consiste em um plar de concreto dotado de um dlspositivo de centragem forçada, locallzado no Campus da Unlversidade Estadual Paulsta (UNESP)

\section{Coordenadas oflclals}

3.1) SIRGAS2000 (Eрoca 2000,4)

\begin{tabular}{|l|r|r|l|}
\hline \multicolumn{5}{|c|}{ Coordenadas Geodesicas } \\
\hline Lattude: & $22^{\circ} 07^{\prime} 11,6571^{\prime \prime} \mathrm{S}$ & Sigma: & $0,001 \mathrm{~m}$ \\
\hline Longtude: & $51^{\circ} 24^{\prime} 30,7225^{\prime \prime} \mathrm{W}$ & Sigma: & $0,001 \mathrm{~m}$ \\
\hline Ait.Elp.: & $431,05 \mathrm{~m}$ & Sigma: & $0,003 \mathrm{~m}$ \\
\hline Ait.orto: & $436,53 \mathrm{~m}$ & Fonte: & GPS/ MAPGEO2004 \\
\hline \multicolumn{5}{|c|}{ Coordenadas Carteslanas } \\
\hline X & $3.687 .624,367 \mathrm{~m}$ & Sigma: & $0,002 \mathrm{~m}$ \\
\hline Y & $-4.620 .818,683 \mathrm{~m}$ & Sigma: & $0,002 \mathrm{~m}$ \\
\hline$Z$ & $-2.386 .880,382 \mathrm{~m}$ & Sigma: & $0,001 \mathrm{~m}$ \\
\hline \multicolumn{5}{|c|}{ Coordenadas Planas (UTM) } \\
\hline UTM (N): & $7.553 .844,608 \mathrm{~m}$ & & \\
\hline UTM (E): & $457.866,057 \mathrm{~m}$ & & \\
\hline MC: & -51 & & \\
\hline
\end{tabular}

\section{Informaçסes do equipamento GPS}

\subsection{Receptor}
4.1.1 Tipo do Receptor
Nümero de serle
- trimble Netr5
- 4651K03593
Data de Instalaçao
- 3.50
- $09-\mathrm{abrll}-2009$ 
Diretorla de Geoclenclas

Coordenaçlo de Geodesia
REMC - Riede Brsslelra de Manllorsmento Continuo Relatorio de Informaçso de Estaçto

Estaçlo Prealdente Prudente - PPTE
4.1.2 Tipo do Receptor Nómero de Serle Versto do Firmware Data de Instalacáo Atualização do FIrmware Data de Remoção

4.1.3 Tipo do Receptor Nómero de Serle Versపo do Firmware Data de Instalacáo Data de Auteraç̆o
- tRIMBLE netRs

- 4427235643

- 12-0

- 11 - dezembro-2005

- 06 - março-2008

- $\quad 08-a b r \|-2009$

- tRIMEle netRs

- 4427235643

- $1.1-5$

- 11 - dezembro - 2005

- $\quad 06$ - março- 2008

4.2 Antena

4.2.1 Tipo de Artena:

Nómero de Serle: 12379370

- ZEPHYR GEODETIC (TRIMELE)

Altura da Antena (m): - $\quad 0,0025$ (dlstancla vertical do topo do olsposlitivo de centragem

Data de Instalaçăo forçada a base da antena, conforme flgura abalxo)

- 11 - dezembro - 2005

\subsection{Esquema da Altura da Antena}

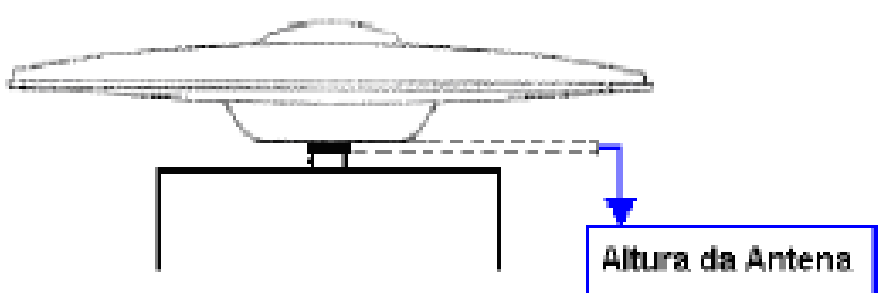

4.4 Esquema da Artena

4.4.1 Escuema da Antena ZEFHYR GEODETIC (TRM 41249.00)

Dlagrama do plano de referéncla da antena ZEPHYR тu GEODETIC Identiflcaçäo IGs: TRM 41249.00

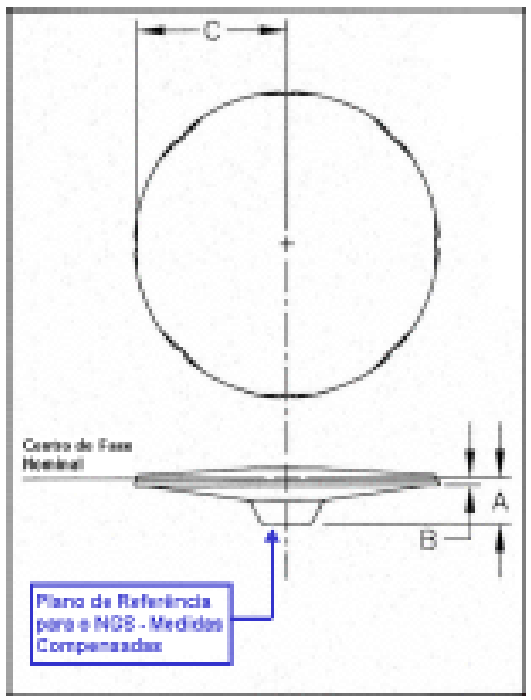




\begin{tabular}{|c|c|c|}
\hline Identeflcaçdo & Dimens $50(m)$ & Diatancls \\
\hline A & 0,0532 & Distancla da base da antena ao centro de fase nominal. \\
\hline B & 0,0589 & Distancia entre o centro de fase nominal e a marca do gancho. \\
\hline c & 0,1698 & Distancia do centro radial da antena a extremisade exterior do gancho. \\
\hline
\end{tabular}

Observaçás:

1. O centro de fase nominal e o plano de reterencls utlizsdo para corrigir a fase nas tabe as Trimble.

2. O fabricante Informs cue valor do centro de fase nominal nbo esta relacionado com os valores de calbraç5o relativa da antens estimsdo pelo NGS.

3. $\mathrm{NGS}$ possul um projeto com 0 objetwo de fornscer um procedimento pacib́o e conalstente na determinsç 50 dos va crea do centro de fase e da varlaçlo do centro de fase (pvc).

4. Calloracbes de outras fortes ndo devem ser misturadas com os resultados do NGS.

\section{Rede Local}

Nåo estabelecida

\section{Informaçסes Complementares}

6.1 - Para informap̧øes tecnicas contatar.

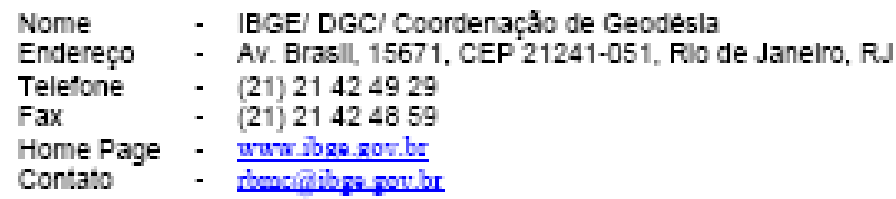

6.2 - Para informạ̧ळes sobre comerclallzaçăo e aquislçăo de dados contatar.

Nome - Centro de Documentaçăo e Disseminaçăo de informaçbes - CDDI/IBGE

Endereço - Rua General Canabarro, 706, CEP 20271-201, Rlo de Janelro, RJ

Teletones - 0800218181

Fax - $(21) 21424933$

Contatos - ibgogabgenger be

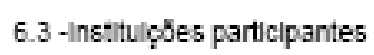

A RBMC conta com o apolo das segulntes Institulọbes:

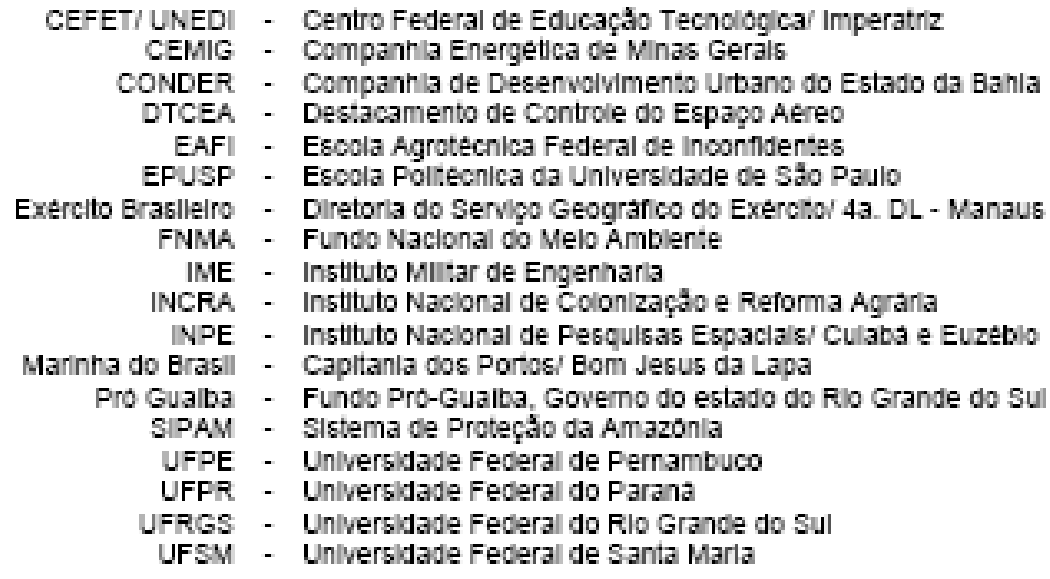


RBNC - Rede Brsslelra de Manllorsmerto Conthus Reistorio de informaçso de Estscha

Estaçalo Presidente Prudente - PPTE

UFU - Universidade Federal de Uberlandla

UFV - Universidade Federal de viçosa

UNESP - Universidade Estadual Paulista/ Campus de Presidente Prudente

UNIDERP - Universidade para o Desenvolvimento do Estado e da Reglåo do Pantanal

URCA - Fundaçăo Universidade Regional do Carin 


\title{
C.5 Estação RIOD
} \\ FBMC - Rede Braslleira de Monlloramento Continuo \\ Relaterio de Inform açálo de EstaçSo \\ EataçSo Rlo de Janeiro - RIOD
}

\section{Formulário}

Preparado por: Equipe Técnica da RBMC - "Centro de Controle Enga". Kátia Duarte Pereira"

Data: $21-$ julho -2001

Atualizaçăo: $\quad 06-\operatorname{marco}-2009$

Atualizaçào do firmware do receptor

\section{Identificação da estação GPS}

Nome da Estação:

Ident. da Estação:

Inscrição no Monumento:

Código Internacional:

Informaçőes Adicionais:
Rio de Janeiro

RIOD

Nằ há inscriçăo

91720

Esta estaçăo pertence à Rede de Referéncia do SIRGAS e à Rede

de Densificaçäo do IGS.

Coincidente com a RN $\underline{30 B 1 E}$ (referência de nivel), que se encontra en cálculo.

\section{Informação sobre a localização}

Cidade: Rio de Janeiro

Estado: Rio de Janeiro

Informações Adicionais: A estaçăo consiste em um pilar de concreto dotado de um dispositivo de centragem forçada, localizado na laje do prédio da Coordenaçâo de Geodésia/ Bloco III, no Rio de Janeiro.

\section{Coordenadas oficiais}

3.1) SIRGAS2000 (Epoca 2000.4)

\begin{tabular}{|c|c|c|c|}
\hline \multicolumn{4}{|c|}{ Coordenadas Geodésicas } \\
\hline Latitude: & $22^{\circ} 49^{\prime} 04,2399^{\prime \prime} \mathrm{S}$ & Sigma: & $0,001 \mathrm{~m}$ \\
\hline Longitude: & $43^{\circ} 18^{\prime} 22,5958^{\prime \prime} \mathrm{W}$ & Sigma & $0,002 \mathrm{~m}$ \\
\hline At.E p.: & $8,63 \mathrm{~m}$ & Sigma: & $0,002 \mathrm{~m}$ \\
\hline At.Orto.: & $14.68 \mathrm{~m}$ & Fonte: & GPS/ MAPGEO2004 \\
\hline \multicolumn{4}{|c|}{ Coordenadas Cartesianas } \\
\hline $\bar{x}$ & $4.280 .284,879 \mathrm{~m}$ & Sigma: & $0,002 \mathrm{~m}$ \\
\hline $\bar{Y}$ & $-4.034 .431,225 \mathrm{~m}$ & Sigma- & $0,002 \mathrm{~m}$ \\
\hline$Z$ & $-2.458 .141,380 \mathrm{~m}$ & Sigma & $0,001 \mathrm{~m}$ \\
\hline \multicolumn{4}{|c|}{ Coordenadas Planas (UTM) } \\
\hline UTM (N): & $7.475 .648,024 \mathrm{~m}$ & & \\
\hline UTM (E): & $673.825,217 \mathrm{~m}$ & & \\
\hline $\mathrm{MC}$ & -45 & & \\
\hline
\end{tabular}


4. Informações do equipamento GPS

\subsection{Receptor}

\begin{tabular}{|c|c|c|}
\hline 4.1.1 & $\begin{array}{l}\text { Tipo do Receptor } \\
\text { Numero de Serrie } \\
\text { Versấo do Firmware } \\
\text { Data de Instalaçăo } \\
\text { Atualizaçấo do Firmware }\end{array}$ & $\begin{array}{ll}- & \text { TRIMBLE NetRS } \\
- & 4636121854 \\
- & 1.2-0 \\
- & 19-\text { março-2007 } \\
- & 06-\text { março-2008 }\end{array}$ \\
\hline 4.1 .2 & $\begin{array}{l}\text { Tipo do Receptor } \\
\text { Número de Série } \\
\text { Versấo do Firmware } \\
\text { Data de Instalaçăo } \\
\text { Data de Atteraçào }\end{array}$ & $\begin{array}{ll}- & \text { TRIMBLE NetRS } \\
- & 4636121854 \\
- & 1.1-5 \\
- & 19-\text { março- } 2007 \\
- & 06-\text { março }-2008\end{array}$ \\
\hline 4.1 .3 & $\begin{array}{l}\text { Tipo do Receptor } \\
\text { Número de Série } \\
\text { Versấo do Firmware } \\
\text { Data de Instalaçăo } \\
\text { Data de Remoçấo }\end{array}$ & $\begin{array}{ll}- & \text { TRIMBLE 4000SSI } \\
- & 3950 A 27335 \\
- & 7.29 \\
- & 01 \text { - agosto }-2006 \\
- & 19 \text { - março - } 2007\end{array}$ \\
\hline 4.1 .4 & $\begin{array}{l}\text { Tipo do Receptor } \\
\text { Número de Série } \\
\text { Versáo do Firmware } \\
\text { Data de Instalaçẵo } \\
\text { Data de Remoçâo }\end{array}$ & $\begin{array}{ll}- & \text { TRIMBLE 4000SSI } \\
- & 3518 A 10740 \\
- & 7.01 \\
- & 24 \text { - fevereiro }-2006 \\
- & 01 \text { - agosto - 2006 }\end{array}$ \\
\hline 4.1 .5 & $\begin{array}{l}\text { Tipo do Receptor } \\
\text { Número de Série } \\
\text { Versâo do Firmware } \\
\text { Data de Instalaçăo } \\
\text { Data de Remoção }\end{array}$ & $\begin{array}{ll}- & \text { TRIMBLE 4000SSI } \\
- & 3950 A 27335 \\
- & 7.29 \\
- & 21 \text { - juho }-2001 \\
- & 24 \text { - fevereiro - } 2006\end{array}$ \\
\hline
\end{tabular}

\subsection{Antena}

4.2.1 Tipo de Antena Numero de Série Altura da Antena (m)

Data de Instalaçăo

ZEPHYR GEODETIC (TRM 41249.00)

- 60177763

- 0.0080 (distáncia vertical do topo do dispositivo de centragem forçada à base da antena, conforme figura abaixo)

4.2.1 Tipo de Antena Número de Série Altura da Antena (m)

Data de Instalaçăo Data de Remoçầo

\section{- DORNE MARGOLIN T}

- 70419

- 0.0080 (distáncia vertical do topo do dispositivo de centragem forçada à base da antena, conforme figura abaixo)

- 21 - julho-2001 $19-$ março -2007 


\subsection{Esquema da Altura da Antena}

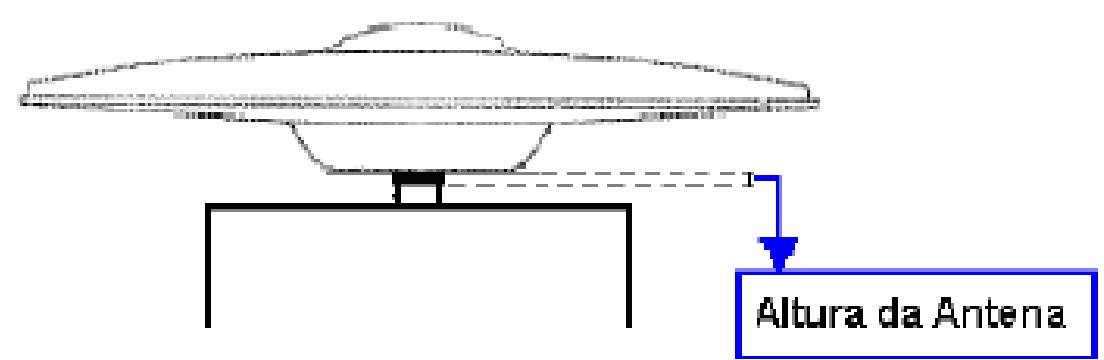

\subsection{Esquema da Antena}

4.4.1 Esquema da Antena ZEPHYR GEODETIC (TRM 41249.00)

Diagrama do plano de referéncia da antena ZEPHYR ти GEODETIC Identificaçäo IGS: TRM 41249.00

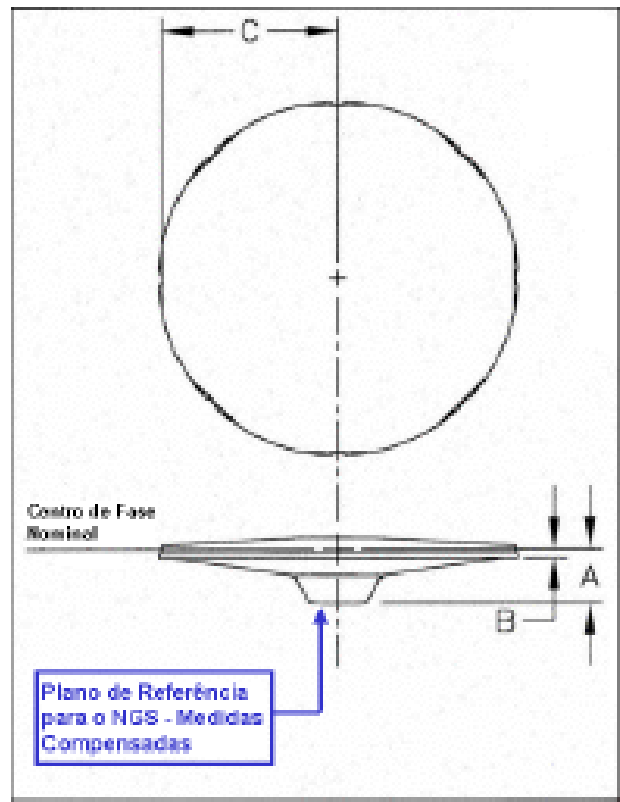

\begin{tabular}{|c|c|l|}
\hline Identincaçăo & Dimensăo $(\mathrm{m})$ & \multicolumn{1}{c|}{ Diståncla } \\
\hline A & 0,0532 & Distancla da base da antena ao centro de fase nominal. \\
\hline B & 0,0089 & Distancla entre o centro de fase nominal e a marca do gancho. \\
\hline C & 0,1698 & Distancla do centro radlal da antena a extremldade exterior do gancho. \\
\hline
\end{tabular}




\begin{tabular}{|c|c|c|}
\hline$\rightarrow=$ & $\begin{array}{l}\text { Diretoria de Geocièncias } \\
\text { Cocrdenaçalo de Geodesta }\end{array}$ & $\begin{array}{c}\text { ReMC - Rede Ersaleirs de Monliorsmento Continuo } \\
\text { Relatorio de informsçbo de Estaçato } \\
\text { Estaçso RJo de Janeiro - RICD }\end{array}$ \\
\hline
\end{tabular}

\subsubsection{Esquema da Antena Dome Margo in T (TRM 29659.00)}

Diagrama do plano de referència da antena Dorne Margolin T Identificação IGS: TRM 29659.00
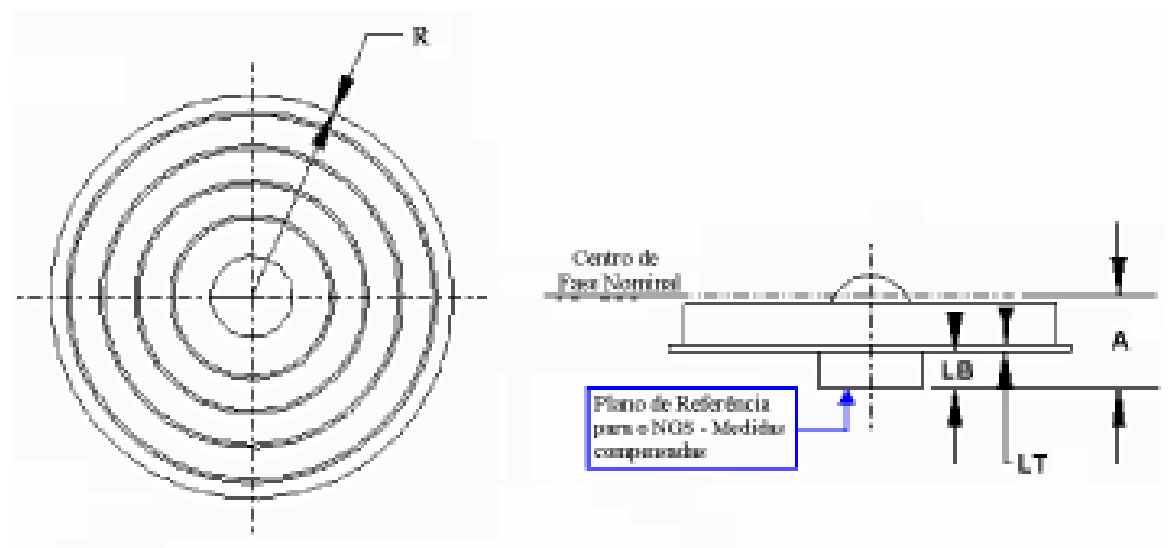

\begin{tabular}{|c|c|c|}
\hline Identilicaçäo & Dimensăo (m) & Distända \\
\hline$A$ & 0,1100 & $\begin{array}{l}\text { Distáncla do plano de refertencla da antena ao centro de fase nominal da } \\
\text { frequencla Li }\end{array}$ \\
\hline LB & 0,0350 & $\begin{array}{l}\text { Distáncla do plano de refertencla da antena ao plano de referéncla Choike } \\
\text { Ring }\end{array}$ \\
\hline LT & 0,0031 & Espessura da antena \\
\hline $\mathbf{R}$ & 0,1905 & Distancla do centro radlal da antena a extremidade exterior do prato. \\
\hline
\end{tabular}

Observaçăo:

1. O centro de fase nominal e o plano de referencla us:lizado para corrigir a fase nas tabelas Trimble.

2. O fabricante infoma que valor do centro de fase nominal nấo esta relacionado com os valores de calbraçấ relatha da antena estmado pelo NGS.

3. O NGS possul um projeto com 0 objettivo de fomecer um procedimento padrâo e consistente na deterninaçăo dos valores do centro de tase e da varlaçao do centro de fase (pvc).

4. Calbrap̧øes de outras fontes năo devem ser misturadas com os resulados do NGS.

\section{Rede local}

Não estabelecida.

\section{Informações Complementares}

6.1 - Para informações técnicas contatar:

\begin{tabular}{|c|c|}
\hline $\begin{array}{l}\text { Nome } \\
\text { Endereco } \\
\text { Telefone } \\
\text { Fax } \\
\text { Home Page } \\
\text { Contato }\end{array}$ & 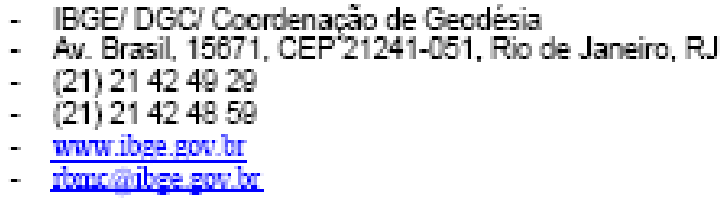 \\
\hline
\end{tabular}

6.2 - Para informaç̧ỏes sobre comercializaçăo e aquisiçấo de dados contatar.
Nome
Endereco
Telefones
- Centro de Documentação e Disseminaçăo de Informações - CDDUBGE
Fax
- Rua General Canabarto, 706, CEP 20271-201, Rio de Janeiro, Ru
(21) 21424933
- 0800218181
Contatos - ibgeanibge gov.br 
6.3 -Instituições participantes

A RBMC conta com o apoio das seguintes instituiģöes:

CEFET/ UNEDI - Centro Federal de Educacâo Tecnológica/ Imperatriz

CEMG - Companhia Energética dé Mnas Gerais

CONDER - Companhia de Desenvolvimento Urbano do Estado da Bahia

DTCEA - Destacamento de Controle do Espaco Aéreo

EAFI - Escola Agrotécnica Federal de Inconfidentes

EPUSP - Escola Politécnica da Universidade de Säo Paulo

Exército Brasileiro - Diretoria do Serviço Gecgráfico do Exército/ 4a. DL - Manaus

FNMA - Fundo Nacional do Meio Ambiente

IME - Insttuto Mlitar de Engenharia

INCRA - Instituto Nacional de Colonização e Reforma Agrária

INPE - Instituto Nacional de Pesquisás Esoaciais/Cuiabá e Euzébio

Marinha do Brasi - Capitania dos Portos/Bom Jesus da Lapa

Pró Guaiba - Fundo Pró-Guába, Govemo do estado do Rio Grande do Sul

SIPAM - Sistema de Protecấo da Amazónia

UFPE - Universidade Federal de Pernambuco

UFPR - Universidade Federal do Paraná

UFRGS - Universidade Federal do Rio Grande do Sul

UFSM - Universidade Federal de Santa Maria

UFU - Universidade Federal de Uberlânda

UFV - Universidade Federal de Vicosa

UNESP - Universidade Estadual Paufista/ Campus de Presidente Prudente

UN DERP - Universidade para o Desenwolvimento do Estado e da Regiăo do Pantanal URCA - Fundaçăo Universidade Regional do Cariri 


\section{C.6 Estação UBER}

Diretorla de Geoclenclas

Coordenaçắo de Gecotesla
REMC - Rede Brsalleira de Manlioramento Cantinuo Reistorio de Informsçlo de Eetsçalo

Estsplo Uberlanda - UeER.

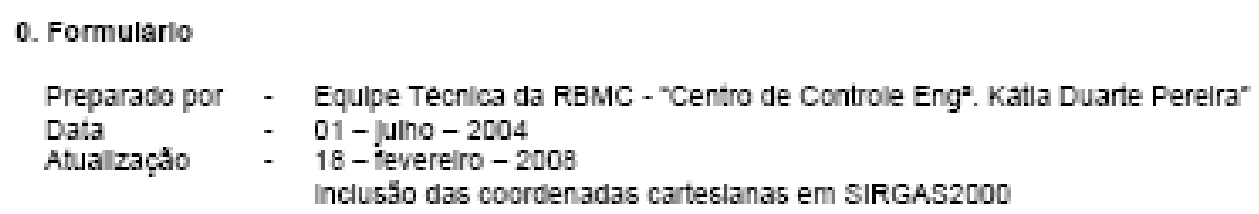

\section{Identıilcaçăo da estaçåo GPS}

Nome da Estaçăo - Uberlandla

Ident. da Estaçăo - UBER

Inscriçăo no Monumento - Nåo ha inscriç̧̃o

Codlgo Internacional - 91909

Informaçbes Adliclonals - Estaçăo administrada pela CEMIG; pertence a Rede de Densilicaçăo do IGS

\section{Informaçao aobre a locallzaçào}

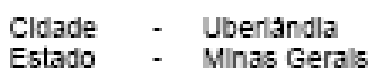

Informaç̋es Adicionals - A estaçăo consiste de uma torre metallca de $3 \mathrm{~m}$, dotada de um dispositivo de centragen forçada cravado no seu topo. Esta situada no predio do Centro Reglonal Integrado de Uberlandla - CRIU, pertencente a CEMIG.

\section{Coordenadas oficlals}

3.1) SIRGAS20C0 (Epoca 2000,4)

\begin{tabular}{|c|c|c|c|}
\hline \multicolumn{4}{|c|}{ Coordenadas Geodesicas } \\
\hline Latltude: & $18^{\circ} 53^{\prime} 22,3291^{*} \mathrm{~S}$ & Sigma. & $0,001 \mathrm{~m}$ \\
\hline Longltude: & $48^{\circ} 19^{\prime} 01,0974^{*} \mathrm{~W}$ & Sigma & $0,001 \mathrm{~m}$ \\
\hline Alt:Elp.: & $791,83 \mathrm{~m}$ & Sigma. & $0,010 \mathrm{~m}$ \\
\hline Alt.Orto.: & $803,64 \mathrm{~m}$ & Fonte & GPS/ MAPGEO2004 \\
\hline \multicolumn{4}{|c|}{ Coordenadas Carteslanas } \\
\hline $\mathrm{X}$ & $4.014 .997,241 \mathrm{~m}$ & Sigma: & $0,006 \mathrm{~m}$ \\
\hline$Y$ & $-4.509 .022,449 \mathrm{~m}$ & Sigma: & $0,007 \mathrm{~m}$ \\
\hline$z$ & $-2.052 .040,720 \mathrm{~m}$ & Sigma: & $0,003 \mathrm{~m}$ \\
\hline \multicolumn{4}{|c|}{ Coordenadas Planas (UTM) } \\
\hline UTM $(\mathrm{N}):$ & $7.909 .251,415 \mathrm{~m}$ & & \\
\hline UTM (E): & $782.656,488 \mathrm{~m}$ & & \\
\hline MC: & -51 & & \\
\hline
\end{tabular}

\section{Informaçסes do equipamento GPS}

\subsection{Receptor}

$$
\begin{aligned}
& \text { 4.1.1 Tipo do Receptor - Ashtech Z-FX } \\
& \text { Número de Serle - UX219995005 } \\
& \text { Versâo do Firmware - UDDD } \\
& \text { Data de Instalaçăo - } 18-a b r l l ~-2001
\end{aligned}
$$




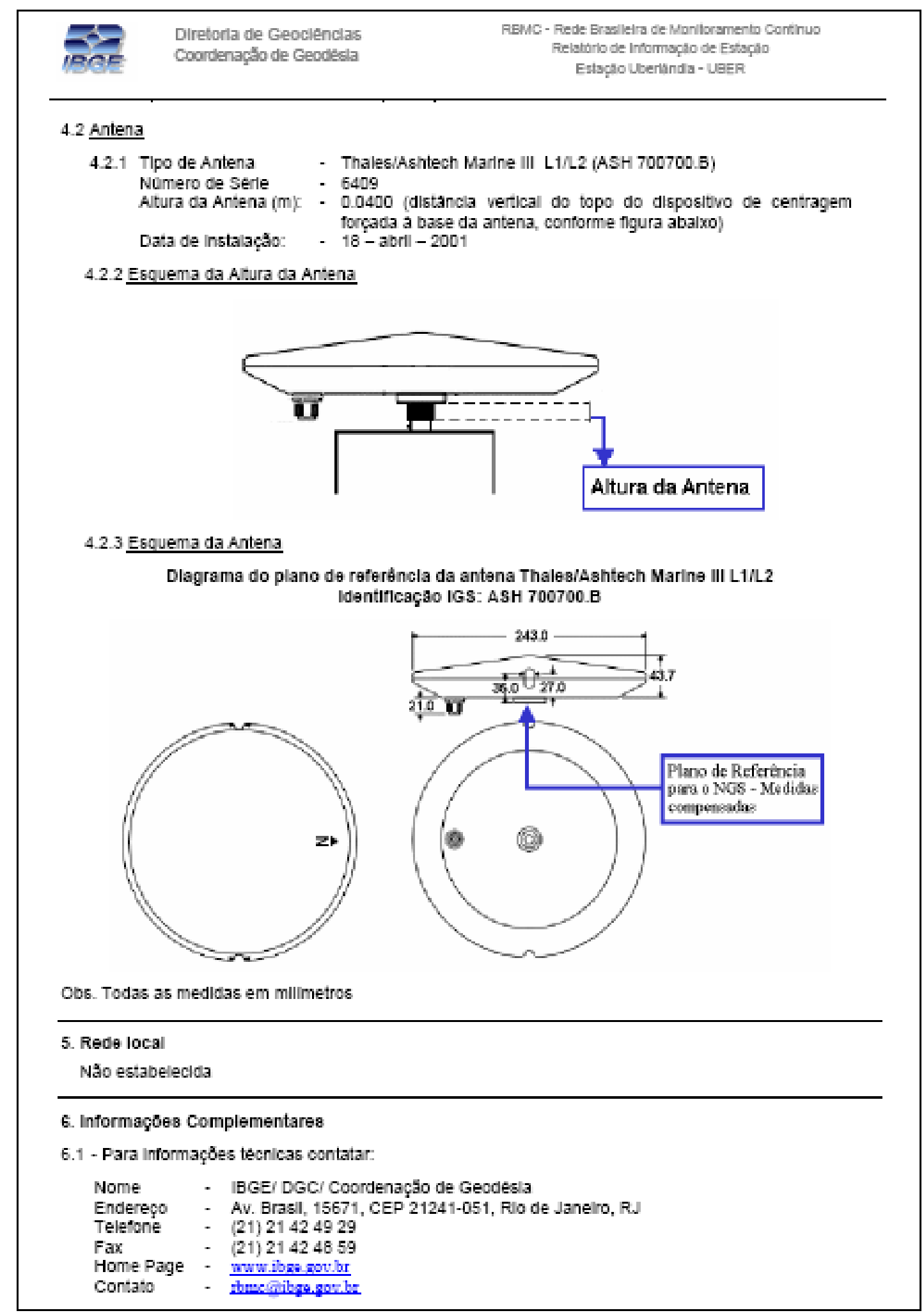


6.2 - Para informaçઠిes sobre comerciallzaçăo e aquls/çăo de dados contatar.

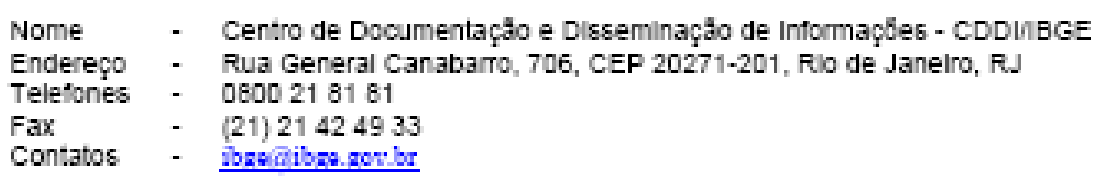

6.3 -Institulęjes participantes

A RBMC conta com o apolo das segulntes Instituloples:

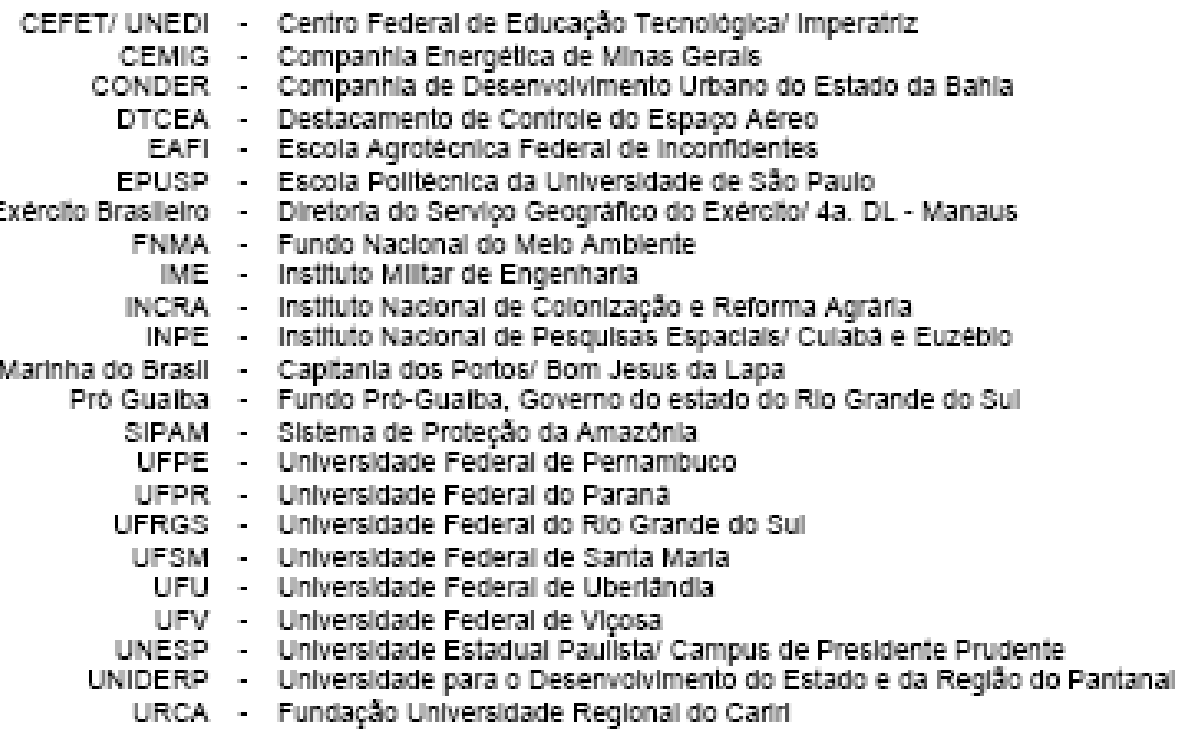




\section{C.7 Estação VARG}

\begin{tabular}{|c|c|c|}
\hline$\rightarrow=$ & $\begin{array}{l}\text { Diretorla de Geoclenclas } \\
\text { coordenaçăo de Geodesta }\end{array}$ & 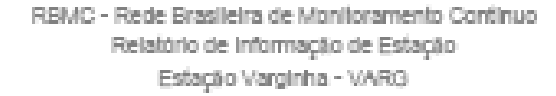 \\
\hline \multicolumn{3}{|l|}{ 0. Formulario } \\
\hline $\begin{array}{l}\text { Preparado por } \\
\text { Data } \\
\text { Atuallzaçâa }\end{array}$ & \multicolumn{2}{|c|}{$\begin{array}{l}\text { Equipe Tecrica da RBMC - "Centro de Controle Enga". Katla Duarte Perelra" } \\
01 \text { - julno }-2004 \\
18 \text { - tevereiro }-2008 \\
\text { Inclusăo das coordenadas carteslanas em SIRGAS2000 }\end{array}$} \\
\hline
\end{tabular}

\section{Identıficaçăo da estaçăo GPS}

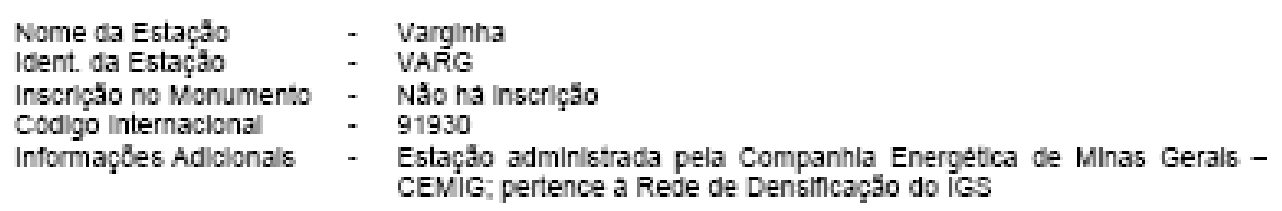

\section{Informaçà sobre a locallzaçăo}

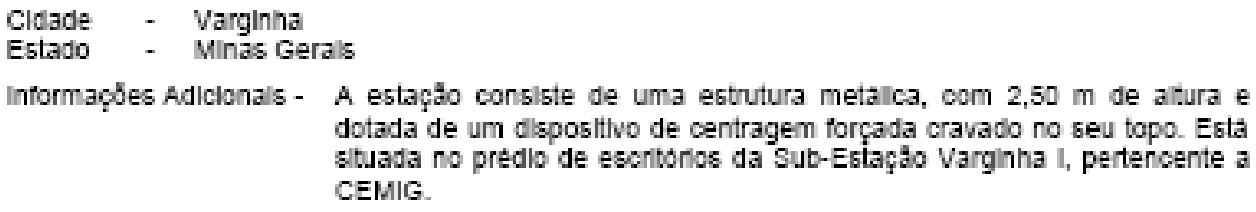

\section{Coordenadas oficlals}

3.1) SIRGAS20C0 (Epoca 2000,4)

\begin{tabular}{|c|c|c|c|}
\hline \multicolumn{4}{|c|}{ Coordenadas Geodesicas } \\
\hline Latitude: & $21^{\circ} 32^{\prime} 33,6645^{\prime \prime} \mathrm{S}$ & Sigma. & $0,001 \mathrm{~m}$ \\
\hline Longltude: & $45^{\circ} 26^{\prime} 05,5518^{*} \mathrm{~W}$ & Sigma: & $0,001 \mathrm{~m}$ \\
\hline Ait. Ellp.: & $958,65 \mathrm{~m}$ & Sigma: & $0,005 \mathrm{~m}$ \\
\hline Alt.Orto.: & $962,52 \mathrm{~m}$ & Fonte & GPS/ MAPGEO2004 \\
\hline \multicolumn{4}{|c|}{ Coordenadas Carteslanas } \\
\hline $\mathrm{x}$ & $4.165 .518,288 \mathrm{~m}$ & Sigma: & $0,003 \mathrm{~m}$ \\
\hline$Y$ & $-4.229 .235,773 \mathrm{~m}$ & Sigma: & $0,003 \mathrm{~m}$ \\
\hline$z$ & $-2.327 .739,656 \mathrm{~m}$ & Sigma: & $0,002 \mathrm{~m}$ \\
\hline \multicolumn{4}{|c|}{ Coordenadas Planas (UTM) } \\
\hline UTM $(\mathrm{N}):$ & $7.617 .727,294 \mathrm{~m}$ & & \\
\hline UTM (E): & $454,968,971 \mathrm{~m}$ & & \\
\hline MC: & -45 & & \\
\hline
\end{tabular}

\section{Informaçoes do equipamento GPS}

\subsection{Receptor}
4.1.1 Tipo do Receptor Nümero de Serle - Ashtech Z-FX Versăo do Firmware
Data de Instalaç̧̌o

$$
\text { - UDOD }
$$$$
\text { - UX219995013 }
$$$$
\text { - } 18-a b r l l-2001
$$ 


\subsection{Antena}
4.2.1 Tipo de Antena
- Thales/Ashtech Marine III L1/L2 (ASH 700700.B)
Numero de serle
- 6450
Altura da Antena (m) - 0.0650 (distancla vertical do topo do dlspositivo de centragem
Data de instalaçăo: forçada a base da antena, conforme flgura abalxo)
- $18-$ abrll -2001

\subsubsection{Esquema da Al:ura da Antena}

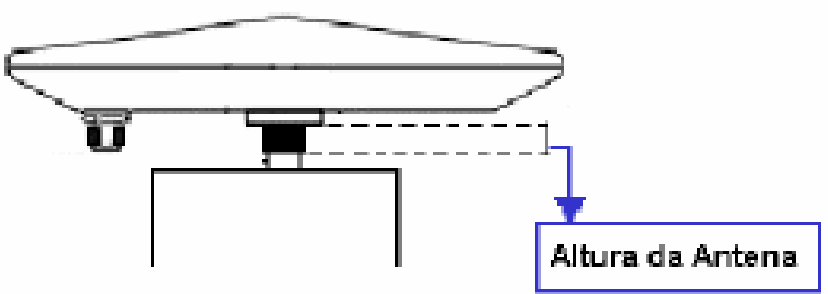

\subsubsection{Esquema da Antena}

Dlagrama do plano de referencla da antena Thales/Ashtech Marine III L1/L2 Identıfleaçà IGS: ASH 700700.B
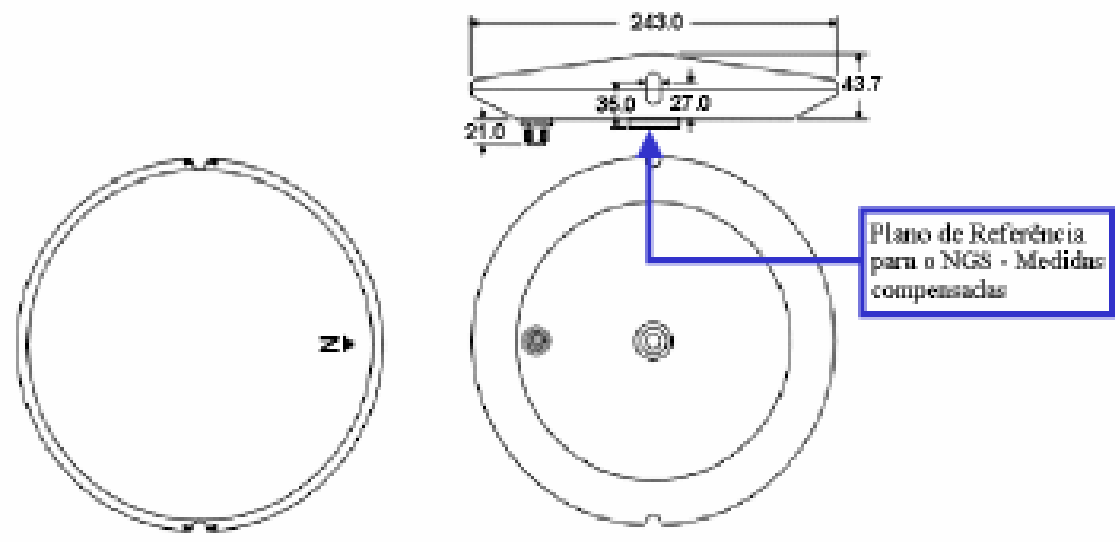

Obs. Todas as medidas em millimetros

\section{Rede local}

Nâo estabelecida

\section{Informaç๐es Complementares}

6.1 - Para informaçbes tecnicas contatar:

Nome - IBGE/ DGC/ Coordenaçăo de Geodesla

Endereço - Av. Brasl, 15671, CEP 21241-051, RJo de Janelro, RJ 


\begin{tabular}{|c|c|}
\hline & - (21) 2142492 \\
\hline $\mathrm{Fa}$ & (21) 214248 \\
\hline Page & 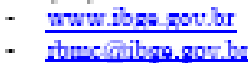 \\
\hline
\end{tabular}

6.2 - Para informaçổes sobre comerciallzaçăo e aquisiçăo de dados contatar.

Nome - Centro de Documentaçăo e Disseminaçăo de Informaçbes - CDDInBGE

Endereço - Rua General Canabarro, 706, CEP 20271-201, Rilo de Janelro, R.J

Telefones - 0800218181

Fax - (21) 21424933

Contatos - ibreinibargenibr

6.3 -institulǫ)es participantes

A RBMC conta com o apolo das seguintes institulçbes:

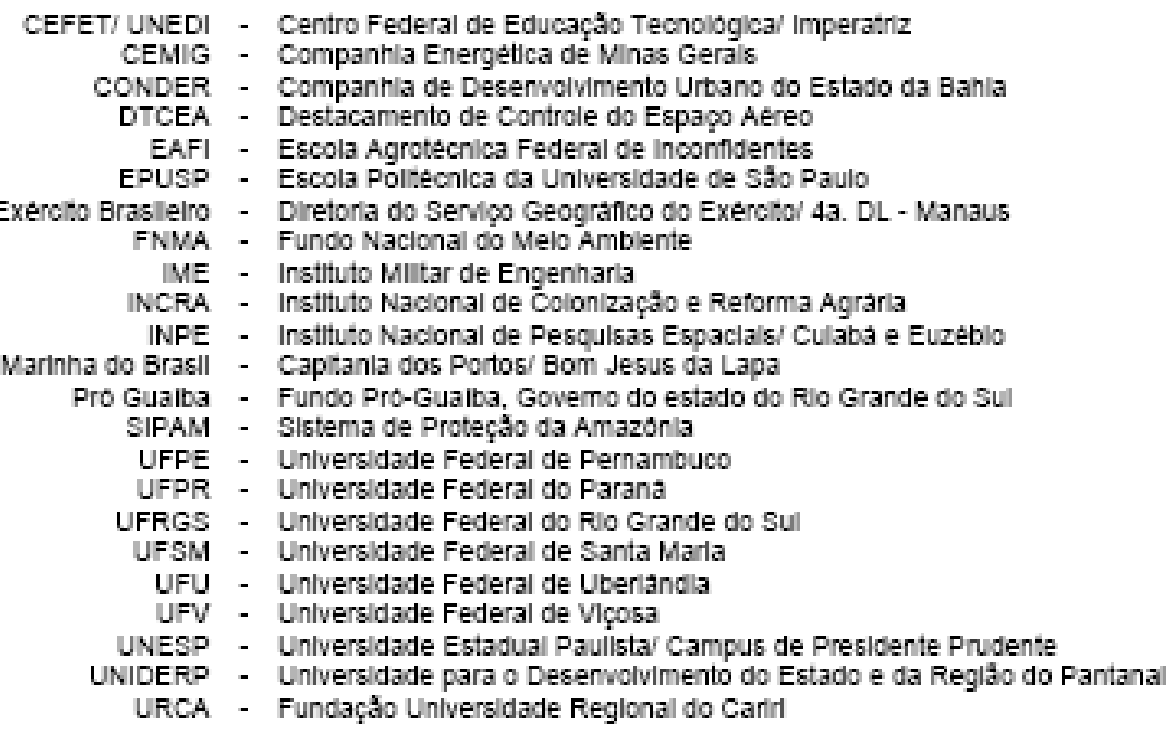




\section{C.8 Estação VICO}

\section{Formulario}

Preparado por - Equlpe Tecnica da REMC - "Centro de Controle Enga. Katta Duarte Pereira"

Data - 23- ulho- 1997

Atuallzaçåo - 18 - tevereiro -2008

Inclusăo das coordenadas carteslanas em SIRGAS2000

\section{Identıflcaçå da estaçào GPS}

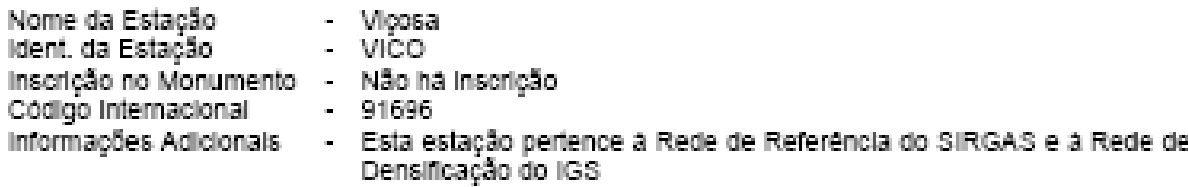

\section{Informaçao aobre a locallzaçao}

Cldade - Vlposa

Estado - Minas Gerals

Informaçdes Adlcionals - A estaçăo consiste em um pllar de concreto dotado de um dlspositwo de centragem forçada, locallzado no Campus da Unlversldade Federal de Vlçosa - UFV

\section{Coordenadas offclals}

3.1) SIRGAS2000 (Epoca 2000,4)

\begin{tabular}{|l|r|r|l|}
\hline \multicolumn{5}{|c|}{ Coordenadas Geodealcas } \\
\hline Latitude: & $20^{\circ} 45^{\prime} 41,4020^{\circ} \mathrm{S}$ & Sigma & $0,001 \mathrm{~m}$ \\
\hline Longltude: & $42^{\circ} 52^{\prime} 11,9622^{\prime} \mathrm{W}$ & Sigma: & $0,002 \mathrm{~m}$ \\
\hline Alt.Ellp.: & $665,96 \mathrm{~m}$ & Sigma: & $0,002 \mathrm{~m}$ \\
\hline Alt.Orto.: & $672,71 \mathrm{~m}$ & Fonte: & GPS/ MAPGEO2004 \\
\hline \multicolumn{5}{|c|}{ Coordenadas Carteslanas } \\
\hline X & $4.373 .283,313 \mathrm{~m}$ & Sigma: & $0,002 \mathrm{~m}$ \\
\hline Y & $-4.059 .639,049 \mathrm{~m}$ & Sigma: & $0,002 \mathrm{~m}$ \\
\hline Z & $-2.246 .959,728 \mathrm{~m}$ & Sigma: & $0,001 \mathrm{~m}$ \\
\hline \multicolumn{5}{|c|}{ Coordenadas Planas (UTM) } \\
\hline UTM (N): & $7.702 .785,751 \mathrm{~m}$ & & \\
\hline UTM (E): & $721.757,711 \mathrm{~m}$ & & \\
\hline MC: & -45 & & \\
\hline
\end{tabular}

\section{Informaçסes do Equlpamento GPS}

4.1 Receptor

$$
\begin{aligned}
& \text { 4.1.1 Tipo do Receptor - TRIMBLE Ne:R5 } \\
& \text { Namero de Serle _ - 4651K03571 } \\
& \text { Versăo do Fimware - } 3.50 \\
& \text { Data de Instalaçåo - 04-abri - } 2007
\end{aligned}
$$




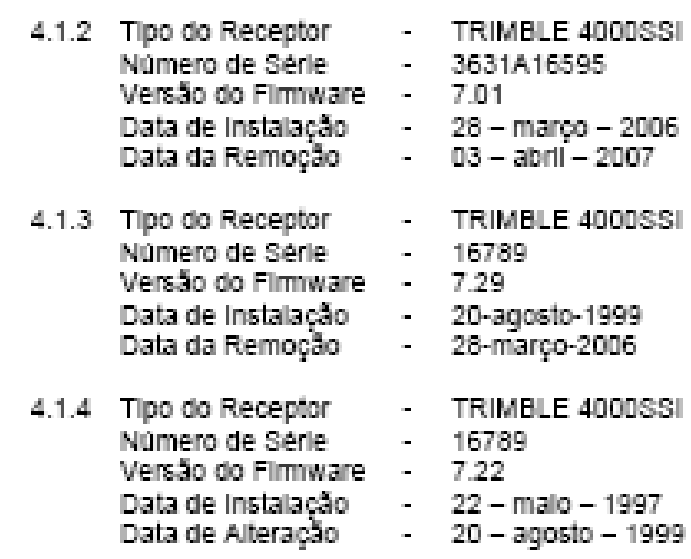

\subsection{Antena}
4.2.1 Tlpo de Antena - ZEPHYR GNSS GEODETIC MODEL 2 (TRM 55971.00) Número de Serle - 30278433
Altura da Antena $(\mathrm{m})$ - 0.0080 (distancla vertical do topo do dlspositivo de centragem forçada a base da antena, conforme figura abalxo)
Data de Instalaçăo: - $04-$ abrill - 2007
4.2.2 Tlpo de Artena - DORNE MARGOLIN T (TRM 29659.00)
Numero de Serle - 070171
Altura da Antena $(\mathrm{m})$ - 0.0160 (distancla vertical do topo do dispositivo de centragem forçada a base da antena, conforme flgura abalxo) Valor utllizado no periodo de 28/11/1998 a 03/04/2007
Data de Instalaç̧⿸丆口 - $\quad 28$ - novembro - 1998
Data de Remoçấ - $03-$ abrll -2007
4.2.3 Tipo de Artena - DORNE MARGOLIN T (TRM 29659.00)
Número de Serle - 070177
Altura da Antena (m) - 0.0080 (distancla vertical do topo do dispositivo de centragem forçada a base da antena, conforme figura abalxo)
Data de Instalaçăo - 30-outubro - 1997
Data de Remoçato - 27 - novembro -1998
4.2.4 Tlpo de Artena - DORNE MARGOLIN T (TRM 29659.00)
Nünero de Serle - 070177
Altura da Antena $(\mathrm{m})$ - 0.0070 (dlstancla vertical do topo do dlspositwo de centragem forçada a base da antena, conforme figura abalxo)
Data de Instalaçăo - $22-$ malo -1997
Data da Mudança - 29 - outubro-1997


4.3 Esquema da Altura da Antena

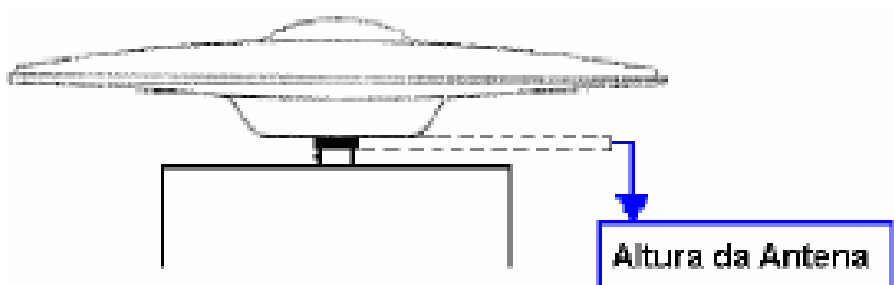

4.4 Esquema da Antena

4.4.1 Esquema da Antena ZEPHYR GNSS GEODETIC MODEL_ 2 (TRM 55971.00$)$

Dlagrama do plano de referéncla da antena ZEPHYR GNSS GEODETIC MODEL 2 Identificaça IGs: TRM 55971.00

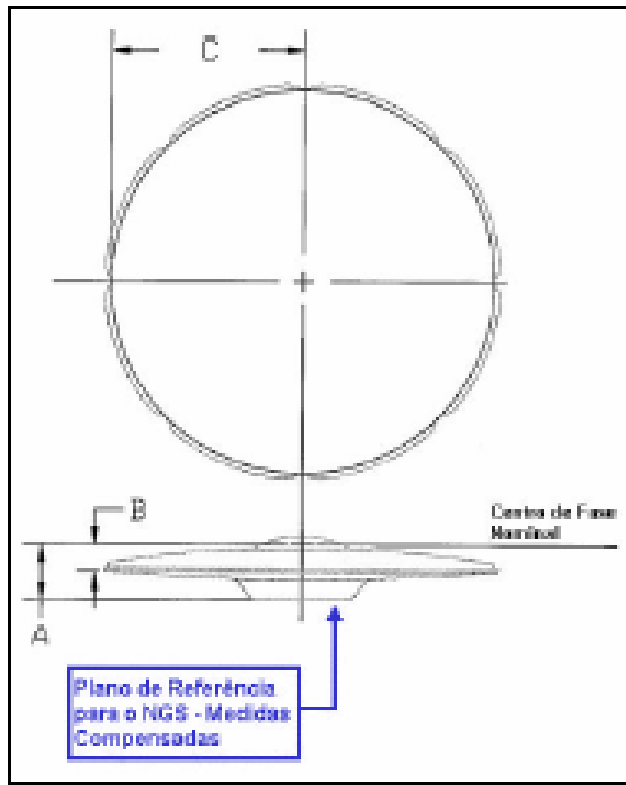

\begin{tabular}{|c|c|c|}
\hline Identincaçato & Dimensăo (m) & Distancla \\
\hline A & 0,0850 & Disiancla da base da antena ao centro de fase noninal L1. \\
\hline 8 & 0,0406 & Distánda do plano da artena ao centro de tase nominal L1. \\
\hline C & 0,1698 & Dlsitancla do centro raclal da antena a exiremidade da marca exterior. \\
\hline
\end{tabular}




\subsubsection{Esquema da Antena DORNE MARGOLIN T (TRM 29659.00)}

\section{Dlagrama do plano de referencla da antena DORNE MARGOLIN T} Identificaçăo IGS: TRM 29659.00

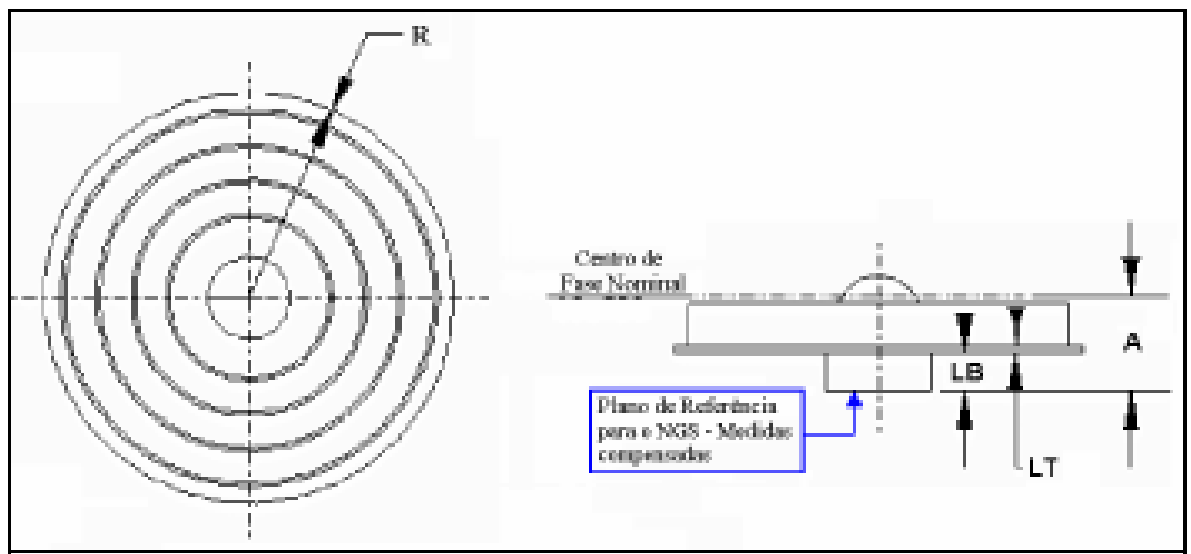

\begin{tabular}{|c|c|c|}
\hline Identticaç5o & Dimensfo (m) & Distancla \\
\hline A & 0,1100 & $\begin{array}{l}\text { Disiancla do plano de refertencla da antena ao centro de fase nominal da } \\
\text { frequencla Lf }\end{array}$ \\
\hline LB & 0,0350 & $\begin{array}{l}\text { Disitancla do plano de referencla da artena ao plano de referencla Choke } \\
\text { Fing }\end{array}$ \\
\hline LT & 0,0031 & Espessura da antena \\
\hline $\mathbf{R}$ & 0.1905 & Disiancla do centro radial da antena a extremidade exterior do prato. \\
\hline
\end{tabular}

Otservaço:

1. Ocentro de fase nominal e o plano de referencla utlizado para corrigir a fase nas tabelas Trimble.

2 O fabricante infoma que valor do centro de fase nominal nక5o esia relasionado $\infty$ os 05 valores de calbraçăo relativa da antena estimado pelo NGS.

3. O NGS possul um projeto com o objetivo de fonecer um proced Imento padta e consistente na determinaçăo dos vaiores do certro de fase e da varlaçăo do certro de fase (pvc).

4. Calbraçles de outras fontes năo devenn ser misturadas com 05 resulados do NGS.

\section{Rede local}

Estaçbles 인. 91697,91698, 91699, 91700, 91701, 91702, 91703

Data de Observaçăo - $26-$ malo- 1995

\section{Informaçס̄es Complementares}

6.1 - Para Informaçð̌es tecnicas contatar:

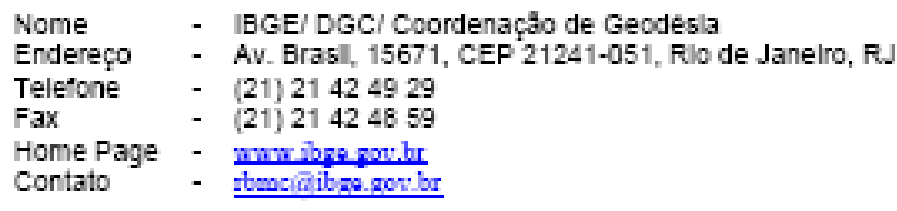


6.2 - Para Informaçðలes sobre comerclallzaçăo e aquısıçăo de dados contatar.

Nome - Centro de Documentaçăo e Disseminaçăo de Informaçdes - CDDI/IBGE

Endereço - Rua General Canabarro, 706, CEP 20271-201, Rlo de Janelro, RJ

Teletones - 0800218181

Fax - (21) 21424933

Contatos - ibreabas.sovibr

6.3 -Institulq̧bes participantes

A REMC conta com o apolo das seguintes institulçbes:

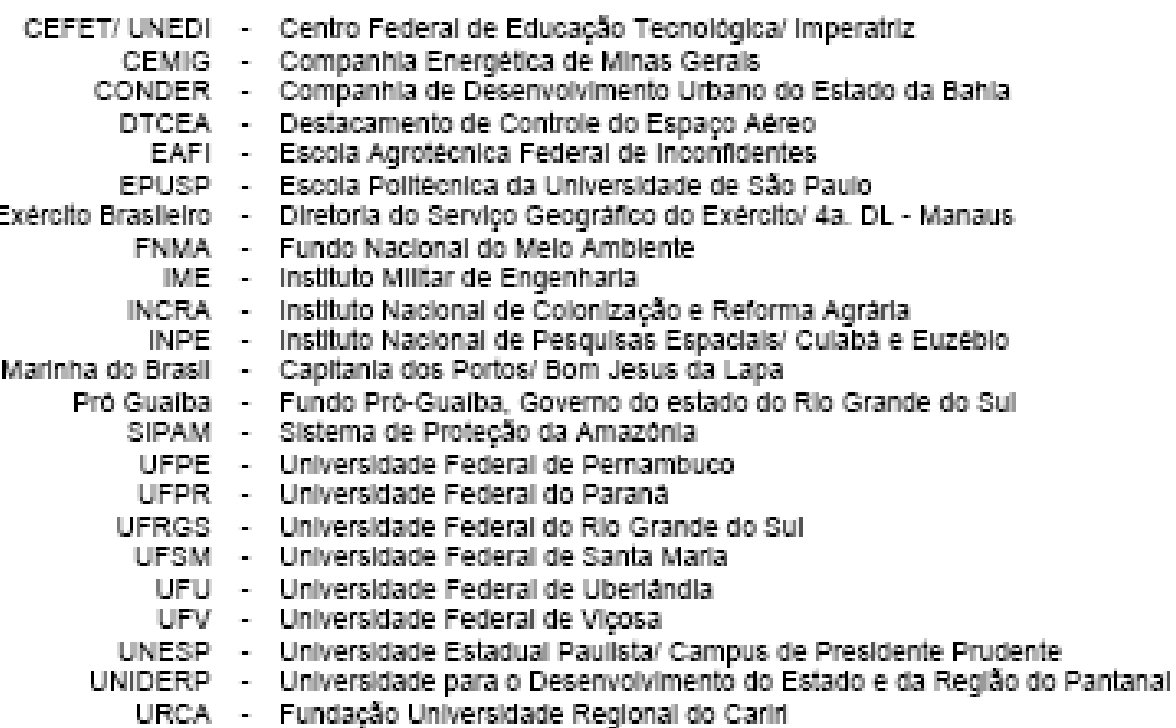


